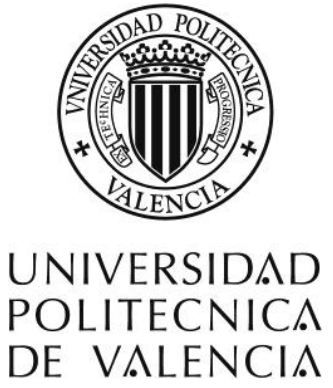

Programa de doctorado en

Ingeniería Hidráulica y Medio Ambiente

\title{
DIAGNÓSTICO DE LA SOSTENIBILIDAD DE UN ABASTECIMIENTO DE AGUA E IDENTIFICACIÓN DE LAS PROPUESTAS QUE LA MEJOREN
}

Tesis doctoral

Presentada por:

Holger Benavides Muñoz

Dirigida por:

Dr. Enrique Cabrera Marcet

Dr. Enrique Cabrera Rochera

Valencia, 2010 
Tema de tesis:

Diagnóstico de la sostenibilidad de un abastecimiento

de agua e identificación de las propuestas que la mejoren

\section{Elaborada por:}

Holger Benavides Muñoz

Dirigida por:

Dr. Enrique Cabrera Marcet

Dr. Enrique Cabrera Rochera

Catedráticos de Mecánica de Fluidos

Departamento de Ingeniería Hidráulica y Medio Ambiente

Universidad Politécnica de Valencia - UPV

\section{Honorable Tribunal Calificador:}

Dr. Jorge García-Serra García

Universidad Politécnica de Valencia

Dr. Ricardo Cobacho Jordán

Universidad Politécnica de Valencia

Dr. Francisco Javier Almandoz Berrondo

Universidad del País Vasco

Dr. José Dolz Ripollés

Universidad Politécnica de Cataluña

Dr. José Roldán Cañas

Universidad de Córdoba

Vocales y Evaluadores Suplentes:

Dr. Manuel Gómez Valentín

Universidad Politécnica de Cataluña

Dr. Ricardo Aliod Sebastián

Universidad de Zaragoza

Dra. María Helena Veríssimo Colaço Alegre

Laboratorio Nacional de Engenharia Civil

Dr. José Manuel De Eça Guimaraes De Abreu

Universidad de Coimbra

Programa de Doctorado en Ingeniería Hidráulica y Medio Ambiente

Valencia - España, 2010.

Códigos UNESCO:

$330538 \quad$ - $\quad$ Abastecimientos de agua

332905 - Desarrollo regional

$330515 \quad$ - Ingeniería Hidráulica

$330800 \quad$ - Ingeniería y tecnología del medio ambiente 


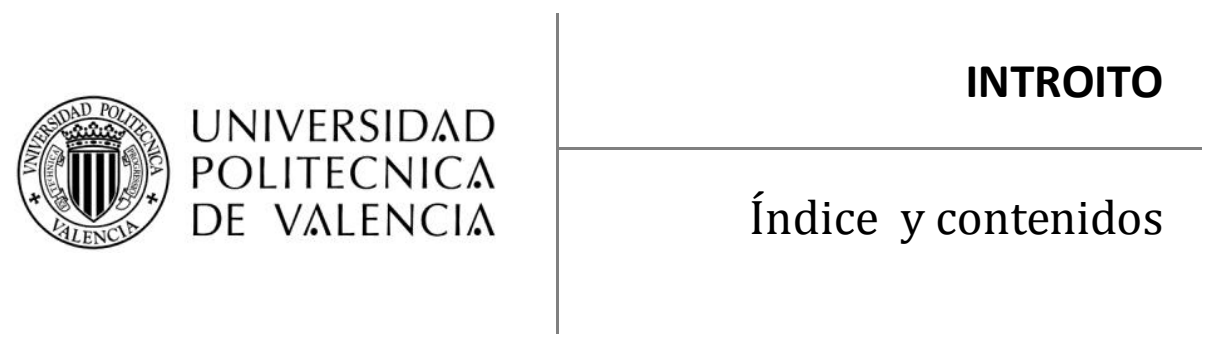



Índice

CAPITULO I: $\quad$ INTRODUCCIÓN

Resumen / summary / resum 3

1.1 Exordio 5

1.1.1 Motivación y problemática 5

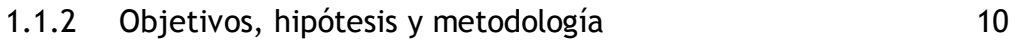

$\begin{array}{lll}\text { 1.1.3 Estructura de la tesis } & 16\end{array}$

$\begin{array}{lll}1.2 & \text { La gestión integral de recursos hídricos - GIRH } & 18\end{array}$

1.2.1 Directiva Marco del Agua 20

1.2.2 Gestión integral urbana del recurso hídrico 24

1.3 Indicadores de desempeño y gestión para la mejora del servicio $\quad 39$

1.3.1 Alcance de una gestión efectiva con base en la valoración de auditorías $\quad 40$

1.3.2 Valoración de la auditoría de sistemas de agua mediante indicadores de gestión 42

1.3.3 Los indicadores 45

1.3.4 Propuesta IWA y la Norma ISO 24500

1.3.5 Otras iniciativas 52

Anexo 1.1 Extracto de la Directiva Marco del Agua 67

Anexo 1.2 Artículos de la Constitución relacionados con el agua 70

CAPITULO II: SOSTENIBILIDAD DE UN ABASTECIMIENTO URBANO $\quad 77$

$\begin{array}{lll}2.1 & \text { Sostenibilidad } & \mathbf{7 9}\end{array}$

$\begin{array}{lll}2.1 .1 & \text { Concepto de sostenibilidad } & 79\end{array}$

2.1.2 Origen de la sostenibilidad 84

$\begin{array}{lll}2.1 .3 & \text { Ejes de la sostenibilidad } & 101\end{array}$

$\begin{array}{lll}2.1 .4 & \text { Gobernanza de recursos hídricos } & 103\end{array}$ 
2.2 Interpretación de la sostenibilidad hacia los abastecimientos de agua potable

$\begin{array}{lll}2.3 & \text { Criterios de selección y desarrollo } & 107\end{array}$

$\begin{array}{lll}2.4 & \text { Sostenibilidad económica } & 110\end{array}$

$\begin{array}{lll}2.5 & \text { Sostenibilidad social } & 114\end{array}$

$\begin{array}{lll}2.6 & \text { Sostenibilidad ambiental } & 117\end{array}$

$\begin{array}{lll}\text { Anexo 2.1 Ciertos aspectos de la sostenibilidad económica } & 120\end{array}$

Anexo 2.2 Gestión para la mejora de la eficiencia energética en sistemas de distribución de agua

CAPITULO III: DIAGNÓSTICO DE LA SOSTENIBILIDAD DE UN ABASTECIMIENTO DE AGUA

3.1 Definición del índice de sostenibilidad de abastecimiento - ISA

3.1.1 Acciones que apoyan la búsqueda de la sostenibilidad de un abastecimiento

3.1.2 Valoración 155

3.1.3 Metodología ISA 156

3.1.4 Diagnóstico y caracterización 157

$\begin{array}{lll}3.1 .5 & \text { Plan } & 157\end{array}$

3.1.6 Ejecución 158

$\begin{array}{lll}3.1 .7 & \text { Seguimiento } & 159\end{array}$

3.2 Componentes cualitativos de la metodología ISA 160

3.2.1 Entrevistas técnicas guiadas 160

3.2.2 Importancias ponderadas 161

3.2.3 Funciones de conversión 163

3.2.4 Proceso de agregación 203

3.3 Clasificación de los abastecimientos según su ISA 205

$\begin{array}{lll}\text { Anexo } 3.1 \text { Vocabulario } & 209\end{array}$ 


\section{CAPÍTULO IV: INTERPRETACIÓN DEL DIAGNÓSTICO Y}

4.1 Análisis e interpretación del diagnóstico ISA 227

$\begin{array}{lll}4.2 & \text { Matriz de prioridades relativas } & 229\end{array}$

4.3 Directrices y actuaciones para mejorar la sostenibilidad 231

4.3.1 Directrices para mejorar la sostenibilidad social 233

4.3.2 Directrices para mejorar la sostenibilidad económica 235

4.3.3 Directrices para mejorar la sustentabilidad 238

4.4 Manual para el diagnóstico de la sostenibilidad en Abastecimientos mediante el ISA

4.4.1 La encuesta, como una parte del guión para la entrevista

4.4.2 Sondeo técnico participativo - STP

4.4.3 Procedimiento del diagnóstico con el índice de sostenibilidad del abastecimiento

Anexo 4.1 Ejemplo de aplicación del diagnóstico ISA

Anexo 4.2 Búsqueda de mejoras de la gestión de un abastecimiento.

CAPÍTULO V: VALIDACIÓN Y APLICACIÓN DEL MODELO MEDIANTE ANÁLISIS DE CASOS PRÁCTICOS

5.1 Aplicación del modelo de diagnóstico de sostenibilidad de abastecimientos -ISA- en sistemas urbanos de agua del Ecuador

5.1.1 Validación

5.1.2 Zona de aplicación

5.1.3 Actividades de campo

5.2 Ejemplo de informe de diagnóstico.- Sistema G01 294

5.2.1 Introducción y ámbito de aplicación 294

5.2.2 Objetivos y alcance del diagnóstico 295

5.2.3 Descripción del levantamiento de la información 295

5.2.4 Características generales 296

5.2.5 Agregación según la metodología de diagnóstico ISA 296 
5.2.6 Visualización de la información en diagramas tela de araña 301

5.2.7 Clasificación del abastecimiento por su ISA 301

5.2.8 Juicio de la situación real actual, con base en el diagnóstico ISA

5.2.9 Conclusiones y recomendaciones 305

$\begin{array}{lll}\text { Anexo 5.1 Diagramas de resultados } & 313\end{array}$

CAPITULO VI: CONCLUSIONES Y RECOMENDACIONES 321

6.1 Conclusiones 323

6.1.1 Conclusiones de los objetivos 324

6.1.2 Conclusiones de la hipótesis 325

6.1.3 Conclusiones generales 326

$\begin{array}{lll}6.2 & \text { Recomendaciones } & 327\end{array}$

$\begin{array}{ll}\text { Bibliografía } & 333\end{array}$ 
Diagnóstico de la sostenibilidad de un abastecimiento de agua e identificación de las propuestas que la mejoren

\section{AGRADECIMIENTO}

Dejo constancia de mi sincero agradecimiento a:

Directivos, personal Administrativo y Docentes de la Universidad Politécnica de Valencia -UPV - a través del Departamento de Ingeniería Hidráulica y Medio Ambiente y a sus destacados Coondinadones del Programa Doctoral.

Al Dr. Enrique Cabrena Narcel y al Dr. Ennique Cabrena Rochera, magnánimos Directores de la presente tesis y fraternos Tutores; por su paciente atención y valioso tiempo brindado, siempre con generosidad, amistad, sobrado Don de Gentes, natural inteligencia y franco apoyo, durante todo el proceso del Programa Doctoral 2006 2010.

A los expositones - facilitadones de cada uno de los cursos de academia impartidos durante esta formación, gracias a quienes pude adquirin conocimientos y experiencias lécnicas trascendentes; todo mi especial reconocimiento y amistad, for sw destacada labor y magistral exposición.

A los Directivos, personal Administrativo y Docente de la Universidad Técnica Particular de Loja -UTPL-, por ser los auspiciantes y principales apoyos para mi participación en el presente programa de doctorado, del mismo modo a los representantes de la Secretaria Nacional de Ciencia y Tecnología -SENACYT, BECAS DOCTORALES -2007-del Ecuador, gracias por sw confianza.

A los Dinectivos y funcionarios de las Unidades Municipales de Agua Potable y Allcantarillado de las ciudades y cantones investigados, a sus Gerentes, Directores, Técnicos, Operadores, miembros de diferentes departamentos; pues gracias a sw tiempo y generosa participación se pudo intewenin y recabar información valiosa para este estudio.

Alos amigos, colegas, compañeros (as) de labores, y a los profesionales en formación que de una w otra forma se involucraron en el presente trabajo de tesis, a lodas las personas que sin estav inscritas en este breve recuento, son merecedoras de mi reconocimiento, for todo sw apoyo y colabonación desinteresada.

De lodo corazón, gracias.

Elesulow. 

Diagnóstico de la sostenibilidad de un abastecimiento de agua e identificación de las propuestas que la mejoren

\section{DEDICATORIA}

A mi esposa: Rosalba Elizabeth,

a mis hijos: Holgev Nohacid, Leyris Naria y Daniel Andrés,

a mis padres: Tili Ëhina y Holgen Hhmberto; y,

a lodos los Framiliares y Amigos.

ConeAmov: Holgev Nanuel. 



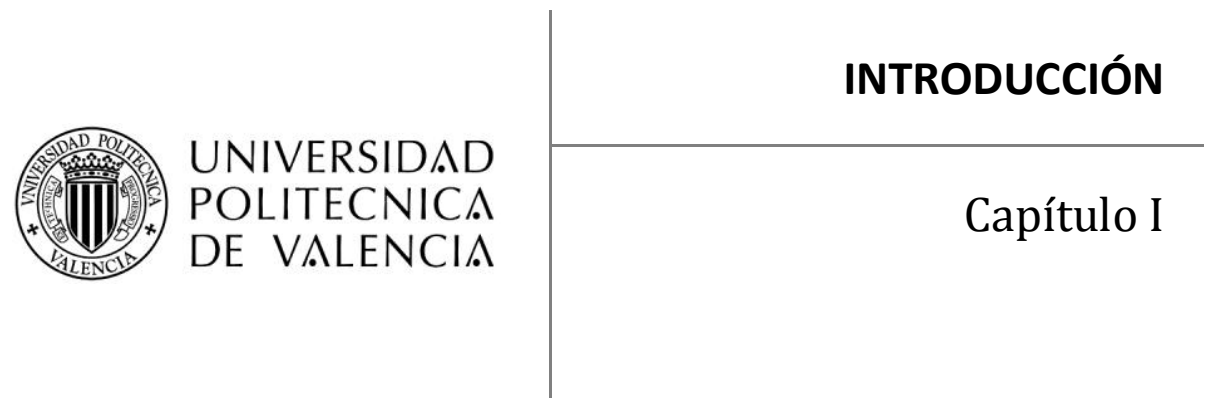





\section{INTRODUCCIÓN}

\section{Resumen}

La creciente demanda de agua, en cantidad y calidad, percibida en los países en desarrollo, debido a la búsqueda por satisfacer las múltiples necesidades de una cada vez mayor población urbana que requiere mejorar su nivel de vida, ejerce permanente presión sobre los gestores del agua, a base de la mejora constante de su desempeño y los obliga a replantearse su plan de acción, hasta ahora inconsistente y trivial en la mayoría de ellos, comprometiendo el equilibrio entre los aspectos que se involucran en el servicio de abastecimiento de agua.

Mejorar el desempeño de los abastecimientos les significará que deben convertirse, temprano mejor que tarde, en gestores de sistemas de agua sostenibles, siempre que se comprendan bien y acaten las normas y políticas recomendadas para este fin, con sensatez y disciplina, por todos los involucrados del escenario hídrico urbano.

Por nuestra parte, conocedores que la optimización del desempeño en los abastecimientos de agua aún debe concretarse y plantearse de forma más comprensible, práctica y sencilla para todos los organismos operadores del entorno, en un lenguaje técnico específico e integral, nace este trabajo de investigación para adaptar un primer conjunto de indicadores sociales, económicos y ambientales que permitan diagnosticar la sostenibilidad en sistemas urbanos de agua potable mediante el "Índice de Sostenibilidad de Abastecimientos - ISA -"; y con base en ello, su clasificación y posterior selección de alternativas generales para ser incluidas en un plan de medidas que permita mejorarla.

El método ISA aquí propuesto, se evalúa mediante la intervención y puesta en práctica en varios abastecimientos de agua del Ecuador. Buscándose recabar siempre las mejores experiencias, conclusiones y recomendaciones aprovechables en los países aún en vías de desarrollo.

\section{Summary}

The growing demand for water, in quantity and quality, perceived in the countries in development, due to search by the multiple needs of a growing urban population that requires improving their standard of living, permanent 
pressure on the managers of water, based on the constant improvement of its performance and forces them to rethink its plan of action, up to now inconsistent and trivial in most of them, committing the balance among the aspects involved in the water service.

To improve the acting of the supplies will mean them that they should become, early better than late, in agents of sustainable systems of water, whenever they are understood well and the norms and politicians accept recommended for this end, with good sense and it disciplines, for all those involved of the scenario urban hydraulic.

For our part, experts that the optimization of the acting in the supplies of water should still be summed up and to think about in a more comprehensible way, practice and simple for all the organisms operators of the environment, in a specific and integral technical language, this investigation work is born a first group of social, economic and environmental indicators that you/they allow to diagnose the sustainable in urban systems of drinkable water by means of the Index of Sustainable of Supplies to adapt - ISA -; and with base in it, their classification and later selection of general alternatives to be included in a plan of measures that allows to improve it.

The method ISA here proposed, it is evaluated by means of the intervention and setting in practice in several supplies of water of the Ecuador. Being always looked for manage to get the best experiences, conclusions and profitable recommendations in the even developing countries.

\section{Resum}

La creixent demanda d'aigua, en quantitat i qualitat, percebuda en els països en desenrotllament, a causa de la intenció de satisfer les múltiples necessitats d'una cada vegada major població urbana que busca millorar el seu nivell de vida, exercix permanent pressió sobre els gestors de l'aigua, a base de la millora constant del seu exercici i els obliga a replantejar-se el seu pla d'acció, fins ara inconsistent i trivial en la majoria d'ells, comprometent l'equilibri entre els aspectes que s'involucren en el servici d'abastiment d'aigua.

Millorar l'exercici dels abastiments els significarà que han de convertir-se, enjorn millor que vesprada, en gestors de sistemes d'aigua sostenibles, sempre que es comprenguen bé i acaten les normes i polítiques recomanades per a este fi, amb sensatesa i disciplina, per tots els involucrats de l'escenari hídric urbà. 
Per la nostra part, coneixedors que l'optimització de l'exercici en els abastiments d'aigua encara ha de concretar-se i plantejar-se de forma més comprensible, pràctica i senzilla per a tots els organismes operadors de l'entorn, en un llenguatge tècnic específic i integral, naix este treball d'investigació per a adaptar un primer conjunt d'indicadors socials, econòmics i ambientals que permeten diagnosticar la sostenibilitat en sistemes urbans d'aigua potable per mitjà de l'Índex de Sostenibilitat d'Abastiments - ISA -; i amb base en això, la seua classificació i posterior selecció d'alternatives generals per a ser incloses en un pla de mesures que permeta millorar-la.

El mètode ISA ací proposat, s'avalua per mitjà de la intervenció i posada en pràctica en diversos abastiments d'aigua de l'Equador. Buscant-se demanar sempre les millors experiències, conclusions i recomanacions aprofitables en els països encara en via de desenrotllament.

\subsection{Exordio}

\subsubsection{Motivación y problemática}

Es bien conocido que el desarrollo económico, social y ambiental se convierte cada uno en parte de los tres pilares de base para el soporte y crecimiento sostenible de la población, elementos catalogados como claves para la supervivencia humana en un futuro próximo; por su importancia, esta última como fuente del bienestar humano incide para que la demanda de agua aumente, y lo hace al ritmo que se incrementa la población, empero la disponibilidad del recurso es constante en el mejor de los casos y decreciente en la mayoría de los sitios.

Es así como la gestión integral sostenible de los abastecimientos de agua para consumo humano agranda su importancia y se torna necesaria, sin embargo en los países considerados “en vías de desarrollo" es más que necesaria, pues resulta imperiosa y vital, debido al estado situacional en la que la gran mayoría de sistemas se encuentran; por tal, se despierta un significativo interés para optimizar la utilización de sus recursos, tanto en las propias empresas operadoras, en sus administradores y abonados, así como en la clase política, gobernante, también en los organismos financieros locales e internacionales así como en los entes reguladores existentes, puesto que involucrar el tema de sostenibilidad en el quehacer de los suministros de agua es el fin perseguido desde hace varios años por la humanidad para mejorar entre otras cosas su calidad de vida.

Congruentemente, no han sido pocos los intentos ni las recomendaciones brindadas en el ámbito internacional para alcanzar la tan ansiada sostenibilidad (Marquardt 2006; Calabuig 2008). La sostenibilidad es un 
concepto que, la más de las veces, se considera sinónimo de desarrollo sostenible y que tiene su punto de partida relativo desde mediados de 1968, cuando por la convocatoria del Club de Roma a hombres de ciencia, economistas, políticos, docentes - investigadores $e$ industriales, principalmente, se reunieron para razonar en las actuaciones a tomar, frente a la alteración y daño que el ser humano le propicia al ambiente y lo ubican al borde de una crisis mundial (Díaz R. y Escárcega S. 2009).

Si los políticos, gobernantes y operadores de sistemas de agua de los países en vías de desarrollo se comprometen con su entorno social y ambiental para la búsqueda de la sostenibilidad e inician, de forma sustentable, su actuación basados en una gestión integral de los abastecimientos bajo su responsabilidad, entonces se pondrá inmediatamente de manifiesto y a la luz que falta casi todo por hacer en este ámbito.

Existen varias causas cuyos efectos conducen hacia impactos sinérgicos, cíclicos y de vuelco permanente a una entropía global del abastecimiento, que impiden estar en el nivel deseado; dichos aspectos se resumen a continuación, en la tabla 1.1.

Tabla 1.1 Matriz de percepción de problemas generales en abastecimientos de agua

\begin{tabular}{|c|c|c|}
\hline Causa & Efecto & Impacto \\
\hline $\begin{array}{l}\text { Baja eficiencia en el manejo de } \\
\text { agua potable por parte de los } \\
\text { organismos } \\
\text { responsables. }\end{array}$ & $\begin{array}{l}\text { Cantidad y calidad de agua } \\
\text { insuficiente, en tiempo y espacio. }\end{array}$ & $\begin{array}{l}\text { Insostenibilidad } \\
\text { social. }\end{array}$ \\
\hline 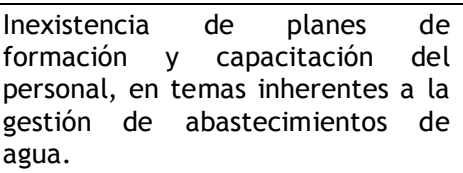 & $\begin{array}{l}\text { Desconocimiento técnico para la } \\
\text { mejora de la gestión de la oferta } \\
\text { y la demanda. Escaso "know how" } \\
\text { institucional en operación y } \\
\text { mantenimiento. }\end{array}$ & $\begin{array}{l}\text { Insostenibilidad } \\
\text { social. }\end{array}$ \\
\hline \multirow{2}{*}{$\begin{array}{l}\text { Tarifas por pago de consumo de } \\
\text { agua suministrada insuficientes. } \\
\text { Subsidios mal estructurados, pues } \\
\text { no propician el uso eficiente. }\end{array}$} & $\begin{array}{l}\text { Sistema de mantenimiento y de la } \\
\text { mejora constante desfinanciados. } \\
\text { Inestabilidad e ineficiencia } \\
\text { financiera. }\end{array}$ & \multirow{2}{*}{$\begin{array}{l}\text { Insostenibilidad } \\
\text { social y } \\
\text { económica. }\end{array}$} \\
\hline & $\begin{array}{l}\text { Deterioro incontrolado y } \\
\text { totalizado de la infraestructura } \\
\text { hidro-sanitaria del sistema. } \\
\text { Servicio intermitente. }\end{array}$ & \\
\hline $\begin{array}{l}\text { Cultura inapropiada para la oferta } \\
\text { y demanda de agua. }\end{array}$ & $\begin{array}{l}\text { No existe gestión de la oferta ni } \\
\text { de la demanda con base en la } \\
\text { relación: costo / beneficio. } \\
\text { Derroche y gasto. }\end{array}$ & $\begin{array}{l}\text { Insostenibilidad } \\
\text { económica. }\end{array}$ \\
\hline
\end{tabular}


Diagnóstico de la sostenibilidad de un abastecimiento de agua e identificación de las propuestas que la mejoren

\begin{tabular}{|c|c|c|}
\hline Causa & Efecto & Impacto \\
\hline $\begin{array}{l}\text { Infraestructura de los sistemas con } \\
\text { vida útil cumplida. Estado físico } \\
\text { actual de las redes y sus } \\
\text { componentes de distribución } \\
\text { vetustos y condiciones deficientes. }\end{array}$ & $\begin{array}{l}\text { Mala calidad y cantidad de } \\
\text { servicio. Fugas. Contaminación } \\
\text { por intrusión. Racionamientos, } \\
\text { etc. }\end{array}$ & $\begin{array}{l}\text { Insostenibilidad } \\
\text { económica. }\end{array}$ \\
\hline $\begin{array}{l}\text { Descoordinación legal, política y } \\
\text { social. }\end{array}$ & 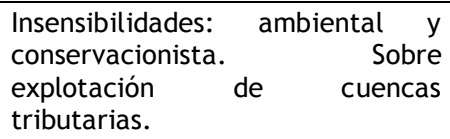 & $\begin{array}{l}\text { Insostenibilidad } \\
\text { ambiental. }\end{array}$ \\
\hline $\begin{array}{l}\text { Inapropiadas prácticas y políticas } \\
\text { de gestión de cuencas hidrográficas } \\
\text { que sirven de fuente para el } \\
\text { abastecimiento. }\end{array}$ & $\begin{array}{l}\text { Degradación } \text { de } \\
\text { tributarias o fuentes.- Sobre } \\
\text { explotación de sus recursos. } \\
\text { Época de sequía aumentada. } \\
\text { Contaminación aguas abajo. } \\
\text { Erosión de suelos. }\end{array}$ & $\begin{array}{l}\text { Insostenibilidad } \\
\text { ambiental. }\end{array}$ \\
\hline $\begin{array}{l}\text { Politización de las estructuras } \\
\text { administrativas de la institución } \\
\text { operadora, que afectada por } \\
\text { superposiciones institucionales } \\
\text { administrativas limitan la } \\
\text { continuidad de planes, programas y } \\
\text { trabajos técnicos prioritarios. }\end{array}$ & $\begin{array}{l}\text { Discontinuidad de ejecución de } \\
\text { obras de infraestructura, } \\
\text { inversiones desordenadas y caos } \\
\text { constructivo. }\end{array}$ & $\begin{array}{l}\text { Insostenibilidad } \\
\text { social, económica } \\
\text { y ambiental }\end{array}$ \\
\hline $\begin{array}{l}\text { Crecimiento horizontal } \\
\text { desorganizado de las ciudades. }\end{array}$ & $\begin{array}{l}\text { Sistemas insuficientes. Desorden } \\
\text { territorial. } \\
\text { insatisfechos. }\end{array}$ & $\begin{array}{l}\text { Insostenibilidad } \\
\text { social y } \\
\text { ambiental. }\end{array}$ \\
\hline
\end{tabular}

Adicionalmente existen problemas que pueden ser la causa y el efecto de otros, que combinados entre sí agravan aún más la situación actual; así tenemos:

La demanda de agua potable es superior que la ofertada, debido entre otras cosas a la limitada capacidad instalada con la que cuentan dichos sistemas.

En la mayoría de los abastecimientos de agua, el servicio tiene problemas de cantidad, básicamente por utilizar infraestructuras hidráulicas fatigadas, cuyas actividades de operación y mantenimiento cada vez son más preocupantes. La calidad (física, química y bacteriológica) del agua también se enfrenta a procesos irregulares en su tratamiento y serios descuidos operativos en la desinfección, tanto por empirismo cuanto por actitud idiosincrática costumbrista del personal, lo que influye directamente para que disminuya la eficiencia de potabilización y el agua deje de tener características aceptables para consumo humano. Así entonces, los sistemas son insuficientes hidráulicamente, con usuarios que con el ánimo de mitigar este problema, y normalmente de una forma arcaica, suplen la falta de volumen del líquido (cantidad requerida) a cambio de un alto costo de su calidad, afectándose esta última por la interposición de depósitos de 
almacenamiento domiciliar (aljibes) entre la red de distribución y el consumo final, implicándose por esto una inminente intrusión patógena en el líquido consumido.

Además, son limitadas las acciones emprendidas por los gestores para obtener los recursos técnico-económicos que lleven a las empresas municipales de agua a ser eficientes cada año, provocando por ejemplo, que las redes se operen sin una sectorización adecuada, o sin un sistema de macro medición, ni procedimientos que ajusten (regulen) el servicio con depósitos de almacenamiento, ni monitoreo o regulación de la presión, así como tampoco se invierte en los instrumentos que permitan medir u optimizar la cantidad y calidad del flujo distribuido, menos aún, en la igualmente importante, renovación de la infraestructura del abastecimiento. Dentro de las instituciones que se encargan de velar por la gestión del agua varía notoriamente la capacidad humana y técnica, cuyos niveles de gestión se aprecia como parcialmente apropiado y en ciertos casos nulos o contrapuestos a lo deseado, lo que evidencia la mayoría de las veces un desorden administrativo-operativo (también denominado una no conformidad de sostenibilidad) que afecta a sus abonados y al sistema de suministro.

Son varias las coincidencias que podemos percibir en el entorno Sudamericano de sistemas de agua con la problemática de aquellos abastecimientos Españoles que los Profesores (Cabrera E. y Garcia-Serra J. 1997) resumieron en su libro "Problemática de los abastecimientos urbanos. Necesidad de su modernización". Por anotar alguno, entre varios de ellos, tenemos: el descontrol administrativo, que con una superposición de competencias deja de lado la posibilidad de contar con un solo ente responsable que actúe bajo el manto legal de una normativa particular concerniente al tema de los sistemas de abastecimiento.

Las políticas preventivas de daños en las redes y detección de fugas son inexistentes, ocasionando esto que un gran número de abastecimientos no contabilicen hasta en un $70 \%$ del volumen inyectado. Concatenado con un limitado sistema de micro medición, tanto por cobertura como por antigüedad del parque de contadores domiciliares. Hasta enero de 2005, por ejemplo, la empresa operadora de agua de Loja (UMAPAL), no contabilizaba el $72 \%$ de su volumen suministrado. (Altamirano F. - Reporteros: Yanez C. y Jaramillo D. 2007).

Se denota que la mayoría de gestores de abastecimientos de países en vías de desarrollo no prestan mayor importancia al tema de la rehabilitación, renovación o mejora de los sistemas actuales. Así, el proceso de envejecimiento de la infraestructura hidráulica registra una disminución significativa de las disponibilidades hídricas puestas al servicio de la colectividad. 
En ciertos abastecimientos de agua potable (medianos y pequeños) hace falta un rediseño y reconstrucción general de sus componentes, ya que presentan defectos de "origen", o se han visto afectados por un cambio actual en el uso del suelo, o por aumento poblacional en el núcleo céntrico urbano, por zonas no previstas que se convierten en áreas urbanas consolidadas con gran demanda de servicios básicos, principalmente.

En este ámbito, el desconocimiento del tema de gestión sostenible de redes que involucre un duradero equilibrio económico, social y ambiental de la operación y mantenimiento del sistema de abastecimiento en pleno, empeora la situación. Súmese como otro agravante el hecho que se deja de lado la tarea de capacitación a la comunidad para lograr un uso racional del agua y a los propios técnicos - operadores de la red.

A esto debemos concatenar el escenario del consumo de agua envasada, ya que el usuario, no da la suficiente credibilidad a la calidad y pureza del agua que le llega a su domicilio por la red pública, de tal modo que siente la obligación de invertir más dinero en comprar un tipo de agua con posiblemente mejor calidad. En el Ecuador, el consumo promedio anual de agua embotellada por persona es de 39 litros y el gasto en bebidas sin alcohol (agua, gaseosas y jugos) asciende a 34 millones de dólares americanos por mes y 0.41 millardos de dólares americanos al año, (Negrete 2009); pues, a nivel del mundo la empresa del agua embotellada mueve 22 millardos de dólares americanos por año. (Delgado 2004).

En el aspecto académico formativo, son muy pocas las Universidades de estos países "aquellos en vías de desarrollo" en las que a nivel de pregrado o postgrado brindan a los profesionales en formación elementos de juicio básico en torno al tema de gestión urbana sostenible del agua.

Con estos detalles expuestos - bien que de manera moderada y breve - y sentida la necesidad de buscar alternativas que coadyuven a la solución de los problemas implícitos, nace esta tesis, entre cuyo resultado constará como herramienta práctica una propuesta que permita diagnosticar la sostenibilidad de los abastecimientos de agua potable de países en desarrollo. Pues, será luego de su aplicación cuando le permita al gobernante, administrador, operador y usuario identificar el estado actual de su abastecimiento de agua para orientar sus decisiones y acciones que encaminen una mejora de la sostenibilidad y del propio desempeño. Así mismo, el presente trabajo, dentro del contexto académico-investigativo de nuestro entorno, se convierte en el primero que se propone de este estilo; intitulado: "Diagnóstico de la sostenibilidad de un abastecimiento de agua e identificación de las propuestas que la mejoren".

Diremos entonces que el resultado así alcanzado permitirá, además de lo anterior, incorporar entre los gobiernos locales y operadores de los 
abastecimientos de agua de los países en vías de desarrollo una base técnica para implantar una filosofía de diagnóstico de la gestión sostenible de sus sistemas de abastecimiento, con la posibilidad de mejorar la calidad de servicio a sus abonados y equilibrar su accionar entre lo social, económico y ambiental. A pesar que es muy perceptible la diferencia legislativa, capacidad de gestión, konw how e institucionalidad, respecto al uso efectivo del agua entre los países, y entre municipios dentro del mismo Ecuador; de tal modo que, toda propuesta de selección de alternativas para la búsqueda de la mejora de sostenibilidad de un abastecimiento tiene que ser bien flexible, para que se pueda adaptar con facilidad a cada caso y ser aprovechado de la mejor manera.

Entre los potenciales beneficios de implantar un sistema de diagnóstico de la sostenibilidad de los abastecimientos del Ecuador y de varios países en desarrollo, está además el hecho de proponer por vez primera un instrumento técnico, que facilite iniciar el proceso de transformación y mejora progresiva en los aspectos constitutivos de la sostenibilidad de los sistemas urbanos de agua, ofreciendo un conjunto de alternativas metodológicas para la toma de decisiones con base en su sostenibilidad, y de cierto modo mostrar al menos uno de los caminos que pueden seguirse para conseguir dicho fin.

\subsubsection{Objetivos, hipótesis y metodología}

\section{a) Objetivos:}

Como objetivos centrales de la investigación se plantean los siguientes:

1. Proponer un conjunto metodológico de directrices para diagnosticar la sostenibilidad de un abastecimiento de agua para consumo humano e identificar las propuestas que la mejoren.

2. Estructurar un instrumento que posibilite evaluar la sostenibilidad económica, social y ambiental, en los abastecimientos de agua, mediante su propio índice.

3. Proponer directrices y actuaciones que permitan identificar las alternativas para mejorar la sostenibilidad según corresponda a su índice de sostenibilidad de abastecimiento, ISA, obtenido en el diagnóstico previo correspondiente. 


\section{b) Hipótesis:}

La hipótesis de este trabajo pertenece a un tipo de investigación exploratorio, ya que poco se sabe sobre el tema; $y$, no se utiliza, como base de nuestro estudio, ningún modelo anterior de diagnóstico de la sostenibilidad de abastecimientos de agua, porque hasta el momento no existe uno que se adapte de manera efectiva a los países en vías de desarrollo y que al igual que todos, también sienten la imperiosa necesidad de gestionar de forma integradora sus recursos vitales.

Tomando en cuenta el estado del arte relacionado al tema de investigación, junto con las bases que han de sentar la evolución de los abastecimientos hacia una mejora sostenible, suponemos entonces que: El índice de sostenibilidad de un abastecimiento (ISA) se puede medir siempre que se consideren para su valoración indicadores (sociales, económicos y ambientales) relacionados con el abastecimiento.

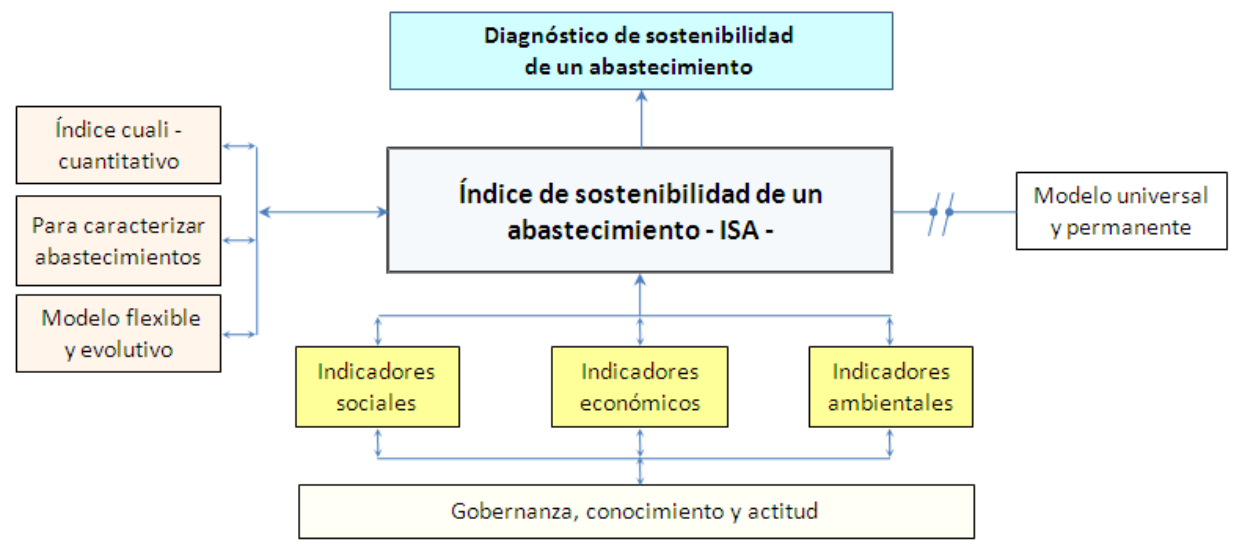

Figura 1.1 Mentefacto ${ }^{1}$ conceptual de la hipótesis investigativa

\section{Descriptores del mentefacto conceptual de la hipótesis:}

Los infraordinar: Lo constituyen los indicadores sociales, económicos y ambientales, relacionados con el componente de gobernanza, conocimiento y actitud. Su interrelación 
brinda la estructura portante del modelo ISA. Los indicadores se seleccionaron y ordenaron estratégicamente, como resultado de combinar la investigación documental con el sondeo y observación participativos de campo.

El concepto: Es el modelo del índice de sostenibilidad de un abastecimiento -ISA- propiamente dicho. En el modelo ISA se incluye la transformación de indicadores a factores de calidad y estos a su vez forman parte del ISA, según su peso e importancia en todo el contexto valorativo.

El supraordinar: Es la clase superior conseguida con el modelo ISA, luego de su aplicación, denominada "diagnóstico de sostenibilidad de un abastecimiento".

Los isoordinar: Son las características esenciales del modelo ISA. Al constituirse el modelo como un "índice de agregación cuali - cuantitativa", se prevé que está conformado de varios componentes que a su vez son el resultado de datos del propio abastecimiento, más la información recabada de la observación de campo, sondeo participativo, entrevistas, encuestas y experiencias de la evidencia in situ. Otra característica mostrada es que se trata de un "modelo flexible y evolutivo", dejando de manifiesto que el modelo ISA, se deberá adaptar a la mayoría de los abastecimientos de forma general, pero que amerita acople y evolución, en espacio y tiempo; y, otro aspecto isoordinar, es que con el valor del ISA se podrá "caracterizar y clasificar el abastecimiento".

La excluyente: Nos indica que el modelo ISA no es un modelo universal y permanente; es decir que no se podrá cumplir siempre y en todos los abastecimientos del planeta; a pesar que la intención primera de este trabajo de investigación, es el de proponer un modelo de diagnóstico general, aplicable a la gran mayoría de sistemas de agua de los países en vías de desarrollo sostenible.

\section{c) Metodología:}

Brevemente se expone la forma del planteamiento epistemológico que se adoptó para desarrollar este trabajo de investigación; que incluye un modelo de medición del índice de sostenibilidad de un abastecimiento, luego el 
proceso de aplicación y experimentación de la propuesta; y, finalmente recomendaciones a las acciones que se pueden aplicar para aquellos abastecimientos que deben centrar su accionar en buscar la sostenibilidad, con base en el diagnóstico practicado.

En este sentido, la investigación se ubica en un campo de estudio cualicuantitativo, que se evolucionó durante todo el proceso formativo de cuarto grado en el que hemos podido participar; este suceso, flexible y positivamente cambiante, nos permitió converger de forma gradual y sistemática en el resultado que aquí se presenta.

De los métodos particulares que se emplean para desarrollar una investigación exploratoria se utilizaron el método experimental y deductivo, que luego de una indagación documentada se adaptó hacia una incursión aplicada.

En las líneas siguientes se expone concretamente la estrategia adoptada como más conveniente para el desenlace investigativo del tema planteado; así:

- Estudio del estado del arte.- Se seleccionó y ordenó conceptos, técnicas e instrumentos que mejor se adaptaron para la comprensión y evaluación de la sostenibilidad de los sistemas de abastecimiento de agua. Se seleccionó los indicadores que identifican y caracterizan la sostenibilidad de un abastecimiento en los aspectos: social, económico y ambiental.

- $\quad$ Definición del modelo.- se propuso un modelo de diagnóstico de la sostenibilidad basado en los indicadores (sociales, económicos y ambientales) y estos a su vez convertidos en factores de calidad, que combinados entre sí proporcionalmente a su importancia, nos arrojaron el índice de sostenibilidad del abastecimiento (ISA).

- $\quad$ Aplicación del modelo.- El modelo se aplicó y experimentó, mediante su utilización in situ en más de catorce abastecimientos de agua potable ubicados en ciudades del Ecuador. Seguidamente se coligió y formó el compendio narrativo expuesto más adelante, como una opción general que reúne el conjunto de directrices que apoyen un consenso razonado para la búsqueda de la sostenibilidad.

- $\quad$ Declaración de conclusiones.- luego del análisis del modelo propuesto y de su validación se formuló las conclusiones junto con las recomendaciones de la investigación. 
El estudio de una propuesta de mejora bajo un enfoque de gestión (y management), incluye técnicas cualitativas; para cumplir con este propósito, se investigó a varios organismos operadores (observación participante), a través de múltiples visitas de campo, aplicación de encuestas y entrevistas técnicas guiadas (Delphi) a los involucrados y administradores de los mismos; además, por ser un tópico que requiere de una técnica descriptiva y de investigación documental, se buscó apoyo en información múltiple, recabada de publicaciones de organismos internacionales involucrados en la gestión del agua, las normas pertinentes y bibliografía relacionada con el tema, de tal forma que se conformó un panorama teórico, sólido y suficiente, como plataforma del modelo propuesto y su posterior aplicación.

\section{d) Desafíos y retos:}

El deseo ferviente de este trabajo de tesis es que su resultado contribuya, de una forma potente y robusta, en la toma de decisiones y orientación de la planificación estratégica para la gestión sostenible del abastecimiento, a sus principales decidores, como: la sociedad política, los entes de financiamiento y el cuerpo gerencial y coordinador del sistema de agua. Esto requiere que la herramienta propuesta simplifique al máximo dicha tarea.

La herramienta de diagnóstico de la sostenibilidad de los abastecimientos de agua se proyecta para su fácil agregación al momento de calcular el indicador, que permita caracterizar al abastecimiento, eso implica sintetizar en una sola cifra toda la información que conduce a la sostenibilidad del abastecimiento, de forma práctica y trazable, lo que la convierte en igualmente sencilla a la hora de desagregarla para sustentar la selección de medidas correctoras como línea base de la planificación. Este obliga a que la trayectoria de cálculo del índice de sostenibilidad debe quedar visible en el proceso.

La presentación gráfica del diagnóstico debe facilitar la comprensión del resultado del índice de sostenibilidad y las características de sus subcomponentes, por la mayoría de los actores de la sociedad civil.

La herramienta debe permitir, además, una evaluación comparativa autonómica; es decir, que la comparación de los resultados de sostenibilidad no dependa de la información que puedan o quieran propiciar gestores de otros abastecimientos homólogos (terceros), sino por el contrario, que lleve implícito los aspectos de verificación y la referencia de medidas deseables.

La herramienta debe aprovechar y potenciar al máximo los datos, información y recursos con los que se cuente; y su impacto, coadyuvar a promover el cambio para la mejora. 
Todo esto, circunscrito en la realidad del entorno de aplicación, que marca los retos del trabajo; tales como:

Los abastecimientos investigados carecen de datos e información ordenada, completa y suficiente.

La mayoría de los gestores de los abastecimientos seleccionados, a la fecha del trabajo, no cuentan con una base de indicadores que les permitan mejorar su desempeño; y, existe una gran limitación a la hora de seleccionar las variables que contribuyan a la evaluación continua para la mejora del sistema de agua que operan. Otro no menos importante aspecto que afecta el entorno de la aplicación de la propuesta, es la idiosincrasia de los involucrados y la actitud de indiferencia respecto del tema, en algunos de ellos.

Otra característica del tema objetivo, es que al momento el diagnóstico de la sostenibilidad de abastecimientos de agua, a nivel mundial, es un tema sin resolver. Si bien es cierto, y nos sirve como un referente técnico, las Universidades de Yale y Columbia, en colaboración con: World Economic Forum, Joint Research Centre - JRC European Commission, Design and Data Visualization, y Lead Scientific Experts, desde 2008 vienen desarrollando el programa "Environmental Performance Index", en el que plantean al mundo la comparación, mediante un ranking, el desempeño ambiental de 163 países, mediante la aplicación de 25 indicadores ambientales, organizados en 10 categorías que cubren la salud pública, medioambiente y vitalidad de los ecosistemas. Este ranking mundial, pretende entre otros detalles particulares, proporcionar una medida comparativa global para medir el comprometimiento de los gobiernos de cada nación respecto de las metas medioambientales establecidas.

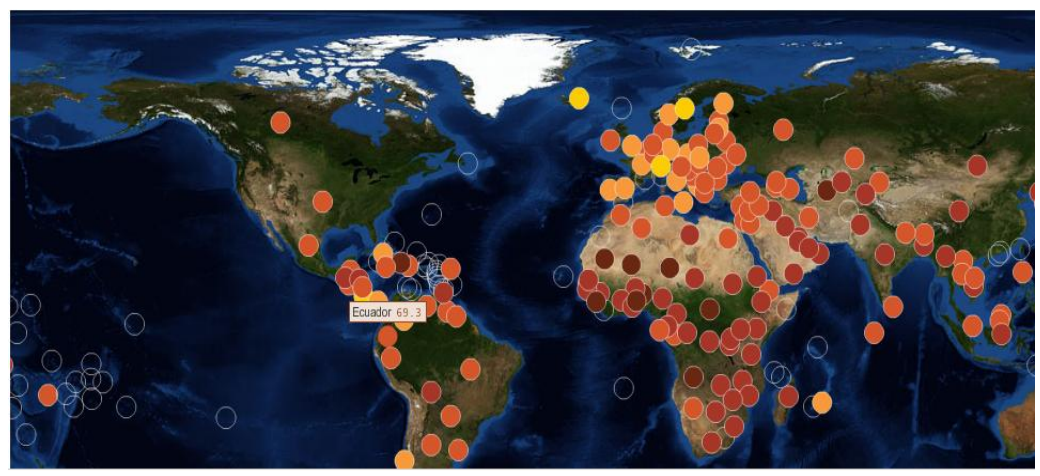

Mapa 1.1 Distribución mundial del índice de desempeño ambiental Fuente: (EPI-Index 2010, Yale and Columbia University). 


\subsubsection{Estructura de la tesis}

El guión investigativo que se utilizó para el presente trabajo se enmarca en los componentes siguientes:

\section{i) Introducción}

Alcance: Narrar el exordio del trabajo investigativo.

Contenido: En este acápite se recopila una plataforma introductoria del tema investigado, que agrupa: antecedentes, motivación, problemática y estado actual de los abastecimientos, necesidad de diagnosticar su sostenibilidad; los objetivos e hipótesis del presente trabajo; y, además se incluye una descripción de los componentes de la Directiva Marco del Agua, la Gestión Integral de Recursos Hídricos.

\section{ii) Sostenibilidad de un abastecimiento urbano de agua}

Alcance: Conceptualizar la sostenibilidad, en su ámbito global y más puntualmente para los abastecimientos urbanos de agua.

Contenido: Se expone el marco teórico de la sostenibilidad en un contexto general. Seguidamente las características requeridas para abastecimientos urbanos de agua, junto con sus componentes en la combinación: social, económica y ambiental. En cada componente se recopila los indicadores de gestión del sistema de abastecimiento que mejor se adaptan a la realidad de los países en desarrollo y define su factor de calidad. Se considera el enfoque estratégico de la IWA para plantear los objetivos, estrategias, factores críticos de éxito y los indicadores de gestión. Se propone los niveles de sostenibilidad deseados en un abastecimiento, bajo normativas y estándares deseables, urgentes o importantes, provenientes de entrevistas técnicas personales.

\section{iii) Diagnóstico de la sostenibilidad de un abastecimiento de agua}

Alcance: Proponer el modelo para el diagnóstico de la sostenibilidad de abastecimientos urbanos (ISA), con base en los indicadores previamente seleccionados.

Contenido: Para diagnosticar la sostenibilidad de un sistema de agua urbano se lo hizo a través del índice de sostenibilidad de abastecimiento (ISA); en este componente se involucra, las funciones de conversión de cada indicador de gestión (IG) a su correspondiente factor de calidad (FC); factores que en la valoración final influyen ponderadamente en el índice (ISA), de forma 
proporcional a su importancia; constituyéndose de esta forma el modelo de diagnóstico de la sostenibilidad.

Asimismo, con base en el ISA, se caracteriza y clasifica los sistemas de suministros según el nivel de sostenibilidad que le identifique. Se resume también un manual práctico para llevar a cabo un diagnóstico de abastecimientos, mediante el método ISA.

\section{iv) Catálogo de directrices y actuaciones.}

Alcance: Clasificar actuaciones acordes a cada realidad, para la mejora de la sostenibilidad del abastecimiento estudiado; $y$, proponer criterios para priorizarlas.

Contenido: Con el diagnóstico de los abastecimientos, implicada una valoración y clasificación, se presenta las potenciales alternativas de actuación para mejorar el estado y desempeño del abastecimiento. Las medidas de acción se orientan hacia el incremento de la sostenibilidad en lo social, económico y ambiental.

Son varias las acciones que se proponen, entre ellas se hace constar los temas de capacitación, los balances hídricos y la detección de fugas, la reestructuración tarifaria para recuperar costos, entre otros.

Una vez que se tiene clasificado cada abastecimiento corresponde analizar los ejes de la sostenibilidad que están en un estado crítico de afectación y en función de esto se recomienda las alternativas de solución - tratamiento -; dando prioridad de rescate y salvamento, según convenga; de tal modo que el sistema sea re-direccionado hacia una sostenibilidad progresiva, mientras no se descontinúe dicho tratamiento. Para la priorización se propone, también por adaptación propia del autor, una matriz que combina los métodos del $A B C$ con el de pares.

v) Aplicación del modelo mediante análisis de casos prácticos.

Alcance: Aplicación del diagnóstico de la sostenibilidad de abastecimientos a través del modelo ISA, en catorce sistemas urbanos de agua del Ecuador. Luego de su aplicación y de las experiencias recabadas de campo, se valida el modelo metodológico propuesto.

Contenido: El modelo para el diagnóstico de la sostenibilidad de un abastecimiento se ajusta y se aplica según corresponde luego de recopilar las experiencias de los casos prácticos en los abastecimientos urbanos de Ecuador. Además se proponen las acciones recomendadas para su mejora y el modelo de informe del diagnóstico de uno de ellos. 
vi) Conclusiones y recomendaciones.

Alcance: Redactar las conclusiones y recomendaciones que procedan del presente estudio.

Contenido: Conclusiones y recomendaciones de: objetivos, hipótesis y del estudio en sí.

\subsection{La gestión integral de recursos hídricos - GIRH}

Se conoce que entre los temas que se analizaron en la Cumbre Mundial de Desarrollo Sostenible de Johannesburgo del 2002, estuvieron los de concienciar en los participantes y a través de ellos a sus representados, la importancia y trascendencia futura que tiene la gestión sostenible del agua junto con las acciones para la conservación de recursos naturales, principalmente los hídricos. Así fue que hasta el año 2005, los países Sudamericanos que participaron en dicha Cumbre, se comprometieron a desarrollar planes de gestión integral de recursos hídricos (GIRH) y de eficiencia hídrica (EH). Dichos planes debieron ser nacionales y regionales. No obstante, hasta la fecha es Brasil el único país del Continente que cumplió mayormente con tales compromisos (IW-LEARN 2009).

Frente a esta situación, en el año 2008, varios organismos internacionales como el PNUMA (Programa de las Naciones Unidas para el Medio Ambiente), CAN (Comunidad Andina de Naciones), IUCN-SUR (Unión Internacional para la Conservación de la Naturaleza), FONAG (Fondo para la protección del agua Ecuador), CNRH (Consejo Nacional de Recursos Hídricos), Ministerio del Ambiente, junto con los sectores: ambientales, hídricos y representantes de la sociedad civil, organizaron un taller nacional para la GIRH en el Ecuador, cuyo resultado se utilizó para la elaboración de un decreto emitido desde la Presidencia de la República a través de la autoridad en recursos hídricos, para mejorar todos estos aspectos inmersos en la gestión, dentro del marco de la Estrategia Andina de Recursos Hídricos (IUCN 2008). El fin perseguido con múltiples acciones internacionales planteadas, es el de buscar una apropiada gestión de cuencas transfronterizas y nacionales, optimizado y garantizado para sus usuarios y comunidad en general.

Los recursos hídricos, al formar parte de ecosistemas cambiantes, requieren para su permanencia en el tiempo, tanto en calidad como en cantidad, de una gestión integral que implica un estilo general adaptativo y flexible. Es allí entonces cuando se requiere de una evaluación permanente apoyada por un monitoreo constante de las variables constitutivas del desempeño del gestor y 
la sociedad. Pues, el aprender con los interesados o involucrados en el consumo de recursos hídricos - aprendizaje social - es la forma idónea para gestionar el agua compartida, (Bergkamp 2003).

Según se puso de manifiesto en la sala 5 (ExpoZaragoza 2008) "Agua para el mundo", durante el transcurso del Siglo XX la población mundial se triplicó y la demanda de agua se sextuplicó, y queda como un privilegio de muy pocos habitantes del planeta el hecho de tener agua dulce (potable) en sus domicilios. Muestra de ello se presenta mediante las siguientes estadísticas:

- Una de cada cinco personas no tiene acceso al agua potable.

- Dos de cada cinco personas no tiene acceso a un sistema saneamiento adecuado.

- Más de dos millones de personas / año mueren por falta de agua potable (en su mayoría niños).

Así mismo se publicó que, con base en información de las Naciones Unidas, que para el año 2025, las dos terceras partes de la población mundial sufrirá, en diferente grado y medida, la falta de agua potable. Es así que la Unión Europea, consciente de este problema desde varios años atrás adoptó una serie de medidas de protección del recurso hídrico, como:

- Reducción de la contaminación industrial.

- $\quad$ Depuración de aguas residuales, previo a su vertido a los cuerpos receptores naturales.

- $\quad$ Prevención de contaminación de acuíferos y aguas superficiales por malas prácticas agrícolas.

- Conservación del equilibrio acuático natural.

- Control de calidad del agua, entre otras.

Para cumplir a cabalidad con estos propósitos fue necesario aplicar una gestión del agua por cuencas hidrográficas, involucrándose en ello todos los actores, así: autoridades locales, consumidores, comercios e industrias y los agro-productores, sin que la frontera administrativa, internacional o regional, sea un impedimento; $y$, por el contrario con los acuerdos o tratados internacionales los usuarios del agua de la cuenca baja no resultan ser víctimas de los errores que se puedan cometer en cuenca alta o media. Dejando ver que la intención es crear una estructura de gobernanza del agua capaz de aprovechar de forma eficaz las ayudas (político-técnico-económicas) existentes, involucrando participativamente a todos los agentes locales. (ExpoZaragoza 2008). 


\subsubsection{Directiva Marco del Agua}

El Parlamento Europeo y el Consejo de la Unión Europea, establecen en el ámbito de gestión del agua un marco de actuación y protección, mediante la Directiva Marco del Agua (DMA). Esta directiva fomenta desde el 18 de julio del año 2000, fecha en la que se formalizó, el uso sostenible del agua con énfasis en la protección y la reducción de vertidos de sustancias contaminantes a los cuerpos receptores.

La DMA tiene como propósito establecer un marco legal para brindar protección y mejorar la calidad de los ecosistemas acuáticos, terrestres y humedales que dependen directamente de los primeros.

Por citar algunos de sus artículos, nos centraremos en aquellos que tienen directa relación con el agua potable y su gestión urbana; en tal caso se puede decir que:

En el Artículo 7, Aguas utilizadas para la captación de agua potable, se dispone que los Estados miembros especificarán dentro de cada demarcación hidrográfica todas las masas de agua destinadas al consumo humano que proporcionen en promedio más de $10 \mathrm{~m}^{3}$ diarios o que abastezcan a más de cincuenta personas; tanto en tiempo presente como en un futuro. Así mismo se dispone también que se efectúe un seguimiento de las masas de agua que proporcionen más de $100 \mathrm{~m}^{3}$ diarios. Además los Estados miembros velarán para que las masas de aguas depuradas cumplan con todos los requisitos de calidad según las directivas correspondientes $(80 / 778 /$ CEE modificada por la $98 / 83 /$ CE). Finalmente, en este mismo artículo, se incluye la necesaria protección de las masas de agua para evitar el deterioro de su calidad con el ánimo de reducir el nivel del tratamiento de purificación necesario para la producción de agua para consumo humano, tarea que puede ser apoyada con el establecimiento de perímetros de protección para aquellas masas de agua. (UE \& PE-CONS 2000), Art. 7.

Un artículo que es muy importante desde cualquier punto de vista, sobre todo del que desde la clase política del resto del mundo, en algún momento se permita concienciar, es el Artículo 9 de la misma DMA, titulada Recuperación de los costos de los servicios relacionados con el agua. En éste se dispone a los Estados miembros a tomar en cuenta el principio de recuperación de costos de los servicios relacionados con el agua; inclúyele costos ambientales, los de recursos y todo el aparataje económico invertido en el servicio, basados en el principio de que "quien contamina paga". Previéndose que hasta este año (2010) las políticas de precios del agua proporcionen incentivos adecuados a sus abonados o clientes para un gasto eficiente del recurso hídrico, tarea que se fundamentará tomando en consideración los efectos sociales, medioambientales, condiciones geográficas y climáticas de la región 
y la recuperación económica propiamente dicha. (UE \& PE-CONS 2000), Art. 9.

En cualquier caso, se estipula necesario contar con un plan hidrológico (hidrogeológico) por cada cuenca hidrográfica. En los casos en que la cuenca comparta con más de un Estado, éstos garantizarán la coordinación plena y suficiente para que exista un único plan hidrológico internacional. (UE \& PECONS 2000), Art. 13. Para ver contenidos de dichos planes hidrológicos ir a Anexo 1.1.

Asimismo la DMA, con su dictamen, pretende garantizar la sostenibilidad del agua basándose en la protección a largo plazo de los recursos hídricos que se disponga, esto mediante la progresiva reducción de vertidos, emisiones y pérdidas de sustancias peligrosas prioritarias, tal como también evitar nuevas contaminaciones. Su objetivo también es el de amainar los efectos e impactos que los cambios bruscos de la cantidad de agua disponible tienen en la cuenca a la que pertenecen; tanto los episodios de inundación cuanto los escenarios de estiaje.

El fin que busca la DMA, es el de permitir un uso libre del agua siempre que sea de una forma sostenible, bajo los principios de equidad y equilibrio, para que se garantice un suministro de agua suficiente y en buen estado, esto implica inferir valores de concentración en el medio marino muy próximos a los básicos -sustancias de origen natural- y cercanas a cero -aquellas sustancias artificiales-. (UE \& PE-CONS 2000).

Si bien, esta normativa se presenta y aplica a nivel Europeo, hasta la fecha no se conoce públicamente de algún acuerdo o tratado intercontinental que permita emular su adaptación en países en vías de desarrollo. Hoy por hoy, para muchos resulta desconocida la aplicación de una estructura legal general que norme, regule y motive a los actores principales de la gestión hídrica a perseguir propósitos y fines internacionales, semejantes a los que con la DMA se están consiguiendo en los Estados donde se aplica.

En la Constitución -carta magna-, que es la norma fundamental del Estado soberano de la República del Ecuador, país que se tomó como piloto del presente estudio, se tiene normado el uso, gestión y aprovechamiento del agua, en sus diferentes componentes legales, dentro de los límites políticos nacionales, sin cerrar la oportunidad de hacerlo con los países vecinos; pues, existe la expresa posibilidad legal de una integración de los países de Latinoamérica y el Caribe, como objetivo estratégico del Estado, para promover tácticas conjuntas de manejo sustentable del patrimonio natural, que contemple una regulación a la actividad extractiva, complementación energética sustentable, conservación de la biodiversidad, ecosistemas y el agua, (República del Ecuador 2009) Ver Art. 423, Anexo 1.2, pero hasta el 
momento son escasos los resultados que se efectúen binacionalmente amparados en esta ley.

En términos generales, según el mandato constitucional ecuatoriano recientemente actualizado por la Asamblea Constituyente, el Estado tiene como deber primordial garantizar a todo ciudadano que vive en el Ecuador, sin discriminación alguna, su derecho humano al agua, como fundamental e irrenunciable. Y para ello proclama al agua como un patrimonio nacional estratégico de uso público, inalienable, imprescriptible, inembargable y esencial para la vida. (República del Ecuador 2009) Ver Art. 12, Anexo 1.2.

Asimismo, el Estado Ecuatoriano reconoce el derecho a la población a vivir en un ambiente sano y ecológicamente equilibrado, que garantice la sostenibilidad y con ello el buen vivir. (República del Ecuador 2009) Ver Art. 14, Anexo 1.2.

Tiene además la obligación de promover, a todo nivel, el uso de tecnologías limpias con el ambiente, de energías alternativas no contaminantes y de bajo impacto. Con el derecho a una vida digna, el Estado ecuatoriano velará para que en ningún caso se afecte el derecho al agua. (República del Ecuador 2009) Ver Art. 15, 32 y 66, Anexo 1.2.

En el Título $\mathrm{V}$ de la misma Constitución, en el capítulo cuarto, asigna como competencia exclusiva de los gobiernos municipales el de prestar los servicios públicos de agua potable, alcantarillado, depuración de aguas residuales, manejo de desechos sólidos, y toda actividad de saneamiento ambiental. (República del Ecuador 2009) Ver Art. 264, Anexo 1.2.

Es potestad y obligación del Estado, recuperar y conservar la naturaleza, mantener un ambiente sano y sustentable, y garantizarlo para toda persona. Esto se apoya con la prohibición del latifundio y concentración de la tierra, prohibición del acaparamiento o privatización del agua y sus fuentes. (República del Ecuador 2009) Ver Art. 276, 281 y 282, Anexo 1.2.

En el artículo 313 de la carta magna, el Estado se reserva el derecho de administrar, regular, controlar y gestionar los sectores estratégicos, entre ellos el agua, basada en un interés social. La provisión de los servicios públicos de agua potable y de riego, saneamiento, energía, etc. Son responsabilidad del Estado, (República del Ecuador 2009) Ver Art. 313 y 314, Anexo 1.2.

Está declarado también que "el agua es patrimonio nacional estratégico de uso público, dominio inalienable e imprescriptible del Estado, y constituye un elemento vital para la naturaleza y para la existencia de los seres humanos. Se prohíbe toda forma de privatización del agua. La gestión del agua será exclusivamente pública o comunitaria. El servicio público de saneamiento, el abastecimiento de agua potable y el riego serán prestados únicamente por 
personas jurídicas estatales o comunitarias.", (República del Ecuador 2009) Ver Art. 318, Anexo 1.2.

Como se puede ver, el proceso de modernización del Estado, involucra nuevas características en las funciones de los gobiernos locales, que descentraliza y desconcentra la gestión de la distribución del agua potable -urbana y rural-, y elimina toda posibilidad de participación al sector privado, en esta labor de prestación de servicios básicos.

No obstante, la "Ley de Aguas del Ecuador", que regule los recursos hídricos, usos y aprovechamiento del agua, que incluye los permisos, plazos, condiciones, mecanismos de revisión y auditoria, para asegurar la formalización y la distribución equitativa de este patrimonio, aún está en análisis legislativo, público y político; pues, consta en una de las disposiciones transitorias de la Constitución, como una de las leyes que deben aprobarse en un mediano plazo.

Por otro lado, la estructura institucional encargada de la gestión del agua en el Ecuador se ha visto inmersa en múltiples cambios y transiciones políticoeconómicas y administrativas.

La Caja Nacional de Riego se inició en 1944 y operó por 22 años; luego se creó el Instituto Ecuatoriano de Recursos Hídricos (INERHI) que cumplió funciones de planificación, construcción y operación de sistemas de riego hasta 1994. Paralelamente, desde 1970 hasta 1992, contribuyó en la gestión del saneamiento ambiental el Instituto Ecuatoriano de Obras Sanitarias (IEOS). (Global Water Partnership 2003).

Desde 1970 hasta la actualidad, el tema hidrológico del Ecuador se atiende y desarrolla por el Instituto Nacional de Meteorología e Hidrología (INAMHI). La gestión para el aprovechamiento hidroeléctrico se inicia en 1962 con la formación del Instituto Ecuatoriano de Electrificación (INECEL) operativo hasta 1996; desde este año y hasta la presente fecha coordina esta actividad el Consejo Nacional de Electricidad (CONELEC). El Ministerio de Desarrollo Urbano y Vivienda (MIDUVI) desde 1992 se encarga de la Subsecretaría de Saneamiento Ambiental; y, el Consejo Nacional de Recursos Hídricos (CNRH) se creó también dos años más tarde, (Global Water Partnership 2003), quien tiene bajo su órgano administrativo a la recientemente creada Secretaría Nacional del Agua (SENAGUA).

Pese al aparataje institucional y legal existente, brevemente sintetizado aquí, los resultados en el ambiente, en la sociedad ecuatoriana y comunidades vecinas, dejan entrever una transposición de actividades inoficiosas, cuyas acciones se alejan enormemente de lo que sería una deseada gestión efectiva. 


\subsubsection{Gestión integral urbana del recurso hídrico}

La gestión de recursos hídricos involucra una visión de entorno a los conceptos relacionados con el medio ambiente y los problemas generados por la actividad humana, con una comprensión sistémica del ambiente desde las perspectivas: natural, antropogénica y psicológica, como una integralidad que hace posible la coexistencia del mundo biótico y lo abiótico del globo.

Para la Secretaría Nacional del Agua del Ecuador (SENAGUA), la gestión integral del agua es la concepción de un manejo que tome en cuenta los aspectos técnicos, como el balance hídrico y la calidad del agua; los de territorialidad, que considera el contexto por donde fluye el agua (cuencas hidrográficas); los de la gestión productiva, que utiliza y necesita el agua, los de la priorización del derecho humano al agua; los de la operación y el manejo con amplia participación ciudadana en donde se consideren los ámbitos cultural, económico, institucional y social.

La gestión de la conservación del agua se prevé como un soporte de vida para la naturaleza. Por lo tanto, la gestión integral apunta hacía el manejo de las relaciones generalmente conflictivas, alrededor del uso y del aprovechamiento del agua.

Así, diremos pues, que la gestión integral sostenible de abastecimientos de agua para consumo humano es el conjunto metodológico de acciones y normas que conducen a un adecuado manejo técnico, administrativo y legal de los sistemas hídricos bajo jurisdicción, sentado en la filosofía del desarrollo antropocéntrico, sin agotar la base de los recursos y buscando siempre una tasa de ingresos del proyecto que de este dependa, tal que le permita asimismo mantenerse -o mejor crecer- en el tiempo.

a) Entorno actual para la gestión del recurso hídrico

i) Evolución demográfica mundial.-

El crecimiento demográfico, desde la aparición del hombre hasta mediados del Siglo XVII, se puede decir que tuvo un lento crecimiento ascendente; a partir de entonces la población mundial se incrementó drásticamente, de 1.5 millardos de personas en el año 1900 hasta 6.9 millardos al año 2010, y se estima que para el año 2075 la población en el mundo será mayor que 9.2 millardos. Ver gráfico 1.1. 


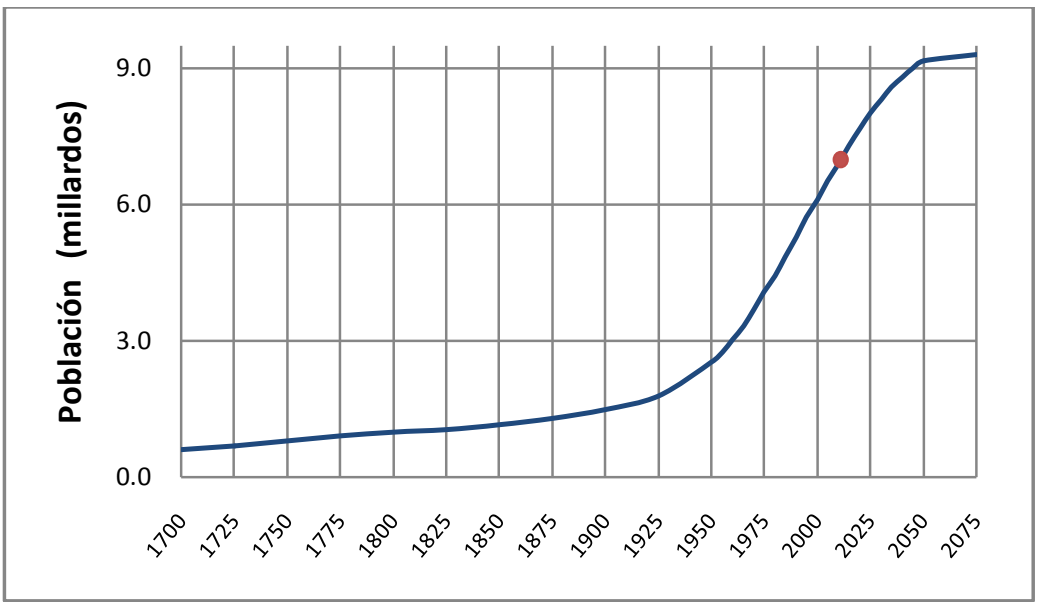

Gráfico 1.1 Cronología del crecimiento demográfico del mundo

Fuente: Referido a (Population Division of the Department of Economic and Social Affairs of the United Nations Secretariat, World Population Prospects: The 2008 Revision)

Según las últimas proyecciones de las Naciones Unidas, a través de Population Division of the Department of Economic and Social Affairs, "The 2009 Revision Population Database", para el año 2050 la población urbana corresponderá al $69 \%$ de la población total. Con lo cual se supone que los sistemas de servicios básicos de las ciudades se vean cada vez más presionados por un cambio en el uso del suelo, crecimiento horizontal y vertical de las ciudades, así como de la densidad poblacional por metro cuadrado de urbe; donde queda implícito el aumento de las demandas de agua. Ver gráfico 1.2.

Hoy en día la población rural representa el $49.5 \%$ de la humanidad, no obstante la tendencia es a reducirse, tanto así que para el año 2050 las Naciones Unidas proyectan que dicha población será el 31.3\% de la total mundial.

Las ciudades de los países en vías de desarrollo serán las que se afecten mayormente por este crecimiento poblacional, de tal modo que parte de la solución preventiva a la escasez del recurso hídrico urbano que se avizora, pasa por mejorar, desde ahora y con prontitud, la gestión local de los sistemas, con políticas que busquen la anhelada sostenibilidad, aspecto que involucra: reducir las pérdidas, modular tarifas que incentiven el ahorro y el consumo racional, protección de cuencas, mejora del conocimiento técnico de los gestores y su know how, optimización de recursos, entre otros tantos aspectos que la constituyen en sus tres pilares, -social, económico y ambiental-. 


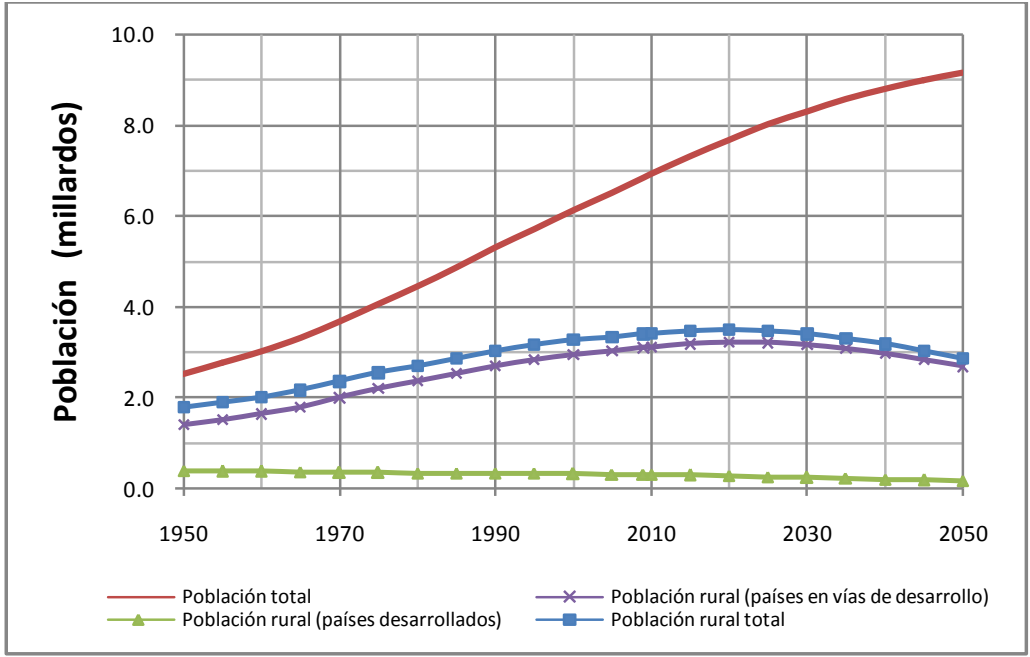

Gráfico 1.2 Distribución temporal de la población mundial

Fuente: Referido a ("The 2009 Revision Population Database", Population Division of the Department of Economic and Social Affairs of the United Nations Secretariat)

ii) La deforestación.-

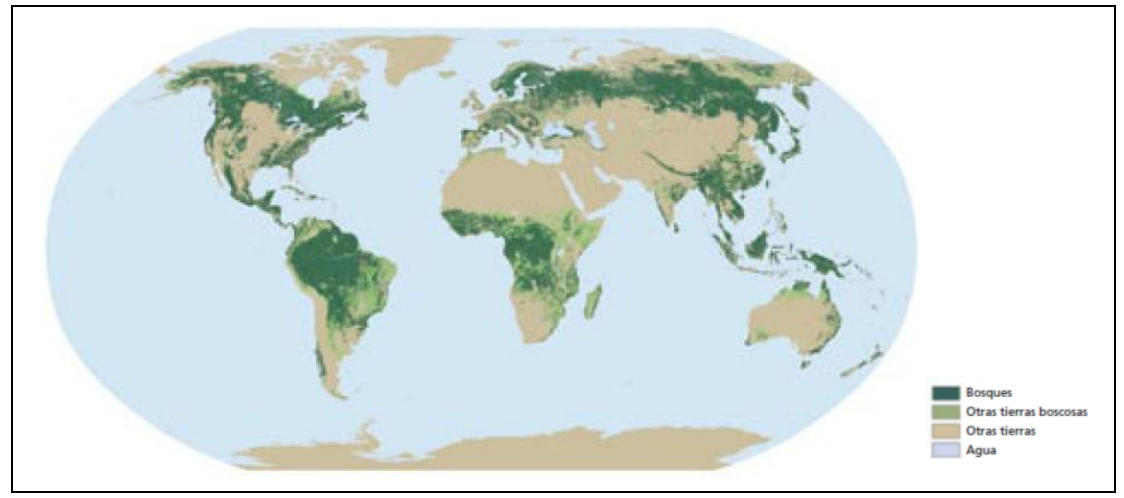

Mapa 1.2 Bosques del mundo

Fuente: (FAO 2006).

Los estudios de la (FAO 2006) reflejan que la deforestación mundial debida a la conversión de los bosques en tierras de cultivo tiene una tasa aproximada de 13 millones $\mathrm{Ha} /$ año; y para el quinquenio 2000-2005 se calcularon en 7.3 millones $\mathrm{Ha} /$ año, y de ésta pérdida neta de bosques 4.3 millones $\mathrm{Ha} /$ año se produjeron en Sudamérica, 4.0 millones Ha / año en África; y 0.35 millones 
Ha / año entre Norteamérica, Centroamérica y Oceanía. Contrarios a las cifras de Asia que registró ganancia neta de bosques de 1.0 millones $\mathrm{Ha} /$ año, gracias principalmente al aporte de China.

Entre las consecuencias de la deforestación están básicamente los siguientes efectos: el primero de ellos es la liberación del carbono almacenado en la masa boscosa y en la parte cultivable del suelo que lo sustenta, otro efecto, es que se reduce la capacidad de captura de ese mismo gas. Además, los gases emitidos - dióxido de carbono $\left(\mathrm{CO}_{2}\right)$ y metano $\left(\mathrm{CH}_{4}\right)$ - aportan en el trópico con hasta el $20 \%$ del total de los gases de efecto invernadero (GEI) que causan el calentamiento global y a su vez el cambio climático del planeta, cambio que se constituye en uno de los principales problemas ambientales, por su incremento de temperaturas, mayores tasas de evapotranspiración y sequías, deshielos de los casquetes polares y en cuencas bajas inundaciones, todo en forma cada vez más desproporcionado. (Camarena 2009).

\section{b) Marco general en Iberoamérica y en los países desarrollados}

\section{i) Los ODM y su influencia en Iberoamérica.-}

Los ocho objetivos de desarrollo del milenio (ODM), compuesta por 18 metas y 48 indicadores pretenden hasta el año 2015 establecer los fundamentos del desarrollo mundial, con énfasis en el combate de la pobreza extrema; entendiendo que ésta no es el único resultado de un decrecimiento o estancamiento económico de los países que la padecen, sino que además es el desenlace sinérgico y creciente de la injusticia social, la desigualdad de género y el desequilibrio en la explotación de los recursos.

No obstante, se propone la agenda del agua, como un espacio para desplegar una visión integradora del desarrollo humano sostenible. Si entendemos este último como el incremento del bienestar de la población, presente y futura, sin agotar la base de los recursos naturales, actuando el hombre como pívot y centro de un equilibrado ecosistema, sin que desemboque en contaminación mediata o futura, con un uso mesurado de recursos humanos, económicofinancieros, biológicos y físicos, cuyo fin es el de satisfacer las necesidades humanas para mejorar su nivel de vida.

El séptimo ODM se relaciona con la gestión de los recursos hídricos, involucra las metas desde la novena hasta la décima primera, que procuran potenciar competitividad satisfaciendo la necesidad hídrica y de saneamiento de la humanidad, preservando los ecosistemas y principalmente las fuentes de agua, impulsado desde los tres ejes principales: crecimiento económico, incremento de la calidad de vida y la sustentabilidad ambiental. 
La mejor verificación del cumplimiento de estas metas lo constituirá el hecho de haber cumplido con los principios de desarrollo en las políticas y los programas nacionales, sumado con la hazaña de haber reducido a la mitad el porcentaje de personas que carecen de acceso sostenible a agua potable y saneamiento básico a nivel mundial; y, finalmente, para el año 2020, haber mejorado considerablemente la vida de no menos que cien millones de habitantes de tugurios; considerados desde una conservación, regeneración y estimulación a la capitalización del patrimonio natural del colectivo.

Siendo Sudamérica, la zona en la que se concentra el $25 \%$ de biodiversidad del planeta y la región del mundo con la mayor oferta de agua dulce (50000 $\mathrm{m}^{3} /$ per cápita/año), es también la zona en la que, en general, peores resultados se tiene en la práctica institucional para dotar de buena cantidad y calidad de agua a sus habitantes.

Podemos indicar que existen muy contadas excepciones de algunos pueblos y ciudades Andinas que intentan mejorar esta realidad; empero, para hablar de planificación participativa e integral se tendrá que trabajar mucho más en este tema y proyectar resultados y metas con pacientes plazos; como urgente se plantea superar notorias diferencias y discriminación: racial, cultural, institucional, política, legal, etc., tales que concatenen un empoderamiento comunitario local participativo de las actividades requeridas en este marco del desarrollo.

$\mathrm{Si}$, por otro lado, el tema es referido por ejemplo, a la contaminación de fuentes de agua para consumo humano por efluentes domiciliares, industriales u otros, se deberá ejecutar primeramente acciones directas de depuración de aguas residuales, introducir tasas de pago por consumo y como un instrumento financiero el impuesto por contaminación bajo una gerencia y políticas efectivas.

La gestión integrada de recursos dicta que los usuarios eco-sistémicos coordinen en una misma mesa de diálogo acciones que conlleven a aplicar intervenciones razonadas que logren la sustentabilidad del recurso y sostenibilidad en su gestión, así como respetar los principios de eficacia y equidad, a la vez que se reconozca que la gestión de los recursos hídricos es política y que esta reforma requiere la combinación de intervenciones ordenadas y prácticas dentro de plazos razonados.

El 31 de enero de 2010 transcurrieron 18 años desde que la Conferencia Internacional sobre el Agua y el Medio Ambiente -CIAMA- celebrada en Dublín (Irlanda - 1992) introdujo el concepto de "gestión integrada de los recursos hídricos - GIRH" en la agenda del desarrollo mundial. La GIRH es aceptada universalmente como una filosofía que advierte sobre el uso del recurso vital y rápidamente aceptada por los entendidos, aunque parece a veces que es poco divulgada y desconocida por la mayoría de actores directos. 
El desordenado y violento crecimiento urbano e industrial que soportan las ciudades, los cambios climáticos, y la costumbre social intolerante frente al uso y explotación del agua, provocan que el ambiente esté apartándose desde su equilibrio natural hacia un estado de caos irreversible (entropía acelerada).

La GIRH encuentra su primer obstáculo en el cuello de botella burocrático e individualista - idiosincrático de las instituciones a las que, hasta ahora, se les ha encargado esta trascendente actividad. No debemos perder de vista que el marco legislativo e institucional del sector del agua actual emergió de tiempos en que los recursos hídricos se consideraban abundantes e infinitos. Como es conocido, en la mayoría de los países Sudamericanos, la responsabilidad por la gestión de los recursos hídricos, para producción agropecuaria, abastecimientos de agua municipal, saneamiento - aguas residuales, hidro-energía, navegación y protección ambiental, recaen en diferentes instituciones ó ministerios que como grandes maquinarias estatales, tras procedimientos burocráticos lentos, cada quién traza su horizonte de acción sin considerar el trabajo colectivo y mancomunado, para alcanzar las metas de forma proactiva; así también se deja de lado un eslabonado concepto de multidisciplinariedad institucional; y, a esto se le añade como otro agravante, la discontinuidad de criterios en los proyectos, abandono e intermitencia de aplicación de planes y programas, con cada temporada política a las que las diferentes instituciones se ven sometidas.

Asimismo, la acción del hombre para la expansión de la frontera agrícola tiene su efecto en la erosión de la superficie de las cuencas y alteración de la cobertura vegetal, situaciones que alteran la cantidad y calidad de agua que en la fuente se genera. Por su parte, el requerimiento que tienen las ciudades de calidad y cantidad del recurso es proporcional a las categorías y número de usuarios que de ella dependan; así por ejemplo, se diferencian consumos domésticos, industriales, oficiales, ornamentales urbanos y privados, entre otros.

\section{ii) La realidad Iberoamericana.-}

No puede haber mayor contraste en la gestión del agua si se compara la península Ibérica con América Latina. En la primera, la amenaza constante de las sequías, y en la segunda las inundaciones y prolongadas épocas invernales.

Tal es el caso que Sudamérica, por ejemplo, posee aproximadamente la cuarta parte de los recursos hídricos del planeta y abastece a un $6 \%$ de la población mundial. No obstante, cada vez más especialistas advierten sobre posibles conflictos políticos internacionales por la apropiación del agua, que a pesar que es abundante, no llega a todos los latinoamericanos en espacio y tiempo suficientes. Por su lado, la mitad de la población Centroamericana, no tiene acceso a agua potable. (Dupont G. 2006). 
Prestatarios y bancos internacionales, en procura de encontrar soluciones al problema de la gestión del agua en América del Sur, en su momento recomendaron la privatización del sector, acción que trajo consigo una reconocida ampliación del aprovisionamiento y servicio de agua en la ciudades, pero también con ella la proliferación de la corrupción de los sectores privado y público que ponen en detrimento la distribución del agua (abusos de tarifas y exigua reingeniería e inversión en los sistemas). (Amorebieta G. 2006), (Egremy N. 2009).

\section{iii) La gestión urbana del agua Iberoamericana.-}

Las características físicas y el estado funcional de cada sistema de distribución de agua es la otra particularidad que se debe considerar a la hora de hablar de eficiencia y gestión. Dentro de esto destaca que la casi totalidad de los municipios o sus empresas operadoras de los sistemas de agua, de los países pertenecientes a lberoamérica y países en desarrollo manejan redes insuficientes, deficientes e ineficientes. (Cabrera E. 2006).

Los problemas principales que dan origen a estas características posiblemente se deban a las fugas o al agua no contabilizada en redes urbanas, debido a la edad del sistema y a la operación de las redes durante plazos que van más allá de su vida útil, a la intrusión patógena, a los frecuentes cortes y racionamientos, junto con las malas costumbres de consumo y una escasa sensibilidad ciudadana para mantener usos moderados; asimismo, no existen criterios para establecer políticas de mantenimiento y renovación; los precios o tarifas de cobro no garantizan sostenibilidad debido a los altos subsidios; y, desconocimiento de los problemas por parte de los técnicos involucrados en la gerencia, administración y operación de los sistemas de agua para consumo humano.

La mayoría de los países Iberoamericanos, por su parte, han estructurado sistemas autónomos de valoración del desempeño, en los que las propias empresas de agua de las principales ciudades han establecido para sí conjuntos de variables cuyos valores son obtenidos de campo y/o gabinete y se combinan de forma aritmética para establecer indicadores de gestión. La buena práctica y aplicación de criterios con base a la interpretación de sus indicadores apoya constantemente a la toma de decisiones y administración mejorada de sus empresas, ocasionando en la mayoría de las veces un progresivo incremento de la eficiencia interna.

De forma un poco más organizada y con una amplia cobertura en los países americanos se involucra en la gestión del agua urbana la Asociación de Entes Reguladores de Agua Potable y Saneamiento de las Américas (ADERASA), quienes con un sistema de indicadores y variables adaptados de varios modelos foráneos, que transferidos y enfocados a la realidad americana se 
ofrecen para ser acogidas con total flexibilidad y voluntad por las empresas reguladoras (ó municipios) que desean incluir entre su administración las metodologías y compromisos de seguimiento del desempeño a través de indicadores homologables y comparables. Entre los principales objetivos que los entes reguladores persiguen, (Jouravlev A. 2003), (Molinari A. 2009), están:

- Promocionar la mejora de la eficacia de la regulación,

- Cooperación en el desarrollo de una contabilidad regulatoria,

- Brindar capacitación a los profesionales y directivos de las empresas reguladoras,

- Intercambiar información sobre el marco y gestión reguladora de sistemas urbanos de agua y saneamiento; $y$,

- Difundir las normas regulatorias de la región.

\section{iv) Marco general de los países desarrollados.-}

Es verdad que el uso del agua puede variar entre los países desarrollados en función del clima, economía, cultura, costumbres sociales y condiciones naturales; cada uno de ellos también afronta el reto de servir a sus demandantes con unos recursos hídricos limitados, en cantidad y a veces en calidad también.

En Europa, por ejemplo, es ampliamente reconocida la necesidad de garantizar el uso sostenible de los recursos hídricos y esto se ha convertido en el objetivo principal de la Directiva Marco sobre la política de aguas para la Unión Europea, como ya se indicó.

Aquí, se trabaja en la configuración de un sistema único de gestión del agua: la gestión por cuencas fluviales. Pues, se parte del principio de que una protección de los recursos hídricos y un suministro de agua fiable a través de una gestión sostenible del agua son esenciales para proteger los aspectos de la vida humana y los ecosistemas dependientes.

Dentro del ámbito urbano se prevé de forma continua los mecanismos para garantizar las suficientes mejoras en infraestructuras, formación y adiestramiento de gestores.

Constantemente se efectúan plenarias, congresos, ferias y eventos para dialogar y consensuar temas que previenen la escasez de agua, la disponibilidad de recursos, el marco legal en la gestión urbana del agua, consumos y tarifas para garantizar su uso urbano de forma permanente; además se divulgan las nuevas tendencias tecnológicas para facilitar la gestión integral de los recursos hídricos. Asimismo, se muestran las tecnologías, metodologías, modelos de gestión del agua, y las técnicas, equipos y 
productos que contribuyen a aprovechar mejor el agua; en estas actividades normalmente se cuenta con la participación de expertos universitarios, organismos abastecedores, asociaciones de abastecimientos y saneamientos, empresas gestoras y empresas proveedoras de equipos y productos.

Buena parte de la mejora permanente de la gestión del agua en el entorno urbano en los países desarrollados se debe a que se han establecido patrones de medición, monitoreo y verificación a través de "performance indicators (PI)" o indicadores de gestión (IG) que con frecuencia son utilizados para auto comparación y para desarrollar prácticas de benchmarking con empresas homólogas. (Cabrera Jr. E.; et al. 2002), (Cabrera E. 2006), (Alegre H.; et al. 2006).

Estos logros se pueden complementar con los siguientes criterios:

- $\quad$ Elaboración actualizada y redefinición de conceptos en el contexto de la globalización y la gestión urbana, con su mercado del agua cada vez más creciente, servicios públicos demandados, entre otros.

- Determinación y dominio de las condiciones locales y territoriales; examen y jerarquización de estas especificidades; implicaciones del cambio de las condiciones.

- Composición pluridisciplinaria, con ejes transversales que empatan apropiadamente: ambiente, economía, oferta y demanda.

- $\quad$ Flexibilidad y apertura a nuevos métodos de trabajo y mejora del desempeño, espacio para seminarios - taller, coloquios, mesas redondas, compendio colectivo de bibliografía apropiada, entre otros.

Voluntad explícita y legal de atender las demandas de la comunidad, empresas, instituciones, asociaciones e intercambiar puntos de vista para su propia retroalimentación.

La gestión integrada de recursos, por concepto, dicta que los usuarios ecosistémicos, actores diversos con usos distintos del recurso, en el presente caso el agua, se sienten en una misma mesa para acordar intervenciones razonadas que logren la sustentabilidad frente al aprovechamiento (explotación) del recurso hídrico.

"El principal desafío de la gestión no es una visión de la gestión integrada de los recursos hídricos, sino un enfoque 'pragmático pero de principios' que respeta los principios de eficacia, equidad y sostenibilidad, a la vez que reconoce que la gestión de los recursos hídricos es sumamente política y que la reforma requiere la articulación de intervenciones priorizadas, ordenadas, prácticas y pacientes". (Moriarty P.; et al. 2006). 


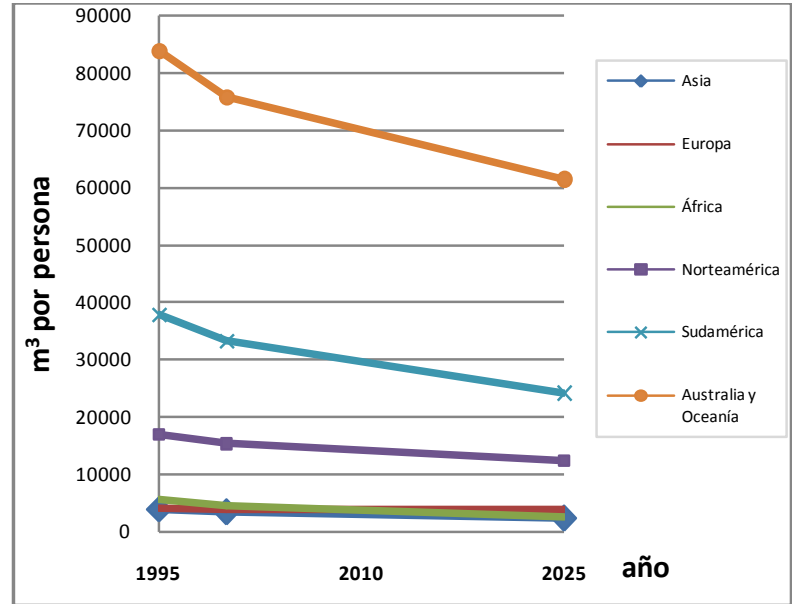

Gráfico 1.3 Pronóstico de la disponibilidad de recursos hídricos per cápita Fuente: Adaptado por el Autor de (Moriarty P.; et al. 2006)

El Stockholm Environment Institute (1997), pronosticó la disponibilidad de recursos hídricos per cápita por región, para ello combinó las proyecciones del crecimiento de la población, la tensión hídrica y los resultados del desarrollo, hasta el año 2025. Ver gráfico 1.3.

Los notables cambios climáticos, el desordenado "crecimiento" industrial y la incultura social frente al uso, y la explotación desequilibrada del agua (recurso natural finito) conducen a que el ambiente esté trasladándose desde su capacidad de campo natural (equilibrio ambiental) a un punto de marchites permanente (impacto negativo irreversible). La implementación de la GIRH es más que un acto de fe o más que unos discursos políticos elocuentemente formulados, acompañados de unas cuantas fotografías relacionadas; pues, implica un compromiso pleno de todos los actores para decidir garantizar sostenibilidad en la gestión y equilibrio al medio ambiente que a cada quién en su jurisdicción le corresponda.

\section{c) Marco general y situación actual del Ecuador}

\section{i) Actores involucrados en la explotación de recursos hídricos}

El área que se podría destinar a riego en el Ecuador es alrededor de 31360 $\mathrm{Km}^{2}$, de las cuales el $93.3 \%$ está en la cuenca del Pacífico y $6.7 \%$ en la vertiente al río Amazonas; del total del área regable, solamente el $18 \%$ de la superficie está bajo riego, de las cuales el $82 \%$ le pertenece al sector privado 
ó particular. Por su extensión se podría categorizar como la cuenca hidrográfica más importante a la del río Guayas, que alberga algo más del $40 \%$ de la superficie apta para riego, le sigue la cuenca del río Esmeraldas con cerca del $13 \%$. La agricultura bajo riego contribuye con el $75 \%$ del valor total de la producción agrícola del país, el otro 25\% proviene de secano. (Galárraga R. 2000) .

El $80 \%$ del consumo total de agua del Ecuador se destina para riego; se asume que existe un $25 \%$ de pérdidas en las diferentes obras de infraestructura hidráulica que componen estos sistemas, desde su captación hasta la distribución en cabecera de parcela. El Instituto Ecuatoriano de Recursos Hídricos (INERHI) administró el agua del Ecuador hasta 1994, año en el que desaparece; a partir de allí se crea el Consejo Nacional de Recursos Hídricos (CNRH), con las responsabilidades de: regular los usos del agua, formular políticas de aprovechamiento y gestión del recurso hídrico disponible, normar el uso del agua, entre otras, todo esto pero sin la facultad para elaborar estudios, construcciones u operar sistemas de riego. Asimismo, como política de Estado se efectuó la transferencia de los sistemas de riego a sus usuarios beneficiarios. (Galárraga R. 2000).

Las instituciones involucradas en la administración y explotación de recursos hídricos en el Ecuador son múltiples, bajo la figura legal de Ministerios, Secretarías o Subsecretarías, Corporaciones de Desarrollo, Institutos de Investigación Aplicada, Entidades Marítimas, etc.; sin embargo, aquellas a las que nos referiremos en este apartado, por su interés descriptivo en nuestro estudio son las dependencias del Ministerio del Ambiente, el Consejo Nacional de Recursos Hídricos (CNRH), constituido como un cuerpo colegiado de cuatro ministerios y la Secretaría Nacional de Planificación, el Instituto Nacional de Meteorología e Hidrología (INAMHI) adscrita al Ministerio de Energías y Minas, la Subsecretaria de Saneamiento Ambiental adscrita al Ministerio de Desarrollo Urbano y Vivienda (MIDUVI), los Consejos Provinciales y Municipalidades, a través de sus departamentos ambientales, obras públicas ó unidades municipales de agua potable y saneamiento.

Esta relación legal administrativa y operativa, a veces redundante entre las distintas organizaciones estatales asignadas para el abastecimiento de agua para consumo humano, saneamiento, abrevadero y riego, genera una superposición de funciones, en medio de un marco legal poco efectivo al momento de su aplicación.

Consecuencia de ello es el aumento de los volúmenes de desechos líquidos y sólidos producto del crecimiento poblacional y la actividad industrial que toda ciudad debe enfrentar; así como un desbordado incremento de la demanda de agua de buena calidad para abastecimiento humano, industrial y agrícola. Es lógico esperar una inminente carga contaminante por desechos peligrosos originados de la industria petrolera, minera y de agroquímicos. 
ii) Alcance esperado de la gestión integral de recursos hídricos en Ecuador

La gestión integrada e integradora de los recursos hídricos del país provocará, seguramente, un incremento en la mejora de la calidad ambiental y de vida de todo nuestro país y países vecinos.

Una parte de la propuesta macro de la búsqueda de gestión integradora es el aprovechamiento técnico de los recursos, entonces se plantea un trasvase de aguas hacia cuencas deficitarias desde cuencas con abundancia de ellas; por ejemplo, las aguas que sobran en la cuenca del Guayas se pueden utilizar en la Península de Santa Elena; las aguas del río Pastaza pueden sumarse a la de los ríos Chimbo y Chanchán, (Galárraga R. 2000). Otro caso concreto es el aprovechamiento de las aguas del río Puyango, para riego y generación hidroeléctrica -luego de su trasvase al embalse de Tahuín-, en la cuenca del Arenillas. Estas actividades se deben complementar con programas de conservación, manejo y ordenamiento técnico de territorio y optimización del uso de suelos.

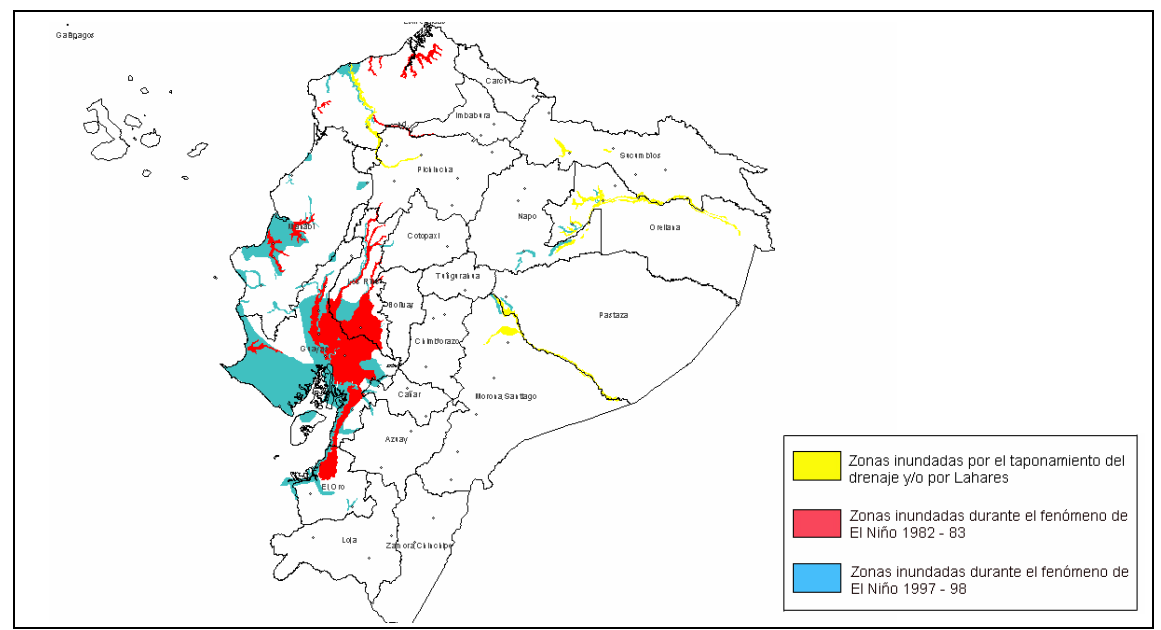

Mapa 1.3 Mapa de las últimas inundaciones más críticas en el Ecuador Fuente: Mapa 1. (Vásquez N. 2005)

Al actuar con conciencia de gestión de recursos se intenta reducir muchos de los impactos negativos al que se somete nuestro medio. Resulta singularmente crítico el efecto de las inundaciones en los componentes: salud, empleo, educación, alimentación, vivienda, vialidad, agro productivo, bienes y propiedad, tarifas y servicios, entre otros, provocado por las máximas 
precipitaciones estacionales del fenómeno de El Niño. Sólo en la ciudad de Chone se registraron 200 inundaciones en estos últimos 35 años. (Vásquez $\mathrm{N}$. 2005).

Otro impacto no menos importante, es el control de la erosión de origen hidro-meteorológico que también afecta a las cuencas; su repercusión es directa en la producción de sedimentos y en la degradación de las mismas, acentuadas por la acción del hombre, en el afán de expandir la frontera agrícola hacia las altas montañas, páramos y bosques.

En este mismo tópico, se ve la necesidad de efectuar un inventario, luego una cuantificación y así una proyección temporal de las reservas de fuentes de aguas alternativas con la que cuenta el país, (glaciares, nevados, acuíferos, agua en los páramos y en Cordilleras Andinas, aguas atmosféricas, entre otros). Otra actividad imperiosa es la formación mediante capacitación permanente del personal involucrado en el manejo, administración y gestión de los recursos hídricos, en todos sus niveles.

Otro resultado positivo que se espera con una gestión hídrica integral es que deje de ser altamente sectorial y se ofrezca en las mismas condiciones y características de cantidad y calidad a todos los sectores sociales que se involucren, con opción preferencial para las clases marginadas de la población. Es decir, la gobernabilidad sobre el agua tenderá a mejorar, y las diferencias de inequidad en precio y acceso al recurso serán las que se rijan por el concepto, adaptado de la DMA europea que "quien consume y contamine que pague", análogo además con el cuarto principio de la GIRH acordado en Dublín (1992), que dice que el agua tiene un valor económico en todos sus niveles de uso y recomiendan sea reconocida como un bien económico.

iii) Los recursos hídricos, la equidad social y la resolución de conflictos

La gestión del agua requiere que tanto los gobiernos como sus gobernados se encarguen oportunamente de plantear estrategias sociales, económico y ambientales para cumplir con una distribución equitativa del recurso vital, tanto en su uso, acceso y manejo técnico - distribución -, con el propósito siempre de garantizar un desarrollo humano sostenible, sin generar conflictos en el presente y garantizando su cantidad y calidad en el futuro. Cabe entonces la frase..."debemos dejar el ambiente en mejores condiciones que cuando lo utilizamos".

Una explotación de recursos ecológicamente propicia debe reconciliar el crecimiento económico; apoyar para que la calidad de vida de los habitantes mejore y sin contaminar el hábitat de ninguna especie. No obstante, la 
degradación acelerada de la fuente de los recursos naturales y del ambiente en sí, la deforestación en áreas de suelos pobres, zonas escarpadas, junto a vertientes o quebradas, el aumento de la población, la pobreza y la inseguridad socio-ambiental fomentan, con un alto riesgo de vulnerabilidad, los desastres naturales, inundaciones y erosión del suelo.

Este escenario real y actual, demanda la acción inmediata de técnicos capaces de participar en la gestión y manejo de cuencas, integrando las dimensiones biofísicas con las socio-económicas y la protección del ambiente. Esto requiere de enfoques, estrategias y conocimientos modernos sobre manejo de cuencas hidrográficas, introduciéndonos particularmente en la ingeniería hídrica para la sostenibilidad, a fin de lograr un uso y manejo adecuado de los recursos naturales y la recuperación de aquellos que fueron deteriorados.

Es evidente que gran número de cuencas de nuestra geomorfología tienen una intervención humana descontrolada, con sobre-explotación de áridos o agregados pétreos, ó explotación forestal - agropecuaria, disminuyendo de este modo los espacios naturales que conservan las condiciones del ambiente.

Adicionalmente, se introducen especies exóticas que afectan el ecosistema como: suelo, agua, flora y fauna de las micro cuencas, recrudeciendo esta realidad. Súmase, la discordancia entre la política forestal en el marco de un régimen ambiental nacional, así como la deforestación progresiva frente al avance incontrolado de la infraestructura vial en áreas protegidas y bosques naturales, apropiación o invasión de tierras forestales por procesos de colonización y migración, usos no forestales (agropecuarios) de rendimiento inmediato (no sostenible) y usos forestales con fines madereros, en forma destructiva y agresiva en contra natura. Sumamos a esto también, la desinformación y obsoletas maneras de aplicar las leyes de protección ambiental. (Benavides H. 2008).

\section{Conflictos suscitados por el uso}

\section{Causas:}

La producción y el manejo sostenido junto con la conservación de los recursos naturales en la mayoría de las zonas hidrogeológicas, son afectados por varios problemas resumidamente señalados así:

- Ausencia de políticas ambientales y agro-productivas aplicables a cuencas tributarias.

- $\quad$ Cambio de uso del suelo y eliminación del bosque natural primario.

- Tala, socola, tumba, pica y quema de árboles y arbustos, explotación no permitida de madera (normalmente con fines de ornamentación, 
constructivos o como fuente de energía para cocción) y la posterior implementación de pastizales y cultivos introducidos con tecnologías que atentan con el mantenimiento del equilibrio del ecosistema; el cultivo de plantas que necesitan remoción del suelo en áreas de pendiente fuerte (cultivos anuales), en donde tiene origen la erosión desde el mismo momento que se inicia el cultivo; la ganadería con exceso de animales de pastoreo por unidad de superficie y la acción depredadora de la mayoría de animales también introducidos (ejemplo: cabras de monte) que deambulan libremente en las áreas de la cuenca; el inapropiado manejo del agua en la parcela; entre muchos otros aspectos que tienen efectos semejantes en el ambiente.

- Control químico de plagas y enfermedades de cultivos.

- Pérdida, subutilización y desprotección de los recursos genéticos nativos.

- Inexistencia de resultados positivos de una organización político social, respecto de explotación hídrica sostenible.

- Desvalorización de los productos agropecuarios y de los recursos naturales renovables y servicios ambientales eco sistémicos.

Alternativas que encaminan alguna solución:

- $\quad$ Articulación local y global. Acceso libre a información.

- Defensa del "bien común". Democracia y libertad con responsabilidad ambiental. Liderazgo y gestión sostenible.

- Mantener, fortalecer y apoyar las campañas sobre el uso racional del agua.

- $\quad$ Exigir un control estatal de aquellos proyectos de minería, explotación de madera, energía y turismo, que agotan y contaminan el entorno de las fuentes tributarias.

- Transmitir conocimiento y buenas prácticas sobre el uso sostenible del agua a generaciones futuras.

- Generar y poner en marcha sistemas de gestión integral del agua en los sistemas de abastecimiento urbano y rural. 


\subsection{Indicadores de desempeño y gestión para la mejora del servicio}

Alcanzar una gestión sostenible, en general, involucra la combinación de varios conceptos y experiencias prácticas que se sintetizan en una doctrina benéfica, actual y futura; es así que, en la gestión se concibe una combinación entre el manejo técnico con su estructura administrativa y su dictamen normativo-legal, disponiéndose de forma participativa, al servicio del bien común. Así también, el término sostenible, que incluye a la sustentabilidad, se refiere a la vivencia de un episodio socioeconómico que procura mantener en el tiempo una tasa de crecimiento positiva de su producción, medido por ejemplo a través del producto interno bruto de una región, sin contaminar o poner en riesgo la vida a mediano o largo plazo. Uno de los problemas por el que pasa la sostenibilidad entorno al agua, a veces de forma intermitente o cíclica y en otras permanente, es su escasez o insuficiencia para distribuirla de forma equitativa entre sus demandantes.

El Ministro alemán Trittin (2001), puso de manifiesto que la gestión eficiente del agua es el elemento principal para luchar contra la pobreza y lograr efectivamente un desarrollo sostenible y que depende extraordinariamente de una estructura de gestión moderna y eficiente; en donde todos los usuarios e interesados en utilizar el recurso deben participar de forma activa en el proceso de descentralización de su potestad y distribución, ya que los usuarios locales son los que más interés deben mostrar en mantener la disponibilidad de sus recursos hídricos a futuro.

Gestionar sosteniblemente las redes de distribución de agua incluye los siguientes aspectos:

- Gestión de la oferta, que consiste en incrementar cada vez y al ritmo del crecimiento de la demanda las obras hidráulicas necesarias para servir a todos los consumidores del recurso, instituir las tareas de conservación de cuencas y fuentes de abastecimiento y garantizar su producción a largo plazo.

Posiblemente gestionar la oferta esté íntimamente relacionado con la recuperación íntegra de costos (ambientales, sociales, de producción, operación, mantenimiento y expansión). Requiere de una inversión económica, estratégica y permanente.

- Gestión de la demanda, cuyo objetivo principal será el de satisfacer las necesidades de solicitación en épocas críticas o de insuficiencia hídrica, sin afectar la cantidad, ni la calidad ni la presión de servicio. Se trata de brindar un fortalecimiento de distribuidores y mejorar la calidad de vida de los consumidores finales. 
Esto seguramente requiere de la planificación de tareas oportunas para reacondicionar los componentes del sistema, como: tratamiento, almacenamiento y distribución, así como un correcto manejo de la presión; la rapidez y buena calidad de las reparaciones también suman en esta tarea.

- Regulación, voluntaria, participativa, consensuada, apolítica, justa y multidisciplinaria, que se encargue de controlar, fiscalizar y auditar, tanto a los involucrados del lado de la oferta como de la demanda.

Un sistema que se gestiona efectivamente en todos sus componentes, garantiza niveles de presión, calidad y caudal de agua siempre satisfactorios; además, comparte su información y datos de variables operacionales con sus clientes, otros operadores y el público en general; protege siempre a sus clientes y minimiza los problemas vinculados al tema del agua en su geografía.

\subsubsection{Alcance de una gestión efectiva con base en la valoración de auditorías}

En los países desarrollados, la valoración de auditorías de la gestión urbana del agua propuesta, pretende entre otros aspectos, analizar sus sistemas de agua para valorar la rentabilidad de la implantación de medidas pasivas de ahorro de recursos, optimización de tiempos y rendimientos laborables, prevención de estados críticos o de estrés hídrico, garantía de la cantidad y calidad del servicio en zonas vulnerables de la red, gestión de la presión, entre otros. Se convierte en la forma cuali-cuantitativa para auscultar una red de agua decadente y formular así un procedimiento que lo convierta en un sistema robusto y lozano.

Gestionar efectivamente un sistema con base en la valoración de auditorías significa que, una vez seleccionado y aplicado un plan de seguimiento del desempeño (evaluación) a través de indicadores, se podrá cuantificar las variaciones que se suscitan en él; así por ejemplo, los balances volumétricos y determinación de pérdidas (aparentes y reales).

Para la reducción de las pérdidas aparentes se debe incluir un plan para minimizar el error de medición del parque de contadores junto con el control de los consumos no autorizados (instalaciones clandestinas).

Para el caso de las pérdidas reales se prefiere manejar técnicamente la infraestructura hidráulica y sanitaria del sistema, junto con un adecuado y planificado sistema "planning" de presiones en las redes constitutivas; es válido y complementario incluir además un programa de control activo de 
fugas tal que inmediatamente después de su localización la reparación se efectúe con prontitud y efectividad.

Está claro que la valoración de las auditorias en sistemas de abastecimiento de agua para consumo humano en los países desarrollados se utiliza además para analizar los procedimientos internos, evaluar infraestructuras o el aprovechamiento de recursos (humano, natural, económico, financiero, entre otros), verificación del desempeño, detección temprana de falencias y no conformidades metodológicas, a las que se las soluciona mediante toma de decisiones para la mejora de competencias. Esta auscultación que se practica a cada sistema de suministro de agua debe partir de datos verificables, para que emita resultados válidos y aprovechables en su propia reingeniería de procesos o que ratifiquen el incremento progresivo de su sostenibilidad.

Otros alcances proyectados con las auditorías en sistemas de agua para consumo humano se pueden matizar así:

- Garantizar un buen servicio, tanto en condiciones de emergencia como en las normales.

- Brindar a los abonados una cantidad de agua con calidad y a presiones mínimas suficientes en todos los puntos de entrega y a toda hora.

- Establecer medidas efectivas de la gestión de la energía consumida, para mitigar impactos negativos al ambiente y ayudar a sostener su propio presupuesto.

- Maximizar ganancias a través de minimizar pérdidas.

- Reducir las pérdidas de agua, -aparentes y reales- mediante un control activo de fugas, sustentándose en el tiempo con una política institucional adecuada.

- Actualizar tarifas reales que guarden coherencia con el costo de operación, mantenimiento y conservación ambiental del entorno impactado.

- Monitorear en período extendido el comportamiento hidráulico sanitario del sistema. Para ello hará falta sectorizar la red, erigir y equipar suficientes nudos de control en la red (creación de parcelas hidrométricas).

- Cuantificar el volumen perdido por las conexiones clandestinas y cuentas no registradas.

- $\quad$ Proyectar el error del parque de contadores y caracterizar su origen.

- Gestionar flujos nocturnos y concatenar con las presiones del sistema.

Con la auscultación técnica y valorativa de los sistemas, se pretende entre otros detalles que las entidades operadoras garanticen entre sus clientes la promoción masiva acerca del uso eficiente del agua; o que proporcionen un vuelco positivo a su manejo actual y puedan simplificar y aclarar su esquema 
administrativo; de tal forma que las consecuencias a mediano y largo plazo se vean reflejadas en una mejora de la calidad de vida de los usuarios.

\subsubsection{Valoración de la auditoría de sistemas de agua mediante indicadores de gestión}

Una de las formas que la mayoría de los países desarrollados vienen experimentado para aplicar una metodología de valoración de auditorías en sistemas de abastecimiento de agua para consumo humano, es mediante el balance hídrico de la red, el mismo que facilita el cálculo de rendimientos volumétricos.

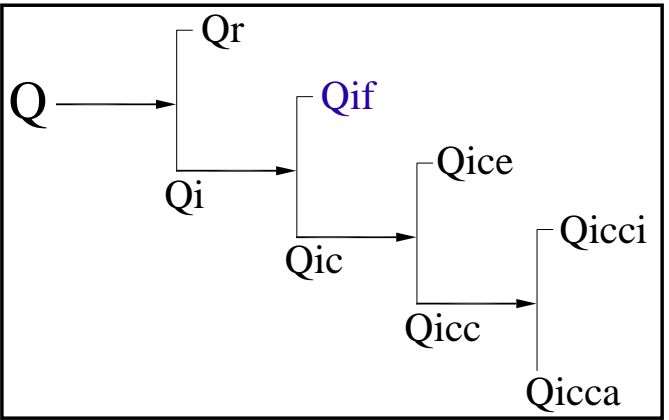

Figura 1.33 Esquema del balance hídrico, criterio técnico

Fuente: Adaptado de apuntes personales,

Donde: (UPV - Instituto Tecnológico del Agua (ITA) 2006).

Q - volumen inyectado en el sistema. Instalación de caudalímetros en las entradas de la red.

Qr - volumen registrado. Debe instalarse contadores en todos los usos.

Qi - volumen incontrolado. Por diferencia de caudales entre $Q$ y $Q r$.

Qif - volumen incontrolado fugado. Detección de fugas, (flujos nocturnos).

Qic - volumen incontrolado consumido. Por diferencia entre Qi y Qif.

Qice - volumen incontrolado consumido con error en la medición. Se obtiene mediante proyección del error del parque de contadores. 
Qicc - volumen incontrolado consumido carente de contador. Por diferencia entre Qic y Qice.

Qicci - volumen incontrolado consumido carente de contador instalado de forma ilegal. Este valor se determina con campañas permanentes para la identificación de acometidas clandestinas o ilegales.

Qicca - volumen incontrolado consumido carente de contador, con uso autorizado por la propia empresa. Qicca $=$ Qic - (Qice + Qicci).

El resultado del balance hídrico, nos conduce al cálculo de los rendimientos volumétricos:

$$
\begin{array}{lr}
\eta_{g}=\frac{Q r}{Q} & \text { [Ec. 1.01] } \\
\eta_{r}=\frac{Q s}{Q} & \text { [Ec. 1.02] } \\
\eta_{m}=\frac{Q r}{Q s} & \text { [Ec. 1.03] } \\
Q s=Q-Q i f=Q r+Q i c & \text { [Ec. 1.04] }
\end{array}
$$

Donde:

$\begin{array}{lll}\eta_{\mathrm{g}} & - & \text { rendimiento global } \\ \eta_{\mathrm{r}} & - & \text { rendimiento de la red } \\ \eta_{\mathrm{m}} & - & \text { rendimiento de medición y registro } \\ \mathrm{Qs} & - & \text { volumen suministrado }\end{array}$

El rango comparativo del estado de la gestión, respecto del rendimiento volumétrico global, es el siguiente:

$$
\begin{aligned}
\eta_{\mathrm{g}} \geq 0.9 & \text { excelente } \\
0.8 \leq \eta_{\mathrm{g}} \leq 0.9 & \text { muy bueno } \\
0.7 \leq \eta_{\mathrm{g}} \leq 0.8 & \text { bueno } \\
0.6 \leq \eta_{\mathrm{g}} \leq 0.7 & \text { regular } \\
0.5 \leq \eta_{\mathrm{g}} \leq 0.6 & \text { malo } \\
\eta_{\mathrm{g}} \leq 0.5 & \text { inaceptable }
\end{aligned}
$$


Con este sistema de rendimientos volumétricos se debe tener particular cuidado al momento de interpretarlos. "El rendimiento es un indicador "'perverso"' pues a mayor consumo, mejor rendimiento, aunque las fugas sean iguales" (García-Serra J. 2009).

El balance hídrico propuesto por la International Water Association - IWA, no considera el término Agua No Contabilizada, porque según su filosofía las pérdidas de agua también se pueden cuantificar; mas, se involucra el término agua no rentable (NRW), por sus siglas en inglés, Non Revenue Water.

La división de los componentes de un suministro de agua con base en su rentabilidad se lo presenta en el cuadro 1.1.

\section{Cuadro 1.1 Balance hídrico propuesto por la IWA}

\begin{tabular}{|c|c|c|c|c|}
\hline \multirow{9}{*}{$\begin{array}{c}\text { Volumen } \\
\text { suministrado } \\
\text { al sistema }\end{array}$} & \multirow{4}{*}{$\begin{array}{c}\text { Consumo } \\
\text { autorizado }\end{array}$} & \multirow{2}{*}{$\begin{array}{l}\text { Consumo autorizado } \\
\text { facturado }\end{array}$} & Consumo medido facturado & \multirow{2}{*}{$\begin{array}{l}\text { agua } \\
\text { rentable }\end{array}$} \\
\hline & & & Consumo no medido facturado & \\
\hline & & \multirow{2}{*}{$\begin{array}{c}\text { Consumo autorizado no } \\
\text { facturado }\end{array}$} & Consumo medido no facturado & \multirow{7}{*}{$\begin{array}{l}\text { agua no } \\
\text { rentable }\end{array}$} \\
\hline & & & Consumo no medido no facturado & \\
\hline & \multirow{5}{*}{$\begin{array}{l}\text { Pérdidas de } \\
\text { agua }\end{array}$} & \multirow[b]{2}{*}{ Pérdidas aparentes } & Consumo no autorizado & \\
\hline & & & $\begin{array}{l}\text { Errores de medición y de manejo de } \\
\text { información }\end{array}$ & \\
\hline & & \multirow{3}{*}{ Pérdidas reales } & Fugas en conducción y/o distribución & \\
\hline & & & $\begin{array}{l}\text { Fugas debidas a derrames en tanques } \\
\text { de regulación y/o almacenamiento }\end{array}$ & \\
\hline & & & $\begin{array}{c}\text { Fugas en tomas ocurridas antes de la } \\
\text { medición }\end{array}$ & \\
\hline
\end{tabular}

Fuente: (Lambert A. 2002)

Las auditorías a sistemas de agua potable, son el resultado de elaborar un inventario de todos sus componentes, luego desarrollar una evaluación integral del sistema mediante variables indicativas de las características del comportamiento en operación y con ellas proceder a calcular los indicadores de desempeño; y, con base en estos últimos fundamentar un diagnóstico técnico - comparativo con empresas homólogas, que pueden o no tener deficiencias. Las auditorias nos permiten además aprovecharlas para planificar los procedimientos o medidas correctoras que formulen soluciones sostenibles en el tiempo.

Para practicar una auditoria con indicadores relativos se utiliza las siguientes ecuaciones: 


$$
\begin{aligned}
& V I F=\frac{\mathrm{Qif}}{\mathrm{N} a \times \mathrm{d}} \\
& U M F=\frac{\left(18 \times L_{t}+0.8 \times N_{a}+25 \times L_{a}\right) \times p}{N_{a}}
\end{aligned}
$$

Donde:

$\begin{array}{lll}\text { IFE } & - & \text { índice de fugas estructural } \\ \text { VIF } & - & \text { volumen incontrolado fugado, [L/acom./día] } \\ \text { UMF } & - & \text { umbral mínimo de fugas, [L/acom./día] } \\ \mathrm{L}_{\mathrm{t}} & - & \text { longitud total de tubería } \\ \mathrm{L}_{\mathrm{a}} & - & \begin{array}{l}\text { longitud de acometidas, (número de acometidas por } \\ \text { longitud promedio de acometidas), [km] }\end{array} \\ \mathrm{N}_{\mathrm{a}} & - & \text { número de acometidas, [unidades] } \\ \mathrm{p} & - & \text { presión, [m c.a.] } \\ \mathrm{d} & - & \text { número de horas al día de presión de la red, [días] }\end{array}$

Si el índice de fugas estructural es igual a uno (IFE $=1$ ) se considera un sistema gestionado de muy buena manera; para un IFE $>\mathbf{4}$ (en países desarrollados) y un IFE $>\boldsymbol{8}$ (en países en vías de desarrollo) diremos entonces que las características del sistema son muy mejorables y se recomienda intensificar esfuerzos para reducir pérdidas. Deducido de (Liemberger R. \& Partners 2010).

En la expresión para el $U M F$, los factores: $18,0.8$ y 25 son el resultado de un estudio de 27 abastecimientos bien gestionados. (García-Serra J. 2008).

Auditar una red de distribución de agua significa conocer el punto de partida en todos sus aspectos (línea base). Asimismo, permiten organizar estructuradamente la información y la empresa en su conjunto. La organización y correcta interpretación de esta información tiene su éxito en la veracidad y confiabilidad de los datos proporcionados (o levantados) y el alto grado de compromiso de los operadores para legitimarlos en el tiempo.

\subsubsection{Los indicadores}

El término indicador hace referencia a calificaciones cuantitativas que con una cierta magnitud involucra sucesos ó percepciones, que permiten conocer el estado de las cosas; se construyen mediante la combinación aritmética de 
variables, que luego son confrontadas con aspectos reales que nos interesa conocer ó mejorar.

Los indicadores reflejan la naturaleza, características, nexos, resultados y costos de los procesos de la empresa, con particulares atributos de comprensión, comparación y persistencia. La gestión de una empresa no se podrá medir con uno sólo de ellos, mas, es necesario construir un sistema interrelacionado de indicadores, cubriendo una cantidad suficiente de variables y magnitudes que permitan tener control y verdadero seguimiento de la gestión del sistema de abastecimiento.

La comparación de los IG, a lo largo del tiempo de servicio de una institución que figura como operadora de un sistema, consigo mismo o con otros operadores homólogos es conocida como "benchmarking". Se busca comparar el desempeño de cada operador, ya sea con su propia historia o con la de otros, estableciéndose al mejor entre éstos como punto de referencia.

David T. Kearns, director general de Xerox Corporation, en 1979 indicó que el "Benchmarking es el proceso continuo de medir productos, servicios y prácticas contra los competidores más duros o aquellas compañías reconocidas como líderes...". (Mora C. 2005). El benchmarking busca e identifica las mejores prácticas en gestión de sistemas de agua con el propósito de implementar prácticas operativas que perfeccionen paulatinamente su performance.

Conocer las buenas prácticas de desempeño y transferir información de sus manejos en la gestión es trascendente para la subsistencia de las empresas operadoras de agua y saneamiento. La recopilación e interpretación de datos es un paso fundamental en el camino del benchmarking. (Garcia D. 2006).

i) Importancia de los indicadores de gestión.

- $\quad$ Permiten medir cambios en alguna condición o situación a través del tiempo.

- $\quad$ Permiten evaluar y mejorar procesos.

Muestran los resultados de iniciativas o acciones.

Orientan las acciones que permitan alcanzar mejores resultados.

ii) Bases de medición.

Los datos de campo se conocen como la base de medición, obtenida mediante encuestas o entrevistas; la medición es un proceso de recolección de datos que se inserta en el sistema de toma de decisiones de forma muy adecuada. 
iii) Importancia de la medición.

La medición permite conocer, planificar y discernir con precisión las oportunidades de progreso de un proceso y explicar el suceso de los hechos. También nos orienta para: evaluar, diseñar, prevenir, corregir, mantener e innovar componentes que concatenados entre sí nos conducen a plasmar un propósito general.

Las características y atributos de una buena medición son: pertinencia y precisión:

- $\quad$ El grado de pertinencia (valoración propiamente dicha) debe revisarse periódicamente, ya que algo que sea muy importante en un momento determinado, puede dejar de serlo al transcurrir el tiempo. Por tal razón, es ineludible el mantenimiento y calibración periódica de contadores y sensores.

- $\quad$ Precisión, es el grado en el que la medida obtenida refleje fielmente la magnitud que queremos analizar.

iv) El uso de indicadores de gestión.

Permiten a los prestadores del servicio organizar su información y su empresa.

Facilitan información clave, unificada y ordenada a los organismos.

Crean un incentivo para adoptar medidas correctivas.

Son ideales también cuando los organismos están interesados en implantar sistemas de aseguramiento de la calidad.

Permiten medir la eficiencia y logro de objetivos en el tiempo.

Facilitan y mejoran el proceso de auditoría.

Todo sistema de Indicadores de Gestión (I.G.) debe estar orientado por objetivos claramente definidos. Por ejemplo, el sistema de I.G. propuesto por el Banco Mundial proporciona a los usuarios de cualquier empresa operadora de agua una herramienta que le permita evaluarse periódicamente y que le facilita a su vez la comparación con otros sistemas locales, regionales y globales.

Los indicadores, por tanto, serán seleccionados y definidos en tanto y en cuanto las empresas a evaluarse sean homologables, según estándares internacionales adecuados y adaptados a la realidad de cada empresa prestadora del servicio. Dos o más empresas serán consideradas homologables 
entre sí cuando sus aspectos físicos - topológicos, hidráulicos, políticoadministrativos y económicos se asemejen mucho entre sí, inclusive se involucrará los detalles socio-culturales de los usuarios.

La comparación supone además un marco legal que contribuya al incremento de la eficiencia en la operación, mantenimiento, supervisión y control de las actividades del sector de agua potable y saneamiento. (Berg S. y Lin C. 2005).

\subsubsection{Propuesta IWA y la Norma ISO 24500}

Los indicadores de gestión - I.G. de un organismo operador están en función de los objetivos que establezca la propia entidad o alguna relacionada con la temática ó servicio. Los I.G. propuestos por la IWA y las normas ISO 24512 se los puede esquematizar de la siguiente manera:

\section{Sinóptico 1.1 Estructura de variables}

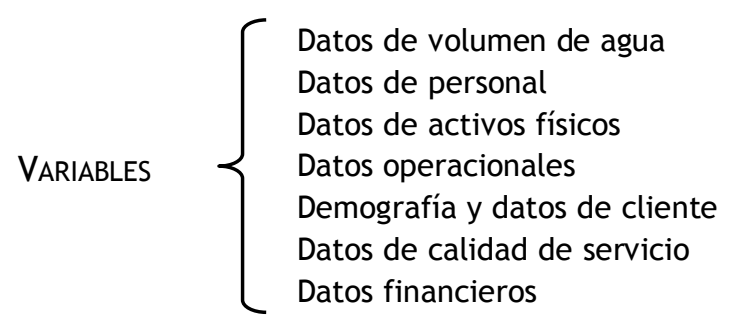

Fuente: Referido al software SIGMA Lite.

Sinóptico 1.2 Estructura de indicadores

INDICADORES $\quad\left\{\begin{array}{l}\text { Recursos hídricos } \\ \text { Personal } \\ \text { Físicos } \\ \text { Operacionales } \\ \text { Calidad de servicio } \\ \text { Económicos y financieros }\end{array}\right.$

Fuente: Referido al software SIGMA Lite.

Los indicadores en este caso son el resultado de la combinación de dos o más variables (mesurables). 
Cuadro 1.2 Resumen de datos presentados en SIGMA 2.0

\begin{tabular}{|l|c|l|}
\hline Descripción & $\begin{array}{c}\text { Número de } \\
\text { componentes }\end{array}$ & \multicolumn{1}{|c|}{ Uso } \\
\hline Contexto & 100 & Información técnica-general \\
\hline Variables & 232 & Cálculo de indicadores \\
\hline Indicadores & 170 & Benchmarking, valoración de auditorías \\
\hline
\end{tabular}

Por su parte, la norma ISO 24512 relacionada con la gestión de abastecimientos de agua, expuesta para ser acogida de forma voluntaria por los operadores de sistemas urbanos de agua, pretende entre otros objetivos:

- Garantizar la provisión del servicio mediante protección de la red pública.

- Tiempo razonable y específico para las instalaciones.

- Reparaciones oportunas para previsión del servicio con un mínimo de inconvenientes y previo anuncio.

- $\quad$ Precio del servicio, con equidad y accesibilidad financiera.

- Cantidad suficiente de agua suministrada en cada punto de entrega.

- $\quad$ Calidad apta para garantizar salud humana.

- Buen aspecto estético del agua, olor, sabor y color.

- Adecuado nivel de presión en el punto de conexión de cada usuario.

- Servicio continuo, y suficiente información de los racionamientos.

- $\quad$ Dar acceso a todos los abonados al servicio de agua.

- $\quad$ Red física suficiente para dar acceso.

- Cobertura garantizada.

- $\quad$ Direccionar la facturación y el contrato de servicios.

- Disponibilidad de un acuerdo claro y legal.

- $\quad$ Emisión de facturas claras por el servicio.

- Consumos medidos con exactitud y cobros justos.

- Respuesta oportuna ante quejas por facturación.

- Facturación regular con métodos convenientes de cobro.

- $\quad$ Promover una buena relación con los usuarios. 
- Contacto escrito, mediante cartas, correo, fax, sms, entre otros.

- Contacto telefónico rápido y directamente con el departamento adecuado.

- $\quad$ Ante visitas personales del usuario a las oficinas de la agencia pública, atención que solucione sus inquietudes y problemas de forma confidencial.

- Pronta atención y solución a las quejas y solicitudes de los usuarios.

- Notificación oportuna de restricciones ó interrupciones al servicio.

- $\quad$ Actividades participativas con la comunidad servida.

- $\quad$ Proteger el ambiente.

- Garantizar un uso sostenible del recurso líquido.

- Mínimo impacto ambiental negativo al entorno.

- Brindar un servicio adecuado de depuración de aguas servidas urbanas, antes de devolverlas al cuerpo receptor.

- $\quad$ Suscitar certeza y dirección solvente cuando se produzca un estado crítico o de emergencia.

- Solución estratégica de eventos emergentes respecto de calidad y cantidad.

- Prevención de posibles contaminaciones de recursos y del ambiente.

Seguidamente se listan algunos ejemplos de indicadores de desempeño relacionados con el dimensionamiento de los elementos constitutivos del sistema:

Cuadro 1.3 Indicadores de desempeño que valoran la sostenibilidad en la operación

\begin{tabular}{|l|l|c|}
\hline \multicolumn{1}{|c|}{ Indicador } & \multicolumn{1}{|c|}{ Variables } & \multicolumn{1}{c|}{ Relación } \\
\hline $\begin{array}{l}\text { Ph4. Utilización de } \\
\text { la capacidad de } \\
\text { bombeo (\%) }\end{array}$ & $\begin{array}{l}\text { D2 - Consumo de energía máxima } \\
\text { diaria para bombeo (kWh). } \\
\text { C7 - Máxima capacidad de potencia } \\
\text { de bombeo que puede ser utilizada } \\
\text { simultáneamente en el sistema (kW). }\end{array}$ & $P h 4=\frac{D 2}{24 \times C 7} \times 100$ \\
\hline
\end{tabular}

Fuente: Software SIGMA Lite 2.0. Cuadro ajustado por el autor.

Ejemplos de indicadores relacionados con el personal de la empresa. 
Cuadro 1.4 Indicadores de desempeño que valoran el personal con título académico

\begin{tabular}{|c|l|c|}
\hline \multicolumn{1}{|c|}{ Indicador } & \multicolumn{1}{|c|}{ Variables } & Ecuación \\
\hline $\begin{array}{l}\text { Pe16. Personal } \\
\text { con grado } \\
\text { universitario (\%) }\end{array}$ & $\begin{array}{l}\text { B15 - Número de personal a tiempo completo } \\
\text { equivalente de la empresa que tiene título } \\
\text { universitario (unidades). } \\
\text { B1 - Número total del personal a tiempo } \\
\text { completo equivalente de la empresa. }\end{array}$ & $P e 16=\frac{B 15}{B 1} \times 100$ \\
\cline { 2 - 4 } $\begin{array}{l}\text { Pe17. Personal } \\
\text { con educación } \\
\text { básica (\%) }\end{array}$ & $\begin{array}{l}\text { B16 - Número de personal a tiempo completo } \\
\text { equivalente de la empresa que carece de título } \\
\text { universitario pero tiene educación básica } \\
\text { (unidades). }\end{array}$ & $P e 17=\frac{B 16}{B 1} \times 100$ \\
\hline
\end{tabular}

Fuente: (Instituto Tecnológico del Agua (ITA) - UPV 2000). Cuadro ajustado por el autor.

Ejemplos de indicadores de desempeño relacionados con la reducción de las cantidades de energía consumida.

Cuadro 1.5 Indicadores de desempeño que valoran el consumo de energía

\begin{tabular}{|c|c|c|}
\hline Indicador & Variables & Ecuación \\
\hline $\begin{array}{l}\text { Ph5. Consumo de } \\
\text { energía normalizado } \\
\left(\mathrm{kWh} / \mathrm{m}^{3} / 100 \mathrm{~m}\right)\end{array}$ & $\begin{array}{l}\text { D1 - Consumo medio de energía para bombeo } \\
\text { (kWh). } \\
\text { D3 - Factor de estandarización, expresado como } \\
\text { volumen bombeado }\left(\mathrm{m}^{3}\right) \text { por altura de bombeo }\end{array}$ & $P h 5=\frac{D 1}{D 3}$ \\
\hline $\begin{array}{l}\text { Ph7. Recuperación } \\
\text { de energía (\%) }\end{array}$ & $\begin{array}{l}\text { (m). } \\
\text { D5 - Energía de bombeo recuperada por el uso de } \\
\text { turbinas o bombas de flujo reversible }(\mathrm{kWh}) \text {. }\end{array}$ & $P h 7=\frac{D 5}{D 1} \times 100$ \\
\hline
\end{tabular}

Fuente: (Instituto Tecnológico del Agua (ITA) - UPV 2000). Cuadro ajustado por el autor.

Ejemplos de indicadores de desempeño relacionados con las pérdidas de agua.

Cuadro 1.6 Indicadores de desempeño que valoran las pérdidas reales

\begin{tabular}{|c|c|c|}
\hline Indicador & Variables & Ecuación \\
\hline $\begin{array}{l}\text { Op } 27 \text {. Pérdidas reales } \\
\text { por conexión } \\
\text { (L/conexión/día de } \\
\text { red a presión) }\end{array}$ & $\begin{array}{l}\text { A19 - Pérdidas reales, como resultado de } \\
\text { restar las pérdidas aparentes del total de } \\
\text { pérdidas de agua que tiene el sistema }\left(\mathrm{m}^{3}\right) \text {. } \\
\text { C24 - Número de conexiones servidas }\end{array}$ & $O p 27=\frac{A 19 \times 1000}{\left(\frac{C 24 \times H 2}{24}\right)}$ \\
\hline $\begin{array}{l}\text { Op28. Pérdidas reales } \\
\text { por longitud de } \\
\text { tubería } \\
\text { (L/km/ día de red a } \\
\text { presión) }\end{array}$ & $\begin{array}{l}\text { (unidades). } \\
\text { C8 - Longitud total de tubería }(\mathrm{km}) \text {. } \\
\text { H2 - Tiempo en el que el sistema se } \\
\text { encuentra presurizado }(\mathrm{h}) \text {. }\end{array}$ & Op $28=\frac{A 19 \times 1000}{\left(\frac{C 8 \times H 2}{24}\right)}$ \\
\hline
\end{tabular}

Fuente: (Instituto Tecnológico del Agua (ITA) - UPV 2000). Cuadro ajustado por el autor. 
Los indicadores de desempeño propuestos por la IWA se deben calcular con base en las variables que se pretenden y se pueden evaluar. Así, por ejemplo, cuando la evaluación se enfoca al consumo de energía en el sistema global, se puede utilizar la variable del volumen de agua inyectada con el indicador consumo de energía por volumen de agua inyectada en el sistema; en otro caso, si lo que se desea evaluar es la eficiencia energética, se puede aplicar como variable el volumen de agua bombeada y se utiliza el indicador consumo de energía por cada metro cúbico de agua bombeada, medido en ambos casos en $\mathrm{kWh} / \mathrm{m}^{3}$.

\section{Las pérdidas reales según la concepción de la IWA}

Se establece que las pérdidas reales de la red no se pueden eliminar por completo de los sistemas de abastecimiento.

Existirá, en la totalidad de los casos, un volumen mínimo de pérdidas reales inevitables y un volumen de pérdidas potencialmente recuperables. La reducción del volumen de pérdidas se puede conseguir aplicando las consideraciones siguientes:

a) Control activo de fugas; detección y localización.

b) Reparaciones oportunas y efectivas.

c) Gestión de presión; reducción y control funcional.

d) Rehabilitación y mantenimiento permanente de la infraestructura hidráulica.

Es de fácil deducción el hecho que para aplicar la valoración de los indicadores de desempeño propuestos por la IWA y por las normas ISO, los sistemas requieren contar con un mínimo de características constructivas, de equipamiento y de inversión, que permitan obtener los datos requeridos para luego introducirlos en las variables correspondientes y finalmente determinar los indicadores que se necesitan.

\subsubsection{Otras iniciativas}

i) Propuesta del Banco Mundial

La International Benchmarking Network for Water and Sanitation utilities IBNET - nace apoyado por el Banco Mundial, con el propósito de brindar acceso a información comparativa para las empresas dedicadas a operar o regular sistemas de abastecimiento urbano de agua potable y alcantarillado. IBNET proporciona a los interesados información para mejorar el desempeño de sus actividades. 
Brindan mejor organización en la aplicación de programas de vigilancia, seguimiento y adaptación de políticas del sector. Así, el personal directivo, administrativo y operativo de las empresas, con el uso de estas herramientas, identificarán áreas vulnerables o susceptibles de mejoramiento.

Una vez que se tenga bien definido los datos de contexto, se haya medido las variables y se hayan calculado los indicadores de cada empresa, se recomienda:

1) Utilizar el resultado del ejercicio de benchmarking métrico para identificar áreas potencialmente prioritarias.

2) Identificar y priorizar las áreas emergentes, basados en una evaluación del impacto financiero, su importancia para los interesados y la habilidad para el cambio.

3) Identificar y documentar cómo se llevan a cabo los componentes en las áreas focalizadas.

4) Establecer el costo de cada una de las partes componentes del área priorizada.

5) Determinar a qué nivel deben buscarse los socios de benchmarking (por ciudad, por región, a nivel nacional ó a nivel mundial) y seleccionar los socios de benchmarking apropiados.

6) Toda visita de benchmarking debe ser enfocada, planificada, realizada y adecuadamente registrada para ulterior referencia. El ejercicio se completa cuando se consigue beneficios a través de la implementación de cambios estratégicos.

7) Identificar la mejor práctica observada en la empresa homóloga para su implementación.

8) Planificar, implementar y monitorear el beneficio de las recomendaciones y mejoras de las prácticas.

9) Considerar la aplicación de benchmarking sobre una base anual y en evolución.

Cuadro 1.7 Resumen de ítems utilizados por IBNET

\begin{tabular}{|l|c|l|}
\hline Descripción & $\begin{array}{c}\text { Número de } \\
\text { componentes }\end{array}$ & \multicolumn{1}{|c|}{ Uso } \\
\hline Datos & 112 & $\begin{array}{l}\text { Información técnica- } \\
\text { general }\end{array}$ \\
\hline Indicadores & 117 & Benchmarking \\
\hline
\end{tabular}

Fuente: Startup indicators and data items IBNET. 
Cuadro 1.8 Indicadores IBNET de arranque

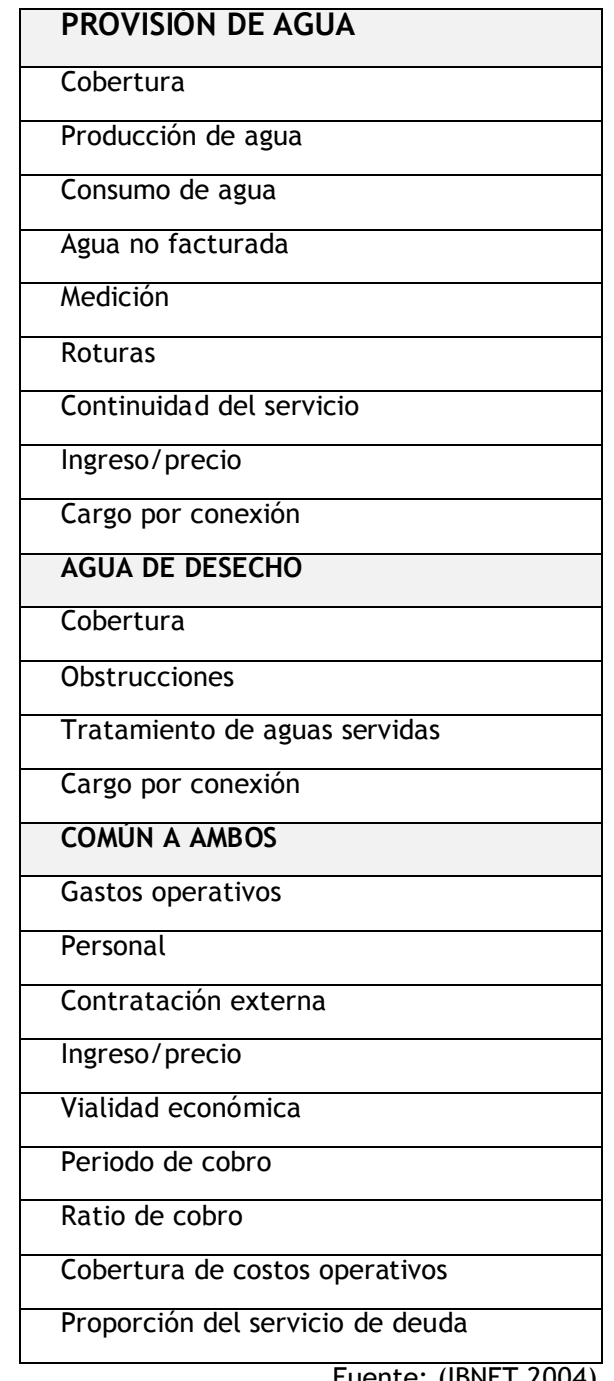

La herramienta de IBNET para el cálculo de indicadores fue desarrollada para ofrecer apoyo en las comparaciones de indicadores de desempeño e incluye indicadores principales, que los interesados pueden seleccionar según sus necesidades y con base en las facilidades que disponen para obtener la información requerida; un sistema de captura de datos y cálculo de indicadores; y un método para compartir información y obtener el mayor beneficio del benchmarking que se pueda llegar a practicar. Como comparaciones de desempeño de grupos de pares y homologables. 
IBNET pone en contacto a gerentes $u$ operadores cuyos intereses son comunes entre sí, con el ánimo de identificar y compartir las mejores prácticas que cada uno pueda haber generado, o sumar un nuevo conocimiento o conjunto de experiencias para ofrecer un mejor servicio al usuario del sistema.

Se tomó para el cuadro siguiente una muestra de la forma como se calculan los indicadores según IB-NET:

Cuadro 1.9 Características de los indicadores de desempeño según IB-NET

\begin{tabular}{|c|c|c|}
\hline Indicador & Variables & Relación \\
\hline $\begin{array}{l}\text { 014. Densidad de las } \\
\text { conexiones de agua } \\
(\# / \mathbf{k m})\end{array}$ & $\begin{array}{l}\text { NC - Número de conexiones de } \\
\text { agua, (\# en miles). } \\
\text { LR - Longitud de red de } \\
\text { distribución de agua }(\mathrm{km}) .\end{array}$ & $D C_{014}=\frac{N C}{L R}$ \\
\hline $\begin{array}{l}\text { 4,1. Consumo total } \\
\text { de agua } \\
\text { (L/persona/día) }\end{array}$ & $\begin{array}{l}\text { Wv - Volumen de agua vendida, } \\
\text { (millones de } \mathrm{m}^{3} \text { / año). } \\
\text { Pa - Población atendida }(\mathrm{km}) \text {. }\end{array}$ & $C T_{4,1}=10^{6} \times \frac{W v}{365 \times P a}$ \\
\hline $\begin{array}{l}6,1 . \text { Agua no } \\
\text { facturada (\%) }\end{array}$ & $\begin{array}{l}\text { Wp - Volumen de agua } \\
\text { producida, (millones de } \\
\mathrm{m}^{3} / \text { año). }\end{array}$ & $A n F_{6,1}=\frac{W p-W v}{W p}$ \\
\hline $\begin{array}{l}\text { 6,2. Agua no } \\
\text { facturada } \\
\left(\mathrm{m}^{3} / \mathrm{km} / \text { día }\right)\end{array}$ & $\begin{array}{l}\text { Wv - Volumen de agua vendida, } \\
\text { (millones de } \mathrm{m}^{3} \text { /año). }\end{array}$ & $A n F_{6,2}=10^{6} \times \frac{W p-W v}{365 \times L R}$ \\
\hline $\begin{array}{l}\text { 6,3. Agua no } \\
\text { facturada } \\
\left(\mathrm{m}^{3} / \text { conx/día) }\right.\end{array}$ & $\begin{array}{l}\text { distribución de agua }(\mathrm{km}) \text {. } \\
\text { NC - Número de conexiones de } \\
\text { agua, (\# en miles). }\end{array}$ & $A n F_{6,3}=10^{3} \times \frac{W p-W v}{365 \times N C}$ \\
\hline
\end{tabular}

Fuente: (IBNET 2004). Cuadro ajustado por el autor.

ii) Procedimientos de países Centro Americanos. Caso AyA

A manera de ejemplo se tomará el caso del Sistema Comercial Integrado del Instituto Costarricense de Acueductos y Alcantarillados - AyA, institución que mide su desempeño con sus propios indicadores de gestión; son contrastados con los indicadores homólogos de todas las empresas cantonales de Costa Rica, y determinan comparativamente el comportamiento operativo-comercial de las empresas operadoras bajo su jurisdicción.

Los indicadores aplicados por la AyA pretenden:

- $\quad$ Percibir de forma indirecta la impresión de sus consumidores.

- Medir la calidad del parque de contadores y su cobertura.

- Conocer la calidad de lecturas de contadores domiciliares.

- $\quad$ Percatarse del sistema de gestión de cobro de las empresas. 
Los indicadores de desempeño aplicados son seis:

- $\quad$ Área operativa

- $\quad$ Porcentaje de agua no contabilizada (ANC)

- Calidad de agua

- $\quad$ Área comercial

- Número de días para conectar un nuevo servicio con medidor

- Porcentaje de micro medición efectiva

- Razón de la facturación (Facturación bruta/Facturación neta)

- Período medio de cobro

Los datos son obtenidos, del programa de control y reducción de pérdidas, de los informes del Laboratorio Nacional de calidad de agua, y del Área Comercial.

Cuadro 1.10 Ponderación de indicadores AyA

\begin{tabular}{|c|l|c|}
\hline \multirow{2}{*}{ Área } & \multicolumn{1}{|c|}{ Indicador } & $\begin{array}{c}\text { Peso } \\
\%\end{array}$ \\
\hline \multirow{2}{*}{ Operativa } & Porcentaje de agua no contabilizada (ANC) & 25.0 \\
\cline { 2 - 3 } & Calidad de agua & 25.0 \\
\hline \multirow{3}{*}{ Comercial } & $\begin{array}{l}\text { Número de días para conectar un nuevo } \\
\text { servicio con medidor }\end{array}$ & 05.0 \\
\cline { 2 - 3 } & Porcentaje de micro medición efectiva & 12.5 \\
\cline { 2 - 3 } & Razón de la facturación & 15.0 \\
\cline { 2 - 3 } & Período medio de cobro & 17.5 \\
\hline
\end{tabular}

La calificación se asigna en porcentaje a cada indicador; el máximo puntaje se inscribe siempre que cumpla la meta mínima preestablecida. Existe un sistema de penalidad a través de la calificación, para cuando los resultados de las variables se distancian del mínimo señalado.

Los resultados obtenidos hasta ahora permiten verificar y comparar las diferencias de gestión entre sistemas cantonales y a nivel de toda Costa Rica, en función de los parámetros definidos, optimizar la gestión de aquellos sistemas en los que aún el desempeño no es el deseable, además establecen un sistema de incentivos para una mejora continua de la gestión operativa y comercial. (Vindas J. 2005).

\section{iii) Propuesta Mexicana; caso CEMCAS}

Con el ánimo de citar algún caso mexicano vamos a considerar la situación particular del Centro Mexicano de Capacitación en Agua y Saneamiento - 
CEMCAS, quienes brindan su asistencia técnica y adiestramiento a técnicos y profesionales que trabajan en los organismos operadores, responsables de áreas técnicas y administrativas de los sistemas de agua potable y alcantarillado, e ingenieros civiles en general, interesados en adquirir un grado de conocimiento mayor y que les permita mejorar su desempeño dentro de las empresas de aguas.

El método de medición del desempeño propuesto por el CEMCAS como estrategia de evaluación de las entidades operadoras, es el basado en el balance hídrico del sistema de agua, calculando luego los rendimientos y seguido de un análisis e interpretación de cada término resultante, para integrar criterios de mejora en la red. A esta etapa se la denomina diagnóstico; la siguiente fase, es la evaluación del costo de las actuaciones prioritarias recomendadas por el evaluador para mejorar las condiciones que conducen a un balance hidráulico idóneo.

Los Indicadores de valoración del rendimiento hidráulico de un sistema de agua potable que el CEMCAS propone tienen gran similitud con aquellos propuestos por el Instituto Tecnológico del Agua ITA - UPV.

Las siguientes expresiones matemáticas se utilizan para conocer los rendimientos de un sistema de agua potable, tanto en la conducción, red de distribución, en el sistema en general y en la gestión técnico administrativa.

a) Para medir el rendimiento de la conducción (Rc) se aplica la ecuación 1.08 .

$$
R c=\frac{W s}{W p}
$$

Donde:

$\begin{array}{lll}\text { Ws } & - & \text { volumen total de agua suministrado } \\ \text { Wp } & -\quad & \text { volumen total de agua producido }\end{array}$

El rendimiento de la conducción se puede interpretar como el estado físico de la infraestructura de producción.

b) El rendimiento global del sistema (Rs) se determina con la ecuación 1.09 , éste considera el aprovechamiento de la red de distribución y el de gestión del conjunto del abastecimiento.

$$
R s=\frac{W r}{W p}
$$


Donde:

Wr - volumen de agua registrado

Wp - volumen total de agua producido

c) La ecuación 1.10 se establece para el cálculo del rendimiento de la red de distribución $(\mathrm{Rr})$.

$$
R r=\frac{W s}{W p}
$$

Donde:

Ws - volumen de agua suministrado a la red de distribución, medido o no a los usuarios.

Wp - volumen total de agua producida

El rendimiento de la red pone de manifiesto la situación física de la red y la forma en la que es operada.

d) El rendimiento de la gestión técnico administrativa ( $\mathrm{Rg})$, expone el grado de efectividad que la empresa tiene en el registro del caudal suministrado al total de abonados; se obtiene con la ecuación 1.11 .

$$
R g=\frac{W r}{W s}
$$

Donde:
$\mathrm{Wr}$
volumen de agua registrado
Ws
volumen de agua suministrado.

Existen otras formas de expresar la valoración de los indicadores de desempeño que también se aplican en la mayoría de operadores mexicanos referentes a las pérdidas de agua real, y se las comunica en:

- Volumen perdido por conexión y por día.

- Volumen perdido por tipo de cliente y por día.

- Volumen perdido por kilómetro de red y por día.

- $\quad$ Porcentaje perdido respecto al volumen inyectado.

Siendo este último el más utilizado por su facilidad de cálculo. 
iv) Características de la metodología Chilena

El Gobierno Chileno, a través de la Superintendencia de Servicios Sanitarios, por cerca de siete años consecutivos, viene aplicando su propio sistema de evaluación de la calidad del servicio de los veinte principales prestadores de agua potable y alcantarillado en zonas urbanas del país.

Los indicadores de desempeño y de calidad de servicio de agua potable evaluados son:

- $\quad$ Calidad del agua potable.

- Continuidad del servicio de agua potable.

- $\quad$ Presión del servicio.

- Calidad del tratamiento de aguas servidas.

- $\quad$ Exactitud en el cobro.

- Tiempo de respuesta a reclamos de clientes.

a) Calidad de agua potable.-

El indicador de calidad del agua potable, se determina con base al grado de cumplimiento de la normativa chilena NCh 409-2006, para agua potable, lo correspondiente a requisitos de calidad y muestreo.

Según el grado de cumplimiento normativo de cada empresa, se asigna un valor porcentual para bacteriología, turbiedad, Cloro libre residual, parámetros críticos y no críticos. El rango del indicador está entre 0 y 1.

\section{b) Continuidad del servicio de agua potable.-}

Este atributo es medido con la estimación de los clientes no servidos con agua a partir del corte del suministro y el tiempo de duración de dicho corte; se considera un rango de penalidades adicionales que afectan este indicador en caso que los fallos del sistema no sean avisados con la debida anterioridad a los clientes.

Este indicador lo que viene consiguiendo entre las empresas, desde 2002, es un mejoramiento en las programaciones de las suspensiones o cortes de servicio; además, incorporar en sus presupuestos anuales los debidos rubros para reposición de tuberías.

Las variables que se involucran para determinar este indicador son:

- $\quad$ Número de interrupciones no programadas ocurridas por año.

- Número total de interrupciones (programadas o no y de fuerza mayor). 
- $\quad$ El tiempo en horas de duración del corte.

- $\quad$ Número de clientes afectados por la interrupción.

c) Presión del servicio.-

Se establece para este atributo de desempeño penalidad tanto por un exceso de presión como por una falta de presión, según el parámetro establecido en la norma chilena NCh 691 para agua potable, conducción, regulación y distribución.

Se determina su valor considerando el porcentaje de clientes que tienen el servicio de agua potable que presentaron problemas de presión durante el año de análisis.

d) Exactitud en el cobro del servicio.-

Las variables tomadas en cuenta para la obtención del valor del indicador de exactitud en el cobro del servicio son:

- $\quad$ Número de facturas que la empresa debe corregir y refacturar.

- $\quad$ Frecuencia de repetición de los motivos por los que se genera la refacturación.

- $\quad$ Origen de la refacturación; puede ser solicitada por el cliente, por detección del error en la propia empresa ó por instrucción de la autoridad correspondiente (Superintendencia).

e) Tiempo de respuesta a reclamos de clientes.-

El tiempo de respuesta para reclamos de clientes, desde su recepción hasta la respuesta propiamente dicha, debe ser igual o menor que 10 días laborables. Tiempos de respuesta mayor a lo indicado penaliza disminuyendo el valor del indicador.

v) Propuesta del sistema regulador Sudamericano; caso ADERASA

La Asociación de Entes Reguladores de Agua Potable y Saneamiento de las Américas - ADERASA, propuso desde finales del año 2002 un primer manual de indicadores de gestión que incluye una guía metodológica para su comprensión y aplicación, la lista de datos necesarios y los indicadores propiamente dichos, tal que los decisores de las empresas operadoras de América dedicadas al servicio público del agua los utilicen como una herramienta de gestión, con posibilidad de realizar valoración de auditorías, diagnósticos técnicos -integradores y comparables- entre empresas 
homólogas; permiten además identificar al equipo gerencial sus fortalezas, debilidades, oportunidades y amenazas, respecto de los temas humanos, hidráulicos, administrativos, financieros y de servicio al cliente, principalmente. (Molinari A. 2009).

Estos indicadores se agrupan en:

- Indicadores de estructura de servicio.

- Cobertura de servicio

- Micromedición

- Indicadores de operación.

- Personal

- Agua potable

- Alcantarillado sanitario

- Depuración y disposición de aguas servidas

- Indicadores de calidad de servicio.

- Continuidad del servicio de agua potable

- Calidad del servicio de agua potable

- Calidad del vertido del alcantarillado al cuerpo receptor

- Reclamos

- Indicadores económicos.

- Facturación

- Costos

- Costos de administración y ventas

- Costos operativos en agua potable y alcantarillado

- Ejecución de inversiones

- Índices financieros

- Rentabilidad

Cuadro 1.11 Ejemplo de indicadores:

Estructura del servicio, propuestos por ADERASA

\begin{tabular}{|c|c|c|}
\hline Indicador & Variables & Ecuación \\
\hline $\begin{array}{l}\text { ies- } 01 \text {. } \\
\text { Cobertura de } \\
\text { servicio. } \\
\text { (\%) }\end{array}$ & $\begin{array}{l}\text { DS01 - Conexiones en general (número) } \\
\text { DS02 - Disposición a menos de } 200 \text { m } \\
\text { (número) } \\
\text { DM10 - Población residente en el área de } \\
\text { responsabilidad (número) }\end{array}$ & $i e s 01=\frac{\mathrm{DS} 01+\mathrm{DS} 02}{\mathrm{DM} 10} \times 100$ \\
\hline $\begin{array}{l}\text { ies- } 09 . \\
\text { Cobertura de } \\
\text { micromedició } \\
\text { n. } \quad(\%)\end{array}$ & $\begin{array}{l}\text { DA10 - Total de medidores domiciliarios } \\
\text { operativos (número) } \\
\text { DA08 - Conexiones de agua potable (número) }\end{array}$ & ies $09=\frac{\mathrm{DA} 10}{\mathrm{DA} 08} \times 100$ \\
\hline
\end{tabular}

Fuente: Manual de Benchmarking (ADERASA 2007). 
Cuadro 1.12 Ejemplo de indicadores de operación, propuestos por ADERASA

\begin{tabular}{|c|c|c|}
\hline Indicador & Variables & Ecuación \\
\hline $\begin{array}{l}\text { ioa-02. } \\
\text { Personal / km } \\
\text { de red } \\
\text { (Empleados por } \\
\text { cada } 100 \mathrm{~km})\end{array}$ & $\begin{array}{l}\text { DI33 - Cantidad de personal en } \\
\text { operación y mantenimiento de reservas } \\
\text { y redes de agua potable (unidades) } \\
\text { DA04 - Longitud total de la red }(\mathrm{km}) \text {, no } \\
\text { incluye conexiones }\end{array}$ & ioa $02=\frac{\mathrm{DI} 33}{\frac{\mathrm{DA} 04}{100}}$ \\
\hline \multicolumn{3}{|c|}{ Pérdidas en red de agua potable } \\
\hline $\begin{array}{l}\text { ioa-09. } \\
\text { En \% de agua } \\
\text { despachada } \\
\text { (\%) }\end{array}$ & $\begin{array}{l}\text { DP04 - Total de agua potable } \\
\text { comercializada }\left(\mathrm{m}^{3}\right) \\
\text { DP03 - Total de agua potable } \\
\text { despachada }\left(\mathrm{m}^{3}\right)\end{array}$ & ioa $09=\frac{\mathrm{DP} 04}{\mathrm{DP} 03} \times 100$ \\
\hline $\begin{array}{l}\text { ioa-10. } \\
\text { Por conexión / } \\
\text { día } \\
\text { ( } \mathrm{m}^{3} / \text { conexión) }\end{array}$ & \multirow{2}{*}{$\begin{array}{l}\text { DP05 - Total diario de agua potable no } \\
\text { comercializada }\left(\mathrm{m}^{3}\right) \\
\text { DP08 - Cantidad de conexiones de agua } \\
\text { potable (unidades) } \\
\text { DP05 - Total diario de agua potable no } \\
\text { comercializada }\left(\mathrm{m}^{3}\right) \\
\text { DA04 - Longitud total de la red }(\mathrm{km}) \text {, no } \\
\text { incluye conexiones }\end{array}$} & ioa $10=\frac{\mathrm{DP} 05}{\mathrm{DP} 08}$ \\
\hline $\begin{array}{l}\text { ioa- } 14 \text {. } \\
\text { Por } \mathrm{km} \text { de red } \\
\text { / día } \\
\left(\mathrm{m}^{3} / \mathrm{km}\right)\end{array}$ & & ioa $14=\frac{\mathrm{DP} 05}{\mathrm{DA} 04}$ \\
\hline \multicolumn{3}{|c|}{ Densidad de roturas } \\
\hline $\begin{array}{l}\text { ioa-11. } \\
\text { En redes } \\
\text { (Número/km) }\end{array}$ & \multirow{2}{*}{$\begin{array}{l}\text { DC03 - Roturas en redes de agua } \\
\text { potable, inclusive en válvulas y } \\
\text { accesorios (unidades) } \\
\text { DC04 - Número de roturas en } \\
\text { conexiones domiciliares, excluye } \\
\text { contadores (unidades) } \\
\text { DA08 - Número total de conexiones de } \\
\text { agua, no incluye conexiones }\end{array}$} & ioa $11=\frac{\mathrm{DC} 03}{\mathrm{DA} 04}$ \\
\hline $\begin{array}{l}\text { ioa-12. } \\
\text { En conexiones } \\
\text { (Número/1000 } \\
\text { conexiones) }\end{array}$ & & ioa $12=\frac{\mathrm{DC} 04}{\mathrm{DA} 08} \times 1000$ \\
\hline
\end{tabular}

Fuente: Manual de Benchmarking (ADERASA 2007).

Cuadro 1.13 Ejemplo de indicadores de calidad del servicio, ADERASA

\begin{tabular}{|c|c|c|}
\hline Indicador & Variables & Ecuación \\
\hline $\begin{array}{l}\text { ica-02. } \\
\text { Cortes de } \\
\text { servicio } \\
\text { continuos. } \\
(\%)\end{array}$ & $\begin{array}{l}\text { DC01 - Conexiones afectadas por } \\
\text { cortes de servicio de agua (unidades) } \\
\text { DA08 - Conexiones de agua potable } \\
\text { (unidades) }\end{array}$ & $i c a 02=\frac{\mathrm{DC} 01}{\mathrm{DA} 08} \times 100$ \\
\hline
\end{tabular}




\begin{tabular}{|c|c|c|}
\hline Indicador & Variables & Ecuación \\
\hline $\begin{array}{l}\text { icu-03. } \\
\text { Reclamos por } \\
\text { servicio de agua } \\
\text { potable por } \\
\text { conexión. (\%) }\end{array}$ & $\begin{array}{l}\text { DU03 - Reclamos por servicio de agua } \\
\text { potable (unidades) }\end{array}$ & iси $03=\frac{\mathrm{DU} 03}{\mathrm{DA} 08} \times 100$ \\
\hline
\end{tabular}

Cuadro 1.14 Ejemplo de indicadores económico-financieros, ADERASA

\begin{tabular}{|c|c|c|}
\hline Indicador & Variables & Ecuación \\
\hline $\begin{array}{l}\text { iec-09. } \\
\text { Incidencia del } \\
\text { costo de la } \\
\text { energía. (\%) }\end{array}$ & $\begin{array}{l}\text { DE15 - Costo de la energía para el } \\
\text { sistema de agua potable }\end{array}$ & $i e c 09=\frac{\mathrm{DE} 15}{\mathrm{DE} 13} \times 100$ \\
\hline $\begin{array}{l}\text { iec-10. } \\
\text { Costo de } \\
\text { productos } \\
\text { químicos para } \\
\text { el agua. (\%) }\end{array}$ & $\begin{array}{l}\text { DE16 - Costo de los productivos } \\
\text { químicos para agua potable } \\
\text { DE13 - Costo operativo total del agua } \\
\text { potable }\end{array}$ & $i e c 10=\frac{\mathrm{DE} 16}{\mathrm{DE} 13} \times 100$ \\
\hline
\end{tabular}

Fuente: Manual de Benchmarking (ADERASA 2007).

Se incluye en el análisis de eficiencia del operador el concepto de empleado equivalente, que se expresa según la ecuación 1.12:

$$
E E T=\frac{C P T \times E t}{C L t}
$$

Donde:

$\begin{array}{lll}\text { EET } & - & \text { empleados equivalentes tercerizados } \\ \text { CPT } & - & \text { costo de las prestaciones de terceros } \\ \text { Et } & - & \text { empleados totales } \\ \text { CLt } & - & \text { costo laboral total }\end{array}$

Se deriva, además, el concepto de costo anual por empleado que equivale al costo laboral total (CLt) dividido para el número de empleados totales.

ADERASA, está trabajando con más de 128 operadores pertenecientes a quince países activos y dos adjuntos del Continente Americano. (Molinari A. 2009). 
vi) Caso Ecuador

\section{Dificultades percibidas}

Con escalofriante normalidad, en nuestra región, se ve que el mayor porcentaje de los sistemas de agua para consumo humano tienen las siguientes particularidades:

- $\quad$ Son sistemas ineficientes, es decir que distribuyen agua de mala calidad, física, química y bacteriológica. Debido posiblemente a que se almacena el agua por más de 24 horas en depósitos de la propia red; ó, porque además existe intrusión patógena a través de sus tuberías; ó, por un mal sistema de tratamiento del agua.

- Insuficientes, en cobertura de infraestructura y en caudal. Puesto que no todas las zonas de una ciudad cuentan con los componentes idóneos de una red completa y también en las horas de máximo consumo la cantidad de agua demandada supera ampliamente a la que el sistema puede ofertar.

- La otra característica de los sistemas de agua potable es la deficiencia, entendido así al escaso y hasta con frecuencia nulo presupuesto disponible en las empresas o municipios para invertir en mantenimiento, tal que las fugas reales y aparentes se incrementan libremente; adicionalmente, un alto nivel de desconocimiento técnico para gestionar, operar y mantener los sistemas.

- Tarifas insuficientes que obedecen a precios políticos. Así entonces las tasas de pago por consumo de agua se subsidia, con el consecuente despilfarro y mal uso del recurso vital por parte del cliente.

- $\quad$ No existe inversión en formación, ni de operadores ni formación cultural del uso racional del agua entre los pobladores servidos.

Se conoce además que los países en vías de desarrollo, principalmente del Cono Sur, deben con urgencia reorganizar sus planteamientos de administración de los sistemas urbanos de agua, con el ánimo de gestionar eficientemente este recurso. No es una tarea fácil dadas las características de mínima infraestructura, desconocimiento de técnicas modernas, casi nulo know how institucional, tarifas insuficientes y escasa capacidad instalada, frente a un constante crecimiento demográfico, cuya cultura de consumo hídrico aún es desordenada y poco conservadora.

\section{Dificultades para aplicar sistemas de auditoría en el país}

Las dificultades de los sistemas urbanos de agua del Ecuador las podemos resumir de la siguiente manera: 
a. En la gran mayoría de sistemas no se dispone de información básica como topología, conformación física, tipos de tuberías, número real de abonados, longitud de tuberías, distribución hidráulica de caudales ni presiones, demandas, fugas, etc. La casi totalidad de los abastecimientos de agua carecen además de un archivo (físico o magnético) de información de contexto de su sistema, sin que exista algún seguimiento histórico de clientes, tarifas, gastos de operación y mantenimiento, o de rupturas y fallos reparados, o el propio seguimiento de quejas de los clientes.

b. La casi totalidad de redes de distribución de agua no están sectorizadas mediante válvulas, ni están provistas de nudos de control para medición y monitoreo de flujos inyectados, ni se cuenta con el equipo para detección y/o localización de fugas, o para la investigación de conexiones clandestinas, o un sistema sostenido de tarifas, facturación y cobro, entre otros.

c. Otra dificultad percibida en las empresas operadoras del sistema de agua para abastecimiento humano es el notorio descuido y falta de atención técnica al momento de planificar tareas, u organizar la conformación de equipos efectivos, junto con su capacitación y equipamiento mínimo para que puedan desempeñar su labor.

d. Notoria negligencia de los administradores del agua, en lo referente a dotar de un soporte económico suficiente y prioritario para actualizar (mantener) la infraestructura constitutiva de sus sistemas.

e. Para poder aplicar metodologías de avanzada y robustas para la conformación de indicadores de gestión, como las normas ISO 24500 o la propuesta de la IWA para el seguimiento del desempeño y valoración de las auditorías internas o externas, hace falta adaptarlas y transferirlas a la realidad de cada sistema de agua.

A pesar de lo expuesto antes, son pocos los sistemas de abastecimiento del Ecuador que orientan su desempeño basados en indicadores institucionales, aunque por el momento se apliquen sólo al interior de cada empresa y de forma intermitente; las empresas municipales que se pueden destacar en este relativo "mejor nivel de gestión" son las de aquellas que pertenecen a las 4 ó 5 ciudades más importantes del Ecuador.

\section{Indicadores de gestión de la EMAAP-Q}

Por citar un ejemplo concreto, anotaremos que la Empresa Metropolitana de Alcantarillado y Agua Potable de Quito - EMAAP-Q, a partir del año 2001 aplica 
su propio sistema de indicadores de gestión, cuya intención final conduce al mejoramiento estratégico de la eficiencia del sistema en todos sus componentes, afrontar la problemática existente en la infraestructura hidráulica y sanitaria; y, establecer los planes anuales óptimos para aplicar las acciones y procedimientos que conduzcan a incrementar las eficiencias volumétricas de distribución, control oportuno de daños, control en la calidad, cantidad y presión de servicio, incremento en la facturación mensual, optimización de recursos, entre otros principales.

- $\quad$ Índice de cobertura de agua potable

- Población total servida / población total (a nivel de todo el cantón)

- Población servida en la ciudad / Población total de la ciudad

- Población servida en las parroquias / Población total en parroquias

- Conexiones domiciliarias instaladas

- $\quad$ Índice de agua no contabilizada

- Volumen de agua facturada total / volumen total de agua distribuida

- Volumen de agua facturada en ciudad / volumen de agua distribuida en ciudad

- Volumen de agua facturada en parroquias / Volumen de agua distribuida en parroquias

- $\quad$ Atención al cliente

Número de reclamos justificados / total de clientes

- Número de clientes con lectura real / total de medidores funcionando 


\section{ANEXO 1.1}

\section{Extracto de la directiva marco del agua}

Tomado del Anexo VII de la Directiva Marco del Agua (DMA) para los Estados Europeos. (UE \& PE-CONS 2000)

A. Los planes hidrológicos de cuenca incluirán los elementos siguientes:

1. Una descripción general de las características de la demarcación hidrográfica como se estipula en el artículo 5 y el anexo II, que comprenderá:

1.1. Para las aguas superficiales:

mapas con la localización y límites de las masas de agua;

mapas de las ecorregiones y tipos de masas de agua superficial dentro de la cuenca hidrográfica;

identificación de las condiciones de referencia para los tipos de masas de agua superficiales;

1.2. Para las aguas subterráneas:

mapas con la localización y límites de las masas de agua subterránea.

2. Un resumen de las presiones e incidencias significativas de las actividades humanas en el estado de las aguas superficiales y subterráneas, que incluya:

Una estimación de la contaminación de fuente puntual;

Una estimación de la contaminación de fuente difusa, incluido un resumen del uso del suelo; - una estimación de las presiones sobre el estado cuantitativo del agua, incluidas las extracciones;

Un análisis de otras incidencias de la actividad humana sobre el estado del agua.

3. La identificación y elaboración de mapas de las zonas protegidas como establecen el artículo 6 y el anexo IV.

4. Un mapa de las redes de control establecidas para los objetivos del artículo 8 y del anexo $\mathrm{V}$, así como una presentación en forma de mapa 
de los resultados de los programas de control llevados a cabo con arreglo a las citadas disposiciones relativa al estado de las:

4.1. Aguas superficiales (ecológico y químico);

4.2. Aguas subterráneas (químico y cuantitativo);

4.3. Zonas protegidas.

5. Una lista de los objetivos medioambientales establecidos en el artículo 4 para las aguas superficiales, las aguas subterráneas y las zonas protegidas, incluida en particular la identificación de los casos en los que se haya recurrido a sus apartados $4,5,6$ y 7 y la información complementaria exigida en dicho artículo.

6. Un resumen del análisis económico del uso del agua de conformidad con el artículo 5 y el anexo III.

7. Un resumen del programa o programas de medidas adoptado en virtud del artículo 11 que incluya los modos de conseguir los objetivos establecidos con arreglo al artículo 4:

7.1. Un resumen de las medidas necesarias para aplicar la legislación comunitaria sobre protección del agua;

7.2. Un informe sobre las acciones prácticas y las medidas tomadas para la aplicación del principio de recuperación de los costes del uso del agua de conformidad con el artículo 9;

7.3. Un resumen de las medidas tomadas para cumplir los requisitos estipulados en el artículo 7;

7.4. Un resumen de los controles sobre la extracción y el embalse del agua, incluida la mención de los registros e identificación de las excepciones efectuadas en virtud de la letra e) del apartado 3 del artículo 11;

7.5. Un resumen de los controles previstos para los vertidos de fuente puntual y otras actividades con incidencia en el estado del agua conforme a lo dispuesto en las letras e) y i) del apartado 3 del artículo 11;

7.6. Una identificación de los casos en que se hayan autorizado vertidos directos en las aguas subterráneas conforme a lo dispuesto en la letra j) del apartado 3 del artículo 11;

7.7. Un resumen de las medidas tomadas conforme al artículo 16 sobre las sustancias prioritarias; 
7.8. Un resumen de las medidas tomadas para prevenir o reducir las repercusiones de los incidentes de contaminación accidental;

7.9. Un resumen de las medidas adoptadas de conformidad con el apartado 5 del artículo 11 para masas de agua con pocas probabilidades de alcanzar los objetivos fijados en el artículo 4.

7.10. Detalles de las medidas complementarias consideradas necesarias para cumplir los objetivos medioambientales establecidos;

7.11. Detalles de las medidas tomadas para evitar un aumento de la contaminación de las aguas marinas de conformidad con el apartado 6 del artículo 11 .

8. Un registro de los programas y planes hidrológicos más detallados relativos a subcuencas, sectores, cuestiones específicas o categorías de aguas, acompañado de un resumen de sus contenidos.

9. Un resumen de las medidas de información pública y de consulta tomadas, sus resultados y los cambios consiguientes efectuados en el plan.

10. Una lista de autoridades competentes con arreglo al anexo i.

11. Los puntos de contacto y procedimientos para obtener la documentación de base y la información a la que se refiere el apartado 1 del artículo 14 y en particular los detalles de las medidas de control adoptadas conforme a las letras g) e i) del apartado 3 del artículo 11 y los datos reales de control recogidos según lo dispuesto en el artículo 8 y el anexo $v$.

B. La primera actualización del plan hidrológico de cuenca y todas las actualizaciones subsiguientes incluirán asimismo:

1. Un resumen de todos los cambios o actualizaciones efectuados desde la publicación de la versión precedente del plan hidrológico de cuenca, incluido un resumen de las revisiones que hayan de efectuarse en virtud de los apartados 4, 5, 6 y 7 del artículo 4 .

2. Una evaluación de los progresos realizados en la consecución de los objetivos medioambientales, incluida la presentación en forma de mapa de los resultados de los controles durante el período del plan anterior y una explicación de los objetivos medioambientales no alcanzados. 
3. Un resumen y una explicación de las medidas previstas en la versión anterior del plan hidrológico de cuenca que no se hayan puesto en marcha.

4. Un resumen de todas las medidas adicionales transitorias adoptadas en virtud del apartado 5 del artículo 11 desde la publicación de la versión precedente del plan hidrológico de cuenca.

\section{ANEXO 1.2}

\section{Artículos de la constitución de la república del Ecuador que se relacionan con el agua y su gestión}

a) Título I. Elementos constitutivos del Estado

a. Capítulo primero. Principios fundamentales

Art. 3.- $\quad$ Son deberes primordiales del Estado

1. Garantizar sin discriminación alguna el efectivo goce de los derechos establecidos en la Constitución y en los instrumentos internacionales, en particular la educación, la salud, la alimentación, la seguridad social y el agua para sus habitantes.

b) Título II. Derechos

a.

Capítulo segundo. Derechos del buen vivir

i. Sección primera. Agua y alimentación

Art. 12.- El derecho humano al agua es fundamental e irrenunciable. El agua constituye patrimonio nacional estratégico de uso público, inalienable, imprescriptible, inembargable y esencial para la vida.

ii. Sección segunda. Ambiente sano

Art. 14.- Se reconoce el derecho de la población a vivir en un ambiente sano y ecológicamente equilibrado, que garantice la sostenibilidad y el buen vivir, sumak kawsay.

Art. 15.- El Estado promoverá, en el sector público y privado, el uso de tecnologías ambientalmente limpias y de energías alternativas no contaminantes y de bajo impacto. La 
soberanía energética no se alcanzará en detrimento de la soberanía alimentaria, ni afectará el derecho al agua.

iii. Sección séptima. Salud

Art. 32.- La salud es un derecho que garantiza el Estado, cuya realización se vincula al ejercicio de otros derechos, entre ellos el derecho al agua, la alimentación, la educación, la cultura física, el trabajo, la seguridad social, los ambientes sanos y otros que sustentan el buen vivir.

b. Capítulo sexto. Derechos de libertad

Art. 66.- Se reconoce y garantizará a las personas:

2. El derecho a una vida digna, que asegure la salud, alimentación y nutrición, agua potable, vivienda, saneamiento ambiental, educación, trabajo, empleo, descanso y ocio, cultura física, vestido, seguridad social y otros servicios sociales necesarios.

c) Título V. Organización territorial del Estado

a. Capítulo cuarto. Régimen de competencias

Art. 264.- Los gobiernos municipales tendrán las siguientes competencias exclusivas, sin perjuicio de otras que determine la ley:

4. Prestar los servicios públicos de agua potable, alcantarillado, depuración de aguas residuales, manejo de desechos sólidos, actividades de saneamiento ambiental y aquellos que establezca la ley.

d) Título VI. Régimen de desarrollo

a. Capítulo primero. Principios generales

Art. 276.- El régimen de desarrollo tendrá los siguientes objetivos:

4. Recuperar y conservar la naturaleza y mantener un ambiente sano y sustentable que garantice a las personas y colectividades el acceso equitativo, permanente y de calidad al agua, aire y suelo, y a los beneficios de los recursos del subsuelo y del patrimonio natural.

b. Capítulo tercero. Soberanía alimentaria

Art. 281.- La soberanía alimentaria constituye un objetivo estratégico y una obligación del Estado para garantizar que las personas, comunidades, pueblos y nacionalidades alcancen 
la autosuficiencia de alimentos sanos y culturalmente apropiado de forma permanente.

4. Promover políticas redistributivas que permitan el acceso del campesinado a la tierra, al agua y otros recursos productivos.

Art. 282.- El Estado normará el uso y acceso a la tierra que deberá cumplir la función social y ambiental. Un fondo nacional de tierras, establecido por ley, regulará el acceso equitativo de campesinos y campesinas a la tierra.

Se prohíbe el latifundio y la concentración de la tierra, así como el acaparamiento o privatización del agua y sus fuentes.

El estado regulará el uso y manejo del agua de riego para la producción de alimentos, bajo los principios de equidad, eficiencia y sostenibilidad ambiental.

c. Capítulo quinto. Sectores estratégicos, servicios y empresas públicas

Art. 313.- El Estado se reserva el derecho de administrar, regular, controlar y gestionar los sectores estratégicos, de conformidad con los principios de sostenibilidad ambiental, precaución, prevención y eficiencia.

Los sectores estratégicos, de decisión y control exclusivo del Estado, son aquellos que por su trascendencia y magnitud tienen decisiva influencia económica, social, política o ambiental, y deberán orientarse al pleno desarrollo de los derechos y al interés social.

Se consideran sectores estratégicos la energía en todas sus formas, las telecomunicaciones, los recursos naturales no renovables, el transporte y la refinación de hidrocarburos, la biodiversidad y el patrimonio genético, el espectro radioeléctrico, el agua, y los demás que determine la ley.

Art. 314.- El Estado será responsable de la provisión de los servicios públicos de agua potable y de riego, saneamiento, energía eléctrica, telecomunicaciones, vialidad, infraestructuras portuarias y aeroportuarias, y los demás que determine la ley.

El Estado garantizará que los servicios públicos y su provisión respondan a los principios de obligatoriedad, generalidad, uniformidad, eficiencia, responsabilidad, 
universalidad, accesibilidad, regularidad, continuidad y calidad. El Estado dispondrá que los precios y tarifas de los servicios públicos sean equitativos, y establecerá su control y regulación.

Art. 318.- El agua es patrimonio nacional estratégico de uso público, dominio inalienable e imprescriptible del Estado, y constituye un elemento vital para la naturaleza y para la existencia de los seres humanos. Se prohíbe toda forma de privatización del agua.

La gestión del agua será exclusivamente pública o comunitaria. El servicio público de saneamiento, el abastecimiento de agua potable y el riego serán prestados únicamente por personas jurídicas estatales 0 comunitarias.

El Estado fortalecerá la gestión y funcionamiento de las iniciativas comunitarias en torno a la gestión del agua y la prestación de los servicios públicos, mediante el incentivo de alianzas entre lo público y comunitario para la prestación de servicios.

El Estado, a través de la autoridad única del agua, será el responsable directo de la planificación y gestión de los recursos hídricos que se destinarán a consumo humano, riego que garantice la soberanía alimentaria, caudal ecológico y actividades productivas, en este orden de prelación. Se requerirá autorización del Estado para el aprovechamiento del agua con fines productivos por parte de los sectores público, privado y de la economía popular y solidaria, de acuerdo con la ley.

d. Capítulo sexto. Trabajo y producción

Sección tercera. Formas de trabajo y su retribución

Art. 326.- El derecho al trabajo se sustenta en los siguientes principios:

15. Se prohíbe la paralización de los servicios públicos de salud y saneamiento ambiental, educación, justicia, bomberos, seguridad social, energía eléctrica, agua potable y alcantarillado, producción hidrocarburífera, procesamiento, transporte y distribución de combustibles, transportación pública, correos y telecomunicaciones. La 
ley establecerá límites que aseguren el funcionamiento de dichos servicios.

e) Título VII. Régimen del buen vivir

a. Capítulo primero. Inclusión y equidad

Sección cuarta. Hábitat y vivienda

Art. 375.- El Estado, en todos sus niveles de gobierno, garantizará el derecho al hábitat y a la vivienda digna, para lo cual:

6. Garantizará la dotación ininterrumpida de los servicios públicos de agua potable y electricidad a las escuelas y hospitales públicos.

b. Capítulo segundo. Biodiversidad y recursos naturales

Sección sexta. Agua

Art. 411.- El Estado garantizará la conservación, recuperación y manejo integral de los recursos hídricos, cuencas hidrográficas y caudales ecológicos asociados al ciclo hidrológico. Se regulará toda actividad que pueda afectar la calidad y cantidad de agua, y el equilibrio de los ecosistemas, en especial en las fuentes y zonas de recarga de agua.

La sustentabilidad de los ecosistemas y el consumo humano serán prioritarios en el uso y aprovechamiento del agua.

Art. 412.- La autoridad a cargo de la gestión del agua será responsable de su planificación, regulación y control. Esta autoridad cooperará y se coordinará con la que tenga a su cargo la gestión ambiental para garantizar el manejo del agua con un enfoque ecosistémico.

f) Título VIII. Relaciones internacionales

a. Capítulo tercero. Integración latinoamericana

Art. 423.- La integración, en especial con los países de Latinoamérica y el Caribe, será un objetivo estratégico del Estado. En todas las instancias y procesos de integración, el Estado ecuatoriano se comprometerá a:

2. Promover estrategias conjuntas de manejo sustentable del patrimonio natural, en especial la regulación de la actividad extractiva; la cooperación y complementación energética sustentable; la conservación de la biodiversidad, los ecosistemas y el agua; la investigación, 
el desarrollo científico y el intercambio de conocimiento y tecnología; y la implementación de estrategias coordinadas de soberanía alimentaria.

DISPOSICINES TRANSITORIAS.- Leyes que deberán aprobarse:

2. La ley que regule los recursos hídricos, usos y aprovechamiento del agua, que incluirá los permisos de uso y aprovechamiento, actuales y futuros, sus plazos, condiciones, mecanismos de revisión y auditoria, para asegurar la formalización y la distribución equitativa de este patrimonio. 



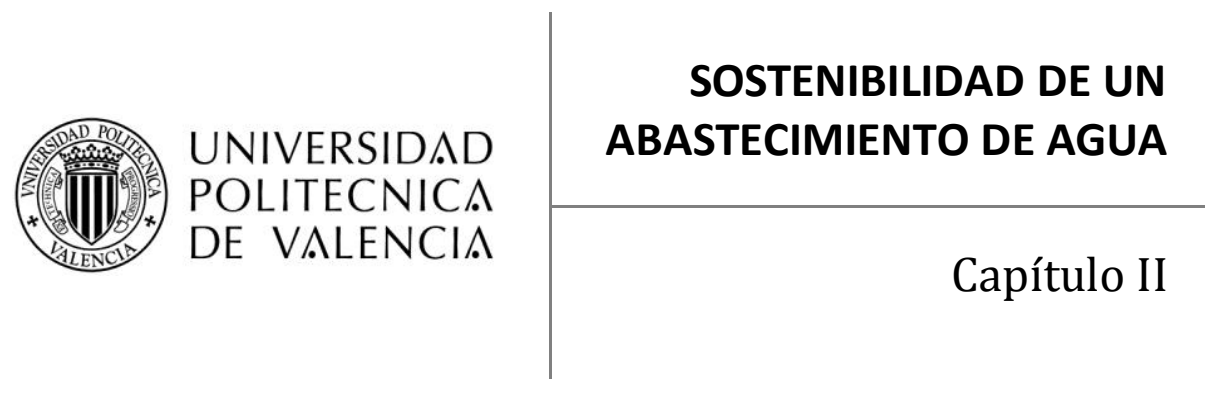





\section{SOSTENIBILIDAD DE UN ABASTECIMIENTO DE AGUA}

Este capítulo es una plataforma en la que se describe la estructura cognitivadirectiva de la propuesta evolucionada para la explotación sostenible de los recursos hídricos; se define entonces, narrativamente la importancia de la interrelación de los tres ejes de la sostenibilidad (el ambiente, la economía y la sociedad), como pilares de la sostenibilidad.

Es también objeto de este acápite puntualizar acerca de las características más importantes del manejo ambiental, económico y social que en un abastecimiento de agua se deben reflexionar al momento de ejecutar un diagnóstico, para brindarle - a gestores y decidores políticos - la capacidad de identificación de fortalezas y oportunidades de mejora en el desempeño.

Es así que para cumplir con este propósito, nos apoyaremos en múltiple información recabada de publicaciones de organismos internacionales involucrados en la gestión sostenible del agua, normativa relacionada y bibliografía pertinente.

\subsection{Sostenibilidad}

\subsubsection{Concepto de sostenibilidad}

En el informe "Nuestro Futuro Común" (Our Common Future) de la Comisión Mundial sobre Medio Ambiente y Desarrollo (World Commission on Environment and Development - 1987), se plantea como alternativa viable y positiva para el planeta la aplicación de políticas de sostenibilidad para el crecimiento económico.

La Comisión observó que el desarrollo -como se lo concebía hasta esa fechaaumentaba la vulnerabilidad del ambiente hasta degradarlo y con ello también el incremento de la pobreza. Se introduce, en aquel entonces, el concepto de desarrollo sostenible, como el instrumento, el cual sirva de base al progreso humano futuro. (CISDL 2005).

Uno de los primeros conceptos del desarrollo sostenible es que "satisface las necesidades de la generación presente sin comprometer la capacidad de las generaciones futuras para satisfacer sus propias necesidades". (Macedo B. 2005), (Segger C. \& Khalfan A. 2004).

El concepto de sostenibilidad en sí engloba múltiples disciplinas y técnicas que son necesarias involucrarlas para poder llevarla a la práctica. La mayoría de las veces y por posiblemente "error de origen", es decir desde quienes lo 
propusieron, se confunden o superponen políticas, normativas y hasta conceptos, que aunque derivados de ellos y de un mismo sentido común por buscar el bienestar, se redunda en explicación y literatura, aunque muy poco en su aplicación y planteamiento de métodos para aterrizarlas a la realidad de cada entorno, salvo muy puntuales excepciones.

Por citar alguna, se indica que una de esas tendencias es la de suponer como sinónimos las palabras sostenible y sustentable, pues en idioma inglés así resulta casi obligado por vocabulario, mas en el castellano y otras lenguas si permiten hacer diferencias que a más de prácticas resultan también interesantes a la hora de comunicar estos principios. Bien se puede entonces hacer una diferencia conceptual entre ambas, de la siguiente manera.

\section{Estructura demostrativa conceptual:}

1) Se parte de la premisa que las palabras sostenibilidad y sustentabilidad implican de forma intrínseca al desarrollo sostenible y sustentable, respectivamente.

2) Desarrollo, es el proceso en el cual se aplican al ambiente recursos humanos, económicos, financieros, bio-físicos y otros, con el fin de obtener resultados, -bienes y servicios- que satisfagan las necesidades humanas en la búsqueda de mejorar la calidad de vida.

El término desarrollo, desde un punto de vista puramente político legal se podría mal aceptar como únicamente el crecimiento económico de los Estados, sin tomar en cuenta la distribución, ni sus efectos sociales, ni el desarrollo de capacidades, ni mucho menos el bienestar colectivo. Es mejor, siempre que se pretenda referir al desarrollo, que se explique en qué pilares se fundamenta; es decir, que sólo la palabra desarrollo sería una forma incompleta de algún tipo de crecimiento; pues, se entiende explicado implícitamente si se la califica con su forma de origen; así, "desarrollo humano", "desarrollo social", "desarrollo sostenible, "desarrollo sustentable", entre otros. (Fajardo L. 2008).

3) Calidad de vida, distinto a nivel de vida que mide ingresos, es un concepto que integra el bienestar de cada individuo en su sociedad, apoyado en indicadores como por ejemplo el propuesto por las Naciones Unidas, el Índice de Desarrollo Humano (IDH, figura 2.3) que a su vez relaciona la esperanza de vida (figura 2.1), educación y el PIB per cápita (figura 2.2). 


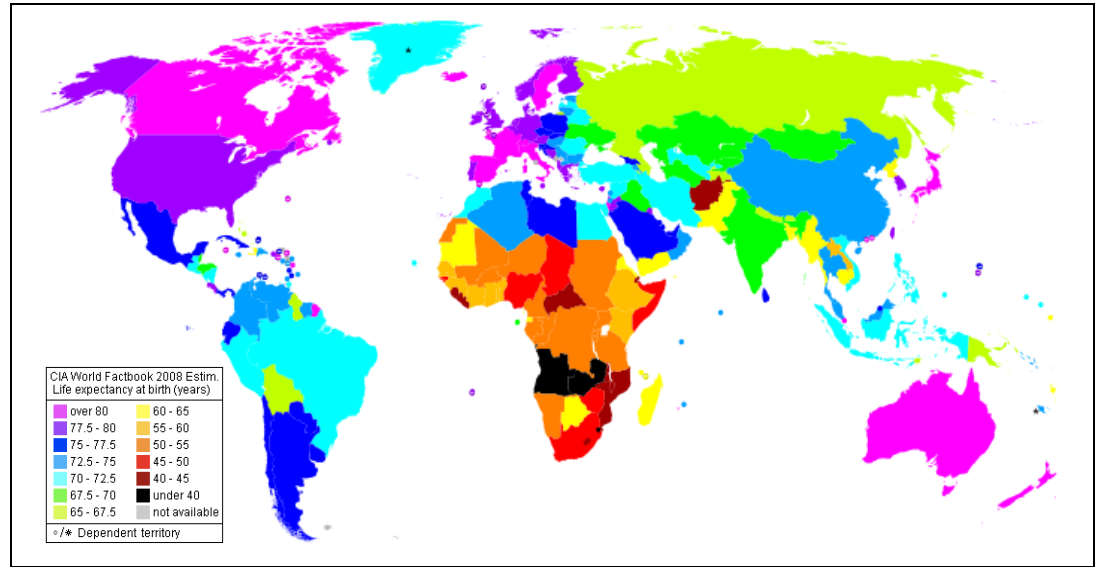

Figura 2.1 Distribución mundial de la Esperanza de vida

Fuente: The World Factbook 2008 - Life Expectancy at birth (Wikipedia 2009)

Además la calidad de vida, asocia la calidad del medio ambiente, la libertad política y económica, la medida del acceso a servicios públicos de calidad, las medidas del bienestar en salud (general, funcional, mental, cardiovasculares, otras), confort y seguridad nacional y personal, el acceso a fuentes de trabajo decentes, número de días de vacaciones al año de cada individuo, entre muchos otros. (World Bank 2002).

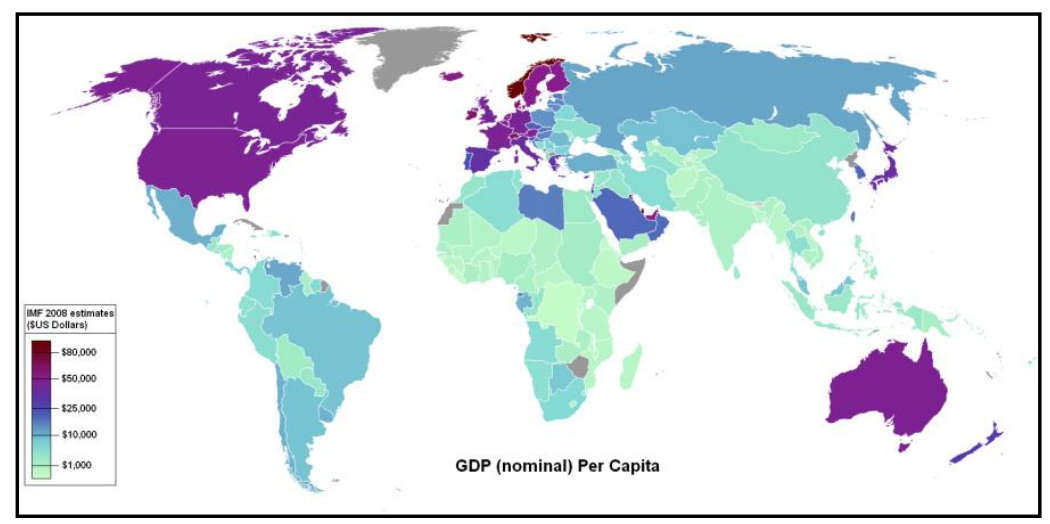

Figura 2.2 Distribución mundial del Producto Interno Bruto per cápita Fuente: International Monetary Fund World Economic (Wikipedia 2009) 


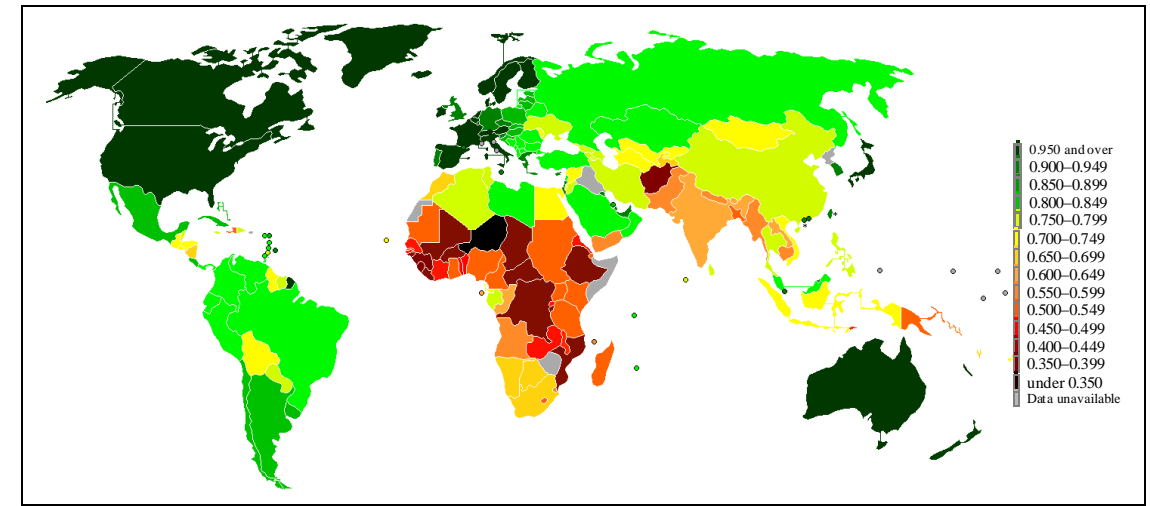

Figura 2.3 Distribución mundial del Índice de Desarrollo Humano, reporte 2009 Fuente: UN Human Development Report 2009 (Wikipedia 2009).

4) Desarrollo humano, diremos entonces que es aquel tipo de desarrollo en el que se considera el - criterio antropocentrista -, es decir el ser humano como centro y pívot de todo el proceso del desarrollo, y nunca el ser humano alrededor del desarrollo.

El Programa de las Naciones Unidas para el Desarrollo especifica que el desarrollo ha de ser participativo; con tal fin, los individuos deben tener la oportunidad de invertir en el perfeccionamiento de sus competencias, en su salud, su educación y su aprendizaje. También se debe dar la oportunidad de usar sus capacidades para participar a fondo en todos los aspectos de la vida y de expresarse libre y creativamente. Además que el desarrollo humano requiere del crecimiento económico ya que sin éste no es posible lograr el mejoramiento sostenido del bienestar humano. (PNUD 1991).

El hecho de que un Estado tenga elevados índices de crecimiento económico no implica que también tenga niveles elevados de desarrollo humano.

5) Desarrollo sustentable, también llamado sostenibilidad ambiental o desarrollo verde, tiene un enfoque referido prioritariamente al ambiente. Es el tipo de desarrollo en el que las modificaciones que actúan en el ambiente producen polución pero no contaminan.

a. Polución, se conoce así a aquella alteración de los componentes ambientales, por causa de la actividad humana, que no pone en peligro la continuidad de la vida natural, pese a su alteración, lo cual implica que el ambiente tiene la capacidad de asimilar y subsidiar dichos cambios. 
b. Contaminación, es un tipo de polución cuyo nivel de afectación sobrepasa la capacidad del ambiente por regenerar o recuperar las condiciones naturales perdidas y se compromete la calidad ambiental de uno o más elementos del medio, de tal modo que constituye un peligro para su permanencia, generación, desarrollo o continuidad, sobre el planeta.

6) Desarrollo sostenible, es considerado con un enfoque socioeconómico-ambiental, e implica mantener -sostener- la producción y desarrollo siempre a una tasa que refleje crecimiento o al menos equilibrio, a corto y largo plazo, de cada aspecto, recurso, componente, bien, capital o ecosistema.

Sostenible o desarrollo sostenible o sostenibilidad, alberga los aspectos de la actividad humana que fortalece su crecimiento económico, con equidad y bienestar social de tal modo que mejora la calidad de vida de los individuos, sin contaminar el ambiente. Esta directiva semántica y conceptual quedó adjudicada y ratificada en las varias Cumbres Mundiales. El término sostenible es más afín con el término susteinable, del inglés.

7) Desarrollo humano sostenible, es aquel tipo de desarrollo sostenible que se efectúa con un criterio antropocéntrico.

Estas características conceptuales dejan la posibilidad de expresar que un proyecto o actividad humana que es sustentable puede o no ser sostenible; en cambio, todo lo que es sostenible necesariamente debe ser sustentable primero.

Investigadores del desarrollo sostenible, como (Parris T. y Kates R. 2003), incorporan al debate cierta incertidumbre sobre las definiciones emanadas de este estadio o escenario mundial. Dejan entrever una ambigüedad inherente y dudan de la generación de posibles conflictos entre lo que se debe y puede rescatar de lo económico, del ambiente y en el tiempo presente o futuro; del mismo modo dan énfasis a la distorsión conceptual existente entre la definición, de la orientación que puede tener la sostenibilidad, puesto que cada sector social, desde su percepción y óptica decide cómo combinar ambiente y desarrollo, o decidan respecto de:
a) ¿Qué desarrollar del ambiente?
b) ¿Qué sostener?, y
c) ¿Para cuánto tiempo? 


\subsubsection{Origen de la sostenibilidad}

\section{i) Reseña histórica}

El camino recorrido hasta ahora por este proceso de búsqueda del cambio colectivo para la mejora de la calidad de vida futura, se concretará con los hitos cronológicos siguientes, -resumen que se referencia con lo publicado por (Cámara J. 2003; Marquardt 2006; Calabuig 2008; Díaz R. y Escárcega S. 2009), principalmente-:

De los registros históricos existentes en torno al tema de explotación de recursos naturales basada en una conciencia de futuro, se puede destacar que en 1456, el señorío de Bludenz (Austria), decretó su primera ley de sostenibilidad sobre los pastizales, bajo un texto semejante a: ... para que disfrutemos nosotros, nuestros herederos y los que nacerán después que ellos.

Con la misma analogía en 1536, el condado de Kyburg (Suiza) y en 1573 el señorío del monasterio de Fall (Eslovenia) permitieron a sus agricultores utilizar sólo la leña y madera necesaria para vivir, y dejar para los hijos y siguientes generaciones que puedan disfrutar del bosque, prohibiéndose la destrucción del bosque del cual todos subsistían.

Se marca como hito importante para la sostenibilidad, el decreto local del señorío de Seisenburg (Austria) en 1604, por el que se prohibió que los individuos ganen dinero a costa de los bienes de la comunidad y el desperdicio de madera.

En 1606 y 1610, los señoríos de Hohenwang (Austria) y la de los caballeros imperiales de Stetten (Alemania) impusieron que la madera se debía recolectar de sitios donde no dañen los bosques y también se impuso un número fijo de árboles para construcción tanto de casas como de establos.

Para esta época la sostenibilidad se estructuró con los cinco principios siguientes:

1. Descentralización política

2. Prevención de la capacidad máxima del sistema natural local

3. Control del consumo medioambiental

4. Subordinar la libertad del individuo al interés de la comunidad

5. Multifuncionalidad del suelo mediante la optimización del uso de la tierra 
En el año 1713, el jurista alemán, Hans Carlowitz expuso la teoría "Nachhaltigkeit" para la utilización óptima de los bosques en la minería de hierro y plata; en ella sugirió que la velocidad de producción de la industria minera debe ser menor a la velocidad de reproducción de los bosques. A pesar que, Francois Quesnay, filósofo - economista, a mediados del siglo XVIII, cuando la economía de Francia se encontraba en una mala situación (1756 1778) producto de las guerras a las que los condujo el Rey Luis XV y a las políticas mercantilistas que restringieron el comercio, propone junto con otros economistas de la época, una política de crecimiento económico basado en la interrelación hombre - naturaleza, bajo el término de fisiocracia.

Luego el gran cambio medioambiental se produce por las leyes de las seis décadas (1789 - 1848) resultado de poner en práctica el espíritu fisiocrático y liberal.

Para 1811 todo esto terminó con la ley de la propiedad privada impuesta en el reino de Prusia, bajo el "Decreto de la cultura de la tierra", donde cada individuo podía disponer con total libertad sobre sí mismo y sobre la naturaleza que le pertenecía, inclusive a destruirla. Este decreto se concibió como una exclusión contra los pobres de los pueblos y escapar de la "amenaza maltusiana"2.

Puede considerarse que el inicio en materia conservacionista estadounidense da su primer paso con el Parque Nacional Yellowstone en el año 1872.

África también fue un actor iniciático de la preservación, cuando emitió en 1900 el Protocolo para la preservación de la vida salvaje en todo su continente.

En París, Francia (1968) se celebró la Conferencia Intergubernamental de Expertos sobre una base científica para el uso racional y conservación de la biósfera denominada "Conferencia de la biósfera", de cuyo resultado trascendente surgió la propuesta para organizar el programa ecológico interdisciplinario "Hombre y biósfera", con la aprobación de la UNESCO.

El 22 de abril de 1970, se festeja por primera vez el "Día de la Tierra". Para diciembre de este mismo año se crea en Washignton la EPA - Environmental Protection Agency.

La UNESCO (1971) crea el programa de investigación Hombre y Biósfera (MAB), orientado a la conservación de la biodiversidad y la mejora de la relación

2 Teoría económica de Thomas Malthus (británico de fines del siglo XVIII), basadas en que el crecimiento poblacional y la producción de alimentos obedecen a una progresión geométrica y aritmética, respectivamente. 
hombre-entorno, mediante la búsqueda en el campo de las ciencias sociales y naturales. El mismo año en la Conferencia de las Naciones Unidas sobre el Medio Ambiente (Estocolmo, Suecia) se produce la primera manifestación de los gobiernos de 113 estados mostrando su preocupación por las consecuencias de la economía sobre el ambiente y se crea el Programa de las Naciones Unidas para el Medio Ambiente (PNUMA - UNEP).

El año 1971 se lleva a efecto la Convención Ramsar, Irán, este es el primer tratado intergubernamental que pretende conservar los recursos naturales a escala mundial y principalmente los humedales y su ecosistema.

En la Conferencia de Estocolmo, Suecia (1972), se formaliza el PNUMA Programa de las Naciones Unidas para el Medio Ambiente. Aquí se decretó como "Día Mundial del Medio Ambiente" al 5 de junio. En esta conferencia se presentó además el informe del Club de Roma "Crecimiento cero" - "Los límites del crecimiento", en el que se mostró de forma catastrófica predicciones respecto del futuro de la humanidad rescatando la necesidad del desarrollo. El mes de diciembre del mismo año en Londres, Inglaterra se realizó la convención para la Prevención de la Contaminación Marina por vertidos.

1973, fue el año en el que se celebró en Washington la "Convención CITES", en la que se creó un mecanismo internacional para la protección de especies en vías de extinción y control del tráfico de especies silvestres y sus derivados.

El Acuerdo de Berna se firma en 1977, para reglamentar y diferenciar a la flora y fauna, terrestre de la marina, y sus medidas protectoras en cada hábitat. Este mismo año, en la Conferencia de las Naciones Unidas - Nairobi, Kenia, se definen las condiciones para que se dé un ambiente desértico, como consecuencia de la destrucción o extracción del potencial biológico de la naturaleza.

En Ginebra, Suiza, el año 1979, se desarrolló la Primera Conferencia Mundial del Clima, en el que por vez primera se topó el tema del cambio climático como amenaza real a escala del planeta. En la Convención de Berna se inició con el tema de la conservación de la vida silvestre y ambientes naturales para Europa.

Con la participación del Programa de las Naciones Unidas para el Medio Ambiente (PNUMA) y el World Wildlife Fund (WWF), en 1980, se introduce el término desarrollo sostenible adaptado a un plan de largo plazo para la conservación de los recursos biológicos del planeta (I Estrategia Mundial para la Conservación - UICN). Tres años más tarde se crea la Comisión Mundial sobre Medio Ambiente y Desarrollo. 
En el año 1980, también se da a conocer el "Programa Mundial del Clima”. Un año más tarde, se publica el "Programa de Montevideo" en Uruguay, aprobada e impulsada por el Consejo de Administración del PNUMA, donde se promovió la codificación del derecho ambiental internacional.

Se estableció la Convención sobre la Conservación de los Recursos Vivos Marinos Antárticos (1980), suscrita por 15 naciones (hoy son 33). Entró en vigencia dos años más tarde.

El primer programa de la ONU sobre ambiente se conoció como la "Carta Mundial de la Naturaleza" y se aprobó en Asamblea General de las Naciones Unidas en 1982.

En 1983, Suecia, Noruega y Finlandia, publicaron la llamada "Propuesta Nórdica", en la que se fijaban limitaciones concretas para el uso de los CFC (clorofluorocarbonados) y se incluyó el convenio marco sobre protección de la capa de ozono, que finalmente se firmó en 1985 en la "Convención de Viena".

El año de 1984 la Asamblea General de las Naciones Unidas constituyó como un organismo independiente a la Comisión Mundial sobre el Medio Ambiente y el Desarrollo.

En Montreal, Canadá (1987), mediante el "Protocolo de Montreal" se publica sobre las cinco especies de CFC y los tres halógenos que afectan la capa de ozono y se los considera contaminantes atmosféricos. Este año, se llevó a cabo el experimento aéreo Antártico para demostrar la evolución del agujero en la capa de ozono Antártico.

En 1987 también se retoma, concreta y publica de manera oficial (por primera vez) la definición más conocida y aceptada en el planeta respecto del desarrollo sostenible, en el documento "Nuestro futuro común", también llamado Informe Brundtland, generado por la Comisión de éste mismo nombre. Además, aquí se insiste en la relación existente entre el ambiente y la economía.

El año de 1988, en Canadá, durante la "Conferencia de Toronto" se hizo un llamado de atención a la población mundial sobre el problema de la capa de ozono y se destacó la necesidad de aplicar soluciones urgentes respecto de las emisiones de gas que lo afectan.

En Ottawa, Canadá (1989), se aprobó la "Declaración de Principios sobre la Protección de la Atmósfera".

La Segunda Conferencia Mundial sobre el Clima se efectuó en Ginebra, Suiza en 1990, año en el que en Londres, en la segunda Reunión de Partes del Protocolo de Montreal se fijó un plazo de 10 años (hasta el año 2000), para la eliminación total de los CFC y halógenos, así como el control del 
metilcloroformo empleado en la industria electrónica, así también el tetracloruro de carbono utilizado en las industrias farmacéuticas, de plaguicidas y pinturas.

En 1991, UICN, PNUMA y WWF, formulan de manera global la II Estrategia Mundial para la Conservación, inspirada en el Informe Brundtland con el propósito de apoyar la construcción de una sociedad sostenible desde los componentes sociales y políticos.

Luego, los principios fundamentales que todo Estado debe perseguir para alcanzar un medio ambiente de calidad, fueron manifestados en la "ECO 92" ó "Cumbre de la Tierra" en Río de Janeiro (1992) en la Conferencia de Naciones Unidas sobre Medio Ambiente y Desarrollo, de la que se derivó el Plan de Acción de las Naciones Unidas - resumido en la "Agenda 21" - para integrar: desarrollo humano - social, medio ambiente y desarrollo económico, tarea que es claramente direccionada a las autoridades locales de cada sector, invitándolos a iniciar procesos de "Agenda 21 Local" para contribuir frontalmente a la sostenibilidad.

En esta Cumbre además se formalizó:

Convenio marco sobre cambio climático.

Protección de bosques.

Convención sobre biodiversidad.

Comisión de Naciones Unidas para el Desarrollo Sustentable.

Fondo Mundial para el Ambiente.

El mismo año, en el $V$ Programa de Acción en Materia de Medio Ambiente (1992-2000) "Hacia un desarrollo sostenible", se presenta una nueva estrategia comunitaria - medio ambiental para la prevención y toma de decisiones para conseguir el desarrollo sostenible.

Copenhague, Dinamarca (1992) se acuerda extender el control a todo lo que afecta la capa de ozono y se bajan los plazos para cumplimiento de cuotas de reducción.

La "Carta de Aalborg", carta de las ciudades europeas hacia la sostenibilidad, se aprueba y firma, el 27 de mayo de 1994 en la Conferencia Europea sobre ciudades Sostenibles, (Dinamarca), por 253 representantes de organismos internacionales, centros científicos, asesores, gobiernos nacionales y 80 autoridades locales europeas, bajo el compromiso de seguir los postulados e iniciativas locales de la Agenda 21, de la Declaración de Río. 
En París, Francia (1994), se acuerda preparar un Plan de Acción de Combate de la Desertificación, con el aval de la Convención de las Naciones Unidas. México fue la primera en el mundo en entregar el Plan - PACD.

El año de 1995, en Yakarta, Indonesia se desarrolla la Segunda Conferencia de las Partes del Convenio sobre Diversidad Biológica (COP2). Se firma también en Ginebra, Suiza la Convención de Lucha Contra la Desertificación PNUMA/IUC. Por su parte en Viena, Austria, se celebra la Séptima Reunión de las Partes del protocolo de Montreal.

La II Conferencia Europea de Ciudades Sostenibles, desarrollado en LisboaPortugal, y la II Conferencia de las Naciones Unidas sobre Asentamientos Humanos (Hábitat II), Estambul - Turquía, se llevaron a cabo ambas en 1996. La primera conferencia de Hábitat se desarrolló en Vancouver - Canadá en 1976.

En Buenos Aires, Argentina (1996), se desarrolla la Tercera Conferencia de las Partes del Convenio sobre Diversidad Biológica (COP3). Este mismo año se lleva a cabo la Cumbre de las Américas sobre Desarrollo Sostenible en Santa Cruz de la Sierra, Bolivia.

Las Convenciones Internacionales sobre lucha contra la desertificación se desarrollaron en 1996 en Ciudad de México y la de 1997 en La Habana, Cuba.

En Kyoto, Japón (1997), se desarrolló la Tercera Conferencia de Cambio Climático, en el que se suscribió el denominado Protocolo de Kyoto. Los compromisos consistieron en que 39 países desarrollados reducirían en $5 \%$ respecto de las de 1990 sus emisiones de gas entre los años 2008 y 2012. Los gases a reducir son: metano, dióxido de carbono, óxido nitroso, hidrofluorocarbonos, perfluorocarbono y hexafluoruro de azufre.

La cumbre conocida como "Río + 5", o Cumbre Mundial sobre desarrollo Sostenible se desarrolló en Nueva York, USA, (1997), cuyo propósito era el de analizar la ejecución de la Agenda 21 (Cumbre de 1992).

La Segunda Cumbre de las Américas se lleva a cabo en Santiago de Chile en abril de 1998. Para noviembre de este mismo año, el PNUMA / OMM crean el Panel Intergubernamental de Expertos sobre Cambio Climático (IPCC).

Se publica el Convenio de Róterdam (1998) como un procedimiento de consentimiento previo fundamentado, aplicable a ciertos plaguicidas y productos químicos peligrosos de comercio internacional.

En enero de 1999, en Quito, Ecuador, se emite la Declaración Latinoamericana sobre Organismos Transgénicos, se firma como un rechazo firme sobre la invasión de organismos transgénicos en América Latina. Un mes 
más tarde, en Cartagena de Indias, Colombia, se formalizó la Conferencia sobre Biodiversidad.

En el año 2000, se aprobaron las Declaraciones de Hannover y de Malmö (febrero y mayo, respectivamente) en las que se formalizan los compromisos de aceleración de esfuerzos locales y contribuir más decisivamente en el desarrollo sostenible. Este mismo año, en los -ODM- Objetivos de Desarrollo del Milenio producto de la Cumbre del Milenio de las Naciones Unidas, se plasmaron aquellos acuerdos que implican una lucha mancomunada por un mundo sin pobreza y bajo el compromiso del desarrollo sostenible.

En marzo del 2000, en la cumbre de Lisboa, los líderes europeos se comprometieron a convertir a la Unión Europea en la economía más dinámica y competitiva del mundo basada en el conocimiento, capaz de producir un crecimiento económico sostenible. A este compromiso se lo conoce como la "Estrategia de Lisboa".

Este mismo año, se lleva a cabo el Segundo Foro Mundial del Agua, en La Haya, Holanda; destaca el llamamiento para administrar el agua de una manera razonada, para garantizar una buena gestión, participativa y que se incluya la ordenación de recursos hídricos para satisfacer las necesidades de todos.

También en el año 2000, se publica el Protocolo de Cartagena sobre Seguridad de la Biotecnología y se dispone a la firma de los Estados en las dos oficinas de las Naciones Unidas - Nairobi, Kenia y Nueva York, USA -.

En Göteborg ó Gotemburgo de Suecia, (junio del 2001), en la reunión: Estrategia de la Unión Europea para el "Desarrollo Sostenible en Europa para un mejor mundo", se establece como objetivo global estudiar las repercusiones económicas, sociales y ambientales de las políticas, para tenerlas en cuenta en la toma de decisiones, así como también conseguir precios correctos que reflejen mejor los costos de las actividades humanas.

Por su parte, el Comité Andino de Autoridades Ambientales (CAAAM), reunidas en Quito (2001) plantean los "Lineamientos para la Gestión Ambiental y el Desarrollo Sostenible en la Comunidad Andina", cuyos principales ámbitos de trabajo se relacionan con la conservación y uso sostenible de la biodiversidad, calidad ambiental, comercio y medio ambiente. (CAAAM 2001). Este mismo año, en Québec, Canadá se realizó la Tercera Cumbre de las Américas.

El Parlamento Europeo y el Consejo de 22 de julio de 2002, establece el Sexto Programa de Acción Comunitario en materia de Medio Ambiente, "Medio ambiente 2010: el futuro está en nuestras manos", cuyo ámbito de actuación fue el cambio climático, naturaleza y biodiversidad, medio ambiente, salud y calidad de vida, uso y gestión sostenible de recursos naturales y los residuos, 
entre otros. El mismo 2002, en Johannesburgo - Sudáfrica, se celebró la Cumbre Mundial sobre el Desarrollo Sostenible, con el tema principal: ¿Cómo se debe transformar al mundo para asegurar el desarrollo sostenible? Esto se convirtió también en una evaluación de los éxitos alcanzados por la comunidad mundial en el tema de sostenibilidad durante los 10 años transcurridos desde la Cumbre de Río de Janeiro. Asimismo, se reafirmó el compromiso de cada gobierno local - municipal con los principios de la Agenda 21.

En marzo de 2003 se celebra en Kyoto, Japón, el Tercer Foro Mundial del Agua. Encuentro en el que se ratificó el compromiso mundial por reducir hasta el año 2015 a la mitad el número de personas sin acceso a agua potable.

A pesar que la comunicación final no se publicó en el Diario Oficial, en diciembre de 2003 existió la Comunicación al Consejo y al Parlamento Europeo titulada "La Cumbre Mundial sobre el Desarrollo Sostenible un año después: cumplimiento de nuestros compromisos. Se establecen medidas fuera de la UE como el de formular iniciativas en el ámbito del agua, la energía y los bosques, entre ellas destacan "agua para la vida" y "energía para la erradicación de la pobreza y el desarrollo sostenible", (Síntesis de la legislación de la UE 2007), otro aspecto a apoyar es el de comercio y mundialización, así como también la UE considera necesario reforzar la gobernanza internacional a favor del desarrollo sostenible, a través de la consolidación del PNUMA.

En Cascais - Portugal (2004), en el IV Foro Ibero-Americano de Ministros de Ambiente, se decidió institucionalizar la Red Iberoamericana de Oficinas para el Cambio Climático; (Secretaría General Comunidad Andina 2004), año en que también la Comisión Económica para América Latina y el Caribe (CEPAL) y el Programa de las Naciones Unidas para el Desarrollo (PNUD) celebraron en Chile el Seminario Internacional sobre Perspectivas para América Latina y el Caribe de los Mercados de Carbono.

En Valencia, España (2004) se efectuó el Foro Mundial de Reforma Agraria, con representantes de 70 países. Se emitió aquí la declaración "La reforma agraria y los recursos naturales: una exigencia de los pueblos".

En Buenos Aires, Argentina (2004) se celebró la Cumbre sobre Cambio Climático, oportunidad en la que se evaluó los avances respecto de la propuesta del Protocolo de Kyoto, muchos países en vías de desarrollo lograron consolidar instrumentos de financiamiento para enfrentar los efectos del cambio climático.

En Roma (2004), se reúne el grupo de Adelboden para iniciar con el proyecto de Desarrollo Sostenible en las regiones de montaña. 
El 16 de febrero de 2005, entró en vigor el protocolo de Kyoto como un instrumento para el desarrollo sostenible, obligándose a los países industrializados a reducir sus emisiones de gases que producen efecto de invernadero. Se oficializa además que los países industrializados puedan compensar cantidades limitadas de sus emisiones invirtiendo en los países en desarrollo con bosques que fijen reducciones certificadas del carbón, convirtiéndose éste en una mercancía con un valor inicial de entre 15 y 25 dólares. (FAO 2005).

La Cuarta Cumbre de las Américas, Declaración de Mar del Plata, celebrada en Argentina en noviembre de 2005, bajo el tema: "Crear trabajo para enfrentar la pobreza y fortalecer la gobernalidad democrática", 34 países del Continente Americano ratificaron su compromiso para apoyar los mandatos y compromisos asumidos en la Cumbre Mundial sobre el Desarrollo Sostenible de Johannesburgo 2002, y en otras Cumbres, como condición fundamental para el desarrollo sostenible de estos países. Esto implica el apoyo a políticas de esfuerzos internacionales, para el apoyo a la creación de trabajo decente y apoye la viabilidad sostenible de las comunidades involucradas. (IV Cumbre de las Américas 2005). Paralelamente, en este mismo mes, en Kampala, Uganda se desarrolló la Novena Reunión de la Conferencia de la Convención sobre los humedales, con el tema "Los humedales y el agua: ¡mantienen la vida nos dan el sustento!".

La FAO y el Gobierno brasileño, en la ciudad de Porto Alegre, Brasil (2006), efectuaron la Conferencia Internacional sobre Reforma Agraria y Desarrollo Rural (CIRADR), con el tema "Nuevos desafíos y opciones para revitalizar las Comunidades Rurales".

El Cuarto Foro Mundial del Agua tuvo lugar en Ciudad de México en marzo de 2006, bajo el lema "Acciones locales para un reto global", evento que estuvo a cargo del Consejo Mundial del Agua. Entre los objetivos se destacó el de asegurar un mejor nivel de vida para la humanidad del mundo entero, con un comportamiento social más responsable con el uso del agua, como parte de alcanzar el desarrollo sostenible. Paralelamente en Curitiba, Brasil, se efectuó la Octava Conferencia de la Convención sobre Diversidad Biológica.

Para junio del 2006, en Vancouver, Canadá, se celebró la Tercera sesión del foro urbano mundial, con el tema "Nuestro futuro: ciudades sostenibles convirtiendo ideas en acciones". En el mes de noviembre, en Nairobi, Kenia, se buscaron otros mecanismos para la reducción de emisiones después del 2012 y avanzar en el cumplimiento del Protocolo, en la Segunda Conferencia de las Partes del Protocolo de Kyoto. En la misma ciudad, el año 2007, se desarrolló la Séptima edición del Foro Social Mundial, con el propósito de 
continuar con el proceso de construcción de alternativas a las políticas neoliberales.

En la Cumbre de Bali (2007), se buscó redefinir el protocolo de Kyoto y adaptarlo a las nuevas necesidades por el cambio climático. Como principales invitados a firmar nuevos acuerdos estuvieron, entre muchos otros del mundo, Ministros de USA y China, por ser los grandes emisores de contaminantes al planeta.

En Zaragoza, España (2008), se llevó a cabo una exposición internacional con el eje temático "Agua y desarrollo sostenible" evento que duró 93 días; la Tribuna del Agua se manifestó con el tema "El agua, una responsabilidad compartida". Además se desarrolló el "Foro Mundial de las luchas de agua".

En Estambul, Turquía (2009), se celebró el "Quinto Foro Mundial del Agua", bajo iniciativa del Concejo Mundial del Agua, cuyos propósitos principales tuvieron relación con la promoción y apoyo a la elaboración de políticas a nivel global para asegurar un mejor nivel de vida de la humanidad. Aquí se presento el Informe de las Naciones Unidas sobre el Desarrollo de los Recursos Hídricos en el Mundo. El día mundial del agua, celebración que cerró este foro, se hizo énfasis en los recursos hídricos transfronterizos, considerando que existe suficiente agua para satisfacer las necesidades de todos, no obstante su distribución no es equitativa y menos gestionada como se requiere.

En 2009 también, en Buenos Aires, Argentina se desarrolló la Novena Convención de las Naciones Unidas para la Lucha contra la Desertificación (UNCCD) llamada oficialmente "Convención de las Naciones Unidas sobre la Lucha contra la Desertificación en los países gravemente afectados por la sequía y la desertificación, en particular en África", las acciones apuntaron a apoyar la productividad de la tierra, conservar y restaurar los suelos, y una mejor utilización de los recursos hídricos con la noción de desarrollo sostenible en las zonas afectadas por la desertificación.

La Novena Cumbre sobre el desarrollo sostenible, efectuada en Delhi, India (2009), tuvo como tema el "Cambio climático - Hacia Copenhague: un enfoque ético y justo", los temas se enfocaron a intensificar la cooperación a todos los niveles y de forma global para garantizar que la conferencia de las Naciones Unidas sobre Cambio Climático (diciembre) aporte con resultados y soluciones concretas.

En México (febrero 2010), se llevó a cabo la reunión para la presentación del informe sobre cumplimiento del séptimo objetivo de Desarrollo el Milenio: avances en la sostenibilidad ambiental del desarrollo en América Latina y el Caribe. Coordinado por CEPAL, PNUMA, ONU-Hábitat, UNICEF, OPS, entre 
otros. Para agosto del mismo 2010, se tiene previsto desarrollar en Brasil, la "Segunda Conferencia Internacional en Clima, Sostenibilidad y Desarrollo en regiones semiáridas", ICID. En el desarrollo de este acto se pretende dar respuesta a preguntas muy concretas, por ejemplo ¿Cómo podrían los negociadores, los responsables políticos, científicos y profesionales traducir los acuerdos mundiales en medidas concretas?, ¿Qué acciones se tomarán después de Copenhague?, entre otros.

Para septiembre de este año (2010), y a sólo 5 años para la fecha límite de alcanzar los Objetivos de Desarrollo del Milenio, el Secretario General, Ban Kimoon, convoca a los líderes mundiales para impulsar el progreso y consecución de los mismos.

\section{ii) Cumplimiento de los objetivos del milenio}

Para la década de los noventas aún era muy notoria la falta de éxito de todos los intentos por mejorar la calidad de vida de los individuos, por reducir la pobreza, por procurar un progreso económico que proteja el medio ambiente, que se derivarían a un procedimiento pragmático, porque los objetivos económicos, sociales y ambientales se mantenían separados. En muchos casos los excesos de contaminación y sobreexplotación de recursos naturales se producían debido a los fallos del mercado existentes y distorsiones políticas exacerbadas por el desempleo, los sin tierra y la pobreza. (Munasinghe M. 1993).

La Estrategia planteada en Lisboa propuso de forma global, entre otros:

- Acelerar reformas estructurales.

- Mejorar la política I+D.

- Invertir en capital humano y luchar contra la exclusión social.

- Manejar políticas macroeconómicas adecuadas a un crecimiento sostenible y de estabilidad.

La Estrategia de Gotemburgo, complementó con:

- $\quad$ El estudio de las repercusiones económicas, sociales y ambientales.

- Conseguir precios que recuperen costos reales de toda actividad social.

- Lucha contra el cambio climático.

- Garantizar el transporte sostenible.

- Afrontar amenazas contra la salud pública.

- Gestión responsable de recursos naturales. 
La combinación de estas dos estrategias (la de Lisboa y la de Gotemburgo) se comprende que conduce a un desarrollo sostenible. No obstante, hasta el momento se han conseguido muy pocos progresos, por lo que aún falta mucho para alcanzar los objetivos planteados desde hace varios años atrás. (Ministerio de Economía y Hacienda 2005).

En este orden de cosas, por ejemplo, falta crear alrededor de 21 millones de empleos; en este año (2010) los gases invernadero debieron reducirse en un $15.2 \%$ referido a 1990, desde el 2005; y, al parecer los únicos que cumplen con el objetivo de investigación y desarrollo (I+D) son Finlandia y Suecia.

\section{a) Tendencia observada por las Naciones Unidas entre los resultados del año 1990 y 2005}

En el informe de 2005 de las Naciones Unidas de los Objetivos de Desarrollo del Milenio, se muestra una evaluación respecto del avance en la consecución de dichos objetivos a nivel mundial. Seguidamente se resume algunas de aquellas conclusiones. (Naciones Unidas 2005).

Cuadro 2.1 Análisis del estado de cumplimiento de los ODM al 2005 por las UN

\begin{tabular}{|c|c|}
\hline Objetivo & Estado de situación al 2005 \\
\hline $\begin{array}{l}\text { 1.- Erradicar la } \\
\text { pobreza } \\
\text { extrema y el } \\
\text { hambre }\end{array}$ & $\begin{array}{l}\text { - } 1100 \text { millones de personas del mundo han caído en pobreza extrema } \\
\text { (menos de } 1 \text { dólar / día); la mayoría de África subsahariana. } \\
1600 \text { millones de personas viven en condiciones de pobreza (menos de } \\
2 \text { dólares / día). } \\
\text { - A nivel mundial, las tasas de pobreza han disminuido, principalmente } \\
\text { en Asia Oriental y el Pacífico. } \\
\text { - En África subsahariana y Asia, la mitad de los niños padecen } \\
\text { malnutrición. }\end{array}$ \\
\hline $\begin{array}{l}\text { 2.- Lograr } \\
\text { educación } \\
\text { primaria } \\
\text { universal }\end{array}$ & $\begin{array}{l}\text { - Cinco regiones en desarrollo se están acercando a una tasa de } \\
\text { matriculación del } 100 \% \text {. } \\
\text { - En África subsahariana, menos de } 2 / 3 \text { de los niños están matriculados } \\
\text { en escuelas primarias. } \\
\text { - En } 2015,47 \text { millones de niños y niñas no irán a la escuela. } \\
\text { - El } 80 \% \text { de niños y niñas sin escolarizar viven en África subsahariana o } \\
\text { - Asia meridional. } \\
\text { En Asia Meridional, Oceanía y otras regiones se debe trabajar para que } \\
\text { los niños no abandonen la escuela o reciban educación de calidad. }\end{array}$ \\
\hline $\begin{array}{l}\text { 3.- Promover la } \\
\text { igualdad de } \\
\text { género y el } \\
\text { empoderamiento }\end{array}$ & $\begin{array}{l}\text { - Reducción lenta de la diferencia entre géneros en la tasa de } \\
\text { matriculación en educación primaria del mundo en desarrollo. } \\
\text { - Las mujeres aún se ven relegadas a trabajos inestables y mal } \\
\text { remunerados. }\end{array}$ \\
\hline
\end{tabular}




\begin{tabular}{|c|c|}
\hline Objetivo & Estado de situación al 2005 \\
\hline de la mujer & $\begin{array}{l}\text { - Las mujeres ocupan sólo el } 16 \% \text { de los escaños de los parlamentos del } \\
\text { mundo, por lo que siguen sin representatividad equitativa en los } \\
\text { niveles gubernamentales. }\end{array}$ \\
\hline $\begin{array}{l}\text { 4.- Reducir } \text { la } \\
\text { mortalidad de } \\
\text { los } \\
\text { menores de } 5 \\
\text { años }\end{array}$ & $\begin{array}{l}\text { - Mueren } 30000 \text { niños por día ( } 11 \text { millones/año), por enfermedades que } \\
\text { se pueden prevenir o tratar con programas de bajo costo. } \\
\text { - La tasa de reducción de mortalidad de niños menores de } 5 \text { años nos es } \\
\text { la necesaria. }\end{array}$ \\
\hline $\begin{array}{l}\text { 5.- Mejorar la salud } \\
\text { materna }\end{array}$ & $\begin{array}{l}\text { - } 500000 \text { mujeres (embarazadas o en parto) mueren por año. } \\
\text { - } 10 \text { millones de mujeres sufren lesiones graves y discapacidad. } \\
\text { - En África subsahariana, } 1 \text { de cada } 16 \text { mujeres tiene el riesgo de morir } \\
\text { en el embarazo o durante el alumbramiento. En los países } \\
\text { desarrollados } 1 \text { de cada } 3800 \text {. (AEP 2006). } \\
\text { - No se logra reducir la mortalidad materna en las regiones en } \\
\text { desarrollo, al nivel esperado. }\end{array}$ \\
\hline $\begin{array}{lr}\text { 6.- } & \text { Combatir } \\
\text { VIH/SIDA, el } & \text { el } \\
\text { paludismo } & \text { y } \\
\text { otras } & \\
\text { enfermedades }\end{array}$ & $\begin{array}{l}\text { - La muerte por SIDA se ha convertido en la cuarta causa de muerte en } \\
\text { el mundo y la primera en Asia subsahariana. } \\
\text { - El } 2005 \text { hubo } 4.1 \text { millones de nuevos infectados de VIH/SIDA. } \\
\text { - El } 12 \% \text { de los infectados de SIDA tiene acceso a los retro virales. } \\
\text { - En África, la malaria provoca la muerte de } 1 \text { niño cada } 30 \text { segundos. } \\
\text { (AEP 2006). } \\
\text { - El paludismo y la tuberculosis juntos, provocan un número muy } \\
\text { - semejante que las muertes por SIDA. }\end{array}$ \\
\hline $\begin{array}{l}\text { 7.- Garantizar la } \\
\text { sostenibilidad } \\
\text { del medio } \\
\text { ambiente }\end{array}$ & $\begin{array}{l}\text { - El modelo actual de uso y consumo mundial de recursos naturales no } \\
\text { permitirá alcanzar la sostenibilidad deseada. } \\
\text { - Aún perdura el hecho de que la subsistencia cotidiana de los pobres } \\
\text { suele con más frecuencia depender directamente de la extracción de } \\
\text { recursos naturales de su entorno. } \\
\text { - El } 50 \% \text { de la población del mundo en desarrollo no dispone de retretes } \\
\text { u otras formas básicas de saneamiento. (AEP 2006). } \\
1000 \text { millones de personas viven en tugurios por superar la tasa de } \\
\text { crecimiento poblacional a la de las mejoras de viviendas o generación } \\
\text { de puestos de trabajo productivos. }\end{array}$ \\
\hline $\begin{array}{l}\text { 8.- Fomentar una } \\
\text { alianza mundial } \\
\text { para el } \\
\text { desarrollo }\end{array}$ & $\begin{array}{l}\text { - } 100 \text { millardos de dólares pagan los países en desarrollo por barreras } \\
\text { arancelarias de los países desarrollados. (AEP 2006). } \\
\text { - El compromiso del alivio de la deuda externa y la apertura de mejores } \\
\text { intercambios comerciales aún no ha sido cumplida. }\end{array}$ \\
\hline
\end{tabular}

Fuente: Referenciado con el informe (Naciones Unidas 2005).

En el cuadro 2.2 se agrupa el balance porcentual del cumplimiento de indicadores que componen el conjunto de los ODM por regiones, desde el punto de vista global de algunos indicadores. 
Cuadro 2.2 Tendencia 1990 - 2005, acerca del cumplimiento de los ODM, proyectada por las Naciones Unidas.

\begin{tabular}{|c|c|c|c|c|c|c|c|c|c|c|}
\hline \multirow{2}{*}{\multicolumn{2}{|c|}{ Objetivo }} & \multirow{2}{*}{ Indicador } & \multicolumn{8}{|c|}{ REGIONES: Clasificación Naciones Unidas } \\
\hline & & & $\begin{array}{c}\text { Regiones en } \\
\text { desarmollo }\end{array}$ & \begin{tabular}{c|c} 
África \\
Septentrional
\end{tabular} & \begin{tabular}{c|} 
Africa \\
Subsahariana
\end{tabular} & $\begin{array}{c}\text { América Latina } \\
\text { y Caribe }\end{array}$ & $\begin{array}{c}\text { Asia } \\
\text { Oriental }\end{array}$ & $\begin{array}{c}\text { Asia } \\
\text { Meridional }\end{array}$ & $\begin{array}{l}\text { Sudeste } \\
\text { Asiatico }\end{array}$ & $\begin{array}{c}\text { Asia } \\
\text { Occidental }\end{array}$ \\
\hline \multicolumn{2}{|c|}{ Objetivo 1. Pobreza extrema y hambre } & Indicador 1 & $140 \%$ & $165 \%$ & $43 \%$ & $55 \%$ & $250 \%$ & $101 \%$ & $240 \%$ & $-491 \%$ \\
\hline \multicolumn{2}{|c|}{ Objetivo 2. Educación primaria universal } & Indicador 6 & $69 \%$ & $132 \%$ & $64 \%$ & $134 \%$ & $-472 \%$ & $109 \%$ & $0 \%$ & $52 \%$ \\
\hline \multirow{3}{*}{\multicolumn{2}{|c|}{ Objetivo 3. Equidad de género }} & Indicador $9 \mathrm{~b}(1)$ & $152 \%$ & $238 \%$ & $-46 \%$ & $-60 \%$ & $417 \%$ & $144 \%$ & $556 \%$ & $66 \%$ \\
\hline & & Indicador $9 \mathrm{c}(1)$ & $246 \%$ & $444 \%$ & $-81 \%$ & $-174 \%$ & $324 \%$ & $124 \%$ & $365 \%$ & $162 \%$ \\
\hline & & Indicador 11 & - & $2 \%$ & $27 \%$ & $64 \%$ & $37 \%$ & $23 \%$ & $16 \%$ & $24 \%$ \\
\hline \multicolumn{2}{|c|}{$\begin{array}{l}\text { ODM 6. VIH/SIDA, paludismo y otras } \\
\text { enfermedades }\end{array}$} & Indicador 18 & $-41 \%$ & $100 \%$ & $-37 \%$ & $-38 \%$ & $100 \%$ & $-48 \%$ & $-45 \%$ & $100 \%$ \\
\hline \multicolumn{2}{|c|}{ Objetivo 7 . Medio ambiente } & Indicador 30 & $111 \%$ & $65 \%$ & $49 \%$ & $168 \%$ & $86 \%$ & $166 \%$ & $89 \%$ & $143 \%$ \\
\hline$G C<0 \%$ & \multicolumn{10}{|c|}{ Retroceso respecto a la situación de partida (UN: en retroceso) } \\
\hline $0 \%<\mathrm{GC}<=50 \%$ & \multicolumn{10}{|c|}{ Cumplimiento del objetivo en menos del 50\% (UN: Progreso lento) } \\
\hline $50 \%<G C<100 \%$ & \multicolumn{10}{|c|}{ Cumplimiento del objetivo en más del $50 \%$, pero no al $100 \%$ (UN: Progreso moderado) } \\
\hline$G C>=100 \%$ & \multicolumn{10}{|c|}{$\begin{array}{l}\text { Cumplimiento del objetivo superior al establecido (UN: Progreso rápido), pero sin erradicar el problema que se pretende paliar } \\
\text { Erradicación del problema que pretende paliar el objetivo }\end{array}$} \\
\hline
\end{tabular}

Fuente: Tomado de (Gil M. Fernández A. Callejón M. 2007).

Esta proyección nos permite conjeturar las marcadas diferencias que existen en la consecución de los ODM entre regiones.

b) Análisis de cumplimiento del séptimo de los Objetivos de Desarrollo del Milenio, "garantizar la sostenibilidad del medio ambiente" en América Latina y el Caribe, referido con el informe de (CEPAL 2010).

El séptimo Objetivo de Desarrollo del Milenio, oficialmente se compone de cuatro metas y diez indicadores. Pese a que estos últimos no reflejan la realidad de cada subregión o región analizada, de forma general (contraste mundial) ayudan a evaluar y comparar en su conjunto las características de aquellos elementos que se califican como importantes para el común de los individuos del planeta. 
Meta A.- Incorporar los principios del desarrollo sostenible en las políticas y los programas nacionales e invertir la pérdida de recursos del medio ambiente.

\section{Cuadro 2.3 Evaluación del avance de los indicadores de la Meta A, 5 años antes de} vencer el plazo establecido para su cumplimiento.

\begin{tabular}{|c|c|c|}
\hline Indicador & Problemas percibidos & $\begin{array}{c}\text { ¿Cumple } \\
\text { meta? }\end{array}$ \\
\hline $\begin{array}{l}\text { Proporción de } \\
\text { la superficie } \\
\text { cubierta por } \\
\text { bosques }\end{array}$ & $\begin{array}{l}\text { - } \quad \text { Tasa de deforestación en aumento. } \\
\text { - } \quad \text { Insuficiente incentivo económico para conservación de } \\
\text { bosques. } \\
\text { - } \quad \text { Es más rentable deforestar que preservar los bosques. }\end{array}$ & No \\
\hline $\begin{array}{l}\text { Emisiones de } \\
\text { dióxido de } \\
\text { carbono (total } \\
\text { / persona / } \\
\text { dólar PPA del } \\
\mathrm{PIB}^{3} \text { ) }\end{array}$ & $\begin{array}{l}\text { - Quema de combustibles fósiles y producción de } \\
\text { cemento aumentan las emisiones de carbono. } \\
\text { - } \quad \text { El crecimiento demográfico y económico de la región } \\
\text { genera el aumento sostenido en el tiempo de las } \\
\text { emisiones de carbono. } \\
\text { - } \quad \text { La deforestación aumenta emisiones de carbono. } \\
\text { - Escasos avances en el desarrollo de fuentes renovables } \\
\text { de energía y eficiencia energética. } \\
\text { - Parsimoniosa búsqueda de apoyo tecnológico y } \\
\text { financiero para el desarrollo de energías limpias. }\end{array}$ & No \\
\hline $\begin{array}{l}\text { Consumo de } \\
\text { sustancias que } \\
\text { agotan la capa } \\
\text { de ozono }\end{array}$ & $\begin{array}{l}\text { - Reducción incompleta del consumo de sustancias que } \\
\text { agotan la capa de ozono. }\end{array}$ & $\mathrm{Si}$ \\
\hline $\begin{array}{l}\text { Proporción de } \\
\text { poblaciones } \\
\text { de peces que } \\
\text { están dentro } \\
\text { de límites } \\
\text { biológicos } \\
\text { seguros }\end{array}$ & $\begin{array}{l}\text { - Inexistencia de estadísticas para referir el indicador. } \\
\text { - Crecimiento de la presión sobre los recursos } \\
\text { hidrobiológicos por aumento de pesca e industria } \\
\text { acuícola, por cambio climático y contaminación. } \\
\text { - Insuficiente incorporación de prácticas de gestión } \\
\text { sostenible de especies acuáticas. }\end{array}$ & No \\
\hline
\end{tabular}

Fuente: Adaptado por el Autor de (CEPAL 2010).

Meta B.- Reducir la pérdida de biodiversidad, alcanzando, para el año 2010, una reducción significativa de la tasa de pérdida.

PPA del PIB: Paridad del Poder Adquisitivo del Producto Interno Bruto, que permite comparar estándares de vida con más validez, puesto que parte de una comparación en unidades monetarias hipotéticas con el mismo poder adquisitivo que lo que tiene el dólar estadounidense en la USA, en un momento dado. 
Cuadro 2.4 Evaluación del avance de los indicadores de la Meta B.

\begin{tabular}{|c|c|c|}
\hline Indicador & Problemas percibidos & $\begin{array}{c}\text { ¿Cumple } \\
\text { meta? }\end{array}$ \\
\hline $\begin{array}{l}\text { Proporción del } \\
\text { total de } \\
\text { recursos } \\
\text { hídricos } \\
\text { utilizada }\end{array}$ & $\begin{array}{l}\text { - } \quad \text { Inequidad en la distribución del agua. } \\
\text { - } \quad \text { Destrucción de cuencas tributarias - fuente. } \\
\text { - } \quad \text { Consumo excesivo para agricultura y minería. } \\
\text { - } \quad \text { Agotamiento de acuíferos. } \\
\text { - } \quad \text { Elevados riesgos por mala calidad del agua. } \\
\text { - } \quad \text { Escasa gestión efectiva de los recursos hídricos. }\end{array}$ & No \\
\hline $\begin{array}{lr}\text { Proporción } & \text { de } \\
\text { las as areas } & \\
\text { terrestres y y } & \text { marinas } \\
\text { protegidas } & \end{array}$ & $\begin{array}{l}\text { - } \quad \text { Pérdida de hábitats por la deforestación y actividad } \\
\text { económica. } \\
\text { - } \quad \text { Introducción de especies foráneas. } \\
\text { - Insuficiente cantidad de área protegida, para } \\
\text { preservar la biodiversidad. } \\
\text { - Técnicas de conservación no son ni adecuadas ni } \\
\text { suficientes para satisfacer la necesidad. } \\
\text { - Estructuras financieras y regulatorias no internalizan } \\
\text { los costos ambientales y sociales de la pérdida de } \\
\text { biodiversidad. }\end{array}$ & No \\
\hline $\begin{array}{ll}\text { Proporción } & \text { de } \\
\text { especies } & \text { en } \\
\text { peligro } & \text { de } \\
\text { extinción } & \end{array}$ & $\begin{array}{l}\text { - Insuficiente información estadística. } \\
\text { - Pérdida estimada del } 75 \% \text { de la diversidad genética } \\
\text { de los cultivos agrícolas de la región, en el último } \\
\text { siglo. } \\
\text { Inexistencia de un régimen equitativo de } \\
\text { participación de los beneficios de la explotación de la } \\
\text { biodiversidad. }\end{array}$ & No \\
\hline
\end{tabular}

Fuente: Adaptado por el Autor de (CEPAL 2010).

Meta C.- Reducir a la mitad, para el año 2015, el porcentaje de personas sin acceso sostenible al agua potable y a servicios básicos de saneamiento.

Cuadro 2.5 Evaluación del avance de los indicadores de la Meta C, 5 años antes de vencer el plazo establecido para su cumplimiento.

\begin{tabular}{|l|l|c|}
\hline \multicolumn{1}{|c|}{ Indicador } & \multicolumn{1}{c|}{ Problemas percibidos } & $\begin{array}{c}\text { ¿Cumple } \\
\text { meta? }\end{array}$ \\
\hline $\begin{array}{l}\text { Proporción de } \\
\text { la población } \\
\text { con acceso a } \\
\text { fuentes } \\
\text { mejoradas de }\end{array}$ & $\bullet \quad \begin{array}{l}\text { Notorias diferencias entre la cobertura de agua potable, } \\
\text { entre el sector urbano y el rural, entre ciudades, entre } \\
\text { municipios y entre provincias. }\end{array}$ & No \\
$\begin{array}{l}\text { abastecimiento } \\
\text { de agua potable }\end{array}$ & $\bullet \quad \begin{array}{l}\text { Mala calidad del agua distribuida, intermitencia de servicio } \\
\text { y pérdidas de agua en las redes. } \\
\text { Escasos avances en las políticas a la gestión de recursos. }\end{array}$ & \\
\hline
\end{tabular}




\begin{tabular}{|l|l|c|}
\hline \multicolumn{1}{|c|}{ Indicador } & \multicolumn{1}{|c|}{ Problemas percibidos } & $\begin{array}{c}\text { ¿Cumple } \\
\text { meta? }\end{array}$ \\
\hline $\begin{array}{l}\text { Proporción de } \\
\text { la población } \\
\text { con acceso a } \\
\text { servicios de } \\
\text { saneamiento } \\
\text { mejorados }\end{array}$ & $\begin{array}{l}\text { Desigual distribución de los servicios, entre sectores } \\
\text { sociales, entre ciudades y entre países. } \\
\text { Sectores pobres y rurales tienen limitado acceso al servicio } \\
\text { de saneamiento. }\end{array}$ & No \\
\hline $\begin{array}{l}\text { Escasos avances en los mecanismos de financiamiento y } \\
\text { regulación del servicio. }\end{array}$ & \\
\hline
\end{tabular}

Fuente: Adaptado por el Autor de (CEPAL 2010).

Meta D.- Haber mejorado considerablemente, para el año 2020, la vida de por lo menos 100 millones de habitantes de tugurios.

Cuadro 2.6 Evaluación del avance de los indicadores de la Meta D, 10 años antes de vencer el plazo establecido para su cumplimiento.

\begin{tabular}{|l|l|c|}
\hline \multicolumn{1}{|c|}{ Indicador } & \multicolumn{1}{c|}{ Problemas percibidos } & $\begin{array}{c}\text { Cumple } \\
\text { meta? }\end{array}$ \\
\hline $\begin{array}{l}\text { Proporción de } \\
\text { la población } \\
\text { urbana que vive } \\
\text { en tugurios }\end{array}$ & - $\begin{array}{l}\text { Aún viven más de 100 millones de personas en condiciones } \\
\text { inaceptables. }\end{array}$ & No \\
& $\begin{array}{l}\text { La crisis económica mundial se interpone para que los países } \\
\text { cumplan con la reducción del número de personas que viven } \\
\text { en tugurios. } \\
\text { No se asegura el derecho a la vivienda por los países de la } \\
\text { región, según como su compromiso internacional asumido. }\end{array}$ & \\
\hline
\end{tabular}

Fuente: Adaptado por el Autor de (CEPAL 2010).

Al intentar buscar las razones para no haber cumplido con el avance previsto, se podría indicar que el impulso político no es el adecuado, posiblemente por problemas de visibilidad del horizonte al cual se desea llegar, puede existir trasposición entre directivas, sumado a una falta de incentivos, o no se facilita la innovación, ni la introducción de las nuevas tecnologías de la información y la comunicación (NTIC) acerca de la explotación sostenible de recursos, ni se optimiza la inversión pública o privada, o en determinados sectores y países falta aplicar el seguimiento al cumplimiento de las directivas mediante Programas Nacionales, entre muchos otros aspectos inherentes a este lento proceso de avance hacia la sostenibilidad. Parece ser que el aumento de las oportunidades que los individuos dispongan para su desarrollo, depende mucho de la búsqueda de su propia dignidad, su entorno y ampliación del bienestar, reconquistar su libertad, el encuentro con el bien común, formación humana en principios y valores, entre otros. 
Varios autores coinciden en que todavía muchos de nosotros vivimos por arriba de la capacidad ambiental del mundo, por ejemplo respecto del consumo energético, la generación de basura, la contaminación del agua y atmósfera, con un escenario de necesidades creadas cada vez más exigentes y caprichosas, que la mayoría del tiempo resultan difíciles de subsanar por el ambiente.

\subsubsection{Ejes de la sostenibilidad}

Según el concepto del Banco Mundial "el desarrollo sostenible es un proceso de administración de una cartera de activos que permita preservar y mejorar las oportunidades que tiene la población. El desarrollo sostenible comprende la viabilidad económica, ambiental y social, que se puede alcanzar administrando racionalmente el capital físico, natural y humano" (World Bank 2002).

Desarrollo sostenible, extraído desde el Informe Brundtland en el año 1987 que textualmente dice: “... Believing that sustainable development, which implies meeting the needs of the present without compromising the ability of future generations to meet their own needs, should become a central guiding principle of the United Nations, Governments and private institutions, organizations and enterprises ..." (United Nations 1987); y, oficialmente definido en el Principio tercero de la Declaración de Río de 1992 y de allí hasta el Documento final de la Cumbre Mundial de 2005, ítem 48 que dice: "Reafirmamos nuestro compromiso de alcanzar el objetivo relativo al desarrollo sostenible, entre otras cosas, mediante la aplicación del Programa 21 y el Plan de Aplicación de las Decisiones de Johannesburgo. Con tal fin, nos comprometemos a emprender acciones y medidas concretas a todos los niveles y fomentar la cooperación internacional, teniendo en consideración los principios de Río. En ese esfuerzo también se promoverá la integración de los tres componentes del desarrollo sostenible - desarrollo económico, desarrollo social y protección del medio ambiente - como pilares interdependientes que se refuerzan mutuamente. La erradicación de la pobreza, la modificación de las modalidades insostenibles de producción y consumo y la protección y ordenación de la base de recursos naturales del desarrollo económico y social son objetivos generales y requisitos indispensables del desarrollo sostenible." (Naciones Unidas 2005). 


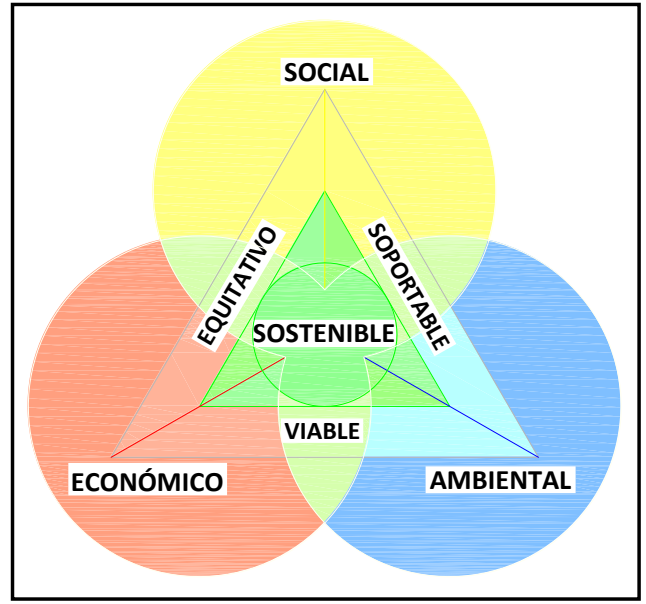

Figura 2.4 Esquema de la interdependencia de los componentes del desarrollo sostenible

Fuente: Adaptado del concepto y apoyado en (Dréo J. 2007).

Estos pilares interdependientes y componentes del desarrollo sostenible, sugieren tres reglas elementales a seguir y que están sujetas al ritmo de crecimiento demográfico, son:

a) Ninguna sustancia o acción contaminante debe producirse a una tasa mayor que la que pueda ser absorbida por el ambiente, o reciclada o neutralizada.

b) Ningún recurso renovable podrá ser utilizado a una tasa mayor que la de su natural regeneración.

c) Ningún recurso no renovable deberá explotarse a una tasa mayor que aquella que permita sustituirlo por un recurso renovable aprovechado sosteniblemente.

El desarrollo social.- Tiene su pívot de actuación en el mejoramiento de la calidad de vida de todos los individuos, a través de la búsqueda incesante de la equidad, justicia social, acceso racional a servicios básicos, saneamiento, vivienda, educación, empleo decente, seguridad, transporte, erradicación de tugurios y zonas vulnerables, libertad de pensamiento, credo y política sin que esto afecte el bien común, acceso a la información y energía y libre movilidad.

El desarrollo económico.- Busca que los Estados formalicen un sistema de producción de bienes y servicios con mecanismos de explotación, procesamiento y distribución acordes a mercados locales e internacionales, 
que satisfagan las necesidades de sus demandantes, a precios racionales y accesibles. Asimismo, que se motive la inversión, la productividad limpia, y el fomento de generación de empleo, distribución equitativa de la riqueza y que aporte significativamente al desarrollo humano.

La protección del ambiente.- Acción humana global comprometida con la preservación del medio ambiente, basado en un sistema ecológico frágil, del que los individuos forman parte y necesitan su cobijo, independiente de su distribución demográfica. Para ello es necesario, entre muchas otras acciones, el de gestionar efectivamente los residuos, la eficiencia energética, conservación de recursos naturales, reducir al máximo la emisión de sustancias contaminantes de suelo, agua y aire; y, hacer un uso de elementos del hábitat sin que ello deje consecuencias que repercutan en un cambio climático. Esto implica también, velar porque la explotación de recursos, renovables y no renovables, no tenga efectos de los cuales el planeta no pueda recuperarse en un tiempo tal que se vea comprometida la vida de especie alguna.

\subsubsection{Gobernanza de recursos hídricos}

La gobernanza, se puede entender como una herramienta que le permite a la sociedad definir su autoridad económica, administrativa, social y política para gestionar y desarrollar sus recursos en todos los niveles.

Por su parte la gobernalidad, según el Banco Mundial, se refiere a toda forma de coordinación social para la cooperación e interacción entre Estado y actores no estatales.

i) Código de Gobernanza de las Naciones Unidas

Los principios de buena gobernanza propuestos por las UN se estructuran como un cuerpo conjunto de seis temas íntimamente ligados entre sí, que son:

1. La estrategia, la misión, la planificación y el órgano rector: marca la obligación del órgano rector de trabajar por los propósitos de la entidad. Ello se conseguirá mediante la planificación, evaluación y normativa general.

2. El órgano rector y las estructuras de los comités: el órgano rector debe delegar ciertas actividades de gobernanza, sin que ello provoque abandonar sus responsabilidades globales. 
3. Gestión de los recursos humanos: plantea las políticas y prácticas de recursos humanos que el órgano rector junto con el grupo de administración aplicarán.

4. Transparencia y comunicación: incluye la demostración de trabajo y del cumplimiento de objetivos del órgano rector, sus miembros y la administración ejecutiva de la entidad.

5. Entorno ético: aborda las normas de gobernanza responsable y directivas de conducta ética aplicada en toda la entidad.

6. Auditoría, riesgo y observancia: auditoría enfocada a lo financiero y operativo y la gestión del riesgo de la entidad, debe existir controles internos y el cumplimiento de las normas, políticas, reglamentos y leyes que les aplique.

En estos temas, se denomina como órgano rector a los consejos, juntas directivas, juntas ejecutivas y otros de semejantes responsabilidades.

La gobernanza debe permitir que los componentes elementales del desarrollo sostenible interactúen, se complementen y entre todos sumen sinergias al bien común, así:

La gobernanza en su dimensión económica buscará las vías óptimas para maximizar el bienestar de cada individuo, involucrando en ello las restricciones de capital natural e incentivando la participación equitativa de la sociedad. (Díaz R. y Escárcega S. 2009).

Del mismo modo, la gobernanza en su dimensión social, permitirá el reconocimiento del derecho a un acceso justo y equitativo, en cantidad y calidad, de los recursos (hídricos en nuestro caso). Para tal fin, el órgano rector normará para que el conjunto de las relaciones que se establezcan en toda sociedad no afecte género, cultura, generación o raza. Permitirá potenciar la buena relación entre sector público, el privado y el ciudadano común.

La dimensión ambiental de la gobernanza, propondrá y hará cumplir las directivas necesarias para que todos los involucrados, actores y agentes económicos, usen, manejen y gestionen los recursos (hídricos) con conocimiento y perspectiva para que perdure a largo plazo, sin agotar la fuente de los recursos y conservando el hábitat idóneo de los que vendrán, priorizando su atención a la biodiversidad y elementos ambientales (aire, agua, suelo, flora, fauna, otros). (Artaraz M. 2002).

La gobernanza del desarrollo sostenible, bien puede, a la hora de fijar los precios y tarifas, encontrar apoyo en las etapas siguientes: 
a) Aplicar el principio de quien contamina paga.

b) Elección informada y diversa del consumidor.

c) Diseño ecológico aplicado al servicio y producto distribuido.

Dichos aspectos requieren de herramientas como el inventario del ciclo de vida (ICV) y el análisis del ciclo de vida (ACV). (Artaraz M. 2002).

\subsection{Interpretación de la sostenibilidad hacia los abastecimientos de agua potable}

En el Documento Final de la Cumbre Mundial 2005, de las Naciones Unidas, se propone respecto del agua y su uso, en resumen, lo siguiente:

i) $\quad / 25 / \ldots$ b) Inversiones.- Las Naciones Unidas se comprometen a adoptar políticas que aseguren una inversión adecuada y sostenible en salud, agua potable y saneamiento, vivienda y educación.

ii) $\quad / 56 / . .$. a) Promover la educación para el Desarrollo Sostenible y para la Acción "El agua, fuente de vida".

iii) $\quad / 56 / \ldots$ h) Alcanzar el desarrollo sostenible y los ODM.- Para lo que las UN asistirán a los países en desarrollo en su esfuerzo por preparar planes de ordenación integrada y eficacia de los recursos hídricos, como parte de sus estrategias nacionales de desarrollo y por propiciar acceso a agua potable segura y servicios básicos de saneamiento, de conformidad al ODM correspondiente.

La sostenibilidad de un abastecimiento de agua requiere de decisiones que canalicen la gobernanza hacia la gestión integral sostenible de sistemas de agua para consumo humano y que se la entiende como el conjunto metodológico de acciones y normas que conducen a un adecuado manejo técnico, administrativo y legal, sentado en la filosofía del desarrollo antropocéntrico, sin agotar la base de los recursos y buscando siempre una tasa de ingresos de la empresa operadora (municipio) tal que le permita a sí mismo mantenerse -o mejor crecer- en el tiempo.

Nuestra tarea consiste en transferir, de una manera flexible y adecuada a cada situación y contexto, el criterio de la gestión integrada de los recursos hídricos a los abastecimientos de agua, concepto que la Asociación Mundial para el Agua (GWP por sus siglas en inglés - Global Water Partnership) y el Banco Interamericano de Desarrollo (BID) lo presentan como la toma de decisiones y gestión para el aprovechamiento coordinado del agua y los recursos relacionados, con el propósito de hacer que el bienestar económico, 
social y ambiental se maximice, sin comprometer la equidad ni contaminar el ecosistema y tomando en cuenta siempre las necesidades de los usuarios e interesados. La gestión del agua a nivel de abastecimientos debe también combinar estratégicamente los siguientes aspectos, (Dourojeanni A.; Jouravlev A.; Chávez G. 2002):

- Gestión sostenible de recursos a nivel de las cuencas involucradas, tanto en la fuente como en la zona de distribución y aprovechamiento.

- Gestión del agua urbana, para un aporte al desarrollo social, económico y ambiental.

- Gestión de oferta y demanda; evaluar cantidad, calidad, espacio y tiempo, con base en los intereses de usuarios del agua y del colectivo, para la reducción de conflictos.

- Ciclo urbano - hidrogeológico del agua. Optimización y descontaminación.

- Gestión de la recuperación de costos, con tarifas apropiadas, justas y diferenciadas según condición social y volumen de gasto.

- Maximizar eficiencia del servicio, en tratamiento, almacenamiento, conducción y distribución, medición y regulación, facturación y cobro. Operación y mantenimiento.

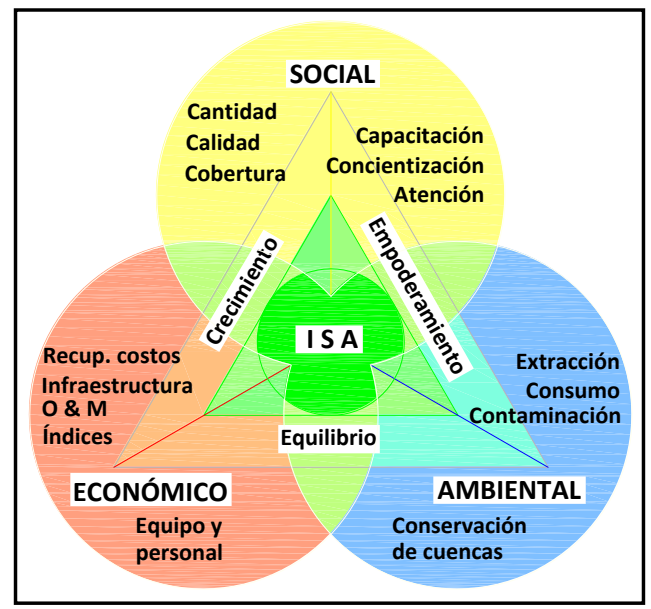

Figura 2.5 Elementos para diagnosticar la sostenibilidad de abastecimientos 
Si bien gráficamente se puede percibir, por su ubicación, que los elementos son únicos, en su causa y efecto, dentro de cada pilar de la sostenibilidad, pues se debe indicar que su origen y consecuencia, en la gran mayoría de ellos, dependen y actúan entre sí con repercusión en todos, generando vínculos de combinación y dependencia relativa, entre los tres aspectos que los albergan.

A continuación se describen los indicadores y subcomponentes que se toman en consideración para el diagnóstico de la sostenibilidad de un sistema de agua para consumo humano, mediante el I.S.A. - Índice de Sostenibilidad de un Abastecimiento, propuesta central de esta investigación.

\subsection{Criterios de selección y desarrollo}

El tema de la selección de indicadores de gestión o indicadores de desempeño, se abordó tomando en cuenta el enfoque estratégico de la IWA, correlacionado directamente con las competencias de cada empresa municipal de agua, con la importancia, necesidad y prioridad de cada elemento constitutivo dentro de la empresa para integrarlo en los tres ejes de la sostenibilidad de la gestión, además la trazabilidad y la necesidad de su desagregación para su utilidad y aprovechamiento futuro, así como también su simplicidad, funcionalidad, representatividad y relevancia; y, tomando en cuenta la eficiencia del indicador, es decir que no se convierta en una carga económica infructuosa frente a su aporte y uso final.

Para conseguir que los resultados obtenidos con la aplicación de la metodología ISA permitan orientar las decisiones y motivar el cambio hacia la sostenibilidad económica, social y ambiental, se desarrolló de la siguiente manera:

a) Objetivos:

Para desdoblar el objetivo estratégico, se planteó la pregunta ¿qué constituye un abastecimiento sostenible?; pues, su respuesta nos marca una expresión de alto nivel a la cual se apunta con todo este proceso metodológico.

b) Estrategias

Las estrategias por su propia naturaleza se crean para estructurar los factores que actúen según las tácticas planteadas para su logro. En nuestro caso, esas asignaciones estratégicas de evaluación que 
determinan la sostenibilidad se analizan para delegar responsabilidades en la toma de datos así como instruir apoyos en las actividades de campo y oficina, tras ser desagregadas.

c) Factores críticos de éxito

Las claves para medir la sostenibilidad en la realidad del entorno, ligadas a que la oportunidad de fallo e inobservancia de actividades por alguno de los miembros pueden conducir a un detrimento de la sostenibilidad del sistema. Se tomó en cuenta también que no se pueden plantear demasiados factores, para que no exista la posibilidad de perder el enfoque general.

d) Indicadores

Los indicadores que se seleccionaron de sistemas compatibles y otros también que se propusieron, obedecen al criterio que deben facilitar, al gestor de la organización, medir un aspecto en particular y que forme parte de la estructura de sostenibilidad del abastecimiento; de tal modo que una vez conocido su valor, refleje su estado y le permita orientar las acciones correctivas pertinentes.

En nuestro caso se concretaron tres metas estratégicas, que son a la vez los tres ejes de la sostenibilidad. Aquí también denominados componentes.

Cada meta se compone de entre cuatro y seis factores estratégicos. Quince en total para la presente aplicación. Aquí se los denomina subcomponentes.

Y a su vez cada factor agrupa a los indicadores, un total de cuarenta y nueve.

Para la selección de indicadores se organizó y comparó las bases de datos existentes, relacionados con indicadores de desempeño de diferentes organizaciones mundiales, como la IWA, IBNET, la propuesta de auditoría de pérdidas del Laboratorio de Ingeniería Civil de Portugal, el SANFLOW de Sudáfrica, las consideraciones estratégicas de la norma ISO 24512, el sistema de la AyA de Costa Rica, entre muchos otros. De allí y tras una acción de "aterrizment" ${ }^{4}$ se optó por buscar aquellas que más hábilmente se pueden aplicar a la mayoría de abastecimientos de nuestro país, caracterizados, entre otros, por los tópicos siguientes: universal existente -en un determinado tema- a la realidad del entorno en la cual se la desea aplicar, para garantizar su aprovechamiento efectivo. Esta palabra no consta en el diccionario de la RAE. 
- $\quad$ Actitud de los gestores de las empresas para levantar datos y transformarlos en información útil, verificable y confiable.

- Directores y gerentes con suficiente responsabilidad, autoridad y control. (UNICEF 1999).

- $\quad$ Trascendencia histórica de las acciones que no se llevan a cabo en la empresa y que están generando fallos en el sistema de gestión.

- Importancia, actual y futura, de las variables seleccionadas, respecto de la mejora del desempeño interno.

- Oportunidad financiera para recapitular, reorientar o iniciar con la planificación de acciones hacia la sostenibilidad del abastecimiento.

- Características de espacio y tiempo técnicamente adecuados para monitoreo y medición.

- Optimización del recurso humano contemplando que con sólo el levantamiento de información no se reste la actividad de la empresa.

- Seleccionar las variables mínimo necesarias para dar el comienzo de la gestión integral del agua.

- $\quad$ Contrastar y aprovechar las experiencias de aquellas empresas que ya han iniciado tiempo atrás con la mejora de gestión, con base a indicadores.

- $\quad$ Conocimiento práctico y know how establecido.

- Que la recolección y organización de datos tengan una utilidad continua y que el resultado de conocer estos indicadores permitan luego de un análisis comparativo orientar decisiones para la mejora.

- $\quad$ Posibilidad de mejora de la actitud política basados en argumentos técnicos demostrables y cuantificables.

Dadas las condiciones actuales, posiblemente aún estos indicadores resulten muchos, tediosos o irreconocibles por algunos gestores de abastecimiento; no obstante, se proponen como una primera herramienta que permita "empezar" a recorrer el trayecto para alcanzar la sostenibilidad en un plazo prudencial.

En los abastecimientos de agua cuya característica de gestión es "novel" y aún entre sus miembros no se avizora un horizonte claro de mejora del desempeño, bien se puede aplicar un ISA con un menor número de indicadores, aquellos cuyos datos sean de fácil obtención y verificación y que del mismo modo contribuyan a cambiar el curso de la gestión hacia la sostenibilidad; cabe la frase: "Es preciso saber hacia dónde se camina, sin importar cuán lejos se encuentre”. 


\subsection{Sostenibilidad económica}

El criterio económico para la sostenibilidad de un abastecimiento de agua, contempla los siguientes subcomponentes:

El criterio económico para la sostenibilidad de un abastecimiento de agua, contempla los siguientes subcomponentes:

i) Recupera todos los costos invertidos, mediante tarifas justas, accesibles por equidad y que a su vez motiva en sus clientes el consumo racional.

ii) Las actividades de operación y mantenimiento, son plenamente subsidiadas por el consumidor a través del pago por consumo de agua y le dan a la empresa la oportunidad de aplicar una política de control activo de fugas, y tomar acciones para la mejora de la eficiencia en la conducción, almacenamiento, distribución y cobro.

iii) Desde la óptica financiera, le permite manejarse con buena liquidez, además con un stock de deuda que le facilite aprovechar situaciones favorables del mercado financiero para la búsqueda de mayores plazos a menores costos; $\mathrm{y}$, una situación financiera de servicio que contemple la búsqueda inminente de la eliminación de subsidios.

iv) Invierte en infraestructura moderna para el abastecimiento, facilitando cada vez más cumplir con las normativas de seguridad, calidad y cantidad, en espacio y tiempo.

v) Mantiene capacitado a todo su personal, en todos los niveles de la empresa y cuenta con el suficiente equipamiento para el desempeño eficiente.

Selección de indicadores de gestión relacionados con la sostenibilidad económica de un abastecimiento

a. Organización de indicadores dentro de subcomponentes

i) Subcomponente: recuperación de cotos

- $\quad$ Porcentaje de recuperación de costos, mediante cobro de facturación por año 
- Ingresos por facturación (propios) $(\$ /$ año)

- Costos totales (\$/año)

- $\quad$ Porcentaje de autosuficiencia financiera anual

- Ingresos propios (\$/año)

- Gastos corrientes (\$/año)

- Porcentaje de eficiencia en recaudación anual

- Recaudación (\$/año)

- Emisión (\$/año)

- $\quad$ Porcentaje de agua no facturada por año

- Volumen de agua producida e inyectada al sistema ( $\left.\mathrm{m}^{3} / \mathrm{año}\right)$

- Volumen de agua registrada y facturada para cobro $\left(\mathrm{m}^{3} / \mathrm{año}\right)$

ii) Subcomponente: operación y mantenimiento

- Índice de fugas estructural

- Volumen incontrolado fugado (L/acom./ día)

- Umbral mínimo de fugas (L/acom./día)

- Longitud total de tubería $(\mathrm{km})$

- $\quad$ Número de acometidas

- $\quad$ Longitud promedio de acometidas $(\mathrm{km})$

- $\quad$ Presión media (m c.a.)

- $\quad$ Número de roturas por longitud de tubería por año

- Número de roturas (fallos en tuberías, válvulas y accesorios) por año

- Longitud total de tubería $(\mathrm{km})$

- Número de inspecciones acústicas a la red para control de fugas / año

- Longitud de red que se inspecciona con equipo acústico para control de fugas en $\mathrm{km}$ por año

- Longitud total de tubería $(\mathrm{km})$ 
- Porcentaje de información del abastecimiento disponible en una base de datos informática - SIG.

- Longitud de redes ingresada en SIG con información hidráulica completa, como: cotas altimétricas, longitud, material, diámetro, hidrantes, válvulas, depósitos, impulsiones, pozos, etc.) $(\mathrm{km})$.

- Longitud total de tubería $(\mathrm{km})$

- Número de clientes ingresados en SIG con información comercial completa

- Total de clientes _ abonados

- Porcentaje de superficie interior de depósitos que son impermeabilizados y con mantenimiento por año

- Superficie interior de depósito impermeabilizada y con mantenimiento por año

- Superficie total interior de depósito

- Búsqueda de conexiones ilegales (acústica y visual) en porcentaje de tuberías de la red por año

- Longitud de red en la que se aplica búsqueda de conexiones ilegales (visual y acústica) por año (en km)

- Longitud total de tubería $(\mathrm{km})$

iii) Subcomponente: índices financieros

- $\quad$ Porcentaje de liquidez

- Ingresos corrientes ( $\$ /$ año)

- Gastos corrientes ( $\$ /$ año)

- $\quad$ Stock de deuda

- Pasivo total (\$/año)

- Ingreso total (\$/año)

- Venta de agua

- Fuente de financiamiento

- Venta de activos

- Transferencias de capital 
iv) Subcomponente: infraestructura del abastecimiento

- Número de parcelas hidrométricas *(Anexo ${ }^{3.1)}$ por cada 10000 conexiones

- Número de parcelas hidrométricas funcionando en la red de distribución

- Número de conexiones total

- $\quad$ Número de hidrantes contra incendios funcionando por $\mathrm{km}$ de tubería de distribución

- Número de hidrantes contra incendios funcionando en la red

- Longitud total de red de distribución $(\mathrm{km})$

- $\quad$ Porcentaje de renovación de collarines de acometida por año

- Número de collarines de acometida renovados por año

- Número total de collarines de acometida

- $\quad$ Porcentaje de contadores domiciliares funcionando

- Número de contadores domiciliarios funcionando con normalidad

- Número total de contadores domiciliarios

- $\quad$ Porcentaje de contadores domiciliares con más de 8 años de instalación

- Número de contadores domiciliarios con más de 8 años de instalación

- Número total de contadores domiciliarios

- Porcentaje de contadores domiciliares cuyas lecturas superan $\operatorname{los} 4000 \mathrm{~m}^{3}$

- Número de contadores domiciliarios cuyas lecturas superan los $4000 \mathrm{~m}^{3}$

- Número total de contadores domiciliarios

- $\quad$ Porcentaje de tuberías renovadas por año

- Longitud de tuberías renovadas ( $\mathrm{km} / \mathrm{año}$ )

○ Longitud total de red $(\mathrm{km})$ 
v) Subcomponente: equipamiento y personal

- $\quad$ Porcentaje de maquinaria y equipo financiados (horas / mes) para OO\&MM

- Maquinaria y equipo financiados para OO\&MM (h/mes)

- Maquinaria y equipo necesaria óptima para OO\&MM (h/mes)

- $\quad$ Número de empleados por cada 10000 abonados

- $\quad$ Número de empleados en la empresa (para agua potable y alcantarillado)

- Número de clientes _ abonados

\subsection{Sostenibilidad social}

El criterio social para la sostenibilidad de un abastecimiento de agua, incorpora aspectos que reflejen los beneficios de los seres humanos que se involucran al mismo, con el propósito de incrementar la calidad de vida de las familias que tienen acceso al servicio de agua. La organización, el confort y comodidad, la salud, participación y capacitación y la responsabilidad, son aspectos que con los procedimientos más adecuados crecerán paulatinamente para gestionar el sistema de forma sostenible.

Entre los múltiples indicadores que están propuestos en el mundo, se toman en cuenta para este trabajo, aquellos que cumplen con las características de prioritarios (urgentes, importantes y deseables), adaptables a la realidad del entorno y aportan a mejorar la eficiencia del desempeño de la empresa operadora. Están estructurados y organizados por subcomponentes, de la siguiente manera:

i) Subcomponente operativo: cantidad

- Número de reducciones de la cantidad de caudal hasta un $50 \%$ por año

- $\quad$ Número de reducciones de la cantidad de caudal hasta un $50 \%$ / año

- Tiempo total acumulado de la duración de interrupciones (horas/año) 
- Tiempo acumulado de duración de cortes de suministro general (horas/año)

- $\quad$ Porcentaje de acometidas con presión de servicio diferente al rango (entre $10 \mathrm{~m} \mathrm{c.a.} \mathrm{y} 50 \mathrm{~m} \mathrm{c.a.)}$

- Número de acometidas con presión de servicio inferior a $10 \mathrm{~m}$ c.a.

- Número de acometidas con presión de servicio superior a $50 \mathrm{~m}$ c.a.

- Número de acometidas totales del abastecimiento

ii) Subcomponente operativo: calidad

- $\quad$ Número de muestras para análisis de calidad de agua (según NTE INEN 1108) por mes por cada 1000 habitantes

- Número de análisis de calidad de agua (según NTE INEN 1108) por mes

- Total de población servida

- Número promedio de horas por día que el agua permanece estancada (almacenada en depósitos del sistema) previo a su consumo

- Número de horas promedio por día que el agua permanece estancada (almacenada en depósitos) previo a su consumo

- Porcentaje de conexiones con cantidad de cloro residual diferente al rango de norma (entre $0.30 \mathrm{mg} / \mathrm{L}$ a $1.5 \mathrm{mg} / \mathrm{L}$ )

- Número de conexiones con presión de servicio inferior a $0.3 \mathrm{mg} / \mathrm{L}$

- Número de conexiones con presión de servicio superior a $1.5 \mathrm{mg} / \mathrm{L}$

- Número de conexiones totales del abastecimiento

iii) Subcomponente operativo: cobertura

- $\quad$ Porcentaje de predios que cuenta con conexión al sistema

- Número de predios conectados al sistema

- Número total de predios en la jurisdicción 
- $\quad$ Porcentaje de predios que cuenta con buen servicio en horas pico

- Número de predios que está bien servida cantidad, presión y calidad en horas pico

- Número total de predios conectados

iv) Subcomponente formativo: capacitación a empleados

- Número promedio de horas de capacitación invertidas en cada técnico de campo y miembros de planificación / año

- $\quad$ Número de horas de capacitación invertidas en técnicos de campo

- Número de horas de capacitación invertidas en miembros de planificación

- $\quad$ Número promedio de horas de capacitación invertidas en cada administrador y coordinador del abastecimiento / año

- Número de horas de capacitación invertidas en administradores

- Número de horas de capacitación invertidas en coordinadores

v) Subcomponente formativo: concientización al cliente

- Número de horas de curso para clientes por cada 10000 conexiones / año

- Horas de capacitación para clientes por cada 10000 conexiones / año; (bien en colegios, escuelas, otros)

- $\quad$ Tiempo, en minutos/mes, de campaña de concientización del consumo, radial o TV

- Minutos/mes de campaña de concientización en radio para uso de agua a los clientes

- Minutos/mes de campaña de concientización en TV para uso de agua a los clientes

vi) Subcomponente comercial: atención al cliente

- $\quad$ Tiempo que la empresa tarda en responder las quejas de sus abonados 
- Número de días que la empresa tarda en responder las quejas de sus abonados

- $\quad$ Tiempo ponderado en los que la empresa atiende nuevas conexiones, obras de reparación o reinstalación (días desde el ingreso del pedido)

- Tiempo (en días) en los que la empresa atiende nuevas conexiones

- Tiempo (en días) en los que la empresa atiende reparaciones

- Tiempo (en días) en los que la empresa atiende reinstalaciones domiciliarias

- $\quad$ Existe en ejecución un plan de marketing publicitario de la empresa, para promocionar el ahorro de agua y difusión pública de su actividad gestora

- $\quad$ Existe en ejecución un plan de marketing publicitario de la empresa, promoción al ahorro y difusión pública

- infraestructura de atención al cliente organizada, equipada y cómoda

- Existe la infraestructura de atención al cliente: organizada, equipada y cómoda

\subsection{Sostenibilidad ambiental (ó sustentabilidad)}

La sostenibilidad de un abastecimiento de agua, respecto al tópico ambiental se orienta en los planos de conservación, acción de 00\&MM con bajo impacto negativo, recuperable y mitigable en el corto tiempo; $y$, aprovechamiento eficiente de recursos.

Como subcomponentes e indicadores que se proponen son:

i) Subcomponente explotación: agua captada y vertida

- $\quad$ Porcentaje de caudal de agua captado para el abastecimiento, en época de estiaje

- Caudal de agua captada para el abastecimiento, en época de estiaje 
- Caudal de agua total disponible en época de estiaje

- Existe estricto control legal y regulación efectiva de explotación de otros recursos y uso de suelo, en las cuencas fuente, por el gobierno local

- Si existe estricto control legal y regulación efectiva de explotación de otros recursos y uso de suelo, en la cuenca fuente por el gobierno local.

ii) Subcomponente explotación: consumos

- Cantidad promedio de consumo de agua por conexión domiciliar por mes

- Volumen promedio de consumo por conexión $\left(\mathrm{m}^{3} /\right.$ mes)

- Promedio del número de personas que habitan por conexión

- Número de días en los que se registró el volumen

- $\quad$ Aprovechamiento de recursos hídricos

- Volumen de agua perdido (real) desde las captaciones $\left(\mathrm{m}^{3} / \mathrm{mes}\right)$

- Volumen de agua extraído de la cuenca $\left(\mathrm{m}^{3} / \mathrm{mes}\right)$

- Consumo energético relativo del abastecimiento por mes. Ver anexo 2.2

- Energía eléctrica consumida en el abastecimiento (kWh/mes)

- Energía eléctrica óptima que se debió consumir (kW$\mathrm{h} / \mathrm{mes}$ )

iii) Subcomponente contaminación por $00 \& M M$

- $\quad$ Porcentaje de lodos y desechos generados por el sistema de potabilización (filtros, floculadores y sedimentadores) que se vierten sin depuración a cuerpos receptores, por mes, por año.

Cantidad de lodos y desechos que se depuran y gestionan correctamente, $\left(\mathrm{en}^{3}\right.$ ), por año

- Cantidad total de lodos y desechos que se generan por el sistema de potabilización, $\left(\mathrm{en}^{3}\right)$, por año 
- $\quad$ Sistema de depuración de aguas servidas, para los vertidos de alcantarillados de la ciudad

- $\quad$ Existe un sistema de depuración de aguas servidas, para los vertidos de alcantarillados de la ciudad

- Aplicación de medidas correctoras o de mitigación para reducción de impacto por ruido, polvo y gases en apertura y cierre de zanjas para reparaciones o conexiones domiciliares

- Se aplica medidas de mitigación para reducción de impacto por ruido, polvo y gases en apertura y cierre de zanjas para reparaciones o conexiones domiciliares y otras obras de OO\&MM del sistema

iv) Subcomponente conservación: cuenca fuente

- $\quad$ Superficie de la cuenca fuente o tributaria que es propiedad del sistema en hectáreas por cada (L/s) de agua producida para el abastecimiento

- Superficie de cuenca tributaria (zona boscosa con importante aporte hídrico) que le pertenece exclusivamente al abastecimiento $\mathrm{(Ha})$

- Caudal medio producido en planta (en L/s)

- $\quad$ Porcentaje de superficie de la o las cuencas tributarias que tienen en marcha un plan anual de silvicultura y reforestación, gestionado ó coordinado directamente por la empresa operadora del sistema

- Superficie de la o las cuencas tributarias que tienen en marcha un plan anual de silvicultura y reforestación, gestionado ó coordinado directamente por la empresa operadora del sistema $\left(\mathrm{m}^{2}\right)$

- Superficie total de la o las cuencas tributarias $\left(\mathrm{m}^{2}\right)$

- $\quad$ Porcentaje de industrias que funcionan dentro de la cuenca tributaria, que depuran sus vertidos y controlan sus desechos correctamente

- Número de industrias que funcionan dentro de la cuenca tributaria, que depuran sus vertidos y controlan sus desechos sin contaminar

- Número total de industrias que funcionan dentro de la cuenca tributaria 
- $\quad$ Porcentaje del ingreso total recaudado por venta de agua que se destina a adquisición y conservación de cuencas tributarias

- Ingreso recaudado por venta de agua que se destina a adquisición y conservación de cuencas tributarias, por mes, por año

- Ingreso total recaudado por venta de agua, por mes, por año

\section{ANEXO 2.1}

\section{Ciertos aspectos de la sostenibilidad económica}

\section{A.2.1.1 Recuperación de costos}

La sostenibilidad en un abastecimiento de agua posibilita a sus usuarios un servicio de buena calidad y cantidad, efectivo (eficiente y eficaz), estable y continuo. Estas características demandan de una inyección constate de recursos (naturales, humano, económico-financieros, técnicos, legales, cognitivos, entre otros); $y$, los costos que se implican en todo esto, necesariamente deben ser cubiertos por los abonados, mediante tarifas que recuperen costos. Esta última condición obliga a que se optimicen y direccionen correctamente los subsidios y por consiguiente mejore la eficiencia de forma también creciente. En el Segundo Foro Mundial del Agua (La Haya, marzo del 2000), se destaca que para apoyar la gestión del agua es preciso valorarla y caminar hacia tarifas que reflejen la recuperación de costos. (Fundación Ecológica y Desarrollo 2003).

Si bien es cierto que el agua es un bien nacional de uso público, fuera de comercio, con dominio inalienable e imprescriptible, que no se reconoce apropiación ni derechos de dominio sobre ella y su derecho al uso debe implicar un aprovechamiento eficiente a favor de todos los usuarios y el desarrollo humano, normado según la Ley de Aguas, (lo que le implica ser gratuita y tener ningún costo), también es verdad que el costo que debe ser subsanado por los abonados por su consumo es por el gasto que implica invertir en la conservación de cuencas fuente, infraestructura hidráulica, potabilización, operación y mantenimiento del sistema, regulación y control de cantidad y calidad, mejoramiento de la eficiencia, gestión para la mejora del desempeño, entre otros. 
La (UNICEF 1999), por su parte, determina que los costos de operación y mantenimiento frecuentemente incrementan a largo plazo y que se deben tomar en cuenta variables que las afectan, como:

- $\quad$ Opción tecnológica

- $\quad$ Nivel de servicio

- $\quad$ Costos de operación y materiales

- Calidad y accesibilidad a la fuente

- Eficiencia y eficacia del costo de dirección

- Co-fiscalización y participación de la comunidad

- Criterio de género

Por todo ello es preciso trabajar en cada abastecimiento para procurar aplicar a la brevedad posible, aunque de forma gradual, una política tarifaria para la sostenibilidad, la misma que permite entre más:

- Recuperar costos completamente.

- Erradicar subsidios o subvenciones y con ello la ineficiencia, escapando al máximo de los precios políticos.

- Motivar al abonado a un consumo racional, para favorecer el ahorro.

- Mejorar, controlar y registrar la calidad y cantidad del servicio en todo espacio y tiempo.

- Diferenciar tipos de consumo y de consumidores.

- $\quad$ En demandas domésticas se debe garantizar el acceso universal a un "consumo básico", focalizado y diferencial al estrato que más lo requiera.

- Renovación anual y modernización de componentes de la infraestructura.

- Introducción de programas de sectorización de redes y prevención de fugas.

- Gestión de la medición fiable, macro y micro. Incluye actualización de catastros y SIG informático.

- Contemplar una gestión para la mejora de la eficiencia, basada en indicadores de desempeño y benchmarking.

En ningún caso, las tarifas deben traspasar al usuario los costos por la ineficiencia de los gestores. 


\section{A.2.1.2 Consideraciones para el cálculo de tarifas}

Según (Beato P. \& Díaz J. 2003), las políticas tarifarias se referencian tanto a la estructura o forma de repartir los costos de los servicios entre los usuarios como al nivel medio de la tarifa. Incluye componentes fijos y variables que de forma periódica paga el cliente por el servicio de agua, por la instalación o conexiones y por los contadores - medidores. La tarifa está diseñada para cumplir objetivos de:

- eficiencia económica, que se obtiene al aplicar la recuperación de costos económicos o el costo incremental promedio.

- $\quad$ suficiencia financiera, para satisfacer costos de operación y mantenimiento, costos de capital, expansión de servicios, gastos administrativos y de recurso humano, tasas ambientales, entre otros.

- $\quad$ acceso universal a los servicios, que cumple con un derecho humano necesario para la vida, la equidad social y la cobertura del servicio.

- $\quad$ simplicidad y transparencia, al momento de aplicarlo.

Apoyados en un sistema de regulación y vigilancia de los servicios y un sistema comercial que mantenga información actualizada y confiable. (Yepes G. 2003).

\section{a) Elementos constitutivos de la tarifa}

La tarifa tal como se la plantea en el presente estudio, incluye tres parámetros constitutivos: un social, otro económico y un ambiental. Cada uno de ellos podrá abarcar los ítems que se recomiendan a en el cuadro siguiente.

Como se puede apreciar en el cuadro A.2.1.1, el aspecto social se relaciona con el ítem de recursos humanos y de servicios. En lo económico se incluyen los gastos de capital, infraestructura, logística y servicios de inversión o deuda. Para el costo ambiental se recomienda se tome en cuenta aquellos que la empresa municipal deberá considerar para invertir en la conservación de la fuente, en el control de calidad y en planes de manejo ambiental que hagan falta por la contaminación generada al momento de la operación y mantenimiento. 
Diagnóstico de la sostenibilidad de un abastecimiento de agua e identificación de las propuestas que la mejoren

Cuadro A.2.1.1 Propuesta de componentes a considerarse en una tarifa sostenible

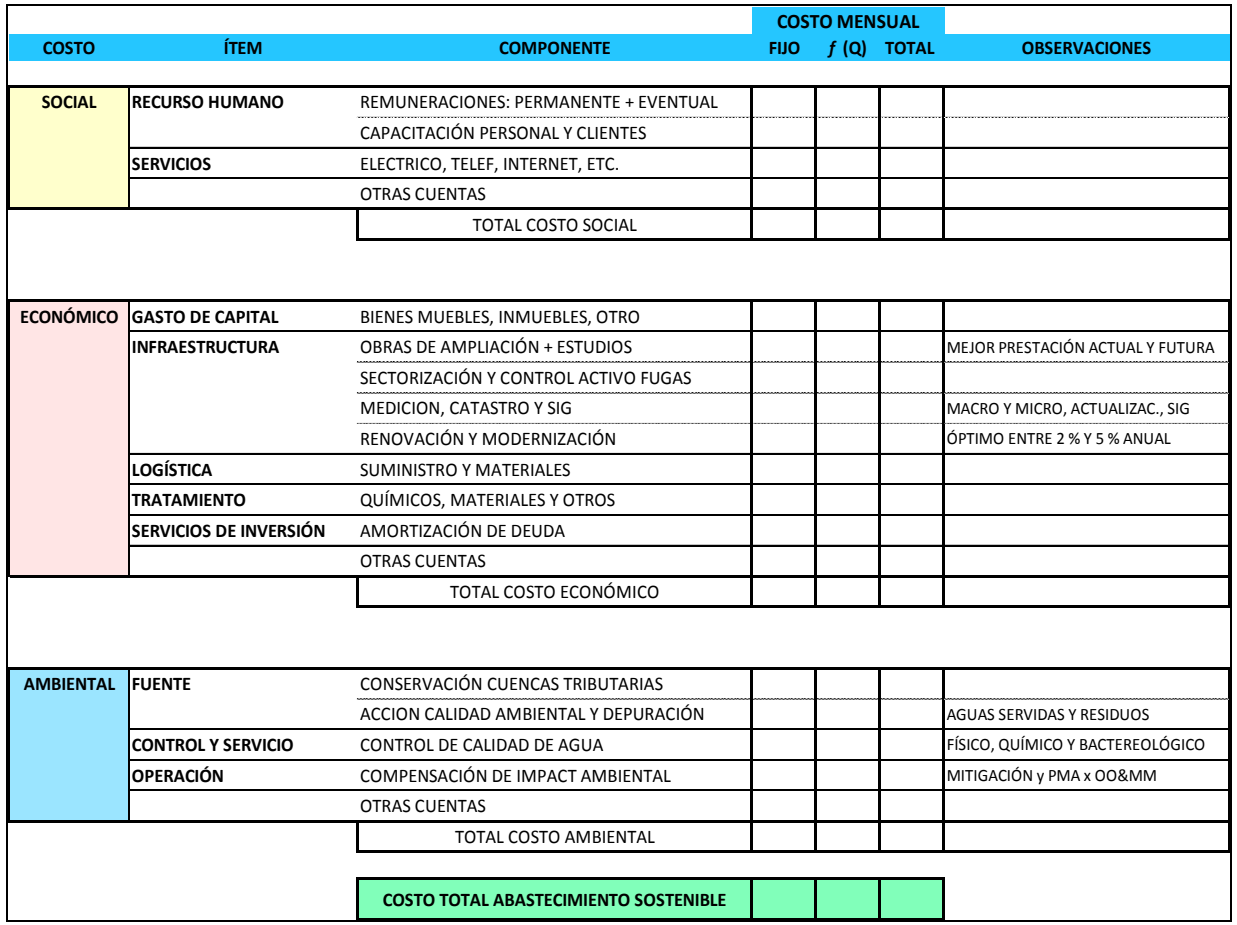

\section{A.2.1.3 Procedimiento de cálculo de tarifas para agua potable}

Tarifa de agua, es la cantidad monetaria o precio que se le asigna a un metro cúbico de agua servido a cada cliente.

1. El costo total mensual de un abastecimiento sostenible.- Se compone de costos fijos y costos variables, esto induce a que la tarifa también varíe según el consumo y cubra cada uno de ellos tal como corresponda.

$$
\mathrm{C}_{\mathrm{a}}=\mathrm{c}_{\mathrm{f}}+\mathrm{c}_{\mathrm{v}}
$$

Donde:

$\begin{array}{lll}\mathrm{C}_{a} & - & \text { costo total } \\ \mathrm{C}_{f} & - & \text { costo fijo } \\ \mathrm{C}_{\mathrm{v}} & - & \text { costo variable }\end{array}$


La tarifa del abonado se estructura de un costo fijo y otro variable que debe cubrirlo en función, este último, del consumo que registre. Además se recomienda incluir la tarifa por alcantarillado para aquellas empresas que también se encargan del servicio.

$$
\mathrm{T}_{\mathrm{a}}=\mathrm{c}_{\mathrm{f}}+\overbrace{(\mathrm{c} \times \mathrm{D})}^{\text {agua potable }}+\overbrace{\left(\mathrm{c}^{\prime} \times \mathrm{D}^{\prime}\right)}^{\text {alcantarilado }}
$$

Donde:

\begin{tabular}{|c|c|c|}
\hline D & $\begin{array}{l}\text { volumen de agua registrado } \\
\text { (demanda) }\end{array}$ & como consumo \\
\hline $\mathrm{T}_{\mathrm{a}}$ & tarifa para el abonado & \\
\hline c & $\begin{array}{l}\text { costo (marginal dinámico) por } \\
\text { consumidor }\end{array}$ & $\mathrm{m}^{3}$ registrado al \\
\hline$c^{\prime}$ & $\begin{array}{l}\text { costo (marginal dinámico) por } \\
\text { alcantarillado }\end{array}$ & $\mathrm{m}^{3}$ servicio de \\
\hline , & volumen del servicio de alcantarill & \\
\hline
\end{tabular}

Para considerar el volumen ( $\left.D^{\prime}\right)$ del servicio de alcantarillado se suele asignar una cantidad de aguas servidas que varía entre el $80 \%$ y el $90 \%$ del que se registró por consumo de agua potable.

Desde el punto de vista de la ciencia económica, el mercado del agua potable en los países donde, por Ley, sólo lo puede gestionar el Gobierno Local (municipalidad) se desempeña bajo el concepto de monopolio natural, con una situación de privilegio legal en donde el mercado le pertenece a una sola empresa; eso deja que el productor controle la cantidad de producción y el precio.

El costo marginal dinámico por $\mathrm{m}^{3}$ es el costo para proveer una unidad adicional de consumo; también se lo conoce como costo incremental promedio, o costo marginal del monopolista natural; constituye la oferta total del mercado y el precio por unidad facturada, representa la curva de demanda del mercado de agua en cada zona (MIDUVI 2003), (Yepes G. 2003).

Se lo expresa de la siguiente manera: 


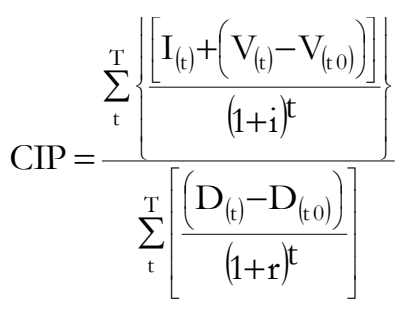

Donde:

$$
\begin{aligned}
& \mathrm{I}_{(\mathrm{t})} \quad-\quad \text { inversión en el año }(\boldsymbol{t}) \\
& \left(\mathrm{V}_{(\mathrm{t})}-\mathrm{V}_{(0)}\right) \text { - costo incremental de OO\&MM debido a una nueva } \\
& \text { demanda en el año }(t) \\
& \left(\mathrm{D}_{(\mathrm{t})}-\mathrm{D}_{(0)}\right) \text { - demanda marginal o consumo incremental en el año }
\end{aligned}
$$

$\begin{array}{lll}i, r & - & \text { tasas de crecimiento, de costos y consumos } \\ \text { to } & - & \text { año del punto de partida } \\ \mathrm{T} & - & \text { Tiempo total de análisis }\end{array}$

2. El subsidio cruzado.- Este sistema de subsidio permite a la empresa de agua compensar entre los mismos abonados los ingresos por tarifas diferenciadas. Es decir que, un porcentaje mayoritario de clientes paga lo que no puede el grupo de familias que se han seleccionado como beneficiarias del mismo. (Yepes G. 2003).

El subsidio debe ser acertadamente direccionado a aquellas familias que verdaderamente lo necesiten, pese a que no existe un procedimiento concreto para identificarlas, pero un buen indicio de aproximación será aquel que se pueda obtener (desde la empresa municipal) mediante encuesta socioeconómica; se recomienda que el pago máximo de una familia pobre no exceda el $5 \%$ de sus ingresos mensuales.

La otra forma de aplicar un subsidio es por referencia a un volumen mínimo de consumo y para una misma categoría de usuarios preestablecidos, por ejemplo puede ser $10 \mathrm{~m}^{3} /$ familia/mes. Finalmente, se debe estipular que el número de usuarios a los que se direccionará el subsidio no supere el $30 \%$ del total de clientes. (MIDUVI 2003); (Beato P. \& Díaz J. 2003).

Para determinar la cantidad a ser subsidiada en la tarifa se puede optar por el siguiente proceso: 
Determinar la tarifa máxima $\left(\mathrm{T}_{\text {MAX }}\right)$ :

$$
\mathrm{T}_{\mathrm{MAX}}=\mathrm{K}_{\mathrm{m}} \times \overline{\mathrm{I}_{\mathrm{BAJO}}}
$$

Donde:

$$
\begin{array}{lll}
\mathrm{K}_{\mathrm{m}} & -\quad \text { coeficiente. Ver cuadro A.2.1.2 } \\
\overline{\mathrm{I}_{\mathrm{BAJO}}} & -\quad & \text { promedio de los } 5 \text { ingresos más bajos registrados } \\
& \text { entre los clientes }
\end{array}
$$

Cuadro A.2.1.2 Valores de $\mathrm{K}_{\mathrm{m}}$

\begin{tabular}{|l|c|}
\hline $\begin{array}{c}\text { Característica energética } \\
\text { del sistema }\end{array}$ & $\begin{array}{c}\text { Valor del coeficiente } \\
\mathrm{K}_{\mathrm{m}}\end{array}$ \\
\hline Sólo a gravedad & $2.5 \%$ \\
\hline A gravedad y bombeo & $4.0 \%$ \\
\hline Sólo bombeo & $5.0 \%$ \\
\hline
\end{tabular}

Determinar el subsidio (S):

$$
\mathrm{S}=(\mathrm{c}_{\mathrm{f}}+\overbrace{(\mathrm{c} \times 10)}^{\text {agua potable }}+\overbrace{\left(\mathrm{c}^{\prime} \times 8\right)}^{\text {alcantarilado }})-\left(\mathrm{K}_{\mathrm{m}} \times \overline{\mathrm{I}_{\text {BAJO }}}\right)
$$

El valor de 10 es el volumen de agua máximo consumido y 8 representa el $80 \%$ para alcantarillado, que se aplicará por igual a un número $(N)$ de familias pobres. Esto implica, que exista también un número $(\boldsymbol{M})$ de abonados que cubran este subsidio, tal que el universo de clientes $U$ sea igual a $\boldsymbol{M}+\boldsymbol{N}$. Así entonces:

$$
\mathrm{S} \times \mathrm{N}=\mathrm{Tsa} \times \mathrm{M}
$$

Donde:

Tsa Tasa adicional que se aplica a los clientes sin subsidio (M) 
Las tarifas con y sin subsidio serán ( $\left.T_{\text {subs }}\right)$ y $\left(T_{\text {usuarios }}\right)$, respectivamente:

$$
\begin{aligned}
& \mathrm{T}_{\text {subs }}=\mathrm{c}_{\mathrm{f}}+\overbrace{(\mathrm{c} \times \mathrm{D})}^{\text {agua potable }}+\overbrace{\left(\mathrm{c}^{\prime} \times \mathrm{D}^{\prime}\right)}^{\text {alcantarilado }}-\mathrm{S} \\
& \mathrm{T}_{\text {us uarios }}=\mathrm{c}_{\mathrm{f}}+\overbrace{(\mathrm{c} \times \mathrm{D})}^{\text {agua potable }}+\overbrace{\left(\mathrm{c}^{\prime} \times \mathrm{D}^{\prime}\right)}^{\text {alcantarilado }}+\text { Tsa }
\end{aligned}
$$

3. Reajuste de tarifas por la fórmula polinómica.- Para reajustar tarifas, por ejemplo, se puede aplicar el método de la fórmula polinómica, que toma en cuenta la variación de los precios al consumidor, mediante sus índices (INEC 2005):

$$
\begin{gathered}
\frac{T \mathrm{p}}{\mathrm{Ta}}=\left(\frac{\varsigma_{\mathrm{j}}}{\varsigma_{\mathrm{a}}} \times \Gamma \mathrm{m}\right)+\left(\frac{\chi_{\mathrm{j}}}{\chi_{\mathrm{a}}} \times \Gamma \mathrm{e}\right)+\left(\frac{\rho_{\mathrm{j}}}{\rho_{\mathrm{a}}} \times \Gamma \mathrm{q}\right)+\left(\frac{\psi_{\mathrm{j}}}{\psi_{\mathrm{a}}} \times \Gamma \mathrm{f}\right)+\left(\frac{\varphi_{\mathrm{j}}}{\varphi_{\mathrm{a}}} \times \Gamma \mathrm{at}\right) \\
\Gamma \mathrm{m}+\Gamma \mathrm{e}+\Gamma \mathrm{q}+\Gamma \mathrm{f}+\Gamma \mathrm{at}=1
\end{gathered}
$$

Donde:

$\begin{array}{lll}T p & - & \text { tarifa proyectada } \\ T \mathrm{a} & - & \text { tarifa actual } \\ \Gamma \mathrm{m} & - & \text { mano de obra empleada para el servicio } \\ \Gamma \mathrm{e} & - & \text { energía eléctrica consumida por el sistema } \\ \Gamma \mathrm{q} & - & \text { productos químicos para potabilización } \\ \Gamma \mathrm{f} & - & \text { depreciación de activos } \\ \Gamma \mathrm{at} & - & \text { materiales para mantenimiento del abastecimiento } \\ j & - & \text { año al cual se proyecta } \\ a & - & \text { año anterior al reajuste } \\ \varsigma & - & \text { salario mínimo vital } \\ \chi & - & \text { costo de la energía eléctrica } \\ \rho & - & \text { costo promedio de productos químicos (por kg) } \\ \psi & - & \text { índice de precios al consumidor IPC del INEC-Ecuador } \\ \varphi & - & \text { depreciación de activos fijos según estado financiero }\end{array}$
Los ingresos a la empresa operadora son, normalmente, referidos a:

- Ingreso por venta de agua, mediante facturación mensual. 
- Nuevas conexiones.

- $\quad$ Pagos por re-conexión de servicio o reparaciones.

- Multas e intereses.

- Venta de activos.

- Otras tasas.

Adicionalmente se puede determinar la elasticidad del precio (Ep) y elasticidad de ingreso (Ei) así:

$$
\begin{aligned}
& E p=\frac{\left(D_{j}-D_{k}\right) \times\left(T_{j}+T_{k}\right)}{\left(D_{j}+D_{k}\right) \times\left(T_{j}-T_{k}\right)} \\
& E i=\frac{\left(D_{j}-D_{k}\right) \times\left(I_{j}+I_{k}\right)}{\left(D_{j}+D_{k}\right) \times\left(I_{j}-I_{k}\right)}
\end{aligned}
$$

Donde:

$\begin{array}{lll}\mathrm{D} & - & \text { volumen de demanda mensual por cliente } \\ \mathrm{T} & - & \text { tarifa por unidad de volumen } \\ \mathrm{I} & - & \text { ingreso económico familiar mensual } \\ j, k & - & \text { instantes diferentes }\end{array}$

Es decir que $(E p)$, mide el efecto del precio sobre el volumen demandado por cada abonado. La variación entre la cantidad consumida en cada instante respecto de su precio; significa que se consumirá $D_{j}$ cuando la tarifa es $T_{j}$, y $D_{k}$ cuando rige $T_{k}$.

De forma similar se puede determinar la elasticidad del consumo respecto del aumento de ingresos económicos en la familia. Expresado en términos semejantes, se consumirá $D_{j}$ cuando el ingreso familiar es $\boldsymbol{I}_{j}$, y $\boldsymbol{D}_{k}$ cuando ingresa $I_{k}$.

\section{A.2.1.4 Algunos ejemplos de sistemas tarifarios vigentes}

De la experiencia vista en los abastecimientos se puede destacar que algunas empresas consideran como pagos incrementales en la planilla de pago mensual, los siguientes aspectos:

- $\quad 5 \%$ del total facturado, por pago de servicios ambientales

- $\quad 5 \%$ del total facturado, por servicios de alcantarillado

- $\quad Y$ una cantidad fija por recolección de desechos (entre $\$ 0.20$ y $\$ 0.70)$ 
Ejemplo 1.- En abastecimientos municipales de Ecuador existen varios sistemas tarifarios. Uno de ellos, posiblemente uno de los mejor estructurados y que más se aproxima a la recuperación de costos es aquel que en sus componentes separan claramente un precio fijo y otro variable según su rango de consumo y categoría comercial a la que pertenece. A continuación se muestra mediante un cuadro lo anotado.

El volumen básico es el mismo para todos (para el ejemplo $15 \mathrm{~m}^{3}$ ), aunque la tarifa básica es la que cambia para cada sector; luego, para cada rango volumétrico de consumo también combina los precios fijos y variables, así:

$$
\begin{aligned}
& \mathrm{T}_{\mathrm{C}-\mathrm{R}}=[\text { precio fijo }]+[\text { precio variable }] \\
& \mathrm{T}_{\mathrm{C}-\mathrm{R}}=\mathrm{B}_{\mathrm{C}-\mathrm{R}}+\left(\mathrm{C}_{\mathrm{C}-\mathrm{R}} \times \mathrm{D}\right)
\end{aligned}
$$

Donde:

$$
\begin{aligned}
& \mathrm{T}_{\mathrm{C}-\mathrm{R}} \text { - tarifa para cada categoría comercial y rango de } \\
& \text { consumo } \\
& \mathrm{B}_{C-R} \quad-\quad \text { tarifa fija por categoría y rango } \\
& \mathrm{C}_{C-\mathrm{R}} \quad \text { - base imponible a la tarifa variable según rango y } \\
& \text { categoría } \\
& \text { D - consumo registrado al abonado (demanda / cliente) }
\end{aligned}
$$

Asimismo la empresa operadora, luego de su análisis de costos totales, debe asignar los valores constantes para cada rango de volumen de consumo y por categoría comercial, semejante como se muestra a continuación:

Cuadro A.2.1.3 Estructura tarifaria que disgrega precios fijos y variables por rango de consumo y categoría comercial

\begin{tabular}{|r|c|c|c|c|c|c|c|c|}
\hline \multirow{2}{*}{$\begin{array}{c}\text { Rango de } \\
\text { volumen }\left(\mathbf{m}^{3}\right)\end{array}$} & \multicolumn{7}{|c|}{ Residencial } & \multicolumn{7}{c|}{$\begin{array}{c}\text { Comercial y } \\
\text { Gran cliente }\end{array}$} & \multicolumn{2}{c|}{$\begin{array}{c}\text { Oficial y } \\
\text { Familia pobre }\end{array}$} & \multicolumn{2}{c|}{ Industrial } \\
\cline { 2 - 10 } & $\mathrm{B}_{C-\mathrm{R}}$ & $\mathrm{C}_{\mathrm{C}-\mathrm{R}}$ & $\mathrm{B}_{\mathrm{C}-\mathrm{R}}$ & $\mathrm{C}_{\mathrm{C}-\mathrm{R}}$ & $\mathrm{B}_{\mathrm{C}-\mathrm{R}}$ & $\mathrm{C}_{\mathrm{C}-\mathrm{R}}$ & $\mathrm{B}_{\mathrm{C}-\mathrm{R}}$ & $\mathrm{C}_{\mathrm{C}-\mathrm{R}}$ \\
\hline Hasta 15.0 & 1.60 & 0.00 & 1.95 & 0.05 & 0.80 & 0.00 & 2.30 & 0.05 \\
\hline De 15.1 a 35.0 & 1.60 & 0.07 & 1.95 & 0.10 & 0.80 & 0.05 & 2.30 & 0.15 \\
\hline De 35.1 a 55.0 & 2.70 & 0.09 & 3.40 & 0.12 & 2.50 & 0.09 & 4.75 & 0.20 \\
\hline De 55.1 a 75.0 & 4.70 & 0.11 & 6.40 & 0.14 & 4.50 & 0.11 & 8.75 & 0.24 \\
\hline De 75.1 a 100.0 & 7.70 & 0.13 & 12.40 & 0.17 & 7.50 & 0.13 & 14.75 & 0.28 \\
\hline Más de 100.0 & 11.70 & 0.15 & 14.80 & 0.20 & 11.50 & 0.15 & 20.75 & 0.32 \\
\hline
\end{tabular}


Además, se toma en cuenta un cargo por servicios ambientales y conservación de fuentes, el servicio de alcantarillado y la recolección, transporte y disposición final de desechos.

Cuadro A.2.1.4 Estructura tarifaria por servicios complementarios

\begin{tabular}{|c|c|c|c|c|c|c|c|c|}
\hline \multirow{2}{*}{$\begin{array}{c}\text { Descripción } \\
\text { (Rubros) }\end{array}$} & \multicolumn{6}{|c|}{ Precios fijos y variables en US \$ } \\
\cline { 2 - 10 } & \multicolumn{2}{|c|}{ Residencial } & \multicolumn{2}{c|}{$\begin{array}{c}\text { Comercial y } \\
\text { Gran cliente }\end{array}$} & $\begin{array}{c}\text { Oficial y } \\
\text { Familia pobre }\end{array}$ & \multicolumn{2}{c|}{ Industrial } \\
\cline { 2 - 10 } & $\mathrm{B}_{\mathrm{C}-\mathrm{R}}$ & $\mathrm{C}_{\mathrm{C}-\mathrm{R}}$ & $\mathrm{B}_{\mathrm{C}-\mathrm{R}}$ & $\mathrm{C}_{\mathrm{C}-\mathrm{R}}$ & $\mathrm{B}_{\mathrm{C}-\mathrm{R}}$ & $\mathrm{C}_{\mathrm{C}-\mathrm{R}}$ & $\mathrm{B}_{\mathrm{C}-\mathrm{R}}$ & $\mathrm{C}_{\mathrm{C}-\mathrm{R}}$ \\
\hline Sv. Ambientales & 0.05 & 0.05 & 0.10 & 0.07 & 0.00 & 0.05 & 0.15 & 0.07 \\
\hline Alcantarillado & 0.25 & 0.08 & 0.10 & 0.10 & 0.20 & 0.00 & 0.25 & 0.12 \\
\hline Desecho sólido & 0.50 & & 0.75 & & 0.25 & & 1.00 & \\
\hline
\end{tabular}

Ejemplo 2.- El sistema de abastecimiento de Guayaquil está operado por la empresa Interagua (no municipal), la misma que cuenta con su propio sistema tarifario, cuya facturación obedece al volumen de consumo. El volumen total registrado en el contador del cliente se disgrega según sus componentes de volumen preestablecidos; en cada rango se paga la tarifa básica que le corresponde y el valor de la factura final obedece a la sumatoria de estos parciales más unas tasas que ajustan el monto según diámetro de acometida. En el siguiente cuadro se muestra su estructura tarifaria.

Cuadro A.2.1.5 Sistema tarifario de una empresa no municipal del Ecuador

\begin{tabular}{|c|c|}
\hline \multicolumn{2}{|c|}{ AGUA POTABLE } \\
\hline $\begin{array}{c}\text { RANGO DE } \\
\text { CONSUMO } \mathrm{m}^{3}\end{array}$ & $\begin{array}{c}\text { VALOR } \\
\text { US } \$ / \mathrm{m}^{3}\end{array}$ \\
\hline $0-15$ & 0.275 \\
\hline $16-30$ & 0.405 \\
\hline $31-60$ & 0.578 \\
\hline $61-100$ & 0.763 \\
\hline $101-300$ & 0.835 \\
\hline $301-2500$ & 1.222 \\
\hline $2501-5000$ & 1.53 \\
\hline 5001 o más & 2.429 \\
\hline
\end{tabular}

\begin{tabular}{|c|c|}
\hline \multicolumn{2}{|c|}{ CARGO FIJO } \\
\hline $\begin{array}{c}\text { DIÁMETRO } \\
\text { DE LA } \\
\text { ACOMETIDA }\end{array}$ & $\begin{array}{c}\text { VALOR } \\
\text { US \$ }\end{array}$ \\
\hline $1 / 2$ " & 1.18 \\
\hline $1 / 4 "$ & 7.89 \\
\hline $1 "$ & 20.29 \\
\hline $11 / 2 "$ & 33.82 \\
\hline 2 " & 33.82 \\
\hline 3 " & 56.38 \\
\hline 4 " & 169.12 \\
\hline 6 " o más & 225.5 \\
\hline
\end{tabular}

\begin{tabular}{|c|}
\hline CEM \\
\hline $\begin{array}{c}\text { VALOR } \\
\text { US } \$\end{array}$ \\
\hline 0.27 \\
\hline 0.62 \\
\hline 1.65 \\
\hline 2.61 \\
\hline 8.92 \\
\hline 16.47 \\
\hline 54.2 \\
\hline 219.54 \\
\hline
\end{tabular}

Fuente: (INTERAGUA 2009) 
Ejecución de cobro.- La factura por consumo de agua potable se calcula en función del consumo, la tarifa base cambia por cada rango de volumen, dicha tarifa se multiplica por el valor medido según su rango. Por ejemplo si se consumió $40 \mathrm{~m}^{3}$, entonces $15 \mathrm{~m}^{3}$ se pagan con una tarifa de $\$ 0.275$, otros 15 $\mathrm{m}^{3}$ con una tarifa de $\$ 0.405$ y los últimos $10 \mathrm{~m}^{3}$ a una tarifa de $\$ 0.578$.

A esta suma se le agrega el valor por servicio de alcantarillado cuyo valor es el $80 \%$ del facturado por concepto de agua. Además, existe un cargo fijo mensual por costos de comercialización y se aplican según el diámetro de la acometida de abastecimiento.

Adicionalmente se agrega a la factura la contribución especial de mejoras (CEM), valor mensual que cubre algunos costos de construcción de obras de rehabilitación y mejoramiento. El valor del CEM está en relación al consumo total de agua potable que se registró. Las tarifas se ajustan cada tres meses con base al índice de precios al consumidor, energía eléctrica y salario mínimo vital.

Ejemplo 3.- A continuación se muestra un modelo de estructura tarifaria que se maneja en Sudáfrica, con mayor aplicación en su zona rural:

\section{Cuadro A.2.1.6 Ejemplo de una estructura tarifaria para Sudáfrica}

\begin{tabular}{|c|c|}
\hline Rango en $\mathrm{m}^{3}$ & Tarifa $\left(\right.$ Rand $\left./ \mathrm{m}^{3}\right)$ \\
\hline Hasta 10 & 1.0 \\
\hline De 10 a 40 & 3.0 \\
\hline De 40 a 100 & 4.0 \\
\hline Más de 100 & 5.0 \\
\hline
\end{tabular}

A estas cifras, en cada factura de cobro se agrega el pago por lectura de contador domiciliar, amortización de la conexión y el contador, costos de facturación, recolección y mora por deuda. (Marah L.; O'Donovan M.; et. al. 2004). 
ANEXO 2.2

Síntesis de investigación intitulada:

\section{GESTIÓN PARA LA MEJORA DE LA EFICIENCIA ENERGÉTICA EN SISTEMAS DE DISTRIBUCIÓN DE AGUA}

(Benavides H. y Sánchez J. 2010)

\section{RESUMEN}

La eficiencia, en términos generales, es la relación entre los servicios (o productos) finalmente obtenidos o brindados al consumidor y la cantidad de recursos (o energía) consumidos para ese propósito.

Así, en sistemas urbanos de distribución de agua, la eficiencia hidráulica es la relación entre el volumen de agua efectivamente utilizado por los abonados y el volumen total extraído de la fuente para cumplir con tal servicio. Síncronamente, mientras menor es la eficiencia hidráulica en el sistema, menor es también la eficiencia energética debido a la energía consumida para dar ese servicio.

Gestionar la mejora de la eficiencia significa reducir pérdidas de recursos (tiempo hombre, hídrico, energético, ambiental, otros) para optimizar progresivamente los índices, a través de un adecuado manejo técnico, adaptación legal y optimización administrativa, dirigido a beneficiar a la comunidad involucrada y servida.

El resultado del presente trabajo es presentar propuestas técnicas alternativas para mejorar la eficiencia hidráulica y energética de un sistema urbano de agua, mediante la detección de fugas y reducción de consumos energéticos.

PALABRAS-CLAVE: Eficiencia hidráulica, eficiencia energética, detección de fugas, consumo energético, flujos mínimos nocturnos, curvas características, condición resistiva del sistema.

\section{INTRODUCCIÓN}

La gestión sostenible del recurso hídrico en el entorno urbano, escenario constitutivo del desarrollo, precisa - para ser efectiva un manejo técnico de todos los componentes que la conforman -, de la aplicación de un marco legal y político - práctico, en un tiempo adecuado y con estrategias de intervención efectivas, teniendo como actor principal al usuario presente y futuro. 
Es la buena gestión de los sistemas de ingeniería urbana la que de forma general aporta para que la eficiencia sea creciente durante su vida útil. La poca o gran incidencia del aporte que los proyectos de infraestructura civil brindan al entorno, con frecuencia depende de lo razonadamente diseñados, estratégicamente evaluados y prolijamente ejecutados que estén. Cuando se encuentran en una fase de concepción ideal hasta la etapa de diseño definitivo son sometidos a evaluaciones técnicas, económico-financieras, ambientales y socio-políticas, principalmente, los resultados ayudan a entender y prevenir el comportamiento dinámico - temporal que el sistema tendrá una vez que sea puesto en marcha y al servicio correspondiente.

Los sistemas urbanos de agua, infraestructura civil básica e imprescindible para el bienestar y salubridad de la población, incluyen elementos cuyas características hidráulicas-energéticas varían con el tiempo. El uso, las maniobras de mantenimiento, los sucesos eventuales operativos, la variación de presión, los incrementos de velocidad, entre otros agentes, provocan en las redes $\mathrm{y}$ en sus elementos desgaste, deterioro y fallo.

Un sistema de abastecimiento de agua se mantendrá dentro de una franja de eficiencia siempre que se lo gestione de forma proactiva y se tome las decisiones en el tiempo y espacio más propicias. Esto significa, entre otras acciones directivas, agenciar correctamente los componentes del sistema: personal (técnicos - de gabinete y campo -, administrativo y su "know how"); infraestructura (captaciones, aducciones, conducciones, tratamiento, almacenamientos, distribuciones, redes.- nudos y líneas, etc.); operación y mantenimiento (planificación, demanda y oferta, presiones, consumo energético, fugas, renovaciones parciales de tubería); económico (tarifas y costos, amortizaciones, inversiones versus oportunidad, búsqueda de capitales, etc.); recurso (cuencas fuente, calidad de agua, calidad de vida); tecnología (ofimática, instrumentación para medición en línea, SCADA, telemetría, SIG, etc.); logística y bodega (vehículos, maquinaria, herramientas, instrumentos y equipo), entre otros.

Para el presente caso de estudio (fase uno), tomando en consideración el nivel de profundidad del tema, nos hemos propuesto investigar únicamente la eficiencia hidráulica y la eficiencia energética.

\section{PROBLEMÁTICA}

En países considerados "en vías de desarrollo", la disminución gradual de la eficiencia hidráulica y energética de sus abastecimientos urbanos de agua se debe principalmente a que sus gestores no toman "a tiempo" las acciones de 
operación y mantenimiento adecuadas, ora por la no gestión de recursos, ora por criterios políticos.

Está claro que ningún sistema de agua potable del mundo es totalmente estanco, mucho menos los nuestros. Para desagregar las pérdidas de agua de los sistemas de distribución urbana se dice que estas son: pérdidas reales o físicas y pérdidas aparentes o comerciales. Las primeras se producen principalmente por fugas (en las tomas o conexiones domiciliares, en las tuberías, válvulas, accesorios, nudos, etc.); las pérdidas aparentes son aquellos volúmenes de agua que se consumieron pero no fueron identificados ni facturados por la empresa.(Cabrera E. 2007).

Al producirse considerables pérdidas de agua se producen también pérdidas económicas cuantiosas, por un exceso de energía consumida. El consumo energético principalmente costoso, es aquel que se utiliza en impulsar la masa líquida a través de estaciones de bombeo.

Con el tiempo y el uso, el rendimiento del grupo motor-bomba de cada estación de bombeo del sistema disminuye, y cada vez cuesta más impulsar una misma cantidad de agua a las mismas cotas. El problema se agrava si tampoco se dispone de las curvas características actualizadas, tanto del nudo de impulsión $\left(\mathrm{H}_{B}\right)$ como del sistema resistivo $\left(\mathrm{H}_{\mathrm{R}}\right)$.

Se presentan entonces otros problemas que, ya sea de forma sinérgica o directa, son consecuencia de los anteriores, así por ejemplo:

a) Los sistemas de agua que no gestionan fugas a tiempo, se deterioran crecientemente; con mayores pérdidas de agua ( $y$ por ende de energía), menores volúmenes registrados y facturados (con gastos energéticos superiores a los obligados).

b) Aumento de la huella ecológica por mal-gasto energético (volúmenes fugados o no contabilizados).

c) La gestión del sistema de agua disminuye su eficiencia y sostenibilidad.

\section{OBJETIVO}

- $\quad$ Proponer alternativas para mejorar la eficiencia energética de un sistema urbano de agua, mediante la actualización de las curvas características en estaciones de bombeo y resistivas del sistema, a través de su modelación y ajuste práctico. 


\section{ESTADO DEL ARTE}

Las características físicas y el estado funcional de cada sistema de distribución de agua es una particularidad que se debe considerar a la hora de hablar de eficiencia y gestión. Dentro de esto destaca que, la casi totalidad de los municipios de los países en vías de desarrollo, manejan abastecimientos insuficientes, deficientes e ineficientes.

El origen de los múltiples problemas que se generan en sistemas urbanos de agua, carentes de una apropiada gestión, posiblemente se debe al creciente porcentaje de agua no contabilizada, a la edad del sistema, a la no gestión de la presión ni de la demanda, a los frecuentes cortes y racionamientos con la consecuente intrusión patógena, junto con las malas costumbres de consumo y una escasa sensibilidad ciudadana para mantener consumos moderados; asimismo, no existen criterios para establecer políticas de mantenimiento; además, las tarifas de cobro al abonado no garantizan sostenibilidad, afectado por subsidios que no permiten la sostenibilidad característica de un sistema bien gestionado.

La mayoría de los países Iberoamericanos, por su parte, han estructurado sistemas autónomos de valoración del desempeño, en los que las propias empresas de agua de las principales ciudades han establecido y adaptado para sí, conjuntos de variables cuyos valores (que son obtenidos de campo y/o gabinete) se combinan de forma aritmética para establecer indicadores de gestión. La buena práctica y aplicación de criterios en base a la interpretación de sus indicadores apoya constantemente a la toma de decisiones y buena administración de sus empresas, ocasionando en la mayoría de las veces un progresivo incremento de la eficiencia interna. (Benavides H.; et. al. 2008)

\section{Mejora de la eficiencia de la gestión urbana de sistemas de agua}

Una alternativa recomendada por los expertos a nivel mundial para mejorar la gestión de sistemas de agua, es aquella que la empresa operadora encargada de esta tarea, selecciona estratégicamente una gama de variables e indicadores de gestión (performance indicators) que le permitan evaluar la efectividad (eficacia + eficiencia) de los procesos que lleva a cabo para servir a sus usuarios abonados. Entre los expertos antes mencionados se puede citar que, por ejemplo el Banco Mundial - BM -,la International Water Assosiation IWA - conjuntamente con el Instituto Tecnológico del Agua - ITA -; la OFWAT, entre otros, propusieron cada uno de ellos una herramienta que permite: medir el desempeño y comparar la gestión de las operadoras de sistemas de agua urbana, mediante la práctica de benchmarking métrico entre empresas homologables, (Benavides H. 2007). 
Los indicadores relacionan variables que tienen su base en la información que se recaba de cada sistema operador y de los componentes de los distritos hidrométricos contemplados en el sistema de agua. Para mejorar la calidad del servicio de las empresas operadoras de forma permanente se recomienda implementar procedimientos para recopilación y manejo de información veraz y oportuna, que den a conocer en cualquier momento los resultados y metas alcanzadas; $y$, que permitan ser verificados fácilmente, en espacio y tiempo.

Asimismo, dentro de la mejora de la gestión hídrica y energética de sistemas urbanos de agua, cuya capacidad instalada aún esté en proceso de mejoramiento, se plantea actividades para la reducción del agua no contabilizada y concretamente de las fugas reales de agua; y, optimización de consumo energético mediante el incremento en los rendimientos de los grupos motor-bomba de las estaciones de impulsión que incluya el sistema.

La propuesta para mejorar la eficiencia hidráulica y energética se basa en dos aspectos:

a) Reducir las fugas de agua; primeramente requiere detectarlas en la red, luego localizarlas, a veces también confirmarlas y finalmente repararlas.

b) Reducir los gastos de energía; implica que se debe mejorar el rendimiento de los grupos motor-bomba, y esto significa, primeramente conocer su estado actual, comportamiento hidráulico y condición resistiva del sistema.

Una metodología apropiada para esta actividad, aplicable a nuestro entorno, es la que resulta de combinar la detección de fugas mediante el análisis de flujos mínimos nocturnos y la actualización de las curvas características de las estaciones de bombeo.

Resumidamente se anota que un sistema de agua para consumo humano mejorará su eficiencia hidráulica y energética cuando al mismo tiempo sus redes fuguen menos y sus impulsiones trasieguen más caudal con menor consumo de energía. Dicho de otro modo, el consumo energético será menor en tanto y en cuanto las fugas de agua disminuyan y los rendimientos de los grupos de impulsión se mantengan o incrementen.

\section{Eficiencia hidráulica}

Las pérdidas reales según la concepción de la IWA, establece que estas pérdidas de agua desde la red no se pueden eliminar por completo de los sistemas de abastecimiento. Existirá, en la totalidad de los casos, un volumen mínimo de pérdidas reales inevitables y un volumen de pérdidas potencialmente recuperables. 
La reducción del volumen de pérdidas se puede conseguir aplicando las consideraciones siguientes: (Benavides H.; et. al. 2008).
a) Control activo de fugas; detección y localización.
b) Reparaciones oportunas y efectivas.
c) Gestión de presión; reducción y control funcional.
d) Rehabilitación y mantenimiento permanente de la infraestructura hidráulica.

Es de fácil deducción el hecho que para aplicar la valoración de los indicadores de desempeño propuestos por la IWA, la OFWAT y por las normas ISO 24512, los sistemas requieren contar con un mínimo de características constructivas, de equipamiento y de inversión, que permitan obtener los datos requeridos para luego introducirlos en las variables correspondientes y finalmente determinar los indicadores que se necesitan. (Benavides H.; et. al. 2008).

\section{Eficiencia energética}

Para la República del Ecuador, hoy más que nunca, es urgente que se apliquen planes estratégicos de reducción del consumo energético y principalmente en el sector de los abastecimientos urbanos. Como referencia, los operadores de servicio de sistemas de agua y saneamiento de Brasil gastan más del $2 \%$ del consumo eléctrico total de su país (7 PW-h/año $\left.\equiv 7 \times 10^{12} \mathrm{~kW}-\mathrm{h}\right)$. (PROCEL SANEAR 2005).

Esta crisis del sector eléctrico obliga al Estado a, cuanto antes, plantear políticas y acciones para una gestión de la demanda y usos racionales de la electricidad.

La mejora de la eficiencia energética se relaciona directamente con la reducción de la cantidad de energía consumida, y este hecho, en términos generales, se pude conseguir sobre la base de disminuir los consumos de agua y reacondicionar los sistemas de bombeo. Dicho de un modo ampliado, los gastos inadecuados de electricidad que se producen en los sistemas de agua potable se deben, entre otros aspectos, a:

a) Fugas de agua en las redes, principalmente en aquellas en que es impulsada con energía eléctrica.

b) Redes con características resistivas superiores a las concebidas en el diseño.

c) Desconocimiento de las curvas características actuales del grupo motor-bomba.

d) Instalación de grupos motor-bomba con bajos rendimientos. 
e) Mantenimiento inadecuado de los motores.

f) Mala gestión de la oferta y demanda del agua.

g) Sistemas de impulsión que cumplieron su vida útil y siguen operando sin renovación de sus elementos.

h) Tarifas desactualizadas de cobro por consumo de agua.

i) No utilización de variadores de frecuencia, donde puedan ser aprovechados.

j) Prácticas operativas y administrativas no acordes con la eficiencia requerida.

k) Desperdicios y consumos inapropiados de agua. **

l) Mal dimensionamiento de las redes. ${ }^{* *}$

m) Mala aplicación de tecnologías. **

** Referidas a (Gomes H. 2005).

Las medidas correctoras pueden ser de: Operación y mantenimiento, y administrativas; estas últimas no requieren de mayor inversión para ser ejecutadas. (Gomes P. H. 2005). En el marco de los abastecimientos, son los grupos motor-bomba y sistema resistivo, los elementos a los que se les debe un mayor consumo energético. En este análisis se proyecta determinar las curvas características y las resistivas de cada sistema de impulsión.

\section{Creación de curvas características, caso práctico}

Mediante una evaluación física, hidráulica y energética se verificó la calidad del servicio de agua que el sistema presta a sus usuarios; además se constató el comportamiento hidráulico de los componentes de las estaciones de bombeo del sistema local.

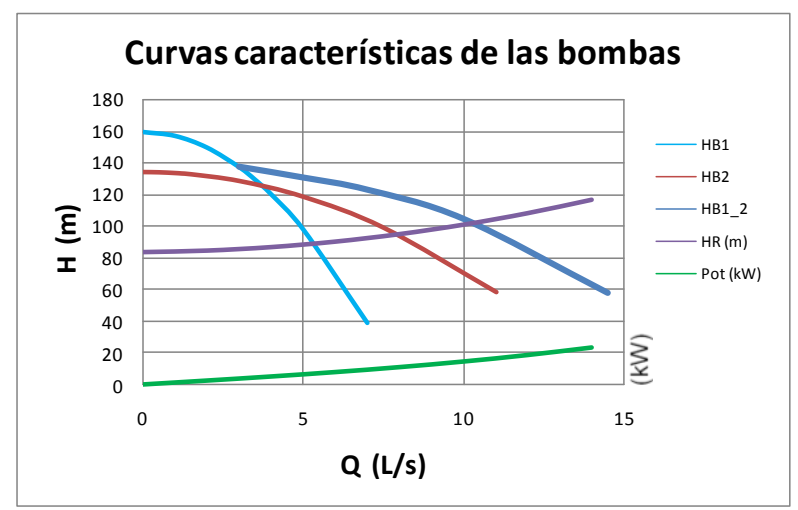

Gráfico A.2.2.1 Esquema del funcionamiento de dos bombas diferentes en paralelo 
Cálculo de las curvas características de los conjuntos motor-bomba

Para actualizar las curvas características de los conjuntos motor-bomba del sistema investigado se procedió así:

- $\quad$ Aforo a la salida de la línea de impulsión (Q).

a) Estaciones con dos conjuntos motor-bomba, con las combinaciones: $\mathrm{B}_{1} ; \mathrm{B}_{2} ; \mathrm{B}_{1-2}$.

b) Estaciones con tres conjuntos motor-bomba, posibles combinaciones: $\mathrm{B}_{1} ; \mathrm{B}_{2} ; \mathrm{B}_{3} ; \mathrm{B}_{1-2} ; \mathrm{B}_{1-3} ; \mathrm{B}_{2-3}$.

- Cálculo de la altura estática total $(\mathrm{Hg})$.

- Cálculo de las pérdidas de carga en las tuberías de succión e impulsión $\left(\mathrm{hf}_{\text {suc }}, \mathrm{hf}_{\text {imp }}\right)$.

- Proyección de las curvas características (grupos motor-bomba y resistiva del sistema).

\section{Cálculo de la curva resistiva del sistema $\mathrm{Hr}$}

La curva resistiva del sistema muestra la variación altura $\mathrm{H}$-caudal Q; se observa cómo las variaciones de caudal provocan aumentos notables en las pérdidas.

Para determinar la curva resistiva del sistema partimos de la expresión:

$$
\mathrm{Hr}=\mathrm{H}_{\mathrm{g}}+\mathrm{H}_{\mathrm{f}_{\text {_succión }}}(\mathrm{Q})+\mathrm{H}_{\mathrm{f}_{-} \text {impulsioón }}(\mathrm{Q})+\mathrm{H}_{\mathrm{v}}(\mathrm{Q}) \quad \text { Ec. (A.2.14) }
$$

Donde:

$$
\begin{array}{lll}
\mathrm{Hr} & - & \text { ordenada de la curva resistiva } \\
\mathrm{Hg} & - & \text { columna estática total } \\
\mathrm{Hv} & - & \text { carga residual } \\
\mathrm{H}_{\mathrm{f}_{\text {suc }}}(\mathrm{Q}) & - & \begin{array}{l}
\text { pérdidas por fricción en el sistema en función del } \\
\text { caudal de impulsión }
\end{array} \\
\mathrm{H}_{\mathrm{f}_{\text {_imp }}}(\mathrm{Q}) & -\quad \begin{array}{l}
\text { pérdidas locales en el sistema en función del caudal } \\
\text { de impulsión }
\end{array}
\end{array}
$$


Por tratarse de bombas con características diferentes entre sí, fue preciso encontrar una relación de pesos, para ponderar el caudal aportado por ellas cuando trabajan en paralelo, así:

$$
\begin{gathered}
\Delta_{\mathrm{i}}=\frac{\mathrm{Q}_{\mathrm{Bi}}}{\mathrm{Q}_{\mathrm{Bj}}} \\
\Delta_{j}=\frac{Q_{B j}}{Q_{B i}}
\end{gathered}
$$

Luego se establece un sistema de dos ecuaciones con dos incógnitas para cada par de grupos motor-bomba, de la siguiente manera:

$$
\begin{aligned}
& \mathrm{H}_{\mathrm{B}}=\mathrm{f}(\mathrm{Q}) \\
& \mathrm{H}_{\mathrm{B}}=\mathrm{A}-\overbrace{\mathrm{B} \times\left(\mathrm{Q}_{\mathrm{B}}\right)}^{\approx 0}-\mathrm{C} \times\left(\mathrm{Q}_{\mathrm{B}}\right)^{2}
\end{aligned}
$$

Entonces para la bomba $i$, tendremos que:

$$
\left\{\begin{array}{l}
H_{B i}=A-C \times\left(Q_{B i}\right)^{2} \\
H_{B i j}=A-C \times\left(\frac{Q_{B i j}}{1+\Delta_{j}}\right)^{2}
\end{array}\right\}
$$

Los valores de $\mathrm{A}$ y $\mathrm{C}$ nos permitirán determinar la ecuación característica de la bomba $i$, y con ella construir la curva característica correspondiente $\mathrm{H}_{\mathrm{B} i}$.

\section{Entonces:}

$$
\mathrm{C}=\frac{\mathrm{H}_{\mathrm{Bi}}-\mathrm{H}_{\mathrm{Bij}}}{\left(\frac{\mathrm{Q}_{\mathrm{Bij}}}{1+\Delta_{\mathrm{j}}}\right)^{2}-\mathrm{Q}_{\mathrm{Bi}}{ }^{2}} \quad \vee \quad \mathrm{A}=\mathrm{H}_{\mathrm{Bi}}+\mathrm{C} \times \mathrm{Q}_{\mathrm{Bi}}{ }^{2}
$$

En la curva de la bomba, corresponde para cada valor de $\mathrm{Q}_{j}$ uno de $\mathrm{H}_{\mathrm{B} i}$, y con ellos nos basamos para construir la curva de las dos bombas trabajando en paralelo, regentados por las expresiones siguientes:

$$
\mathrm{H}_{\mathrm{Bij}}=\frac{\mathrm{H}_{\mathrm{Bi}} \times \Delta_{\mathrm{i}}+\mathrm{H}_{\mathrm{Bj}} \times \Delta_{\mathrm{j}}}{\Delta_{\mathrm{i}}+\Delta_{\mathrm{j}}}
$$




$$
\mathrm{Q}_{\mathrm{Bij}}=\mathrm{Q}_{\mathrm{Bi}}+\mathrm{Q}_{\mathrm{Bj}}
$$

Ecuaciones adoptadas para determinar las pérdidas por fricción y locales

$$
\begin{aligned}
& \mathrm{H}_{\mathrm{f}}=\frac{8 \times \mathrm{f} \times \mathrm{L} \times \mathrm{Q}^{2}}{\pi^{2} \times \mathrm{g} \times \mathrm{D}^{5}} \\
& \mathrm{H}_{\mathrm{fm}}=\frac{8 \times \mathrm{k} \times \mathrm{Q}^{2}}{\pi^{2} \times \mathrm{g} \times \mathrm{D}^{4}}
\end{aligned}
$$

Donde:

$\begin{array}{lll}\mathrm{H}_{f} & - & \text { pérdida de carga por longitud } \\ \mathrm{H}_{f \mathrm{~m}} & - & \text { pérdida de carga en accesorios } \\ \mathrm{k} & - & \text { sumatoria de coeficientes para accesorios } \\ \mathrm{f} & - & \text { factor de fricción } \\ \mathrm{L} & - & \text { longitud de la tubería } \\ \mathrm{D} & - & \text { diámetro de la tubería } \\ \mathrm{g} & - & \text { aceleración de la gravedad } \\ \mathrm{Q} & - & \text { caudal }\end{array}$

Con los valores generados de $\mathrm{Q}_{\mathrm{Bij}}$ y $\mathrm{H}_{\mathrm{Bij}}$ para las dos bombas en paralelo, podemos obtener los valores de los coeficientes $A_{i j}$ y $C_{i j}$, mediante mínimos cuadrados.

$$
\begin{aligned}
& \mathrm{A}_{\mathrm{ij}}=\frac{\sum \mathrm{H}_{\mathrm{Bi}} \times \sum \mathrm{Q}_{\mathrm{Bi}}{ }^{4}-\left(\sum\left(\mathrm{H}_{\mathrm{Bi}} \times \mathrm{Q}_{\mathrm{Bi}}{ }^{2}\right) \times \sum \mathrm{Q}_{\mathrm{Bi}}{ }^{2}\right)}{\mathrm{n} \times \sum \mathrm{Q}_{\mathrm{Bi}}{ }^{4}-\left(\sum \mathrm{Q}_{\mathrm{Bi}}{ }^{2}\right)^{2}} \\
& \mathrm{C}_{\mathrm{ij}}=\frac{\mathrm{n} \times \sum\left(\mathrm{H}_{\mathrm{Bi}} \times \mathrm{Q}_{\mathrm{Bi}}\right)-\sum \mathrm{H}_{\mathrm{Bi}} \times \sum \mathrm{Q}_{\mathrm{Bi}}{ }^{2}}{\mathrm{n} \times \sum \mathrm{Q}_{\mathrm{Bi}}{ }^{4}-\left(\sum \mathrm{Q}_{\mathrm{Bi}}{ }^{2}\right)^{2}} \\
& \mathrm{H}_{\mathrm{Bij}}=\mathrm{A}_{\mathrm{ij}}-\mathrm{C}_{\mathrm{ij}} \times\left(\mathrm{Q}_{\mathrm{Bij}}\right)^{2}
\end{aligned}
$$

La variación de las condiciones físicas que las tuberías experimentan con el paso del tiempo, son un factor importante a la hora de proyectar pérdidas de carga por fricción. Se demostró en laboratorio el aumento del valor de rugosidad absoluta de algunas tuberías de diferente material; así para tuberías de hierro fundido, con más de 35 años de uso, se determinó que ésta aumenta hasta 4.6 veces más que el valor original, de un valor inicial de 0.25 $\mathrm{mm}$ (dado por algunos fabricantes para tubo nuevo) hasta un valor de 1.15 $\mathrm{mm}$. 

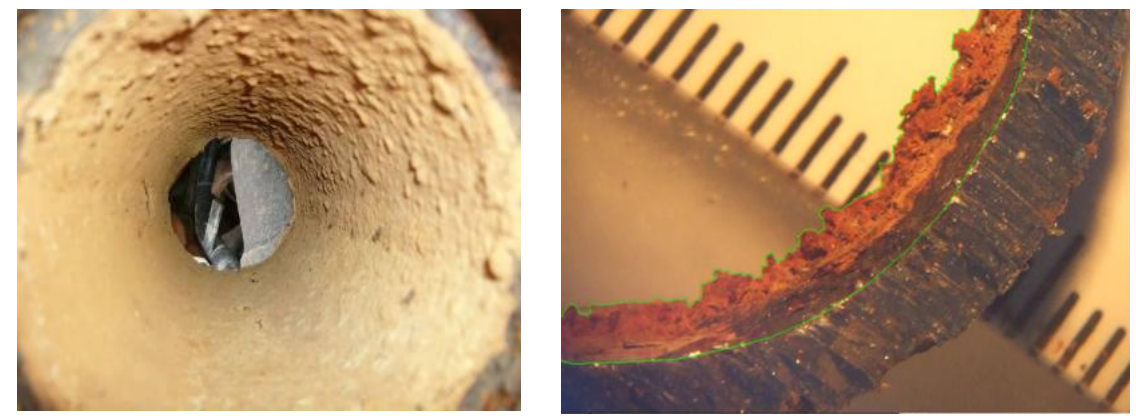

Figura A.2.2.1 Cambio de las condiciones físicas internas de una tubería con su uso Fuente: (Pineda E. y Benavides H. 2008).

La expresión Ec. (A.13) es válida para relacionar el coeficiente $C$ de HazenWilliams, la velocidad y el diámetro, respecto del factor de fricción $f$ para Darcy - Weisbach.

$$
\mathrm{f}=\frac{133.9}{\mathrm{C}_{\mathrm{HW}}{ }^{1.852} \times \mathrm{D}^{0.167} \times \mathrm{V}^{0.1482}}
$$

Para este análisis, se experimentó para un $C_{H W}=89$ para 20 años y $C_{H W}=70$ para 35 años.

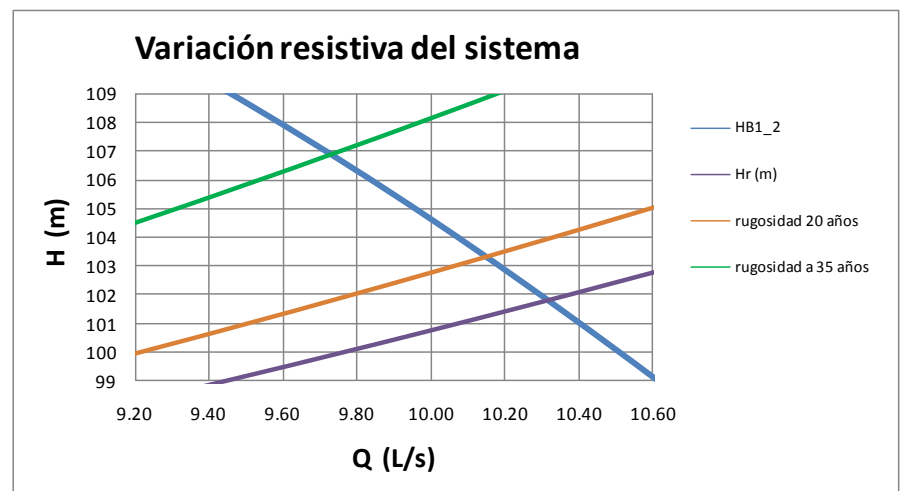

Gráfico A.2.2.2 Cambio de las condiciones resistivas del sistema, a 5, 20 y 35 años 
Del gráfico se deduce que por cambio en la resistividad del sistema a los 35 años, el caudal disminuye $5.5 \%$ y la carga requerida se incrementa en un $5 \%$. El factor de fricción aumenta entre 2 y 3 veces. Al disminuir el caudal impulsado, significa que para tener el mismo volumen de agua debemos incrementar el tiempo de bombeo un porcentaje aproximadamente semejante.

\section{Consumo energético}

El consumo energético depende directamente de la potencia requerida por la estación de impulsión ( $\mathrm{P}$ en $\mathrm{kW}$ ); la misma se determina con:

$$
\mathrm{P}=\frac{9.81 \times \mathrm{Q} \times \mathrm{H}}{\eta}
$$

Donde:

$$
\begin{aligned}
& \text { H - altura total ó altura manométrica de elevación en } \mathrm{m} \\
& \text { c.a. } \\
& \eta \quad \text { - } \quad \text { rendimiento global }(\eta \text { motor } \times \eta \text { bomba }) \\
& Q \quad \text { - caudal en } \mathrm{m}^{3} / \mathrm{s}
\end{aligned}
$$

Para proyectar la potencia requerida en la impulsión con las características del sistema al año 35 de operación, se debe considerar el nuevo valor resistivo del sistema, así como también el aumento del tiempo de bombeo.

La energía necesaria ( $\mathrm{E}$ en $\mathrm{kWh}$ ) se calcula con la siguiente expresión:

$$
\mathrm{E}=\left(\frac{9.81 \times \mathrm{Q} \times \mathrm{H}}{\eta}\right) \times \mathrm{t}
$$

Donde:

$t \quad$ - número de horas de bombeo (24 h para el presente análisis) 


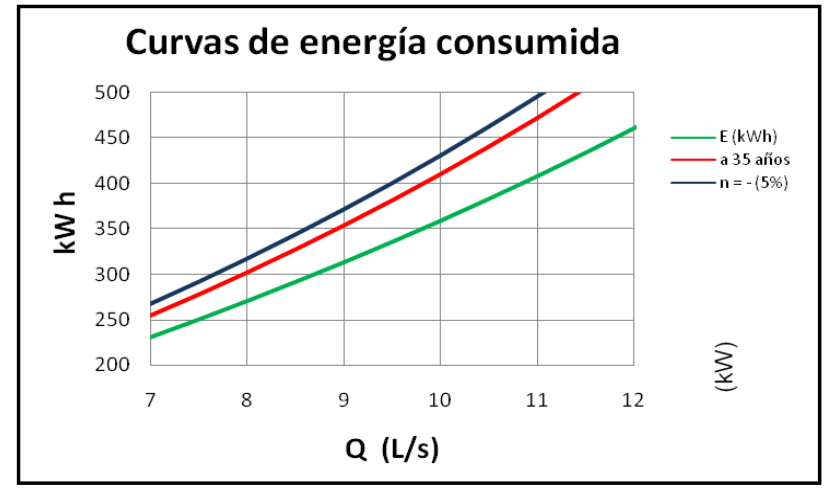

Gráfico A.2.2.3 Variación del requerimiento energético

Se observan dos situaciones, para cuando las dos bombas trabajan en paralelo:

1) El incremento porcentual del consumo energético en un $14.5 \%$, para las condiciones resistivas del sistema proyectadas al año $35 \mathrm{y}$ suponiendo el mismo rendimiento del grupo motor-bomba con el que se diseñó inicialmente.

2) El incremento porcentual del consumo energético es mayor que el $20 \%$, para las condiciones resistivas del sistema proyectadas al año 35 y suponiendo una reducción del rendimiento del grupo motor-bomba en solamente un $5 \%$, que es lo mínimo que se podría esperar por deterioro y uso.

El costo de energía $\left(C_{e}\right.$ en unidades monetarias para el intervalo de tiempo, \$/mes, \$/año) será entonces:

$$
\mathrm{C}_{\mathrm{e}}=\mathrm{E} \times \mathrm{C}_{\text {unit }}
$$

Donde:

$\mathrm{C}_{\text {unit }} \quad$ - costo unitario de energía (para el intervalo de análisis)

Los costos de explotación, son el resultado de sumar los costos energéticos con los costos por mantenimiento (labores y reparaciones previstas) y con los costos por personal (salarios necesarios para el buen funcionamiento de la estación). 


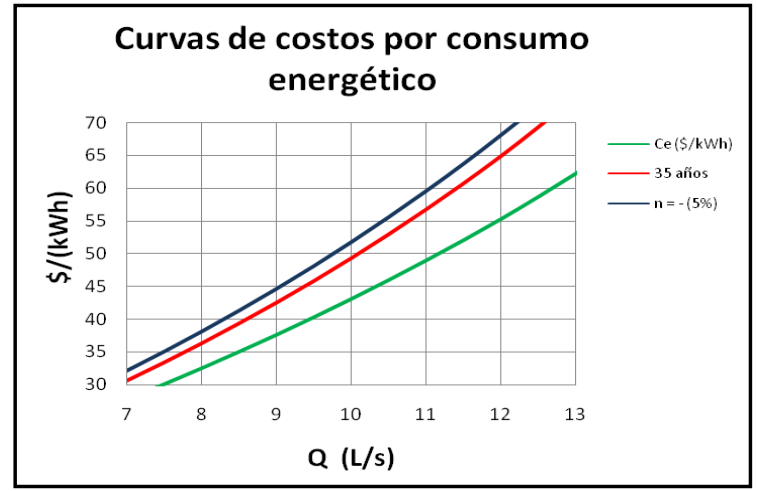

Gráfico A.2.2.4 Variación del costo por consumo energético

Del mismo modo que el caso anterior -resistiva del sistema proyectada a 35 años-, el incremento del costo por consumo energético, visto para las dos bombas trabajando en paralelo, varía desde un $14.4 \%$ hasta un valor superior al $20 \%$, según se considere o no una reducción del $5 \%$ del rendimiento de los grupos motor-bomba.

En nuestro caso de estudio, los datos de consumo eléctrico acumulado en $\mathrm{kWh}$ e inversión económica en dólares americanos, para un intervalo de análisis de siete meses, para once estaciones de impulsión, se presentan en los siguientes gráficos:

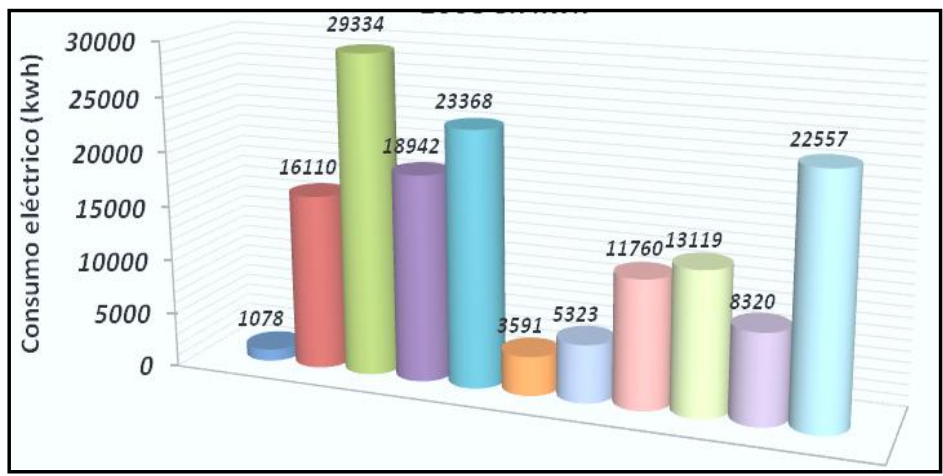

Figura A.2.2.2 Consumo eléctrico acumulado (kWh). Oct. 2007 - Abr. 2008 FUENTE: (Idrobo D. y Benavides H. 2008) 


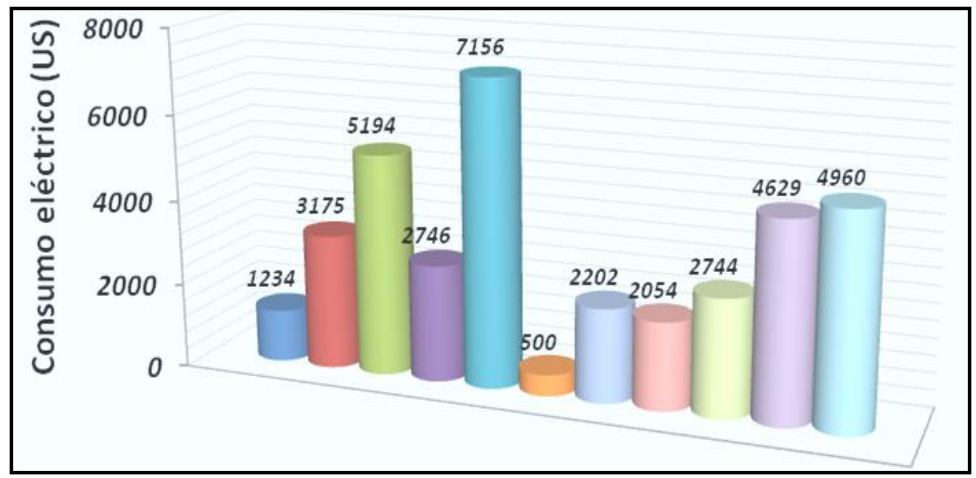

Figura A.2.2.3 Costo de consumo eléctrico entre Oct. 2007 - Abr. 2008, en US\$. FUENTE: (Idrobo D. y Benavides H. 2008)

\section{CONCLUSIONES:}

1) La gestión de sistemas de agua con base en la mejora de la eficiencia hidráulica y energética reduce el consumo de recursos.

2) Los valores de gasto económico por consumo energético en estaciones de bombeo se podrían reducir hasta en un $20 \%$, siempre que se mejore las condiciones físicas - resistivas del sistema y se garantice un rendimiento adecuado para los grupos de impulsión. No obstante, se debe considerar cada sistema de impulsión como un caso particular, al cual se lo puede y debe gestionar para optimizar su desempeño hidráulico y de este modo su eficiencia energética.

A estos valores, además se debe sumar también el costo del agua fugada (agua no facturada) y por ende la reducción de eficiencia del sistema de impulsión del caudal.

3) Las dificultades de aplicación de las metodologías se debe principalmente a que:

a. La gran mayoría de los sistemas de abastecimiento de agua potable del Ecuador no cuentan con la infraestructura para poder practicar periódicamente medición, control y seguimiento de caudales y presiones, ó calidad en línea.

b. El no contar con redes sectorizadas es otra de las causas para imposibilitar la operación de las líneas de distribución de agua. 


\section{RECOMENDACIONES:}

La mejora de la eficiencia hidro-energética significa, entre otros, servir mejor al cliente, con menores gastos de recursos, un incremento en los niveles de productividad y satisfacción junto con una, no menos importante, reducción de costos.

Se proponen algunas alternativas que podrían sentar las bases para marchar hacia ese rumbo.

Para sortear estas dificultades y mejorar la gestión, hace falta tomar en consideración los siguientes detalles:

- Inversión económica en las redes de distribución, para sectorizarlas y con ello conformar distritos hidrométricos, o subsectores de medición.

- $\quad$ Seguidamente es necesario instalar sistemas de medición y registro continuo de volúmenes, caudales y presiones, tanto en tramos de inyección como en los de distribución y consumo.

- En los depósitos será necesario instalar, entre otros equipos al menos, un aparato de medición y registro de volúmenes ingresados y extraídos, medición de niveles de superficie libre del agua almacenada, válvulas y accesorios para evitar derrames e intrusión de aire. Hará falta dotar de loggers de presión con almacenamiento de información.

- $\quad$ Seguimiento estadístico y almacenamiento permanente de los datos obtenidos de los nudos de control para su análisis, interpretación y diagnóstico independiente y oportuno.

- Coordinar una campaña mediática informativa para que la población esté al tanto de todos los cambios que se producirán en el sistema a nivel administrativo, hidráulico, sanitario, ambiental, financiero, social y político, entre los principales.

Consideraciones para la mejora de la gestión:

a. La sectorización de las redes se debe incluir como un ítem prioritario para la detección, localización y reparación de fugas.

b. El control activo de fugas, demanda por su parte una estrategia autónoma e integradora al proceso de reducción de pérdidas reales del sistema. Al menos una detección de fugas trimestral / subsector. 
c. Reparación y renovación de tuberías cuyos daños y materiales así lo exijan. El cabio o mantenimiento de tuberías cuyas pérdidas sean muy superiores a las de diseño, se deberán analizar de forma particular en lo técnico y económico.

d. De la misma manera en este análisis se debe incluir la renovación de válvulas, hidrantes y accesorios que hayan cumplido su vida útil y que estén ocasionando problemas en la operación de la red.

e. El enfoque de calidad deberá pasar por un progresivo incremento de la capacidad constructiva y de efectivas reparaciones en las redes, junto con un sistema integral de gestión de la información.

2) Financiamiento y ejecución de actividades programadas

a. Todos los proyectos que componen este programa de mejora de la gestión de sistemas de abastecimiento deben tener, de forma oportuna y estable, su partida presupuestaria completa. Esto significa que se deberá incluir entre las estrategias gerenciales, la búsqueda pertinaz de fuentes de financiamiento.

b. Entre las fuentes de financiamiento recomendadas en la sostenibilidad, están los ingresos por las propias tarifas, reajustadas para estos nuevos episodios incluidos en la gestión; (dar un precio sostenible del agua).

c. Instituir convenios de pago y recuperación de cartera vencida. Mejorar la calidad de atención al cliente.

3) Operación, mantenimiento y retroalimentación

a. La operación requiere de la selección de un distrito hidrométrico (o un subsector) que previamente se lo haya identificado como crítico y prioritario de intervención.

b. Obtener el rango de caudales de consumos: doméstico, industrial, comercial, oficial y discapacitados o tercera edad.

c. Estructurar el balance hídrico del distrito en evaluación y determinación de las características hidráulicas (caudal y presión) en diferentes puntos de la red.

d. El equipo de la institución operadora deberá escoger un sistema de variables e indicadores, según sea su capacidad de generar valores confiables y permanentes. Luego se emprenderá con el cálculo de indicadores de desempeño: operacional, hídrico- 
energéticos, rehabilitación, económico - financieros y de calidad de servicio al cliente, principalmente.

e. Determinación del nivel óptimo de fugas. Inspección de campo y aplicación de las metodologías más competentes para detección y localización de fugas.

f. Políticas para la gestión del suministro de agua en época de sequía o temporadas críticas.

g. Puntualizar las experiencias mejor adaptadas y buenas prácticas para una reingeniería de procesos y retroalimentación continua al programa de mejora de la calidad.

h. Almacenamiento y actualización de la base de datos e información del desempeño de la institución operadora. Plasmar resultados de forma pública.

i. Mantenimiento y calibración periódica de equipos y herramientas para obtención veraz de información.

Además será necesario contar con el análisis, interpretación y modelación de los balances hídricos, así como el planteamiento de medidas correctoras a la gestión para mejorar su desempeño anual, reduciendo al mínimo económico el caudal de agua no contabilizada.

- Contar con las curvas características actualizadas permitirá al gestor, realizar mejoras en la operación de las EB, ya que se podrá identificar los conjuntos motor-bomba con un rendimiento limitado, para así darles mantenimiento y remplazarlos si hace falta.

- Las curvas resistivas de los sistemas adoptan mayor concavidad, cuanto menor es el diámetro de la conducción. Esta particularidad significa que a un mayor caudal circulando por la impulsión, será necesario mayor consumo energético.

- El caudal aforado denota claras diferencias en el rendimiento de conjuntos motor-bomba con iguales características teóricas.

- Cada EB debe contar con un medidor de volumen impulsado (caudalímetro electromagnético o ultrasónico).

- $\quad$ El mantenimiento de las EB debe ser preventivo (política activa).

- Implementar alarmas de nivel en las cámaras húmedas y depósitos receptores (mejor si se instalan válvulas de altitud).

- Instalar sensores de arranque y parada automáticos.

- $\quad$ Aumentar el nivel de automatización en toda la estación de bombeo. 


\section{VOCABULARIO RELACIONADO}

Para una mejor comprensión de los temas aquí presentados será conveniente abordar, brevemente, los conceptos y teorías aplicados en el mismo.

La eficiencia mide el grado de aprovechamiento y uso de los recursos disponibles en las empresas operadoras de sistemas de abastecimiento.

La eficacia, por su parte, indica el grado de cumplimiento de los objetivos trazados por la empresa.

El costo de oportunidad: Es el valor máximo sacrificado alternativo al tomar una decisión económica. Existen varias nociones adicionales que pueden servir:

- El costo alternativo de oportunidad de producir una unidad del bien $\mathrm{X}$, es la cantidad del bien Y que se debe sacrificar para el efecto.

- Valor que representa el desaprovechar una oportunidad.

- Tasa de interés o retorno esperado más alto alternativo al del activo en cuestión. 


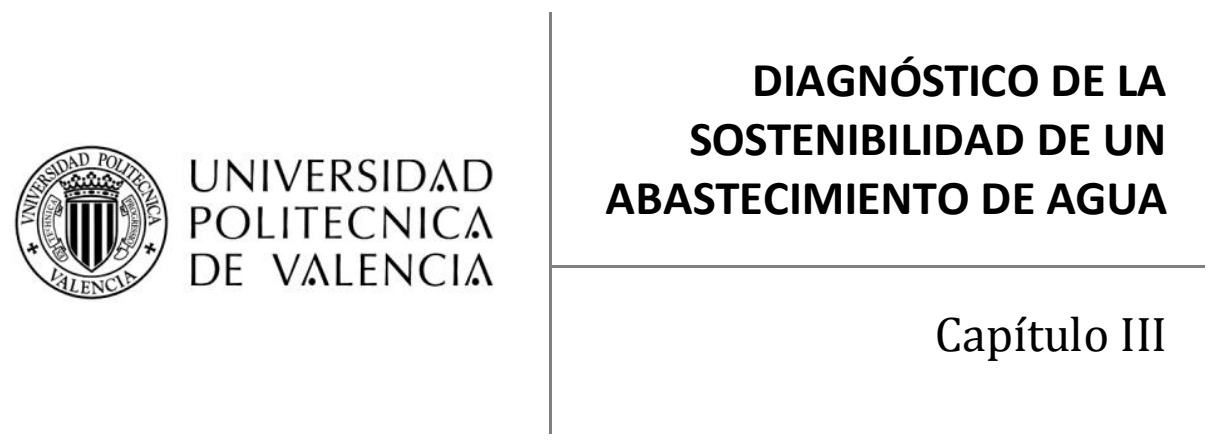





\section{DIAGNÓSTICO DE LA SOSTENIBILIDAD DE UN ABASTECIMIENTO DE AGUA}

El presente capítulo tiene como propósito desarrollar narrativamente el aspecto central de este trabajo; en él se define el Índice de Sostenibilidad de Abastecimiento - ISA; se presenta el método de agregación, que incluye las funciones cuali-cuantitativas de conversión, que permiten pasar de una valoración de indicador a un factor de calidad (isométrico); y, se acompaña las expresiones matemáticas para el cálculo de los indicadores.

Es también objeto de este acápite proponer una caracterización que permita clasificar los abastecimientos según su ISA y posterior trazabilidad para su desagregación.

\subsection{Definición del índice de sostenibilidad de abastecimiento - ISA}

Diagnóstico, en términos generales, es un acto que da a conocer la naturaleza de una situación, necesidad, problema o patología, mediante observación y medida de los indicios reveladores de lo que está sucediendo con apoyo de una valoración de las causas que lo producen. Adaptado de (RAE 2001).

El diagnóstico de un abastecimiento de agua, es un proceso continuo, que se diseña para conocer el estado de sostenibilidad de un sistema de agua, mediante una calificación cuali-cuantitativa que permite establecer sus patologías (administrativas, legales; económicas - de infraestructura; y, ambientales) que son advertidas luego de un análisis comparativo de datos (sociales, económicos y ambientales) con los niveles deseados.

Al término patología se lo interpreta como el conjunto de fenómenos, inconsistencias y no conformidades - en un momento dado - que afectan las condiciones que le dan sostenibilidad a un abastecimiento de agua potable. Una patología requiere de un plan de mejora.

Plan de mejora para un abastecimiento se entiende como el conjunto de acciones e intervenciones recomendadas de forma sistemática para disminuir y hasta eliminar las patologías que afectan a los sistemas de agua. En la ejecución del plan se incluirá las medidas prioritarias - inmediatas, mediatas y de largo plazo -. 


\subsubsection{Acciones que apoyan la búsqueda de la sostenibilidad de un abastecimiento}

Es preciso que los gestores de abastecimientos de agua potable trabajen para elevar su nivel de sostenibilidad permanentemente. Para ello se propone a continuación una variante del ciclo Deming (planificar, hacer, verificar y actuar), que previo a la planificación considere los aspectos de evaluación y diagnóstico, que le permitan conocer al decidor la situación en la cual se encuentra el abastecimiento. En definitiva, gracias a la evaluación y diagnóstico previo poder sentar la línea base de la planificación y toma de decisiones; dicho ciclo de búsqueda de la sostenibilidad se compone de seis fases, según se muestra en la figura siguiente.

Figura 3.1 Ciclo propuesto para la búsqueda de la sostenibilidad de un abastecimiento

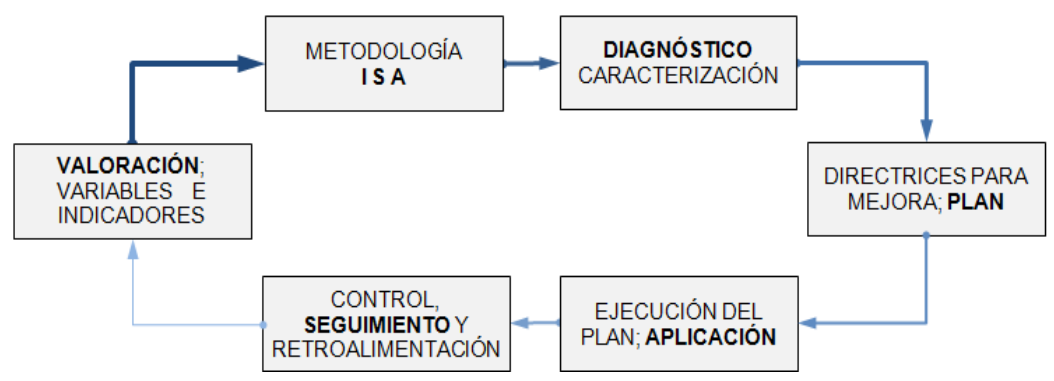

El ciclo aquí propuesto, para la búsqueda de la sostenibilidad de un abastecimiento, inicia por la valoración, que sustenta la línea base del sistema, luego aplicación de la metodología ISA que nos permitirá diagnosticar ó caracterizarlo y tras desagregar este resultado, siguiendo su trazabilidad, identificar las patologías del abastecimiento, para proponer las directrices de mejora. Luego de la fase de ejecución del plan y un estricto seguimiento, se puede valorar el nuevo estado de sostenibilidad -social, económico y ambiental-, y continuar nuevamente con el proceso hasta alcanzar el nivel deseado.

En fases posteriores, cuando se haya conseguido un mejor nivel de sostenibilidad, se deberá entonces ampliar, ajustar, mejorar y reorganizar los indicadores, redistribuir las importancias ponderadas, y afinar las funciones de conversión, que conforman la plataforma de diagnóstico ISA, según las nuevas necesidades que surjan y las que se avizoren. 
Asimismo, se sugiere seleccionar dentro de la empresa, un grupo humano que destaque por su dominio y experiencia en cada aspecto de la sostenibilidad del abastecimiento, para que forme parte activa de este proceso; eso puede significar crear una comisión de sostenibilidad del abastecimiento, apolítica y que sus miembros no sean de libre remoción, entre cuyas tareas principales estará la de velar por cumplir y hacer cumplir el ciclo metodológico para la búsqueda de la sostenibilidad del abastecimiento.

\subsubsection{Valoración}

La valoración se presenta como la primera fase de exploración, en la que se estructura la línea base del sistema según sus aspectos social, económico y ambiental. Para ello el gestor debe recolectar los datos de cada variable que se necesita para el cálculo de los indicadores; y, para dicho acto es recomendable tener presente, además de los criterios que cada empresa haga prevalecer, los siguientes:

- La recopilación y almacenamiento de la información se debe efectuar por un representante o responsable del diagnóstico, pero mejor si se encarga de esta tarea a una comisión plenamente identificada por todos los miembros de la empresa e involucrados en la gestión (directores, ingenieros, administrativos, coordinadores técnicos, personal de campo, etc.).

- La información debe ser completa, verificable y organizada en archivos departamentales de custodio, especialmente adecuado para este proceso.

- $\quad$ El período de registro a tomarse en cuenta en cada diagnóstico será el que la empresa disponga: trimestral, semestral, u otro; no obstante, se recomienda que sean los datos provenientes del último año.

- Se da por descontado, además, que los directivos y decidores políticos, deben destinar (invertir) en recursos adicionales necesarios para el cumplimiento cabal de estas actividades.

La valoración, a más de otorgar la descripción detallada de la línea base del abastecimiento en un momento determinado, permite también, por un lado la agregación de sus indicadores en una sola cifra, y por otro, al término del ciclo, hacer una comparación objetiva y particular del efecto que se consiguió en cada indicador, luego de la aplicación de medidas correctoras en el desempeño de la empresa a lo largo del período analizado. De allí que resulta muy importante poder almacenar correctamente cada evaluación que se practique al sistema de agua, ya que de ello dependerá el ajuste cíclico del derrotero de las directivas generales seleccionadas para la gestión futura. 


\subsubsection{Metodología ISA}

La fase de la agregación o metodología ISA propiamente dicha, brevemente se resume aquí, (no obstante, más adelante se amplía y explica con mayor profundidad).

- La agregación se consigue gracias al hecho de convertir los valores de los indicadores en isométricos y luego afectarlos según sus importancias ponderadas, ambos aspectos, provienen de relaciones y criterios cualitativos (como procesos auxiliares - relativos), recabados de las entrevistas técnicas.

- El valor del indicador conseguido de los datos del gestor (de sus variables), se penaliza en menor o mayor grado, según si este se aproxima más o menos, respectivamente, a unas características de calidad deseadas. Dicha distinción de calidad se consigue con la aplicación de la funciones de conversión.

- Cada indicador, asimismo, está afectado por una importancia ponderada respecto de un todo, que considera el nivel de trascendencia del indicador para contribuir a que el abastecimiento sea sostenible.

- $\quad$ El cálculo del ISA, se consigue de efectuar la sumatoria de los pesos relativos, que se obtienen de multiplicar los valores isométricos de los indicadores (aquí llamados factores de calidad - FC) por su correspondiente importancia ponderada.

- Gracias a la síntesis y agregación en una sola cifra de todas las características que componen el abastecimiento, se puede catalogar el estado de sostenibilidad del mismo.

Se recomienda que todo el proceso de agregación así como sus resultados se los socialice y analice críticamente, con los involucrados en el proceso de diagnóstico.

Figura 3.2 Estructura y convergencia de los componentes ISA

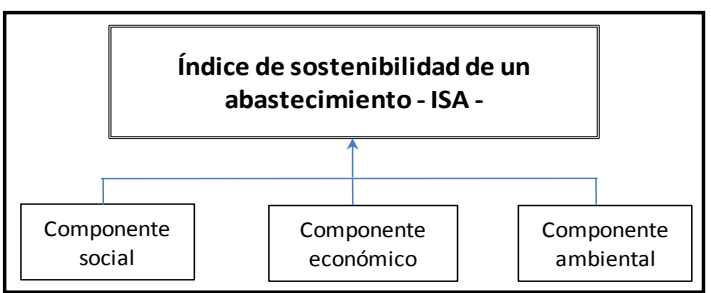




\subsubsection{Diagnóstico y caracterización}

Una vez que se determina el valor del índice de sostenibilidad del abastecimiento -ISA-, se lo compara con una escala de caracterización por rangos predefinida, y se lo clasifica en la escala, según corresponda. Dicha comparación puede atribuirle los siguientes posicionamientos posibles:

$$
\begin{aligned}
& \text { Excelente (de } 100 a>90), \\
& \text { Bueno (de } 90 a>75), \\
& \text { Regular (de } 75 a>60 \text { ), } \\
& \text { Deficiente (de } 60 a>40 \text { ), y } \\
& \text { Malo (de } 40 a>0 \text { ). }
\end{aligned}
$$

- La desagregación de la caracterización resultante (diagnóstico) permite idealizar de mejor manera los criterios para priorizar los problemas y necesidades del sistema según si son: urgentes, importantes u obligatorias.

- $\quad$ Al desagregar el propio del valor del ISA, se detectan y transparentan los elementos (subcomponentes) que le dieron origen y que están afectando el nivel de sostenibilidad y desempeño deseados en el abastecimiento. Los atributos particulares detectados gracias a la trazabilidad del método, muestran la realidad del estado actual de gestión del sistema de agua.

- La manifestación de las patologías mediante valores isométricos comparados con los aspectos deseados, permiten reconocer las mejores acciones -como medidas correctoras-, para orientar y promover la toma de decisiones adecuadas, hacia los nuevos derroteros de la planificación y enfocada a la gestión sostenible.

\subsubsection{Plan}

La planificación estratégica (ó planificación para el manejo corrector de la gestión) nace una vez que se pone de manifiesto visualmente la desagregación del indicador calculado, gracias a los diagramas de tela de araña del ISA y sus componentes satélites). Mas, se debe tomar en cuenta el resultado porcentual de cada subcomponente y luego considerar aquellos de menor valor para delimitar de esta manera las áreas prioritarias de trabajo. 
Es materia de este trabajo, también, adaptar una herramienta (el $A B C$ del planificador de Franklin y comparación por pares) que permita de forma participativa distribuir los subcomponentes o indicadores por su importancia relativa, obligatoriedad y/o urgencia, calificada desde el punto de análisis del grupo involucrado en el diagnóstico junto con los responsables de la planificación para el manejo corrector de la gestión.

Las directrices, y selección de medidas correctoras para la mejora en la organización, deben ser metódicamente analizadas y estructuradas para elevar el estado de sostenibilidad inicial de la empresa. Los supuestos que prevalecen, son:

- Desagregación y análisis del valor del ISA según su proveniencia, desde cada componente, subcomponente $\mathrm{o}$ indicador.

- $\quad$ Las prioridades, luego de la aplicación de la matriz de priorización de subcomponentes (explicada más adelante), son seleccionadas mediante valoraciones participativas de expertos.

- Las mejoras para ser viables deben cumplir con las características sociales, legales, técnicas, económicas, financieras y ambientales del entorno.

- $\quad$ Se trazan claramente los resultados esperados luego de la solución de los problemas y necesidades.

- El tiempo de ejecución planificado, obedece a plazos prudenciales, reales y racionales.

- Las acciones dentro del ciclo de mejora de la sostenibilidad se agrupan por planes anuales y quinquenales.

- La planificación sigue la trayectoria de sostenibilidad deseada y se ajusta según corresponda, de forma cíclica.

\subsubsection{Ejecución}

Los aspectos inherentes a la ejecución y seguimiento del plan, son tareas que dependen de forma exclusiva del grado de compromiso y recursos que cada empresa y gestor le quiera y pueda destinar. 
Es así que, la aplicación del plan debe cumplir plenamente con los objetivos que se plantearon en la fase anterior (planificación para el manejo corrector de la gestión). La etapa de ejecución permite plasmar la proyección deseada y pone en marcha la gestión de la empresa hacia la sostenibilidad, según las prioridades detectadas. Los supuestos en esta fase son:

- Los presupuestos y plazos son cumplidos según el plan de acciones para la mejora.

- Los rubros son ejecutados con los rendimientos recomendados y no existen desfases de ningún tipo.

- $\quad$ La comisión de sostenibilidad, supervisa la adecuada aplicación del plan, bajo funciones de fiscalización.

- Los escenarios políticos de la empresa y del gobierno no interfieren en la ejecución.

\subsubsection{Seguimiento}

El control de la aplicación de medidas de mejora del desempeño y el cumplimiento del plan debe ser minuciosamente atendido por la comisión de sostenibilidad, con el ánimo de que contribuya a seguir el rumbo trazado y recomiende las mejores prácticas de retroalimentación.

Los supuestos planteados para esta fase son:

- $\quad$ La comisión de sostenibilidad mide los logros alcanzados, los compara con el estado de situación inicial y aconseja los ajustes pertinentes.

- $\quad$ Se pone todos los medios y recursos para facilitar y agilitar, en los plazos establecidos, la consecución de los niveles de seguimiento de los procesos que encaminarán la empresa hacia la sostenibilidad.

Una vez cumplidas las seis fases del ciclo propuesto, es pertinente volver a medir el nuevo estado de sostenibilidad alcanzado y con base en ello reiniciar un nuevo ciclo hacia la sostenibilidad. Se recomienda pensar en actividades sostenibles que conduzcan a gestionar "cada vez mejor que antes" el sistema de agua, eso puede requerir de un análisis crítico de los indicadores utilizados (bien se pueden aumentar ó eliminar algunos ó crear otros), re-examinar la fuente de información, contrastar y verificar datos de campo, o hacer una redistribución de importancias ponderadas $y / 0$ ajustar las funciones de conversión. 


\subsection{Componentes cualitativos de la metodología ISA}

\subsubsection{Entrevistas técnicas guiadas}

Para los aspectos cualitativos, que estructuran buena parte del presente trabajo, se tomó como instrumento para recolección de información de expertos y experiencias de los involucrados en la gestión de sistemas de abastecimiento, las entrevistas técnicas personales ó también denominadas entrevistas Delphi. Esta herramienta, permite recabar y agrupar parte de la memoria colectiva, relacionada con un tema en específico; en nuestro caso la gestión de abastecimientos urbanos-.

El proceso de aplicación se esquematiza de la siguiente manera:

Figura 3.3 Esquema del proceso de entrevistas técnicas

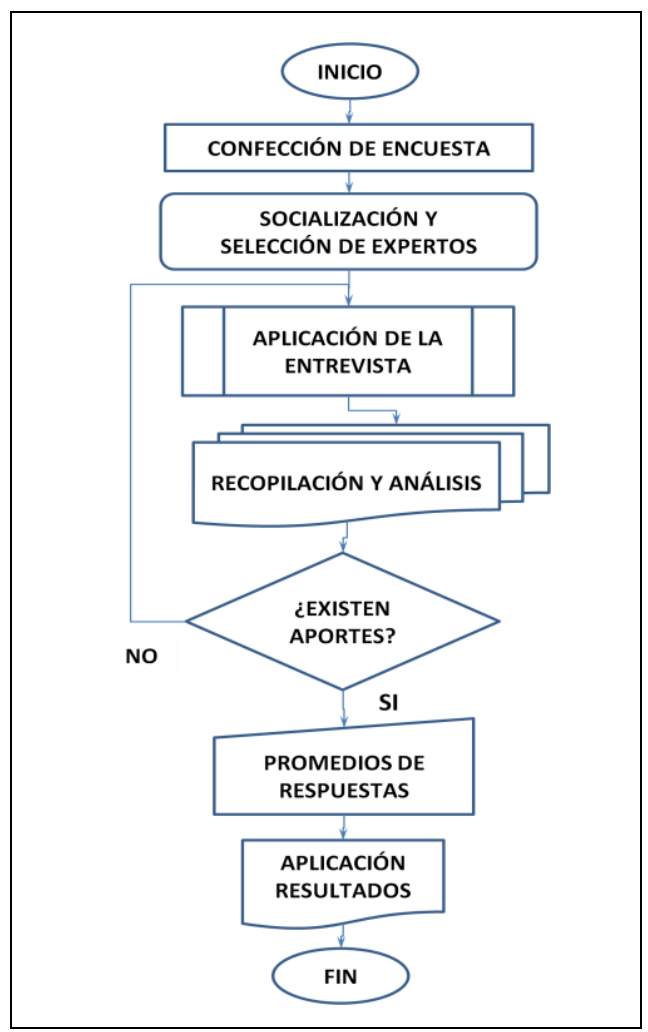


El proceso inicia con organizar los aspectos significativos que conformarán el guión de la entrevista (la parrilla básica de los indicadores y la escala de calidad, para nuestro caso), el paso siguiente es la socialización del tema con cada técnico y gestor involucrado, al tiempo que se efectúa la selección de expertos -aquellos que por su conocimiento y experiencia puedan aportar significativamente para los intereses del estudio-.

A los expertos seleccionados, se les aplica la entrevista, (se obtendrán mejores resultados si se lo hace de forma directa y explicativa en cada aspecto que lo requiera). Luego, una vez que se cuente con los resultados de la entrevista, se los promedia y posteriormente se las utiliza según corresponda.

Cuando el nivel de conocimiento y experiencia difiere significativamente entre los expertos consultados, se puede ponderar sus respuestas por pesos que reflejen esas brechas de conocimiento; lo cual no es nuestro caso.

Las importancias ponderadas que se presentan en este estudio, fueron el resultado de la aplicación de entrevistas técnicas (Delphi) a doce involucrados en la gestión de abastecimientos urbanos del entorno; de ellos, el $67 \%$ concedieron su participación para la creación de las funciones de conversión.

\subsubsection{Importancias ponderadas}

Para la distribución de importancias ponderadas se presentó la parrilla con los 49 indicadores, agrupados en 15 subcomponentes y estos a su vez en 3 componentes.

El componente social cuenta con 16 indicadores distribuidos en 6 subcomponentes, el componente económico cuenta con 22 indicadores agrupados en 5 subcomponentes; y, el componente ambiental lo conforman 12 indicadores reunidos en 4 subcomponentes.

Los criterios de distribución aritmética que se plantearon, para direccionar de forma general la distribución de importancias, fueron las siguientes:

- El valor que se asigne a cada indicador, debe ser aquel que responda a la pregunta:

Según su experiencia y conocimiento, ¿cuánto peso tiene este indicador respecto del total (100) para alcanzar la sostenibilidad del abastecimiento?

- La suma de cada uno de los tres componentes, debe ser un tercio del total; esto significa, un valor de 33.3 para los componentes social y 
ambiental, y un valor de 33.4 para el económico. Es decir que la suma total debe dar un valor de 100.

- La suma de los valores asignados a los indicadores, conforman el valor del subcomponente al cual pertenecen.

- Los valores se deben escribir con una cifra decimal.

- $\quad$ No se admiten ni valores negativos, ni nulos.

El resultado que se obtuvo del procedimiento Delphi para la distribución de importancias ponderadas se presenta en el cuadro siguiente:

Cuadro 3.1 Importancias ponderadas (IP)

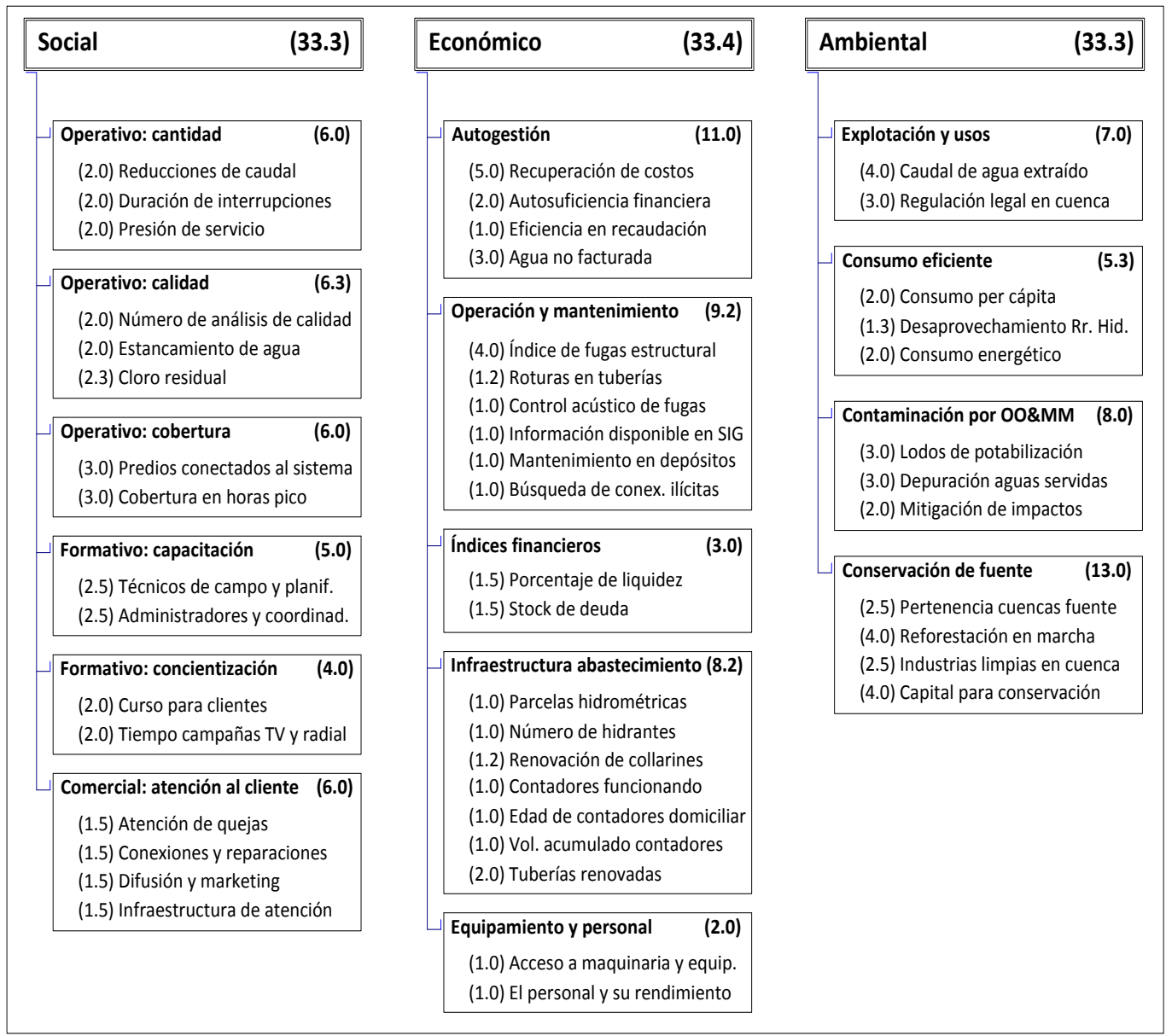




\subsubsection{Funciones de conversión}

Las funciones de conversión de indicadores a factores de calidad se construyeron a partir de pares coordenados, según los siguientes criterios generales:

- El valor que se asignen a cada par coordenado (como cifra de penalización), debe ser aquel que responda a las preguntas:

¿Qué valor del indicador en cuestión le corresponde una calidad máxima de 1.0 ?

¿Qué valor del indicador en cuestión le corresponde una calidad de 0.8?

¿Qué valor del indicador en cuestión le corresponde una calidad mínima considerada de 0.0?

- Los valores se deben escribir con una cifra decimal.

- No se admiten valores negativos.

Figura 3.4 Esquema de la distribución de valoraciones

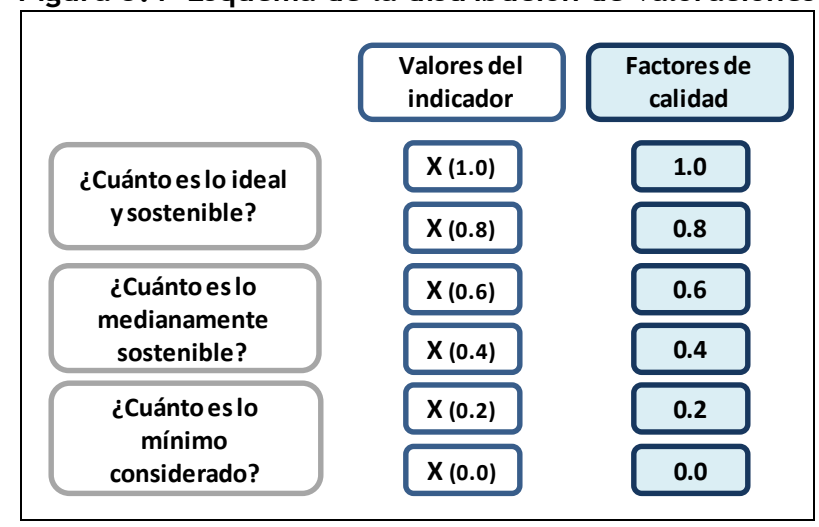

Cada función de conversión fue referida a: normas, literatura técnica relacionada, algunos conceptos económicos del Banco del Estado (Ecuador), criterios y experiencias del propio gestor, apuntes personales del autor; y, 
comparadas con situaciones deseables, casi "idílicas" para los abastecimientos de agua del entorno.

Una vez que se obtuvo los valores medios -por cada indicador-, se dibujaron esos puntos en un sistema coordenado $(\mathrm{X}-\mathrm{Y})$, luego por tanteos se ajustaron los pares de datos, hasta conseguir que la función resultante adquiera una tendencia lo más próxima a la obtenida por alguno de los tipos de regresión (exponencial, lineal, logarítmica, polinómica o potencial), tal que su coeficiente de correlación $\left(\mathrm{R}^{2}\right)$ sea uno.

El resultado de este proceso, se presenta a continuación, en el que se describen las funciones de conversión para cada indicador (junto con sus variables) del presente caso de diagnóstico de la sostenibilidad de abastecimientos.

1) Indicadores y funciones de conversión relacionados con la sostenibilidad económica de un abastecimiento

i) Subcomponente: recuperación de cotos

- $\quad$ Porcentaje de recuperación de costos, mediante cobro de facturación por año

RecCsts $=\frac{\operatorname{In}_{\mathrm{FACT}}}{\text { Csts }} \times 100$

Csts $=$ Gcorr + Gcapit + InvOOPP + Serv $\cdot$ Deuda

[Ec. 3.2]

Donde:

$\begin{array}{lll}\ln _{\text {FACT }} & - & \text { Ingresos por facturación (propios) (\$/año) } \\ \text { Csts }_{j} & - & \text { Costos totales (\$/año) } \\ \text { Gcorr } & - & \text { Gastos corrientes (\$/año) } \\ \text { Gcapit } & - & \text { Gastos de capital }(\$ / a n ̃ o) \\ \text { InvOOPP } & - & \text { Inversiones en obra pública }(\$ / a n ̃ o) \\ \text { ServDeuda- } & \text { Servicio de la deuda }(\$ / a n ̃ o)\end{array}$


Los gastos corrientes incluyen: remuneraciones, intereses de deuda pagados, servicios, suministro, logística y materiales, transferencias e imprevistos.

Los gastos de capital son los gastos por bienes muebles e inmuebles.

La inversión en obra pública, representan todos los gastos de infraestructura civil.

Los servicios de deuda, incluyen la amortización de la deuda pública.

La función de conversión del porcentaje de recuperación de costos a factor de calidad es:

$$
\mathrm{FC}_{\text {RecCsts }}=\left(1.313 \times 10^{-4} \times(\text { RecCsts })^{2}\right)-(0.00477 \times \text { RecCsts })+0.0543 \quad \text { [Ec. 3.3] }
$$

Gráfico 3.1 Curva de conversión para: \% recuperación de costos

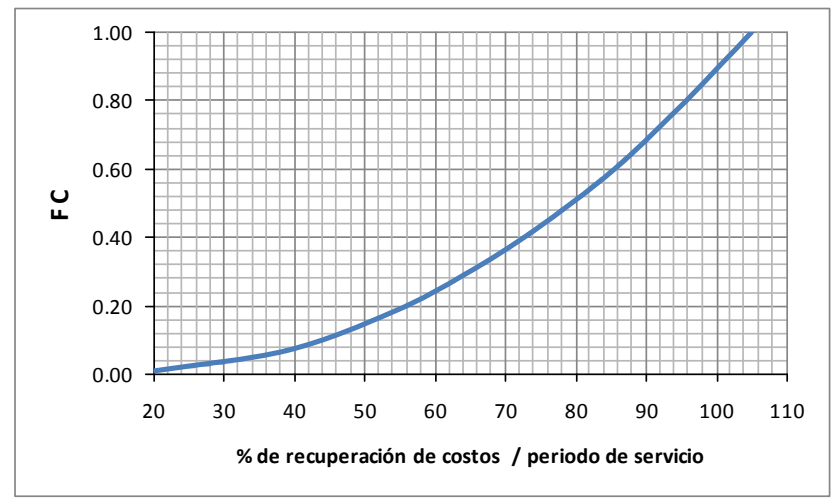

- Porcentaje de autosuficiencia financiera anual

$$
\mathrm{ASuFi}=\frac{\mathrm{In}_{\mathrm{FACT}}}{\mathrm{Gcorr}} \times 100
$$

Los gastos corrientes son el resultado de la suma de los pagos que la empresa efectúa por: remuneraciones, intereses de deuda, servicios, suministro, logística y materiales, transferencias e imprevistos. 
La función de conversión del porcentaje de autosuficiencia financiera a factor de calidad es:

$$
\mathrm{FC}_{\mathrm{ASuFi}}=\left(-1.275 \times 10^{-4} \times(\mathrm{ASuFi})^{2}\right)+(0.0277 \times \mathrm{ASuFi})-0.4955 \quad[\mathrm{Ec} .3 .5]
$$

Gráfico 3.2 Curva de conversión para: \% autosuficiencia financiera

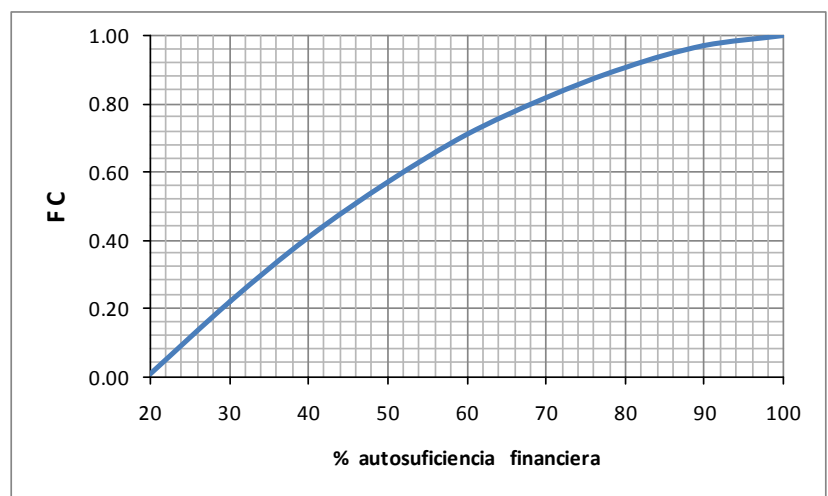

- $\quad$ Porcentaje de eficiencia en recaudación anual

$$
\mathrm{EfRec}=\frac{\mathrm{Rec}}{\mathrm{Emi}} \times 100
$$

Donde:

$$
\begin{array}{lll}
\text { Rec } & - & \text { Recaudación }(\$ / a n ̃ o) \\
\text { Emi } & - & \text { Emisión }(\$ / a n ̃ o)
\end{array}
$$

La función de conversión del porcentaje de eficiencia en la recaudación a factor de calidad es:

$$
\mathrm{FC}_{\text {EfRec }}=0.0356 \times \mathrm{e}^{(0.03338 \times(\mathrm{EfRec}))}
$$


Gráfico 3.3 Curva de conversión para: \% eficiencia en la recaudación

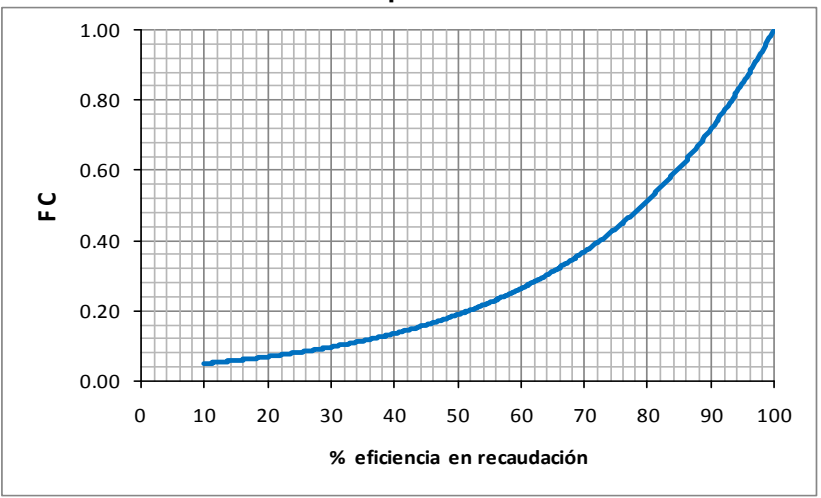

- $\quad$ Porcentaje de agua no facturada por año

$$
\mathrm{ANF}=\left(1-\frac{\mathrm{W}_{\mathrm{FAC}}}{\mathrm{w}_{\mathrm{IN}}}\right) \times 100
$$

Donde:

$$
\begin{array}{lll}
W_{F A C} & - & \text { Volumen de agua facturada }\left(\mathrm{m}^{3} / \mathrm{año}\right) \\
W_{I N} & - & \text { Volumen de agua producida }\left(\mathrm{m}^{3} / \mathrm{año}\right)
\end{array}
$$

La función de conversión del porcentaje de agua no facturada a factor de calidad es:

$$
\mathrm{FC}_{\mathrm{ANF}}=1.26714 \times \mathrm{e}^{(-0.0431 \times(\mathrm{ANF}))}
$$

Gráfico 3.4 Curva de conversión para: \% de agua no facturada

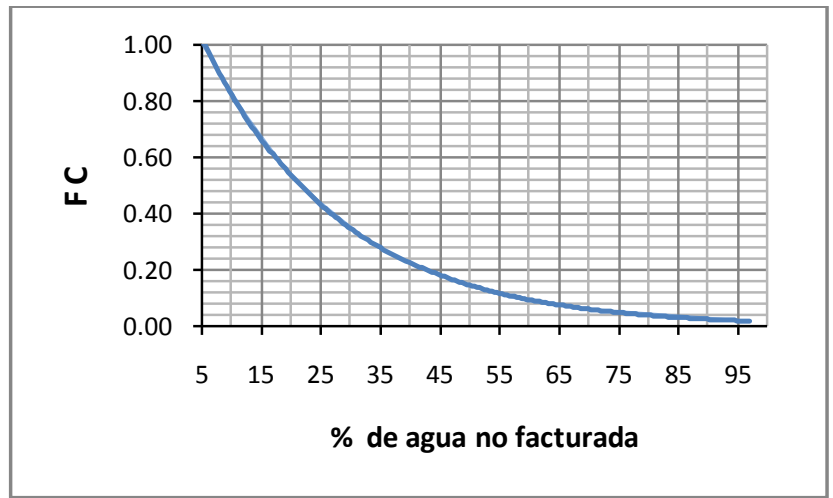


ii) Subcomponente: operación y mantenimiento

- $\quad$ Índice de fugas estructural

$$
\mathrm{IFE}=\frac{\mathrm{VIF}}{\mathrm{UMF}}
$$

Donde:
VIF (Ec. 1.22), Volumen incontrolado fugado (L/acom/día)
UMF - (Ec. 1.23), Umbral mínimo de fugas (L/acom/día)

La función de conversión del índice de fugas estructural a factor de calidad es:

$$
\mathrm{FC}_{\mathrm{IFE}}=2.524 \mathrm{E}-03 \times(\mathrm{IFE})^{2}-0.1091 \times(\mathrm{IFE})+1.107
$$

Gráfico 3.5 Curva de conversión para: índice de fugas estructural

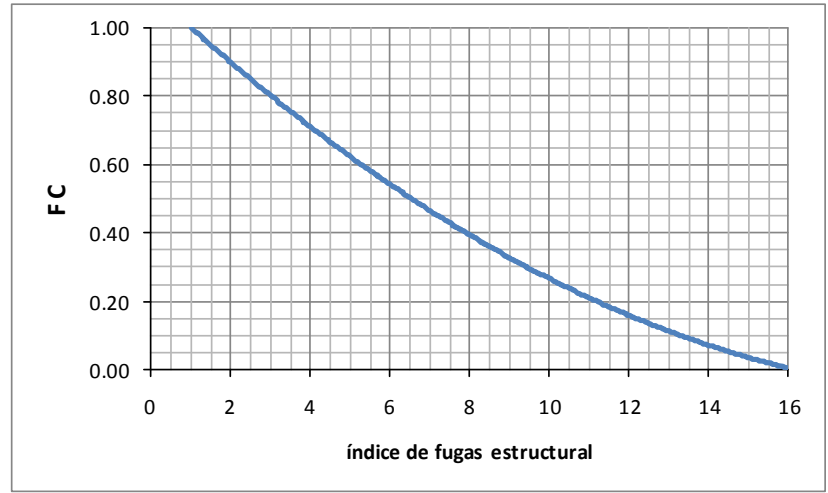

- $\quad$ Número de roturas por longitud de tubería, por año

$$
\mathrm{NRot} A=\frac{\text { Rot }}{\text { Ltub }}
$$

Donde:

Rot - Número de roturas (fallos) por año

Ltub - Longitud total de tubería $(\mathrm{km})$ 
La función de conversión del número de roturas por año a factor de calidad es:

$$
\mathrm{FC}_{\mathrm{NRotA}}=-0.2524 \times \ln (\mathrm{NRot} \mathrm{A})+0.5912
$$

Gráfico 3.6 Curva de conversión para: número de roturas por km por año

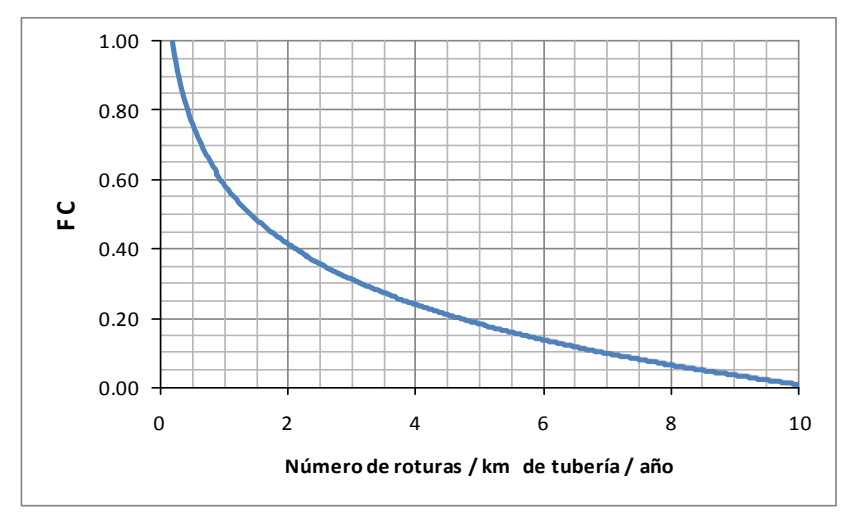

- Número de inspecciones acústicas a la red para control de fugas / año

$$
\mathrm{NAcu}=\frac{\text { InsAcu }}{\text { Ltub }}
$$

Donde:
InsAcu
Longitud de red que se inspecciona con equipo
acústico para control de fugas en km por año
Ltub - $\quad$ Longitud total de tubería $(\mathrm{km})$

La función de conversión del número de inspecciones acústicas para detección de fugas en la red por año a factor de calidad es:

$$
\mathrm{FC}_{\mathrm{NAcu}}=-0.5349 \times(\mathrm{NAcu})^{2}+1.5367 \times(\mathrm{NAcu})-0.0021
$$


Gráfico 3.7 Curva de conversión para: número de inspecciones acústicas a la red para control de fugas por año

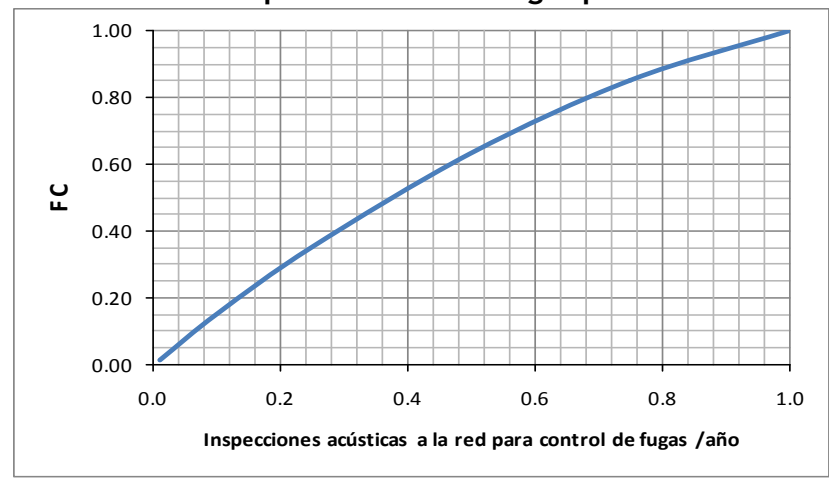

- $\quad$ Porcentaje de información del abastecimiento disponible en una base de datos informática - SIG.

$$
\text { SIG }=50 \times\left(\frac{\text { Ling }}{\text { Ltub }}+\frac{\text { Nclin }}{\text { CliT }}\right)
$$

Donde:
Ling $\quad$ - $\quad$ Longitud de red ingresada al SIG $(\mathrm{km})$
Ltub - $\quad$ Longitud total de tubería $(\mathrm{km})$
Nclin - $\quad$ Acometidas con información comercial, en SIG
CliT - Acometidas totales

La función de conversión del porcentaje de información del abastecimiento disponible en una base de datos informática - SIG a factor de calidad es:

$$
\mathrm{FC}_{\mathrm{SIG}}=-6 \times 10^{-5} \times(\mathrm{SIG})^{2}+0.0156 \times(\mathrm{SIG})-0.0071 \quad \text { [Ec. 3.16] }
$$

Gráfico 3.8 Curva de conversión para: porcentaje de información del abastecimiento disponible en una base de datos informática - SIG

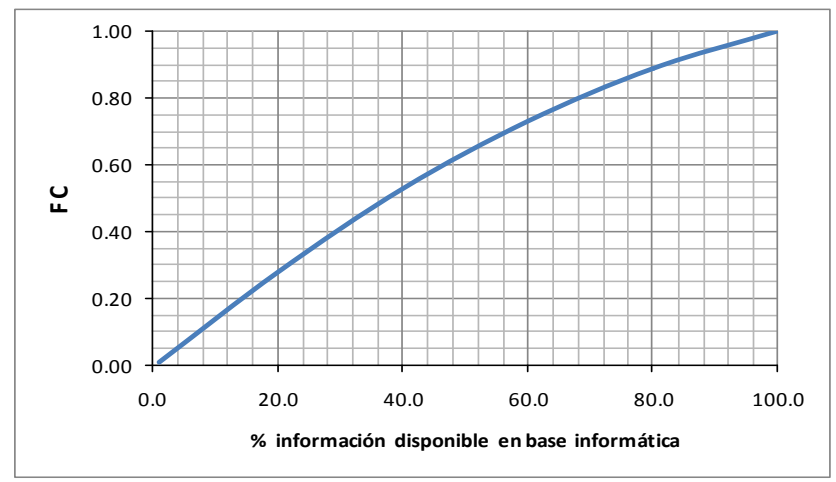


- Porcentaje de superficie interior de depósitos que son impermeabilizados y con mantenimiento por año

$$
\mathrm{DEPm}=\frac{\text { Suint }}{\text { SuTot }} \times 100
$$

Donde:

Su int - Superficie interior de depósito impermeabilizada y con mantenimiento por año $\left(\mathrm{m}^{2}\right)$

Su Tot - Superficie total interior de depósitos $\left(\mathrm{m}^{2}\right)$

La función de conversión del porcentaje de superficie interior de depósitos que son impermeabilizados y con mantenimiento por año a factor de calidad es:

$$
\mathrm{FC}_{\mathrm{DEPm}}=6 \times 10^{-5} \times(\mathrm{DEPm})^{2}+0.0035 \times(\mathrm{DEPm})+0.0087
$$

Gráfico 3.9 Curva de conversión para: superficie interior de depósitos que son impermeabilizados y con mantenimiento por año

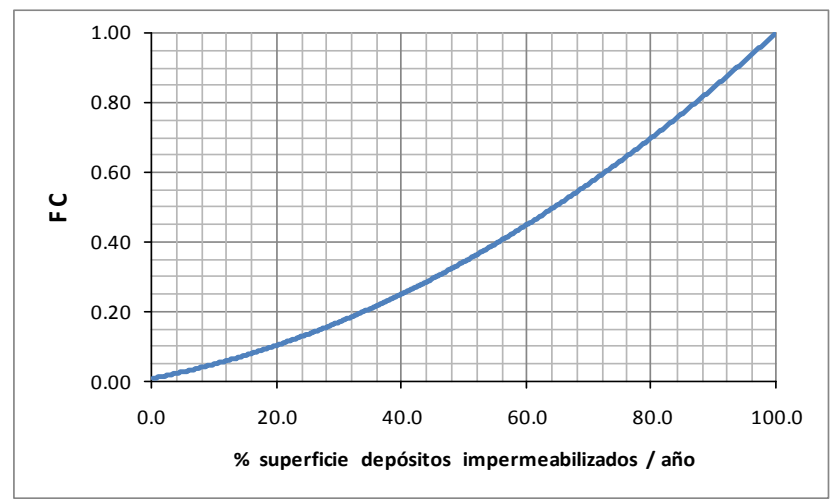

- Búsqueda de conexiones ilegales (acústica y visual) en porcentaje de tuberías de la red por año

$$
\text { Xil }=\frac{\text { Lxi }}{\text { Ltub }} \times 100
$$

Donde: 
Lxi - $\quad$ - Longitud de red en la que se aplica búsqueda de conexiones ilegales (visual y acústica) por año (en $\mathrm{km})$

La función de conversión del porcentaje de tuberías de la red que se buscan conexiones ilegales (acústica y visual) por año a factor de calidad es:

$$
\mathrm{FC}_{\mathrm{Xil}}=0.01 \times(\mathrm{Xil})
$$

Gráfico 3.10 Curva de conversión para: porcentaje de tuberías de la red que se buscan conexiones ilegales (acústica y visual) por año

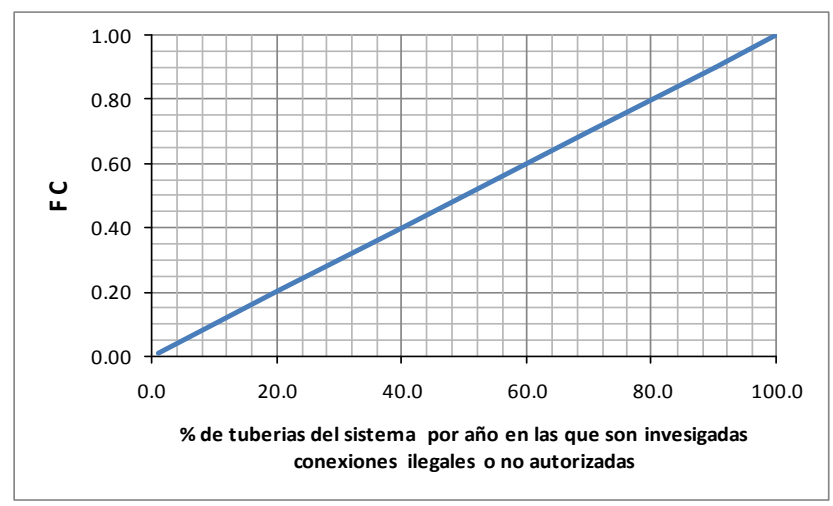

iii) Subcomponente: índices financieros

- $\quad$ Porcentaje de liquidez

$$
\text { Liq }=\frac{\text { ICorr }}{\text { Gcorr }} \times 100
$$

Donde:

ICorr - Ingresos corrientes (\$/año)

Los ingresos corrientes son los ingresos por venta de agua más ingresos por transferencias corrientes: del FODESEC (fondo de desarrollo seccional) más un bono por eficiencia y el $15 \%$ de transferencia corriente por gobiernos seccionales. 
La función de conversión del porcentaje de liquidez a factor de calidad es:

$$
\mathrm{FC}_{\text {Liq }}=0.01981 \times \mathrm{e}^{(0.03923 \times(\mathrm{Liq}))}
$$

\section{Gráfico 3.11 Curva de conversión para: porcentaje de liquidez}

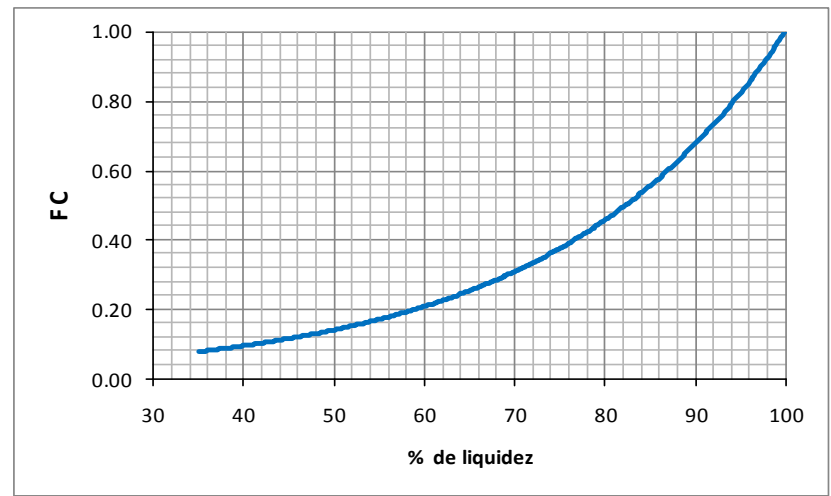

- $\quad$ Porcentaje del stock de deuda (se entiende también como el nivel de endeudamiento de la empresa).

$$
\begin{aligned}
& \text { StockD }=\frac{\text { PasT }}{(\text { ITot }- \text { FF })} \times 100 \\
& \text { ITot }=\text { ICorr }+ \text { ICap } \\
& \text { FF }=\text { CrePub }+ \text { SalCa }
\end{aligned}
$$

Donde:

$\begin{array}{lll}\text { PasT } & - & \text { Pasivo total }(\$) \\ \text { ITot } & - & \text { Ingreso total }(\$) \\ \text { FF } & - & \text { Fuente de financiamiento }(\$) \\ \text { CrePub } & - & \text { Crédito público }(\$) \\ \text { SalCa } & - & \text { Saldo de caja }(\$) \\ \text { ICap } & - & \text { Ingreso de capital }(\$)\end{array}$

Los ingresos de capital corresponden a la sumatoria de transferencias por donación del impuesto a la renta, $5 \%$ de venta de energía eléctrica, $10 \%$ de ingresos por llamadas telefónicas, fondos de desarrollo provincial, entre otros. 
La función de conversión del porcentaje del stock de deuda a factor de calidad es:

$$
\mathrm{FC}_{\text {StockD }}=0.00022 \times(\text { StockD })^{2}+0.0138 \times(\text { StockD })+0.7805 \quad[\text { Ec. 3.26] }
$$

Gráfico 3.12 Curva de conversión para: porcentaje del stock de deuda

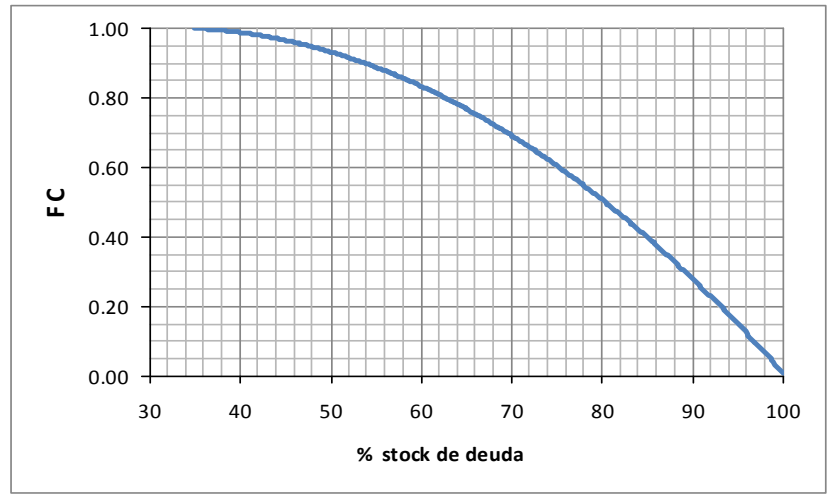

Para niveles de endeudamiento inferiores que $40 \%$ se considerará el factor de calidad igual a 1.

iv) Subcomponente: infraestructura del abastecimiento

- Número de parcelas hidrométricas *(Anexo ${ }^{3.1)}$ (subsectores o distritos hidrométricos) por cada 10000 conexiones

$$
\mathrm{NH}_{\mathrm{d}}=\frac{\text { PHid }}{\text { CliT }} \times 10000
$$

Donde:

PHid - Parcelas hidrométricas en distribución

La función de conversión del número de parcelas hidrométricas por cada 10000 clientes a factor de calidad es:

$$
\begin{aligned}
\mathrm{FC}_{\mathrm{NH}_{\mathrm{d}}} & =0.0043 \times\left(\mathrm{NH}_{\mathrm{d}}\right)^{3}-0.0876 \times\left(\mathrm{NH}_{\mathrm{d}}\right)^{2}+0.6160 \times\left(\mathrm{NH}_{\mathrm{d}}\right)-0.5211 \quad \text { [Ec. 3.28] } \\
& \forall 1.0 \leq\left(\mathrm{NH}_{\mathrm{d}}\right) \leq 8.0
\end{aligned}
$$


Gráfico 3.13 Curva de conversión para: número de parcelas hidrométricas por cada 10000 clientes

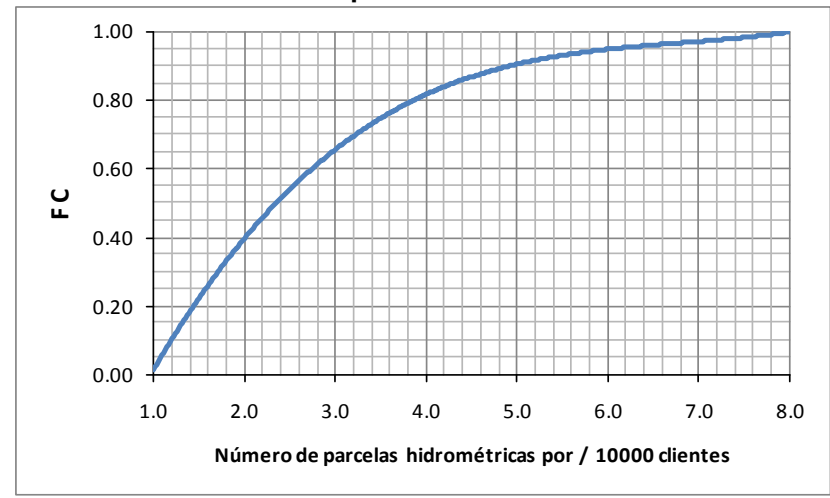

- $\quad$ Número de hidrantes contra incendios funcionando por km de tubería de distribución

Nhidra $=\frac{\text { hidra }}{\text { LTub }}$

Donde:

hidra - Número de hidrantes contra incendios funcionando

La función de conversión del número de hidrantes contra incendios funcionando por km de tubería de distribución a factor de calidad es:

$\mathrm{FC}_{\text {Nhidra }}=0.39943 \times($ Nhidra $)+0.00105$

[Ec. 3.30]

Gráfico 3.14 Curva de conversión para: número de hidrantes contra incendios funcionando por $\mathrm{km}$ de tubería de distribución

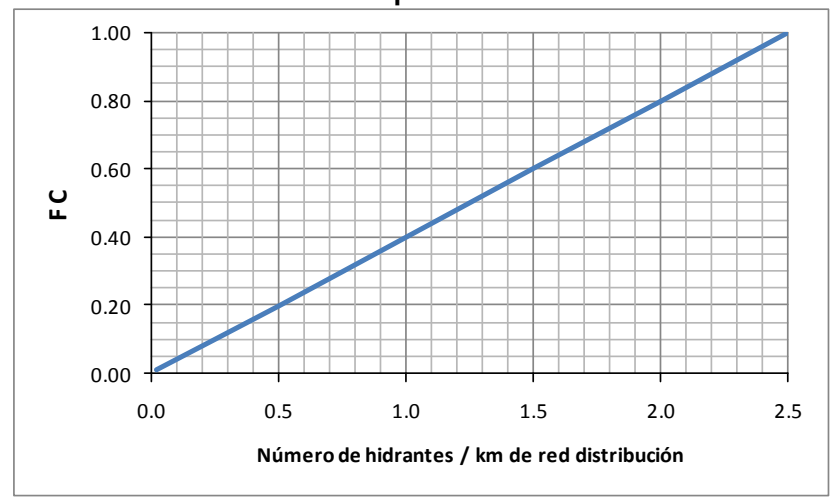


- $\quad$ Porcentaje de renovación de collarines de acometida por año

$$
\text { Coll }=\frac{\text { Ncollar }}{\text { TotColl }} \times 100
$$

Donde:
Ncollar - Número de collarines renovados por año
TotColl - Total de collarines del abastecimiento

La función de conversión del porcentaje de renovación de collarines de acometida por año a factor de calidad es:

$$
\mathrm{FC}_{\mathrm{Coll}}=-0.0247 \times(\mathrm{Coll})^{2}+0.3229 \times(\text { Coll })+0.0029 \quad \text { [Ec. 3.32] }
$$

Gráfico 3.15 Curva de conversión para: porcentaje de renovación de collarines de acometida por año

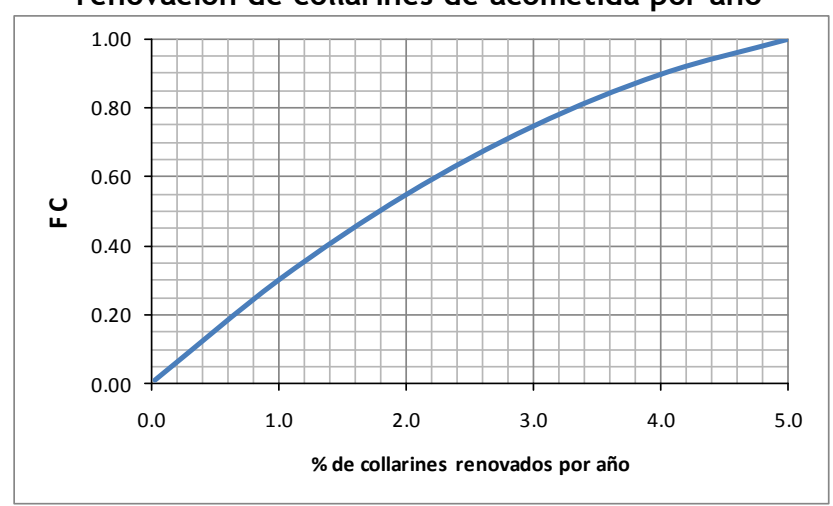

- $\quad$ Porcentaje de contadores domiciliares funcionando

$$
\operatorname{Cont}_{\mathrm{FUN}}=\frac{\mathrm{NCon}_{(\mathrm{FUN})}}{\text { TotCont }} \times 100
$$

Donde:

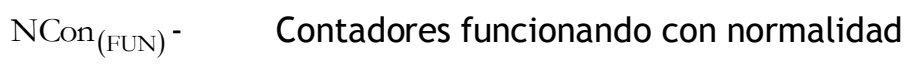

TotCont - Total de contadores instalados en el abastecimiento 
La función de conversión del porcentaje de contadores domiciliares funcionando a factor de calidad es:

$$
\mathrm{FC}_{\mathrm{Cont}_{\mathrm{FUN}}}=2.90346 \mathrm{E}-02 \times \mathrm{e}^{0.035401 \times\left(\text { Cont }_{\mathrm{FUN}}\right)}
$$

Gráfico 3.16 Curva de conversión para: porcentaje de contadores domiciliares funcionando

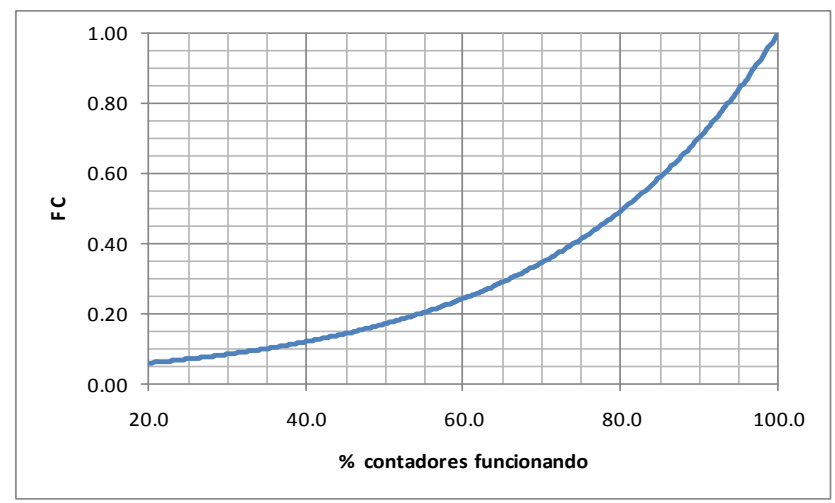

- Porcentaje de contadores domiciliares con más de 8 años de instalación

$$
\operatorname{Cont}_{\text {EDAD }}=\frac{\operatorname{NCon}_{(\geq 8)}}{\text { TotCont }} \times 100
$$

Donde:

$$
\begin{array}{ll}
\operatorname{NCon}_{(\geq 8)}- & \text { Contadores con } 8 \text { años o más de instalación } \\
\text { TotCont - } & \text { Total de contadores instalados en el abastecimiento }
\end{array}
$$

La función de conversión del porcentaje de contadores domiciliares con más de 8 años de instalación a factor de calidad es:

$$
\mathrm{FC}_{\text {Cont }_{\mathrm{EDAD}}}=-0.2436 \times \ln \left(\operatorname{Cont}_{\mathrm{EDAD}}\right)+0.9674
$$


Gráfico 3.17 Curva de conversión para: porcentaje de contadores domiciliares con más de 8 años de instalación

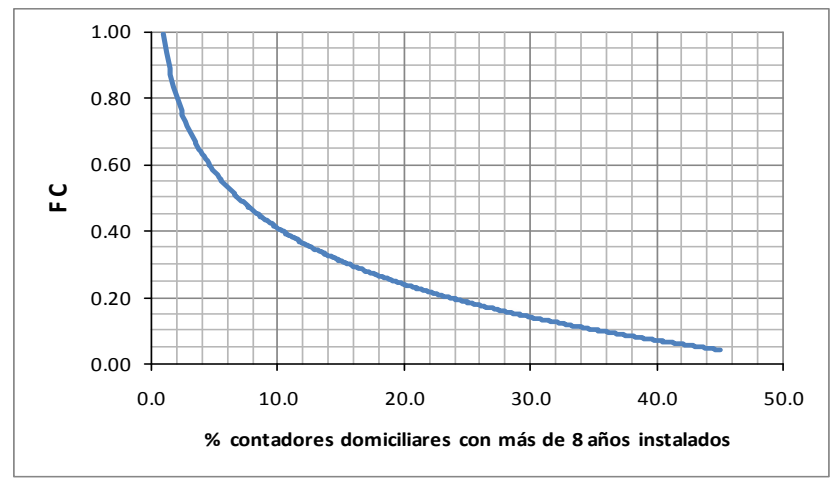

- $\quad \%$ de contadores domiciliares cuyas lecturas superan los $4000 \mathrm{~m}^{3}$

$$
\text { Cont }_{\mathrm{VOL}}=\frac{\mathrm{NCon}(\mathrm{w} \geq 4000)}{\text { TotCont }} \times 100
$$

Donde:

$\mathrm{NCon}(\mathrm{w} \geq 4000)^{-} \quad$ Contadores con volumen registrado mayor a $4000 \mathrm{~m}^{3}$

TotCont - Total de contadores instalados en el abastecimiento

La función de conversión del porcentaje de contadores domiciliares cuyas lecturas superan los $4000 \mathrm{~m}^{3}$ a factor de calidad es:

$\mathrm{FC}_{\text {Cont }_{\mathrm{EDAD}}}=-0.2436 \times \ln \left(\mathrm{Cont}_{\mathrm{VOL}}\right)+0.9674$

Gráfico 3.18 Curva de conversión para: porcentaje de contadores domiciliares cuyas lecturas superan los $4000 \mathrm{~m}^{3}$

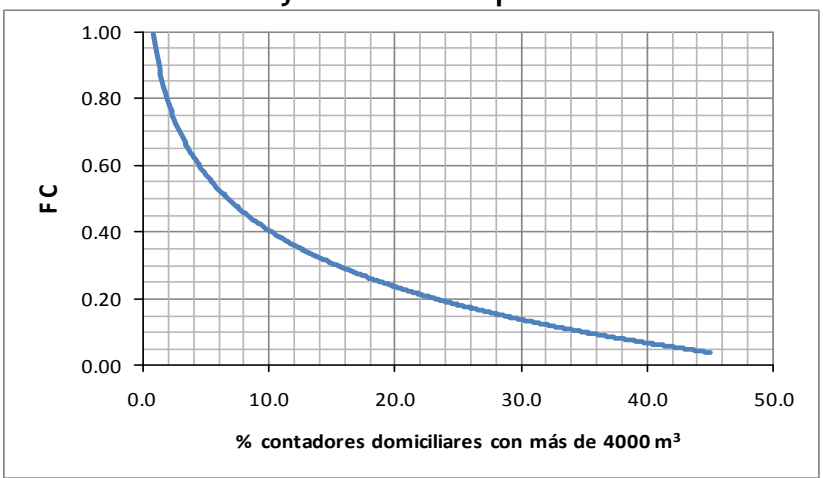


- $\quad$ Porcentaje de tuberías renovadas por año

$$
\text { TubR }=\frac{\text { LTubR }}{\text { LTub }} \times 100
$$

Donde:

LTubR - Longitud de tubería renovada ( $\mathrm{km} / \mathrm{año})$

La función de conversión del porcentaje de tuberías renovadas por año a factor de calidad es:

$$
\mathrm{FC}_{\text {TubR }}=-0.1355 \times(\text { TubR })^{2}+0.7356 \times(\text { TubR })+0.0047
$$

Gráfico 3.19 Curva de conversión para: porcentaje de tuberías renovadas por año

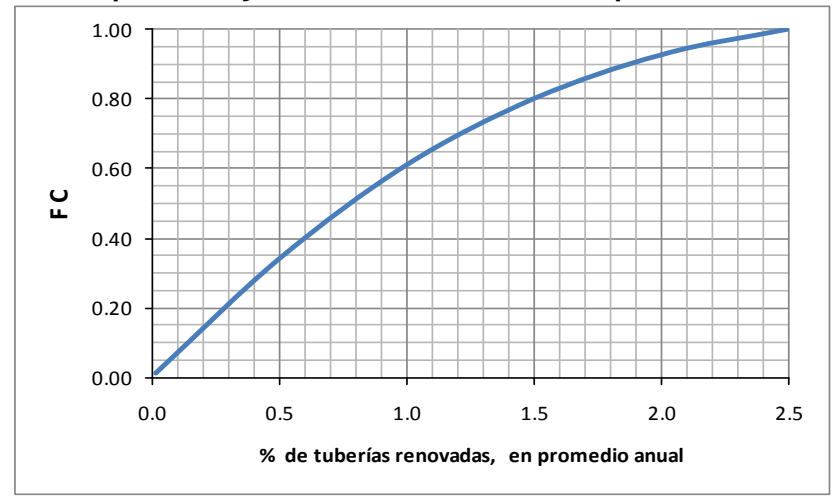

v) Subcomponente: equipamiento y personal

- $\quad$ Porcentaje de maquinaria y equipo financiados (horas / mes) para OO\&MM

$$
\mathrm{AcM}=\frac{\operatorname{AccM}_{\mathrm{OO \& MM}}}{\mathrm{MNec}_{\mathrm{OO \& MM}}} \times 100
$$

Donde:

AccM oоємм - Maquinaria y equipo financiada para OO\&MM (h/mes) MNec oоємм - Maquinaria y equipo necesaria óptima para OO\&MM (h/mes) 
La función de conversión del porcentaje de maquinaria y equipo accesible financiada (horas / mes) para OO\&MM a factor de calidad es:

$$
\mathrm{FC}_{\mathrm{AcM}}=\left(0.08 \times(\mathrm{AcM})^{2}+1.78 \times(\mathrm{AcM})+10.10\right) \times 10^{-3} \quad \text { [Ec. 3.42] }
$$

Gráfico 3.20 Curva de conversión para: porcentaje de maquinaria y equipo financiada (horas / mes) para OO\&MM

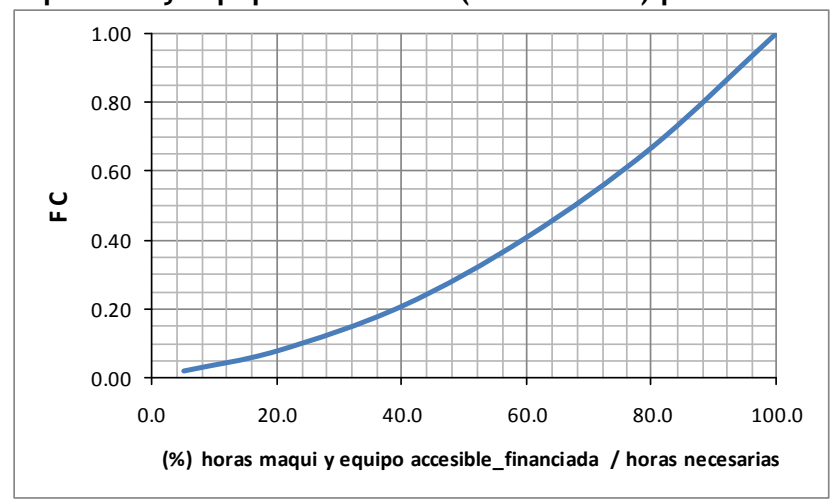

- $\quad$ Número de empleados por cada 10000 abonados

$$
\mathrm{N}_{\mathrm{EMP}}=\frac{\text { Empleados }}{\text { CliT }} \times 10000
$$

Donde:

Empleados - Número de empleados en la empresa (para agua potable y alcantarillado)

La función de conversión del Número de empleados por cada 10000 abonados a factor de calidad es:

$$
\begin{aligned}
\mathrm{FC}_{\mathrm{N}_{\mathrm{EMP}}=} & -6.1439 \mathrm{E}-10 \times\left(\mathrm{N}_{\mathrm{EMP}}\right)^{6}+2.2118 \mathrm{E}-07 \times\left(\mathrm{N}_{\mathrm{EMP}}\right)^{5} \\
& -3.1025 \mathrm{E}-05 \times\left(\mathrm{N}_{\mathrm{EMP}}\right)^{4}+2.1376 \mathrm{E}-03 \times\left(\mathrm{N}_{\mathrm{EMP}}\right)^{3} \\
& -7.5446 \mathrm{E}-02 \times\left(\mathrm{N}_{\mathrm{EMP}}\right)^{2}+1.3066 \times\left(\mathrm{N}_{\mathrm{EMP}}\right)-8.7693 \\
\forall & 21.0 \leq\left(\mathrm{N}_{\mathrm{EMP}}\right) \leq 90.0
\end{aligned}
$$


Gráfico 3.21 Curva de conversión para:

Número de empleados por cada 10000 abonados

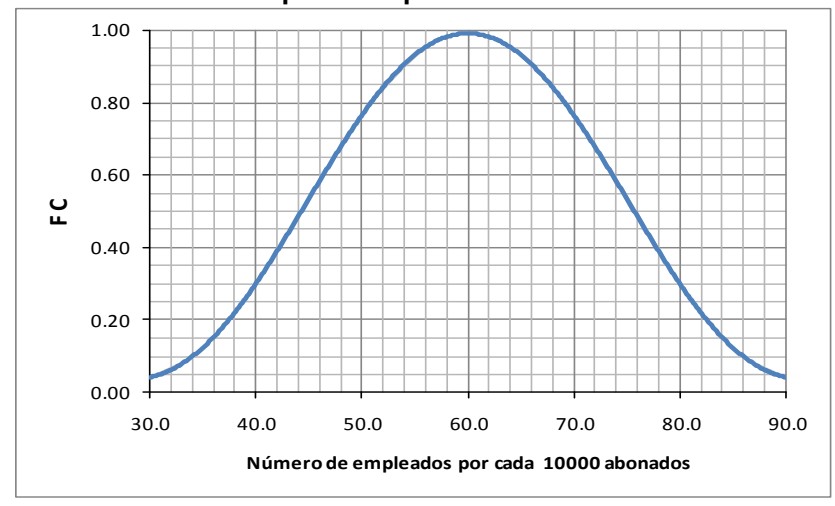

Si se quiere evaluar el número de empleados únicamente para agua potable el número óptimo (para $F C=1$ ) será de treinta por cada diez mil conexiones. (Cáceres V. 2008) da un número de 3.0 empleados de agua / 1000 conexiones; y, (Arana E. 2002) para agua potable y alcantarillado 5.8 empleados / 1000 conexiones.

2) Indicadores y funciones de conversión relacionados con la sostenibilidad social de un abastecimiento

i) Subcomponente operativo: cantidad

- $\quad$ Número de reducciones de la cantidad de caudal hasta un $50 \%$ por año (Nintrr)

La función de conversión del número de reducciones del servicio por año a factor de calidad es:

$$
\mathrm{FC}_{\text {Nintrr }}=1.3507 \times \mathrm{e}^{-(0.0985) \times(\mathrm{Nintrr})}
$$


Gráfico 3.22 Curva de conversión para: número de interrupciones del servicio por año

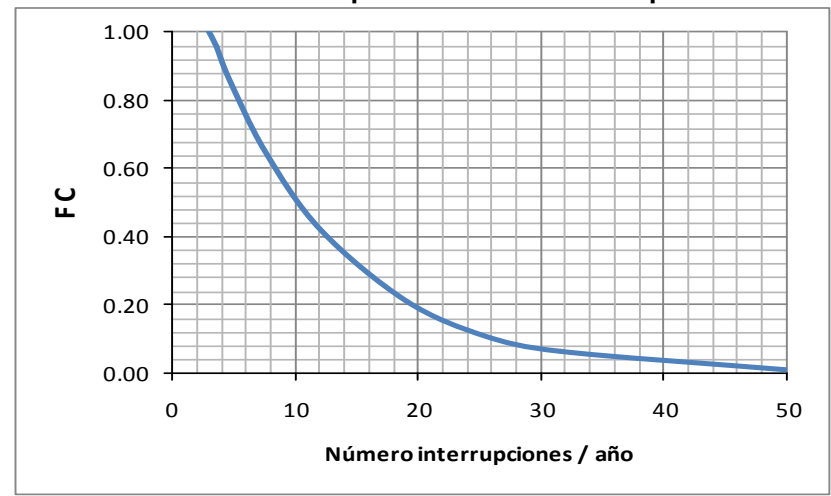

- $\quad$ Tiempo total acumulado de interrupciones (horas/año) (Hintrr)

La función de conversión del tiempo total acumulado de la duración de interrupciones a factor de calidad es:

$$
\mathrm{FC}_{\text {Hintrr }}=-0.2418 \times \ln (\text { Hitrr })+1.2621
$$

Gráfico 3.23 Curva de conversión para: tiempo total acumulado de la duración de interrupciones

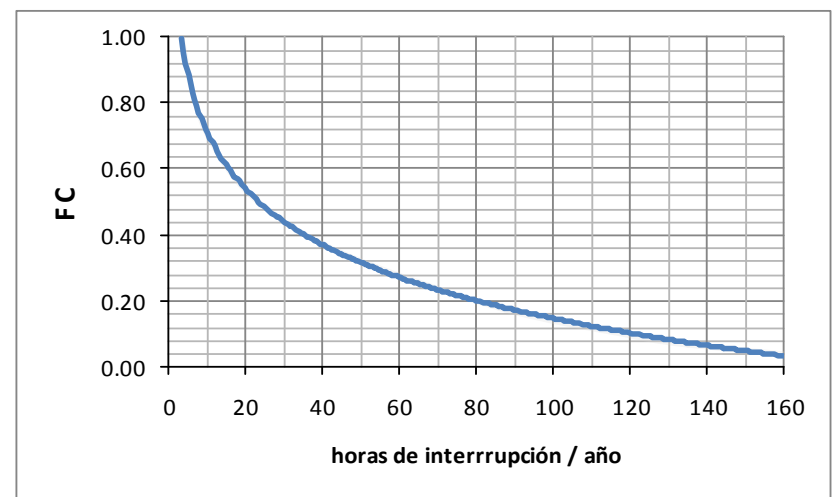


- $\quad$ Porcentaje de acometidas con presión de servicio diferente al rango (entre $10 \mathrm{~m}$ c.a. y $50 \mathrm{~m} \mathrm{c.a.)}$

$$
\mathrm{Pp}_{\mathrm{ACOM}}=\left(\frac{\mathrm{N}_{\mathrm{ACOM}}[\mathrm{p}<10]}{\text { CliT }}+\frac{\mathrm{N}_{\mathrm{ACOM}}[\mathrm{p}>50]}{\text { CliT }}\right) \times 100
$$

Donde:

$$
\begin{array}{ll}
\mathrm{N}_{\text {ACOM }}[\mathrm{p}<10]- & \text { Número de acometidas de clientes con presión de } \\
& \text { servicio inferior a } 10 \mathrm{~m} \text { c.a. } \\
\mathrm{N}_{\mathrm{ACOM}}[\mathrm{p}>50]- & \begin{array}{l}
\text { Número de acometidas de clientes con presión de } \\
\text { servicio superior a } 50 \mathrm{~m} \text { c.a. }
\end{array}
\end{array}
$$

La función de conversión del porcentaje de acometidas con presión de servicio diferente al rango de norma (entre $10 \mathrm{~m} \mathrm{c.a.} \mathrm{y} 50 \mathrm{~m} \mathrm{c.a.)}$ a factor de calidad es:

$$
\mathrm{FC}_{\mathrm{P}_{\mathrm{P} \text { ACOM }}}=-0.30753 \times \ln \left(\mathrm{P}_{\mathrm{P}} \mathrm{ACOM}\right)+0.56164
$$

Gráfico 3.24 Curva de conversión para: porcentaje de acometidas con presión de servicio diferente al rango de norma (entre $10 \mathrm{~m}$ c.a. y $50 \mathrm{~m}$ c.a.)

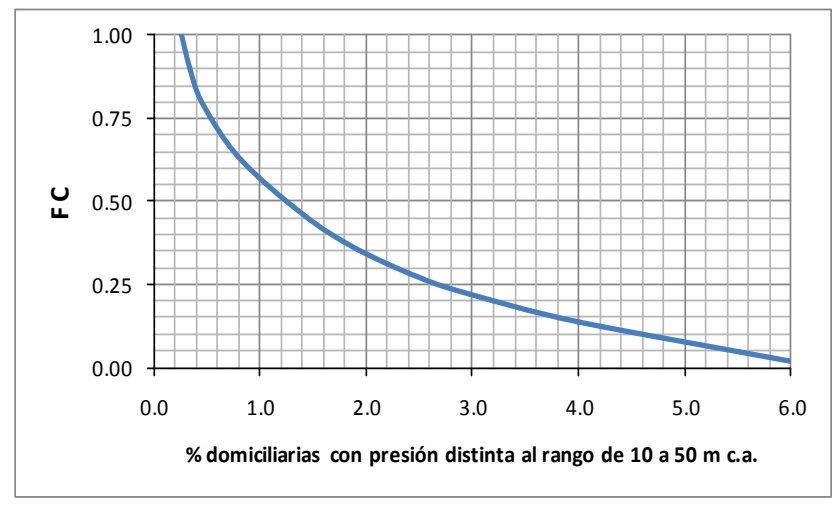

\section{ii) Subcomponente operativo: calidad}

- $\quad$ Número de muestras para análisis de calidad de agua por cada 1000 habitantes por mes

$$
\mathrm{M}_{\text {CALIDAD }}=1000 \times \frac{\mathrm{NM}_{\text {CALIDAD }}}{\text { hab }}
$$


Donde:
NM $M_{\text {CALIDAD }} \quad$ - Número de muestras para análisis de calidad de agua por mes
hab - Total de población

La función de conversión del número de muestras para análisis de calidad de agua por cada 1000 habitantes por mes a factor de calidad es:

$$
\begin{array}{lll}
\forall & \text { hab }<150000 ; \quad \mathrm{FC}_{\mathrm{M}_{\mathrm{CALIDAD}}}=\left(\mathrm{M}_{\mathrm{CALIDAD}}\right) & \text { [Ec. 3.50] } \\
\forall & 150001<\mathrm{hab}<650000 ; \quad \mathrm{FC}_{\mathrm{M}_{\mathrm{CALIDAD}}}=2.009 \times\left(\mathrm{M}_{\mathrm{CALIDAD}}\right)-0.003 & \text { [Ec. 3.51] } \\
\forall & 650001<\mathrm{hab} ; \quad \mathrm{FC}_{\mathrm{M}_{\mathrm{CALIDAD}}}=4.056 \times\left(\mathrm{M}_{\mathrm{CALIDAD}}\right)-0.010 & \text { [Ec. 3.52] }
\end{array}
$$

Gráfico 3.25 Curva de conversión para: número de muestras para análisis de calidad de agua por cada 1000 habitantes por mes (población hasta 150000 )

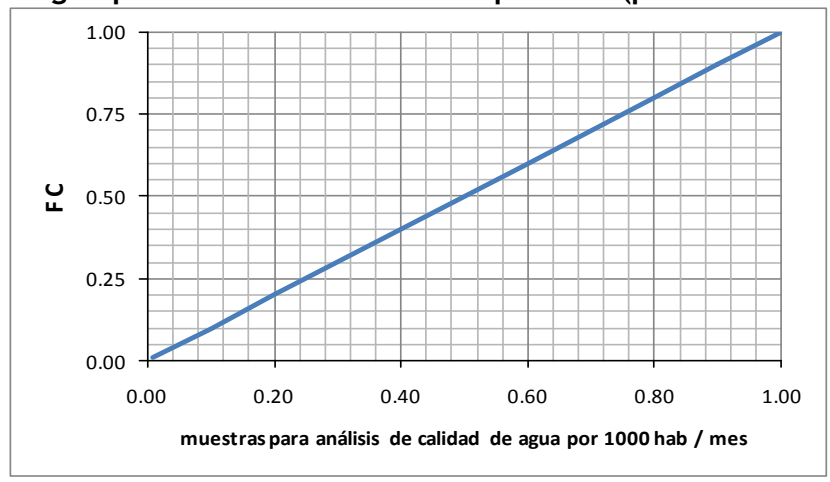

Gráfico 3.26 Curva de conversión para: número de muestras para análisis de calidad de agua por cada 1000 habitantes por mes (población 150001 a 650000 )

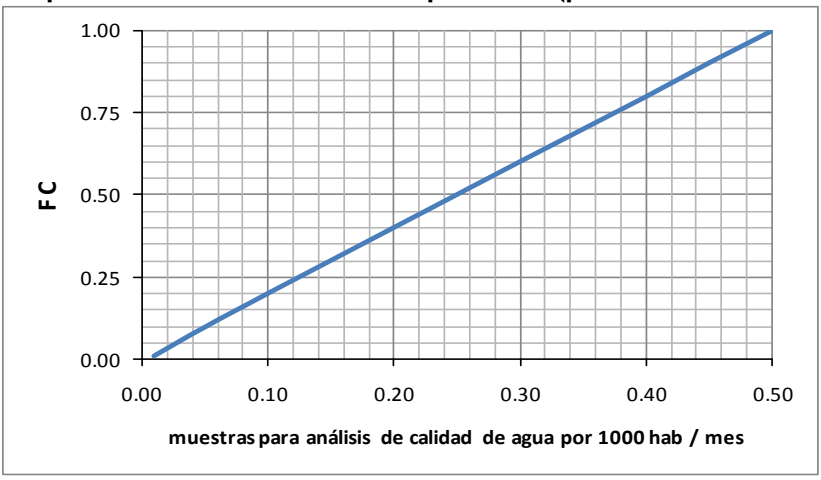


Gráfico 3.27 Curva de conversión para: muestras para análisis de calidad de agua por cada 1000 habitantes por mes (población > 650 001)

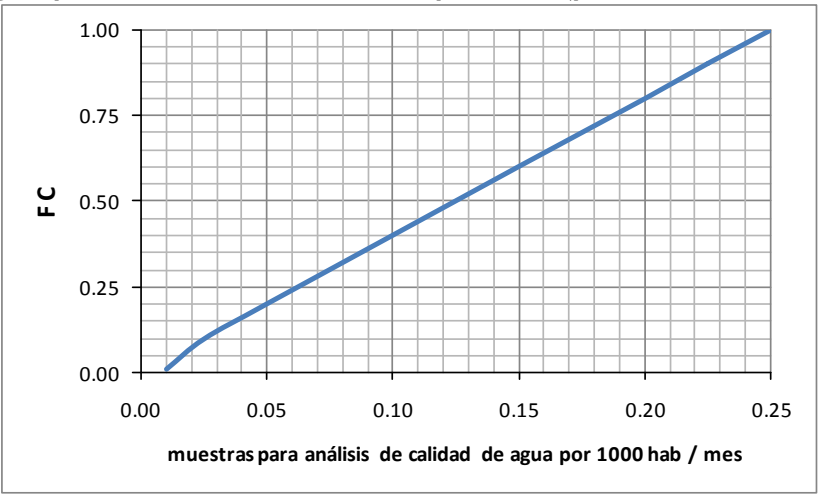

- $\quad$ Número promedio de horas por día que el agua permanece estancada (almacenada en depósitos del sistema) previo a su consumo

La función de conversión del número de horas promedio por día que el agua permanece estancada (almacenada en depósitos del sistema) previo a su consumo a factor de calidad es:

$$
\begin{aligned}
\mathrm{FC}_{\mathrm{h}_{\text {ESTANC }}} & =9 \mathrm{E}-5 \times\left(\mathrm{h}_{\text {ESTANC }}\right)^{3}-0.0071 \times\left(\mathrm{h}_{\text {ESTANC }}\right)^{2}+0.1301 \times\left(\mathrm{h}_{\text {ESTANC }}\right)+0.2989 \quad \text { [Ec. 3.53] } \\
\forall 12<\mathrm{h}_{\text {ESTANC }}<40 &
\end{aligned}
$$

El factor de calidad tendrá un valor de 1 para todo valor menor que 13 horas de estancamiento del agua.

Gráfico 3.28 Curva de conversión para: el número de horas promedio por día que el agua permanece estancada (almacenada en depósitos del sistema) previo a su consumo

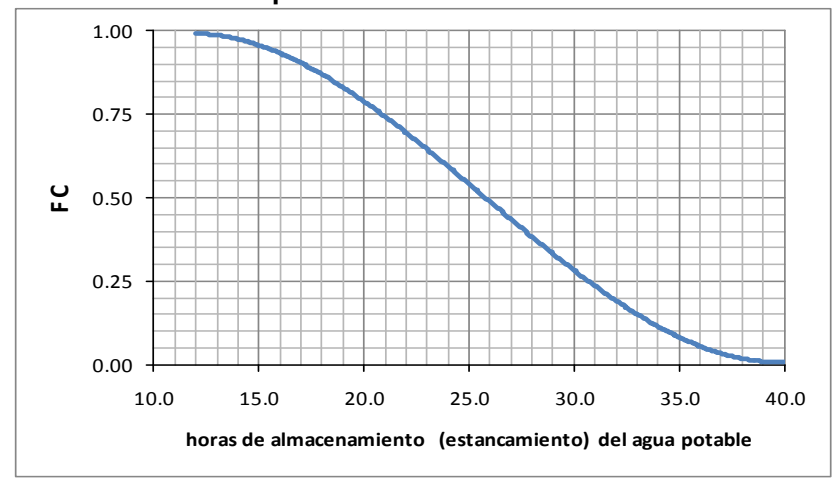


- $\quad$ Porcentaje de conexiones con cantidad de cloro residual diferente al rango (entre $0.30 \mathrm{mg} / \mathrm{L}$ a $1.5 \mathrm{mg} / \mathrm{L}$ )

$$
\text { PCL }_{\text {RES }}=100 \times\left(\frac{\mathrm{N}_{\text {CLRES }}[\mathrm{Cl}<0.3]}{\text { CliT }}+\frac{\mathrm{N}_{\text {CLRES }}[\mathrm{Cl}>1.5]}{\text { CliT }}\right)
$$

Donde:

$$
\begin{array}{ll}
\mathrm{N}_{\text {CLRES }}[\mathrm{Cl}<0.3]- & \begin{array}{l}
\text { Número de acometidas de clientes con cloro residual } \\
\text { inferior a } 0.30 \mathrm{mg} / \mathrm{L} .
\end{array} \\
\mathrm{N}_{\text {CLRES }}[\mathrm{Cl}>1.5]-\quad \begin{array}{l}
\text { Número de acometidas de clientes con presión de } \\
\text { servicio superior a } 1.5 \mathrm{mg} / \mathrm{L} .
\end{array}
\end{array}
$$

La función de conversión del porcentaje de conexiones con cantidad de cloro residual diferente al rango de norma (entre $0.30 \mathrm{mg} / \mathrm{L}$ a $1.5 \mathrm{mg} / \mathrm{L}$ ) a factor de calidad es:

$$
\mathrm{FC}_{\mathrm{PCL}_{\mathrm{RES}}}=0.1296 \times\left(\mathrm{PCL}_{\mathrm{RES}}\right)^{-0.468}
$$

Gráfico 3.29 Curva de conversión para: porcentaje de conexiones con cantidad de cloro residual diferente al rango de norma (entre $0.30 \mathrm{mg} / \mathrm{L}$ a $1.5 \mathrm{mg} / \mathrm{L}$ )

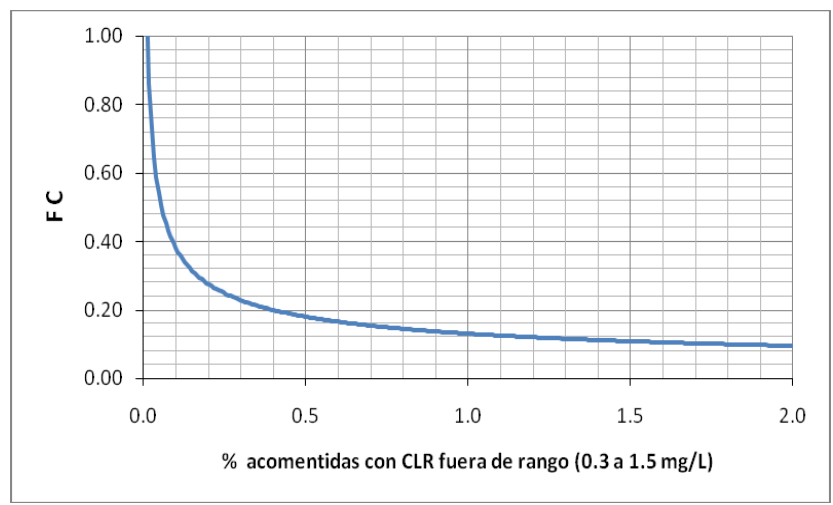

iii) Subcomponente operativo: cobertura

- $\quad$ Porcentaje de predios que cuenta con conexión al sistema

$$
\operatorname{Pobl}_{\mathrm{A}}=\frac{\text { Conx }}{\text { pred }} \times 100
$$


Donde:

Conx $\quad-\quad$ Número de conexiones al abastecimiento de clientes.
pred $\quad-\quad$ Número de predios en jurisdicción.

La función de conversión del porcentaje de predios que cuenta con conexión al sistema a factor de calidad es:

$$
\begin{aligned}
\mathrm{FC}_{\text {PoblA }}= & 1.0 \mathrm{E}-5 \times\left(\mathrm{Pobl}_{\mathrm{A}}\right)^{3}-1.42 \mathrm{E}-3 \times\left(\mathrm{Pobl}_{\mathrm{A}}\right)^{2}+0.0777 \times\left(\mathrm{Pobl}_{\mathrm{A}}\right)-1.2788 \quad \text { [Ec. 3.57] } \\
& \forall \quad 30<\mathrm{h}_{\text {ESTANC }}<100
\end{aligned}
$$

Gráfico 3.30 Curva de conversión para: porcentaje de predios que cuenta con conexión al sistema

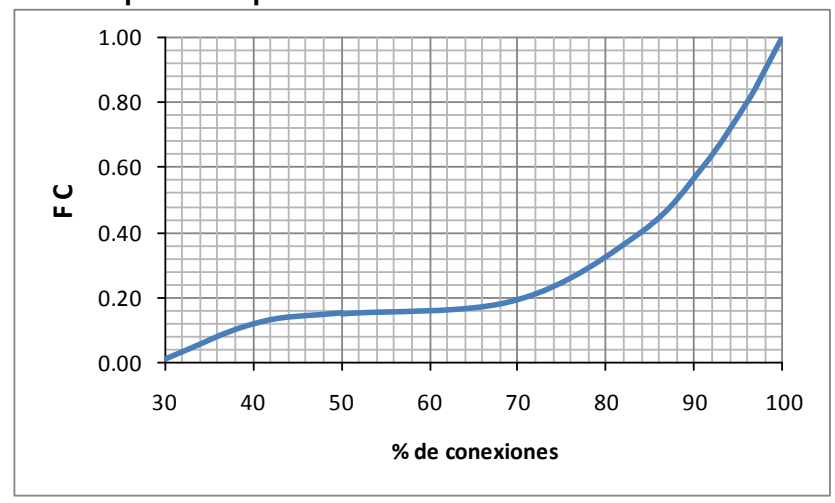

- $\quad$ Porcentaje de predios con buen servicio en horas pico

$$
\mathrm{Pob}_{\mathrm{SP}}=\frac{\text { PobS }_{\mathrm{PICO}}}{\operatorname{Conx}} \times 100
$$

Donde:

PobS PICO $_{\text {- }}$ Predios con buen servicio en horas pico.

La función de conversión del porcentaje de predios con buen servicio en horas pico a factor de calidad es:

$$
\mathrm{FC}_{\mathrm{Pob}_{\mathrm{SP}}}=2.3 \mathrm{E}-4 \times\left(\mathrm{Pob}_{\mathrm{SP}}\right)^{2}-1.6 \mathrm{E}-2 \times\left(\mathrm{Pob}_{\mathrm{SP}}\right)+0.294
$$


Gráfico 3.31 Curva de conversión para: porcentaje de predios con buen servicio en horas pico

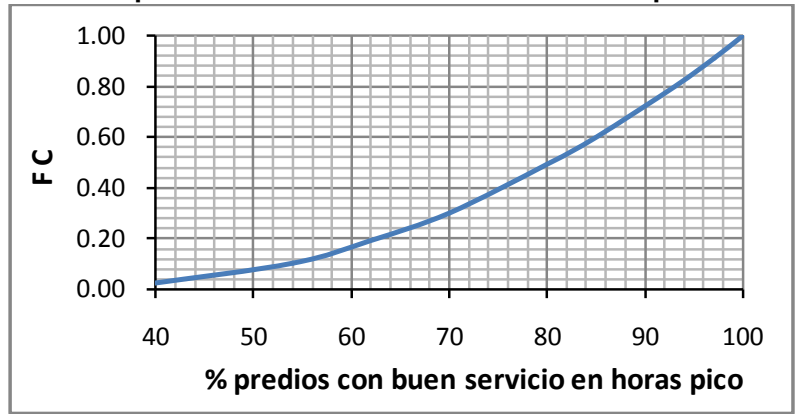

iv) Subcomponente formativo: capacitación a empleados

- $\quad$ Número promedio de horas de capacitación invertidas en cada técnico de campo y miembros de planificación / año

$$
\mathrm{Cap}_{\mathrm{TEC}}=\frac{\mathrm{hC}_{\mathrm{T} . \mathrm{CAMPO}}+\mathrm{hC}_{\mathrm{T} . \text { PLANIF }}}{2}
$$

Donde:

$$
\begin{aligned}
& H c_{T . C A M P O} \text { - horas de capacitación por técnico de campo / año } \\
& H c_{T . P L A N I F} \quad \text { - horas de capacitación por técnico de planificación / } \\
& \text { año }
\end{aligned}
$$

La función de conversión del promedio de horas de capacitación invertidas en cada técnico de campo y miembros de planificación / año a factor de calidad es:

$$
\mathrm{FC}_{\mathrm{Cap}_{\mathrm{TEC}}}=1.4 \mathrm{E}-4 \times\left(\mathrm{Cap}_{\mathrm{TEC}}\right)^{2}+2.4 \mathrm{E}-2 \times\left(\mathrm{Cap}_{\mathrm{TEC}}\right)+5.8 \mathrm{E}-3
$$

Gráfico 3.32 Curva de conversión para: promedio de horas de capacitación invertidas en cada técnico de campo y miembros de planificación / año

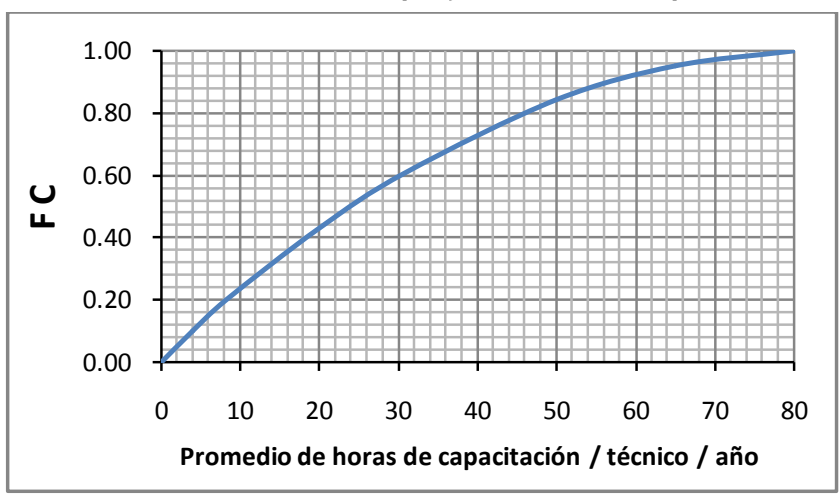


- Número promedio de horas de capacitación invertidas en cada administrador y coordinador del abastecimiento / año

$$
\mathrm{Cap}_{\mathrm{ADM}}=\frac{\mathrm{hC}_{\mathrm{ADMIN}}+\mathrm{hC}_{\mathrm{COORD}}}{2}
$$

Donde:

$$
\begin{aligned}
& H c_{\text {ADMIN }} \quad-\quad \text { horas de capacitación por administrador / año } \\
& H c_{\text {COORD }} \quad-\quad \text { horas de capacitación por coordinador / año }
\end{aligned}
$$

La función de conversión del promedio de horas de capacitación invertidas en cada administrador y coordinador / año a factor de calidad es:

$$
\mathrm{FC}_{\mathrm{Cap}_{\mathrm{ADM}}}=1.9 \mathrm{E}-4 \times\left(\mathrm{Cap}_{\mathrm{ADM}}\right)^{2}+2.7 \mathrm{E}-2 \times\left(\mathrm{Cap}_{\mathrm{ADM}}\right)+5.8 \mathrm{E}-3 \quad \text { [Ec. 3.63] }
$$

Gráfico 3.33 Curva de conversión para: promedio de horas de capacitación invertidas en cada administrador y coordinador / año

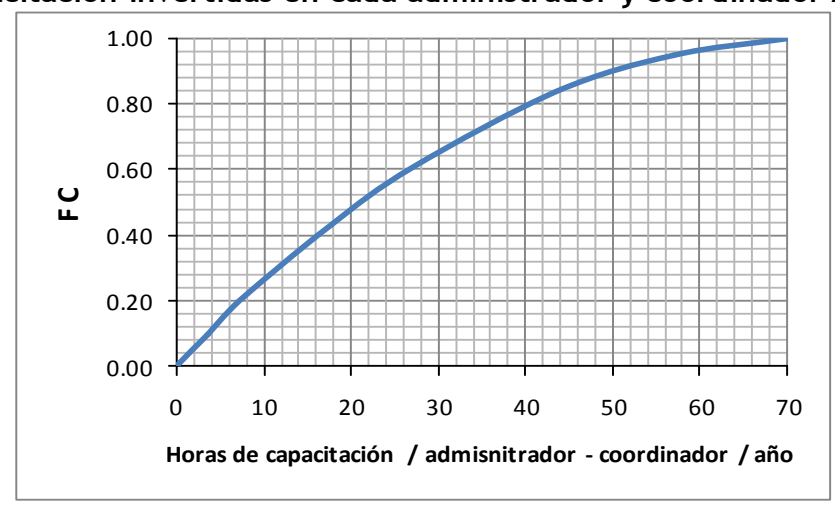

v) Subcomponente formativo: concientización al cliente

- Número de horas de curso para clientes por cada 10000 conexiones / año

$$
\mathrm{hCc}=\frac{\mathrm{h}_{\text {cursoC }}}{\text { CliT }} \times 10000
$$

Donde:

$\boldsymbol{h}_{\text {cursoc }} \quad$ - $\quad$ horas de capacitación para clientes al año; (bien en colegios, escuelas, otros) 
La función de conversión del número de horas de curso para clientes por cada 10000 conexiones / año a factor de calidad es:

$$
\mathrm{FC}_{\mathrm{hCc}}=-4.7 \mathrm{E}-4 \times(\mathrm{hCc})^{2}+4.34 \mathrm{E}-2 \times(\mathrm{hCc})+1.12 \mathrm{E}-2 \quad[\mathrm{Ec} .3 .65]
$$

Gráfico 3.34 Curva de conversión para: número de horas de curso para clientes por cada 10000 conexiones / año

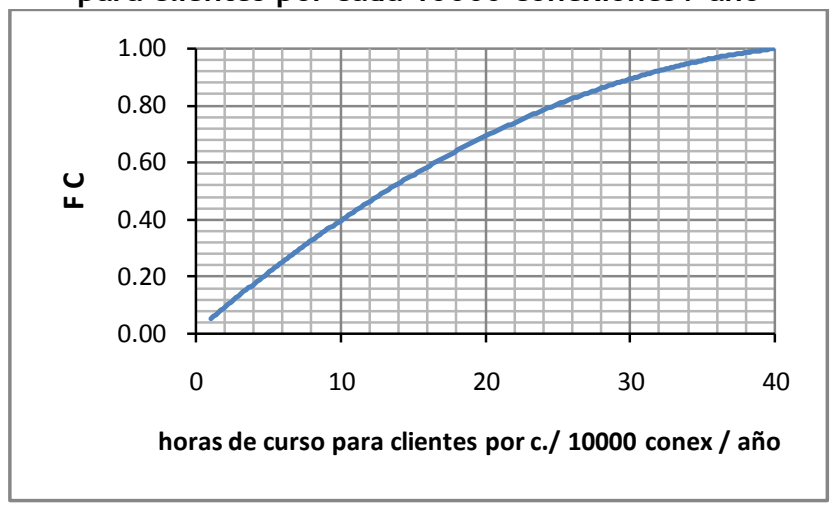

- Tiempo, en minutos/mes, de campaña de concientización del consumo, radial o TV

$$
\mathrm{Tca}_{\mathrm{RTV}}=\frac{\mathrm{Tca}_{\mathrm{TV}}+\mathrm{Tca}_{\mathrm{RAD}}}{2}
$$

Donde:
$\mathrm{Tca}_{T V} \quad$ - $\quad$ minutos/mes de campaña de concientización en TV para uso de agua a los clientes.
$T c a_{R A D} \quad$ - minutos/mes de campaña de concientización en radio para uso de agua a los clientes.

La función de conversión del tiempo total, en minutos/mes, de campaña radial o TV a factor de calidad es:

$$
\begin{aligned}
\mathrm{FC}_{\mathrm{Tca}_{\mathrm{RTV}}} & =2.78 \mathrm{E}-6 \times\left(\mathrm{Tca}_{\mathrm{RTV}}\right)^{3}-5.59 \mathrm{E}-4 \times\left(\mathrm{Tca}_{\mathrm{RTV}}\right)^{2}+3.81 \mathrm{E}-2 \times\left(\mathrm{Tca}_{\mathrm{RTV}}\right)+5.184 \mathrm{E}-4 \\
& \forall 0<\mathrm{h}_{\text {ESTANC }}<100
\end{aligned}
$$


Gráfico 3.35 Curva de conversión para: número de horas de curso para clientes por cada 10000 conexiones / año

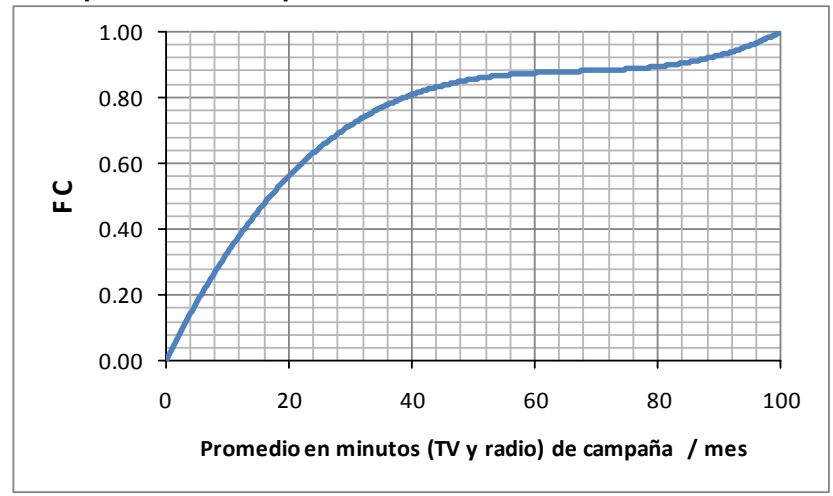

\section{vi) Subcomponente comercial: atención al cliente}

- $\quad$ Tiempo (en días) que la empresa tarda en responder las quejas de sus abonados

La función de conversión del tiempo (en días) que la empresa tarda en responder las quejas de sus abonados a factor de calidad es:

$$
\mathrm{FC}_{\mathrm{TRQ}}=-6.7 \mathrm{E}-3 \times(\mathrm{TRQ})^{2}-3.89 \mathrm{E}-2 \times(\mathrm{TRQ})+1.054 \quad \text { [Ec. 3.68] }
$$

\section{Gráfico 3.36 Curva de conversión para: tiempo (en días) que la} empresa tarda en responder las quejas de sus abonados

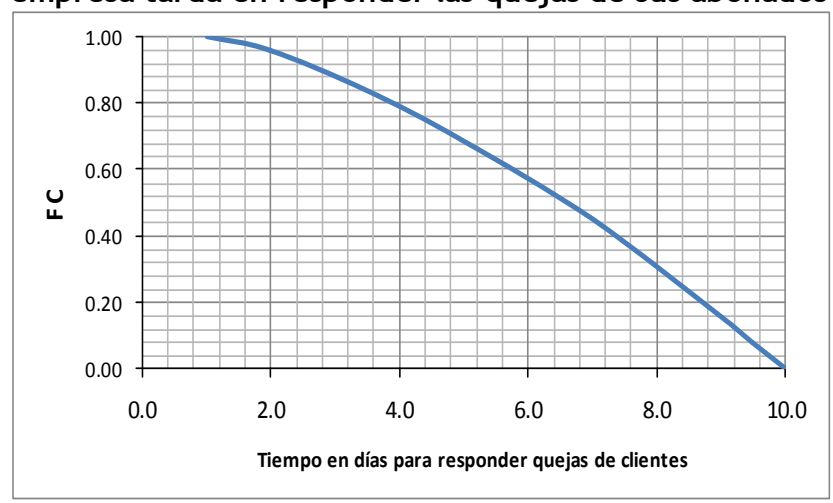

- $\quad$ Tiempo ponderado en los que la empresa atiende nuevas conexiones, obras de reparación o reinstalación (días desde el ingreso del pedido) 


$$
\mathrm{TN}_{\mathrm{CRR}}=\frac{2 \times\left(\mathrm{TN}_{\mathrm{CONX}}\right)^{1.2}+3 \times\left(\mathrm{T}_{\mathrm{REPARA}}\right)^{3.5}+\mathrm{T}_{\mathrm{REINSTAL}}}{6}
$$

Donde:

$\begin{array}{lll}T N_{\text {CONX }} & - & \begin{array}{l}\text { Tiempo en el que la empresa atiende nuevas } \\ \text { conexiones (en días desde el ingreso del pedido) }\end{array} \\ T_{\text {REPARA }} \quad-\quad & \begin{array}{l}\text { Tiempo en el que la empresa atiende reparaciones } \\ \text { (en días desde la detección o aviso del fallo) }\end{array} \\ T_{\text {REINSTAL }} \quad-\quad & \begin{array}{l}\text { Tiempo en el que la empresa atiende reinstalaciones } \\ \text { (en días desde el ingreso del pedido) }\end{array}\end{array}$

La función de conversión del tiempo ponderado en los que la empresa atiende nuevas conexiones, obras de reparación o reinstalación a factor de calidad es:

$\mathrm{FC}_{\mathrm{TN}_{\mathrm{CRR}}}=1.34 \mathrm{E}-2 \times\left(\mathrm{TN}_{\mathrm{CRR}}\right)^{2}-0.3377 \times\left(\mathrm{TN}_{\mathrm{CRR}}\right)+2.1298$

Gráfico 3.37 Curva de conversión para: tiempo ponderado en los que la empresa atiende nuevas conexiones, obras de reparación o reinstalación

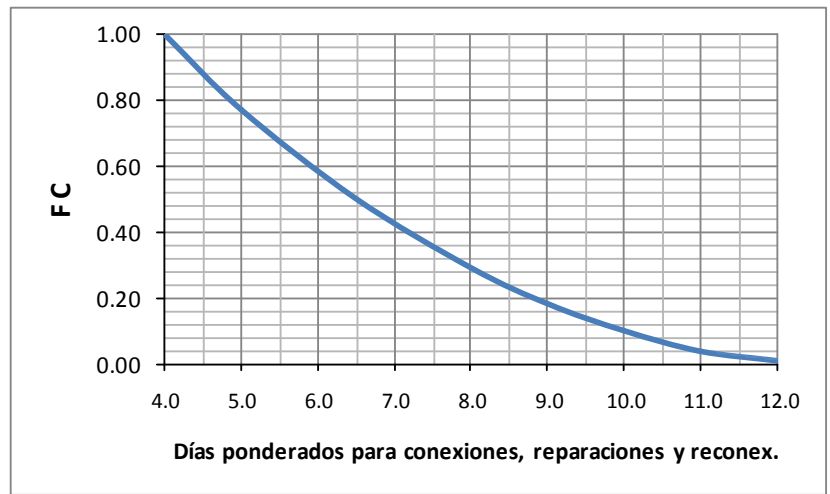

- $\quad$ Existe en ejecución un plan de marketing publicitario de la empresa, para promocionar el ahorro de agua y difusión pública de su actividad gestora 
Gráfico 3.38 Curva de conversión para: existencia en ejecución de un plan de marketing publicitario de la empresa, promoción al ahorro y difusión pública de su actividad gestora

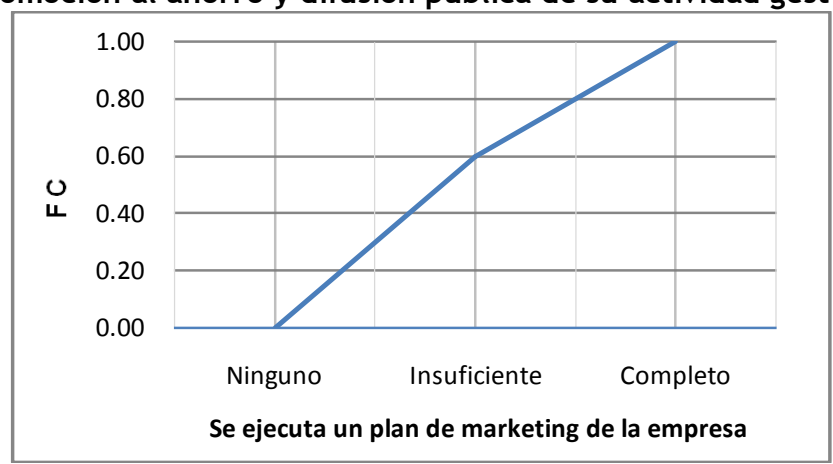

- Infraestructura de atención al cliente organizada, equipada y cómoda

Gráfico 3.39 Curva de conversión para: Infraestructura de atención al cliente organizada, equipada y cómoda

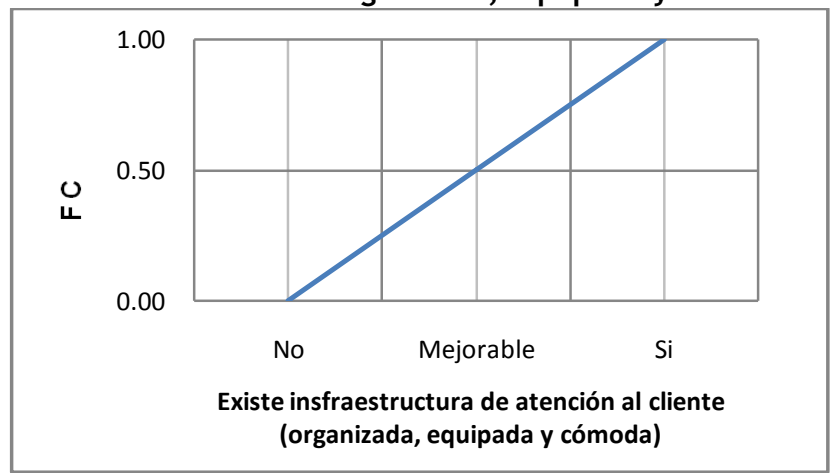

3) Indicadores y funciones de conversión relacionados con la sostenibilidad ambiental de un abastecimiento

i) Subcomponente explotación: agua captada y vertida

- $\quad$ Porcentaje de caudal de agua captada para el abastecimiento, en época de estiaje

$\mathrm{Q}_{\mathrm{ECO}}=\frac{\mathrm{Q}_{\mathrm{CAPTADO}}}{\mathrm{Q}_{\mathrm{EST}}} \times 100$ 
Donde:

$Q_{\text {CAPTADO }} \quad$ Caudal de agua captada para el abastecimiento, en época de estiaje.

QEST - Caudal de agua total disponible, en el punto de captación, en época de estiaje.

La función de conversión del porcentaje de caudal de agua captada para el abastecimiento, en época de estiaje a factor de calidad es:

$$
\mathrm{FC}_{\mathrm{QECO}_{\mathrm{ECO}}}=2.77 \mathrm{E}-3 \times\left(\mathrm{Q}_{\mathrm{ECO}}\right)^{2}-4.93 \mathrm{E}-1 \times\left(\mathrm{Q}_{\mathrm{ECO}}\right)+21.932
$$

Gráfico 3.40 Curva de conversión para: porcentaje de caudal de agua captada para el abastecimiento, en época de estiaje

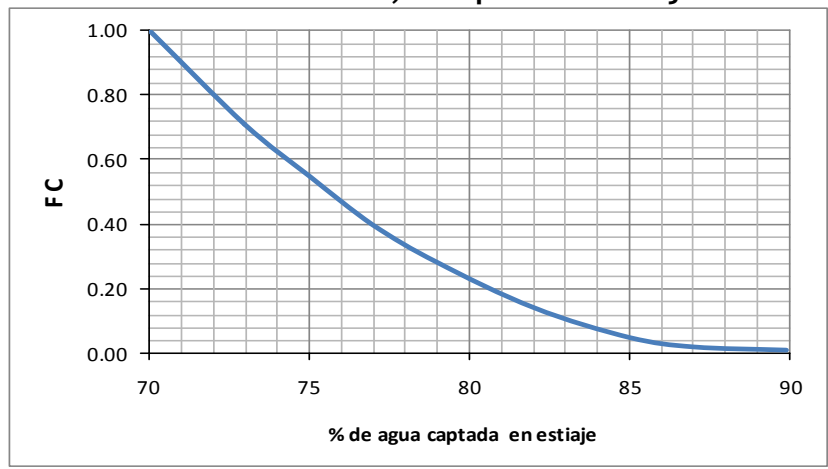

- $\quad$ Existe estricto control legal y regulación efectiva de explotación de otros recursos y uso de suelo, en las cuencas fuente, por el gobierno local.

Gráfico 3.41 Curva de conversión para: existe estricto control legal y regulación efectiva de explotación de otros recursos $y$ uso de suelo, en las cuencas fuente, por el gobierno local

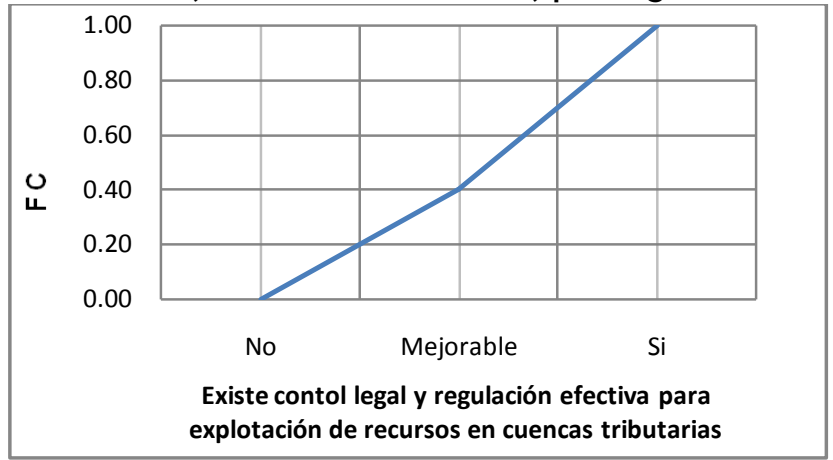


ii) Subcomponente explotación: consumos

- $\quad$ Promedio de consumo de agua por habitante por día

$$
\mathrm{W}_{\text {CAPITA }}=\frac{\overline{\mathrm{W}} \text { CONS_CX } / \text { MES }_{\text {hab }}}{\overline{\text { hanX }}} \times \frac{1000}{\overline{\mathrm{n}_{\mathrm{D}}}}
$$

Donde:

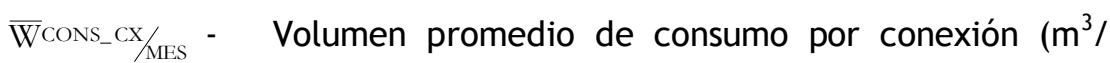 mes).

habconx - Promedio del número de personas que habitan por conexión.

$n_{D} \quad$ - Número de días en los que se registró el volumen.

La función de conversión del promedio de consumo de agua por habitante por día a factor de calidad es:

$$
\mathrm{FC}_{\mathrm{W}_{\text {CAPTA }}}=-6.23 \mathrm{E}-3 \times\left(\mathrm{W}_{\text {CAPTTA }}\right)+1.558
$$

Gráfico 3.42 Curva de conversión para: promedio de consumo de agua por habitante por día

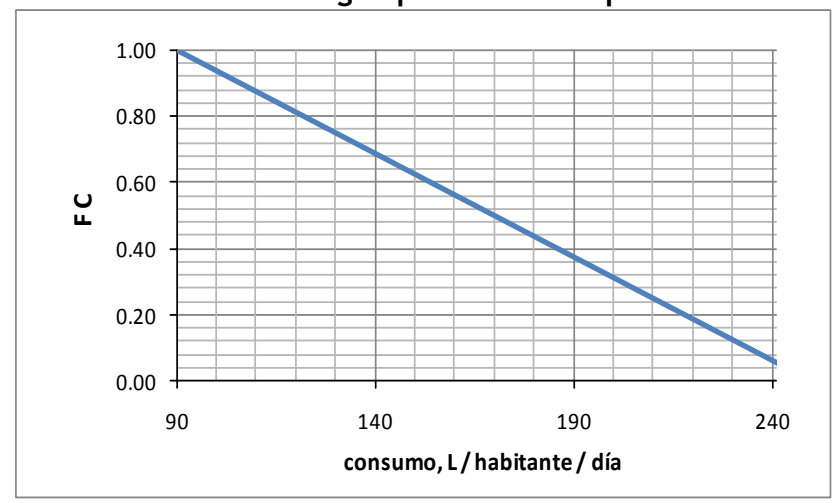

- Desaprovechamiento de recursos hídricos

$$
\mathrm{W}_{\mathrm{H}}=\frac{\overline{\mathrm{W}}_{\text {PERDIDO }}}{\mathrm{W}_{\mathrm{CAP}}} \times 100
$$

Donde:
$\bar{W}_{\text {PERDIDO }}$ - Volumen de agua perdido (real) desde las captaciones $\left(\mathrm{m}^{3} / \mathrm{mes}\right)$.
$W_{C A P} \quad$ - Volumen de agua extraído de la cuenca $\left(\mathrm{m}^{3} / \mathrm{mes}\right)$. 
La función de conversión del aprovechamiento de recursos hídricos a factor de calidad es:

$$
\mathrm{FC}_{\mathrm{W}_{\mathrm{H}}}=1.8 \mathrm{E}-4 \times\left(\mathrm{W}_{\mathrm{H}}\right)^{2}-2.956 \mathrm{E}-2 \times\left(\mathrm{W}_{\mathrm{H}}\right)+1.279 \quad \text { [Ec. 3.76] }
$$

Gráfico 3.43 Curva de conversión para: aprovechamiento de recursos hídricos

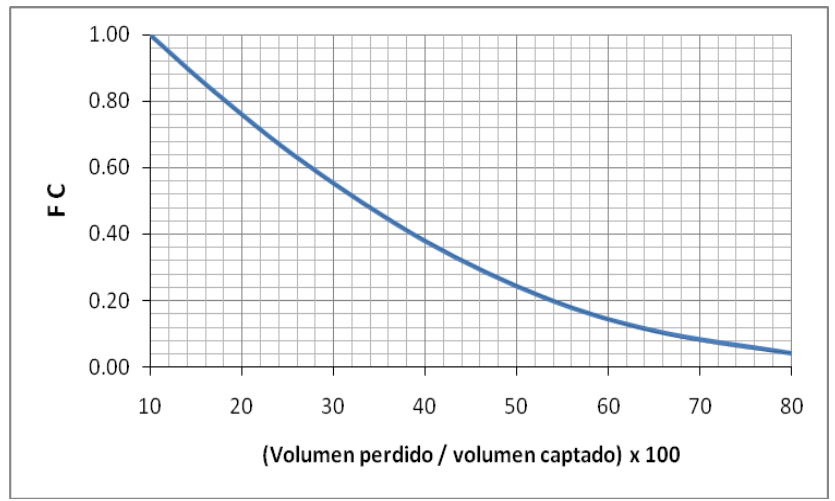

- Consumo energético relativo del abastecimiento por mes.

$$
\mathrm{E}_{\mathrm{R}}=\frac{\mathrm{E}_{\text {CONSUMIDA }}}{\mathrm{E}_{\text {ÓPTIMA }}}
$$

Donde:

$$
\begin{array}{ll}
E_{\text {Consumida }}- & \text { Energía eléctrica consumida en el abastecimiento } \\
& (\$ / \text { mes }) \text {. } \\
E_{\text {ÓPTIMA }}- & \text { Energía eléctrica óptima que se debió consumir } \\
& (\$ / \text { mes }) \text {. }
\end{array}
$$

Valores de $E_{R}$ inferiores a 1 significa que el consumo energético es inferior al planificado, por tal se considera para estos casos un $\mathrm{FC}=1$.

La función de conversión del consumo energético relativo por mes del abastecimiento a factor de calidad es:

$$
\mathrm{FC}_{\mathrm{E}_{\mathrm{R}}}=1.02448 \times\left(\mathrm{E}_{\mathrm{R}}\right)^{-4.34127}
$$




\section{Gráfico 3.44 Curva de conversión para: consumo energético relativo por mes}

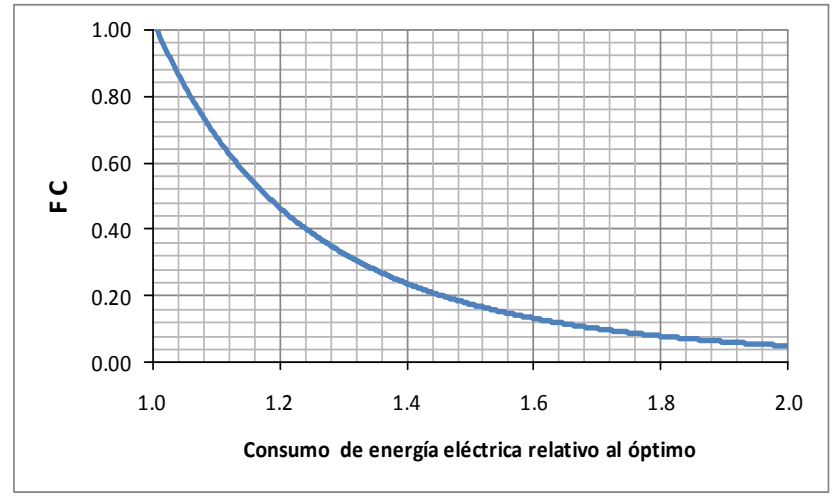

iii) Subcomponente contaminación por $00 \& M M$

- Porcentaje de lodos y desechos generados por el sistema de potabilización (filtros, floculadores y sedimentadores) que se vierten sin depuración a cuerpos receptores, por año.

$$
\mathrm{W}_{\text {LODO }}=\frac{\mathrm{W}_{\mathrm{L} \mathrm{DEPU}}}{\mathrm{W}_{\mathrm{L} \text { PROD }}} \times 100
$$

Donde:
WLPROD - Cantidad de lodos y desechos que se depuran y gestionan correctamente, (en toneladas ó $\mathrm{m}^{3}$ ), por año.
$W_{\text {LDEPU }} \quad$ - $\quad$ Cantidad total de lodos y desechos que se generan por el sistema de potabilización, (en toneladas ó $\mathrm{m}^{3}$ ), por año.

La función de conversión del porcentaje de lodos y desechos generados por el sistema de potabilización que se vierten sin depuración a factor de calidad es:

$$
\mathrm{FC}_{\mathrm{E}_{\mathrm{R}}}=1.02448 \times\left(\mathrm{E}_{\mathrm{R}}\right)^{-4.34127}
$$


Gráfico 3.45 Curva de conversión para: porcentaje de lodos y desechos generados por el sistema de potabilización que se vierten sin depuración

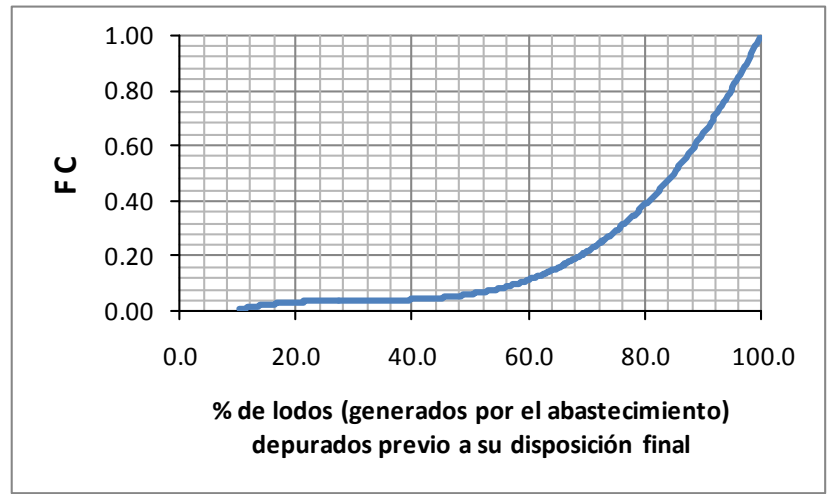

- $\quad$ Existe sistema de depuración de aguas servidas para los vertidos de alcantarillados de la ciudad.

Gráfico 3.46 Curva de conversión para: de depuración de aguas servidas para los vertidos de alcantarillado de la ciudad

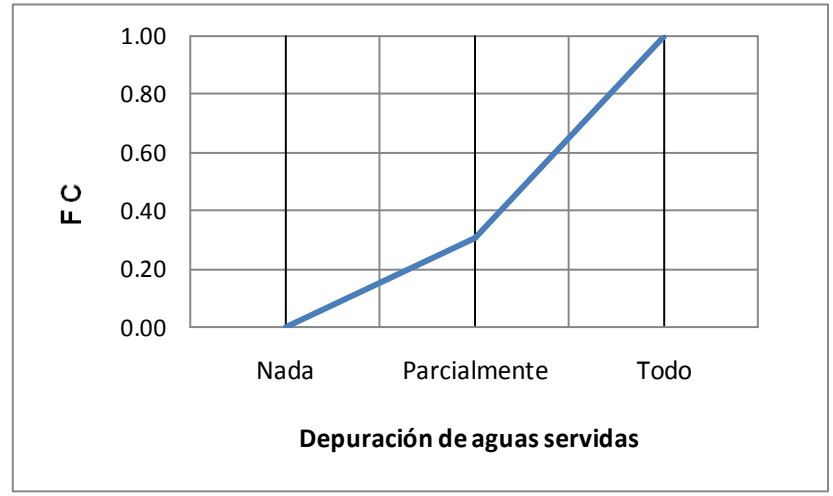

- Aplicación de medidas correctoras o de mitigación para reducción de impacto por ruido, polvo y gases en apertura y cierre de zanjas para reparaciones o conexiones domiciliares 
Gráfico 3.47 Curva de conversión para: medidas correctoras de impactos ambientales

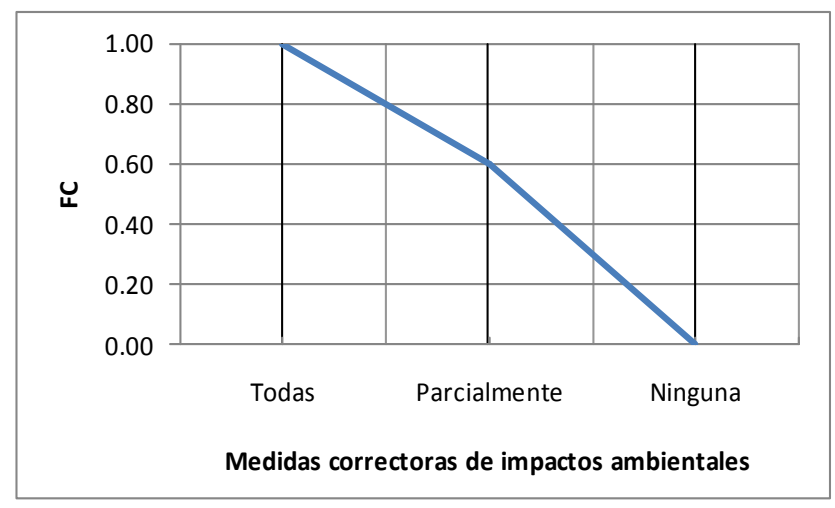

iv) Subcomponente conservación: cuenca fuente

- $\quad$ Superficie de la cuenca fuente o tributaria que es propiedad del sistema en hectáreas por cada (L/s) de agua producida para el abastecimiento

$$
A_{\text {PROPIA }}=\frac{A_{\text {PUENTE }}}{Q_{\text {PRODUC }}}
$$

Donde:
$A P_{\text {FUENTE }}$ -
Superficie de cuenca tributaria (zona boscosa con importante aporte hídrico) que le pertenece exclusivamente al abastecimiento $(\mathrm{Ha})$.
$Q_{\text {PRODUC }} \quad$ Caudal medio producido en planta (en L/s).

La función de conversión de la superficie de la cuenca tributaria que es propiedad del sistema a factor de calidad es:

$$
\mathrm{FC}_{\mathrm{A}_{\text {PROPIA }}}=0.3209 \times \ln \left(\mathrm{A}_{\text {PROPIA }}\right)+0.2629
$$


Gráfico 3.48 Curva de conversión para: superficie de la cuenca tributaria que es propiedad del sistema

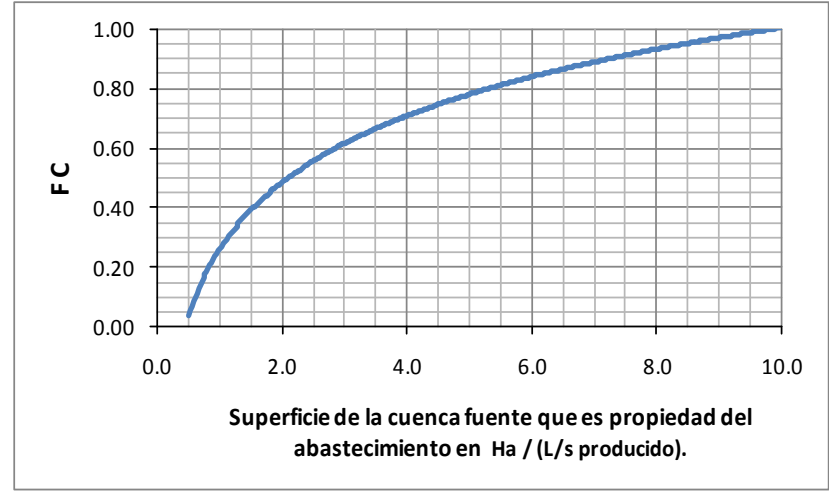

- $\quad$ Porcentaje de superficie de la o las cuencas tributarias que tienen en marcha un plan anual de silvicultura y reforestación, gestionado ó coordinado directamente por la empresa operadora del sistema.

$$
\mathrm{A}_{\mathrm{SILVI}}=\frac{\mathrm{A}_{\text {PLAN }}}{\mathrm{AT}_{\text {CUENCAS }}} \times 100
$$

Donde:
$A_{P L A N}$ Superficie de la o las cuencas tributarias que tienen en marcha un plan anual de silvicultura y reforestación, gestionado ó coordinado directamente por la empresa operadora del sistema $(\mathrm{Ha})$.

$A T_{\text {CUENCAS - }} \quad$ Superficie total de las cuencas tributarias $(\mathrm{Ha})$.

La función de conversión del porcentaje de superficie de las cuencas tributarias que tienen en marcha un plan anual de silvicultura y reforestación a factor de calidad es:

$$
\mathrm{FC}_{\mathrm{A}_{\text {SIIVI }}}=4.195 \mathrm{E}-5 \times\left(\mathrm{A}_{\mathrm{SIVI}}\right)^{2}+5.732 \mathrm{E}-3 \times\left(\mathrm{A}_{\mathrm{SLVI}}\right)+5.756 \mathrm{E}-3
$$


Gráfico 3.49 Curva de conversión para: \% superficie de las cuencas tributarias que tienen en marcha un plan anual de silvicultura y reforestación

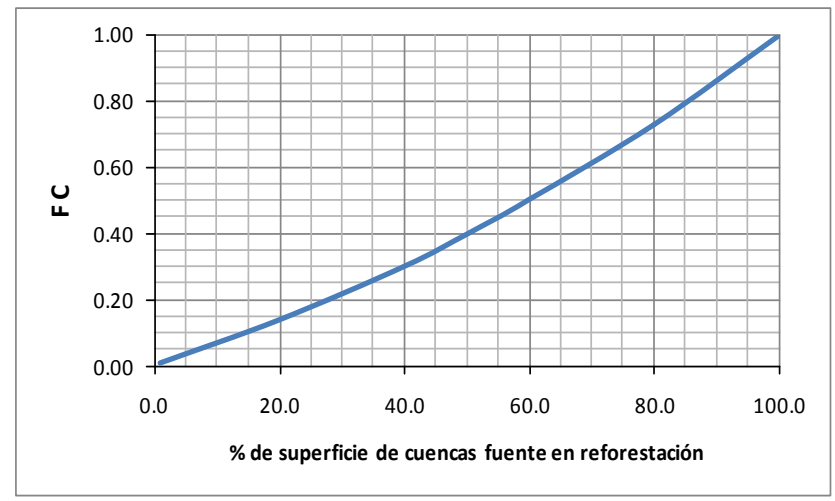

- $\quad$ Porcentaje de industrias que funcionan dentro de la cuenca tributaria, que depuran sus vertidos y controlan sus desechos correctamente

$$
\mathrm{In}_{\mathrm{ECO}}=\frac{\mathrm{In}_{\text {DEPURA }}}{\mathrm{In}_{\mathrm{TOT}}} \times 100
$$

Donde:

In DEPURA - Número de industrias que funcionan dentro de la cuenca tributaria, que depuran sus vertidos $y$ controlan sus desechos sin contaminar.

In $n_{\text {TOT }} \quad$ - Número total de industrias que funcionan dentro de la cuenca tributaria.

La función de conversión del porcentaje de industrias dentro de la cuenca, que depuran sus vertidos a factor de calidad es:

$$
\mathrm{FC}_{\mathrm{In}_{\mathrm{ECO}}}=1.0203 \mathrm{E}-4 \times\left(\operatorname{In}_{\mathrm{ECO}}\right)^{2}-3.1878 \mathrm{E}-4 \times\left(\mathrm{In}_{\mathrm{ECO}}\right)+1.1732 \mathrm{E}-2
$$


Gráfico 3.50 Curva de conversión para: porcentaje de industrias dentro de la cuenca, que depuran sus vertidos

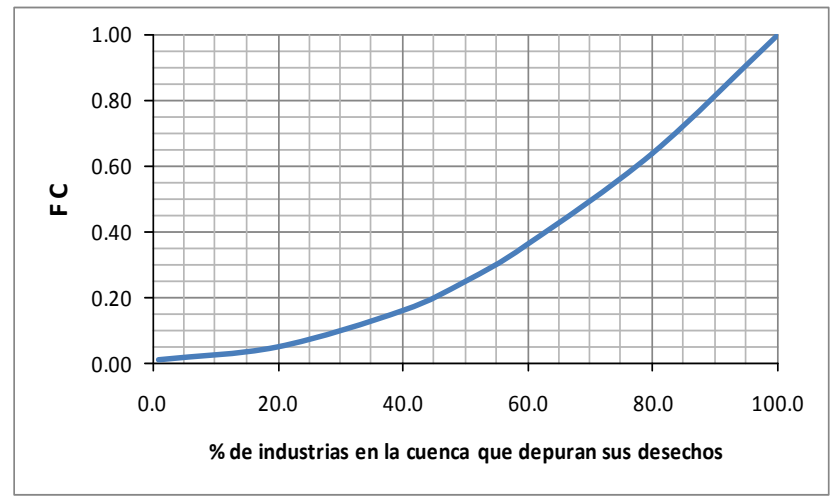

- $\quad$ Porcentaje del ingreso total recaudado por venta de agua que se destina a adquisición y conservación de cuencas tributarias

$$
\mathrm{V}_{\mathrm{FUENTE}}=\frac{\operatorname{Vinv}_{\mathrm{FACT}}}{\mathrm{In}_{\mathrm{FACT}}} \times 100
$$

Donde:

Vinv $V_{\text {FACT }} \quad$ - Ingreso recaudado por venta de agua que se destina a adquisición y conservación de cuencas tributarias, por año.

La función de conversión del porcentaje del ingreso total recaudado por venta de agua que se destina a adquisición y conservación de cuencas tributarias a factor de calidad es:

$$
\mathrm{FC}_{\mathrm{V}_{\text {FUENTE }}}=-5.683 \mathrm{E}-03 \times\left(\mathrm{V}_{\text {FUENTE }}\right)^{2}+0.1507 \times\left(\mathrm{V}_{\text {FUENTE }}\right)+0.010124 \quad \text { [EC. 3.88] }
$$


Gráfico 3.51 Curva de conversión para: porcentaje del ingreso total recaudado por venta de agua que se destina a adquisición y conservación de cuencas tributarias

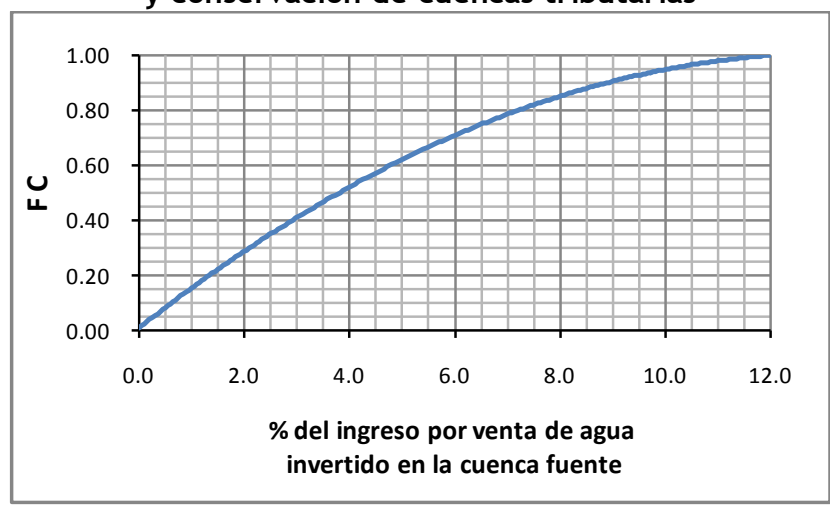

\subsubsection{Proceso de agregación}

La propuesta central de este trabajo se basa en que la sostenibilidad de un abastecimiento se puede determinar con indicadores, asociados cada uno de ellos a estados específicos de calidad (ponderada y relativa), bajo características que establezcan un equilibrio en la gestión. Se confronta sus valoraciones respecto de una situación deseable, -obtenida de entrevistas Delphi-.

El Índice de Sostenibilidad de un Abastecimiento - ISA -, es una proposición convergente, numérica y descriptiva de la relación entre los aspectos: social, económico y ambiental, que interactúan en un sistema de suministro.

El método ISA se convierte así, en una herramienta para la evaluación del nivel de sostenibilidad de un abastecimiento de agua, que se construye con la información y datos generados por el propio gestor y que requiere de la medición continua de variables e indicadores - en la etapa de valoración mismas que se deben expresar como cifras numéricas comparables (isométricas) y que a su vez son el resultado de la agregación ó conversión mediante factores de calidad $(F C)$ en pesos relativos $(P R)$.

$$
\mathrm{ISA}=\sum \mathrm{PR}_{\mathrm{j}}
$$

Donde:

$P R_{j} \quad-\quad$ peso relativo del indicador $j$ 
Existe un peso relativo $(P R)$ para cada indicador $j$. Se obtiene al multiplicar el factor de calidad con la importancia ponderada (IP) correspondiente. El componente social y el componente ambiental, cada una, tienen importancias ponderadas subtotales de hasta $\mathbf{3 3 . 3}$ y el componente económico de hasta 33.4.

La sumatoria de todas las importancias ponderadas puede ser máximo 100 y mínimo 0 (el cero absoluto en ningún caso podría existir). Para un abastecimiento en excelentes (inmejorables) condiciones de sostenibilidad le corresponderá un ISA de 100.

La aplicación del diagnóstico mediante el ISA permite a los gestores de los abastecimientos idealizar con relativa facilidad el grado de vulnerabilidad de su sistema, según la caracterización que sea previamente asignada; con dicha clasificación se presenta de forma gráfica y numérica la situación en la que se encuentra su abastecimiento y los gestores podrán con ello incluir los controles adecuados y se tome las medidas correspondientes para mejorar dicha situación, con base a los criterios técnicos involucrados en ésta (planificar, rediseñar e invertir bajo el horizonte de la sostenibilidad).

Donde:

$$
\mathrm{PR}_{\mathrm{j}}=\mathrm{FC}_{\mathrm{j}} \times \mathrm{IP}_{\mathrm{j}}
$$
$P R_{j}$
peso relativo del indicador $\boldsymbol{j}$
$F C_{j} \quad$ - factor de calidad del indicador $j$
$I P_{j} \quad$ - importancia ponderada del indicador $j$

El factor de calidad $(F C)$, proviene de una función matemática cualitativa, que transforma el valor del indicador en un número representativo de la calidad sostenible del abastecimiento (entre 0 y 1 ), para ello toma en consideración las características deseadas -sostenibles- de cada indicador, con base en normas de calidad, experiencias y criterios técnicos que conducen hacia un estado propicio o anhelado.

De este modo los parámetros se pueden comparar por ser isométricos (confrontables).

El factor de calidad $(F C)$ depende de la función de conversión [ $f\left(\operatorname{Ind}_{j}\right)$ ] que caracteriza a cada indicador. La función de conversión es explícita y tiene como variable independiente a la magnitud del indicador (dato facilitado por el gestor del abastecimiento).

$$
\mathrm{FC}_{\mathrm{j}} \rightarrow \mathrm{f}\left(\text { Ind }_{\mathrm{j}}\right)
$$




\subsection{Clasificación de los abastecimientos según su ISA}

En el caso de los abastecimientos de agua potable de las ciudades ubicadas en los países en vías de desarrollo, es urgente implantar metodologías que modifiquen y mejoren el actual modo de gestión, como un nuevo desafío para los directivos y sociedad política a cargo de tan importante responsabilidad; pues, claro está que este hecho no deja de ser un gran reto a la conciencia política, al profesionalismo de los ingenieros a cargo de la gestión y a la sociedad entera. Para cumplir con aquello se propone iniciar con una valoración del estado actual y diagnosticar el nivel de sostenibilidad en el que se ubica cada sistema de agua.

\section{Rangos y categorías}

La evaluación y el diagnóstico de la sostenibilidad de un abastecimiento son continuos, permanentes, sistemáticos y cada vez más exigentes, durante cada fase $y$ en sus distintos componentes.

Antes de cada nueva etapa de planificación y organización de actividades en la gestión de un abastecimiento es preciso conocer la situación (socioeconómico- ambiental) de partida; ISA INICIAL, AÑO CERO. Este diagnóstico tiene como propósito verificar el nivel de sostenibilidad en el que se encuentra el abastecimiento, con el fin de remediar toda patología que se detecte y evitar así un detrimento mayor del servicio, del sistema de agua y del ambiente.

El diagnóstico de sostenibilidad ISA, "puntúa" ó agrega en términos comparables la calidad de gestión en lo social, económico y ambiental, además pone de manifiesto los aspectos vulnerables de tal actividad, al tiempo que permite focalizar el origen de algunos de los problemas o necesidades existentes y que ameritan más atención por parte de los actores involucrados, convirtiéndose en un instrumento base en la toma de decisiones y para establecer las directrices de actuación, de forma sistemática y preceptiva, de su gestión y desempeño.

Según la categoría del abastecimiento obtenida con base en su ISA, se generan las propuestas de acciones que la mejoren. Mas, el proceso se debe aplicar de manera constante; así, una vez que se obtiene los resultados de una primera intervención ISA INIIIAL, AÑO CERO, vendrá luego el diagnóstico ISA AÑO UNO, ISA AÑO DOS, ISA AÑo TRES, ...ISA AÑ̃ n. 
Según el valor del ISA, el estado de sostenibilidad se divide en cinco categorías; para un ISA cuyo valor está dentro del rango de cero a cuarenta se lo denomina como: "abastecimiento con estado de sostenibilidad malo"; un valor de ISA mayor que cuarenta y hasta sesenta se lo clasifica como "abastecimiento con estado de sostenibilidad deficiente"; para valores de ISA mayor que sesenta y hasta setenta y cinco se lo conoce como "abastecimiento con estado de sostenibilidad regular"; aquellos sistemas de agua con un ISA mayor que setenta y cinco y hasta noventa se dice que es un "abastecimiento con estado de sostenibilidad bueno"; y, aquellos cuyos valores de ISA es mayor que noventa y hasta cien, entonces se tratará de un "abastecimiento con estado de sostenibilidad excelente". Ver cuadros siguientes.

Cuadro 3.2 Categorías de los estados de sostenibilidad para un abastecimiento, en función del valor de su ISA

\begin{tabular}{|l|r|r|r|}
\cline { 3 - 4 } \multicolumn{2}{c|}{} & \multicolumn{1}{c|}{ Desde } & \multicolumn{1}{c|}{ Hasta } \\
\hline & MALO & 0.00 & 40.00 \\
& DEFICIENTE & 40.01 & 60.00 \\
& REGULAR & 60.01 & 75.00 \\
& BUENO & 75.01 & 90.00 \\
& EXCELENTE & 90.01 & 100.00 \\
\hline
\end{tabular}

Figura 3.5 Distribución gráfica de la clasificación de los estados de sostenibilidad de un abastecimiento

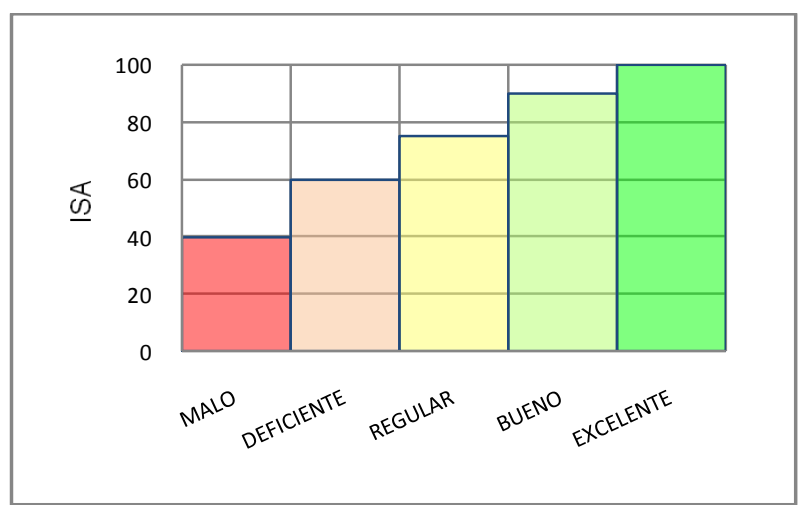

Los resultados de los subcomponentes se pueden presentar en diagramas de tela de araña para una fácil visualización e idealización de la valoración de cada componente y subcomponente, lo que implica transformarlos a una escala porcentual. 
Figura 3.6 Diagrama de distribución del valor ISA y sus componentes satelitales en porcentajes relativos.

Ejemplo de una combinación para ISA $=\mathbf{5 5 . 3}$

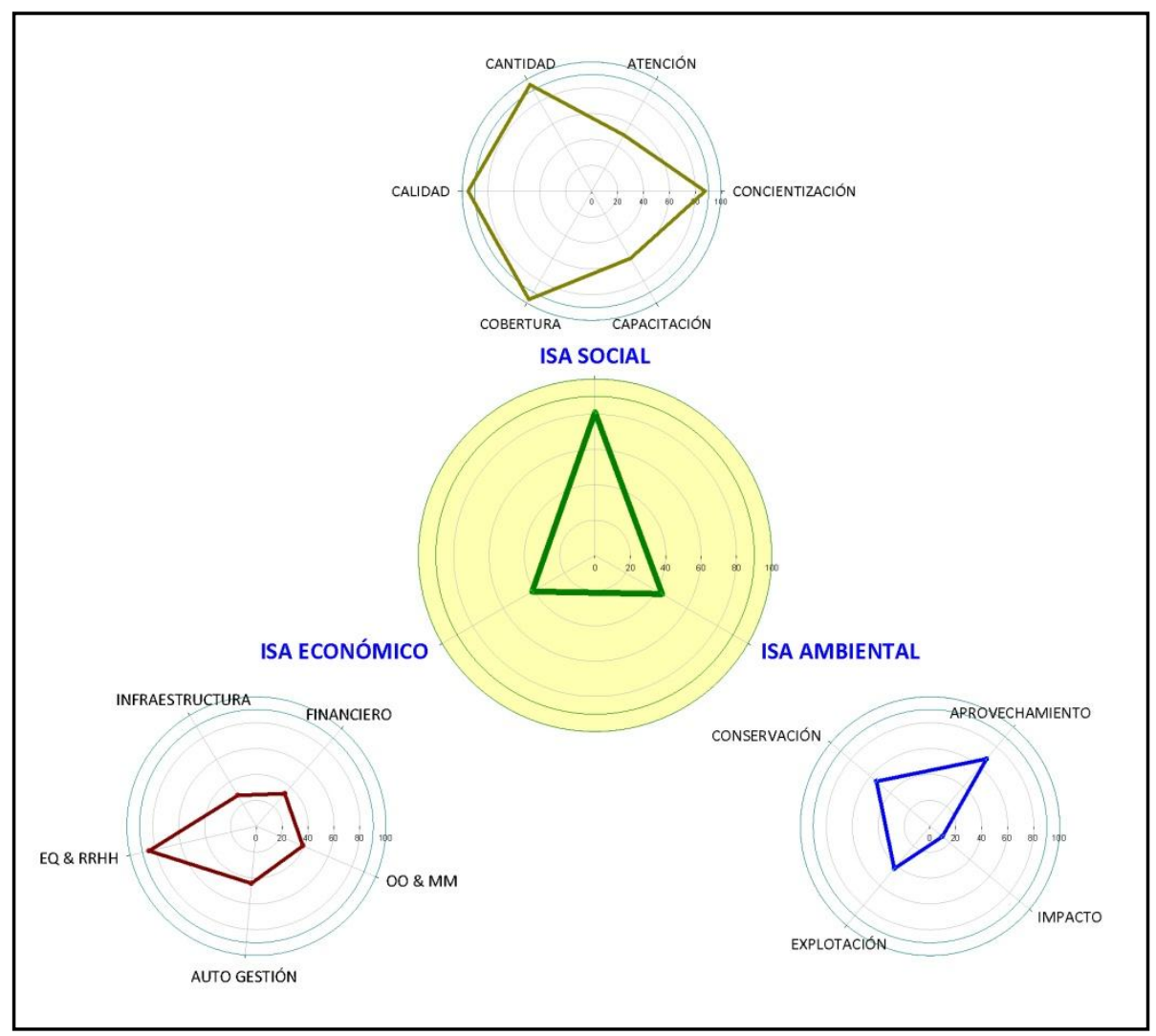

En este ejemplo, el ISA_social es de 27.0 (bueno), el ISA_económico de 13.7 (deficiente) y el ISA_ambiental de 14.6 (deficiente); características que suman un ISA de 55.3 (deficiente). 
Figura 3.7 Diagrama de distribución del valor ISA y sus componentes satélites en $\%$ relativos. Situación deseable, ISA $=100$

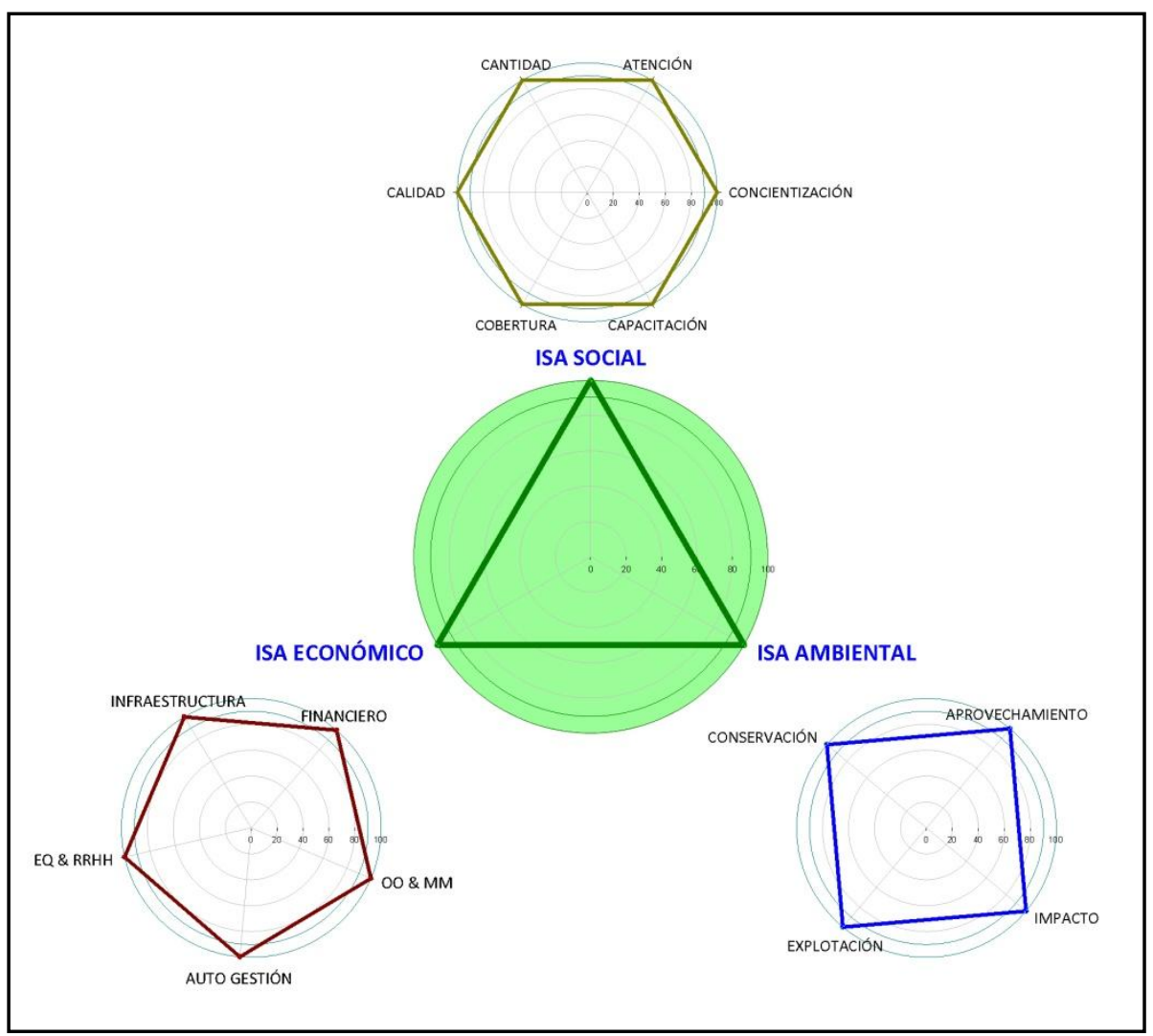

Cuadro 3.3 Categorías por componentes de los estados de sostenibilidad

\begin{tabular}{|c|c|c|c|c|c|c|}
\cline { 2 - 7 } \multicolumn{1}{c|}{} & \multicolumn{2}{c|}{ SOCIAL } & \multicolumn{2}{c|}{ ECONÓMICO } & \multicolumn{2}{c|}{ AMBIENTAL } \\
\cline { 2 - 7 } \multicolumn{1}{c|}{} & Desde & Hasta & Desde & Hasta & Desde & Hasta \\
\hline MALO & 0.00 & 13.32 & 0.00 & 13.32 & 0.00 & 13.32 \\
DEFICIENTE & 13.33 & 19.98 & 13.33 & 19.98 & 13.33 & 19.98 \\
REGULAR & 19.99 & 24.98 & 19.99 & 24.99 & 19.99 & 24.98 \\
BUENO & 24.99 & 29.97 & 25.00 & 29.98 & 24.99 & 29.97 \\
EXCELENTE & 29.98 & 33.30 & 29.99 & 33.40 & 29.98 & 33.30 \\
\hline
\end{tabular}




\section{ANEXO 3.1}

\section{Vocabulario}

El contenido de este anexo, es adaptado de (Medina G. y Benavides H. 2009), que se expone como complemento orientativo del vocabulario que se emplea en este capítulo.

\section{Sectorización de una red de abastecimiento de agua potable.}

La sectorización de la red para crear parcelas hidrométricas, significa limitarla o subdividirla en sectores, subsectores o distritos hidrométricos, aislados hidráulicamente entre sí, que disponen de una o varias entradas monitoreadas a través de nudos de control, mismos que deben estar equipados para macro medición de caudales y presiones.

\section{Sector}

Es la delimitación de la red, en el cual se incluyen distritos hidrométricos y/o subsectores, el sector debe constar de nudos de control al ingreso y puntos de monitoreo de presión distribuidos en varios sitios de la red.

Figura A.3.1.1 Configuración de las parcelas hidrométricas

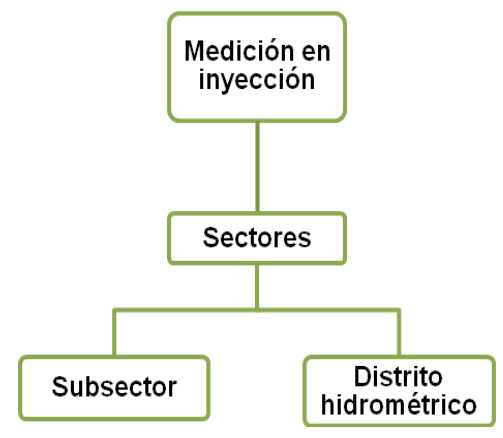

\section{Distrito hidrométrico}

Red que forma parte de un abastecimiento y que puede, en un momento dado, tener más de un punto de inyección; no obstante, en operación normal permanece aislada del resto de líneas y tuberías mediante válvulas, que impiden el paso de agua la casi totalidad del tiempo. 
Figura A.3.1.2 Sectorización y componentes de las parcelas hidrométricas

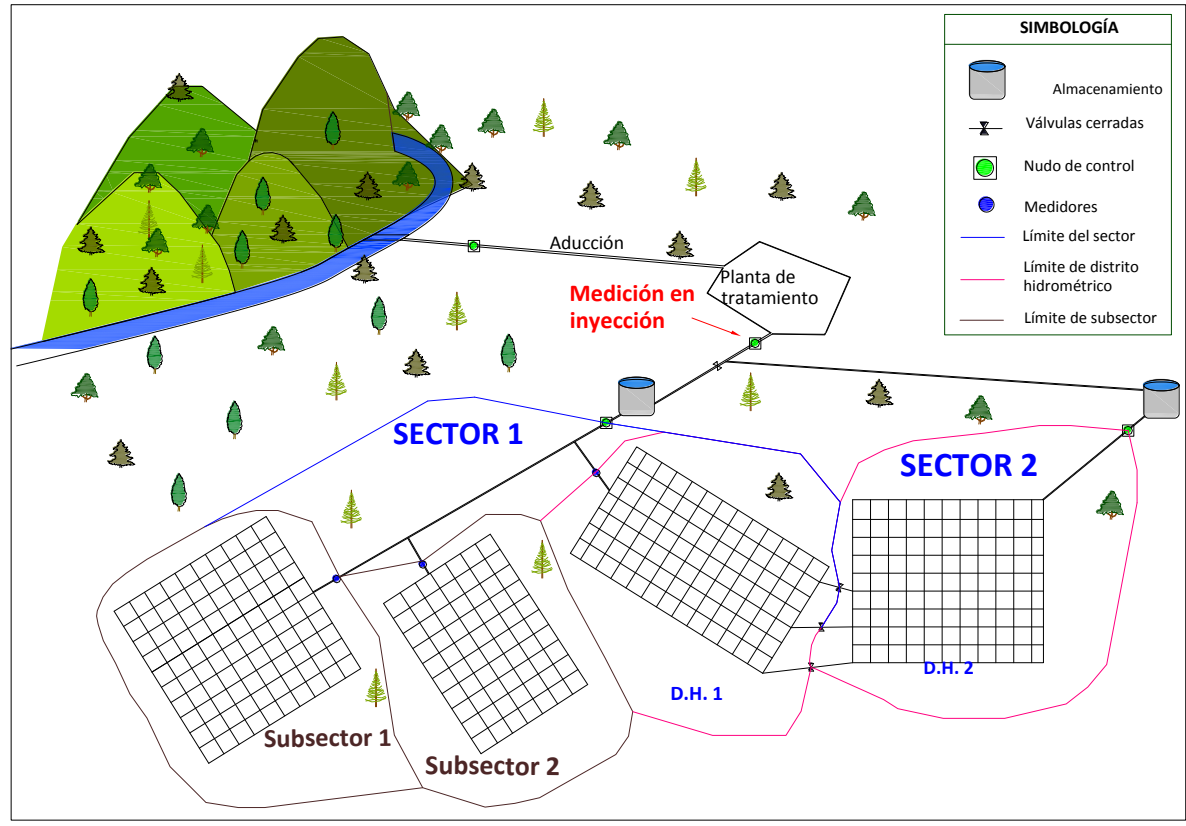

Fuente: Adaptado de (Medina G. y Benavides H. 2009)

Figura A.3.1.3

Características de la red a partir de la sectorización

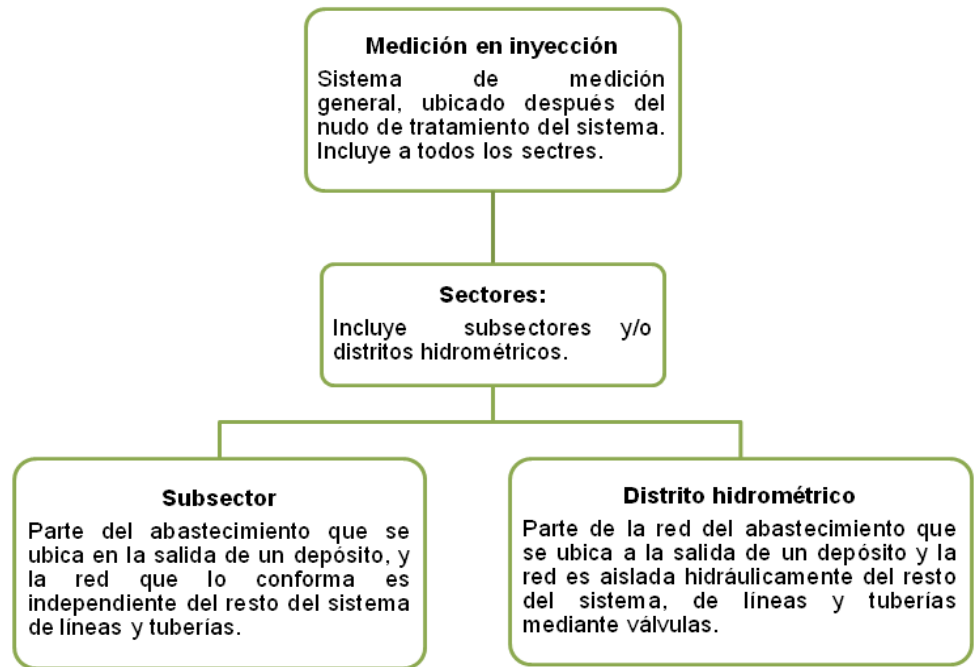




\section{Subsector}

Red que forma parte de un abastecimiento y que tiene un solo punto de inyección, cuenta con nudos de control; $y$, es independiente del resto de la red.

\section{Detección y localización de fugas}

Los métodos de detección y localización acústica se fundamentan en la intensidad y frecuencia del sonido de la fuga, para su ubicación utilizan instrumentos acústicos como: micrófonos de contacto, barras acústicas, geófonos, correlación acústica, micrófonos de suelo, fonómetros, principalmente.

\section{Tipo de ruido de una fuga}

El ruido originado por una fuga en tuberías enterradas es producido por el escape de agua a presión que genera vibraciones y "produce sonidos en un rango de frecuencia comprendido entre 350 y 2000 ciclos por segundo. Aunque el sonido puede mezclarse con los sonidos ambientales, que se encuentran dentro de un rango de 350 ciclos por segundo" ${ }^{4}$.

Tres tipos de sonidos que son producidos por las fugas.

a. La resonancia o vibración de la tubería producida por la salida del agua mediante el orificio, es el ruido más intenso.

b. El ruido por el impacto del agua en el suelo o por la circulación del agua es más débil y es escuchado cuando se está muy cerca de la fuga.

c. El agua impactando directamente sobre el suelo suena a modo de golpe o tintineo mientras que el flujo del agua por el suelo produce un sonido similar a un arroyo o una corriente de montaña.

\section{Factores que afectan el sonido y frecuencia de las fugas}

- $\quad$ Presión de agua en la tubería

- $\quad$ Material y diámetro de la tubería

- $\quad$ Tipo de suelo y grado de compactación

- $\quad$ Profundidad de la tubería

- Cubierta superficial.

4 Recomendaciones para detección y aforo de fugas en tomas domiciliarias. CEPIS. http://www.cepis.org.pe/bvsair/e/repindex/repi48/recomen/recomen.html, consulta Febrero 2009, página activa. 
La intensidad del sonido es directamente proporcional a la presión en el interior de la tubería.

Figura A.3.1.4 Intensidad del sonido vs. presión de agua

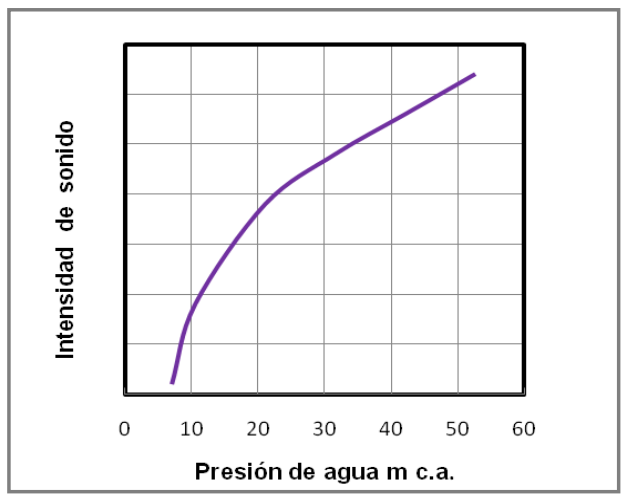

Fuente: Adaptado de SubSurface Leak Detection, Inc. How to find Leaks. http://www.subsurfaceleak.com/find_leaks.html

Conocer el material de la tubería es importante por ejemplo las tuberías metálicas como: hierro, cobre o acero producen una frecuencia de ruido más alta que las tuberías de PVC o de asbesto-cemento.

Las tuberías de diámetro grande generan un ruido menor originado por las fugas que las tuberías de diámetro menor, independientemente del material de la misma.

En suelos arenosos, suelos saturados de agua es difícil la transmisión del ruido, peor aún en un suelo compactado.

Se puede captar con más facilidad aquellos ruidos que se producen e tuberías enterradas hasta $1.25 \mathrm{~m}$ de profundidad.

Difícilmente se capta ruidos en tuberías enterradas más allá de los $2.0 \mathrm{~m}$, a no ser que el agua que el sistema en esos puntos se someta a presiones elevadas.

Las cubiertas superficiales duras suenan con la fuga de agua y el sonido puede ser detectado a una distancia de $2.5 \mathrm{~m}$ a $5.0 \mathrm{~m}$, mientras en superficies como hierba o de suelo flojo el sonido es menor. 
Transmisión del sonido a través de las paredes de la tubería.

La distancia a la que se puede detectar los sonidos de fugas está en función del material y del diámetro de la tubería.

Figura A.3.1.5 Profundidad de tubería vs. frecuencia de sonido de la fuga

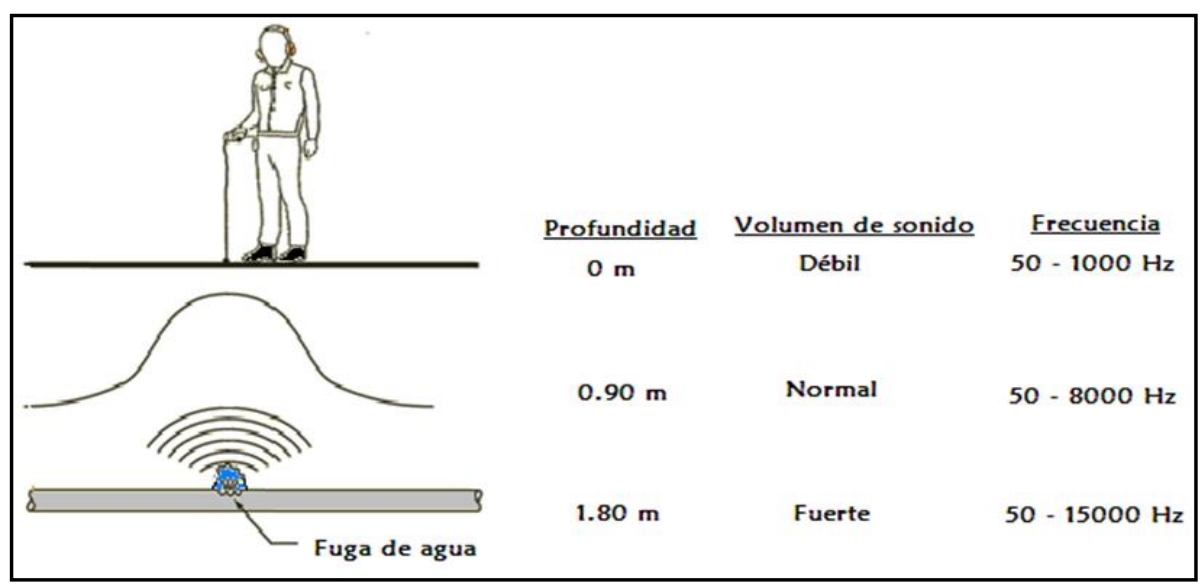

Fuente: Tomado de SubSurface Leak Detection, Inc. How to find Leaks. http:// www.subsurfaceleak.com/find_leaks.html

Figura A.3.1.6 Distancia de transmisión del sonido de la fuga según el material de la tubería, para $1.36 \mathrm{~m}^{3} / \mathrm{h}$, y $42 \mathrm{~m}$ c.a [60 psi]

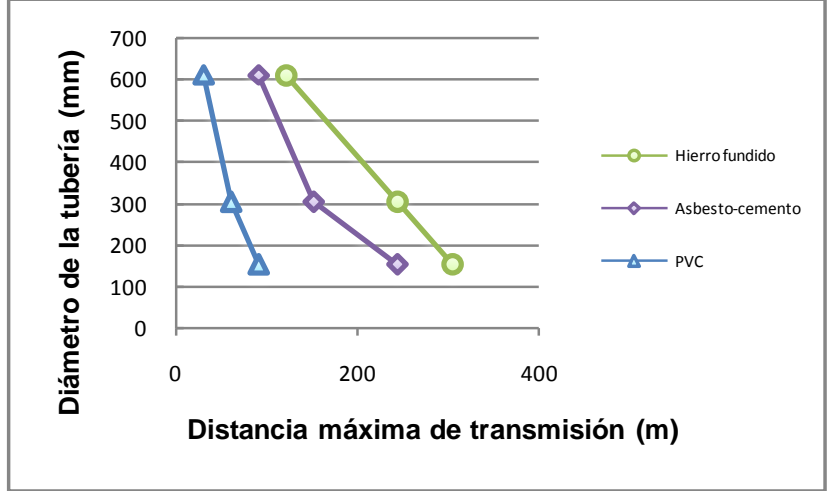

Fuente: Adaptado de SubSurface Leak Detection, Inc. How to find leaks. http://www.subsurfaceleak.com/find_leaks.html 
Equipos para la detección y localización de fugas.

\section{Por correlación acústica}

Este equipo electrónico (correlación acústica) permite localizar de forma precisa el sitio de la fugas, en función de una onda acústica que circula a través de la tubería de agua.

Es el método y equipo más utilizado en los países desarrollados, por su precisión y por su insensibilidad a los ruidos ambientales, se utiliza en redes de distribución con tuberías metálicas y en las plásticas bajo ciertas limitantes.

\section{Principios de funcionamiento}

El correlador acústico consta de dos o más sensores que se ponen en contacto con la tubería, éstos captan el ruido, lo amplifica y lo transmiten a la unidad central.

Las señales transmitidas por los sensores, se procesan en sus componentes de frecuencia, y elimina la información que no es común a la fuga (ruido por automóviles). ${ }^{5}$

Para su efectivo aprovechamiento, se debe conocer los siguientes parámetros:

- Tuberías bajo presión

- Tuberías libres de aire

- Velocidad del sonido

- Ubicación de las tuberías

- $\quad$ Tipo de material y diámetro de la tubería

La localización y reparación de fugas utilizando estos dispositivos permite que el servicio público ahorre tiempo y dinero.

\section{Geófono}

Es un instrumento transmisor y amplificador de sonido de la fuga, utilizado para detectar ruidos subterráneos que se propagan en el suelo.

$\begin{array}{lllll} & \text { Correlador } \\ \text { www.eathisa.com/dat/archivos/MAQ6000.pdf. } & \text { por } & \text { PC, } & \text { Multicorrelación. } & \text { EATHISA }\end{array}$ 
Formado por un micrófono que capta y recoge el sonido de la fuga luego lo transmite como una señal acústica a los auriculares y mediante un micro amperímetro se visualiza a través de un display digital, en el que se muestra el nivel y variación del ruido. Los micrófonos son colocados en puntos de la red, tales como válvulas, llaves de corte, hidrantes, medidores domiciliarios, etc. ${ }^{6}$

El micrófono esta puesto en dos tipos de sondas: sonda de campana o micrófono de suelo y sonda de bastón o micrófono de contacto.

Para facilitar la audición del sonido, es conveniente temporalmente el tráfico vehicular y que la presión en la toma sea mayor que $10 \mathrm{~m}$ c.a. En ocasiones es mejor efectuar esta práctica por la noche, que es cuando se tienen menor ruido ambiental y la presión en la red aumenta.

\section{Gestión de la presión}

La gestión de la presión en los sistemas de distribución de agua potable es una actividad principal para reducir pérdidas reales de agua y bajar la frecuencia de la aparición de fallos en la red y en las conexiones o acometidas.

La presión, por norma de operación, se considera como máxima estática $70 \mathrm{~m}$ c.a., y la máxima dinámica $50 \mathrm{~m}$ c.a.; la mínima es $10 \mathrm{~m} \mathrm{c.a;} \mathrm{en} \mathrm{el} \mathrm{caso} \mathrm{de}$ abastecimiento mediante grifos públicos la presión mínima puede ser de hasta 5 m c.a. (Norma Ex - IEOS, Título VII).

\section{Dispositivos para el control de presión}

La gestión de presión es a menudo lograda por la instalación de válvulas de regulación (reguladoras de presión VRP y sostenedoras de presión VSP). La inadecuada operación y el mantenimiento deficiente dan como resultado problemas en la operación del sistema, generando fenómenos transitorios o problemas de aire atrapado, situaciones que incrementan la generación de fugas.

- $\quad$ Las válvulas reductoras de presión. - regulan la presión aguas abajo del punto de instalación. Actúan además como válvulas de retención, ya que impiden la circulación del agua en sentido contrario al programado.

- Válvulas sostenedoras de presión.- mantiene la presión aguas arriba de su punto de instalación. Cuando los consumos aumentan aguas abajo,

6

Resumido: http://www.inspeccionestecnicas.es/geofono.htm 
la válvula cierra progresivamente para mantener la presión aguas arriba. También actúan como válvulas de retención.

Para seleccionar la válvula de regulación se considera:

- Costo de instalación y mantenimiento,

- Tamaño y contextura del sistema de distribución,

- Pronóstico de ahorro de agua,

- $\quad$ Consecuencias de deterioro,

- $\quad$ Número de consumidores,

- Presión mínima, regulaciones contra incendios ${ }^{7}$.

\section{Factores que se debe considerar en la gestión de la presión}

Relación de la presión y el caudal de fuga

El caudal de fuga $\left(Q_{f}\right)$ depende del área de la fuga $\left(A_{f}\right)$ y de la velocidad de salida del fluido $\left(V_{f}\right)$, que es directamente proporcional a la raíz cuadrada de la presión estática.

$$
Q_{f}=C_{D} \times A_{f} \times \sqrt{2 g h}
$$

Donde:

$C_{D} \quad$ - coeficiente de descarga del orificio, en función del régimen del flujo.

Las fugas pequeñas son sensibles al cambio de presión. Con la teoría FAVAD (Fixed And Variable Area Discharge paths, los trayectos de descarga de área fija y variable) se demuestra que la sección transversal de la fuga (agujeros, roturas en tubos, juntas o accesorios) varía con la presión.

La IWA y UKWIR representan la relación del caudal de fuga y la presión, así:

$$
\frac{Q_{f}}{Q_{o}}=\left(\frac{P_{f}}{P_{o}}\right)^{N 1}
$$


Donde $Q_{f}$ es el caudal de la fuga luego de la reducción de presión; $Q_{0}$ es el caudal de fugas antes de la reducción de presión; $P_{f}$ es la presión después de implementar su reducción; $\mathrm{P}_{\mathrm{o}}$ es la presión antes de implementar su reducción; $N_{1}$ es el exponente que varía entre 0.5 y 1.5 pero puede alcanzar valores de hasta 2.5 , el que depende del tipo de agujero o falla longitudinal y el material de la tubería.

\section{Agujeros circulares:}

- $\quad$ "En tuberías de PVC y metálicas N1 es cercano a 0.5.

- $\quad$ En tuberías de polietileno (PE) y asbesto-cemento (AC) N1 está cerca de 0.5 .

- $\quad$ Para agujeros pequeños, N1 puede estar entre 0.5 y 1.0 .

- $\quad$ En grupos de agujeros formados por la corrosión, N1 puede ser mayor a 1.0

Fallas longitudinales:

- Para tuberías de PVC con bajas relaciones Longitud/Ancho (L/A), $\mathrm{N} 1=0.5$

- $\quad$ Para tuberías de PVC a relaciones $\mathrm{L} / \mathrm{A}=500, \mathrm{~N} 1=2.0$

- Para tuberías de AC, N1 de 0.8 a $1.0 " 8$

Relación entre la presión y frecuencia de nuevas fugas

Mediante parcelas hidrométricas en los sistemas de distribución y con la suficiente información, la reducción de presión presenta una disminución de los caudales de fuga y reduce la aparición de nuevas fugas.

La relación entre la frecuencia de aparición de nuevas fugas y la presión de operación del sistema requiere que se conozca:

- Histórico y distribución espacial de roturas, antes y después de la campaña de control de presiones. La clasificación de las roturas en los componentes del sistema (redes matrices, redes de distribución, conexiones domiciliarias).

- $\quad$ La edad, dimensiones, materiales y condiciones de operación de las tuberías.

- $\quad$ La clasificación de las roturas según sus causas.

8

CONTRERAS GARZÓN, Fabio y THORNTON, Julián. (2006) “Influencia de la presión en las pérdidas de agua en sistemas de distribución”. Asociación Interamericana de ingeniería sanitaría y ambientalAIDIS. XXX Congreso interamericano de ingeniería sanitaría y ambiental. Uruguay. 
- La frecuencia de tuberías reventadas $(x \mathrm{~km})$ se incrementan para presiones superiores a $40 \mathrm{~m}$ c.a.

La IWA desarrolló la siguiente expresión, para pronosticar la frecuencia de aparición de nuevas fugas en función de la presión de operación:

$$
\frac{R 1}{R o}=\left(\frac{P 1}{P o}\right)^{N 2}
$$

Donde R1 es la frecuencia de roturas después de la reducción de la presión y Ro antes de la reducción de la presión, N2 es un exponente que varía entre 0.5 y 6.5 .

Los valores del exponente N2 representa reducciones importantes en la frecuencia de aparición de nuevas roturas.

El valor de N2 se propuso en los 90's, luego de compararlo en varios abastecimientos de Australia, Italia y Reino Unido.

Cuadro A.3.1.1 Valores del exponente $\mathrm{N}_{2}$ según Thornton y Lambert

\begin{tabular}{|l|l|c|}
\hline \multicolumn{1}{|c|}{ País } & \multicolumn{1}{|c|}{ Sistema } & N2 \\
\hline Reino Unido & UKWIR & $>0.5$ \\
\hline \multirow{4}{*}{ Australia } & Brisbane - Sector piloto & 0.5 \\
\cline { 2 - 3 } & Valle Yarra - Sector piloto D & 0.64 \\
\cline { 2 - 3 } & Valle Yarra - Sector piloto B & 0.68 \\
\cline { 2 - 3 } & Valle Yarra - Sector piloto C & 0.91 \\
\cline { 2 - 3 } & Valle Yarra - Sector piloto A & 1.55 \\
\hline Reino Unido & Welsh Water, redes matrices & 3.0 \\
\hline \multirow{4}{*}{ Australia } & $\begin{array}{l}\text { Gold Coast - Sector piloto, } \\
\text { domiciliarias }\end{array}$ & 4.9 \\
\cline { 2 - 3 } & $\begin{array}{l}\text { Gold Coast - Sector piloto, } \\
\text { redes matrices }\end{array}$ \\
\hline Italia & Turin & 6.3 \\
\hline
\end{tabular}

Sin embargo, se encontró que esta idea de relacionar la frecuencia de fallos y la relación de presión elevada al exponente N2 (la ecuación básica FAVAD) no era apropiada y se propuso (luego de estudios presentados del 2005 al 2007) la relación entre la presión y la tasa de fallos, según la figura siguiente. 
Figura A.3.1.7 Influencia de la presión y la frecuencia de rupturas en tuberías

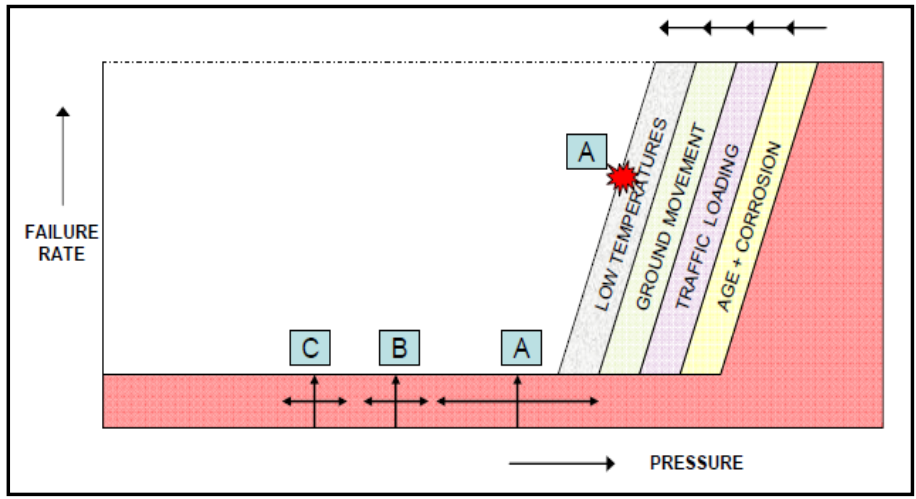

Fuente: Tomado de (Lambert A. y Fantozzi M. 2010).

De donde:

Condición A: la presión máxima diaria interactúa con otros factores para incrementar la tasa de fallos o rupturas en la tubería.

Condición B: la reducción del pico diario y el promedio de presión reducen la tasa de fallos para niveles bajos y se extiende a toda la vida de la infraestructura.

Condición C: $\quad$ Si la presión se reduce de $B$ a $C$, el nivel de fallos y rupturas baja. (Lambert A. y Fantozzi M. 2010).

\section{Gestión de la infraestructura}

\section{Mantenimiento y rehabilitación}

El mantenimiento consiste en actividades para la reparación ágil, acorde a las necesidades del sistema. Se deberá realizar mantenimiento en válvulas, tuberías, conexiones domiciliarias, acometidas y en los aparatos para la detección y localización de fugas, herramientas que son utilizadas para la rehabilitación y reparación de fugas.

La infraestructura de cada red de distribución requiere mantenimiento, actualización y renovación. Si son diseñados con un periodo de vida útil de 40 años, la infraestructura debería en un $2.5 \%$ en promedio ser renovada cada año. 
El permanente y adecuado mantenimiento del sistema de agua potable, mediante inspecciones de los componentes de la red garantiza un menor volumen de fugas debido a reboses, válvulas deterioradas, medidores defectuosos y fisuras en los reservorios.

"Los medidores domiciliarios tienen un tiempo de vida útil de 5 a 8 años" 9 , lapso de tiempo que la confiabilidad de registros es buena con errores máximos permisibles de $+/-5 \%$ para el caudal mínimo y $+/-2 \%$ para los caudales transitorios y máximos, luego de ese tiempo si no hay un adecuado mantenimiento preventivo los datos serán erróneos.

El mantenimiento correctivo: que tiene lugar luego que ocurre una falla o avería, es decir, sólo se actúa cuando aparece el problema.

El mantenimiento preventivo: se realiza en forma planificada antes de que ocurra una falla o avería, y se efectúa bajo condiciones programadas, lo cual garantiza mayor vida útil del sistema, mejor servicio e inminente sostenibilidad.

Para los procesos de limpieza y desinfección de la red se deberá comunicar a los usuarios que no dispondrán del servicio durante la realización de estas tareas, lo cual se procederá al cierre de las válvulas de paso de las conexiones domiciliarias. Las actividades de limpieza de la red se deben realizar en horas que no provoque incomodidad al usuario.

Cuadro A.3.1.2 Actividades de mantenimiento de la red de abastecimiento Ejemplo de listas de chequeo para operadores

\begin{tabular}{|c|c|c|}
\hline \multicolumn{1}{|c|}{ ACTIVIDAD } & SI & NO \\
\hline - & $\begin{array}{l}\text { Limpieza exterior de captación, planta de tratamiento, tanques de } \\
\text { almacenamiento, cámaras de rompe presión. }\end{array}$ & \\
\hline - & $\begin{array}{l}\text { Inspecciones de campo, verificar el buen funcionamiento de los contadores } \\
\text { en nudos de control, caso contario ajustarlo o sustituirlos. }\end{array}$ & \\
\hline - & $\begin{array}{l}\text { Reparación o renovación de la tubería en caso de presentar fugas debido a } \\
\text { material deteriorado. }\end{array}$ & \\
\hline Mantenimiento en cámaras de rompe presión: & & \\
\hline - & Abrir las tapas y revisar el estado de las paredes interiores y los accesorios. & \\
\hline - Limpiar pisos, paredes y accesorios. & \\
\hline - Limpiar los accesorios y las paredes con la solución de hipoclorito de calcio. & & \\
\hline - & & \\
\hline
\end{tabular}

9

Resumido: www.cepis.ops-oms.org/bvsacd/scan3/024553.pdf

https://basedoc.superservicios.gov.co/basedoc/notindexed/2005/CTO_SSPD_0000021_2006.doc 


\begin{tabular}{|c|c|c|c|}
\hline \multicolumn{2}{|r|}{ ACTIVIDAD } & \multirow[t]{2}{*}{ SI } & \multirow[t]{2}{*}{ NO } \\
\hline • & Eliminar los restos de cloro y purgar por la tubería de limpia. & & \\
\hline \multicolumn{4}{|c|}{ Desinfección de la tubería utilizando la solución de hipoclorito } \\
\hline - & Abrir la válvula de salida del reservorio & & \\
\hline & $\begin{array}{l}\text { Abrir las válvulas de purga, para que la tubería se llene de agua clorada e } \\
\text { inmediatamente cerrarlas. }\end{array}$ & & \\
\hline & Dejar actuar la solución durante cuatro horas. & & \\
\hline & Abrir las válvulas de purga para el vaciado de la solución. & & \\
\hline & $\begin{array}{l}\text { Abrir la válvula de salida del reservorio e ingresar agua a la red de } \\
\text { distribución. }\end{array}$ & & \\
\hline - & Cuando no se perciba olor a cloro se pondrá a servicio la red. & & \\
\hline & Abrir las válvulas de paso de las instalaciones domiciliarias. & & \\
\hline \multicolumn{4}{|c|}{ Mantenimiento de válvulas: } \\
\hline & $\begin{array}{l}\text { Realizar inspecciones, observar si hay filtraciones, deterioros externos, } \\
\text { empozamiento de agua en los alrededores, tierra acumulada sobre las cajas, } \\
\text { candados o elementos de cierre en mal estado. }\end{array}$ & & \\
\hline & $\begin{array}{l}\text { Revisar su funcionamiento, haciendo girar lentamente; evitando la presencia } \\
\text { del golpe de ariete. }\end{array}$ & & \\
\hline 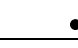 & Abrir y cerrar totalmente cada válvula, varias veces al año. & & \\
\hline & $\begin{array}{l}\text { En caso de la presencia de fugas, se debe ajustar la contratuerca, y; en caso } \\
\text { de desgaste cambiarla. }\end{array}$ & & \\
\hline & $\begin{array}{l}\text { Para facilitar su manejo se debe colocar aceite de baja viscosidad entre el } \\
\text { vástago y la contratuerca superior. }\end{array}$ & & \\
\hline & Mantenimiento con pintura anticorrosiva de válvulas y accesorios metálicos. & & \\
\hline & $\begin{array}{l}\text { Mensualmente limpiar y revisar las cajas de válvulas e inspeccionar las vías } \\
\text { en que se encuentra enterrada la red de distribución, con el fin de detectar } \\
\text { fugas u otras anomalías. }\end{array}$ & & \\
\hline
\end{tabular}

Fuente: Adaptado de (Medina G. y Benavides H. 2009)

\section{Pérdidas de agua}

Es aquel volumen de agua, que siendo inyectado en la red no llega a los abonados, o que llegando a ellos no puede ser medido ni contabilizado efectivamente.

Las pérdidas de agua se dan por: fugas en tuberías principales y secundarias, fugas en conexiones domiciliarias, reboses en tanques de almacenamiento y en estaciones de bombeo, conexiones no-autorizadas (clandestinas), errores de medición domiciliaria, errores de facturación, entre las relevantes. 
Pérdidas reales.- Representa las fugas de agua tanto de la red como de las conexiones domiciliarias. Las pérdidas reales se presentan principalmente por: empates mal realizados, cristalización de gomas en las uniones, daños que no afloran a la superficie o por malos criterios constructivos de la red. "El volumen anual que se pierde a través de todo tipo de fugas, roturas y desbordamientos depende de las frecuencias, caudales y duración promedio de las fugas individuales". ${ }^{10}$

Pérdidas aparentes.- Las pérdidas aparentes representan agua consumida pero no facturada, las salidas de caudal no medidos o no registrados por errores en los medidores o conexiones clandestinas o no autorizadas. Se debe considerar el consumo de hidrantes para fines sociales (incendios principalmente).

Fuga

Una fuga es un escape de agua en cualquier punto del sistema como consecuencia de la pérdida de estanqueidad de la red. Puede ocurrir en conducciones, tanques de almacenamiento, redes de distribución, conexiones domiciliarias e intradomiciliarias. Mientras más pequeña es la fuga más tiempo toma su detección.

\section{Etapas de fugas}

Según Allan Lambert, Stephen Myers y Stuart Trow (Managing water leakage) las etapas de las fugas dependen del procedimiento de identificación y tiempo de duración de la fuga, explicado en tres fases:

Detección.- Intervalo de tiempo de iniciación hasta donde la empresa operadora conoce de la existencia de la fuga, pero no su localización.

Localización.- Tiempo de ubicación de la fuga con instrumentos acústicos.

Reparación.- Tiempo de reparación de la fuga luego de ser localizada por la empresa.

\section{Clasificación de fugas}

Se clasifican en reportadas, no reportadas y de fondo (inevitables).

\footnotetext{
10 Manual de indicadores de gestión para agua potable y alcantarillado sanitario. Asociación de entes Reguladores de Agua Potable y Saneamiento de las Américas (ADERASA). pág. 9 http://www.aderasa.org/aa/img_upload/.../Manual_de_Benchmarking_de_ADERASA_marzo_2007.d $\underline{\mathrm{OC}}$
} 


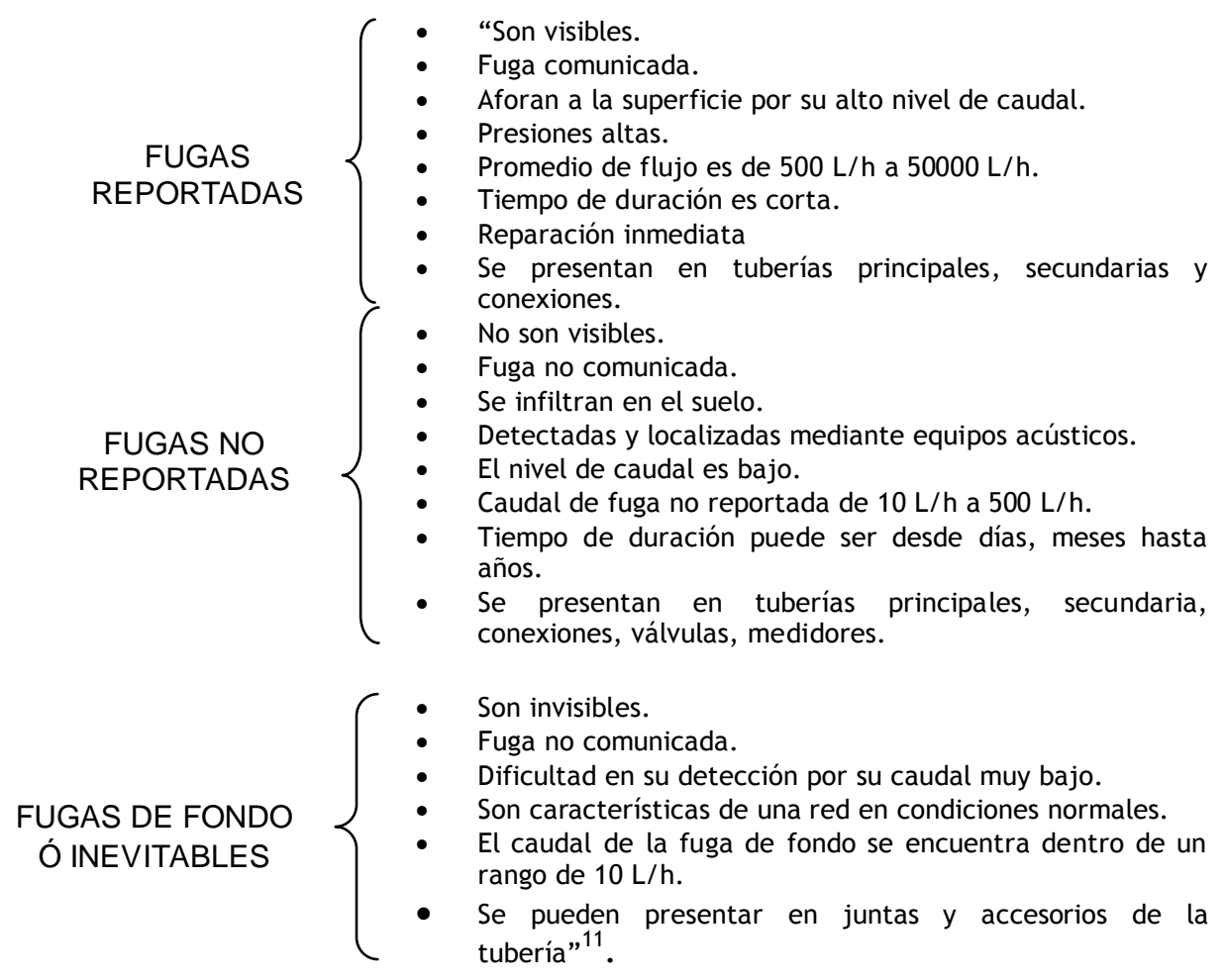

\section{Causas de origen de las fugas}

Fallas estructurales, geotécnicas y de estabilidad de los elementos de la red (deslizamientos del terreno, los diferentes componentes del suelo y algunas obras subterráneas alrededor de la red crean presiones externas en la red, lo cual puede provocar cizallamiento y posterior a la ruptura de las tuberías.)

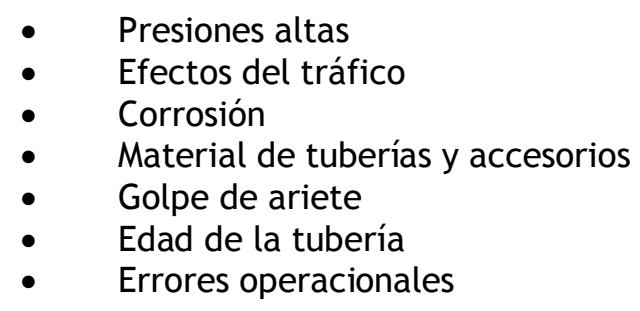

11

Resumido de: M.I. Víctor Bourguet Ortiz. Centro mexicano de capacitación en agua y saneamiento, A.C. AF1_3 Estrategia y organización para la detección de fugas. México 2004; y, apuntes personales. 
- Mano de obra

- Movimiento del suelo

La importancia de las fugas depende de diversos factores como:

- Tamaño del agujero o fisura en la tubería,

- Dimensión y forma,

- $\quad$ Presión en el interior de las tuberías,

- Las fugas también se presentan en los tanques de almacenamiento debido a reboses de agua.

Lugar de ocurrencia de las fugas
a. Fugas en depósitos
b. Fugas en conducciones
c. Fugas en conexiones domiciliarias
d. Fugas en el cuadro del medidor.
e. Fugas en cajas de válvulas.
f. Fugas intradomiciliarias. 


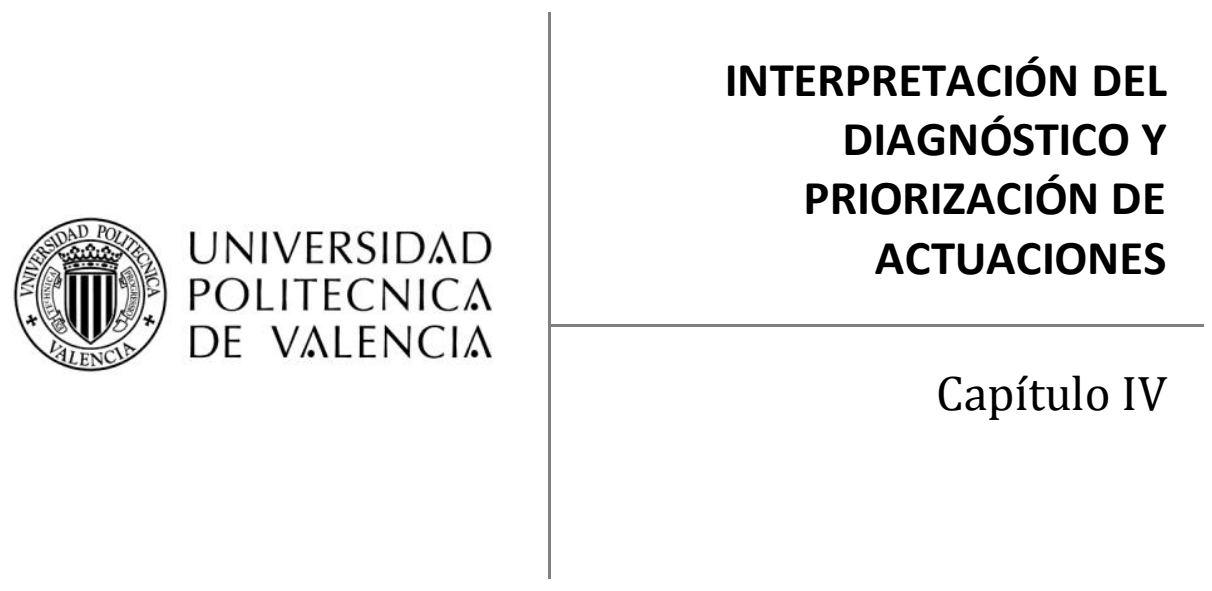





\section{INTERPRETACIÓN DEL DIAGNÓSTICO Y PRIORIZACIÓN DE ACTUACIONES}

En este capítulo se presentan los aspectos necesarios para analizar e interpretar el diagnóstico ISA mediante su desagregación, así como los criterios de análisis e interpretación de los resultados porcentuales de cada subcomponente, para la selección de actividades mediante la matriz de priorización.

Además se propone un catálogo de actuaciones que resume las fases, procedimientos y cálculos implícitos en la metodología ISA, para el diagnóstico de la sostenibilidad de abastecimientos.

\subsection{Análisis e interpretación del diagnóstico ISA}

En un proceso de agregación de componentes para la simplificación de resultados, existe la posibilidad que se pierda información, se eliminen aspectos importantes ó incluso se deteriore su transparencia. Contrariamente a esto, la metodología ISA, permite como herramienta de diagnóstico, simplificar al máximo la información existente respecto de la sostenibilidad de un abastecimiento, pero de una forma que soporta visualizar su trazabilidad y muestra el origen de cada valor condensado, de los componentes, subcomponentes e indicadores, dependiendo del nivel de desagregación que se requiera.

La metodología de diagnóstico ISA, se presenta entonces como un sistema de simplificación potente debido a que, además de lo anterior, involucra procesos de valoración cualitativos que tienen su origen en entrevistas técnicas guiadas - Delphi, lo cual reduce al máximo posible la subjetividad que se podría esperar al agregar los aspectos sociales, con los económicos y con los ambientales que intervienen en un abastecimiento a la hora de evaluarlo.

\section{Interpretación y análisis}

La interpretación del diagnóstico ISA, permite trazar el plan de mejora de la gestión, principalmente para:

- Buscar la sostenibilidad del abastecimiento con acciones referidas a los aspectos técnicos evaluados.

- Direccionar recursos hacia aquellos subcomponentes que se encuentren en peores condiciones respecto de un ideal establecido. 
- Modificar el rumbo de la gestión, prioritariamente, hacia aquellos indicadores cuyo estado se percibió más distante de lo sostenible.

- Enfocar una planificación estratégica en las oportunidades que brinda el propio entorno para su mejora.

- Evitar continuar con la desatención de los aspectos fundamentales del sistema de agua que generan menoscabo de la calidad y eficiencia del servicio.

\section{Desagregación y trazabilidad}

Una vez que se determina el valor del índice -resultante de la agregaciónpara el abastecimiento evaluado y el diagnóstico de sostenibilidad, se debe iniciar el proceso de selección de medidas correctoras. Para ello debemos tomar en cuenta la distribución porcentual de los componentes y subcomponentes del ISA; dicha tarea se facilita por la presentación de resultados mediante el diagrama tela de araña del diagnóstico y sus elementos satélites. Estos diagramas activan la comunicación visual del diagnóstico y promueven la identificación de los problemas reales.

Figura 4.1 Diagrama tela de araña como instrumento de desagregación.

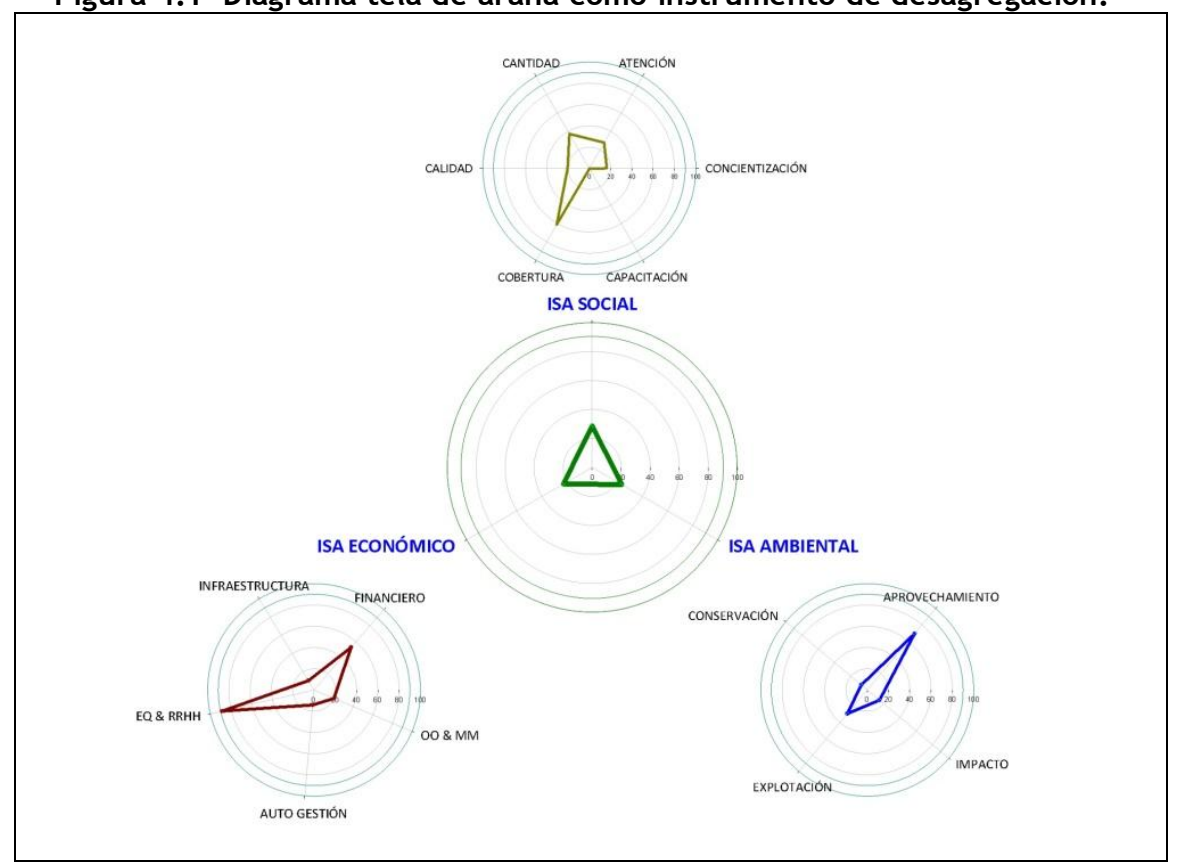


Para desagregar el resultado del diagnóstico ISA, se requiere principalmente, que el equipo que se encarga de su interpretación y de la selección de alternativas de mejora, sea metódico y sistemático a la hora de aplicar sus conocimientos y experiencias, de tal modo que las áreas prioritarias de trabajo se enfoquen, con pensamiento crítico, en aquellos subcomponentes que presenten un menor valor porcentual.

La planificación estratégica, así proyectada desde el diagnóstico ISA, obliga a:

- Seleccionar los problemas por su urgencia, necesidad y obligatoriedad, así como optimizar las posibles soluciones, participativamente entre los involucrados directos e indirectos;

- Buscar las causas que condujeron a tener tal grado de detrimento en los componentes del abastecimiento y orientar las soluciones para bien reducirlas ó bien eliminarlas desde su raíz;

- Agrupar todos los problemas y los resultados que se esperan una vez se ha puesta en marcha el plan de acción;

- Ratificar, ampliar y/o mejorar los indicadores, que permitan medir tales intervenciones, con interposición de los datos recogidos;

- Organizar actividades medibles y específicas, con base en los recursos disponibles; incluir espacios y tiempos centrados en la realidad y en el contexto de cada entorno; y,

- Proyectar los nuevos niveles de sostenibilidad (ISA) que se espera lograr en cada fase de actuación.

El cambio que se precisa, no es ni rápido ni fácil. Sin embargo, siempre antes de aplicar cualquier variante, se debe evaluar, desde todos los puntos, la viabilidad que para la empresa, la sociedad y para el propio sistema tendrá. (Agredano R. 2005).

\subsection{Matriz de prioridades relativas}

Dada la necesidad de organizar las medidas correctoras para mejorar el nivel de sostenibilidad del abastecimiento según su prioridad, urgencia y obligatoriedad, en este trabajo se presenta una variante metodológica de selección participativa de prioridades relativas que resulta de combinar 
las técnicas del $A B C$, extraída del planificador de Franklin y la comparación por parejas; tarea que se adapta y evoluciona con base en lo propuesto por (Pabón L. 2007) y (Páez J. 1996).

En el desarrollo participativo de la priorización de actividades, el equipo involucrado en tan trascendente tarea debe actuar de forma muy responsable y analizar aguda y detenidamente todas las opciones y aspectos de sus decisiones, siempre con fundamento en la literatura técnica y combinado con las buenas prácticas de la empresa.

El presente instrumento tiene como fin: facilitar la priorización de actividades de la gestión del abastecimiento para mejorar su sostenibilidad, como marco estratégico de actuación para la institución. Queda implícito, que la subjetividad del método se subordina al grado de fiabilidad, experiencia y conocimiento de los expertos que participan en ella.

\section{Descripción del método propuesto.-}

1) En una matriz cuadrada, cuyo orden $(n \times n)$ lo marca el número de indicadores (subcomponentes o actividades) que se desea priorizar, se anotan todos, de arriba abajo y de izquierda a derecha, en la misma secuencia.

2) Se escriben ceros en la diagonal principal.

3) Se compara el indicador de cada fila con el de cada columna, desde la diagonal hacia la derecha, mediante la pregunta: ¿El indicador (o actividad o subcomponente) de la fila es más urgente, más importante y más obligatorio que el indicador de la columna?

La respuesta que se anota en la intersección cuestionada puede ser un número de 0 hasta 3 inclusive, según corresponda:

Si no es más urgente, ó ni más importante, ó ni más obligatorio, entonces registramos un cero.

Si sólo es más urgente, ó sólo más obligatorio, ó sólo más importante, anotamos un uno.

Si es más urgente y más obligatorio; ó, es más urgente y más importante; ó, es más obligatorio y más importante, entonces se le asigna el valor de dos.

Si es las tres cosas al mismo tiempo, consignamos el número tres. 
4) En cada fila, se realiza el conteo de las casillas que tienen valor de 0 y se escribe en la columna "conteo de 0". Esta columna luego se transpone en la parte inferior de la matriz de cálculo para ser sumada con la fila de las valoraciones y dar así origen a la fila "suma de conteos".

5) La fila "suma de valoraciones" comprende la sumatoria de todos aquellos números que están por arriba de la diagonal, para cada columna.

6) Finalmente en la fila "niveles de importancia" se asignará los niveles según la suma de conteos; tal que, entre los indicadores evaluados el más importante, urgente y obligatorio, será aquel que menor valor tenga en la suma de conteos, el menos urgente, menos importante y menos obligatorio será el de mayor valor. En la tabla 4.1 se ilustra con un ejemplo lo antes anotado.

Tabla 4.1 Matriz de selección participativa de prioridades relativas (Combina: el $A B C$ de Franklin y selección por pares)

\begin{tabular}{|c|c|c|c|c|c|c|c|c|}
\hline Aspectos a ser priorizados & 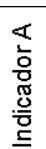 & 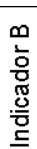 & 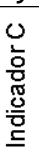 & 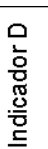 & 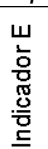 & 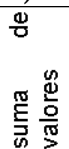 & 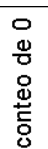 & 悉总 \\
\hline Indicador A & 0 & $\overline{0}$ & 3 & 2 & 0 & 5 & 3 & 8 \\
\hline Indicador B & & 0 & 1 & 2 & 0 & 3 & 2 & 5 \\
\hline Indicador C & & & 0 & 0 & 2 & 2 & 2 & 4 \\
\hline Indicador D & & & & $\mathbf{0}$ & 1 & 1 & 1 & 2 \\
\hline Indicador $\mathrm{E}$ & & & & & $\begin{array}{l}0 \\
0\end{array}$ & 0 & 1 & 1 \\
\hline Suma de valoraciones & 0 & 0 & 4 & 4 & 3 & 11 & & \\
\hline Transpuesta conteo de 0 & 3 & 2 & 2 & 1 & 1 & & 9 & \\
\hline suma de conteos & 3 & 2 & 6 & 5 & 4 & & & 20 \\
\hline Niveles de importancia & II & I & $\mathrm{V}$ & IV & III & & & \\
\hline
\end{tabular}

\subsection{Directrices y actuaciones para mejorar la sostenibilidad}

La mejora de la sostenibilidad, está claro que, no depende de una sola acción en un momento determinado, por el contrario se requerirá de una continua intervención en la gestión (social, económica y ambiental), de un ajuste técnico riguroso y una gobernabilidad dinámica.

El incremento de la sostenibilidad, depende de la búsqueda minuciosa y correcta aplicación de aquellas actuaciones, derivadas del diagnóstico, que permitan equilibrar los aspectos social, económico y ambiental, reduciendo al máximo las patologías o carencias que en un abastecimiento se perciban. Para 
tal fin, es pertinente que se aproveche al máximo los recursos que en la gestión del sistema de agua se consumen, mediante un plan de mejora de aquellos aspectos deficitarios y se proyecte hacia el estado de su situación deseable y sostenible, incluyéndose a todos los actores involucrados en el servicio del abastecimiento.

Las actividades que se deben considerar para ser ejecutadas como parte del proceso de mejora de la sostenibilidad, dependen de la diferencia que exista entre las condiciones reales en la cual se encuentra inmerso el abastecimiento con la situación deseable. A mayor brecha existente, más urgencia en mejorar ese aspecto o subcomponente.

La situación actual se mide a través de algunas variables (previamente seleccionadas para el método de diagnóstico ISA) vinculadas con los componentes de la sostenibilidad; una vez se tiene este dato, se afectan ponderadamente con un factor que indica su situación actual respecto del nivel recomendado, normado o proyectado como mejor y deseable.

El proceso de selección de las acciones a aplicar a la gestión del abastecimiento serán las que permitan subir el nivel medido de la variable e indicador, para cuando se repita su valoración y medida (en un diagnóstico siguiente).

Por ilustrar mejor lo aquí anotado, se puede suponer que el índice de fugas estructural de un abastecimiento es 21 , por otro lado se conoce técnicamente que para que un abastecimiento esté dentro de los parámetros de sostenibilidad su IFE debe ser inferior a 4 (8 para países en vías de desarrollo). Entonces se debe buscar las causas que llevan a que el IFE del abastecimiento esté excedido, y entonces se disgregan analíticamente las variables que lo conforman, para trabajar en la mejora efectiva de cada una. Situación que se explica más adelante.

Antes de actuar en el abastecimiento con las medidas de mejora de la sostenibilidad, se debe organizar y preparar a toda la empresa para una transición al cambio de gestión mediante los nuevos procesos que ameritan incorporarse para dicho fin. El encargado del diagnóstico, junto con los directivos de la empresa deben sentir y transmitir el proceso de cambio, sabiendo que no se trata de una eventualidad - ocasional, y que más bien se convertirá en el proceso continuo de actuación hacia la sostenibilidad, así como también que su desarrollo requiere de tiempo, esfuerzo, responsabilidad y dedicación en cada etapa, para cada actividad. El equipo debe trabajar enfocado siempre en la búsqueda de la calidad en todo lo que le compete a cada quien, por el bien del sistema, de la empresa, del cliente y equilibrio del ambiente. 


\subsubsection{Directrices para mejorar la sostenibilidad social}

\section{Cuadro 4.1 Actividades para mejorar la sostenibilidad. Componente social}

\begin{tabular}{|l|l|l|}
\hline \multicolumn{2}{|c|}{ Indicador } & \multicolumn{1}{c|}{ Actividades recomendadas - deseable } \\
\hline $\begin{array}{l}\text { Número de reducciones de } \\
\text { la cantidad de caudal hasta } \\
\text { un } 50 \% \text { por año }\end{array}$ & $\begin{array}{l}3 \text { reducciones (de caudal hasta un } \\
50 \% \text { ) al año }\end{array}$ & $\begin{array}{l}\text { Gestión de sequías. Gestión de la } \\
\text { demanda y de la oferta. Gestión de } \\
\text { almacenamientos. }\end{array}$ \\
\hline $\begin{array}{l}\text { Tiempo total acumulado, en } \\
\text { horas, de duración de las } \\
\text { interrupciones por año }\end{array}$ & 3 horas al día por año & $\begin{array}{l}\text { Si la interrupción es mayor que } 6 \text { horas } \\
\text { al día, la empresa deberá informar con } \\
\text { antelación y brindar todas las } \\
\text { alternativas posibles para el } \\
\text { abastecimiento estratégico emergente. }\end{array}$ \\
\hline $\begin{array}{l}\text { \% de acometidas con } \\
\text { presión de servicio diferente } \\
\text { al rango (entre } 10 \mathrm{~m} \text { c.a. y } \\
50 \mathrm{~m} \text { c.a.) }\end{array}$ & $\begin{array}{l}\text { Máximo el } 0.6 \% \text { de las acometidas tener presiones fuera de } \\
\text { rango (10 m c.a. a } 50 \mathrm{~m} \text { c.a.) }\end{array}$ & $\begin{array}{l}\text { Gestión de presiones. Regular la } \\
\text { presión en horas pico y valle. Rediseño } \\
\text { y optimización de redes. }\end{array}$ \\
\hline
\end{tabular}

\begin{tabular}{|c|c|c|}
\hline Indicador & Óptimo - deseable & Actividades recomendadas \\
\hline $\begin{array}{l}\text { Número de análisis de } \\
\text { calidad de agua por mes * } \\
1000 \text { / población servida }\end{array}$ & $\begin{array}{l}\text { Muestras en red de distribución.- } \\
\text { Para poblaciones menores que } \\
150000: 1 \text { muestra por cada } 1000 \\
\text { habitantes por mes. Para } \\
\text { poblaciones entre } 150001 \text { y } 600000 \text { : } \\
1 \text { muestra por cada } 2000 \text { habitantes } \\
\text { por mes. Para poblaciones } \\
\text { mayores que } 600000: 1 \text { muestra } \\
\text { por cada } 4000 \text { habitantes por mes }\end{array}$ & $\begin{array}{l}\text { Gestión de calidad del agua de } \\
\text { distribución. Aum ento de muestreos y } \\
\text { análisis de laboratorio físico, químico y } \\
\text { bacterológico del agua. Gestionar con } \\
\text { ayuda de sistemas de purificación y } \\
\text { repurificación del agua. Gestión de } \\
\text { fugas. }\end{array}$ \\
\hline $\begin{array}{l}\text { Número promedio de horas } \\
\text { por día que el agua } \\
\text { permanece estancada } \\
\text { (almacenada en depósitos } \\
\text { del sistema) previo a su } \\
\text { consumo }\end{array}$ & $\begin{array}{l}\text { Menos de } 12 \text { horas al día. En casos } \\
\text { extremos, nunca más de } 36 \text { horas. }\end{array}$ & $\begin{array}{l}\text { Gestión de almacenamientos, altemar } \\
\text { según necesidad. Repurificación previo } \\
\text { a la distribución para consumo. }\end{array}$ \\
\hline $\begin{array}{l}\% \text { de conexiones con un } \\
\text { rango de cloro residual } \\
\text { diferente al de la norma }(0.3 \\
\mathrm{mg} / \mathrm{L} \text { y } 1.5 \mathrm{mg} / \mathrm{L})\end{array}$ & $\begin{array}{l}\text { Porcentaje de acometidas fuera de } \\
\text { los rangos: óptimo } \mathrm{si}<0.02 \% \text { de } \\
\text { acometidas. Nunca }>0.5 \% \text { de las } \\
\text { acometidas totales. }\end{array}$ & $\begin{array}{l}\text { Especial cuidado en plantas de } \\
\text { tratamientos. Alternativas de } \\
\text { repurificación (recloración). Monitoreo } \\
\text { de calidad. Estudio de tiempo de } \\
\text { permanencia y procedencias; y, } \\
\text { reducción de intrusión patógena. }\end{array}$ \\
\hline
\end{tabular}




\begin{tabular}{|c|c|c|}
\hline Indicador & Óptimo - deseable & Actividades recomendadas \\
\hline $\begin{array}{l}\% \text { de predios con conexión } \\
\text { al sistema }\end{array}$ & $\begin{array}{l}\text { Óptimo cuando el } 100 \% \text { de los } \\
\text { predios tienen cobertura del sistema } \\
\text { de agua. }\end{array}$ & $\begin{array}{l}\text { Tareas de ampliación de red hasta } \\
\text { satisfacer todas las conexiones a red. } \\
\text { Gestión de uso de suelo, ordenamiento } \\
\text { territorial; y, regulación de permisos de } \\
\text { construcción. Inversión de autogestión. }\end{array}$ \\
\hline $\begin{array}{l}\% \text { de predios bien servidos } \\
\text { en horas pico }\end{array}$ & $\begin{array}{l}\text { Deseable que el } 100 \% \text { de los } \\
\text { predios contectados cuenten con } \\
\text { excelente servicio en horas pico. }\end{array}$ & $\begin{array}{l}\text { Gestión adecuada de: la demanda, } \\
\text { sequías, presión, almacenamientos y } \\
\text { fugas. Rediseño y optimización de } \\
\text { redes, (reducción de pérdidas de } \\
\text { carga). }\end{array}$ \\
\hline
\end{tabular}

\begin{tabular}{|l|l|l|}
\hline \multicolumn{2}{|c|}{ Óptimo - deseable } & \multicolumn{2}{c|}{ Actividades recomendadas } \\
\hline $\begin{array}{l}\text { Número promedio de horas } \\
\text { de capacitación invertidas en } \\
\text { cada técnico de campo y } \\
\text { miembros de planificación / } \\
\text { año }\end{array}$ & $\begin{array}{l}\text { Ideal que el abastecimiento invierta } \\
\text { en por lo menos } 80 \text { horas de } \\
\text { capacitación por técnico por año }\end{array}$ & $\begin{array}{l}\text { Capacitación permanente, formación } \\
\text { del recurso humano de la empresa. } \\
\text { Incrementar el know how institucional. } \\
\text { Gestión de tarifas para financiar. }\end{array}$ \\
\hline $\begin{array}{l}\text { Número promedio de horas } \\
\text { de capacitación invertidas en } \\
\text { cada administradory } \\
\text { coordinador del } \\
\text { abastecimiento / año }\end{array}$ & $\begin{array}{l}\text { Ideal que el abastecimiento invierta } \\
\text { en por lo menos } 70 \text { horas de } \\
\text { capacitación por técnico por año }\end{array}$ & \\
\hline
\end{tabular}

\begin{tabular}{|l|l|l|}
\hline \multicolumn{2}{|c|}{ Óptimo - deseable } & \multicolumn{2}{c|}{ Actividades recomendadas } \\
\hline $\begin{array}{l}\text { Horas de curso para clientes } \\
\text { por c./10000 conexiones / } \\
\text { año }\end{array}$ & $\begin{array}{l}\text { ldeal que el abastecimiento invierta } \\
\text { en por lo menos } 40 \text { horas de } \\
\text { capacitación por cada 10000 } \\
\text { clientes por año }\end{array}$ & $\begin{array}{l}\text { Tareas de concientización de los } \\
\text { clientes. Puede ser a través de } \\
\text { colegios, escuelas, institutos, ó visitas } \\
\text { barriales. Gestión de tarifas para } \\
\text { financiar. }\end{array}$ \\
\hline $\begin{array}{l}\text { Tiempo total, en minutos, de } \\
\text { campaña radial o TV/mes }\end{array}$ & $\begin{array}{l}\text { ldeal que el abastecimiento invierta } \\
\text { en por lo menos 100 minutos de } \\
\text { campañas radiales y televisivas por } \\
\text { mes, para concientizar a sus } \\
\text { clientes. }\end{array}$ & $\begin{array}{l}\text { Apoyar la gestión con campañas (radio } \\
\text { y TV locales), permanentes y } \\
\text { llamativas. Gestión de tanifas para } \\
\text { financiar. Gestionar convenios } \\
\text { mediáticos. }\end{array}$ \\
\hline
\end{tabular}




\begin{tabular}{|l|l|l|}
\hline \multicolumn{2}{|c|}{ Indicador } & \multicolumn{2}{|c|}{ Óptimo - deseable } & \multicolumn{1}{|c|}{ Actividades recomendadas } \\
\hline $\begin{array}{l}\text { Tiempo (en dias) que la } \\
\text { empresa tarda en responder } \\
\text { las quejas de sus abonados }\end{array}$ & $\begin{array}{l}\text { Deseable que se respondan (y } \\
\text { solucionen) quejas en menos de 2 } \\
\text { dias después de haberlas recibido, } \\
\text { nunca más de 8 dias. }\end{array}$ & $\begin{array}{l}\text { Ajuste de procedimientos internos, y al } \\
\text { personal involucrado, para atenderlas } \\
\text { en un menor tiempo. Inversión y } \\
\text { autogestión. }\end{array}$ \\
\hline $\begin{array}{l}\text { Tiempo (en dias) en los que } \\
\text { la empresa atiende nuevas } \\
\text { conexiones, obras de } \\
\text { reparación y reinstalación }\end{array}$ & $\begin{array}{l}\text { Deseable que la empresa resuelva } \\
\text { nuevas conexiones y reinstalciones } \\
\text { en menos de 5 dias, y que las } \\
\text { reparaciones seán atendidas } \\
\text { inmediatamente, pero nunca en un } \\
\text { tiempo superior a un día. }\end{array}$ & $\begin{array}{l}\text { Ajuste de procedimientos internos, y al } \\
\text { personal involucrado, para atenderlas } \\
\text { en un menor tiempo. Gestión de fugas } \\
\text { y fallos. Mejorar atención al cliente. } \\
\text { Financiamiento con reajuste de tarifas. }\end{array}$ \\
\hline $\begin{array}{l}\text { Se ejecuta un plan de } \\
\text { marketing plubicitario de la } \\
\text { empresa, promoción al } \\
\text { ahorro y difusión pública }\end{array}$ & $\begin{array}{l}\text { Lo deseable es que la empresa } \\
\text { tenga en marcha un plan de } \\
\text { marketing plubicitario, promoción al } \\
\text { ahorro y difusión pública. }\end{array}$ & $\begin{array}{l}\text { lnstaurar un plan de marketing } \\
\text { plubicitario propio para la empresa, que } \\
\text { además promocione el ahorro del agua } \\
\text { y difusión pública de las nuevas tareas } \\
\text { programadas de la empresa para la } \\
\text { búsqueda de la sostenibilidad. }\end{array}$ \\
\hline $\begin{array}{l}\text { Existe la infraestructura de } \\
\text { atención al cliente } \\
\text { organizada, equipada y } \\
\text { cómoda }\end{array}$ & $\begin{array}{l}\text { Deseable que se cuente con las } \\
\text { instalaciones de infraestructura } \\
\text { para atención al cliente de forma } \\
\text { organizada, equipada y cómoda, en } \\
\text { todo momento. }\end{array}$ & $\begin{array}{l}\text { lnversión para adecuar el contexto } \\
\text { físico de las instalaciones para una } \\
\text { mejor atención al cliente. Tareas de } \\
\text { autogestión. }\end{array}$ \\
\hline
\end{tabular}

\subsubsection{Directrices para mejorar la sostenibilidad económica}

\section{Cuadro 4.2 Actividades para mejorar la sostenibilidad. Componente económico}

\begin{tabular}{|c|c|c|}
\hline Indicador & Óptimo - deseable & Actividades recomendadas \\
\hline $\begin{array}{l}\% \text { de recuperación de } \\
\text { costos, mediante cobro de } \\
\text { facturación por año de } \\
\text { servicio }\end{array}$ & $\begin{array}{l}\text { Deseable que se recupere más del } \\
105 \% \text { de gastos totales de la } \\
\text { empresa mediante ingresos por } \\
\text { facturación de venta de agua }\end{array}$ & $\begin{array}{l}\text { Ajuste tarifario. Optimización de gastos. } \\
\text { Reducción de pérdidas. Mejora de la } \\
\text { eficiencia hidráulica y energética del } \\
\text { sistema. }\end{array}$ \\
\hline Autosuficiencia financiera & $\begin{array}{l}\text { Deseable } 100 \% \text {, al menos que los } \\
\text { ingresos por facturación de venta de } \\
\text { agua dividido para los gastos } \\
\text { corrientes sean superiores a } 0.9\end{array}$ & $\begin{array}{l}\text { Ajuste tarifario. Reducción de gastos } \\
\text { corrientes. Reducción de pérdidas. } \\
\text { Gestión financiera eficiente. }\end{array}$ \\
\hline Eficiencia en recaudación & $\begin{array}{l}\text { Óptimo, que todas la facturas } \\
\text { emitidas al mes sean cobradas el } \\
\text { mismo mes y en el peor de los } \\
\text { casos pasados } 45 \text { días desde su } \\
\text { emisión }\end{array}$ & $\begin{array}{l}\text { Incentivo tarifario. Multas al retraso. } \\
\text { Búsqueda de la comodidad de pagos, } \\
\text { mediante servicios de internet, } \\
\text { informática, firma de convenios } \\
\text { banacarios de transferencias. } \\
\text { Campañas públicas de promoción. }\end{array}$ \\
\hline $\begin{array}{l}\% \text { de agua no facturada / } \\
\text { año }\end{array}$ & $\begin{array}{l}\text { Ideal que el agua no facturada sea } \\
\text { menor que el } 5 \% \text { del agua captada. }\end{array}$ & $\begin{array}{l}\text { Política activa de gestión de fugas. } \\
\text { Mantenimiento y renovación oportunos. } \\
\text { Gestión de tarifas. Inspecciones } \\
\text { periódicas de red. Auditorias hídricas } \\
\text { constantes. }\end{array}$ \\
\hline
\end{tabular}




\begin{tabular}{|c|c|c|}
\hline Indicador & Óptimo - deseable & Actividades recomendadas \\
\hline $\begin{array}{l}\text { Índice de fugas estructural } \\
\text { (IFE) }\end{array}$ & $\begin{array}{l}\text { Deseable que el IFE tenga valores } \\
\text { por debajo de } 4 \text {. Nunca más que } 16 \text {. }\end{array}$ & $\begin{array}{l}\text { Reducción del volumen incontrolado } \\
\text { (real y aparente), gestionar para } \\
\text { mantener el servicio continuo las } 24 \\
\text { horas. Regular las presiones. } \\
\text { Mantenimiento y renovación. Gestión } \\
\text { tarifaria para financiar. Rediseñoy } \\
\text { optimización de redes. }\end{array}$ \\
\hline $\begin{array}{l}\text { Número de roturas / } \mathrm{km} \text { de } \\
\text { tubería / año }\end{array}$ & $\begin{array}{l}\text { Óptimo que se tenga menos de } 0.25 \\
\text { roturas por kilómetro por año. }\end{array}$ & $\begin{array}{l}\text { Política activa de gestión de fugas. } \\
\text { Manteniemiento y renovación de redes. } \\
\text { Gestión tarifaria para financiar. }\end{array}$ \\
\hline $\begin{array}{l}\text { Número de inspecciones } \\
\text { acústicas para control de } \\
\text { fugas en la red / año }\end{array}$ & $\begin{array}{l}\text { Ideal que se efectúe una inspección } \\
\text { anual a toda la red. }\end{array}$ & $\begin{array}{l}\text { Incluir en la gestión y mantenimiento } \\
\text { actividades de control acústico de } \\
\text { fugas. Ajuste de actividades de } \\
\text { personal. Incremento de equipamiento } \\
\text { o subcontratarlo con frecuencia. }\end{array}$ \\
\hline $\begin{array}{l}\text { \% de información del } \\
\text { abastecimiento disponible en } \\
\text { una base de datos } \\
\text { informática - SIG }\end{array}$ & $\begin{array}{l}\text { Óptimo si se cuenta con el } 100 \% \\
\text { del catastro redes y clientes están } \\
\text { ingresados a una base informática - } \\
\text { GIS }\end{array}$ & $\begin{array}{l}\text { Mejorar aspectos técnicos mediante } \\
\text { recursos humanos. Capacitación. } \\
\text { Levantamiento de información } \\
\text { permanente. Optimización de recursos. }\end{array}$ \\
\hline $\begin{array}{l}\text { \% de superficie interior de } \\
\text { depósitos de } \\
\text { almacenamiento que son } \\
\text { impermeabilizados y con } \\
\text { mantenimiento por año }\end{array}$ & $\begin{array}{l}\text { Deseable que anualmente se de } \\
\text { mantenimiento al } 100 \% \text { de los } \\
\text { depósitos de almacenamiento de } \\
\text { agua del abastecimiento }\end{array}$ & $\begin{array}{l}\text { Operación de mantenimiento periódico. } \\
\text { Ajuste de actividades al personal. } \\
\text { Inversión y autogestión. }\end{array}$ \\
\hline $\begin{array}{l}\text { Búsqueda de conexiones } \\
\text { ilegales (acústica y visual) } \\
\text { en porcentaje de tuberías de } \\
\text { la red /año }\end{array}$ & $\begin{array}{l}\text { Se considera óptimo que el } 100 \% \\
\text { de la red sea analizada (acústica y } \\
\text { visualmente) al año }\end{array}$ & $\begin{array}{l}\text { Capacitación y equipamiento del } \\
\text { personal. Ajuste a tareas de cuadrilla. }\end{array}$ \\
\hline
\end{tabular}

\begin{tabular}{|l|l|l|}
\hline \multicolumn{2}{|c|}{ Indicador } & \multicolumn{2}{c|}{ Óptimo - deseable } & \multicolumn{2}{c|}{ Actividades recomendadas } \\
\hline \% de liquidez & $\begin{array}{l}\text { Deseable que al menos los ingresos } \\
\text { corrientes cubran el 100\% de los } \\
\text { gastos corrientes }\end{array}$ & $\begin{array}{l}\text { Ajuste tarifario. Reducción de gastos } \\
\text { corrientes. Reducción de pérdidas. } \\
\text { Mejora de la recaudación. }\end{array}$ \\
\hline Stock de deuda & $\begin{array}{l}\text { Deseable que el stock de deuda sea } \\
\text { inferior al 35\% }\end{array}$ & $\begin{array}{l}\text { Gestión financiera austera, para reducir } \\
\text { pasivos y aumentar ingresos. }\end{array}$ \\
\hline
\end{tabular}




\begin{tabular}{|c|c|c|}
\hline Indicador & Óptimo - deseable & Actividades recomendadas \\
\hline $\begin{array}{l}\text { Número de parcelas } \\
\text { hidrométricas (subsectores } \\
\text { o distritos hidrométricos) } \\
\text { por cada } 10000 \text { conexiones }\end{array}$ & $\begin{array}{l}\text { Óptimo si se tiene una parcela } \\
\text { hidrométrica (nudos de control) por } \\
\text { cada } 1250 \text { (hasta } 750 \text { ) clientes }\end{array}$ & $\begin{array}{l}\text { Invertir en infraestructura para instalar } \\
\text { nudos de control para monitoreo } \\
\text { permanente (caudalím etros } \\
\text { ultrasónicos o electromagnéticos, con } \\
\text { varios puntos distribuidos para } \\
\text { monitorear la presión) por cada } 750 \\
\text { hasta } 1250 \text { clientes. }\end{array}$ \\
\hline $\begin{array}{l}\text { Número de hidrantes contra } \\
\text { incendios operativos por } \\
\text { cada } 1.0 \mathrm{~km} \text { de tubería }\end{array}$ & $\begin{array}{l}\text { Ideal que exista un hidrante cada } \\
400 \mathrm{~m} \text { de red (o } 200 \mathrm{~m} \text { por línea de } \\
\text { tubería) }\end{array}$ & $\begin{array}{l}\text { Invertir en infraestructura para instalar } \\
\text { el número de hidrantes contra } \\
\text { incendios. Ylos que existen someterlos } \\
\text { a mantenimiento permanente. }\end{array}$ \\
\hline $\begin{array}{l}\% \text { de renovación de } \\
\text { collarines por año }\end{array}$ & $\begin{array}{l}\text { Deseable que al menos se renueve } \\
\text { el } 5 \% \text { de collarines por año. }\end{array}$ & $\begin{array}{l}\text { Mantenimiento y renovación de } \\
\text { collarines. Incluir pozos de visita a los } \\
\text { collarines. Ajuste tarifario. }\end{array}$ \\
\hline $\begin{array}{l}\% \text { de contadores } \\
\text { domiciliares funcionando }\end{array}$ & $\begin{array}{l}\text { Deseable que más del } 95 \% \text { de } \\
\text { contadores funcionen en perfectas } \\
\text { condiciones }\end{array}$ & $\begin{array}{l}\text { Gestión de contadores. Mantenimiento } \\
\text { y renovación oportuno de medidores } \\
\text { domiciliares. }\end{array}$ \\
\hline $\begin{array}{l}\% \text { de contadores instalados } \\
\text { más de } 8 \text { años }\end{array}$ & $\begin{array}{l}\text { Lo deseable que no existan } \\
\text { contadores instalados más de } 8 \\
\text { años }\end{array}$ & \multirow{2}{*}{$\begin{array}{l}\text { Gestión activa de contadores. } \\
\text { Renovación oportuna de micro- } \\
\text { medidores domiciliares. Promover } \\
\text { mediante facilidades de compra al } \\
\text { usuario y pagos diferidos. }\end{array}$} \\
\hline $\begin{array}{l}\% \text { de contadores instalados } \\
\text { cuyas lecturas superan los } \\
4000 \mathrm{~m}^{3}\end{array}$ & $\begin{array}{l}\text { Lo deseable que no existan } \\
\text { contadores funcionando con un } \\
\text { volúmen total acumulado mayor que } \\
4000 \mathrm{~m}^{3}\end{array}$ & \\
\hline $\begin{array}{l}\% \text { de tuberías renovadas o } \\
\text { repuestas por año }\end{array}$ & $\begin{array}{l}\text { Ideal que en promedio se renueve el } \\
2.5 \% \text { de tuberías de la red por año }\end{array}$ & $\begin{array}{l}\text { Inversión en rediseño de red y } \\
\text { renovación de tuberías. Gestión de } \\
\text { tarifas para financiarlo. }\end{array}$ \\
\hline
\end{tabular}

\section{Indicador}

Porcentaje de maquinaria y equipo financiados (horas / mes) para OO\&MM

Número de empleados por cada 10000 abonados

\section{Óptimo - deseable}

Actividades recomendadas
Ideal que el $100 \%$ del requerimiento de maquinaria y equipo esté disponible todo el tiempo

Óptimo que existan 60 (empleados y trabajadores) por cada 10000 clientes (para agua potable y saneamiento). Sólo agua potable 30 por cada 10000 clientes.
Invertir en equipamiento. Optimización de recursos. Gestión del financiamiento.

Gestión del recurso humano. Ajuste de tareas. Redistribución de responsabilidades. Menos que 60 emp $/ 10000$ se considera carga de trabajo al personal. Más de 60 emp $/ 10000$ pérdidas de rendimiento de la empresa. 


\subsubsection{Directrices para mejorar la sustentabilidad}

\section{Cuadro 4.3 Actividades para mejorar la sostenibilidad. Componente ambiental}

\begin{tabular}{|l|l|l|}
\hline \multicolumn{2}{|c|}{ Indicador } & \multicolumn{2}{|c|}{ Óptimo - deseable } \\
\hline $\begin{array}{l}\% \text { de caudal de agua } \\
\text { captado para el } \\
\text { abastecimiento en época de } \\
\text { estiaje }\end{array}$ & $\begin{array}{l}\text { Lo óptimo es que se consuma en } \\
\text { época de estiaje hasta un 70\% del } \\
\text { caudal de los cauces que aportan al } \\
\text { Pacifico y hasta un } 50 \% \text { los que } \\
\text { aportan al Amazonas }\end{array}$ & $\begin{array}{l}\text { Gestión de cuencas hidrográficas. } \\
\text { Aporte económico para la conservación } \\
\text { y reforestación del área tributaria. } \\
\text { Financiamiento y facturación con base } \\
\text { en los consumos del usuario. }\end{array}$ \\
\hline $\begin{array}{l}\text { Existe estricto control legal y } \\
\text { regulación efectiva de } \\
\text { explotación de otros } \\
\text { recursos y uso de suelo, en } \\
\text { las cuencas fuente, por el } \\
\text { gobierno local }\end{array}$ & $\begin{array}{l}\text { Lo deseable es que si exista un } \\
\text { control estricto para la explotación } \\
\text { cuencursos naturales dentro de la }\end{array}$ & $\begin{array}{l}\text { Revisión y actualización de } \\
\text { ordenanzas, nomativas y leyes } \\
\text { ambientales; aplicarlas con rigor. } \\
\text { Convenios con entidades de } \\
\text { enseñanza y de gestión legal. }\end{array}$ \\
\hline
\end{tabular}

\begin{tabular}{|l|l|l|}
\hline \multicolumn{2}{|c|}{ Indicador } & \multicolumn{2}{c|}{ Óptimo - deseable } & Actividades recomendadas \\
\hline $\begin{array}{l}\text { Cantidad promedio de } \\
\text { consumo de agua por } \\
\text { habitante por día }\end{array}$ & $\begin{array}{l}\text { Lo deseable que se consuma } \\
\text { menos de } 110 \mathrm{~L} / \text { hab / dias. Nunca } \\
\text { más de } 200 \mathrm{~L} \text { /hab / dia }\end{array}$ & $\begin{array}{l}\text { Ajuste de tarifas que promuevan el } \\
\text { ahorro. Campañas de concientización } \\
\text { al usuario, en colegios, escuelas, etc. }\end{array}$ \\
\hline $\begin{array}{l}\text { Desaprovechamiento de } \\
\text { recursos hídricos }\end{array}$ & $\begin{array}{l}\text { Lo óptimo que se pierda como } \\
\text { máximo un } 20 \% \text { del agua total } \\
\text { extraída de la fuente (captación) }\end{array}$ & $\begin{array}{l}\text { Gestión de fugas. Mantenimiento y } \\
\text { renovación permanente de tuberías. } \\
\text { Uso moderado de agua en } \\
\text { retrolavados; y, control de derrames } \\
\text { mediante válvulas de control de altitud. }\end{array}$ \\
\hline $\begin{array}{l}\text { Consumo energético relativo } \\
\text { del abastecimiento por mes }\end{array}$ & $\begin{array}{l}\text { Lo deseable que se consuma la } \\
\text { energía que los motores y máquinas } \\
\text { bajo condiciones óptimas puedan } \\
\text { operar. 1.05 veces. }\end{array}$ & $\begin{array}{l}\text { Mantenimiento y renovación de } \\
\text { elementos eléctricos. Rediseño y } \\
\text { optimización de infraestructura; en } \\
\text { estaciones de bombeo (variador de } \\
\text { frecuencias según corresponda). }\end{array}$ \\
\hline
\end{tabular}




\begin{tabular}{|l|l|l|}
\hline \multicolumn{2}{|c|}{ Indicador } & \multicolumn{2}{|c|}{ Óptimo - deseable } & \multicolumn{1}{|c|}{ Actividades recomendadas } \\
\hline $\begin{array}{l}\text { Porcentaje de lodos y } \\
\text { desechos generados por el } \\
\text { sistema de potabilización } \\
\text { (filtros, floculadores y } \\
\text { sedimentadores) que se } \\
\text { vierten sin depuración a } \\
\text { cuerpos receptores, por año }\end{array}$ & $\begin{array}{l}\text { Se busca que el 100\% de los lodos } \\
\text { que se generan por los procesos de } \\
\text { tratamiento sean depurados y con } \\
\text { una diposición final no } \\
\text { contaminante. }\end{array}$ & $\begin{array}{l}\text { Depuración y disposición final de lodos } \\
\text { técnica y sustentable, para desechos y } \\
\text { lodos que tienen consigo cargas } \\
\text { químicas contaminantes, producidos } \\
\text { por el tratamiento o potabilización } \\
\text { (filtros, floculadores, etc.) }\end{array}$ \\
\hline $\begin{array}{l}\text { Depuración de aguas } \\
\text { servidas para los vertidos de } \\
\text { alcantarillados de la ciudad }\end{array}$ & $\begin{array}{l}\text { Lo urgente es que se depure el } \\
\text { pluviales, previo a su vertido a los } \\
\text { cuerpos receptores.. }\end{array}$ & $\begin{array}{l}\text { Gestión de aguas residuales. Gestión } \\
\text { financiera y ajuste de tarifas para } \\
\text { financiar estudios y construcción de } \\
\text { depuradoras, incluir prevención de } \\
\text { contaminación por "first flush" urbano. }\end{array}$ \\
\hline $\begin{array}{l}\text { Aplicación de medidas } \\
\text { correctoras o de mitigación } \\
\text { para reducción de impacto } \\
\text { por ruido, polvo y gases en } \\
\text { apertura y cierre de zanjas } \\
\text { para reparaciones o } \\
\text { conexiones domiciliares }\end{array}$ & $\begin{array}{l}\text { Que se aplique medidas correctoras } \\
\text { para la actividad del } \\
\text { abastecimiento;p rinicpalmente en } \\
\text { aquellas que provocan mayores } \\
\text { impactos en el ambiente. }\end{array}$ & $\begin{array}{l}\text { Incorporar un plan de manejo ambiental } \\
\text { para la gestión del sistema. Gestión del } \\
\text { financiamiento para las medidas } \\
\text { correctoras de los impactos por } \\
\text { operación y mantenimiento, } \\
\text { principalmente. Financiar tareas con } \\
\text { autogestión. Capacitación de personal. }\end{array}$ \\
\hline
\end{tabular}

Indicador

Óptimo - deseable

Actividades recomendadas

\begin{tabular}{|c|c|c|}
\hline $\begin{array}{l}\text { Superficie de la cuenca } \\
\text { fuente o tributaria que es } \\
\text { propiedad del sistema en } \\
\text { hectáreas por cada }(\mathrm{L} / \mathrm{s}) \text { de } \\
\text { agua producida para el } \\
\text { abastecimiento }\end{array}$ & $\begin{array}{l}\text { Lo deseable que cada } \\
\text { abastecimiento invierta en adquirir } \\
\text { más de } 8 \mathrm{Ha} \text { de superficie tributaria } \\
\text { por cada unidad de caudal } \\
\text { producida en litro por segundo. } \\
\text { Mínimo } 4.5 \mathrm{Ha} /(\mathrm{L} / \mathrm{s}) \text {. }\end{array}$ & $\begin{array}{l}\text { Ajuste de tarifas para invertir en } \\
\text { adquisición, conservación y gestión de } \\
\text { cuencas tributarias (de las principales } \\
\text { superficies que aportan } \\
\text { significativamente a las captaciones del } \\
\text { sistema). Capacitación y } \\
\text { concientización. }\end{array}$ \\
\hline $\begin{array}{l}\text { \% de superficie de la o las } \\
\text { cuencas tributarias que } \\
\text { tienen en marcha un plan } \\
\text { anual de silvicultura y } \\
\text { reforestación, gestionado ó } \\
\text { coordinado directamente por } \\
\text { el operador del sistema }\end{array}$ & $\begin{array}{l}\text { Lo ideal que más del } 80 \% \text { de la } \\
\text { supercicie de la cuenca tributaria - } \\
\text { fuente, tenga en marcha un plan de } \\
\text { conservación, reforestación y } \\
\text { manejo técnico. }\end{array}$ & $\begin{array}{l}\text { Ajuste de tarifas para invertir en } \\
\text { conservación y gestión de cuencas } \\
\text { tributarias. Convenios institucionales } \\
\text { para activar la participación social en la } \\
\text { reforestación de cuencas fuente. }\end{array}$ \\
\hline $\begin{array}{l}\% \text { de industrias y fábricas } \\
\text { instaladas dentro de la } \\
\text { superficie de la cuenca } \\
\text { fuente, que depuran sus } \\
\text { vertidos y controlan sus } \\
\text { desechos correctamente }\end{array}$ & $\begin{array}{l}\text { Lo deseable que no existan } \\
\text { asentamientos industriales en la } \\
\text { supercicie de cuenca que aporta } \\
\text { signific dativamente con caudales } \\
\text { para el abastecimiento. Y si los } \\
\text { existen que no contaminen. }\end{array}$ & $\begin{array}{l}\text { Planes de ordenamiento territorial. } \\
\text { Gestión legal para aplicación de } \\
\text { ordenanzas de uso de suelo. } \\
\text { Capacitación y concientización. }\end{array}$ \\
\hline $\begin{array}{l}\% \text { del ingreso facturado por } \\
\text { venta de agua que se dedica } \\
\text { a adquisición y conservación } \\
\text { de cuencas tributarias }\end{array}$ & $\begin{array}{l}\text { Lo deseable que se destine más del } \\
5 \% \text { de los ingresos. Óptimo }>12 \% \\
\text { y, nunca }<0.5 \% \text { del total facturado. }\end{array}$ & $\begin{array}{l}\text { Gestión legal municipal, para registro } \\
\text { de ordenanzas que obliguen en la tarifa } \\
\text { a cancelar en función del gasto } \\
\text { registrado, un aporte por consumo de } \\
\text { recursos naturales. }\end{array}$ \\
\hline
\end{tabular}




\subsection{Manual para el diagnóstico de la sostenibilidad en abastecimientos mediante el ISA}

Este manual se desarrolla con el propósito de brindar una guía asistida para la aplicación de la herramienta de diagnóstico ISA, dentro de un marco netamente referencial, para los gerentes, auditores, entes financieros y equipo de diagnóstico de la empresa de agua, según corresponda a cada fase de aplicación y evaluación.

Los tres primeros componentes del ciclo para la búsqueda de la sostenibilidad de un abastecimiento (ver figura 3.1.) son:

a) Valoración.- (referido también en 3.1.2), es la fase en la cual recabamos, de la fuente de información (encuestado-entrevistado), todos los datos y cifras de las variables e indicadores que componen la malla de subcomponentes. Se recomiendan dos técnicas principales, la aplicación de encuestas y el desarrollo de sondeos participativos.

El método de investigación que permite interrogar de forma verbal (mediante diálogo técnico) a los encargados y conocedores de la gestión del abastecimiento, con el fin de obtener la información necesaria para el diagnóstico ISA se conoce como la de aplicación de encuestas, que para la interrogación emplea un cuestionario o lista de preguntas que las responden las personas encuestadas, seleccionadas minuciosamente del equipo gestor, entre aquellos que sean identificados como los de mayor conocimiento y experiencia dentro de la actividad investigada.

La otra técnica que resulta práctico aplicarla utilizando el mismo cuestionario pero extendido de forma grupal en un diálogo participativo entre todos los involucrados, se conoce como sondeo técnico participativo (STP); se detallan algunos aspectos de esta técnica más adelante, en el ítem 4.4.2.

b) Diagnóstico (además consta en 3.1.4), comprende la fase en la que, con los datos recabados mediante la encuesta, se calculan los índices e indicadores, luego se determinan los factores de calidad, y finalmente se computan los pesos relativos correspondientes a cada subcomponente y componente, respectivamente, de cuya sumatoria obtendremos el ISA.

c) Caracterización (concatenar en 3.1.4), etapa en la que luego de obtener el valor general del ISA, se analiza dicho valor y se clasifica el nivel de sostenibilidad del abastecimiento en estudio, según 
corresponda. Esta clasificación muestra indirectamente los posibles problemas que afectan y restan la sostenibilidad del sistema de agua.

\subsubsection{La encuesta, como una parte del guión para la entrevista}

La encuesta a aplicar tiene como elementos básicos, los objetivos y el cuestionario, ambos enfocados a facilitar la obtención de los mejores datos del gestor.

\section{Cuadro 4.4 Encuesta para el diagnóstico de la sostenibilidad de abastecimiento, mediante el ISA}

Objetivos de la encuesta:

Con los datos a continuación proporcionados se conseguirá:

- Diagnosticar el nivel de sostenibilidad del abastecimiento bajo su responsabilidad, en los componentes económico, social y ambiental.

- Identificar los componentes de la sostenibilidad más vulnerables y descuidados.

- Visualizar las necesidades de intervención en la gestión del abastecimiento.

- Orientar las alternativas de mejora del desempeño de su empresa.

\section{Información general:}

La encuesta que a continuación se dispone a responder, tiene como propósito, recabar de Usted los datos, valores y situaciones actuales en las cuales se encuentra el abastecimiento bajo su responsabilidad, a través de 86 preguntas (variables) que conforman los parámetros que fueron seleccionados para la aplicación de la metodología de diagnóstico mediante el índice de sostenibilidad de abastecimiento.

La veracidad e idoneidad de los resultados que se consigan dependen directamente de la certeza y realidad de sus respuestas, por lo que se solicita sean éstos lo más aproximados a la realidad y sustentados en documentos o la verdad. Será mejor si se invita a participar en este acto a los encargados de manejar cada tema incluido. Desde ya se anticipa nuestro reconocimiento por su participación.

\begin{tabular}{|c|c|c|}
\hline Pregunta & Dato & Fiable? \\
\hline A) COMPONENTE ECONOMICO & & \\
\hline a) Subcomponente: recuperación de cotos & & \\
\hline $\begin{array}{l}\text { 1) ¿Cuáles son los ingresos (propios) por facturación en } \\
\$ / a n ̃ o ?\end{array}$ & & \\
\hline
\end{tabular}




\begin{tabular}{|c|c|c|}
\hline Pregunta & Dato & Fiable? \\
\hline $\begin{array}{l}\text { 2) ¿Cuáles son los gastos corrientes en } \$ / \text { año? } \\
\text { Gastos corrientes }=\text { remuneraciones + intereses de } \\
\text { deuda pagados + servicios + suministro + logística y } \\
\text { materiales + transferencias + imprevistos }\end{array}$ & & \\
\hline $\begin{array}{l}\text { 3) ¿Cuáles son los gastos de capital en \$/año? } \\
\text { Gastos de capital = gastos por bienes muebles e } \\
\text { inmuebles }\end{array}$ & & \\
\hline $\begin{array}{l}\text { 4) ¿Cuáles son los gastos por inversiones en obra pública } \\
\text { en } \$ / \text { año? } \\
\text { Gastos de capital = gastos por bienes muebles e } \\
\text { inmuebles }\end{array}$ & & \\
\hline $\begin{array}{l}\text { 5) ¿Cuáles son los gastos por servicios de deuda en \$/año? } \\
\text { Gastos de servicios de deuda = amortización de la } \\
\text { deuda pública }\end{array}$ & & \\
\hline $\begin{array}{l}\text { 6) ¿Cuál es la cantidad anual (en \$) que se recauda por } \\
\text { servicios de agua? }\end{array}$ & & \\
\hline $\begin{array}{l}\text { 7) ¿Cuál es la cantidad anual (en \$) que se emite por } \\
\text { servicios de agua? }\end{array}$ & & \\
\hline 8) ¿Cuál es volumen de agua facturada?, en ( $\left.\mathrm{m}^{3} / \mathrm{año}\right)$ & & \\
\hline $\begin{array}{l}\text { 9) ¿Cuál es volumen de agua producida (potabilizada)?, en } \\
\left(\mathrm{m}^{3} / \mathrm{año}\right)\end{array}$ & & \\
\hline b) Subcomponente: operación y mantenimiento & & \\
\hline $\begin{array}{l}\text { 10) ¿Cuántas horas al día la red permanece presurizada?, } \\
\text { (horas al día) }\end{array}$ & & \\
\hline 11) ¿Cuál es la longitud total de tubería?, en $(\mathrm{km})$ & & \\
\hline $\begin{array}{l}\text { 12) ¿Cuál es el promedio de la longitud de acometida?, en } \\
(\mathrm{m})\end{array}$ & & \\
\hline 13) Indique el número total de acometidas & & \\
\hline $\begin{array}{l}\text { 14) ¿Cuál es la presión media de la red mientras se brinda } \\
\text { servicio? (m c.a.) }\end{array}$ & & \\
\hline 15) ¿Cuánto es el volumen fugado?, en $\left(\mathrm{m}^{3} / \mathrm{mes}\right)$ & & \\
\hline $\begin{array}{l}\text { 16) ¿De cuántos días consta un mes de facturación?, en } \\
\text { (días) }\end{array}$ & & \\
\hline
\end{tabular}




\begin{tabular}{|c|c|c|c|}
\hline & Pregunta & Dato & Fiable? \\
\hline & $\begin{array}{l}\text { ¿Cuántas roturas por año existen en el sistema?, en } \\
\text { (roturas al año) }\end{array}$ & & \\
\hline 18) & $\begin{array}{l}\text { ¿Cuántos kilómetros de tubería se inspeccionan, con } \\
\text { equipos acústicos, para el control de fugas por año?, } \\
\text { en ( } \mathrm{km} \text { al año) }\end{array}$ & & \\
\hline 19) & $\begin{array}{l}\text { ¿Cuántos kilómetros de red se tienen ingresados y } \\
\text { están disponibles con toda la información técnica en } \\
\text { una base informática, SIG?, en }(\mathrm{km})\end{array}$ & & \\
\hline 20) & $\begin{array}{l}\text { ¿Cuántas acometidas se tienen ingresadas y están } \\
\text { disponibles con toda la información comercial en una } \\
\text { base informática, SIG?, en (acometidas) }\end{array}$ & & \\
\hline 21) & $\begin{array}{l}\text { ¿Cuánta superficie interna de los depósitos del sistema } \\
\text { cuenta con mantenimiento e impermeabilización por } \\
\text { año?, }\left(\mathrm{m}^{2} / \mathrm{año}\right)\end{array}$ & & \\
\hline 22) & $\begin{array}{l}\text { ¿Cuál es la superficie interna total de los depósitos del } \\
\text { sistema?, en }\left(\mathrm{m}^{2}\right)\end{array}$ & & \\
\hline & $\begin{array}{l}\text { ¿Cuántos kilómetros de red se les aplica búsquedas } \\
\text { (visual y acústica) de conexiones ilegales (ilícitas) por } \\
\text { año?, (km / año) }\end{array}$ & & \\
\hline \multicolumn{4}{|c|}{ c) Subcomponente: índices financieros } \\
\hline & $\begin{array}{l}\text { ¿Cuáles son los ingresos corrientes de la empresa de } \\
\text { agua?, en ( } \$ \text { / año) } \\
\text { Ingresos corrientes = ingresos por venta de agua + } \\
\text { ingresos por transferencias corrientes del FODESEC } \\
\text { (fondo de desarrollo seccional) + bono por eficiencia + } \\
15 \% \text { de transferencia corriente por gobiernos } \\
\text { seccionales }\end{array}$ & & \\
\hline 25) & ¿Cuánto es el pasivo total de la empresa?, (\$) & & \\
\hline 26) & $\begin{array}{l}\text { ¿Cuánto es el ingreso de capital?, (\$) } \\
\text { Ingresos de capital }=\text { ingresos por transferencias por } \\
\text { donación del impuesto a la renta }+5 \% \text { de venta de } \\
\text { energía eléctrica }+10 \% \text { de ingresos por llamadas } \\
\text { telefónicas }+ \text { fondos de desarrollo provincial (+ otros } \\
\text { ingresos semejantes) }\end{array}$ & & \\
\hline & $\begin{array}{l}\text { ¿A cuánto haciende el crédito público (en la empresa)?, } \\
\text { (\$) }\end{array}$ & & \\
\hline 28) & ¿Cuánto es el saldo de caja?, en (\$) & & \\
\hline
\end{tabular}




\begin{tabular}{|c|c|c|}
\hline Pregunta & Dato & Fiable? \\
\hline \multicolumn{3}{|l|}{ d) Subcomponente: infraestructura del abastecimiento } \\
\hline $\begin{array}{l}\text { 29) ¿Cuántas parcelas hidrométricas }{ }^{* \text { (Anexo 3.1) }} \text { existen en el } \\
\text { sistema? }\end{array}$ & & \\
\hline $\begin{array}{l}\text { 30) ¿Cuál es el número de hidrantes contra incendios que } \\
\text { están funcionando en la red? }\end{array}$ & & \\
\hline $\begin{array}{l}\text { 31) ¿Cuál es el número de collarines de acometida que se } \\
\text { cambian y dan mantenimiento por año? }\end{array}$ & & \\
\hline $\begin{array}{l}\text { 32) ¿Cuál es el número total de collarines de acometida de } \\
\text { la red? }\end{array}$ & & \\
\hline $\begin{array}{l}\text { 33) ¿Cuál es el número de contadores que funcionan con } \\
\text { normalidad? }\end{array}$ & & \\
\hline $\begin{array}{l}\text { 34) ¿Cuál es el número total de contadores del } \\
\text { abastecimiento? }\end{array}$ & & \\
\hline $\begin{array}{l}\text { 35) ¿Cuántos contadores existen con } 8 \text { años o más de } \\
\text { instalación? }\end{array}$ & & \\
\hline $\begin{array}{l}\text { 36) ¿Cuántos contadores existen cuyo volumen registrado } \\
\text { sea mayor que } 4000 \mathrm{~m}^{3} \text { ? }\end{array}$ & & \\
\hline $\begin{array}{l}\text { 37) ¿Cuántos kilómetros de tubería es renovada cada año? } \\
(\mathrm{km} / \mathrm{año})\end{array}$ & & \\
\hline d) Subcomponente: equipamiento y personal & & \\
\hline $\begin{array}{l}\text { 38) ¿Cuántas horas al mes de maquinaria y equipo están } \\
\text { financiados y operativos para las tareas de OO\&MM?, } \\
\text { (h/mes) }\end{array}$ & & \\
\hline $\begin{array}{l}\text { 39) ¿Cuántas horas al mes de maquinaria y equipo son los } \\
\text { que la empresa necesita para las tareas de Oo\&MM?, } \\
\text { (h/mes) }\end{array}$ & & \\
\hline $\begin{array}{l}\text { 40) Indique ¿cuál es el número de empleados y } \\
\text { trabajadores de la empresa (para agua potable y } \\
\text { alcantarillado)? }\end{array}$ & & \\
\hline B) COMPONENTE SOCIAL & & \\
\hline a) Subcomponente operativo: cantidad & & \\
\hline $\begin{array}{l}\text { 41) ¿Cuál es el número de reducciones de la cantidad de } \\
\text { caudal hasta un } 50 \% \text { por año? }\end{array}$ & & \\
\hline
\end{tabular}




\begin{tabular}{|c|c|c|}
\hline Pregunta & Dato & Fiable? \\
\hline $\begin{array}{l}\text { 42) ¿Cuál es el número de horas acumuladas por año de } \\
\text { interrupciones por cortes del suministro?, ( } \mathrm{h} / \text { año) }\end{array}$ & & \\
\hline $\begin{array}{l}\text { 43) ¿Cuántas acometidas de clientes tienen presión de } \\
\text { servicio menor que } 10 \mathrm{~m} \text { c.a., en algún momento del } \\
\text { día? }\end{array}$ & & \\
\hline $\begin{array}{l}\text { 44) ¿Cuál es el número de acometidas de clientes con } \\
\text { presión de servicio mayor que } 50 \mathrm{~m} \text { c.a., en algún } \\
\text { momento del día? }\end{array}$ & & \\
\hline \multicolumn{3}{|l|}{ b) Subcomponente operativo: calidad } \\
\hline $\begin{array}{l}\text { 45) ¿Cuántas muestras de agua se someten a un análisis de } \\
\text { calidad físico, químico y bacteriológico, por mes?, } \\
\text { (muestras / mes) }\end{array}$ & & \\
\hline 46) ¿Cuál es el número de habitantes de la ciudad? & & \\
\hline $\begin{array}{l}\text { 47) ¿Cuál es el número promedio de horas por día que el } \\
\text { agua permanece estancada (almacenada en depósitos } \\
\text { del sistema) previo a su distribución y consumo? }\end{array}$ & & \\
\hline $\begin{array}{l}\text { 48) Indique ¿cuál es el número de acometidas de clientes } \\
\text { con cloro residual menor que } 0.30 \mathrm{mg} / \mathrm{L} \text { ? }\end{array}$ & & \\
\hline $\begin{array}{l}\text { 49) Indique ¿cuál es el número de acometidas de clientes } \\
\text { con cloro residual mayor que } 1.50 \mathrm{mg} / \mathrm{L} \text { ? }\end{array}$ & & \\
\hline \multicolumn{3}{|l|}{ c) Subcomponente operativo: cobertura } \\
\hline \multicolumn{3}{|l|}{ 50) ¿Cuántos predios están conectados al abastecimiento? } \\
\hline $\begin{array}{l}\text { 51) ¿Cuál es el número total de predios dentro de la } \\
\text { jurisdicción del sistema de agua? }\end{array}$ & & \\
\hline $\begin{array}{l}\text { 52) ¿Cuántos predios conectados al sistema, tienen buen } \\
\text { servicio en horas pico? }\end{array}$ & & \\
\hline \multicolumn{3}{|l|}{ d) Subcomponente formativo: capacitación a empleados } \\
\hline $\begin{array}{l}\text { 53) ¿Cuántas horas promedio de capacitación se invierte } \\
\text { por técnico de campo al año?, (horas al año) }\end{array}$ & & \\
\hline $\begin{array}{l}\text { 54) ¿Cuántas horas promedio de capacitación se invierte } \\
\text { por técnico de planificación al año?, (horas al año) }\end{array}$ & & \\
\hline $\begin{array}{l}\text { 55) ¿Cuántas horas promedio de capacitación se invierte } \\
\text { por administrador al año?, (horas al año) }\end{array}$ & & \\
\hline
\end{tabular}




\begin{tabular}{|c|c|c|}
\hline Pregunta & \multirow[t]{2}{*}{ Dato } & \multirow{2}{*}{ Fiable? } \\
\hline $\begin{array}{l}\text { 56) ¿Cuántas horas promedio de capacitación se invierte } \\
\text { por coordinador al año?, (horas al año) }\end{array}$ & & \\
\hline \multicolumn{3}{|l|}{ d) Subcomponente formativo: concientización al cliente } \\
\hline \multicolumn{3}{|l|}{$\begin{array}{l}\text { 57) ¿Cuántas horas al año se brinda capacitación a los } \\
\text { clientes respecto al uso racional del agua y temas } \\
\text { relacionados con la gestión, (bien sea en colegios, } \\
\text { escuelas u otros)?, en (h/año) }\end{array}$} \\
\hline \multicolumn{3}{|l|}{$\begin{array}{l}\text { 58) ¿Cuántos minutos al mes se invierte en campañas de } \\
\text { concientización por TV para uso racional del agua a sus } \\
\text { clientes?, en (min / mes) }\end{array}$} \\
\hline \multicolumn{3}{|l|}{$\begin{array}{l}\text { 59) ¿Cuántos minutos al mes se invierte en campañas de } \\
\text { concientización por medio radial para uso adecuado } \\
\text { del agua a sus clientes?, en (min / mes) }\end{array}$} \\
\hline \multicolumn{3}{|l|}{ e) Subcomponente comercial: atención al cliente } \\
\hline \multicolumn{3}{|l|}{$\begin{array}{l}\text { 60) ¿Cuánto tiempo la empresa tarda en responder las } \\
\text { quejas de sus abonados?, (en días) }\end{array}$} \\
\hline \multicolumn{3}{|l|}{$\begin{array}{l}\text { 61) ¿Cuánto tiempo (en días) la empresa tarda en atender } \\
\text { nuevas conexiones (desde el ingreso del pedido)? }\end{array}$} \\
\hline \multicolumn{3}{|l|}{$\begin{array}{l}\text { 62) ¿Cuánto tiempo la empresa tarda en atender } \\
\text { reparaciones a daños (desde el ingreso del pedido)?, } \\
\text { (en días) }\end{array}$} \\
\hline \multicolumn{3}{|l|}{$\begin{array}{l}\text { 63) ¿Cuántos días la empresa tarda en atender re- } \\
\text { conexiones (desde el ingreso del pedido)?, (en días) }\end{array}$} \\
\hline $\begin{array}{l}\text { 64) Seleccione una respuesta con la equis " } X \text { ", según } \\
\text { corresponda. }\end{array}$ & No & \\
\hline \multirow{2}{*}{$\begin{array}{l}\text { ¿Existe en ejecución un plan de marketing publicitario } \\
\text { de la empresa, para promocionar el ahorro de agua y } \\
\text { hacer difusión pública de su actividad gestora? }\end{array}$} & Insuficiente & \\
\hline & Si & \\
\hline \multirow{2}{*}{$\begin{array}{l}\text { 65) Seleccione una respuesta con la equis “X”, según } \\
\text { corresponda. }\end{array}$} & No & \\
\hline & Mejorable & \\
\hline $\begin{array}{l}\text { ¿Existe en la empresa la infraestructura de atención al } \\
\text { cliente organizada, equipada y cómoda? }\end{array}$ & Si & \\
\hline \multicolumn{3}{|l|}{ C) COMPONENTE AMBIENTAL } \\
\hline a) Subcomponente explotación: agua captada y vertida & & \\
\hline
\end{tabular}




\begin{tabular}{|c|c|c|}
\hline Pregunta & \multirow[t]{2}{*}{ Dato } & \multirow{2}{*}{ Fiable? } \\
\hline $\begin{array}{l}\text { 66) ¿Cuánto caudal de agua se capta para el } \\
\text { abastecimiento, en época de estiaje?, en }(\mathrm{L} / \mathrm{s})\end{array}$ & & \\
\hline $\begin{array}{l}\text { 67) ¿Cuál es el caudal de agua disponible en el punto de } \\
\text { captación, en época de estiaje?, en (L/s) }\end{array}$ & & \\
\hline \multirow{3}{*}{$\begin{array}{l}\text { 68) Seleccione una respuesta con la equis “ } X " \text {, según } \\
\text { corresponda. } \\
\text { ¿Existe estricto control legal y regulación efectiva de } \\
\text { explotación de otros recursos y uso de suelo, en las } \\
\text { cuencas fuente, por el gobierno local y la empresa de } \\
\text { agua? }\end{array}$} & No & \\
\hline & Mejorable & \\
\hline & Si & \\
\hline \multicolumn{3}{|l|}{ b) Subcomponente explotación: consumos } \\
\hline $\begin{array}{l}\text { 69) Indique ¿Cuánto es el promedio de consumo de agua } \\
\text { por habitante por día?, (en L/hab./día) }\end{array}$ & & \\
\hline $\begin{array}{l}\text { 70) ¿Cuál es el volumen promedio de consumo por } \\
\text { conexión?, en }\left(\mathrm{m}^{3} / \mathrm{mes}\right)\end{array}$ & & \\
\hline $\begin{array}{l}\text { 71) ¿Cuántas personas promedio habitan en los predios } \\
\text { conectados al sistema? }\end{array}$ & & \\
\hline $\begin{array}{l}\text { 72) ¿Cuál es el volumen de agua perdido (real) en toda la } \\
\left.\text { red, desde las captaciones?, en ( } \mathrm{m}^{3} / \mathrm{mes}\right)\end{array}$ & & \\
\hline $\begin{array}{l}\text { 73) ¿Cuánta agua promedio mensual es extraída de la } \\
\left.\text { cuenca para el sistema?, en ( } \mathrm{m}^{3} / \mathrm{mes}\right)\end{array}$ & & \\
\hline $\begin{array}{l}\text { 74) ¿Cuánto es el pago por consumo mensual de energía } \\
\text { eléctrica en el abastecimiento? ( } \$ / \text { mes) }\end{array}$ & & \\
\hline $\begin{array}{l}\text { 75) ¿Cuánto es el pago por consumo mensual de energía } \\
\text { eléctrica que se debió consumir bajo las mejores } \\
\text { condiciones y óptimos rendimientos?, en ( } \$ / \text { mes) }\end{array}$ & & \\
\hline c) Subcomponente contaminación por OO \& MM & & \\
\hline $\begin{array}{l}\text { 76) ¿Cuál es el volumen de lodos y desechos generados por } \\
\text { el sistema de tratamiento y potabilización (filtros, } \\
\text { floculadores, sedimentadores y otros)?, en }\left(\mathrm{m}^{3} / \text { año) }\right.\end{array}$ & & \\
\hline $\begin{array}{l}\text { 77) ¿Cuál es el volumen de lodos y desechos generados por } \\
\text { el sistema de potabilización (en filtros, floculadores, } \\
\text { sedimentadores y otros) que se depuran y gestionan } \\
\text { correctamente?, (en } \mathrm{m}^{3} / \text { año) }\end{array}$ & & \\
\hline
\end{tabular}




\begin{tabular}{|c|c|c|}
\hline Pregunta & Dato & Fiable? \\
\hline $\begin{array}{l}\text { 78) Seleccione una respuesta con la equis “ } X " \text {, según } \\
\text { corresponda. }\end{array}$ & Nada & \\
\hline ¿Se depuran las aguas servidas - residuales, de los & Parcialmente & \\
\hline & Todo & \\
\hline $\begin{array}{l}\text { 79) Seleccione una respuesta con la equis “ } X " \text {, según } \\
\text { corresponda. }\end{array}$ & Todas & \\
\hline $\begin{array}{l}\text { ¿Se aplica medidas (correctoras o de mitigación) para } \\
\text { reducir el impacto por ruido, polvo y gases, cuando se }\end{array}$ & Parcialmente & \\
\hline $\begin{array}{l}\text { desarrollan actividades de OO\&MM ó en apertura y } \\
\text { cierre de zanjas para reparaciones ó cuando se } \\
\text { interviene la red para conexiones? }\end{array}$ & Ninguna & \\
\hline d) Subcomponente conservación: cuenca fuente & & \\
\hline $\begin{array}{l}\text { 80) ¿Cuánta superficie de la cuenca tributaria (zona } \\
\text { boscosa con importante aporte hídrico para el } \\
\text { abastecimiento) le pertenece exclusivamente a la } \\
\text { empresa?, en Ha (Hectáreas) }\end{array}$ & & \\
\hline 81) ¿Cuál es el caudal medio producido en planta?, en (L/s) & & \\
\hline $\begin{array}{l}\text { 82) ¿Cuánta superficie de la o las cuencas tributarias } \\
\text { tienen en marcha un plan anual de silvicultura, bio- } \\
\text { protección ó reforestación, gestionado y coordinado } \\
\text { por la empresa operadora del sistema?, en }(\mathrm{Ha})\end{array}$ & & \\
\hline $\begin{array}{l}\text { 83) ¿Cuál es la superficie total de las cuencas tributarias?, } \\
\text { en }(\mathrm{Ha})\end{array}$ & & \\
\hline $\begin{array}{l}\text { 84) Indique ¿cuál es el número de industrias que funcionan } \\
\text { dentro de la cuenca tributaria, que depuran sus } \\
\text { vertidos y controlan sus desechos, sin contaminar? }\end{array}$ & & \\
\hline $\begin{array}{l}\text { 85) ¿Cuántas industrias en total funcionan dentro de la } \\
\text { cuenca tributaria o fuente? }\end{array}$ & & \\
\hline $\begin{array}{l}\text { 86) ¿Cuánto del ingreso propio, recaudado por venta de } \\
\text { agua, se destina a la adquisición y conservación } \\
\text { técnica de las cuencas tributarias que surten al } \\
\text { sistema?, en ( } \$ / \text { año). }\end{array}$ & & \\
\hline
\end{tabular}

Los datos pueden ser: Altamente fiables, fiables, poco fiables o muy poco fiables. Ver aspectos de la validación en acápite 5.1.1. 


\subsubsection{Sondeo técnico participativo - STP}

Un procedimiento yuxtapuesto que se recomienda en la recolección de información para el diagnóstico de sostenibilidad de abastecimientos mediante su índice ISA, es el sondeo técnico participativo, STP; metodología que permite obtener ágilmente información de los miembros del equipo que trabajan para el sistema de forma directa, y en la que cada miembro destaca como un experto en los temas en los cuales se desempeña dentro de la empresa.

El STP involucra las consideraciones siguientes:

a) Premisas del sondeo técnico participativo (STP):

i) Las dificultades más relevantes que se pueden identificar en un abastecimiento las conocen, posiblemente mejor que cualquiera, los mismos gestores y encargados de la administración, operación y mantenimiento (OO\&MM).

ii) Mediante un diálogo informal o semi formal, bien direccionado a nuestro propósito, con quienes conforman el equipo de trabajo del abastecimiento, se puede recabar significativa información cualitativa y también cuantitativa, confiable y hasta verificable in situ.

iii) La participación en el STP, del equipo interdisciplinario del abastecimiento, facilitará interpretar la realidad social, económica y ambiental, por la cual atraviesa el sistema de agua.

iv) Los involucrados en las actividades cotidianas de la OO\&MM del sistema, por su experiencia y trayectoria, pueden aportar y ratificar datos que lleven a conocer e interpretar las necesidades y no conformidades internas, o conducir hacia la detección de complejos problemas.

v) Los datos proporcionados, se contrastan o verifican rápidamente al existir varias fuentes de información acerca de un mismo tema.

vi) Con el STP, la encuesta se convierte en algo más que un "largo cuestionario a ser respondido"; se transforma en un guión técnico a seguir, y el instrumento que marque el horizonte al cual se desea llegar conjuntamente. 


\section{b) Selección del equipo para el STP}

La selección de los técnicos, empleados y trabajadores idóneos para participar del sondeo técnico participativo, obedece a las características que en ellos destaque su criterio para el acceso, manejo y entrega de la información necesaria - requerida, bien sea por su competencia en el tema o por ser suya la responsabilidad de la adquisición, transporte, procesamiento y almacenamiento de la información.

Las personas recomendadas para esta selección serán: el propio gerente ejecutivo, con los directores del área técnica, comercial y financiera. El equipo para la participación en el STP debería estar conformado, al menos, por las personas mencionadas anteriormente, más los encargados de la parte ambiental, legal, contable, de personal o recursos humanos, los ingenieros de campo, y el encargado del diagnóstico, principalmente.

En la primera reunión, el responsable de aplicar el diagnóstico ISA, debe explicar muy bien todo el proceso que se planifica seguir para el abastecimiento, así como realizar un adiestramiento general a los principales responsables en todos los temas y fases de los cuales se compone la metodología, detallar las características de los componentes, subcomponentes y especificar la importancia que tienen las variables e indicadores que los constituyen.

\section{c) Convocatoria y plazos}

Una vez conformado y formalizado el equipo para el STP, el encargado del diagnóstico responsabilizará a cada involucrado, de la búsqueda, recopilación, organización y comprobación de los datos e información requerida, según le corresponda a cada uno en su tema de dominio. En un plazo prudencial, recomendado por el mismo equipo de STP, se convocará para la siguiente reunión, en la que de una manera documentada o bien respaldada, se empezará con el diálogo para la trasmisión de criterios, datos y características inmersas en la problemática, la indagación y el levantamiento de información propiamente dicha.

Como se indicó en el párrafo anterior, para evitar posibles fallos de coordinación y cruces por coincidencia laboral, serán ellos mismos (todos los miembros del equipo para el STP) quienes asignen un calendario, con las fechas y horarios de trabajo en la que siempre la mitad más uno del equipo del STP estén disponibles; lo que implica una característica de flexibilidad y adaptación según se vaya produciendo el avance. 
Como referencia general, se anota que bajo las mejores condiciones de trabajo y siempre que se cuente con toda la información, buena actitud del equipo y participación proactiva de todos, el STP en su fase de recolección de variables y valoración de las encuestas, podría llevar como mínimo cinco visitas, con hasta 6 horas de trabajo efectivo cada una, dependiendo de las limitantes que afecten cada caso.

\section{d) Información}

Mientras se desarrolla el sondeo técnico participativo (STP) para organizar y levantar la información, el responsable del diagnóstico procurará en todo momento ser un vigilante y activo supervisor de las fuentes de información empleadas para conseguir cada dato proporcionado por el equipo, de esta forma se garantiza mayor certeza al momento de asignarle cualquiera de los 4 grados de confiablidad. Ver acápite 5.1.1, validación.

El tiempo laboral no podrá ser un limitante para conseguir que cada miembro aporte, correcta y completamente, con los datos del tema que se le responsabilizó inicialmente. Por ello, la gerencia de la empresa debe proporcionar a todos los miembros del equipo que conforman el STP, las facilidades y el apoyo logístico necesario, así como también brindar todos los recursos necesarios para solventar estos encargos.

\section{e) Informe}

Finalmente el equipo del STP, emitirá un informe con los datos que se recabaron en esta primera fase; mejor si es oficial. Este informe será el que marque el punto de partida para el ingreso de datos, cálculo del ISA y poder continuar con el proceso de diagnóstico.

\subsubsection{Procedimiento del diagnóstico con el índice de sostenibilidad del abastecimiento}

Una vez que se cuente con todos los datos (bien que sean recabados mediante la encuesta o mejor si provienen de un informe del equipo del STP), el responsable del diagnóstico procederá con las siguientes etapas que la metodología precisa. 
La secuencia se muestra a continuación:

Figura 4.2 Diagrama de flujo del procedimiento para el diagnóstico a través del ISA

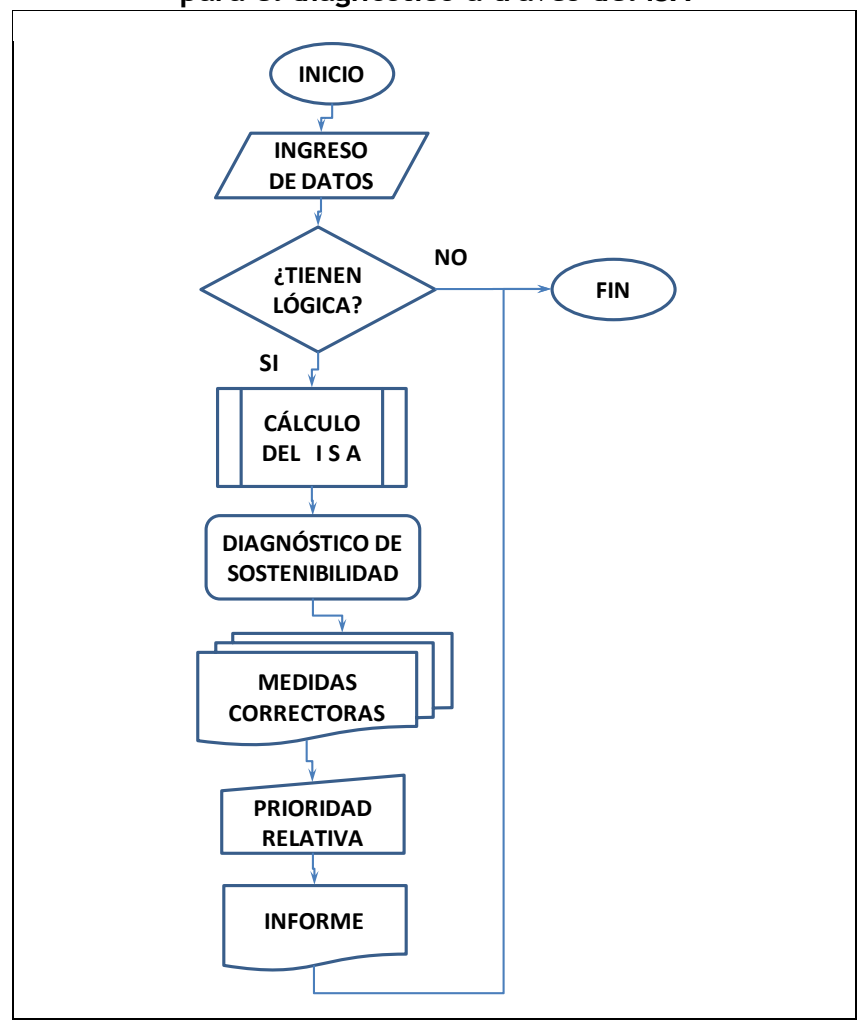

1) Ingreso de datos.-

Los datos se extraerán y combinarán de tal modo que se facilite el cálculo de los indicadores que forman parte del índice de sostenibilidad del abastecimiento. Los indicadores se agrupan por subcomponentes y estos a su vez dan lugar a los componentes.

Cada componente aporta con la tercera parte del valor total del ISA, que se puntúa entre $>0$ y 100 . 


\section{2) Análisis de datos.-}

Se contrasta los datos que han sido ingresados en las hojas de cálculo y se confirma, por simple inspección, que exista coherencia entre los valores que guardan relación entre sí; por ejemplo, volúmenes de producción y los de extracción de la fuente (cuenca), o volúmenes fugados y facturados; volúmenes facturados, recaudados y emitidos; caudales de estiaje y captados en estiaje; de tal manera que buscaremos que no existan contradicciones.

Si no se percibe ninguna anomalía entonces se continúa con el procedimiento, caso contrario se detiene el cálculo y se solicitará al equipo del STP o al personal que proporcionó los datos que satisfagan nuestras inquietudes y dudas en la información recibida.

\section{3) Cálculo del ISA.-}

Pasos para determinar el valor del ISA (agregación):

i) Se calcula cada indicador, con la combinación de los datos proporcionados por el gestor del abastecimiento, ya sea mediante la encuesta o mediante el STP, y las ecuaciones planteadas por indicador, concatenar con el proceso explicado en el capítulo 3 . Así a cada indicador le corresponde al menos una pregunta de la encuesta.

Por ejemplo, se debe combinar las variables (respuestas de las preguntas) 1 y 2 en la ecuación (3.4) para el cálculo del indicador "autosuficiencia financiera"; y, así para los 49 indicadores del método propuesto.

ii) Para el cálculo del factor de calidad, existe la posibilidad de proceder de dos maneras, una gráfica y otra matemática.

Para el primero de los casos, se utiliza las curvas de conversión que se presentan en el capítulo 3; así: con el valor del indicador, en el eje de las abscisas, se interseca en el punto de la función correspondiente, finalmente el valor del factor de calidad será su proyección en el eje de las ordenadas. 
Se muestran a continuación dos ejemplos, de la aplicación del método gráfico para la conversión de valores del indicador a factor de calidad.

Gráfico 4.1 Curva de conversión para: \% autosuficiencia financiera

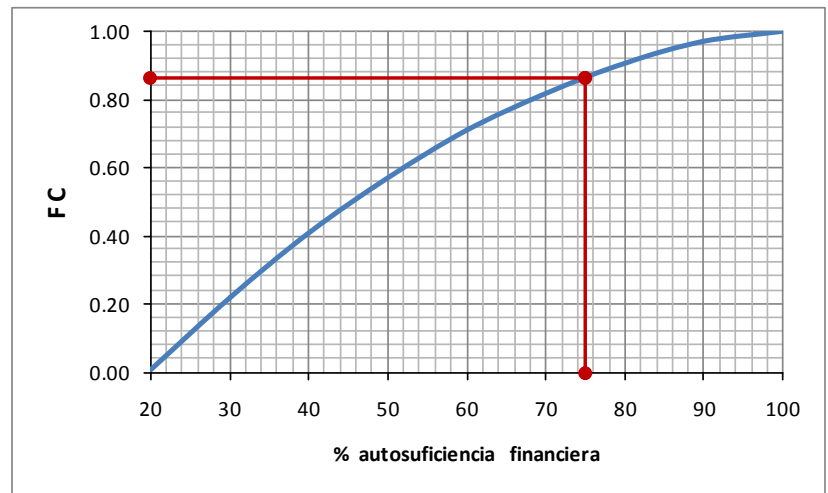

Si el abastecimiento cuenta con un $74 \%$ de autosuficiencia financiera, su proyección en la gráfica nos indica que el factor de calidad correspondiente es, $\mathrm{FC}=0.85$.

Gráfico 4.2 Curva de conversión para: Número de empleados por cada 10000 abonados

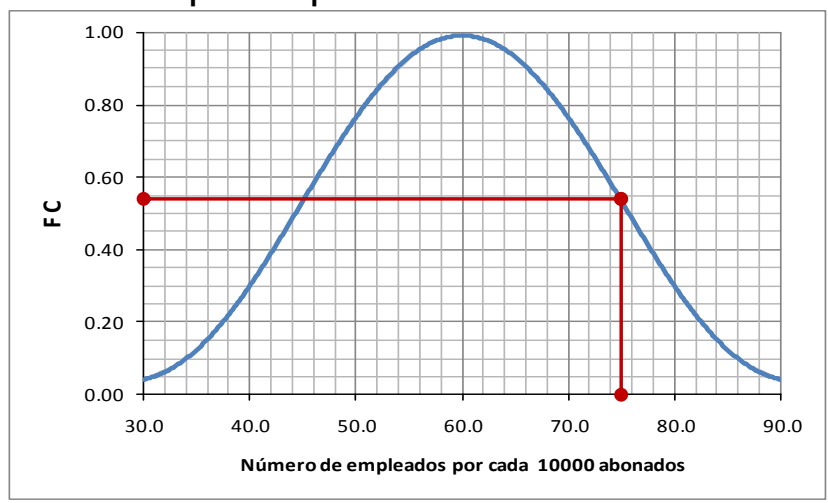

En esta segunda muestra podemos observar que si el abastecimiento cuenta con 75 empleados por cada 10000 abonados, su factor de calidad leído en el eje de las ordenadas es, $\mathrm{FC}=0.54$

Para el cálculo por el método matemático se emplea las funciones de conversión propuestas en el mismo capítulo 3; así, el valor de cada indicador 
se lo reemplaza en la función de conversión que le corresponda, y el resultado será el $F C$ (factor de calidad, isométrico) para ese indicador.

Por ejemplo, si se desea el factor de calidad para la "autosuficiencia financiera" se empleará la ecuación 3.5.

iii) El "peso relativo de cada indicador" se obtiene al multiplicar el FC con el valor de la "importancia ponderada" del indicador, según el cuadro 3.1.

iv) El "peso relativo de cada subcomponente" será igual a la sumatoria de los pesos relativos de los indicadores que lo conforman. A este valor se lo convierte en porcentaje para más adelante incluirlo en el gráfico de "tela de araña".

v) Asimismo, el "peso relativo de cada componente" será el resultado de sumar los "pesos relativos de los subcomponentes". Su puntuación está entre 0 y 33.3 (33.4 para el ambiental).

vi) Finalmente el ISA (índice de sostenibilidad del abastecimiento) será la suma de los pesos relativos de los tres componentes; suma que, como ya se anotó, puede ubicarse en el rango de 0 a 100.

El cálculo del ISA, es una actividad que se facilita mucho con algún tipo apoyo ofimático. (Este aspecto se puede complementar en el apartado 3.2.4). En el presente caso se emplearon hojas electrónicas, como la que se muestra en la tabla siguiente:

Tabla 4.2 Ejemplo del cálculo del índice de sostenibilidad del Abastecimiento, agregación para su componente económico $\mathrm{PR}_{\text {ECONÓMICO }}=11.17 \sim 33.5 \%$

\begin{tabular}{|c|c|c|c|c|c|c|c|}
\hline Subcomponente & indicador & $\begin{array}{l}\text { Importancia } \\
\text { ponderada }\end{array}$ & $\begin{array}{l}\text { valor del } \\
\text { indice }\end{array}$ & $F C$ & $\begin{array}{l}\text { peso } \\
\text { relativo }\end{array}$ & & $\%$ \\
\hline \multicolumn{2}{|l|}{$\begin{array}{l}\text { Subcomponente } \\
\text { autogestión }\end{array}$} & 11.0 & valor del índice & $\mathrm{FC}$ & & 5.17 & $47 . \%$ \\
\hline Variable: $1,2,3,4$ y 5 & $\begin{array}{l}\% \text { de recuperación de costos, mediante } \\
\text { cobro defacturación por año de servicio }\end{array}$ & 5.0 & 80.00 & 0.5125 & & 2.56 & \\
\hline Variable: 1 y 2 & $\begin{array}{l}\text { Autosuficiencia financiera = ingresos propios } \\
\text { / gastos corrientes * } 100\end{array}$ & 2.0 & 60.00 & 0.7094 & & 1.42 & \\
\hline Variable: 6 y 7 & $\begin{array}{l}\text { Eficiencia en recaudación }=\text { emisión } \\
\text { recaudación } * 100\end{array}$ & 1.0 & 80.00 & 0.5142 & & 0.51 & \\
\hline Variable: 8 y 9 & $\%$ de agua no facturada / año & 3.0 & 40.00 & 0.2261 & & 0.68 & \\
\hline
\end{tabular}




\begin{tabular}{|c|c|c|c|c|c|c|}
\hline $\begin{array}{l}\text { Subcomponente de } \\
\text { operación y } \\
\text { mantenimiento }\end{array}$ & & 9.2 & valor del Índice & FC & 1.47 & $16 . \%$ \\
\hline Variable: $10,11,12, \ldots .15$ y 16 & Índice de fugas estructural (IFE) & 4.0 & 51.14 & 0.0000 & 0.00 & \\
\hline Variable: 17 y 11 & Número de roturas / km de tubería / año & 1.2 & 1.10 & 0.5680 & 0.68 & \\
\hline Variable: 18 y 11 & $\begin{array}{l}\text { Número de inspecciones acústicas para } \\
\text { control de fugas en la red / año }\end{array}$ & 1.0 & 0.00 & -0.0021 & 0.00 & \\
\hline Variable: 21 y 22 & $\begin{array}{l}\% \text { de superficie interior de depósitos de } \\
\text { almacenamiento que son impermeabilizados } \\
\text { y con mantenimiento por año }\end{array}$ & 1.0 & 20.00 & 0.1040 & 0.10 & \\
\hline Variable: 23 & $\begin{array}{l}\text { Búsqueda de conexiones ilegales (acústica y } \\
\text { visual) en porcentaje de tuberías de la red } \\
\text { /año }\end{array}$ & 1.0 & 0.00 & 0.0000 & 0.00 & \\
\hline
\end{tabular}

\begin{tabular}{|l|l|c|r|r|r|}
\hline $\begin{array}{l}\text { Subcomponente de índices } \\
\text { financieros }\end{array}$ & $\mathbf{3 . 0}$ & valor del Índice & FC & $\mathbf{1 . 3 8}$ & $\mathbf{4 6 . 1 \%}$ \\
\hline Variable: 24 y 2 & $\begin{array}{l}\text { \% de liquidez = Ingresos Corrientes / Gastos } \\
\text { Corrientes * 100 }\end{array}$ & 1.5 & 65.00 & 0.2537 & 0.38 \\
\cline { 2 - 5 } Variable: $25,26,27$ y 28 & $\begin{array}{l}\text { Stock de deuda = pasivo total / (ingreso total } \\
\text { fuente de financiamiento) * } 100\end{array}$ & 1.5 & 70.00 & 0.6678 & 1.00 \\
\hline
\end{tabular}

\begin{tabular}{|c|c|c|c|c|c|}
\hline $\begin{array}{c}\text { Subcomponente de } \\
\text { infraestructura del } \\
\text { abastecimiento }\end{array}$ & & 8.2 & valor del Índice & FC & 2.02 \\
\hline Variable: 29 y 13 & $\begin{array}{l}\text { Número de parcelas hidrométricas } \\
\text { (subsectores o distritos hidrométricos) por } \\
\text { cada } 10000 \text { conexiones }\end{array}$ & 1.0 & 1.00 & 0.0116 & 0.01 \\
\hline Variable: 30 y 11 & \begin{tabular}{|l|} 
Número de hidrantes contra incendios \\
operativos por cada $1.0 \mathrm{~km}$ de tubería \\
\end{tabular} & 1.0 & 0.03 & 0.0130 & 0.01 \\
\hline Variable: 31 y 32 & $\%$ de renovación de collarines por año & 1.2 & 0.75 & 0.2315 & 0.28 \\
\hline Variable: 33 y 34 & $\begin{array}{|lcr|}\% & \text { contadores } & \text { funcionan } \\
\text { (instalados/conexiones*100) } & \\
\end{array}$ & 1.0 & 80.00 & 0.4930 & 0.49 \\
\hline Variable: 35 y 34 & $\%$ de contadores instalados más de 8 años & 1.0 & 22.60 & 0.2078 & 0.21 \\
\hline Variable: 36 y 34 & $\begin{array}{l}\% \text { de contadores instalados cuyas lecturas } \\
\text { superan los } 4000 \mathrm{~m} 3\end{array}$ & 1.0 & 0.10 & 1.0000 & 1.00 \\
\hline Variable: 37 y 11 & $\%$ de tuberías renovadas o repuestas por año & 2.0 & 0.01 & 0.0100 & 0.02 \\
\hline
\end{tabular}

\begin{tabular}{|l|l|r|r|r|r|}
\hline $\begin{array}{l}\text { Subcomponente de } \\
\text { equipamiento y personal }\end{array}$ & $\mathbf{2 . 0}$ & valor del Índice & FC & $\mathbf{5 6 . 3} \%$ \\
\hline Variable: 38 y 39 & $\begin{array}{l}\text { Porcentaje de maquinaria y equipo } \\
\text { financiados (horas / mes) para OO\&MM }\end{array}$ & 1.0 & 100.00 & 0.9993 & 1.00 \\
\cline { 2 - 6 } Variable: 40 y 13 & $\begin{array}{l}\text { Número de empleados por cada 10000 } \\
\text { abonados }\end{array}$ & 1.0 & 34.55 & 0.1258 & 0.13 \\
\hline
\end{tabular}


Tabla 4.3 Ejemplo de cálculo del índice de sostenibilidad del Abastecimiento, agregación para su componente social

$$
\mathrm{PR}_{\text {SOCIAL }}=18.53 \sim 55.6 \%
$$

\begin{tabular}{|c|c|c|c|c|c|c|c|}
\hline Subcomponente & indicador & $\begin{array}{l}\text { Importancia } \\
\text { ponderada }\end{array}$ & $\begin{array}{l}\text { valor del } \\
\text { indice }\end{array}$ & $F C$ & $\begin{array}{l}\text { peso } \\
\text { relativo }\end{array}$ & & $\%$ \\
\hline \multicolumn{2}{|c|}{$\begin{array}{l}\text { Subcomponente operativo: } \\
\text { cantidad } \\
\end{array}$} & 6.0 & valor del Índice & FC & & 2.19 & $36.6 \%$ \\
\hline Variable: 41 & $\begin{array}{l}\text { Número de reducciones de la cantidad de } \\
\text { caudal hasta un } 50 \% \text { por año }\end{array}$ & 2.0 & 5.00 & 0.8254 & & 1.65 & \\
\hline Variable: 42 & $\begin{array}{l}\text { Tiempo total acumulado, en horas, de } \\
\text { duración de las interrupciones por año }\end{array}$ & 2.0 & 60.00 & 0.2721 & & 0.54 & \\
\hline
\end{tabular}

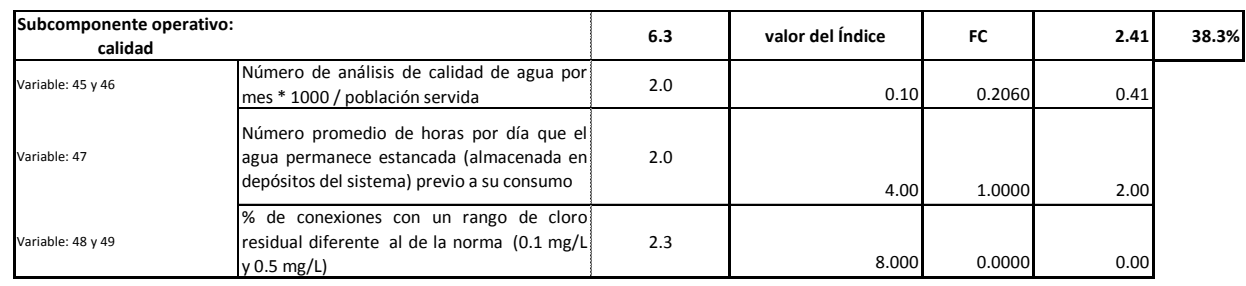

\begin{tabular}{|l|l|r|r|r|r|}
\hline \begin{tabular}{|l|r|r|} 
Subcomponente operativo: \\
cobertura
\end{tabular} & $\mathbf{6 . 0}$ & valor del Índice & FC & $\mathbf{0 . 4 9}$ & $\mathbf{8 . 1 \%}$ \\
\hline Variable: 50 y 51 & \% de predios con conexión al sistema & 3.0 & 62.33 & 0.1618 & 0.49 \\
\cline { 2 - 7 } Variable: 52 y 51 & \% de predios bien servida en horas pico & 3.0 & 20.00 & 0.0000 & 0.00 \\
\hline
\end{tabular}

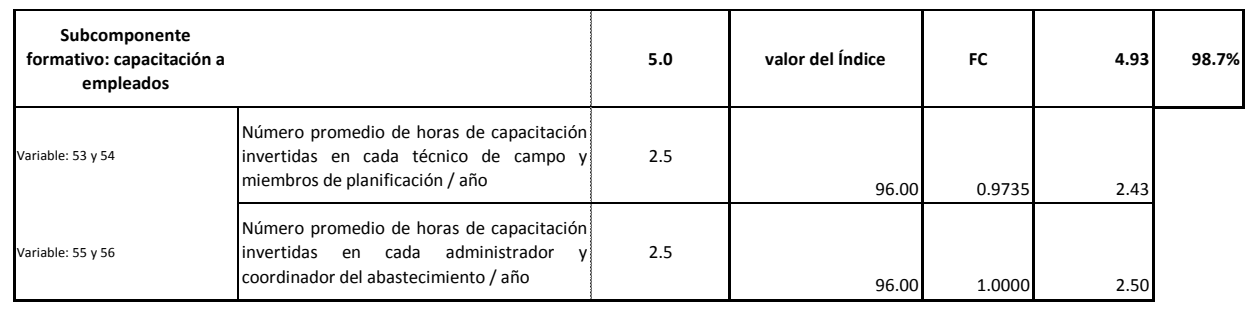

\begin{tabular}{|c|c|c|c|c|c|c|}
\hline Variable: 58 y 59 & $\begin{array}{l}\text { Tiempo total, en minutos, de campaña radial } \\
\text { o TV / mes }\end{array}$ & 2.0 & 13333.00 & 1.0000 & 2.00 & \\
\hline
\end{tabular}




\begin{tabular}{|c|c|c|c|c|c|}
\hline \multicolumn{2}{|c|}{$\begin{array}{c}\text { Subcomponente comercial: } \\
\text { atención al cliente }\end{array}$} & \multirow{2}{*}{$\begin{array}{r}6.0 \\
1.5\end{array}$} & valor del Índice & \multirow{2}{*}{$\begin{array}{l}\text { FC } \\
\\
1.0000\end{array}$} & \multirow{2}{*}{$\begin{array}{l}4.50 \\
1.50 \\
\end{array}$} \\
\hline Variable: 60 & $\begin{array}{l}\text { Tiempo (en días) que la empresa tarda en } \\
\text { responder las quejas de sus abonados }\end{array}$ & & 1.00 & & \\
\hline Variable: 61,62 y 63 & $\begin{array}{l}\text { Tiempo (en días) en los que la empresa } \\
\text { atiende nuevas conexiones, obras de } \\
\text { reparación y reinstalación }\end{array}$ & 1.5 & 0.94 & 1.0000 & 1.50 \\
\hline Variable: 65 & \begin{tabular}{|l|l|}
$\begin{array}{l}\text { Existe la infraestructura de atención al } \\
\text { cliente organizada, equipada y cómoda }\end{array}$ &
\end{tabular} & 1.5 & SI & 1.0000 & 1.50 \\
\hline
\end{tabular}

Tabla 4.4 Ejemplo de cálculo del índice de sostenibilidad del Abastecimiento, agregación para su componente ambiental $\mathrm{PR}_{\text {AMBIENTAL }}=13.05 \sim 39.2 \%$

\begin{tabular}{|c|c|c|c|c|c|c|}
\hline Subcomponente & Indicador & $\begin{array}{l}\text { Importancia } \\
\text { ponderada }\end{array}$ & $\begin{array}{l}\text { valor del } \\
\text { Indice }\end{array}$ & $F C$ & $\begin{array}{l}\text { peso } \\
\text { relativo }\end{array}$ & $\%$ \\
\hline
\end{tabular}

\begin{tabular}{|c|c|c|c|c|c|c|}
\hline $\begin{array}{l}\text { Subcomponente } \\
\text { explotación: del agua } \\
\text { captada y vertida }\end{array}$ & & 7.0 & valor del Índice & FC & 7.00 & $100 . \%$ \\
\hline Variable: 66 y 67 & $\begin{array}{l}\% \text { de caudal de agua captado para el } \\
\text { abastecimiento en época de estiaje }\end{array}$ & 4.0 & 3.00 & 1.0000 & 4.00 & \\
\hline Variable: 68 & $\begin{array}{l}\text { Existe estricto control legal y regulación } \\
\text { efectiva de explotación de otros recursos y } \\
\text { uso de suelo, en las cuencas fuente, por el } \\
\text { gobierno local }\end{array}$ & 3.0 & SI & 1.0000 & 3.00 & \\
\hline
\end{tabular}

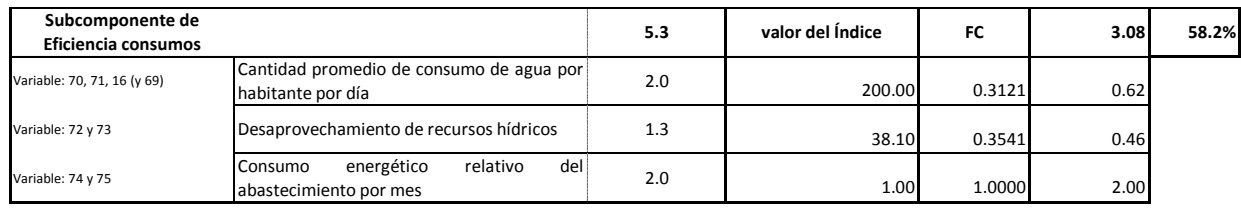

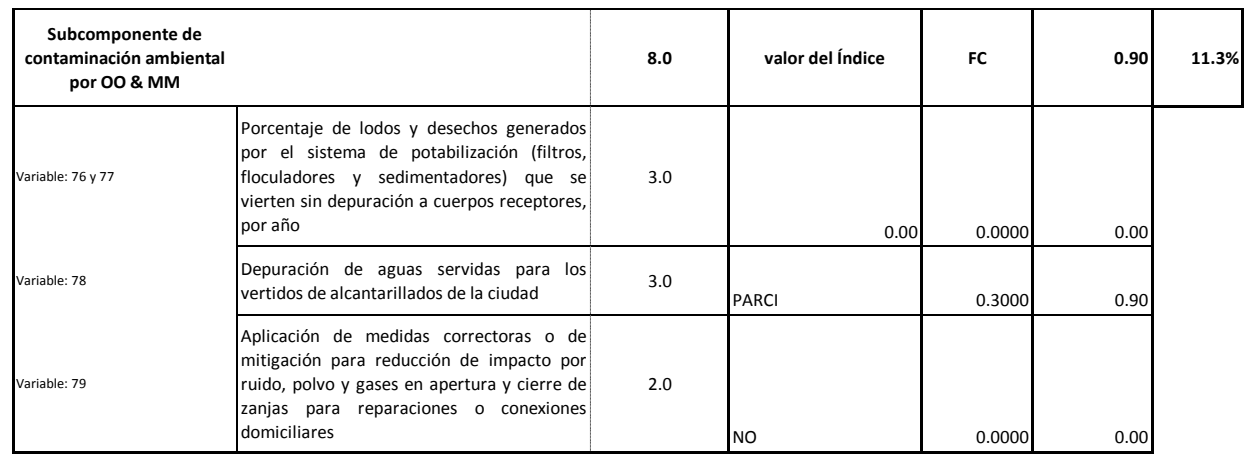




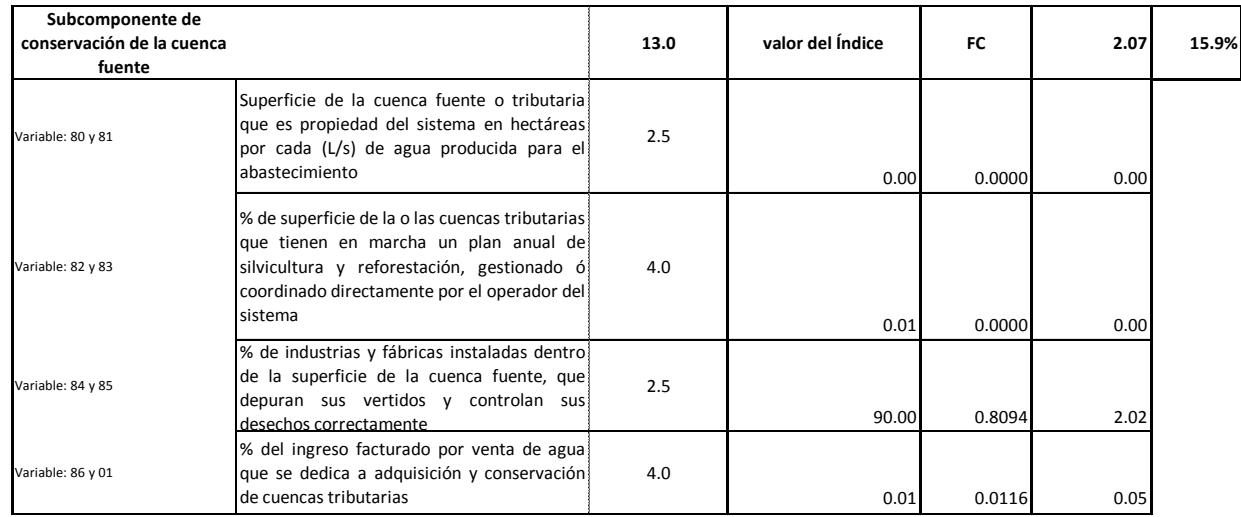

Como resultados de la agregación, se tiene los siguientes pesos relativos - PR:

$\begin{array}{ll}\text { PR }_{\text {ECONÓMICO }} & =11.17 \sim 33.5 \% \\ \text { PR }_{\text {SOCIAL }} & =18.53 \sim 55.6 \% \\ \text { PR }_{\text {AMBIIENTAL }} & =13.05 \sim 39.2 \% \\ \text { I S A } & =\mathbf{4 2 . 7 5} \sim \text { deficiente }\end{array}$

(Ver anexo 4.1)

4) Diagnóstico de la sostenibilidad.-

El diagnóstico de la sostenibilidad de un abastecimiento de agua mediante su índice ISA, constituye una herramienta fundamental para valorar y predecir el estado patológico del sistema de agua, así como identificar y basar técnicamente la propuesta con las medidas correctoras prioritarias, en los componentes social, económico y ambiental, que se relacionan con la gestión del sistema de agua en estudio.

La metodología de diagnóstico ISA, adecuadamente aplicada, se transforma en un instrumento de ayuda a la toma de decisiones en la planificación, ejecución y fiscalización de actividades dentro de los abastecimientos, ya que su valoración se orienta a estados deseables de equilibrio entre la explotación, la conservación y el servicio. Dicha valoración permite medir, a través de variables e indicadores que están íntimamente relacionados con los recursos invertidos en su tarea de servicio (biótico, abiótico, técnico, socioeconómico, etc.), aspectos que influyen en el crecimiento óptimo del abastecimiento hacia la sostenibilidad. 
De tal manera que, el diagnóstico de la sostenibilidad de un abastecimiento, dependerá del rango en el que su índice se encuadre.

Así, si el ISA tiene valores entre cero y cuarenta se trata de un abastecimiento con estado de sostenibilidad "malo"; entre cuarenta y sesenta proyecta una sostenibilidad "deficiente"; valores del ISA entre sesenta y setenta y cinco se entiende que el abastecimiento tiene niveles de sostenibilidad "regular"; si el valor está entre setenta y cinco y noventa el estado de sostenibilidad es "bueno"; y, mayor que noventa el nivel de sostenibilidad es "excelente".

Figura 4.3 Escala cromática para el diagnóstico de sostenibilidad de un abastecimiento, según su ISA

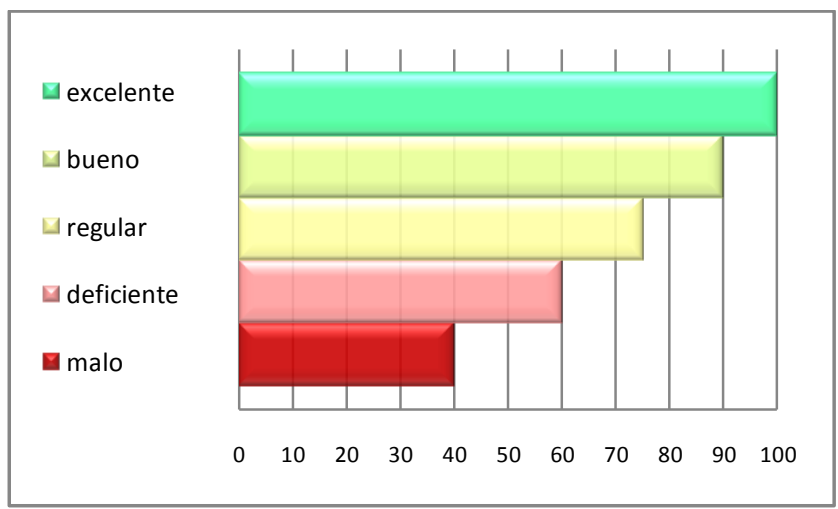

La coordinación para la búsqueda permanente de la sostenibilidad del abastecimiento es responsabilidad de todos sus actores e involucrados: mandatarios, políticos, directivos, empleados, trabajadores, abonados y sociedad en general; mas, el éxito en la aplicación de las medidas correctoras que del diagnóstico se recomienden, implica que cada uno atienda responsablemente el área que le corresponde, amparados en el marco legal vigente.

El empleo de indicadores sociales, económicos y ambientales, que se tornan homogéneos luego de ser agregados, permite que este tipo de diagnóstico se aplique para facilitar la planificación y la gestión del abastecimiento, a mediano y largo plazo, puesto que sus datos son el resultado de la medida del nivel patológico tanto de los componentes como de los recursos que son utilizados en el suministro. 
La suma de los valores de los pesos relativos de los indicadores corresponde al valor del subcomponente, se consideran excelentes aquellos subcomponentes cuyos valores mayores que 30 . Ver figura 4.4

Figura 4.4 Escala cromática para la valoración de los componentes (social, económico y ambiental)

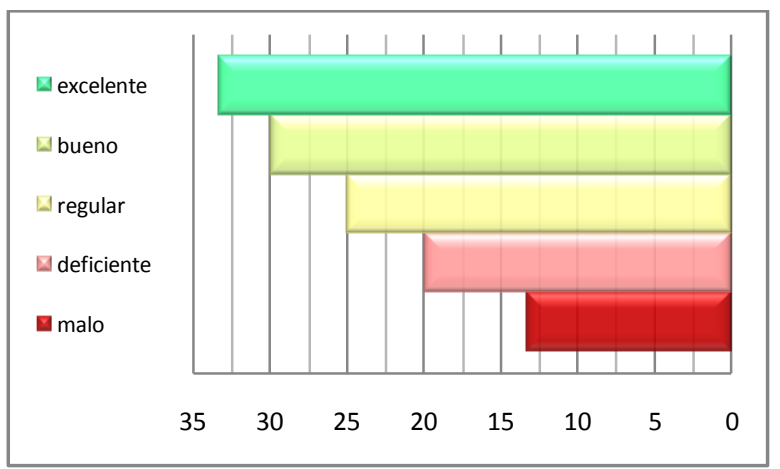

Con la valoración del ISA por componentes y subcomponentes, luego se procede a generar los diagramas tela de araña del abastecimiento y sus componentes satelitales, en porcentajes relativos. Ver figura 3.5.

La ventaja de mostrar gráficamente los resultados del índice de sostenibilidad de abastecimiento -ISA-, facilita su comprensión al momento de compararlos con otros abastecimientos, así como agilitar la detección de alternativas para la toma de decisiones, ya que se comparan pesos ponderados por componentes.

Además se permite, con facilidad visual, evidenciar los subcomponentes con rangos porcentuales críticos y que ameritan inversión de recursos y esfuerzos adicionales para su evolución positiva.

\section{5) Medidas correctoras.-}

El diagnóstico de sostenibilidad que se practica en un instante $\left(t_{0}\right)$ de la vida del abastecimiento y la inmediata aplicación de medidas correctoras, provocan un cambio positivo en la trayectoria de la pronosticada gestión decadente hasta incrementarla a un nivel de sostenibilidad superior, conseguida hasta el tiempo $\left(\mathrm{t}_{1}\right)$. 
Figura 4.5 Proyección esperada de la evolución temporal de la sostenibilidad en un abastecimiento

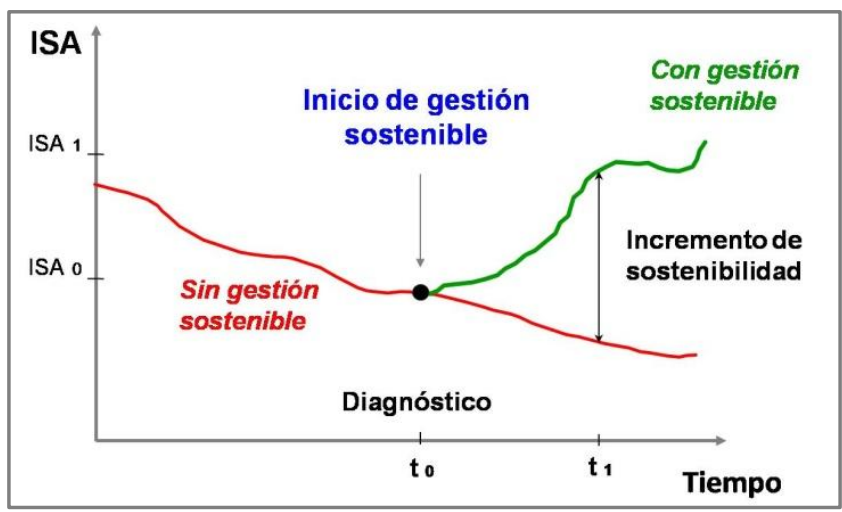

El diagnóstico de sostenibilidad no tendría ningún sentido aplicarlo sí, en una etapa posterior, los responsables de administrarlo, sus directivos o autoridades, no permiten reorientar la gestión y toman la decisión de aplicar soluciones que mejoren su desempeño hacia el siempre buscado equilibrio.

Cambiar el curso, oportunamente, de la gestión se consigue mediante la puesta en práctica de medidas subsidiarias (acciones correctoras) que se incluyen en los planes y programas de la gestión del sistema de agua.

Estas medidas subsidiarias se pueden clasificar según el campo de intervención, en las siguientes:

a) Modificación administrativa.- Son todas aquellas acciones correctoras que se direccionan para transformar parcial 0 totalmente la clase gerencial y directora del abastecimiento, con el ánimo de evitar se continúen tomando decisiones desenfocadas de la sostenibilidad.

b) Evolución técnica.- Así se denominan aquellas medidas correctoras que se aplican en el estadio del aprovechamiento de recursos para mejorar la competitividad técnica tecnológica y profesional. Incremento del "know how" institucional. 
c) Ajuste y enmienda legal.- Consideraciones correctoras que se estudian y dirigen hacia la salvaguarda de los intereses del colectivo en un amparo legal, mediante ordenanzas o decretos normativos que optimicen la trayectoria hacia la sostenibilidad del sistema de agua. Se abolirán, según mejor convenga, todos los reglamentos inútiles y que no apoyen la mejora del sistema.

d) Compensación.- Todo acto, en los escenarios social, económico y ambiental del abastecimiento, que neutraliza las fuerzas contrarias a la sostenibilidad. Caben aquí las actuaciones que merece inversión de recursos para potenciar aquellos cuyos efectos sinérgicos pudieron ser la causa de las patologías detectadas.

e) Restitución.- Prácticas subsidiarias que aporten devolución de la calidad de los elementos del abastecimiento.

f) Estímulo.- Medidas correctoras que instiguen más efectos positivos a aquellos planes o programas del abastecimiento que hasta ahora han provocado bienestar y perfeccionamiento en la gestión.

Una actividad de mejora puede intersecar con una o más de las medidas correctoras, al mismo tiempo. Depende de su característica específica.

En el acápite 4.3 se detallan las directrices y actuaciones generales para mejorar la sostenibilidad.

\section{6) Prioridades relativas.-}

Priorizar medidas correctoras se entiende como la acción de valorar y juzgar, mediante ciertos criterios, el orden sucesivo en las que se suscitarán, sin descartar ninguna.

La técnica que ampara a la metodología del diagnóstico de abastecimientos mediante su ISA se podría explicar como la combinación entre la de factores ponderados y la del árbol de decisiones. El primero de ellos se basa en la valoración global mediante indicadores que a su vez se afectan de forma ponderada por su importancia, (Pabón L. 2007) de tal modo que cada indicador aporta un peso relativo al valor final del ISA. Por su parte la técnica del árbol de indicadores se sustenta en valores que provienen de sus raíces, que en el presente caso son los datos de las variables e indicadores, que a su 
vez crean los subcomponentes y éstos dan lugar a los componentes. La suma de los tres componentes finalmente aflora en la parte superior del árbol con el valor del ISA.

Así entonces, se podría considerar como el más urgente de corregir aquel que tiene el menor porcentaje relativo, de todos los presentados en el diagrama satélite de tela de araña.

No obstante, en un determinado momento de la planificación o ejecución de las medidas correctoras dentro del abastecimiento el gestor y el equipo del STP se pueden topar con que la valoración ponderada relativa de cada indicador (obtenido por el método ISA) no es un determinante taxativo para decidir cuál actividad ejecutar primero, ó resulta impreciso el orden y tiempo en el que se deben ejecutar, bien sea por coincidencia de valores (porcentuales relativos) o por parecer tareas totalmente independientes entre sí (casi nunca excluyentes), entonces es cuando se propone apoyar la tarea de selección y gestión de prioridades en diferentes métodos de selección; más si las prioridades globales de aquellos indicadores no están completamente definidas y terminan atascando la decisión por no precisar entre sí, su urgencia, obligatoriedad o importancia, propiamente dicha.

\section{7) Informe.-}

El proceso de diagnóstico concluye con la redacción del informe y su exposición ante los miembros del equipo del STP o gestores implicados en tal actividad.

Como contenido del informe se redactará:

- Una breve introducción y ámbito de aplicación.

- $\quad$ Objetivos y alcance del diagnóstico.

- Descripción del método utilizado para el levantamiento de la información.

- $\quad$ Resultados del cálculo de indicadores.

- $\quad$ Resultado del cálculo del ISA, por subcomponentes y componentes.

- Visualización de la información en diagramas tela de araña.

- Clasificación del abastecimiento y juicio de la situación real actual, con base en el diagnóstico ISA.

- $\quad$ Propuesta de mejoras y selección de prioridades.

- Conclusiones y recomendaciones.

- $\quad$ Anexos. 


\section{ANEXO 4.1}

\section{Ejemplo de aplicación para el diagnóstico ISA}

Sea el caso en el que el ISA social, económico y ambiental de un abastecimiento tenga los siguientes valores porcentuales:

Cuadro A.4.1.1 Valores porcentuales del ISA social de un abastecimiento

\begin{tabular}{|lc|}
\hline Subcomponente & $\%$ \\
\hline Operativo: cantidad & 36.6 \\
\hline Operativo: calidad & 38.3 \\
\hline Operativo: cobertura & 08.1 \\
\hline Formativo: capacitación a empleados & 98.7 \\
\hline Formativo: concientización a clientes & 100.0 \\
\hline Comercial: atención al cliente & 75.0 \\
\hline
\end{tabular}

El ISA social en su escala de valoración original es de 18.5 y su equivalente porcentual corresponde a $55.6 \%$, valor que marca un estado de sostenibilidad social deficiente. (Ver figura 4.4)

Cuadro A.4.1.2 Valores porcentuales del ISA económico de un abastecimiento

\begin{tabular}{|lc|}
\hline Subcomponente & $\%$ \\
\hline Autogestión & 47.0 \\
\hline Operación y mantenimiento & 16.0 \\
\hline Índices financieros & 46.1 \\
\hline Infraestructura del abastecimiento & 24.7 \\
\hline Equipamiento y personal & 56.3 \\
\hline
\end{tabular}

El ISA económico en su escala de valoración original es de 11.2 y su equivalente porcentual corresponde a $33.5 \%$, valor que marca un estado de sostenibilidad económico malo. (Ver figura 4.4). 
Cuadro A.4.1.3 Valores porcentuales del ISA ambiental de un abastecimiento

\begin{tabular}{|lc|}
\hline Subcomponente & $\%$ \\
\hline Explotación de agua & 100.0 \\
\hline Aprovechamiento & 58.2 \\
\hline Impacto ambiental & 11.3 \\
\hline Conservación & 15.9 \\
\hline
\end{tabular}

El ISA económico en su escala de valoración original es de 13.1 y su equivalente porcentual corresponde a $39.2 \%$, valor que lo sitúa en un estado de sostenibilidad ambiental malo. (Ver figura 4.4).

Luego, el ISA total del abastecimiento es de 43, valor que ubica al abastecimiento en un nivel de sostenibilidad deficiente. (Ver figura 4.3).

Con los valores porcentuales relativos de cada subcomponente se construye los diagramas (tela de araña) del índice de sostenibilidad y sus componentes satélites.

Figura A.4.1.1 Diagramas tela de araña del sistema de diagnóstico ISA y sus componentes satélite

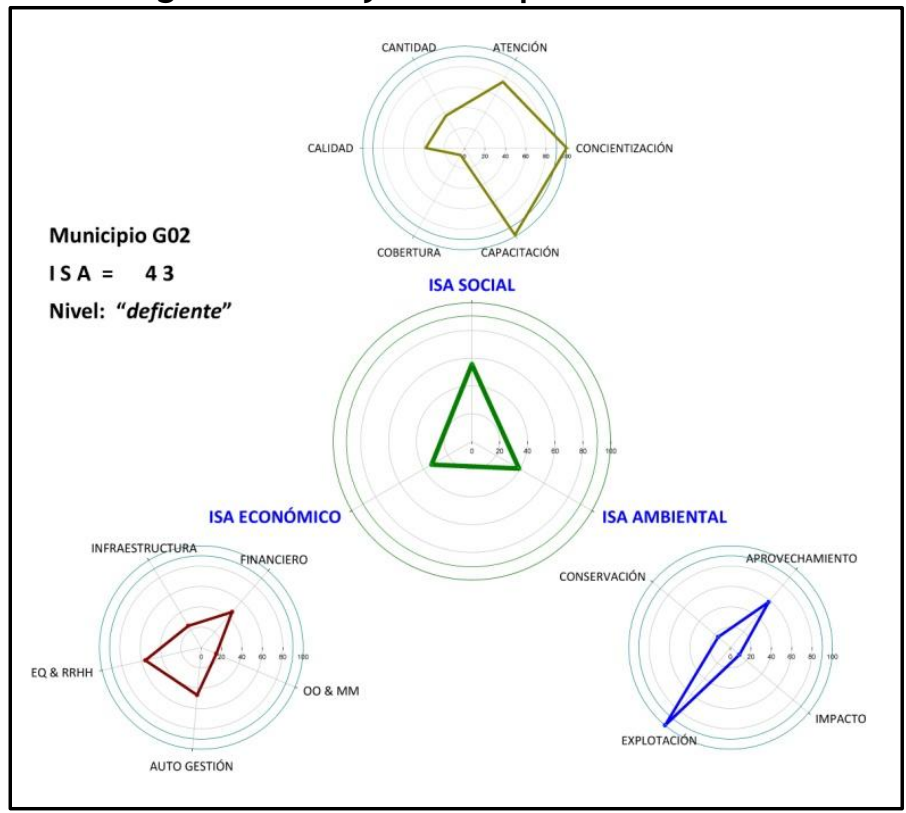

Es visible en este diagrama, que el abastecimiento en análisis requiere que se consideren, por lo menos, las medidas correctoras siguientes: 
a) Modificación administrativa.- para once de los quince subcomponentes que están ubicados por debajo del $75 \%$.

b) Evolución técnica.- En lo social: principalmente para mejorar cobertura, calidad cantidad; en lo económico: infraestructura; y, en lo ambiental: conservación, aprovechamiento e impacto.

c) Ajuste y enmienda legal.- deberán acompañarse los ajustes legales que correspondan, a nivel de ordenanzas o decretos del gobierno local.

d) Compensación.- Principalmente los impactos ambientales, los financieros en lo económico y cobertura en lo social.

e) Restitución.- se incluyen cobertura, calidad y cantidad, en el componente social.

f) Estímulo.- Este tipo de medidas para los cuatro subcomponentes que están arriba del $75 \%$.

\section{ANEXO 4.2}

\section{Búsqueda de mejoras de la gestión en un abastecimiento.}

\section{Caso práctico}

La mejora de la calidad en un abastecimiento significa servir de mejor manera al cliente y cada vez con menores gastos y esfuerzos empresariales. Lograr niveles de calidad de esa índole implica un notorio incremento en los niveles de productividad y satisfacción junto con una, no menos importante, reducción de costos.

Entonces se convierte en fundamental el hecho de saber llevar e interpretar estadísticas de los diferentes y más frecuentes tipos de fallos en las redes y sus orígenes, así se podrá mejorar la performance, como también detectar oportunamente sus causas.

Para que exista una mejora continua se debe alcanzar de forma sistemática mejoras en los indicadores planteados por la organización; los mismos que deben estar relacionados con la calidad y cantidad del agua distribuida, la satisfacción del cliente, la productividad y la rentabilidad interna, los tiempos de respuesta y la seguridad general. 
De allí que, luego de la auditoría hídrica efectuada, a continuación se proponen algunas alternativas que podrían sentar las bases para marchar hacia ese rumbo.

\section{Alternativas para soslayar dificultades y mejorar la gestión}

Para iniciar un sistema de valoración de auditorías, hace falta tomar en consideración los siguientes detalles:

- Inversión económica en las redes de distribución, para sectorizarlas y con ello conformar distritos hidrométricos, o subsectores de medición.

- $\quad$ Seguidamente hará falta instalar sistemas de medición y registro continuo de volúmenes, caudales y presiones, tanto en tramos de inyección como en los de distribución y consumo.

- $\quad$ En los depósitos será necesario instalar, entre otros equipos al menos, un aparato de medición y registro de volúmenes ingresados y extraídos, medición de niveles de superficie libre del agua almacenada, válvulas y accesorios para evitar derrames e intrusión de aire. Hará falta dotar de loggers de almacenamiento de información.

- $\quad$ Seguimiento estadístico y almacenamiento permanente de los datos obtenidos de los nudos de control para su análisis, interpretación y diagnóstico independiente y oportuno.

- Coordinar una campaña mediática informativa para que la población esté al tanto de todos los cambios que se producirán en el sistema a nivel administrativo, hidráulico, sanitario, ambiental, financiero, social y político, entre los principales.

\section{Alternativas para la mejora de la gestión:}

Para los sistemas de abastecimientos del Ecuador y países en desarrollo que pretenden mejorar su servicio y su desempeño en general se recomienda seguir el siguiente protocolo de actividades.

\section{1) Construcción de la línea base}

La conformación de la línea base o situación actual del sistema podría incluir:

a. Levantamiento y/o actualización topográfica. Planimetría y nivelación de redes (a eje de calle).

b. Elaboración de catastros urbanos y censo de clientes actuales. 
c. Localización e inventario de nudos de captación, aducción, tratamiento, almacenamiento, estaciones de bombeo, válvulas, accesorios y redes de distribución.

d. Recuperación de datos históricos de rupturas, mantenimientos (tipo y tiempos), quejas de clientes, etc.

e. Caracterización de la calidad de agua cruda, tratada, almacenada y distribuida.

f. Análisis e interpretación de volúmenes de agua tratada, almacenada y distribuida.

g. Evaluación financiera de las actividades de la empresa. Incluye análisis de ingresos y egresos económicos históricos.

h. Evaluación y diagnóstico de la infraestructura hidráulico sanitario del sistema, en todos sus componentes.

i. Inventario, categorización y actualización de clientes o usuarios del sistema de agua. Identificación de conexiones carentes de contador.

j. Caracterización de contadores domiciliarios.

\section{2) Planificación estratégica con base en prioridades}

La planificación deberá definir líneas directoras a la consecución de objetivos prioritarios tanto para el sistema como para sus clientes. Esta planificación deberá incluir metas a corto, mediano y largo plazo, concatenadas y apoyadas entre sí; a nivel de recomendación se propone las siguientes consideraciones:

a. Garantizar en cualquier tiempo, suficiente cantidad y calidad de agua con presiones reglamentarias (de 10 a $50 \mathrm{~m}$ c.a.). Esto involucra además la fiabilidad de las redes y los aspectos ambientales que la cuenca hidrográfica fuente requiera.

b. Responder oportunamente a roturas y fallos de las redes de tal manera que se garantice un buen nivel de servicio,

c. Consolidar nudos de control en la red, ello implica la instalación de equipos de medición y registro, en nudos de almacenamiento, salida de plantas de tratamiento y estaciones de bombeo y en otros puntos que se considere coherente su inclusión.

d. La sectorización de las redes se debe incluir como un ítem prioritario para la detección, localización y reparación de fugas. 
e. El control activo de fugas, demanda por su parte una estrategia autónoma e integradora al proceso de reducción de pérdidas reales del sistema.

f. Un análisis de costos ambientales, administrativos, de operación y mantenimiento, serán la base para una actualización tarifaria y su categorización valorada por consumos; de esta manera se dejará el espacio necesario para el desarrollo sostenible de la actividad emprendida por cada institución operadora.

g. Reparación y renovación de tuberías cuyos daños y materiales así lo exijan. Por ejemplo, se deberá iniciar con la reposición de las tuberías de asbesto cemento que aún existan por tratarse de materiales cancerígenos para el ser humano.

h. De la misma manera se debe incluir la renovación de válvulas, hidrantes y accesorios que hayan cumplido su vida útil y que estén ocasionando problemas en la operación de la red.

i. El enfoque de calidad deberá pasar por un progresivo incremento de la capacidad constructiva y de efectivas reparaciones en las redes, junto con un sistema integral de gestión de la información.

3) Financiamiento y ejecución de actividades programadas

a. Todos los proyectos que componen este programa de mejora de la gestión de sistemas de abastecimiento deben tener, de forma oportuna y estable, su partida presupuestaria completa. Esto significa que se deberá incluir entre las estrategias gerenciales, la búsqueda pertinaz de fuentes de financiamiento.

b. Entre las fuentes de financiamiento contempladas están: los propios ingresos por las tarifas reajustadas, otra opción son además los préstamos de índole internos del país o también los préstamos de inversionistas externos al país.

c. Será necesario redactar y tener disponible, los proyectos técnicos, en el formato de cada dependencia financista; incluirá al menos una memoria ejecutiva explicativa, un evaluación financiera (VAN, TIR y R B/C) y los planos de detalles. Se recomienda, en cualquier caso tener siempre listos los proyectos, bajo la herramienta del marco lógico.

d. Una vez conseguido el capital presupuestario, con prontitud y diligencia se deberá ejecutar el proyecto. 
e. Instituir convenios de pago y recuperación de cartera vencida. Mejorar la calidad de atención al cliente.

4) Operación, mantenimiento y retroalimentación

a. La operación requiere de la selección de un distrito hidrométrico (o un subsector) que previamente se lo haya identificado como crítico y prioritario de intervención.

b. Obtener el rango de caudales de consumos: doméstico, industrial, comercial, oficial y discapacitados o tercera edad.

c. El paso siguiente será estructurar el balance hídrico del distrito en evaluación y determinación de las características hidráulicas (caudal y presión) en diferentes puntos de la red; según se indició en el capítulo 1.3.

d. El grupo colegiado de la institución operadora deberá escoger un sistema de variables e indicadores, según sea su capacidad de generar valores confiables y permanentes. Luego se emprenderá con el cálculo de indicadores de desempeño: operacional, hídrico-energéticos, rehabilitación, económico financieros y de calidad de servicio al cliente, principalmente.

e. Determinación del nivel óptimo de fugas. Inspección de campo y aplicación de las metodologías más competentes para detección y localización de fugas.

f. Políticas para la gestión del suministro de agua en época de sequía o temporadas críticas.

g. Para el mantenimiento y renovación de tuberías se deberá buscar las técnicas de rehabilitación más apropiadas a cada entorno.

h. Análisis de costos óptimos para asignar un precio sostenible del agua potable.

i. Puntualizar las experiencias mejor adaptadas y buenas prácticas para una reingeniería de procesos y retroalimentación continua al programa de mejora de la calidad.

j. Almacenamiento y actualización de la base de datos e información del desempeño de la institución operadora. Plasmar resultados de forma pública.

k. Mantenimiento y calibración periódica de equipos y herramientas para obtención de información del sistema de agua. 
Además será necesario contar con el análisis, interpretación y modelación de los balances hídricos, así como el planteamiento de medidas correctoras a la gestión para mejorar su desempeño anual, reduciendo al mínimo económico el caudal de agua no contabilizada. Con el cumplimiento de todas las actividades arriba anotadas, estableceremos un plan de gestión de la demanda y una gama de estándares y definiciones de indicadores en el contexto del desempeño - instalación de la plataforma para benchmarking métrico -.

En el marco legal, para garantizar de alguna manera la continuidad de este proceso y prever los cambios políticos, será necesario en las alcaldías municipales redactar y aprobar un sistema de ordenanzas o estatuto básico, en él se inscribirá las relaciones de dependencia de la Empresa Operadora y el Organismo Superior Municipal así como las actividades constantes que conforman la valoración del desempeño y las auditorías respectivas.

\section{Indicadores que se pueden incluir para mejorar la gestión}

A continuación se presentan las variables e indicadores que se pueden adaptar fácilmente a la metodología de cálculo de indicadores propuesto por el I.T.A. ó a través del SIGMA - Lite.

Tabla A.4.2.1 Homologación de variables entre las de la empresa y las del Sigma Lite.

\begin{tabular}{|ccccc|}
\hline EMAAP-Q & SIGMA 2.0 & SIGMA 2.0 & & \\
VARIABLE & VARIABLE & V. DERIVADAS & UNIDAD & CANTIDAD \\
\hline INGRESO TOTAL DE AGUA & $\mathbf{A 3}$ & & $\mathrm{m}^{3}$ & 23169.02 \\
FACTURACION REAL & $\mathbf{A 8}$ & & $\mathrm{m}^{3}$ & 18137 \\
FACTURACION ESTIMADA & $\mathbf{A 9}$ & & $\mathrm{m}^{3}$ & 669 \\
FACTURACION TOTAL & $\mathbf{A 1 0}$ & $\mathbf{A 1 0 = A 8 + A 9}$ & $\mathrm{m}^{3}$ & 18806 \\
CONSUMO AUTORIZADO NO FACTURADO & $\mathbf{A 1 3}$ & & $\mathrm{m}^{3}$ & 0 \\
CONSUMO AUTORIZADO & $\mathbf{A 1 4}$ & $\mathbf{A 1 4 = A 1 0 + A 1 3}$ & $\mathrm{m}^{3}$ & 18806 \\
PÉRDIDAS DE AGUA & $\mathbf{A 1 5}$ & $\mathbf{A 1 5 = A 3 - A 1 4}$ & $\mathrm{m}^{3}$ & 4363.02 \\
HONGITUD DE TUBERÍAS DISTRIBUCION & $\mathbf{C 9}$ & & $\mathrm{km}$ & 9.95 \\
HIDRANTES & $\mathbf{C 2 3}$ & & $\#$ & 7 \\
VÁLVULAS EN REDES DE DISTRIBUCIÓN & $\mathbf{C 2 2}$ & & $\#$ & 25 \\
\# DE PUNTOS DE MEDICIÓN EN EL DISTRITO & $\mathbf{C 1 1}$ & & $\#$ & 2 \\
CONEXIONES DE SERVICIO & $\mathbf{C 2 4}$ & & $\#$ & 450 \\
MEDIDORES FUNCIONANDO EN CLIENTES DIRECTOS & $\mathbf{E 6}$ & & $\#$ & 423 \\
\hline
\end{tabular}

Existen variables que actualmente utiliza la empresa para el cálculo de sus indicadores; no obstante, se puede inferir otras más, en tanto y en cuanto se 
disponga de la información necesaria para combinarlas entre sí siguiendo la metodología del I.T.A. (Sigma, IWA).

Cuadro A.4.2.1 Indicadores que se pueden adicionar a la gestión

\begin{tabular}{|c|c|c|c|}
\hline $\begin{array}{c}\text { SIGMA } 2.0 \\
\text { Nombre del indicador }\end{array}$ & $\begin{array}{c}\text { SIGMA } 2.0 \\
\text { variables combinadas }\end{array}$ & UNIDAD & $\begin{array}{c}\text { SIGMA } 2.0 \\
\text { INDICADORES }\end{array}$ \\
\hline Densidad de válvulas & $\mathrm{Ph} 8=\mathrm{C} 22 / \mathrm{C} 9$ & \#/ Km & 2.51 \\
\hline Densidad de hidrantes & $\mathrm{Ph} 9=\mathrm{C} 23 / \mathrm{Cg}$ & \#/ Km & 0.70 \\
\hline Densidad de distritos hidrométricos & $\mathrm{Ph} 10=\mathrm{C} 11 / \mathrm{C} 24 * 1000$ & \#/ 1000 conexiones & 4.44 \\
\hline Densidad de contadores en clientes & $\mathrm{Ph} 11=\mathrm{E} 6$ / C24 & \# / conexiones & 0.94 \\
\hline
\end{tabular}

\section{Indicadores relativos}

Una vez registrada la presión promedio del distrito analizado, junto con la longitud media de tubería para acometidas domiciliares, se pueden calcular los indicadores relativos: VIF, UMF, IFE, así:

\section{Cuadro A.4.2.2 Presiones registradas en tres puntos del subsector analizado}

\begin{tabular}{|l|c|c|c|}
\hline \multicolumn{1}{|c|}{ ZONA } & BAJA & MEDIA & ALTA \\
\hline P. Máx. (m.c.a.) & 88.57 & 66.35 & 60.77 \\
\hline P. med. (m.c.a.) & 73.30 & 57.15 & 49.24 \\
\hline P. Mín. (m.c.a.) & 8.37 & 13.33 & 11.99 \\
\hline COTA (m.s.n.m.) & $2728 \mathrm{~m}$ & $2734 \mathrm{~m}$ & $2760 \mathrm{~m}$ \\
\hline
\end{tabular}

Fuente: Unidad de agua no contabilizada - EMAAP-Q. Adaptado por el autor.

Gráfico A.4.2.1 Variación de presiones en la zona media durante 3 días de registro

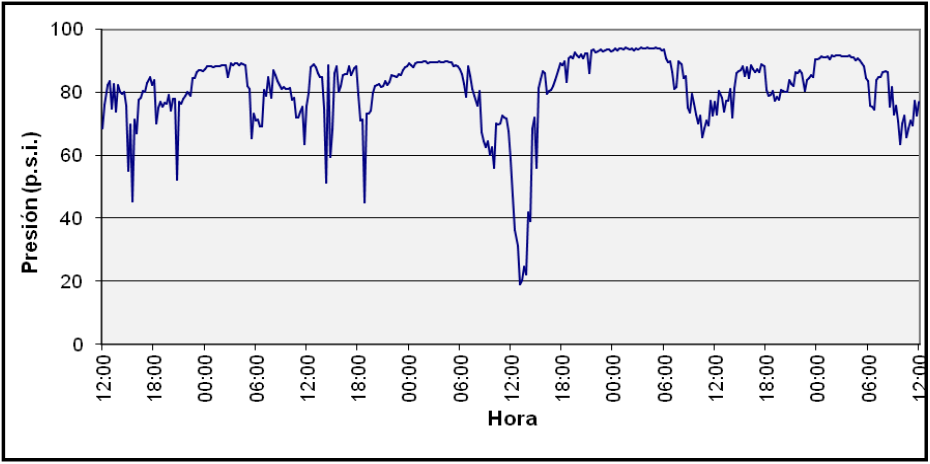

Fuente: Unidad de agua no contabilizada - EMAAP-Q. 
Con estos registros se promedia los valores de las presiones medias de cada una de las tres zonas de monitoreo y para el cálculo de los indicadores relativos se trabajará con la presión de: $60 \mathrm{~m}$ c.a. Se conoce además, que la longitud promedio de acometida es de $5 \mathrm{~m}$.

Entonces, el volumen incontrolado es:

$$
\begin{aligned}
& \mathrm{VIF}=\frac{(\text { Pérdidas reales })}{\mathrm{Na} \times \text { días }} \\
& \mathrm{VIF}=303 \quad[\mathrm{~L} / \text { acometida } / \text { día }]
\end{aligned}
$$

Luego, el umbral mínimo de fugas:

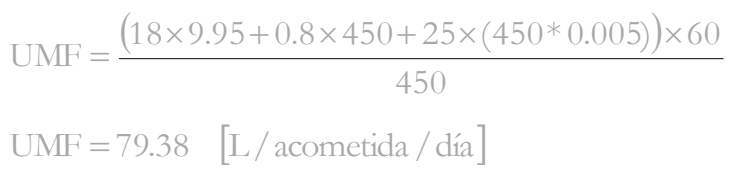

Finalmente, el índice de fugas estructural para el subsector:

$$
\mathrm{IFE}=\frac{303.00}{79.38}
$$

\section{$\mathrm{IFE} \cong 4$}

Un índice de fuga latente o estructural con valor de 1 significa que la red está en perfectas condiciones operativas. Por el contrario un valor del IFE mayor o igual que 8 , indica que la red tiene condiciones que son muy mejorables. Ver cuadro A.4.2.3.

Probablemente estos resultados, con notoria diferencia de la realidad percibida, como ya se explicó anteriormente, se deba a:

- $\quad$ El tiempo de toma y registro de datos con el caudalímetro a la salida del depósito resulta muy escaso (inferior a 4 días) y con certeza que los días en los que se monitoreó los caudales no fueron los más representativos del total de días evaluado.

- Elevados valores de la presión promedio con la que se calcula el denominador del IFE.

- $\quad$ La longitud (La) de tuberías de conexión domiciliar podrían ser muy diferente a la realidad. 
Cuadro A.4.2.3 Relación del IFE y el volumen de fugas por conexión y día

\begin{tabular}{|c|c|c|c|c|c|c|c|c|}
\hline \multirow{2}{*}{\multicolumn{2}{|c|}{$\begin{array}{l}\text { Categoría técnica de } \\
\text { desempeño }\end{array}$}} & \multirow[t]{2}{*}{ IFE } & \multicolumn{6}{|c|}{$\begin{array}{c}\qquad \text { Litros/conexión/dia } \\
\text { (cuando el sistema esta presurizado) a una presión promedio de: }\end{array}$} \\
\hline & & & $10 \mathrm{~m}$ & $20 \mathrm{~m}$ & $30 \mathrm{~m}$ & $40 m$ & $50 \mathrm{~m}$ & $60 \mathrm{~m}$ \\
\hline \multirow{4}{*}{ 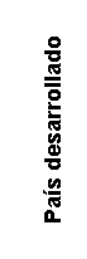 } & A & $1-2$ & & $<50$ & $<75$ & $<100$ & $<125$ & $<150$ \\
\hline & $\mathrm{B}$ & $2-4$ & & $50-100$ & $75-150$ & $100-200$ & $125-250$ & $150-300$ \\
\hline & $\mathrm{C}$ & $4-8$ & & $100-200$ & $150-300$ & $200-400$ & $250-500$ & $300-600$ \\
\hline & $\mathrm{D}$ & $>8$ & & $>200$ & $>300$ & $>400$ & $>500$ & $>600$ \\
\hline \multirow{4}{*}{ 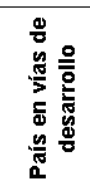 } & A & $1-4$ & $<50$ & $<100$ & $<150$ & $<200$ & $<250$ & $<300$ \\
\hline & B & $4-8$ & $50-100$ & $100-200$ & $150-300$ & $200-400$ & $250-500$ & $300-600$ \\
\hline & $\mathrm{C}$ & $8-16$ & $100-200$ & $200-400$ & $300-600$ & $400-800$ & $500-1000$ & $600-1200$ \\
\hline & D & $>16$ & $>200$ & $>400$ & $>600$ & $>800$ & $>1000$ & $>1200$ \\
\hline
\end{tabular}

Fuente: Adaptado por el autor de (Liemberger R. \& Partners 2010).

Existen otros indicadores que se pueden involucrar en la gestión de la empresa de agua, pero que requieren de más trabajo e inversión de recursos para determinar nuevas variables. Entre ellas tenemos:

Cuadro A.4.2.4 Indicadores en los que alguna variable ya existe y que con trabajo adicional se puede incluir nuevas variables en la gestión

\begin{tabular}{|c|c|c|}
\hline Indicador & Variables faltantes & Ecuación \\
\hline $\begin{array}{l}\text { WR1. } \\
\text { Ineficiencia en el } \\
\text { uso del recurso } \\
\text { hídrico. (\%) }\end{array}$ & A19 - Pérdidas reales. $\left(\mathrm{m}^{3}\right)$ & $\mathrm{WR} 1=\frac{\mathrm{A} 19}{\mathrm{~A} 3} \times 100$ \\
\hline $\begin{array}{l}\text { WR2. } \\
\text { Disponibilidad del } \\
\text { recurso hídrico. (\%) }\end{array}$ & $\begin{array}{l}\text { A2 - Volumen anual de agua } \\
\text { importada. }\left(\mathrm{m}^{3}\right) \text {. }\end{array}$ & $\mathrm{WR} 2=\frac{\mathrm{A} 3 \times 365}{(\mathrm{~A} 1+\mathrm{A} 2) \times \mathrm{H} 1} \times 100$ \\
\hline $\begin{array}{l}\text { WR3. } \\
\text { Recursor hídrico } \\
\text { propio disponible. } \\
(\%)\end{array}$ & $\begin{array}{l}\text { A1 - Volumen anual del } \\
\text { recurso de agua disponible. } \\
\left(\mathrm{m}^{3}\right)\end{array}$ & WR3 $=\frac{\mathrm{A} 3 \times 365}{(\mathrm{~A} 1) \times \mathrm{H} 1} \times 100$ \\
\hline $\begin{array}{l}\text { WR4. } \\
\text { Agua distribuida } \\
\text { reutilizada. (\%) }\end{array}$ & $\begin{array}{l}\text { A22 - Cantidad de agua } \\
\text { suministrada y reutilizada. } \\
\left(\mathrm{m}^{3}\right)\end{array}$ & $W R 4=\frac{\mathrm{A} 22}{\mathrm{~A} 3} \times 100$ \\
\hline
\end{tabular}




\begin{tabular}{|c|c|c|}
\hline Indicador & Variables faltantes & Ecuación \\
\hline $\begin{array}{l}\text { Ph2. } \\
\text { Capacidad de } \\
\text { almacenamiento de } \\
\text { agua cruda. (días) }\end{array}$ & $\begin{array}{l}\text { C1 - Capacidad de } \\
\text { almacenamiento de agua } \\
\text { cruda. }\left(\mathrm{m}^{3}\right)\end{array}$ & $P h 2=\frac{\mathrm{C} 1}{\mathrm{~A} 3} \times H 1$ \\
\hline $\begin{array}{l}\text { Ph12. } \\
\text { Clientes con } \\
\text { contador. } \\
\text { (Número/clientes) }\end{array}$ & $\begin{array}{l}\text { E9 - Medición de grandes } \\
\text { clientes. (número) } \\
\text { E10 - Clientes registrados. } \\
\text { (número) }\end{array}$ & $P h 12=\frac{(\mathrm{E} 6+\mathrm{E} 9)}{\mathrm{E} 10}$ \\
\hline
\end{tabular}

Posteriormente, con algo más de organización, más inversión de recursos y apertura de los administradores de la empresa y/o varios otros sistemas municipales, se podría involucrar varios (no todos) de los indicadores propuestos en Sigma Lite, según corresponda a cada caso.

La re-organización interna de la EMAAP-Q que a partir del año 2008 adoptaron para mejorar su desempeño se lo puede esquematizar en los siguientes organigramas.

Figura A.4.2.1 Organigrama funcional de la EMAAP-Q para evaluación de subsectores

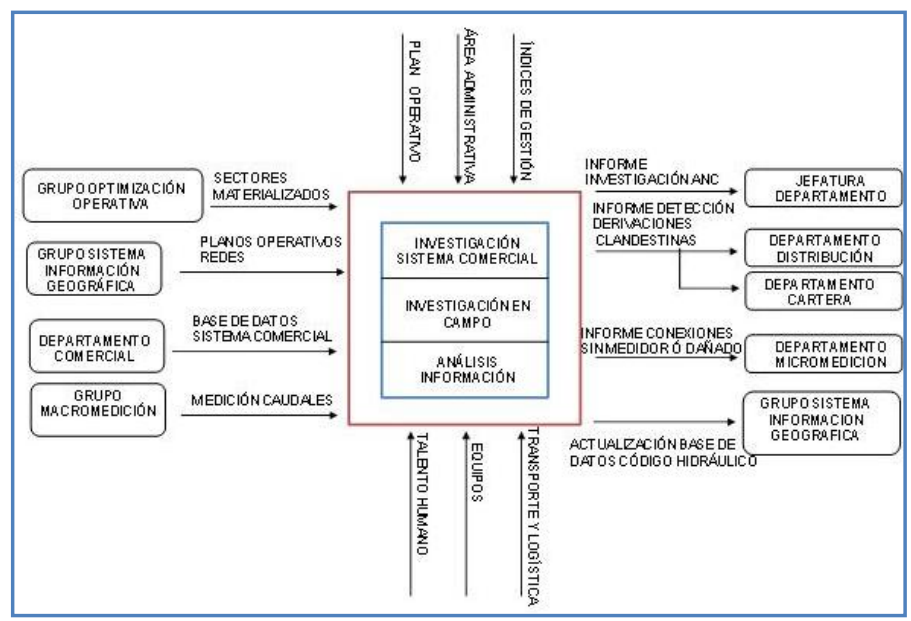

Fuente: Unidad de agua no contabilizada - EMAAP-Q. 
Figura A.4.2.2 Organigrama funcional de la EMAAP-Q para investigación comercial

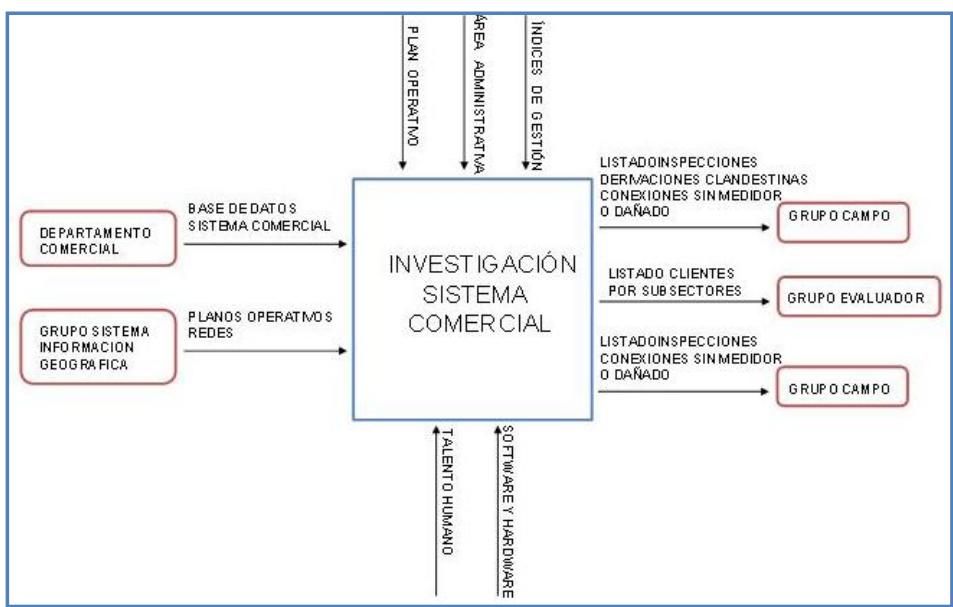

Fuente: Unidad de agua no contabilizada - EMAAP-Q.

Figura A.4.2.3 Organigrama funcional de la EMAAP-Q para investigación de campo

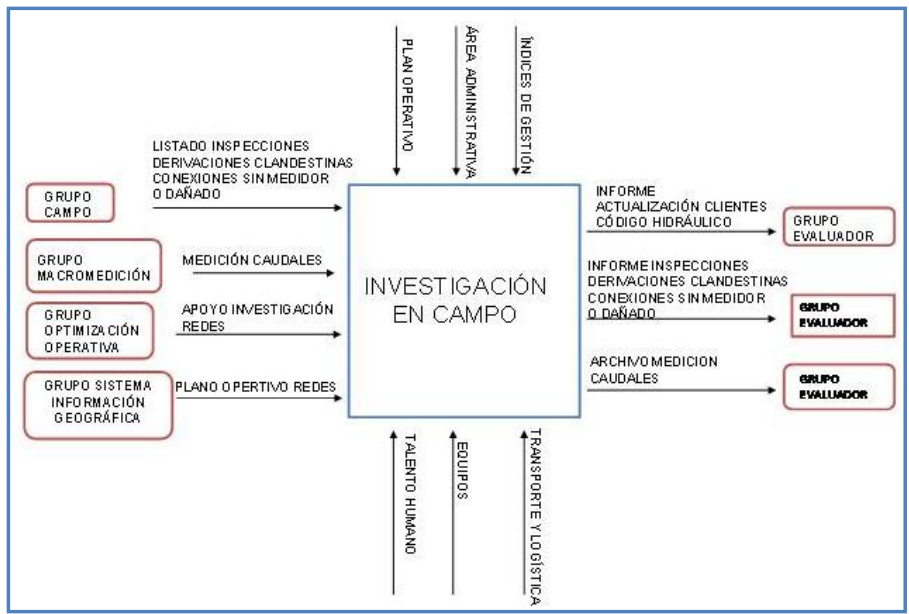

Fuente: Unidad de agua no contabilizada - EMAAP-Q. 
Figura A.4.2.4 Organigrama funcional de la EMAAP-Q para análisis de información

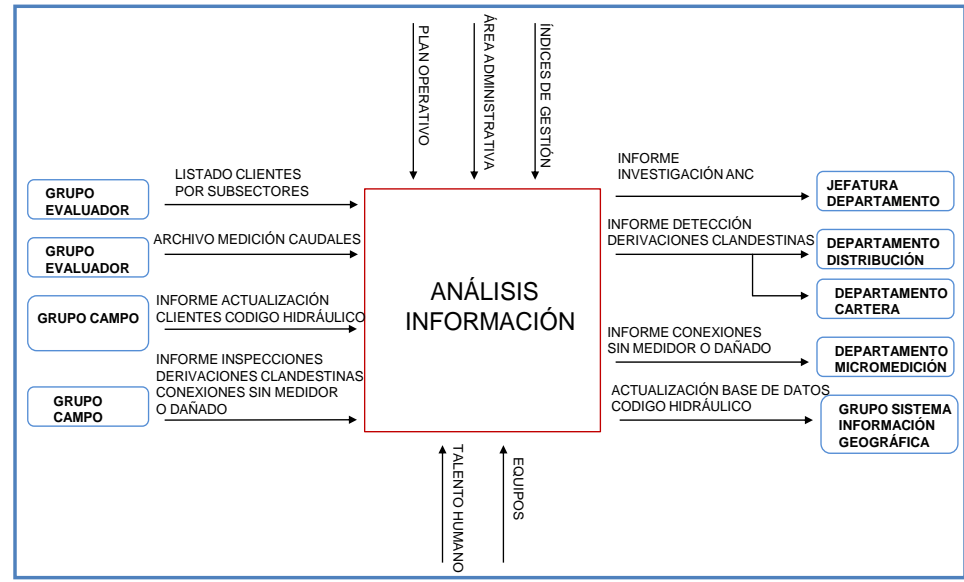

Fuente: Unidad de agua no contabilizada - EMAAP-Q.

\section{$2 \quad$ Alternativas complementarias}

Para la detección de fugas y para estimar su magnitud se puede aplicar la ecuación que deriva de la energía del tramo de tubería afectada, (Colombo y Karney 2002). En el siguiente análisis se plantea esta alternativa que en determinados sistemas de distribución de agua se pudiese aprovechar su facilidad y utilidad práctica para la ubicación de fugas.

Control de presiones en líneas domiciliares. Caracterización y seguimiento para detección de fugas.

\section{Episodio 1}

Inicialmente se determina las características topológicas de la red a evaluar, las presiones de distribución y cálculo de la pendiente de línea de energía (gradiente hidráulico), bajo condiciones normales en función del tiempo (pico, llano y valle).

Consideremos un tramo de la red de distribución en el instante en el que se producen los flujos mínimos nocturnos. 
Figura A.4.2.5 Esquema de un tramo de tubería funcionando bajo características normales (episodio e1)

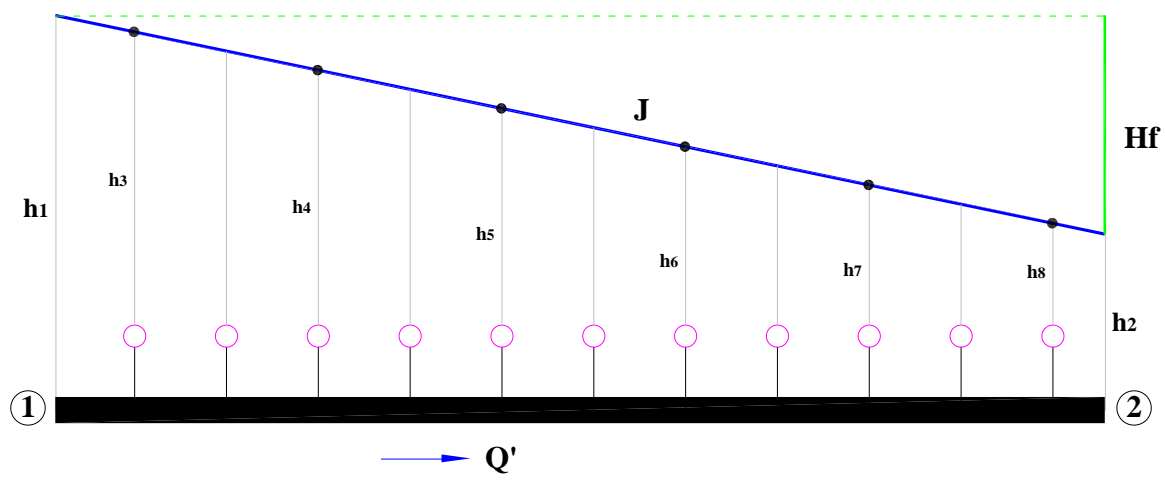

$\mathbf{L}$

\section{Episodio 2}

Figura A.4.2.6 Esquema del mismo tramo de tubería funcionando luego de un fallo (episodio e2).

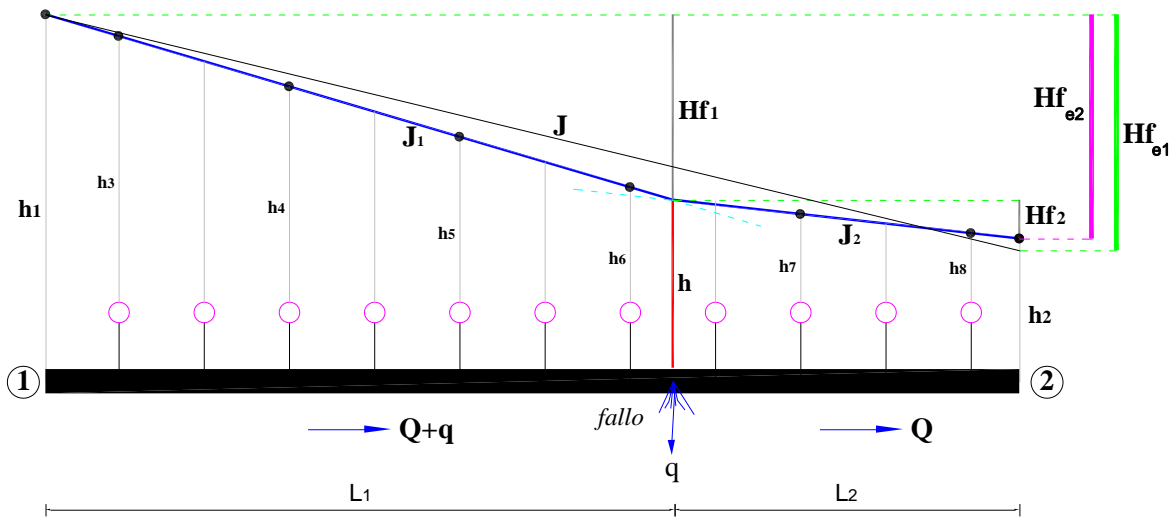

Frente a un fallo en la tubería, se generará una fuga de agua y se identificará la variación de presiones manométricas y el consecuente cambio de gradientes de las líneas de energía. 
En este trabajo se desarrolla el análisis del caudal fugado según las dos situaciones más probables de operación de aquel tramo con la falla física. La primera situación se produce si consideramos alimentación única, es decir que la tubería averiada forma parte de una red ramificada; y, la segunda situación cuando el tubo está alimentado por ambos sentidos, o forma parte de una malla de distribución.

\section{Caso 1: Alimentación única}

$$
\begin{aligned}
& H f_{1-2}=H f_{1}+H f_{2} \\
& L=L_{1}+L_{2}
\end{aligned}
$$

Se aplica la ecuación de Darcy-Weisbach para pérdidas y cuando sea el caso que no existe fuga en el tramo de tubería, entonces se tiene que:

$$
H f_{1-2}=\frac{8 \times f \times L}{\pi^{2} \times g \times D^{5}} \times\left(Q^{\prime}\right)^{2}
$$

Cuando se produce la fuga (e2):

$$
\begin{aligned}
& H f_{1}=\frac{8 \times f \times L_{1}}{\pi^{2} \times g \times D^{5}} \times(Q+q)^{2} ; \quad H f_{2}=\frac{8 \times f \times L_{2}}{\pi^{2} \times g \times D^{5}} \times(Q)^{2} \\
& H f_{1-2}=\left(\frac{8 \times f}{\pi^{2} \times g \times D^{5}}\right) \times\left[L_{1} \times(Q+q)^{2}+L_{2} \times(Q)^{2}\right] \\
& H f_{1-2}=\left(\frac{8 \times f}{\pi^{2} \times g \times D^{5}}\right) \times\left[(L) \times(Q)^{2}+\left(L_{1} \times q\right) \times(2 \times Q+q)\right]
\end{aligned}
$$

Luego se tiene que:

$$
\begin{aligned}
& \mathrm{Hf}_{(\mathrm{e} 1)}-\left[\mathrm{hf}_{(\mathrm{q}) \rightarrow(\mathrm{I} 2)}\right]=\mathrm{Hf}_{(\mathrm{e} 2)} \\
& \mathrm{L} \times\left(\mathrm{Q}^{\prime}\right)^{2}-\mathrm{L}_{2} \times(\mathrm{q})^{2}=\mathrm{L} \times(\mathrm{Q})^{2}+\left[\left(\mathrm{L}_{1} \times \mathrm{q}\right) \times(2 \times \mathrm{Q}+\mathrm{q})\right] \\
& \mathrm{L} \times\left(\mathrm{Q}^{\prime}\right)^{2}=\mathrm{L} \times(\mathrm{Q})^{2}+2 \times\left(\mathrm{L}_{1} \times \mathrm{Q}\right) \times \mathrm{q}+\left(\mathrm{L}_{1}+\mathrm{L}_{2}\right) \times(\mathrm{q})^{2} \\
& (\mathrm{Q})^{2}+2 \times\left(\frac{\mathrm{L}_{1}}{\mathrm{~L}} \times \mathrm{q}\right) \times \mathrm{Q}+\left[(\mathrm{q})^{2}-\left(\mathrm{Q}^{\prime}\right)^{2}\right]=0
\end{aligned}
$$




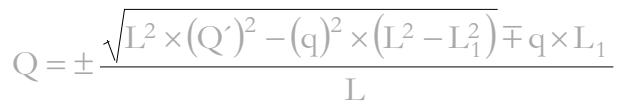

[Ec. A.4.2.5]

Al aplicar como artificio la consideración: $\left[(q)^{2}\right] \approx 0 \quad$ (cuando el caudal fugado $q$ fuese muy pequeño), entonces se obtiene una expresión aproximada, así:

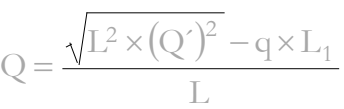

[Ec. A.4.2.6]

De donde despejamos q:

$q=\left(Q^{\prime}-Q\right) \times \frac{L}{L_{1}}$

Expresado en función de los gradientes:

$$
\mathrm{q}=\left(\mathrm{Q}^{\prime}-\mathrm{Q}\right) \times \frac{\mathrm{Hf}_{1-2} \times \mathrm{J}_{1}}{\mathrm{~J}_{1-2} \times \mathrm{Hf}_{1}}
$$

Donde:
q $\quad$ - caudal de fuga proyectado en base a los gradientes característicos.
Q' $\quad$ - caudal total que circula en episodio 1 , es decir sin fuga.
$\mathrm{J}_{1-2} \quad$ - $\quad$ gradiente hidráulico para Q', en tramo $\mathrm{L}$. $\left(\mathrm{J}_{1-2}=\mathrm{J}\right)$.
Q - caudal que trasiega aguas abajo del punto de fallo de la tubería.
$J_{1} \quad$ - gradiente hidráulico para Q', en tramo $L_{1}$.

De la figura anterior (e2) podemos observar además que:

En la tubería horizontal de la figura siguiente, que une los nudos 1 y 2 , la pérdida de carga se traduce directamente a caída de presión que a su vez es proporcional a la longitud. Para el caso que se conozcan al menos cuatro presiones manométricas y las distancias entre los puntos de lectura, producida una fuga se pueden entonces estimar el caudal fugado (q) y la abscisa del fallo $(x)$. 
Figura A.4.2.7 Esquema de la caída de presión por una fuga en una línea hidráulica

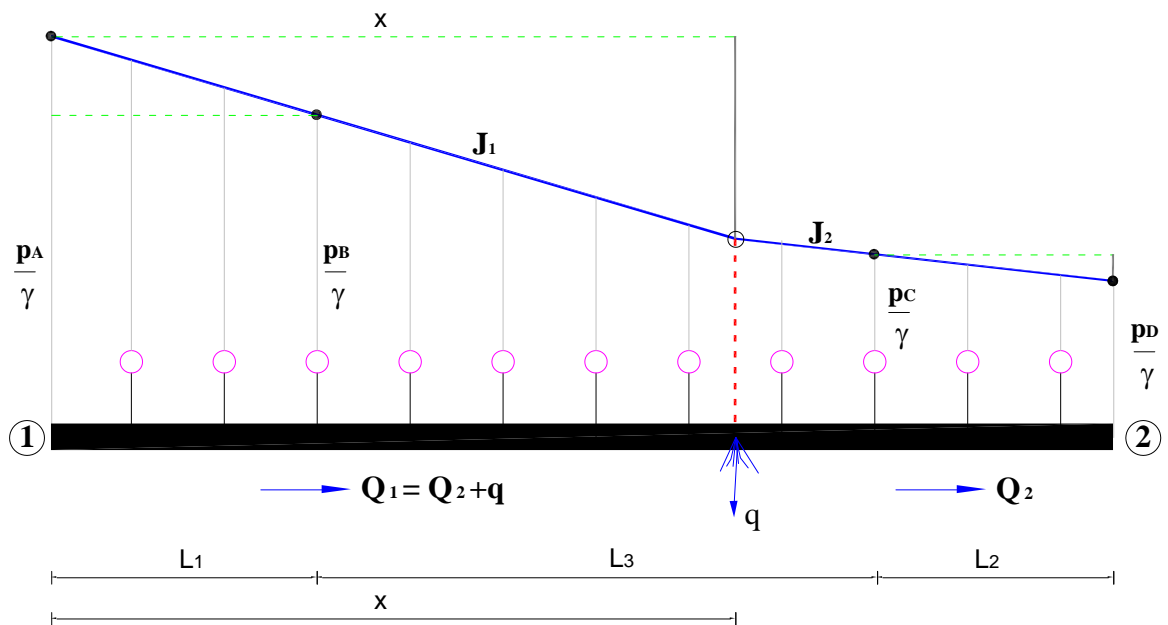

Se tiene entonces que:

$$
\begin{aligned}
& \frac{p_{A}}{\rho}-\frac{p_{B}}{\rho}=K_{1} \times V_{1}^{2} \\
& \frac{p_{C}}{\rho}-\frac{p_{D}}{\rho}=K_{2} \times V_{2}^{2} \\
& K_{i}=\frac{f_{i} \times L_{i}}{2 \times D} \\
& q=Q_{1}-Q_{2}
\end{aligned}
$$

Otro parámetro que también se desconoce en este proceso es el punto del fallo que provoca la fuga en el tramo de tubería; mas, la abscisa se podrá determinar por un análisis geométrico, ya sea gráficamente o analíticamente, mediante intersección de líneas de gradientes y proporcionalidad.

\section{Entonces:}

$$
\begin{aligned}
& \frac{p_{A}-p_{(x)}}{x}=\frac{\left(p_{A}-p_{B}\right)}{L_{1}} \wedge \frac{p_{(x)}-p_{C}}{\left(L_{1}+L_{3}\right)-x}=\frac{\left(p_{C}-p_{D}\right)}{L_{2}} \\
& p_{(x)}=p_{A}-\frac{\left(p_{A}-p_{B}\right) \times x}{L_{1}}=p_{C}+\frac{\left(p_{C}-p_{D}\right) \times\left(\left(L_{1}+L_{3}\right)-x\right)}{L_{2}}
\end{aligned}
$$




$$
x=\frac{L_{1} \times\left(p_{A} \times L_{2}-p_{C} \times\left(L_{1}+L_{2}+L_{3}\right)+p_{D} \times\left(L_{1}+L_{3}\right)\right)}{L_{2} \times\left(p_{A}-p_{B}\right)-L_{1} \times\left(p_{C}-p_{D}\right)}
$$

\section{Caso 2: Línea hidráulica alimentada en ambos sentidos}

Se parte del supuesto que en el tramo de tubería en análisis se produce una fuga, cuyo valor de $\mathrm{h}$ es menor a las presiones registradas en ambos nudos de los extremos ( 1 y 2 ) y que el caudal $q$ que se pierde es un flujo mínimo nocturno, se cumple entonces que:

$$
q=Q_{1-0}+Q_{2-0}
$$

Figura A.4.2.8 Esquema de un tramo de tubería perteneciente a una red mallada

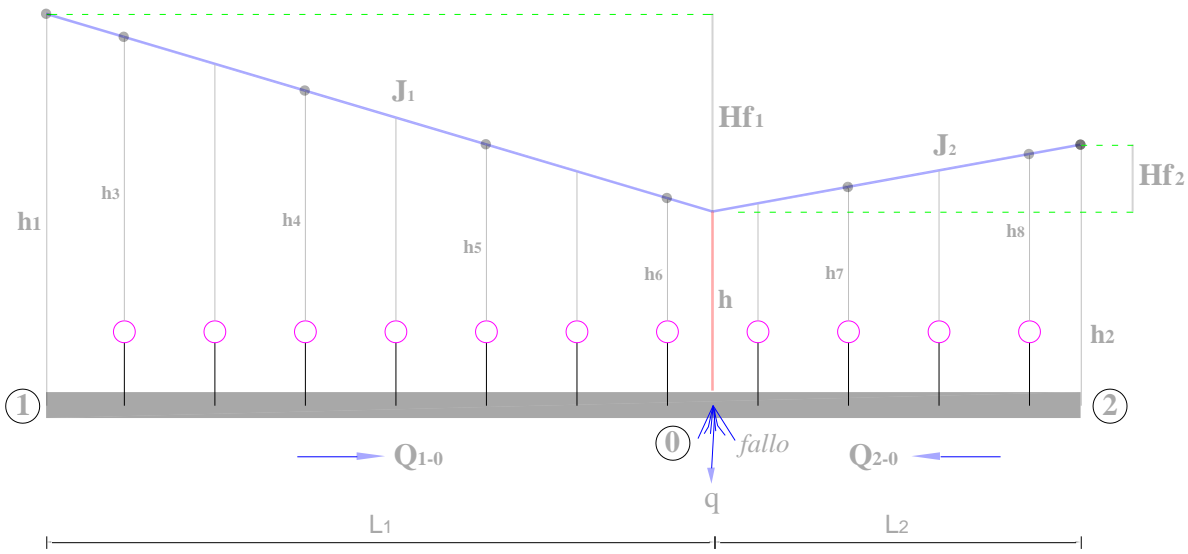

Si en el episodio 1 (sin fuga) se tiene entre los nudos 1 y 2 las condiciones que se esquematizan en la figura correspondiente, para una tubería que forma parte de una red mallada, entonces:

$$
Q^{\prime}=\pi \times \sqrt{\frac{D^{5}}{8 \times f} \times \frac{H f}{L} \times g}
$$


Luego cuando se produce el fallo en la tubería,

$$
\begin{aligned}
& Q_{1-0}=\pi \times \sqrt{\frac{D^{5}}{8 \times f} \times \frac{h_{1}-h}{L_{1}} \times g} \\
& Q_{2-0}=\pi \times \sqrt{\frac{D^{5}}{8 \times f} \times \frac{h_{2}-h}{L_{2}} \times g} \\
& q=\pi \times \sqrt{g \times \frac{\mathrm{D}^{5}}{8 \times f} \times\left(\sqrt{\frac{\mathrm{h}_{1}-h}{\mathrm{~L}_{1}}}+\sqrt{\frac{\mathrm{h}_{2}-h}{\mathrm{~L}_{2}}}\right)}
\end{aligned}
$$

Con esta ecuación se podrá estimar un caudal fugado $q$.

Bajo estas mismas condiciones, se tiene que el caudal fugado será máximo cuando $h$ tiende a cero, y en ese caso extremo tendremos que se cumple:

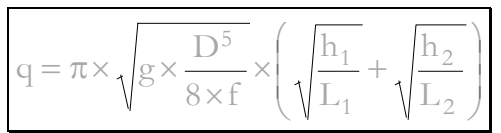

[Ec. A.4.2.18]

Donde:

q - caudal de fuga proyectado en base a las cargas constitutivas.

$\mathrm{h}_{1} ; \mathrm{h}_{2} \quad$ - presiones de los nudos del tramo de tubería analizados.

h $\quad$ - $\quad$ presión en el punto de fuga.

$\mathrm{L}_{1} ; \mathrm{L}_{2} \quad$ - longitud parcial de cada tramo hasta el punto de fuga.

Los estudios de diagnóstico que de aquí resulten junto con una progresiva inversión para sectorización de la red tendrán como finalidad mejorar la eficiencia de los distritos, y por consiguiente una gestión mejorada hacia la sostenibilidad. 


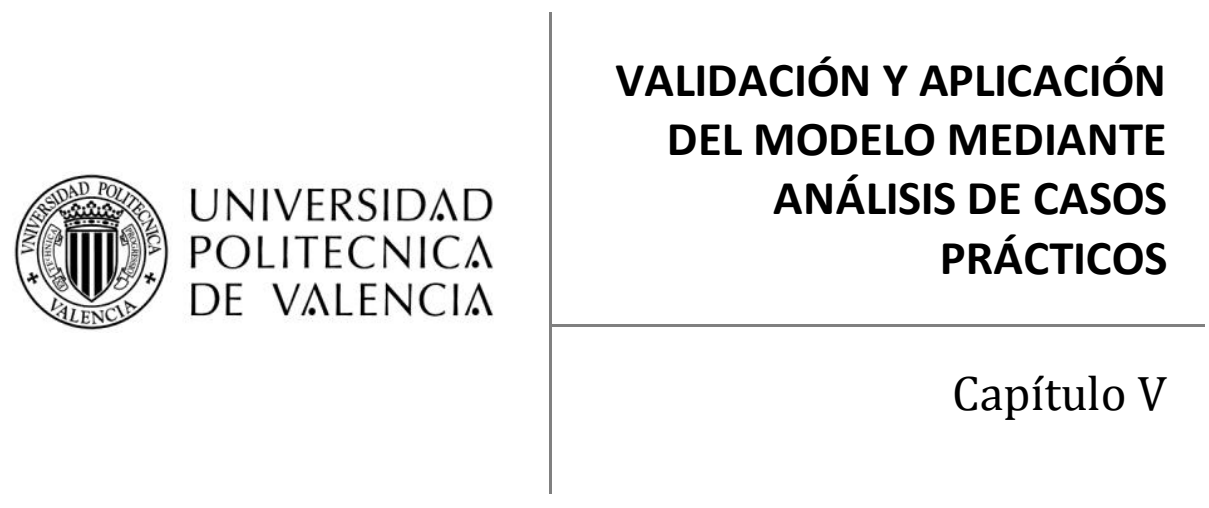





\section{VALIDACIÓN Y APLICACIÓN DEL MODELO MEDIANTE ANÁLISIS DE CASOS PRÁCTICOS}

En el presente capítulo se exponen los resultados de la aplicación de la propuesta para el diagnóstico de sostenibilidad en varios sistemas de agua municipales del Ecuador; además, se exhibe gráficamente los valores del ISA, y su representación a través del modo tela de araña de sus componentes satélites, que permite desagregarlos, para una posterior clasificación y selección de medidas correctoras.

\subsection{Aplicación del modelo de diagnóstico de sostenibilidad de abastecimientos - ISA - en sistemas urbanos de agua del Ecuador}

\subsubsection{Validación}

La actividad por la cual se prueba el procedimiento de diagnóstico, contemplando los datos, personal, infraestructura, materiales y equipos, referida a la información documentada y proporcionada por los gestores de los sistemas de agua potable, se denomina validación de la propuesta ISA.

La información que nos permite construir el primer diagnóstico de cada abastecimiento de agua que se investiga a través del ISA, es exclusiva responsabilidad de quienes la proporcionaron, con parámetros y precisiones que caben dentro de sus propios protocolos y expresas exigencias de confidencialidad al tratamiento de la información.

La práctica de campo que se cumplió para el diagnóstico, -durante todo este período formativo-, permite recabar datos, y desarrollar una investigación exploratoria, in situ, que es una indagación documentada (algunas veces proyectada por el propio entrevistado) para permitirnos conseguir una incursión aplicada mediante una encuesta y entrevista personal con cada uno de los responsables de la dirección, operación y mantenimiento de los sistemas de agua, así como los encargados de los aspectos ambientales, de personal y contables. 
En nuestro país - Ecuador - no es común, ni fácil, ubicar un sistema de agua que se gestione de una forma efectiva, es decir: eficiente -que ejecuta las cosas bien, con un óptimo gasto de recursos en el mejor tiempo- y eficaz -que hace y cumple con todo lo que debe hacer y cumplir, para precautelar la calidad y cantidad de su servicio-; interponiendo diversas situaciones, necesidades y problemas que encierran a la gran mayoría de estos a no ser convincentes a la hora de su gestión y menos a la hora de medir su sostenibilidad (social, económica y ambiental).

Asimismo, se ve la urgente necesidad de contar con un rumbo marcado para caminar legal y públicamente hacia la sostenibilidad de los abastecimientos, ya sea que venga de un ente regulador o de una institución gubernamental o de la misma academia; sumada con la oportunidad de estructurar una línea base claramente establecida para el sector hídrico de servicio humano, que incluya indicadores con los cuales se permita medir y comparar el rendimiento y desempeño de la totalidad, o por lo menos de una buena mayoría, de las empresas operadoras involucradas. Tarea que seguro facilitará la operación y mantenimiento de los sistemas en el ciclo urbano del agua, con el implicado cumplimiento de normas o parámetros mínimos - máximos y requerimientos básicos de calidad, cantidad y equidad.

Frente a esto, proponemos, con este trabajo, dar un primer paso hacia la búsqueda de la sostenibilidad, a través primero de su diagnóstico. En esta oportunidad se puede adaptar de forma general a la situación técnica característica de cada operador, esta herramienta que además cabe utilizarla para dar seguimiento, control, y efectuar auditorías técnicas con cierta periodicidad (mínimo en períodos anuales).

Como ya se anotó, la medición del índice de sostenibilidad del abastecimiento -ISA- está basada en variables e indicadores de gestión (IG) que implican, directa o indirectamente, un buen procedimiento para empezar a articular un sistema de servicios de saneamiento organizadamente duraderos.

Este instrumento, flexible por naturaleza, se aplicó por primera vez a varias empresas municipales de agua potable y alcantarillado, por lo que esperamos encontrar todo tipo de información, una muy válida y otras tal vez imprecisa, estimada o proyectada, incompleta, desorganizada, poco transparente, verificable con limitaciones, aunque tolerable para la realidad y niveles de gestión en el que se desempeñan en la actualidad; hasta tal vez los resultados nos muestren realidades muy pobres o incluso hasta críticas respecto de la sostenibilidad; pero, habremos dado el primer paso, y lo mejor sabiendo hacia dónde debemos dirigir el esfuerzo en este proceso de mejora constante.

Se tiene claro también que cada gestor al recibir los resultados, casi inmediatamente, la utilizará como una guía o instrumento de comparación y 
control continuo, tanto para su propia empresa, como con otras que estén en el radio de influencia y que deseen mejorar su desempeño, consecuentemente la sostenibilidad en su gestión y servicio.

El desempeño sostenible de una empresa municipal de agua mejora si y sólo si el servicio es continuo en cantidad, presión y calidad durante todo el tiempo, si además los elementos que conforman su infraestructura se mantienen y renuevan estricta y periódicamente, si se cuenta con registros confiables, verificables y precisos de sus elementos y usuarios, si además conoce la cantidad de agua que produce, la que distribuye y factura a sus abonados, si se encarga de gestionar intensivamente las cuencas tributarias (bosques fuente), si dispone de un sistema tarifario que le permite recuperar sus costos (sin recibir subsidios estatales o aportes económicos externos) sin transferirle a sus usuarios su inoperancia, si aprovecha toda la capacidad de sus unidades de tratamiento, almacenamiento, impulsión, trasiego y distribución, si son atendidos todos los clientes con calidad en cualquier espacio y tiempo, así como sus quejas se atienden y solucionan oportuna y adecuadamente, si dan el entrenamiento debido y periódico a sus empleados y trabajadores, así también concientizan el uso racional del recurso a sus usuarios, entre otros. Estos aspectos son considerados para el diagnóstico del abastecimiento, cuyos resultados se verán más adelante.

En nuestro caso, la información conseguida no es de la más precisa que pueda existir, cosa que la esperamos desde un inicio, puesto que bien se conoce que la mayoría de gestores no cuentan con los equipos, infraestructura e instrumentos suficientes para levantar esta información; sin embargo, estos aspectos son características que forman parte de las mejoras que se deben incluir para caminar a la gestión deseable de los abastecimientos.

Según el origen de los datos, se los clasifica por niveles de fiabilidad, dichos niveles de confianza permiten calificar cada dato en base a sus grados de confianza y precisión. Los parámetros o intervalos de fiabilidad se presentan a continuación.

a) Se consideró un primer nivel como altamente fiable, "AF", cuya característica es que los datos provienen de registros oficiales, obtenidos con procedimientos legales, instituidos, demostrados técnica o científicamente y debidamente documentados. Los registros son de alta calidad y actualizados, con la oportunidad de ser verificados en cualquier tiempo. Se asigna una variación porcentual de hasta $\pm 2 \%$. 
b) El segundo nivel es el fiable "F", en la que el dato sufre algún tipo de imprecisión, ya sea por origen, por precisión métrica o lectura. Puede afectar la antigüedad de la documentación. El dato que se ubica en esta categoría, también puede ser el resultado de proyecciones o extrapolaciones, de hasta tres años atrás, dependiendo del aspecto a medir. La variación porcentual aceptable para este nivel es de $\pm 5 \%$.

c) El nivel poco fiable, "PF", categoriza así a aquellos datos que están basados en la extrapolación o proyección de una muestra limitada y con más de cinco años de antigüedad. Resulta muy difícil verificar el dato en campo y es aceptable, pero con limitaciones. Su rango de variación es de $\pm 10 \%$.

d) El último nivel se denomina muy poco fiable, "MPF", se trata de un dato basado en resultados informales, de muy poca consistencia y robustez. Son el resultado "a priori" de una inspección o concepción que el gestor imagina o supone por su experiencia en la tarea encomendada. Con este tipo de datos se pueden esperar variaciones superiores al $\pm 20 \%$.

\subsubsection{Zona de aplicación}

El presente instrumento de diagnóstico se aplicó en veinte sistemas de abastecimiento de agua potable y alcantarillado del Ecuador; sin embargo, se presentan los resultados de catorce de ellos, por tener más concordancia y lógica entre los datos aportados. Dichos sistemas de agua están repartidos principalmente en las provincias de El Oro, Zamora Chinchipe y Loja. Se direccionó a empresas que pertenecen a ciudades o cabeceras cantonales con número de habitantes que varía entre 2300 y 235000.

La división política de la República del Ecuador, organiza la administración del Estado por provincias, cantones, parroquias y barrios. La capital de una provincia y de un cantón es una ciudad ubicada dentro de la superficie de su jurisdicción. Por mandato Constitucional, cada municipalidad se encarga exclusivamente de gestionar los servicios de saneamiento en su cantón.

Los abastecimientos que nos permitieron aplicar el modelo de diagnóstico ISA según el número de habitantes se agrupan de la siguiente manera: seis sistemas abastecen poblaciones entre 2300 y 10000 ; seis brindan sus servicios a una población entre 10000 y 100 000; y, dos sirven a poblaciones cuyo número es superior a 100000. 


\section{Características generales y de contexto}

En el cuadro siguiente se listan algunas características de los mismos.

Cuadro 5.1 Empresas operadoras investigadas

\begin{tabular}{|c|c|c|c|c|}
\hline Núm. & Cabecera cantonal & Población & $\begin{array}{l}\text { Temp. } \\
{ }^{\circ} \mathbf{C}\end{array}$ & $\begin{array}{l}\text { Altitud } \\
\text { m s.n.m. }\end{array}$ \\
\hline \multicolumn{5}{|c|}{ Provincia Uno } \\
\hline 1 & Municipio A01 & 2325 & 23 & 800 \\
\hline 2 & Municipio A02 & 4834 & 20 & 1320 \\
\hline 3 & Municipio A03 & 5268 & 15 & 1900 \\
\hline 4 & Municipio A04 & 6330 & 18 & 1183 \\
\hline 5 & Municipio A05 & 12950 & 20 & 1932 \\
\hline 6 & Municipio A06 & 14727 & 25 & 444 \\
\hline 7 & Municipio A07 & 22015 & 25 & 1000 \\
\hline \multicolumn{5}{|c|}{ Provincia Dos } \\
\hline 8 & Municipio B01 & 8052 & 23 & 887 \\
\hline 9 & Municipio B02 & 2990 & 26 & 1200 \\
\hline \multicolumn{5}{|c|}{ Provincia Tres } \\
\hline 10 & Municipio C01 & 11000 & 20 & 650 \\
\hline 11 & Municipio C02 & 13325 & 20 & 1450 \\
\hline 12 & Municipio C03 & 15925 & 20 & 1014 \\
\hline \multicolumn{5}{|c|}{ Otras ciudades } \\
\hline 13 & Municipio D01 & 155070 & 19 & 2180 \\
\hline 14 & Municipio D02 & 231621 & 29 & 4 \\
\hline
\end{tabular}

Fuente: Adaptado de apuntes personales; (AME 2009); (Webber L. 2009).

Gráfico 5.1 Distribución de empresas investigadas según el número de habitantes

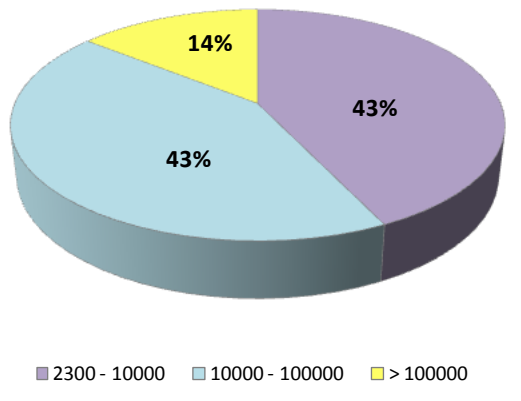


De los catorce sistemas evaluados, seis están situados a una altitud hasta de 1000 m s.n.m., siete entre 1000 y 2000 y uno arriba de los 2000 m s.n.m.

Del mismo modo, dos de las ciudades tienen una temperatura media anual hasta $18^{\circ} \mathrm{C}$, seis abastecimientos tienen temperaturas entre $18{ }^{\circ} \mathrm{C}$ y $20^{\circ} \mathrm{C}$, e igual número tienen temperaturas superiores a los $20^{\circ} \mathrm{C}$.

Gráfico 5.2 Distribución de empresas investigadas por su altitud

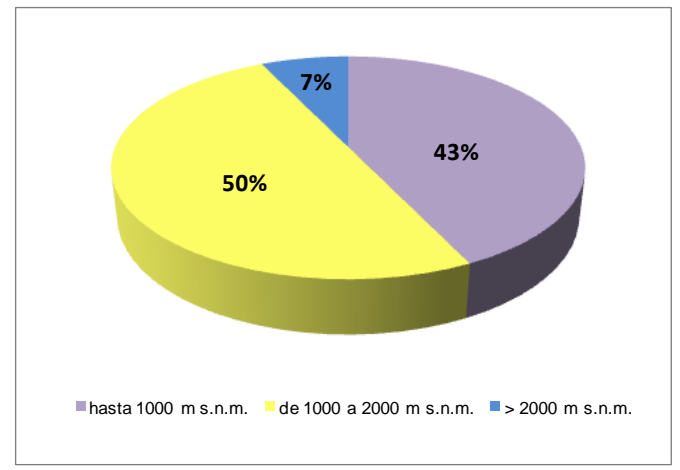

\subsubsection{Actividades de campo}

El levantamiento de información e inspección física de las empresas de agua investigadas se la realizó mediante entrevista y aplicación de encuestas a los responsables de la administración, operación ó mantenimiento del sistema urbano de agua.

Las visitas de campo se organizaron en su mayoría bajo el siguiente orden:

a) Acercamiento.- Momento en el que se mostró la propuesta y creamos interés en los máximos administradores, directores o gerentes, para aplicarla en su sistema.

b) Reconocimiento.- Una vez dado el consentimiento del máximo responsable de la empresa, se procede a mantener visitas periódicas a cada sitio de donde se recaban los datos. Se "busca" en los documentos $\mathrm{e}$ información disponible, en tanto y en cuanto la 
particular actitud de límite y celo profesional nos lo permite, en ciertos sistemas. A través de encuestas y diálogos se estructura una línea base. Los recorridos por los componentes de los sistemas también dependieron de cuanto se permitió.

c) Entrevista.- Las entrevistas siempre se direccionaron a directores, supervisores, gerentes o personas encargadas de la gestión, operación o mantenimiento de la empresa. Se recolecta de primera mano datos e información lo más posible: fidedigna, demostrable y verificable, según se dispuso en cada caso.

d) Gabinete.- Etapa en la que se organiza y procesa toda la información recabada. se ejecutan cálculos complementarios, como es el caso de ciertos índices, se calcula el ISA y se categoriza al abastecimiento. Finalmente se grafica la información del diagnóstico.

Los resultados que se obtuvieron, con los datos recabados, son los que se presentan a continuación, tanto para el IFE (índice de fugas estructural) como para el ISA (índice de sostenibilidad del abastecimiento):

Gráfico 5.3 Comparativo del índice de fugas estructural

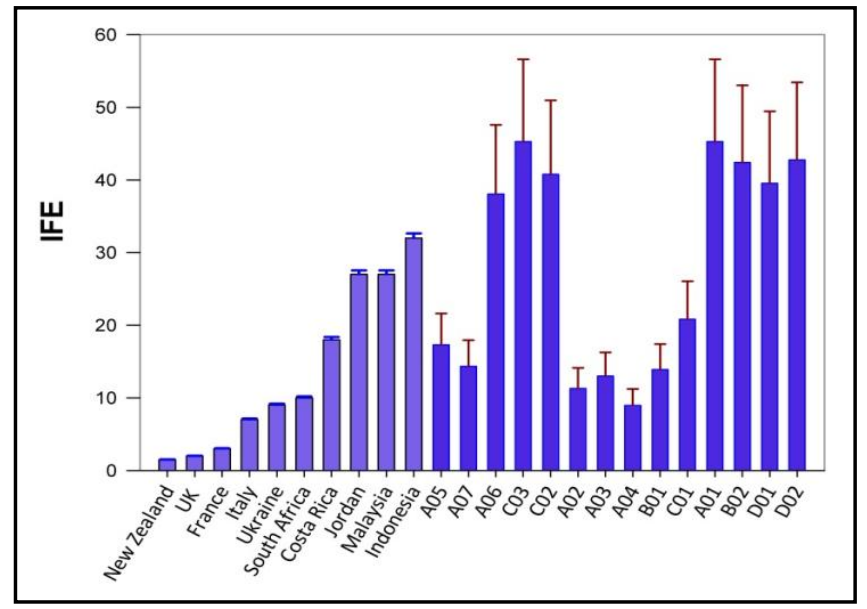

Fuente: El Autor, concatenado con (Liemberger R. \& Partners 2010).

De los catorce abastecimientos investigados, uno tiene un valor de IFE próximo a 10 , seis sistemas tienen un IFE entre 10 y $25 ; y$, siete están con un 
valor del IFE por arriba de 38. Es preciso en un trabajo futuro, confirmar estos valores, con información verificada en campo, a cada abastecimiento.

Respecto del índice de sostenibilidad de abastecimiento - ISA -, los catorce abastecimientos están en valores entre 25 y 43; cuatro de ellos se los clasifica como abastecimientos de sostenibilidad deficiente y diez como abastecimientos de sostenibilidad mala; lo cual confirma la realidad percibida en el entorno. Dichos resultados se muestran en el gráfico siguiente.

\section{Gráfico 5.4 Comparativo del índice de sostenibilidad de abastecimiento}

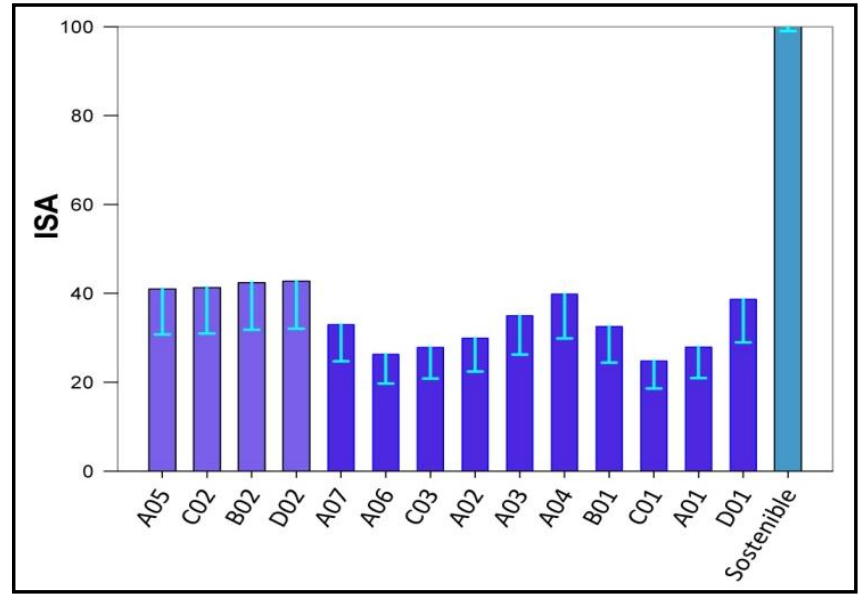

\subsection{Ejemplo de informe de diagnóstico.- Sistema D01}

\subsubsection{Introducción y ámbito de aplicación.}

Los abastecimientos de agua requieren de una intervención técnica urgente para mejorar su nivel de sostenibilidad, reducir sus problemas y solventar las necesidades fundamentales para brindar un excelente servicio.

Mejorar la sostenibilidad del abastecimiento de agua de la ciudad es un desafío para políticos, gerentes, directores, empleados y trabajadores, y sociedad en general, que es posible de conseguir, siempre que los actores involucrados se comprometan fehacientemente a ello, cada uno en su escenario.

Este proceso de mejora y búsqueda de la sostenibilidad amerita que se inicie con un diagnóstico, que lleve a conocer el estado actual del abastecimiento a 
través de la medida comparativa de variables e indicadores generales, respecto de sus aspectos más relevantes en lo, ya dicho, social, económico y ambiental.

El diagnóstico permitirá conocer mejor la naturaleza de la situación actual del sistema de agua, mediante un conjunto de medidas que a su vez muestren el origen de las patologías que están relacionadas con su actividad gestora.

\subsubsection{Objetivos y alcance del diagnóstico.}

1) Identificar el nivel de sostenibilidad del abastecimiento, mediante el ISA.

2) Cuantificar las relaciones en lo social, económico y ambiental, que afectan la gestión sostenible del abastecimiento.

3) Plantear medidas correctoras generales, para mejorar el estado actual de sostenibilidad.

\subsubsection{Descripción del levantamiento de la información.}

La calidad de la información para el diagnóstico (recolectada o proporcionada por los involucrados) afecta directamente en la calidad de sus resultados. De tal modo que, mientras más confiable es la información introducida al cálculo del ISA, más precisa será la clasificación de sostenibilidad que se le asigne al abastecimiento, así como efectivas las alternativas de mejora.

La información se recopiló, principalmente, de fuentes involucradas al propio abastecimiento, así:

i) Archivos históricos, bases estadísticas, planes de desarrollo ejecutados y aportes informáticos vigentes.

ii) Estudios, diseños, iniciativas y actualizaciones de información existentes.

iii) Datos proporcionados por los actores y responsables de varios sectores al interno de la empresa.

iv) Entrevistas personales para completar el cuestionario correspondiente al diagnóstico, con directivos y coordinadores 
de los componentes: operación y mantenimiento, ambiental, comercialización y financiero.

\subsubsection{Características generales.}

El abastecimiento sirve a una población de 155070 habitantes, con 31014 conexiones, se encuentra a una altitud media de 2180 m s.n.m., y le influye una temperatura ambiental media anual de $19{ }^{\circ} \mathrm{C}$. Su sistema de tratamiento produce un caudal medio de $670 \mathrm{~L} / \mathrm{s}$, que los distribuye a través de $1850 \mathrm{~km}$ de tubería.

El personal total con el que cuenta el sistema de agua de la ciudad es de 207 (entre directivos, empleados y trabajadores), para agua potable y alcantarillado.

\subsubsection{Agregación según la metodología de diagnóstico ISA}

Con los datos levantados, se consiguieron los siguientes resultados:

Tabla 5.1 Cálculo del peso relativo social

\begin{tabular}{|c|c|c|c|c|c|}
\hline Subcomponente & Indicador & $\begin{array}{l}\text { Importancia } \\
\text { ponderada }\end{array}$ & Valor delíndice & $F C$ & Peso relativo \\
\hline \multicolumn{2}{|c|}{$\begin{array}{l}\text { Subcomponente operativo: } \\
\text { cantidad }\end{array}$} & 6.0 & valor del Índice & FC & 0.00 \\
\hline & $\begin{array}{l}\text { Número de reducciones de la cantidad de } \\
\text { caudal hasta un } 50 \% \text { por año }\end{array}$ & 2.0 & 90.00 & 0.0002 & 0.00 \\
\hline & $\begin{array}{l}\text { Tiempo total acumulado, en horas, de } \\
\text { duración de las interrupciones por año }\end{array}$ & 2.0 & 360.00 & 0.0000 & 0.00 \\
\hline & $\begin{array}{l}\text { \% de acometidas con presión de servicio } \\
\text { diferente al rango (entre } 10 \mathrm{~m} \text { c.a. y } 50 \mathrm{~m} \\
\text { c.a.) }\end{array}$ & 2.0 & 15.01 & 0.0000 & 0.00 \\
\hline
\end{tabular}

\begin{tabular}{|l|l|c|r|r|r|}
\hline $\begin{array}{l}\text { Subcomponente operativo: } \\
\text { calidad }\end{array}$ & 6.3 & valor del Índice & FC & 2.80 \\
\hline & $\begin{array}{l}\text { Número de análisis de calidad de agua por } \\
\text { mes *1000/ población servida }\end{array}$ & 2.0 & 0.40 & 0.4000 & 0.80 \\
\hline & $\begin{array}{l}\text { Número promedio de horas por día que el } \\
\text { agua permanece estancada (almacenada en } \\
\text { depósitos del sistema) previo a su consumo }\end{array}$ & 2.0 & 4.00 & 1.0000 & 2.00 \\
\hline & $\begin{array}{l}\text { \% de conexiones con un rango de cloro } \\
\text { residual diferente al de la norma (0.3 mg/L } \\
\text { y1.5 mg/L) }\end{array}$ & 2.3 & 10.000 & 0.0000 & 0.00 \\
\hline
\end{tabular}

\begin{tabular}{|l|l|r|r|r|r|}
\hline $\begin{array}{c}\text { Subcomponente operativo: } \\
\text { cobertura }\end{array}$ & 6.0 & valor del Índice & FC & 3.16 \\
\hline & \% de predios con conexión al sistema & 3.0 & 90.00 & 0.5653 & 1.70 \\
\cline { 2 - 6 } & $\%$ de predios bien servida en horas pico & 3.0 & 80.00 & 0.4893 & 1.47 \\
\hline
\end{tabular}




\begin{tabular}{|c|c|c|c|c|c|}
\hline Subcomponente & Indicador & $\begin{array}{c}\text { Importancia } \\
\text { ponderada }\end{array}$ & Valor del Indice & $F C$ & Peso relativo \\
\hline \multicolumn{2}{|l|}{$\begin{array}{l}\text { Subcomponente formativo: } \\
\text { capacitación a empleados }\end{array}$} & 5.0 & valor del Índice & FC & 0.00 \\
\hline & $\begin{array}{l}\text { Número promedio de horas de capacitación } \\
\text { invertidas en cada técnico de campo y } \\
\text { miembros de planificación / año }\end{array}$ & 2.5 & 0.00 & 0.0000 & 0.00 \\
\hline & $\begin{array}{l}\text { Número promedio de horas de capacitación } \\
\text { invertidas en cada administrador y } \\
\text { coordinador del abastecimiento / año }\end{array}$ & 2.5 & 0.00 & 0.0000 & 0.00 \\
\hline
\end{tabular}

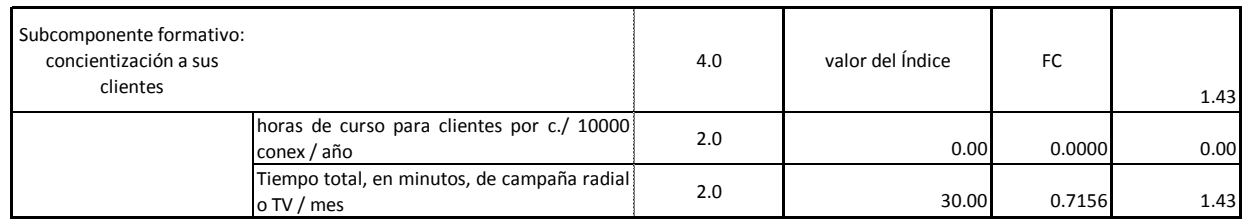

\begin{tabular}{|l|l|c|c|c|}
\hline $\begin{array}{l}\text { Subcomponente comercial: } \\
\text { atención al cliente }\end{array}$ & 6.0 & valor del Índice & FC & 1.50 \\
\hline & $\begin{array}{l}\text { Tiempo (en días) que la empresa tarda en } \\
\text { responder las quejas de sus abonados }\end{array}$ & 1.5 & 1.0000 & 1.50 \\
\hline & $\begin{array}{l}\text { Tiempo (en días) en los que la empresa } \\
\text { atiende nuevas conexiones, obras de } \\
\text { reparación y reinstalación }\end{array}$ & 1.5 & 1.60 & 1.0000 \\
\hline $\begin{array}{l}\text { Se ejecuta un plan de marketing plubicitario } \\
\text { de la empresa, promoción al ahorro y } \\
\text { difusión pública }\end{array}$ & 1.5 & & 1.50 \\
\hline $\begin{array}{l}\text { Existe la infraestructura de atención al } \\
\text { cliente organizada, equipada y cómoda }\end{array}$ & 1.5 & & 1.0000 & 1.50 \\
\hline
\end{tabular}

Tabla 5.2 Cálculo del peso relativo económico

\begin{tabular}{|c|c|c|c|c|}
\hline Subcomponente & Indicador & $\begin{array}{c}\text { importancia } \\
\text { ponderada }\end{array}$ & Valor delíndice & FC Peso relativo \\
\hline
\end{tabular}

\begin{tabular}{|c|c|c|c|c|c|}
\hline $\begin{array}{l}\text { Subcomponente } \\
\text { autogestión }\end{array}$ & & 11.0 & valor del Índice & $\mathrm{FC}$ & 6.44 \\
\hline & $\begin{array}{l}\% \text { de recuperación de costos, mediante } \\
\text { cobro de facturación por año de servicio }\end{array}$ & 5.0 & 91.20 & 0.7107 & 3.55 \\
\hline & $\begin{array}{l}\text { Autosuficiencia financiera }=\text { ingresos propios } \\
\text { / gastos corrientes } * 100\end{array}$ & 2.0 & 91.40 & 0.9741 & 1.95 \\
\hline & $\begin{array}{l}\text { Eficiencia en recaudación }=\text { emisión } / \\
\text { recaudación } * 100\end{array}$ & 1.0 & 83.70 & 0.5818 & 0.58 \\
\hline & $\%$ de agua no facturada / año & 3.0 & 55.00 & 0.1185 & 0.36 \\
\hline
\end{tabular}




\begin{tabular}{|c|c|c|c|c|c|}
\hline Subcomponente & Indicador & $\begin{array}{c}\text { importancia } \\
\text { ponderada }\end{array}$ & Valor delíndice & FC Peso relativo \\
\hline
\end{tabular}

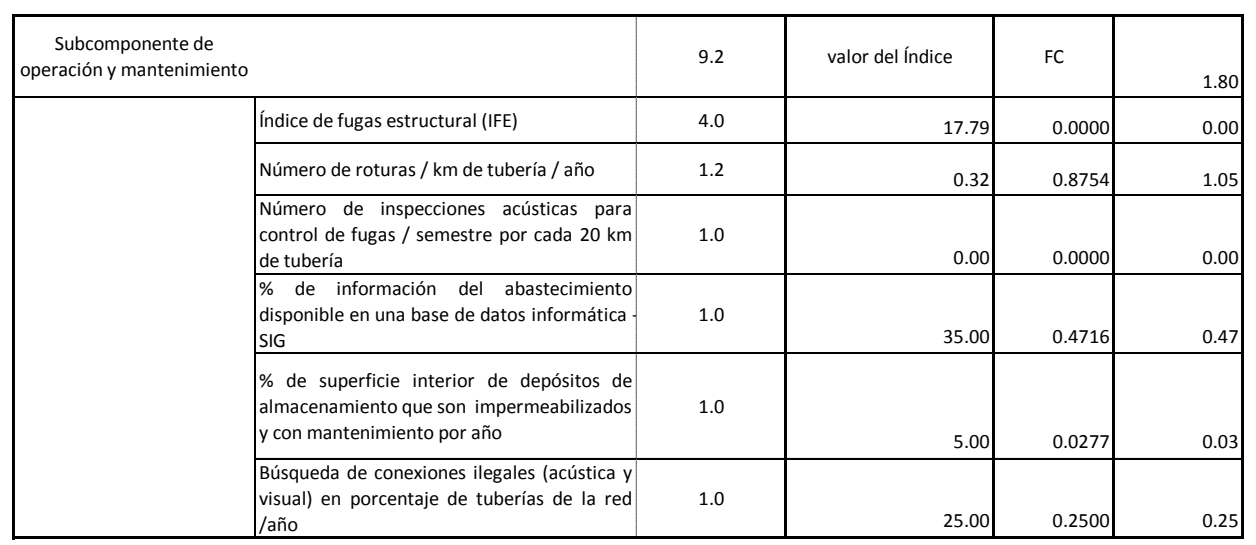

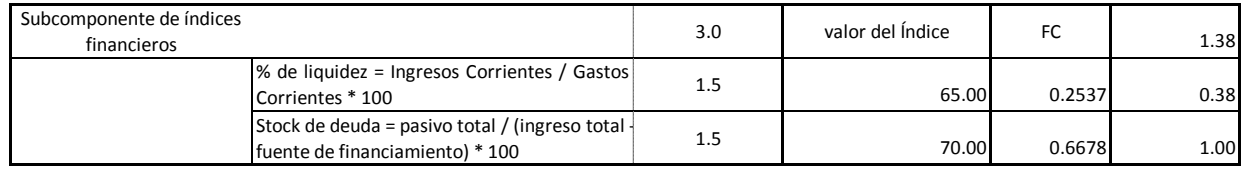

\begin{tabular}{|c|c|c|c|c|c|}
\hline $\begin{array}{c}\text { Subcomponente de } \\
\text { infraestructura del } \\
\text { abastecimiento }\end{array}$ & & 8.2 & valor del Índice & $\mathrm{FC}$ & 3.08 \\
\hline & $\begin{array}{l}\text { Número de parcelas hidrométricas } \\
\text { (subsectores o distritos hidrométricos) por } \\
\text { cada } 10000 \text { conexiones }\end{array}$ & 1.0 & 1.00 & 0.0116 & 0.01 \\
\hline & $\begin{array}{l}\text { Número de hidrantes contra incendios } \\
\text { operativos por cada } 1.0 \mathrm{~km} \text { de tubería }\end{array}$ & 1.0 & 0.14 & 0.0555 & 0.06 \\
\hline & $\begin{array}{|lcl|}\% & \text { contadores } & \text { funcionan } \\
\text { (instalados/conexiones*100) } & \\
\end{array}$ & 1.0 & 85.00 & 0.5885 & 0.59 \\
\hline & $\%$ de contadores instalados más de 8 años & 1.0 & 35.00 & 0.1012 & 0.10 \\
\hline & $\begin{array}{l}\text { \% de contadores instalados cuyas lecturas } \\
\text { superan los } 4000 \mathrm{~m} 3\end{array}$ & 1.0 & 35.00 & 0.1012 & 0.10 \\
\hline
\end{tabular}

\begin{tabular}{|c|l|r|r|r|}
\hline $\begin{array}{c}\text { Subcomponente de } \\
\text { equipamiento y personal }\end{array}$ & 2.0 & valor del Índice & FC \\
\hline \multirow{2}{*}{$\begin{array}{l}\text { Porcentaje de maquinaria y equipo } \\
\text { financiados (horas/mes) para OO\&MM }\end{array}$} & 1.0 & 50.00 & 0.3019 \\
\cline { 2 - 6 } & $\begin{array}{l}\text { Número de empleados por cada 10000 } \\
\text { abonados }\end{array}$ & 1.0 & 0.30 \\
\hline
\end{tabular}


Tabla 5.3 Cálculo del peso relativo ambiental

\begin{tabular}{|c|c|c|c|c|c|}
\hline Subcomponente & Indicador & $\begin{array}{c}\text { Importancia } \\
\text { ponderada }\end{array}$ & Valor delíndice & $F C$ & Peso relativo \\
\hline \multirow[t]{2}{*}{$\begin{array}{l}\text { Subcomponente } \\
\text { explotación: del agua } \\
\text { captada y vertida }\end{array}$} & & 7.0 & valor del Índice & FC & 3.85 \\
\hline & $\begin{array}{l}\% \text { de caudal de agua captado para el } \\
\text { abastecimiento en época de estiaje }\end{array}$ & 4.0 & 80.00 & 0.2119 & 0.85 \\
\hline
\end{tabular}

\begin{tabular}{|c|c|c|c|c|c|}
\hline \multicolumn{2}{|l|}{$\begin{array}{l}\text { Subcomponente de } \\
\text { Eficiencia consumos }\end{array}$} & 5.3 & valor del Índice & FC & 2.22 \\
\hline & $\begin{array}{l}\text { Cantidad promedio de consumo de agua por } \\
\text { habitante por día }\end{array}$ & 2.0 & 213.33 & 0.2291 & 0.46 \\
\hline & Desaprovechamiento de recursos hídricos & 1.3 & 38.10 & 0.3541 & 0.46 \\
\hline & $\begin{array}{|lll|}\begin{array}{l}\text { Consumo energético } \\
\text { abastecimiento por mes }\end{array} & \text { relativo del } \\
\end{array}$ & 2.0 & 1.11 & 0.6484 & 1.30 \\
\hline
\end{tabular}

\begin{tabular}{|c|c|c|c|c|c|}
\hline \multicolumn{2}{|l|}{$\begin{array}{c}\text { Subcomponente de } \\
\text { contaminación ambiental } \\
\text { por } 00 \text { \& MM }\end{array}$} & 8.0 & valor del Índice & FC & 0.00 \\
\hline & $\begin{array}{l}\text { Porcentaje de lodos y desechos generados } \\
\text { por el sistema de potabilización (filtros, } \\
\text { floculadores y sedimentadores) que se } \\
\text { vierten sin depuración a cuerpos receptores, } \\
\text { por año }\end{array}$ & 3.0 & 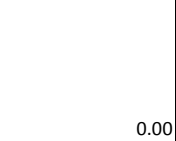 & 0.0000 & \\
\hline & $\begin{array}{l}\text { Depuración de aguas servidas para los } \\
\text { vertidos de alcantarillados de la ciudad }\end{array}$ & 3.0 & NO & 0.0000 & 0.00 \\
\hline & $\begin{array}{l}\text { Aplicación de medidas correctoras o de } \\
\text { mitigación para reducción de impacto por } \\
\text { ruido, polvo y gases en apertura y cierre de } \\
\text { zanjas para reparaciones o conexiones } \\
\text { domiciliares }\end{array}$ & 2.0 & NO & 0.0000 & 0.00 \\
\hline
\end{tabular}

\begin{tabular}{|c|c|c|c|c|c|}
\hline $\begin{array}{l}\text { Subcomponente de } \\
\text { conservación de la cuenca } \\
\text { fuente }\end{array}$ & & 13.0 & valor del Índice & FC & 6.81 \\
\hline & $\begin{array}{l}\text { Superficie de la cuenca fuente o tributaria } \\
\text { que es propiedad del sistema en hectáreas } \\
\text { por cada (L/s) de agua producida para el } \\
\text { abastecimiento }\end{array}$ & 2.5 & 5.97 & 0.8363 & 2.09 \\
\hline & $\begin{array}{l}\% \text { de superficie de la o las cuencas tributarias } \\
\text { que tienen en marcha un plan anual de } \\
\text { silvicultura y reforestación, gestionado ó } \\
\text { coordinado directamente por el operador del } \\
\text { sistema }\end{array}$ & 4.0 & 75.00 & 0.6733 & 2.69 \\
\hline & $\begin{array}{l}\% \text { de industrias y fábricas instaladas dentro } \\
\text { de la superficie de la cuenca fuente, que } \\
\text { depuran sus vertidos y controlan sus } \\
\text { desechos correctamente }\end{array}$ & 2.5 & 75.00 & 0.5616 & 1.40 \\
\hline
\end{tabular}


Cuadro 5.2 Valores porcentuales del ISA social

\begin{tabular}{|lc|}
\hline Subcomponente & $\%$ \\
\hline Operativo: cantidad & 00.0 \\
\hline Operativo: calidad & 44.4 \\
\hline Operativo: cobertura & 52.7 \\
\hline Formativo: capacitación a empleados & 00.0 \\
\hline Formativo: concientización a clientes & 35.8 \\
\hline Comercial: atención al cliente & 75.0 \\
\hline
\end{tabular}

El peso relativo social es de 11.9 , que equivale a $35.7 \%$, valor que marca un estado de sostenibilidad social malo.

\section{Cuadro 5.3 Valores porcentuales del ISA económico}

\begin{tabular}{|lc|}
\hline Subcomponente & $\%$ \\
\hline Autogestión & 58.5 \\
\hline Operación y mantenimiento & 19.6 \\
\hline Índices financieros & 46.0 \\
\hline Infraestructura del abastecimiento & 37.6 \\
\hline Equipamiento y personal & 58.7 \\
\hline
\end{tabular}

El peso relativo económico es igual a 13.87, su equivalente porcentual es de $41.5 \%$, valor que lo clasifica como de sostenibilidad económica deficiente.

\section{Cuadro 5.4 Valores porcentuales del ISA ambiental}

\begin{tabular}{|lc|}
\hline Subcomponente & $\%$ \\
\hline Explotación de agua & 55.0 \\
\hline Aprovechamiento & 41.8 \\
\hline Impacto ambiental & 00.0 \\
\hline Conservación & 52.4 \\
\hline
\end{tabular}

El peso relativo económico es de 12.87 que corresponde a $38.7 \%$, lo que significa que su estado de sustentabilidad es malo. 


\subsubsection{Visualización de la información en diagramas tela de araña.}

Con los valores de la agregación se construyen los diagramas (tela de araña) del índice de sostenibilidad y sus componentes satélites.

Figura 5.1 Diagramas tela de araña del sistema de diagnóstico ISA y sus componentes satélite

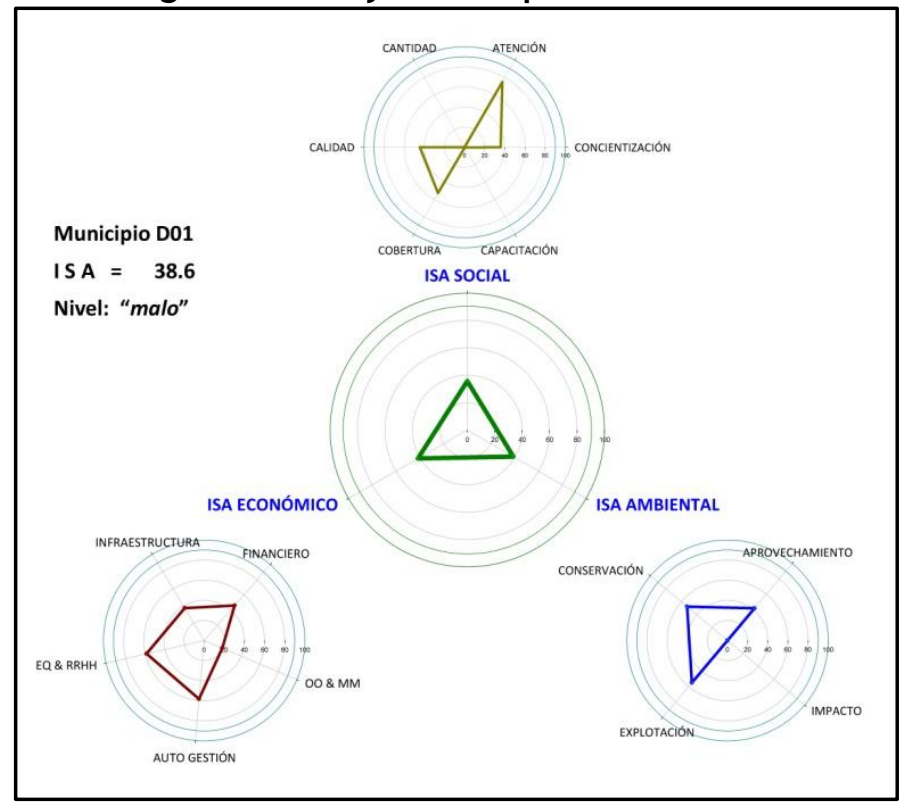

\subsubsection{Clasificación del abastecimiento por su ISA.}

La suma de los pesos relativos arroja un valor del ISA de 38.64. La sostenibilidad del abastecimiento se enfrenta a limitaciones importantes en los tres componentes, por lo que el diagnóstico para este abastecimiento es que se encuentra en un nivel de sostenibilidad malo.

\subsubsection{Juicio de la situación real actual, con base en el diagnóstico ISA.}

Sus mejoras se apoyarán en tareas que correspondan proporcionalmente a su déficit, respecto de lo deseable para ser sostenible, dichas tareas se concatenan y apoyan en lo que se propone en los contenidos del acápite 4 . 
a) En lo social.- se deben orientar los esfuerzos institucionales para mejorar todos los subcomponentes que lo conforman, pero con urgencia cantidad y capacitación.

El valor porcentual de los pesos relativos se ordena por la necesidad de inversión de recursos, según su detrimento (mayores recursos al de menor valor). De tal manera que la intensidad-profundidad con la que las prioridades del subcomponente se deben atender, se recomiendan así: cantidad, capacitación, concientización, cobertura, calidad y atención.

Se complementa la selección de los esfuerzos y recursos dedicados para mejorar la sostenibilidad con las actividades prioritarias tras la selección de ellas según cuán importante, obligatorio y urgente son.

Tabla 5.4 Matriz de selección de prioridades, subcomponentes sociales

\begin{tabular}{|c|c|c|c|c|c|c|c|c|c|}
\hline Aspectos a ser priorizados & 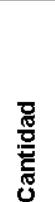 & 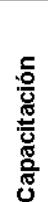 & 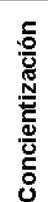 & 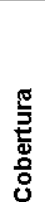 & $\begin{array}{l}\text { ్ㅠ } \\
\text { ס्ञ } \\
\text { J }\end{array}$ & 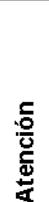 & 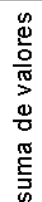 & 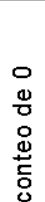 & 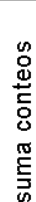 \\
\hline Cantidad & 0 & 2 & 1 & 0 & 0 & 2 & 5 & 3 & 8 \\
\hline Capacitación & & $\mathbf{0}$ & 3 & 0 & 0 & 1 & 4 & 3 & 7 \\
\hline Concientización & & & $\mathbf{0}$ & 0 & 0 & 1 & 1 & 3 & 4 \\
\hline Cobertura & & & & $\mathbf{0}$ & 0 & 2 & 2 & 2 & 4 \\
\hline Calidad & & & & & $\mathbf{0}$ & 2 & 2 & 1 & 3 \\
\hline Atención & & & & & & $\mathbf{0}$ & 0 & 1 & 1 \\
\hline Suma de valoraciones & 0 & 2 & 4 & 0 & 0 & 8 & 14 & & \\
\hline Transpuesta conteo de 0 & 3 & 3 & 3 & 2 & 1 & 1 & & 13 & \\
\hline suma de conteos & 3 & 5 & 7 & 2 & 1 & 9 & & & 27 \\
\hline Niveles de importancia & III & IV & $\mathrm{V}$ & II & I & VI & & & \\
\hline
\end{tabular}

De la anterior distribución de subcomponentes, analizadas sus prioridades relativas de urgencia, importancia y lo deseable que son para mejorar la sostenibilidad del abastecimiento, por pares y por $A B C$, se recomienda que las actividades a ser emprendidas para mejorar la sostenibilidad del abastecimiento en su componente social tengan el siguiente orden: Calidad, cobertura, cantidad, capacitación, concientización y atención.

Esta clasificación, se combina con el ordenamiento por su ISA, con base en la capacidad de gestión, de la disponibilidad de recursos y de la actitud 
proactiva de los actores principales, luego se procede a incluirlas en la fase de planificación, ejecución y siguientes. Además, el criterio de clasificación para ser ratificado, mejor que sea socializado también con el equipo de gestión, operación y mantenimiento del abastecimiento. Sin embargo, aquí se plantean las dos formas de selección, 1) al de menor valor porcentual en el ISA; y, 2) según la selección a través de la matriz de priorización, ambas válidas como instrumentos de apoyo a la planificación participativa.

b) En lo económico.- el abastecimiento requiere que se inviertan bastos esfuerzos institucionales para mejorar todos los subcomponentes que éste incluye.

El orden de dichos subcomponentes, que según el valor del ISA ameritan una mayor inversión de recursos por su menoscabo o baja puntuación, es: infraestructura, operación y mantenimiento, financiero, equipo y recurso humano, autogestión.

El orden prioritario según cuán importante, obligatorio y urgente son, se presenta en la tabla siguiente:

Tabla 5.5 Matriz de selección de prioridades, subcomponentes económicos

\begin{tabular}{|c|c|c|c|c|c|c|c|c|}
\hline Aspectos a ser priorizados & 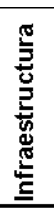 & $\begin{array}{l}\bar{\Sigma} \\
\sum_{0}^{0} \\
8 \\
0\end{array}$ & 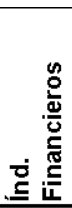 & 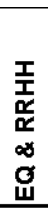 & 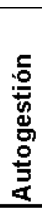 & 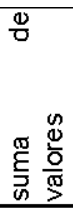 & $\begin{array}{l}0 \\
0 \\
0 \\
0 \\
0 \\
0 \\
0 \\
0 \\
\end{array}$ & 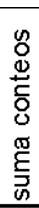 \\
\hline Infraestructura & $\mathbf{0}$ & 0 & 1 & 2 & 0 & 3 & 3 & 6 \\
\hline OO\&MM & & 0 & 3 & 2 & 0 & 5 & 2 & 7 \\
\hline Índ. Financieros & & & $\mathbf{0}$ & 1 & 0 & 1 & 2 & 3 \\
\hline $\mathrm{EQ} \& \mathrm{RRHH}$ & & & & $\mathbf{0}$ & 0 & 0 & 2 & 2 \\
\hline Autogestión & & & & & 0 & 0 & 1 & 1 \\
\hline Suma de valoraciones & 0 & 0 & 4 & 5 & 0 & 9 & & \\
\hline Transpuesta conteo de 0 & 3 & 2 & 2 & 2 & 1 & & 10 & \\
\hline suma de conteos & 3 & 2 & 6 & 7 & 1 & & & 19 \\
\hline Niveles de importancia & III & II & IV & $\mathrm{V}$ & $\mathbf{I}$ & & & \\
\hline
\end{tabular}

Las prioridades entonces quedan ordenadas así: autogestión, operación y mantenimiento, infraestructura, índices financieros y equipamiento \& personal. 
c) En lo ambiental.- El aspecto ambiental de la gestión del abastecimiento requiere de urgentes medidas correctoras en aquellas cuyo índice porcentual relativo es malo. Seguidamente los subcomponentes se ordenan según su necesidad de inversión de recursos y esfuerzos institucionales, así: impacto ambiental por su actividad de operación y mantenimiento, aprovechamiento del recurso hídrico, conservación y explotación, y con ellos todos los indicadores y variables que los incluyen.

Por su parte, el orden de los subcomponentes según cuán importantes, obligatorios y urgentes son, se presenta así:

Tabla 5.6 Matriz de selección de prioridades, subcomponentes ambientales

\begin{tabular}{|c|c|c|c|c|c|c|c|}
\hline Aspectos a ser priorizados & 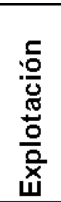 & 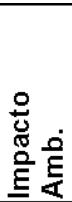 & 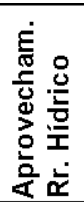 & 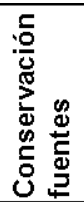 & 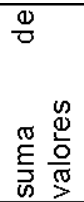 & $\begin{array}{l}0 \\
0 \\
0 \\
0 \\
0 \\
\stackrel{0}{ \pm} \\
\stackrel{0}{0} \\
0\end{array}$ & 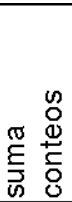 \\
\hline Explotación & 0 & 2 & 0 & 1 & 3 & 2 & 5 \\
\hline Impacto Amb. & & 0 & 1 & 0 & 1 & 2 & 3 \\
\hline Aprovecham. Rr. Hídrico & & & 0 & 0 & 0 & 2 & 2 \\
\hline Conservación fuentes & & & & 0 & 0 & 1 & 1 \\
\hline Suma de valoraciones & 0 & 2 & 1 & 1 & 4 & & \\
\hline Transpuesta conteo de 0 & 2 & 2 & 2 & 1 & & 7 & \\
\hline suma de conteos & 2 & 4 & 3 & 2 & & & 11 \\
\hline Niveles de importancia & $\mathrm{I}$ & III & II & I & & & \\
\hline
\end{tabular}

En este caso se puede considerar como semejantes en su importancia, urgencia y obligatoriedad para la sostenibilidad del abastecimiento, tanto la conservación de cuencas como la explotación de recursos; pues tienen íntima relación y en ningún caso serán excluyentes entre sí, por el contrario son complementarias sin subordinación de ninguna por la otra.

Luego le siguen, según esta clasificación, los subcomponentes de aprovechamiento de recursos e impacto ambiental. 


\subsubsection{Conclusiones y recomendaciones.}

\section{Los problemas, las patologías y sus tratamientos auxiliares.-}

El abastecimiento de agua evaluado, que según el ISA tiene una categoría de sostenibilidad malo, en sus características generales y particulares debe ser atendido con urgente diligencia; parte de las posibles acciones complementarias se presentan a continuación:

\section{a) Aspectos sociales.-}

\section{Cantidad}

Las reducciones de caudal supera el máximo deseable, principalmente en época de verano, lo cual se puede mejorar, bien con una gestión integral de los recursos hídricos en las cuencas tributarias; ó bien si se considera implantar un sistema de macro almacenamientos (embalses) en puntos estratégicos de la cuenca y cuencas aledañas.

Los cortes de suministro son repetidos y afectan a gran parte de la red, la causa principal son los múltiples deslizamientos y deslaves en el trayecto de las aducciones, generando daños en las tuberías. Una alternativa a mediano plazo puede ser mejorar el sistema de anclajes y apoyos de la aducción. A largo plazo, se recomienda buscar variantes a dicha trayectoria.

La reducción de volúmenes de agua para suministro, debido a fugas físicas, provoca racionamientos más críticos y alargados.

Es preciso mejorar las tareas de regulación de la presión de servicio, puesto que existen múltiples zonas de la ciudad en las que se sobrepasa los límites máximos y mínimos de presión, viciando la calidad y cantidad del servicio a los clientes.

En conclusión la empresa investigada aún presenta riesgos operacionales que afectan seriamente a sus abonados y por muchos días al año, al no contar con alternativas prácticas de satisfacción de necesidades hídricas de la población a la hora de verse afectados por daños (de origen natural) en las líneas de aducción o por defectos técnicos en la operación y mantenimiento. El reto es obtener suficiencia hídrica en cualquier época del año.

\section{Calidad}

Es bien conocido que la buena calidad del agua suministrada es fundamental para garantizar la salud de la población. Por ello es urgente e importante, 
para llevar un control más acertado de este aspecto, que se aumente el número de muestras de la red de distribución, para ensayos de calidad física, química y bacteriológica, en un $35 \%$ más de lo que actualmente se maneja.

Puesto que son altos los porcentajes de clientes que cuentan con un servicio de agua con cantidades de cloro residual fuera de los rangos $(0.3 \mathrm{mg} / \mathrm{L}$ a 1.5 $\mathrm{mg} / \mathrm{L}$ ), se propone actuar de manera urgente con un programa de muestreo, modelación, calibración, análisis de la velocidad de disminución del cloro residual y evaluación del riesgo sanitario al que los clientes se encuentran sometidos, en toda la red.

\section{Cobertura}

Tanto la cobertura como el servicio en horas pico pueden ser mejorados, siempre que la empresa invierta en la ampliación de la red, incremento de diámetros de aquellos tramos directores; así como se incremente la cantidad y calidad de agua con depósitos de compensación a una mejor cota de carga.

\section{Capacitación y concientización}

El recurso humano debe contar con un programa de adiestramiento y capacitación permanente, en temas generales y particulares según le corresponda a cada grupo. La buena evaluación de la efectividad en la gestión mucho depende del conocimiento, know how, que la empresa disponga en operación y mantenimiento.

Además, el cliente debe disponer de campañas de educación continuas, respecto del uso racional del agua y los recursos naturales en general. Dicho cometido se puede facilitar mediante programaciones de transmisión pública (impresa, gráfica y audiovisual). Potenciar convenios con empresas mediáticas, es una de las alternativas viables.

\section{Atención al cliente}

La empresa puede invertir en un plan de marketing y difusión pública de las actividades, necesidades y enmiendas que en la gestión se procuran para alcanzar la sostenibilidad. Su sistema de atención al cliente se puede mejorar con el incremento de sitios (distritales) en los que se brinde atención a clientes que requieren nuevas conexiones, recepción de pagos por consumos, atención de quejas, entre otros. 


\section{b) Aspectos económicos.-}

\section{Recuperación de costos}

Muchas de las actividades que se requieren que sean incluidas para alcanzar la sostenibilidad del abastecimiento ameritan que sean financiadas desde los consumidores-abonados, por lo que se recomienda se analice la reestructuración del sistema tarifario. Se recomienda incluir como premisa que ninguna empresa de agua debe subsistir o completar su financiamiento con los subsidios y aportes del Estado. El precio del agua tampoco podrá estar afectado por intereses políticos.

De la primera intervención investigativa del abastecimiento, se percibe que en cierto modo, al interno de la empresa y del propio municipio que lo regenta, realizan un control de costos y gastos; sin embargo, la empresa aún muestra su vulnerabilidad frente a los riesgos por la deficiencia e insuficiencia de las redes, para brindar buen servicio en todo espacio y tiempo. Las inversiones se pueden optimizar siempre que se practiquen ajustes a la gestión global del sistema, a corto, mediano y largo plazo.

Es fundamental que la empresa mejore su autosuficiencia financiera; así como también busque optimizar su porcentaje de liquidez y el stock de deuda.

El porcentaje de agua no facturada, es un dato muy poco fiable, puesto que la ausencia de distritos hidrométricos, en redes sectorizadas, obliga a los gestores y responsable a "proyectar - estimar" cifras, por lo que bien pueden tener mayores márgenes de error.

\section{Operación y mantenimiento}

En este subcomponente lo importante, urgente y obligatorio, es que la empresa inicie con estrategias agresivas para desarrollar inspecciones acústicas que le permitan localizar fugas y detectar conexiones ilícitas, concatenado con el análisis de flujos mínimos nocturnos para detección de fugas.

El índice de fugas estructural - IFE - del abastecimiento tiene un valor cercano a 18, el que comparado con otros abastecimientos investigados resulta aceptable con muchas limitaciones; sin embargo, está lejos de lo deseable que se aceptaría entorno a 4 , dadas las características de la red. Se recalca que los datos (de volúmenes y presión) proporcionados para el diagnóstico no se adquieren de campo con los procedimientos y equipos recomendados y por el contrario, como se anotó párrafos atrás, se trabaja con datos proyectados o 
estimados, y hasta el momento sin ninguna posibilidad formal de verificación o constatación in situ.

El rubro de impermeabilización interna de depósitos (medido en $\mathrm{m}^{2}$ ) es más usual en el país, no obstante las actividades de mantenimiento en la empresa del diagnóstico (impermeabilización) sólo se hace en un $5 \%$ anual, actividad que resulta escasa para lo deseable.

La información sobre las actividades de operación y mantenimiento del sistema es insuficiente, inconsistente y de poca fiabilidad. No existen registros históricos continuos sobre caudales (o volúmenes) producidos y distribuidos. Tampoco los volúmenes de agua empleados en el proceso de tratamiento y mantenimiento de unidades que conforman el sistema. Se manejan estadísticas con bases de datos muy pobres y poco confiables, como los consumos per cápita, o características de la variación del consumo durante el día, (pico, llano y valle).

Inexistencia de información registrada de las actividades de mantenimiento, reparación o renovación.

El sistema de información que se maneja a nivel informático, es muy limitado. Se cuenta con planimetría y altimetría de una poca superficie, los detalles hidráulicos de la red, son incompletos y se desconoce de su comportamiento dinámico. Inexistencia de protocolos y control de información.

Insuficiente control sobre los caudales, las presiones y la calidad del agua que se distribuye por el sistema.

En definitiva, la red no cuenta con un catastro actualizado tanto de clientes (componente comercial) como la parte hidráulica-sanitaria.

Como alternativas complementarias se recomienda:

Mejoramiento de las bases de datos.- Incluir protocolos para la generación de información fidedigna y verificable, por todos los miembros del abastecimiento.

Organizar los datos e información de todo lo que concierne al sistema de agua, en todos sus componentes e históricos.

Se puede verificar que el departamento de operación y mantenimiento no lleva un registro eficaz de los cambios, reparaciones y renovaciones en la red, por posible desorganización y escaso adiestramiento de su personal en el tema, situación que dificulta las tareas de actualización del catastro y de la base informática respectiva. 
Modelación y calibración.- Ajustar y calibrar el modelo de la red, utilizando alguna herramienta técnico-ofimática confiable.

Simplificación de redes y cargado del modelo. Redes directoras y aducciones, para diámetros mayores que $500 \mathrm{~mm}$. Red de distribución primaria, inclúyase diámetros de $250 \mathrm{~mm}$ a $500 \mathrm{~mm}$. Redes secundarias entre $250 \mathrm{~mm}$ hasta 100 $\mathrm{mm}$.

Cargado del modelo, con información del catastro de clientes, concatenado con la sectorización. Cálculo de consumos per cápita y proyectado por nudo. Monitoreo de una muestra característica de los abonados, con equipos e instrumentos apropiados.

El modelo se ajusta con la variación de los coeficientes de consumo y rugosidad de tuberías, concatenados con la información de campo. Las variaciones temporales del consumo, se ajustan para períodos cuasi estáticos, hasta que satisfagan lo más posible la realidad.

\section{Infraestructura y equipamiento}

Está pendiente el plan de sectorización de la red para la identificación de parcelas hidrométricas; construcción de nudos de control y puntos de monitoreo, así como actualizar el inventario de tuberías (catastro hidráulico) en toda la red, con su diámetro, longitud, material, antigüedad, ubicación espacial, accesorios, etc.

Es elemental, urgente e importante ejecutar políticas de medición, registro, transporte y almacenamiento de datos, relacionados con caudales, presiones y calidad en línea del agua del suministro; macro-medición, a la entrada y salida de los depósitos que conformarán las parcelas hidrométricas. El dato de presiones debe obedecer el mismo tratamiento, mediante la instalación de sensores de presión en puntos estratégicos, en las zonas de carga media, máxima y mínima.

Tomar medidas de seguridad y prevención contra vandalismo, en nudos de control, para brindar la protección necesaria a los instrumentos y equipamiento en general.

Los equipos e instrumentos de control y registro electrónico de caudales producidos en planta ameritan de calibración semestral o por lo menos anual.

Se debe invertir en el número de hidrantes contra incendios, puesto que su cantidad está por debajo de los parámetros de seguridad urbana.

De la literatura técnica, se conoce que entre el $70 \%$ y el $80 \%$ de las fugas de las redes se producen en los collarines o conexiones domiciliares, por lo que 
se recomienda se inspeccione y renueve los collarines a una tasa mínima anual del 5\%. Para evitar elevar los gastos por este rubro de inspección y cambio de collarines, por excavación, taponamiento de zanjas y repavimentación de calles, se propone como alternativa, para las nuevas urbanizaciones y zonas que lo ameriten, la construcción de pozos de visita en cada acometida, de lo cual ya se tiene algunas experiencias positivas en algunas ciudades costeras del Ecuador.

Un porcentaje no menos importante de agua no contabilizada se puede deber al sub-contaje de los contadores domiciliares, por lo que se considera ideal que se cambien todos aquellos que tengan más de 8 años de servicio o hayan pasado los $4000 \mathrm{~m}^{3}$ de registro. La gestión de contadores también debe incluir una proyección del error del parque de medidores domiciliares, con extracción de un número de muestras que obedezcan a procedimientos estadísticos. Entonces se recomienda, invertir en gestión de micro-medición y proyección del error del parque de contadores.

La renovación de tuberías, mejor que se produzca dentro de los 40 años que se estiman confiables desde su instalación, por ello se deben renovar a una tasa promedio anual del $2.5 \%$, dicha recomendación amerita de autofinanciamiento y gran actitud socio-política para implantarla efectivamente en el abastecimiento.

La empresa debe optimizar las tareas de su recurso humano, pese a que no sobrepasa con exageración el número recomendado, pero si cuenta con 6.7 personas más por cada 10000 habitantes, respecto del deseable.

\section{Gestión de fugas}

La recomendación es que se destine recursos para aplicar el método de detección de fugas por flujos mínimos nocturnos, pues, por ser un método apropiado para abastecimientos con este tipo de características.

Determinar los volúmenes de agua no contabilizados y dar seguimiento exhaustivo a la información sobre fugas reales y aparentes. Como fuga inevitable (indetectable según la IWA) se puede considerar el valor aproximado a $18 \mathrm{~L} / \mathrm{km}$ de red / día / m c.a. de presión media y de $25 \mathrm{~L} / \mathrm{km}$ de acometida / día / m c.a. de presión media, para las que se considera reparación no económica.

Desarrollar el balance hídrico de la red, que incluya la determinación de volúmenes de agua: facturada medida, facturada no medida, no facturada no medida, consumos no autorizados, error en micro medición, fugas y reboses en reservorios y fugas en acometidas domiciliares, principalmente. 


\section{c) Aspectos ambientales}

En la cuenca hidrográfica, si bien la empresa de agua, a través de su departamento de medio ambiente y un ONG internacional, tienen en marcha un sistema de conservación y reforestación en gran parte de la superficie de las cuencas tributarias, aún falta mucho por regular legalmente la tenencia del suelo y ordenamiento territorial.

En época de estiaje, los operadores se ven en la necesidad de captar más del $80 \%$, inclusive la totalidad, por repetidas ocasiones, del caudal de algunos cursos naturales, pero incluso así es insuficiente para satisfacer la demanda poblacional, básicamente entre los meses de noviembre a enero. Esta insuficiencia de caudales empeora cada vez, puesto que la red además fuga, y se producen muchas pérdidas del recurso desde la captación hasta la planta de tratamiento y en todo el sistema de almacenamiento y distribución del suministro.

El control legal de la explotación de recursos naturales dentro de las cuencas tributarias puede mejorar mucho más, pese a que con mucha paciencia y tiempo, hasta ahora, se toman medidas importantes para la compra de las fincas y propiedades para administrarlas y conservarlas desde la propia empresa municipal, y son directamente financiadas en la facturación por consumo mensual de agua.

Un detalle particular que la mayoría de abastecimientos investigados lo tiene como instrumento ficticio de mejora, es que se asigna al consumo per cápita el consumo propiamente dicho más gran parte de los volúmenes no contabilizados; hecho que incrementa considerablemente el valor por habitante y por día, aunque no sea el real. Se tiene entonces que diferenciar entre el consumo per cápita facturado y el consumo per cápita distribuido.

Para la medida de la eficiencia energética aún falta mucho todavía por hacer y aprender. Varios de los motores de las estaciones de bombeo fueron puestos en mantenimiento de una forma artesanal (rebobinados) por lo que su rendimiento, a decir de los propios operadores, decayó notablemente. Se recomienda que el rendimiento de los motores y su consumo eléctrico se mida y compare con las características óptimas de funcionamiento, luego se determinen rendimientos (hidráulicos y energéticos) y finalmente se haga un análisis comparativo de costos.

La planta de potabilización no se responsabiliza actualmente de los lodos que se producen en el proceso de tratamiento (floculación y filtración principalmente), mas son vertidos directamente en el sistema de alcantarillado que a su vez carece de sistema de depuración alguno. 
Las aguas residuales y desechos se vierten directamente a los cuerpos receptores provocando una inminente contaminación aguas abajo.

Se recomienda se ponga especial cuidado y con la urgencia debida, al diseño y construcción del sistema de depuración de aguas residuales de la ciudad.

Es pertinente y deseable además que se elabore un plan de manejo ambiental de las actividades de operación y mantenimiento que generan impacto ambiental, para que se diseñen protocolos y procedimientos de aplicación de medidas correctoras.

Mediante ordenanzas locales, se deberá obligar a empresas, hospitales e industrias en general, a depurar sus vertidos.

Analizados los resultados de este diagnóstico, en términos generales, se concluye que el nivel de sostenibilidad del abastecimiento es malo, clasificación que se fundamenta en el índice ISA, que es igual a 38.64.

Hay mucho por hacer aún en los componentes social, económico y ambiental, para convertir el sistema de gestión de agua en sostenible. 


\section{ANEXO 5.1}

\section{Diagramas de resultados}
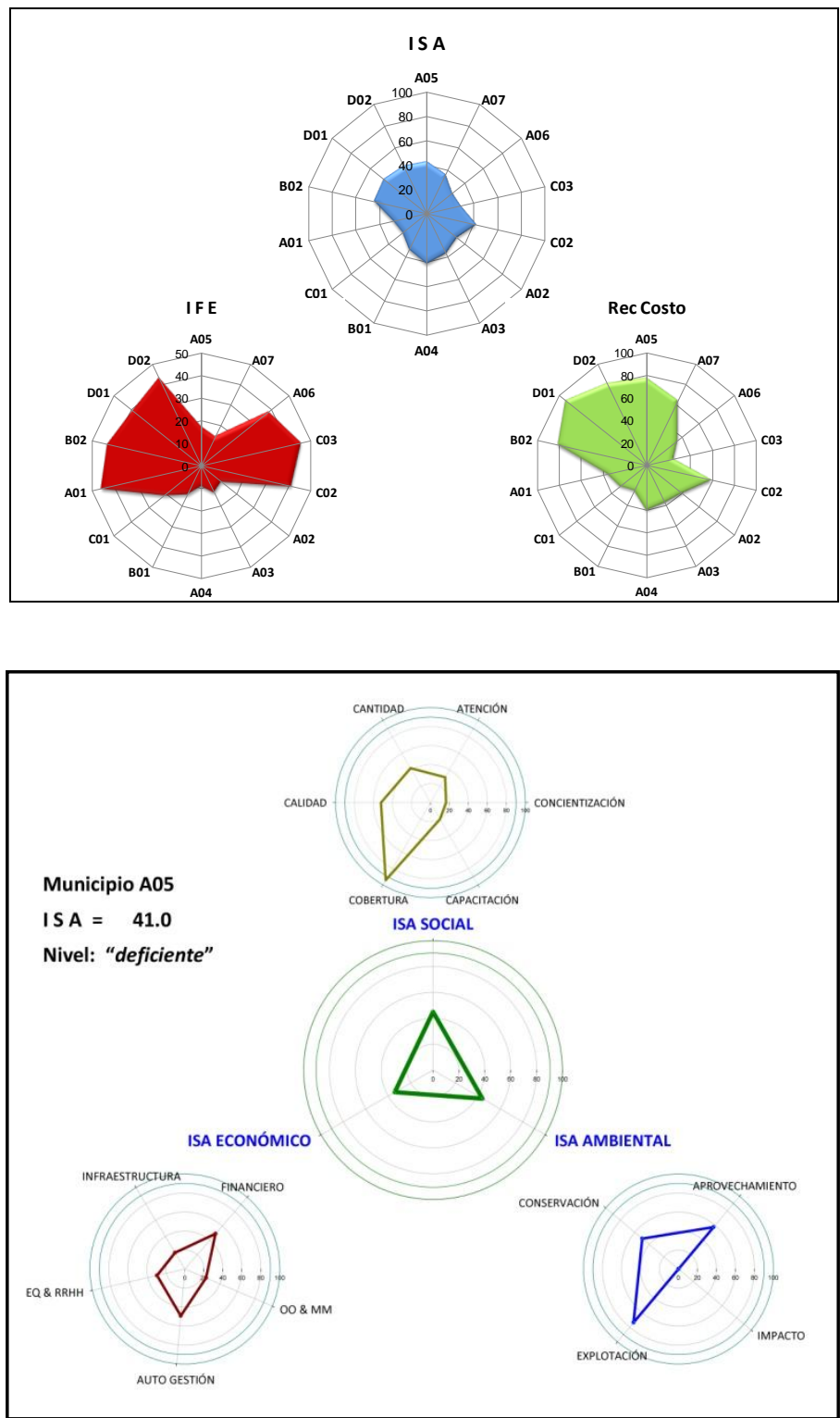

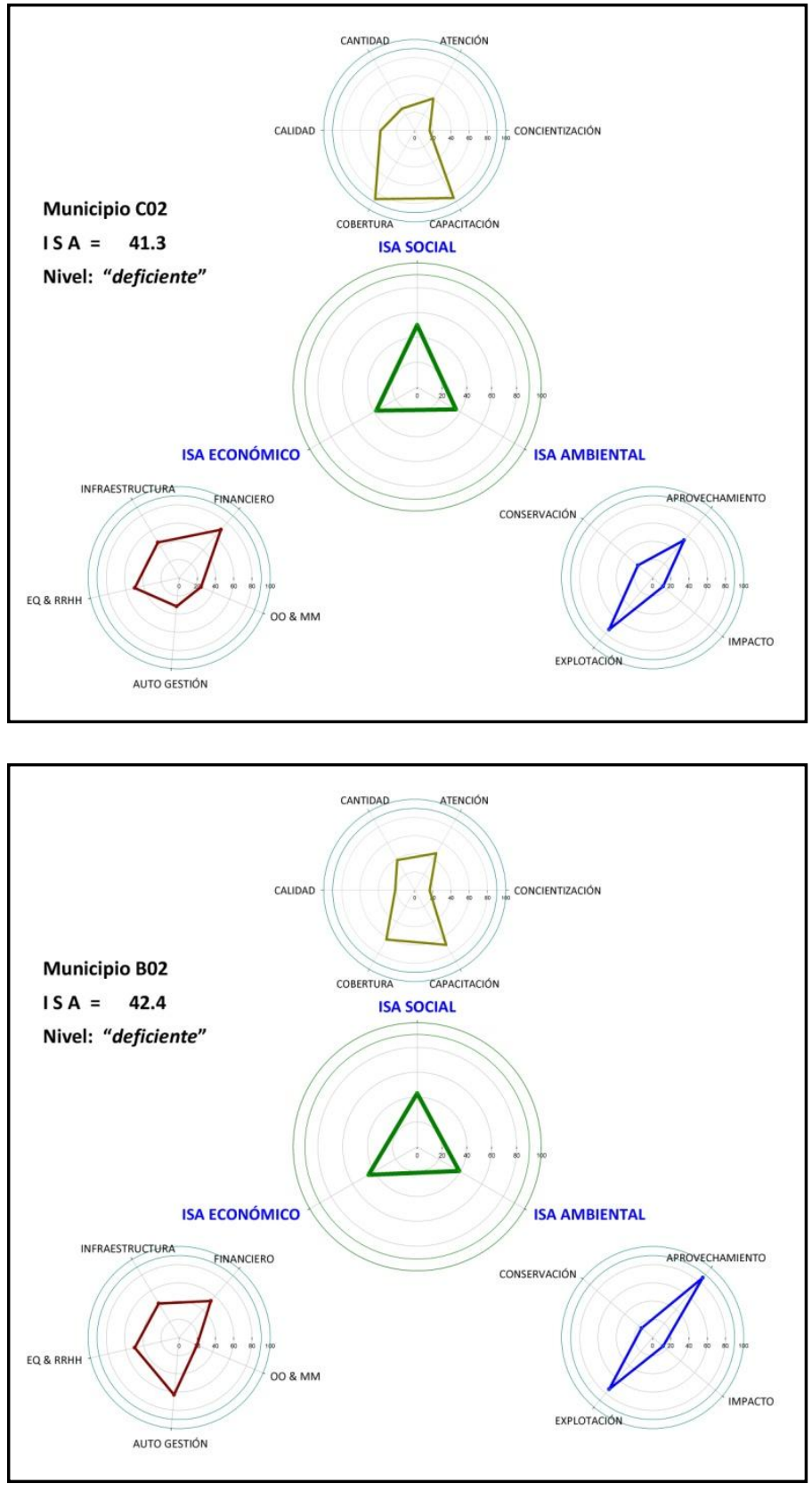

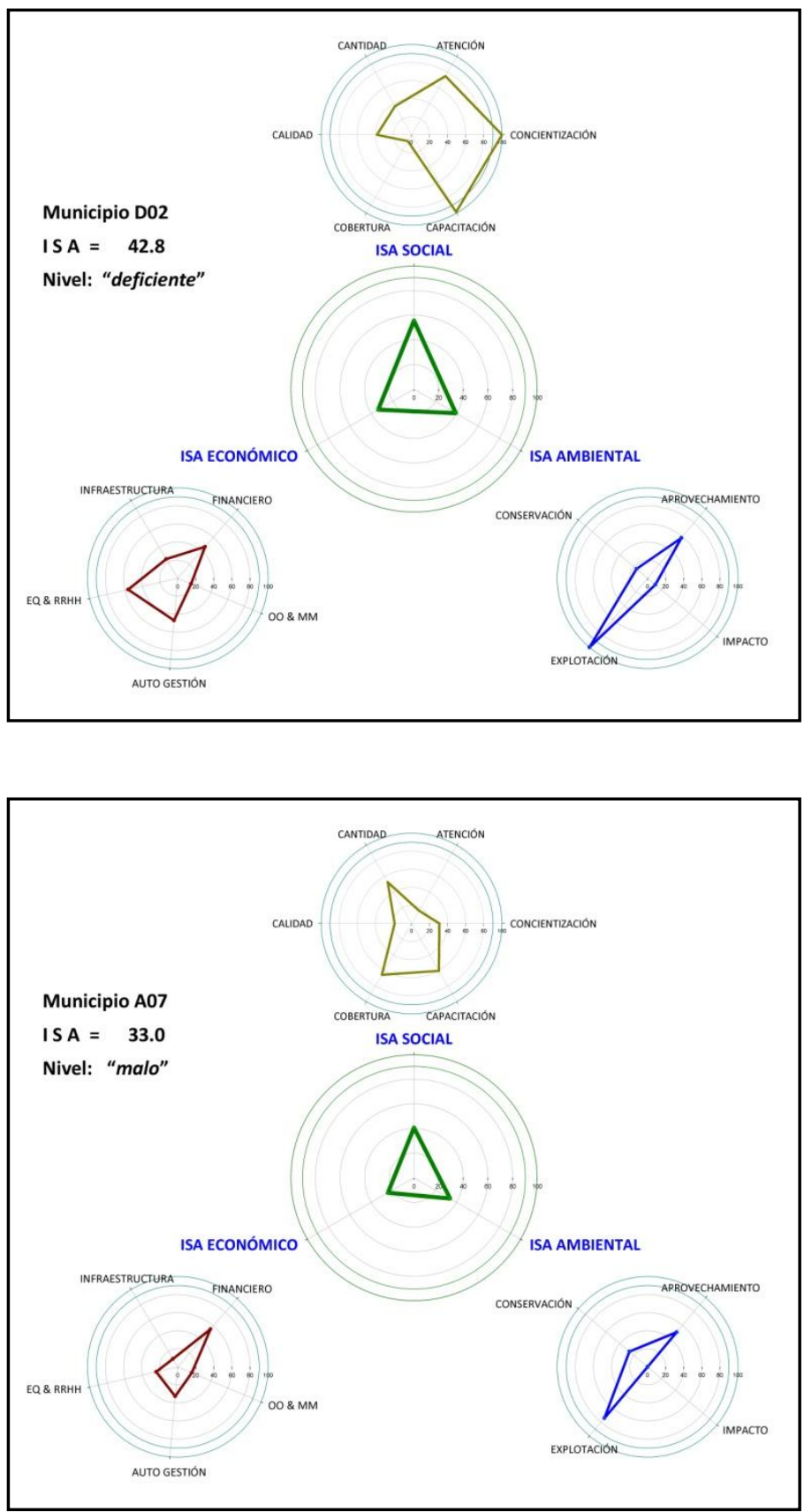

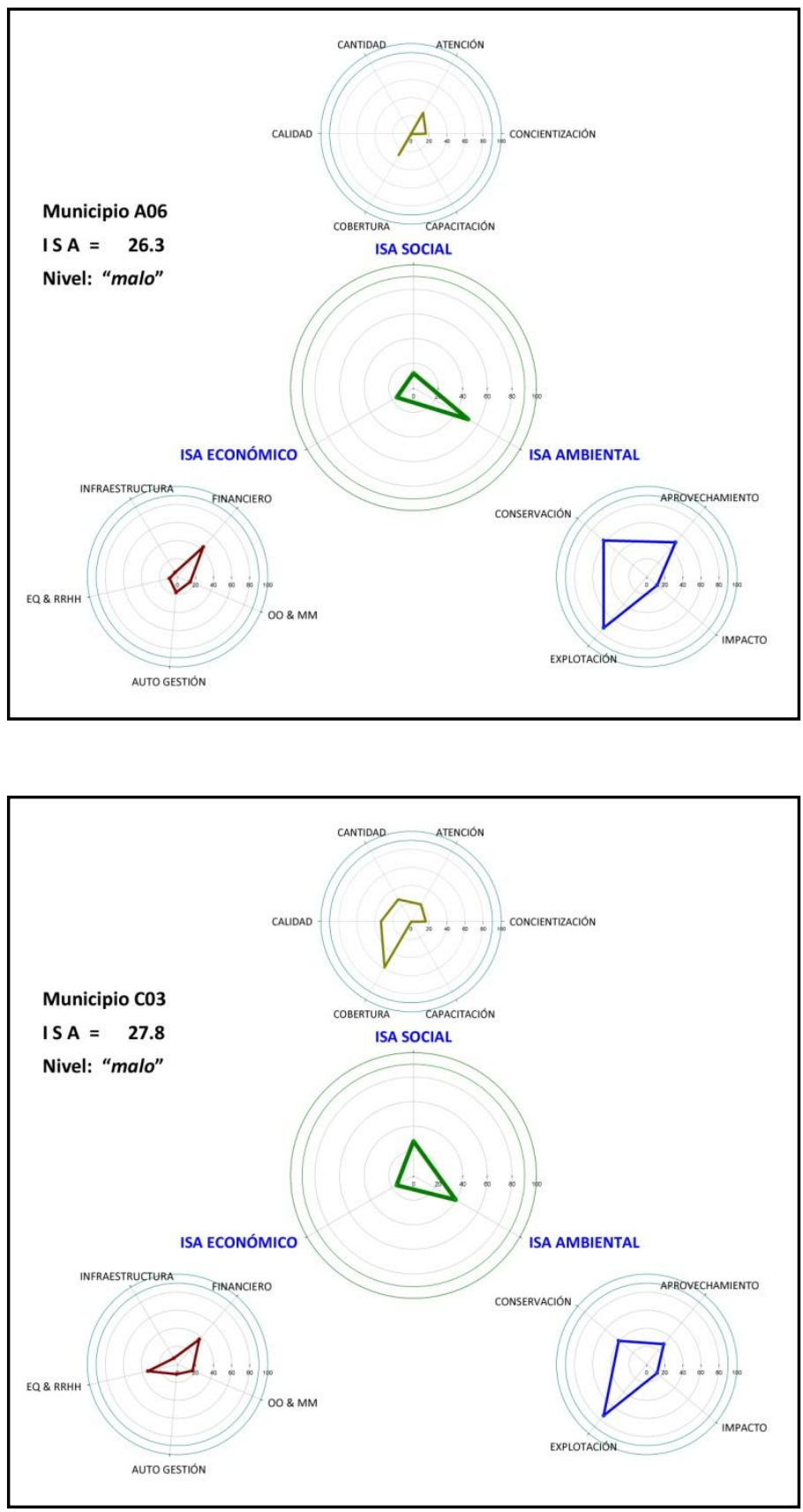

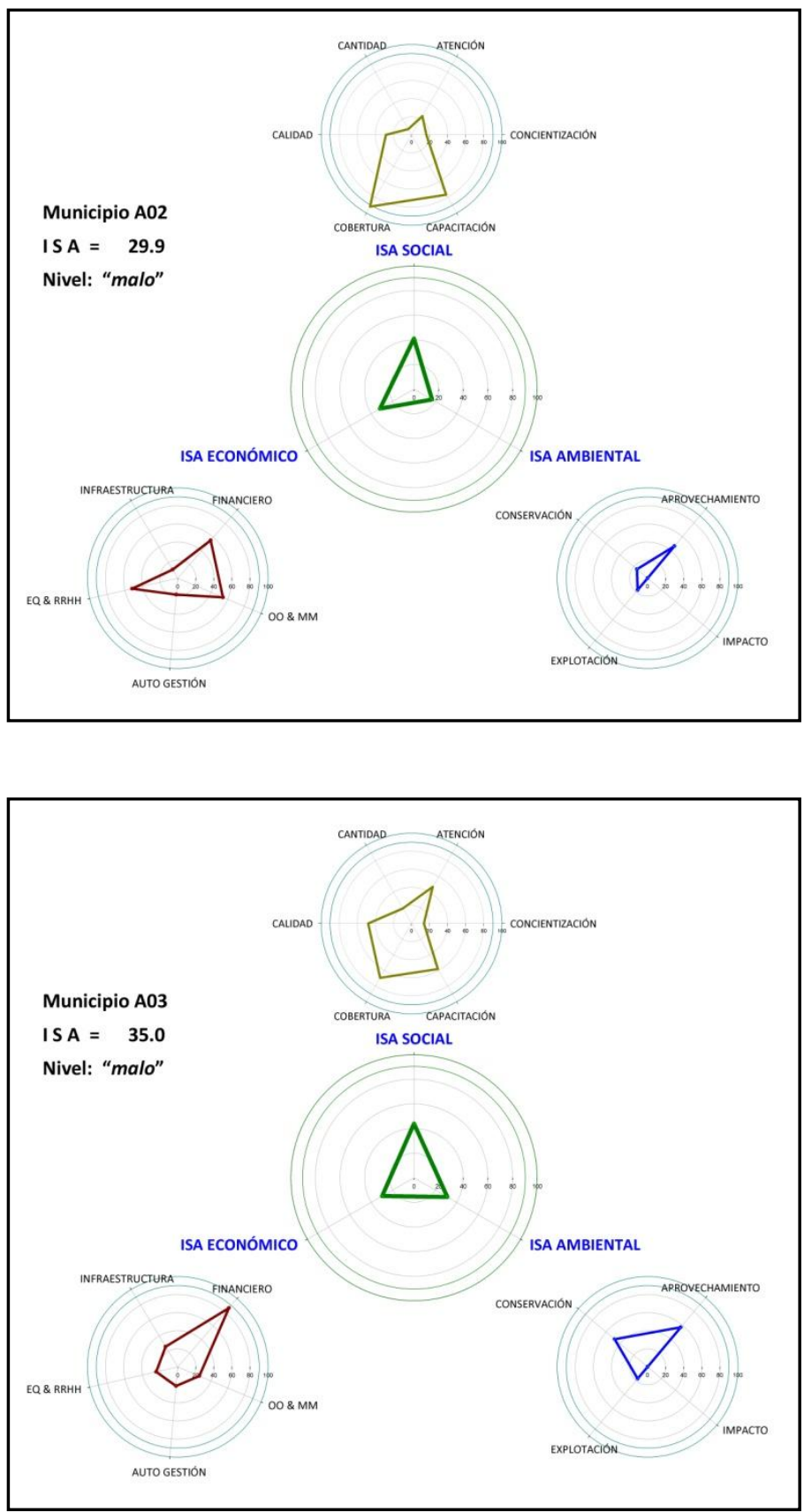

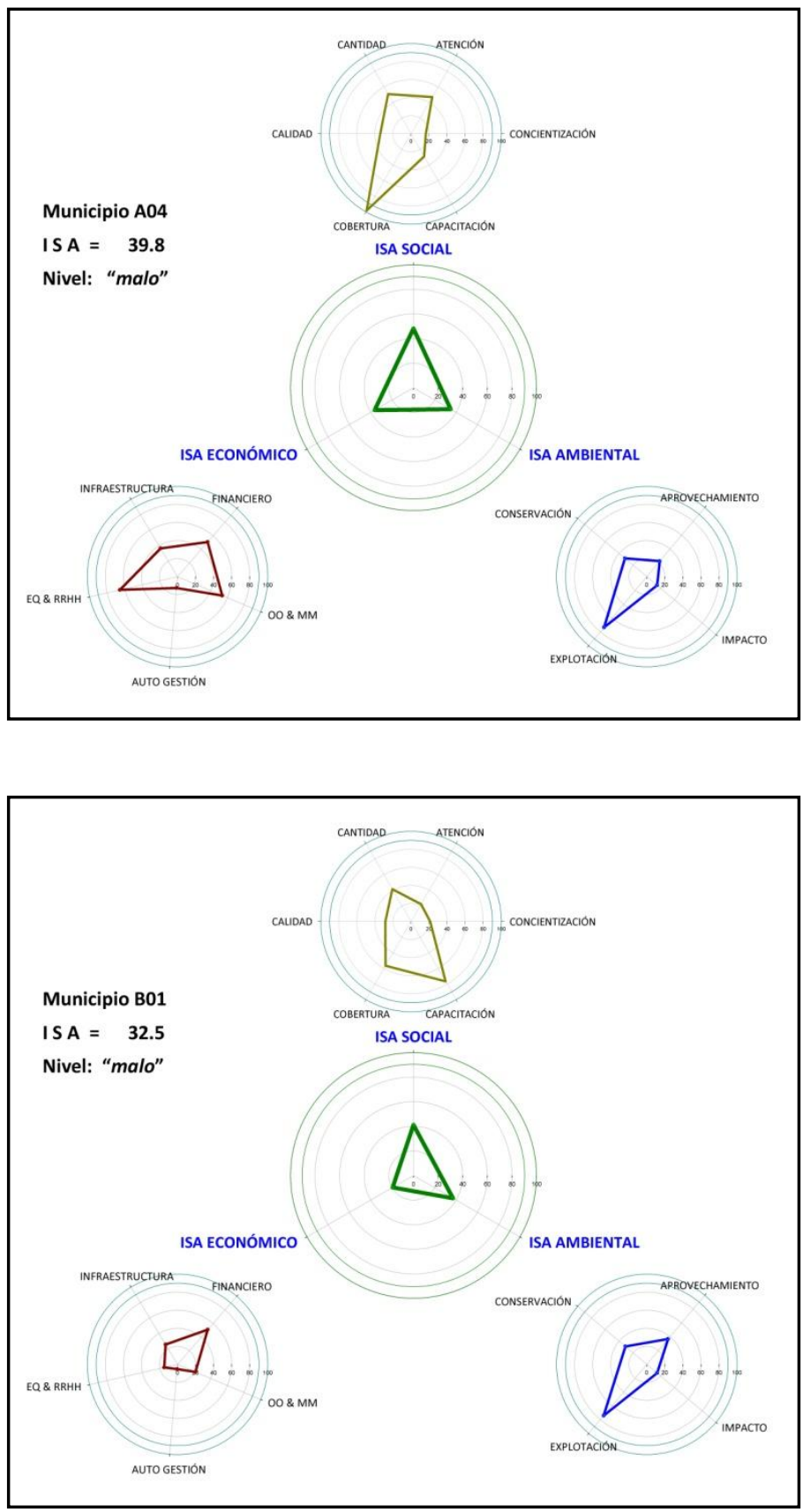

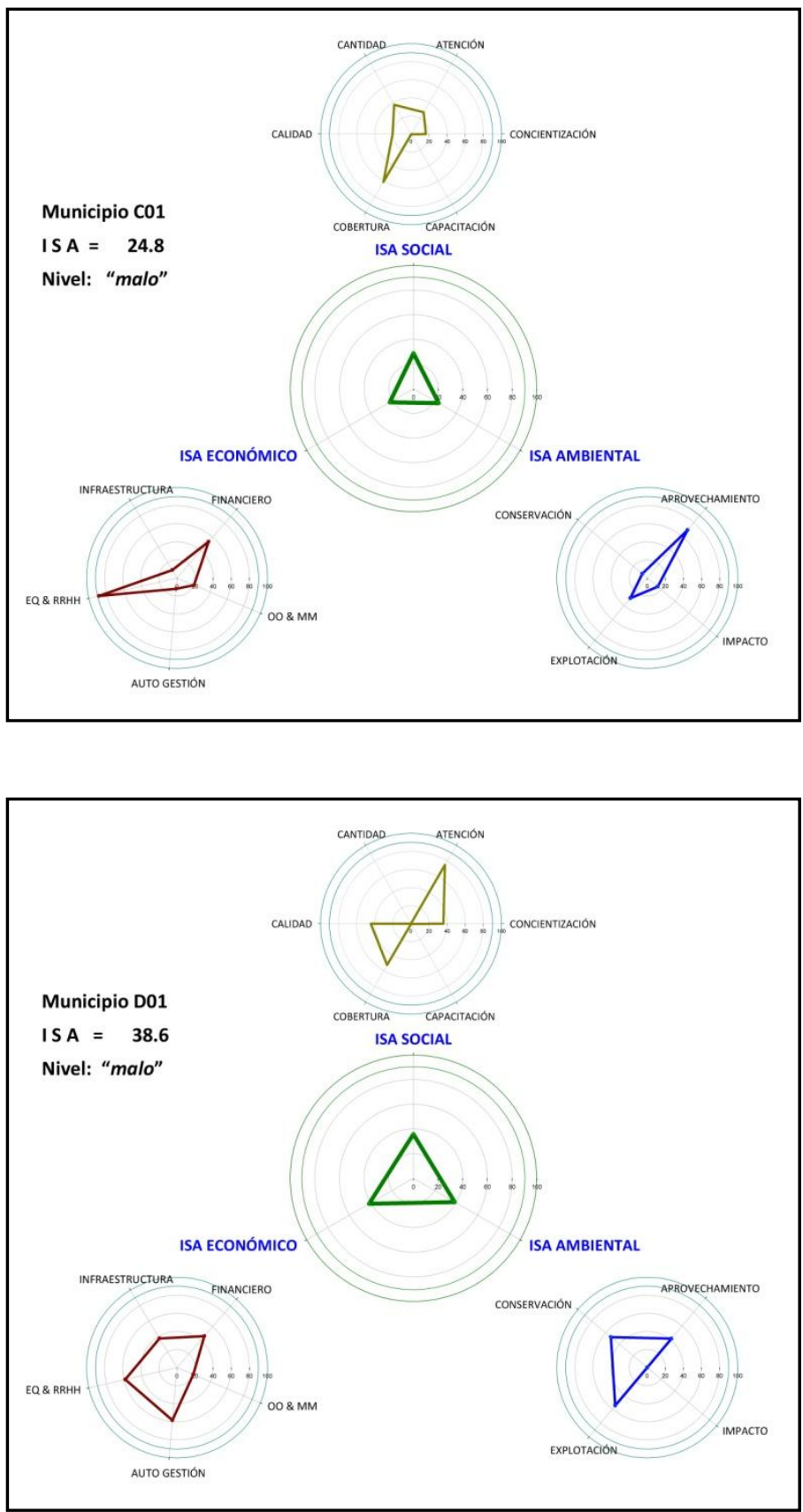


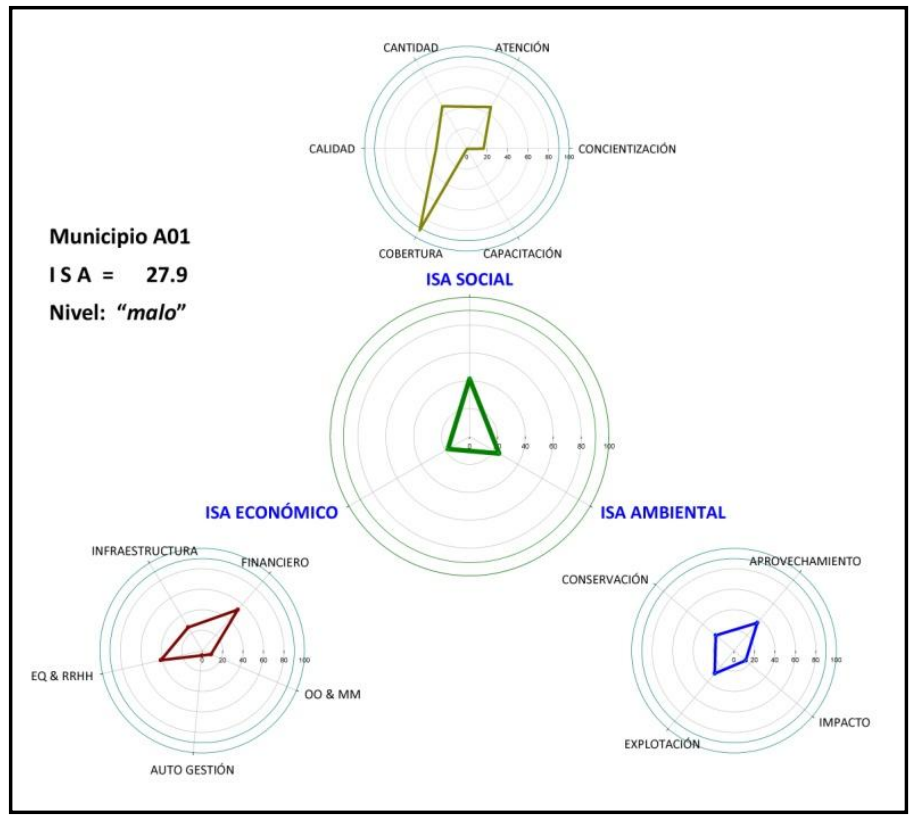




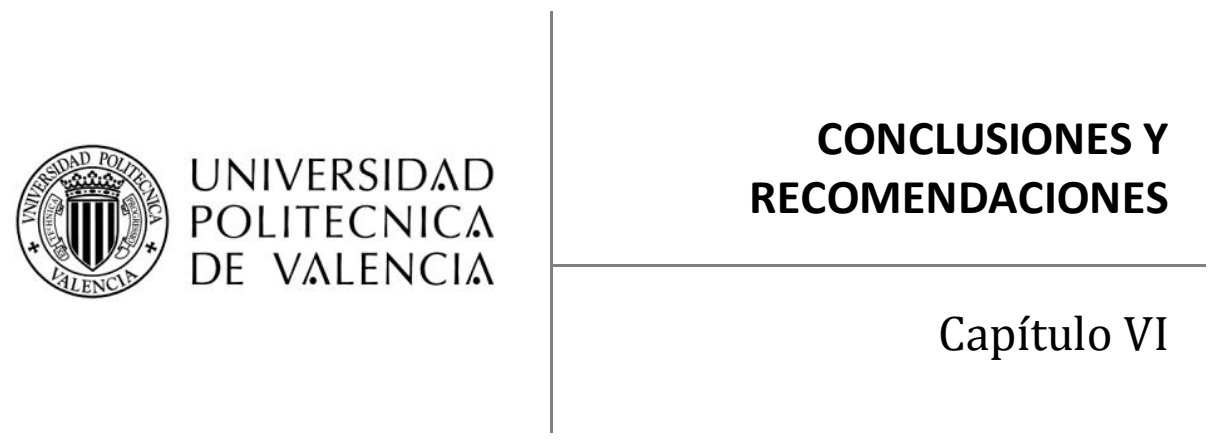





\section{CONCLUSIONES Y RECOMENDACIONES}

\subsection{Conclusiones}

La gestión sostenible de suministros así como el uso eficiente del agua es una necesidad vital y urgente en los sistemas de abastecimiento de nuestro país y países en vías de desarrollo, tal que permita garantizar un equilibrio entre sus componentes social, económico y ambiental, con impactos positivos en las cuencas tributarias de agua, sobre los ecosistemas que lo conforman y mejor calidad del servicio para los usuarios o abonados.

La gestión sostenible de sistemas de agua potable significa involucrar criterios de eficiencia y manejo integrador más limpios y oportunos, este tipo de gestión debe considerar al agua como un sistema de sustento de vida sana dentro del ciclo antropocéntrico, concatenando beneficios transversales en sus tres ejes constitutivos.

El presente trabajo se desarrolló para brindar apoyo a la consecución y comprensión, por parte de los gestores y operadores involucrados, del camino a seguir para convertir en sostenible su actuación y a su sistema. Y al dar este primer paso, cognitivo - experimental mediante una propuesta práctica, adaptada a la realidad local, se deja sentado que falta mucho camino por recorrer, pero al menos sabemos, ahora sí, a dónde queremos y debemos llegar.

Citaremos, bien que de manera sucinta, que al término de esta fase investigadora y propositiva se consigue sumar con nuevos aportes, a la gestión de empresas de abastecimientos de agua, a la academia y al colectivo en general, lo siguiente:

1) Herramienta para el diagnóstico de la sostenibilidad de abastecimientos - ISA.

- $\quad$ Método de agregación para los indicadores de sostenibilidad de abastecimientos, en cada componente que lo conforman (social, económico y ambiental), mediante la aplicación de procedimientos cuali - cuantitativos. 
- $\quad$ Ejemplo de adaptación con 49 indicadores de sostenibilidad, agrupados en tres ejes, con sus respectivas funciones matemáticas y curvas de conversión a factores de calidad.

- Clasificación y diagnóstico de abastecimientos, según su índice de sostenibilidad de abastecimiento - ISA y las medidas generales correctoras para buscar su mejora.

- $\quad$ Línea base para la generación futura de un benchmarking métrico, entre abastecimientos involucrados.

2) Matriz de prioridades relativas, combinando al análisis por pares y el del $A B C$.

\subsubsection{Conclusiones de los objetivos}

1) Se propuso una metodología para el diagnóstico de la sostenibilidad de un abastecimiento de agua potable, así como la identificación de las necesidades o patologías, mediante visualización gráfica de sus subcomponentes en diagramas de tela de araña.

2) Se estructuró un procedimiento que permite diagnosticar los sistemas de suministro, mediante su índice de sostenibilidad de abastecimiento -ISA-, como herramienta de apoyo a la toma de decisiones tanto de la sociedad política, gerencial y financieros, involucrados a cada empresa de gestión del agua potable.

3) Según el valor del ISA, es posible clasificar y diagnosticar los abastecimientos y apreciar su nivel de vulnerabilidad o patologías, en sus tres componentes: social, económico y ambiental. Así, se puede conocer los subcomponentes e indicadores que se encuentran en condiciones críticas o malas, deficientes, regulares, buenas y excelentes.

4) Se presenta las directrices generales para mejorar las condiciones de cada indicador medido para el diagnóstico.

5) La metodología de diagnóstico ISA se aplicó a sistemas de abastecimiento de agua del Ecuador, constatándose su funcionalidad, su practicidad y versatilidad. 
6) De los resultados del diagnóstico obtenidos se concluye que los abastecimientos para los que se calculó el ISA (catorce sistemas de suministro) ameritan una intervención urgente y con pensamiento crítico.

Su clasificación final es: cuatro abastecimientos tienen un nivel de sostenibilidad deficiente y diez proyectan un nivel de sostenibilidad malo.

Los resultados confirmaron lo que por simple inspección se percibía desde un inicio.

7) Para la selección de alternativas se propuso, complementariamente, un instrumento participativo, de fácil comprensión y flexible en su aplicación, dicho instrumento se apoya en una matriz triangular superior, que permite seleccionar (por $A B C$ y por pares, al mismo tiempo) aquellas condiciones que sean urgentes, importantes $y$ deseables, para mejorar su sostenibilidad.

\subsubsection{Conclusiones de la hipótesis}

1) Se desarrolló una investigación exploratoria, y por primera vez se presenta y aplica una herramienta para el diagnóstico de la sostenibilidad de abastecimientos de agua - ISA.

2) Para el cálculo del índice de sostenibilidad de un abastecimiento -ISAse requiere que su estructura valorativa cuente con los datos suficientes, (generados y proporcionados por el gestor del abastecimiento), que conducen a calcular los indicadores (en el presente caso son cuarenta y nueve), que transformados a factores de calidad mediante funciones de conversión son afectados por un peso ponderado general, que generan los pesos relativos en los tres componentes de la sostenibilidad.

3) El índice de sostenibilidad de un abastecimiento es un modelo flexible que requiere de retroalimentación y evolución continua, en tanto y en cuanto los abastecimientos cada vez alcancen la excelencia, que deberá ser medida de forma anual y reajustando cada vez sus indicadores, la distribución de importancias ponderadas y las funciones de conversión, principalmente. 
Dicha flexibilidad se relaciona a que el método permite introducir en los pasos de valoración criterios cuali-cuantitativos que coadyuvan a agregar la información proporcionada en criterios isométricos u homogéneos de sostenibilidad.

4) La evaluación y medida del sistema de suministro con el ISA permite clasificar los abastecimientos en cinco categorías, emitiendo de esa manera un diagnóstico general de sostenibilidad del mismo.

\subsubsection{Conclusiones generales}

1) Las catorce empresas investigadas están ubicadas según su ISA, entre 24 y 43. Lo cual apoya el diagnóstico de sostenibilidad global de los abastecimientos como malo. Diagnóstico que debería convertirse en un llamado de atención a los gestores del país para tomar las medidas correctoras oportunamente.

2) Diez de los catorce sistemas de agua tienen nivel de sostenibilidad malo y cuatro sostenibilidad deficiente.

3) De los catorce abastecimientos investigados, siete tienen un valor del IFE entre 9 y $21 ; y$, los otros siete entre 38 y 45 .

4) De los catorce abastecimientos investigados ninguno depura las aguas residuales, y son vertidas directamente a los cuerpos receptores.

Las dificultades encontradas para la aplicación de la propuesta se deben principalmente a que:

a. La gran mayoría de los sistemas de abastecimiento de agua potable del Ecuador no cuentan con la infraestructura que permita practicar periódicamente medición, control y seguimiento de caudales y presiones, ó calidad en línea.

b. El no contar con redes sectorizadas ni equipadas para medición, es otra de las causas para no poder administrar y gestionar información confiable y verificable, por lo que la los datos del subcomponente de infraestructura, cantidad, caudales, y pérdidas poseen muy poca fiabilidad. 
c. Los gerentes administrativos, personal profesional y técnicos operadores de los sistemas de abastecimiento investigados no aplican, en su mayoría, las metodologías que existen para la valoración de auditorías hídricas en su propia empresa, ni tampoco crean una base de datos con sus indicadores para compararse públicamente con empresas homólogas o semejantes.

d. Los procedimientos de operación y mantenimiento que se acostumbra en un gran número de sistemas de agua municipales se efectúan "al ojo", o siguiendo viejas costumbres heredadas de pasados operadores de la red.

e. La gestión de fugas percibida obedece a una política pasiva, en la casi totalidad de abastecimientos.

f. Las personas involucradas en el tema del agua, en cada sitio investigado, no le dan ni le ven la importancia que este tema requiere para mejorar la calidad y cantidad de servicio de agua potable en su jurisdicción, menos aún el tema de la sostenibilidad del abastecimiento.

\subsection{Recomendaciones.}

\section{Propuesta para los desarrollos futuros de la metodología ISA}

Pese al éxito directamente percibido con la aplicación de la metodología ISA, bien se puede y debe recomendar incluírsele para futuras investigaciones, los siguientes detalles:

a) Investigar mucho más de cerca y detallar las causas y efectos de los aspectos que afectan negativamente al crecimiento de la sostenibilidad de un abastecimiento de agua; y, luego plasmarlos en la matriz de medidas correctoras.

b) Con la intervención de un ingeniero informático, crear un software que automatice y facilite el proceso completo de la metodología de diagnóstico aquí planteada.

c) Como ajustes al sistema en general, se recomienda tener más prácticas de selección de indicadores y plantear otra plataforma de distribución de importancias ponderadas en ellos. Actividad que requiere de la participación comprometida de más expertos en el tema. 
d) Es tarea necesaria además, pulir las entrevistas técnicas personales, o Delphi, para reajustar las funciones de conversión, penalización de la calidad.

e) Como sustentos adicionales a la propuesta ISA, se podría aplicarla en más ciudades ó países y con los nuevos resultados que se obtengan, retroalimentar los aspectos cualitativos de la metodología.

\section{Propuestas para la mejora del desempeño}

1) Algunas alternativas para mejorar el desempeño de los sistemas de abastecimiento municipales del Ecuador, podrían ser:

a. Iniciar con campañas agresivas de actualización de catastros y digitalización de la información.

b. Generar protocolos y procedimientos internos para el desarrollo de balances hidráulicos de redes.

c. Aplicación del método de análisis de flujos nocturnos, como técnica alternativa y fácil de aplicar en los sistemas de agua potable del Ecuador y en los países en vías de desarrollo, para detectar fugas en las redes.

d. Reestructurar las empresas operadoras municipales y tomar decisiones gerenciales prioritarias, como son:

- Elaborar la línea base de cada sistema de agua,

- Planificar tareas de forma técnica a largo plazo; y,

- Conformar equipos de trabajo concatenados a apoyar estos plannings futuros.

e. Es necesario invertir en infraestructura hidráulica en la casi totalidad de los sistemas de agua. Esto es:

- Incorporación de nudos de control.

- $\quad$ Sectorización de las redes.

- Equipamiento con contadores volumétricos o caudalímetros a la salida de los depósitos.

- Mantenimiento o renovación de hidrantes, válvulas y accesorios que constituyen las redes.

- Mantenimiento de estaciones de bombeo y depósitos.

2) Para la práctica de valoración de las auditorías de los sistemas de abastecimiento urbano es conveniente analizar y adaptar aquellas variables que sí se podrían determinar en campo, y cuyos datos obtenidos sean confiables, continuos y verificables. 
a. Para poder aplicar una buena parte de las metodologías para la determinación de indicadores de gestión propuestas por la norma ISO 24500 o la propuesta de la IWA, o cualquier otra metodología de avanzada y robusta,

i. Primeramente habrá que capacitar y entrenar al personal involucrado en la operación y mantenimiento de las redes municipales y en la metodología que se pretende implantar.

ii. Luego se deberá equipar con infraestructura adecuada las redes que conforman el sistema.

iii. Recabar y analizar constantemente los datos descargados de cada nudo de control, generar información a través de variables y calcular los indicadores correspondientes.

iv. Será necesario disponer de los servicios de un laboratorio especializado en el tema de la mejora de la gestión y agua no contabilizada, ya sea propio o independiente a la empresa.

v. Generar un modelo hidráulico y calibrarlo constantemente.

b. Asimismo, se siente la necesidad de la creación de una figura institucional que se encargue de regular las actividades de los sistemas de agua del país. Consorcio que se encargaría, entre otras cosas, de:

i. Organizar a los municipios para que en plazos prudenciales puedan elaborar, cada uno, su propio plan de mejoramiento del desempeño en los sistemas de agua bajo su competencia.

ii. Plantear metas generales, conjuntas, y mínimas de valoración y control de su desenvolvimiento, mediante variables e indicadores de gestión.

iii. Normalizar el servicio de calidad y cantidad de agua distribuida, según las características propias de cada municipio y las necesidades particulares de los usuarios.

iv. Legalizar los comportamientos institucionales a largo plazo para la ejecución de planes y programas encaminados a cumplir con la mejora de su desempeño en cuanto al servicio de agua, y se garantice la continuidad de trabajos e inversión, independientemente de la línea política de turno. 


\begin{abstract}
v. Disciplinar el comportamiento empresarial de cada operador, mediante la exigencia del cumplimiento de indicadores y estándares mínimos generales.

vi. Velar por la calidad y cantidad de agua servida a los clientes, con tarifas adecuadas que les garanticen sostenibilidad.

vii. Controlar la veracidad y calidad de los datos e información que todas las empresas deberán someter a publicación semestral.
\end{abstract}

- La propuesta presentada con este trabajo pretende ser una contribución para la evaluación y diagnóstico de la sostenibilidad y desempeño de los abastecimientos.

- $\quad$ Es importante que las empresas municipales que operan los sistemas de agua del Ecuador consideren cuanto antes en sus plannings, estrategias para ejecutar programas que incorporen el diagnóstico de la sostenibilidad de sus abastecimientos, valoración de auditorías mediante balance hídrico, selección de indicadores de gestión y cálculo de indicadores relativos en sus redes.

3) Se propone a los involucrados en la operación de sistemas de agua potable, aplicar a su gestión lo siguiente:

a. Análisis hidrogeológico del potencial hídrico de las cuencas tributarias de las cuales se abastecen.

b. Concretar un sistema tarifario que propicie la sostenibilidad y autonomía financiera del sistema.

c. Aplicar sistemas de conservación en las cuencas fuente.

d. Crear un plan de manejo ambiental que organice y corrija las actividades de operación y mantenimiento.

e. Inversión económica en las redes hidráulicas para sectorizarlas y con ello conformar distritos hidrométricos, o sectores de medición.

f. Instalar sistemas de medición y registro continuo de volúmenes, caudales y presiones, tanto que se inyectan, distribuyen o consumen.

g. En los depósitos será necesario instalar, entre otros equipos al menos, un aparato de medición y registro de volúmenes ingresados y extraídos, medición de niveles de superficie libre del agua almacenada, válvulas y accesorios para evitar 
derrames. Asimismo, dotar de loggers para almacenamiento de datos. Impermeabilización y mantenimiento constante.

h. Seguimiento y análisis de los datos obtenidos de los nudos de control para su análisis, interpretación y diagnóstico independiente y oportuno.

i. Reducción del agua no contabilizada, para ello es necesario invertir en tecnología para la detección y localización de fugas, así como para la detección de conexiones clandestinas.

j. Es pertinente asimismo, emprender en las políticas de inversión y autofinanciamiento de presupuestos operativos de las empresas operadoras, progresivamente disminuir la dependencia financiera Estatal; mejorar el plan de facturación y cobro de cartera vencida; y, motivar a la población, mediante el pago, para que tenga consumos más racionales.

k. Dar el debido mantenimiento, renovación y/o incremento de: tuberías, hidrantes, válvulas y accesorios, cuyas características del material de fabricación o por daños debidos al tiempo de servicio, hacen que no se cumpla con normas de calidad o afectando esto hacia una operación incorrecta del sistema.

l. Proponer alternativas para practicar auditorías entre los operadores de redes municipales del Ecuador y dar cabida a un benchmarking métrico a nivel del país.

m. Impulsar la generación de un ente regulador para los sistemas de agua del país.

- $\quad$ Según la característica actual de los sistemas de abastecimiento de agua de nuestro país, resulta ineluctable y urgente la actuación diligente de los gerentes y directores de las empresas para introducir un plan estratégico de modernización junto con la readecuación del marco legal - institucional del sector del agua potable y saneamiento, a efecto de mejorar su calidad de servicio, desempeño y salud de los usuarios bajo su jurisdicción.

- La mejora de la gestión en los servicios de agua potable y saneamiento urbano es el instrumento básico para la promoción de la calidad de vida y por ende del desarrollo humano con profundas vinculaciones y repercusiones sociales positivas.

- El Estado y gobiernos locales deberán garantizar bajo el principio de solidaridad y buena práctica técnica el acceso al agua potable de todos los sectores hasta ahora excluidos del servicio, por razones técnicas, socio-económicas, políticas, culturales y/o raciales. 
- Se debe, paralelamente, iniciar con una campaña agresiva de capacitación, entrenamiento y equipamiento para la valoración de auditorías de cada empresa operadora.

- Es necesaria la búsqueda incansable de fuentes de financiamiento permanente y estable para cubrir los rubros del nuevo plan estratégico de modernización y mejora de la calidad del servicio de agua para consumo humano. Parte de esta actividad involucra la aplicación de tasas reales para el cobro por el uso del agua.

- $\quad$ Es necesario que los organismos municipales actualicen el padrón de clientes ó usuarios del sistema, incluirlos en un software apropiado y actualizarlo constantemente.

- $\quad$ Se debe involucrar a la comunidad de forma participativa para el cuidado y conservación de las cuencas tributarias (fuentes); así también, que se concientice para una reducción del consumo de agua diario. Asimismo, la comunidad deberá involucrarse en el plan de mantenimiento y reducción de fugas, mediante reportes oportunos y congruentes. 


\section{Bibliografía}

ADERASA (2007). Manual de Benchmarking. ADERASA, http://www.aderasa.org/es/index.htm.

ADERASA (2007). Manual de indicadores de gestión para agua potable y alcantarillado sanitario. http://www.aderasa.org/aa/img_upload/.../Manual_de_Benchmarking_de_ADERASA_marzo_2007.doc

AEP (2006). Objetivos de Desarrollo del Milenio, de las palabras a los hechos, Alianza Española contra la Pobreza: 6.

Agredano R. (2005). El benchmarking como alternativa para mejorar los procesos. Nuevo León, México, The Paradigma Commitment 7.

Aguirre A. (2004). Gestión integral del agua en cuencas hidrológicas desde la perspectiva de un modelo vertical. Guadalajara, Carta Económica Regional: págs. 15.

Alegre H.; et al (2006). Performance Indicators for Water Supply Services. IWA Publishing. London.

Altamirano F. - Reporteros: Yanez C. y Jaramillo D. (2007). Agua y alcantarillado. Memoria de Gestión del Ilustre Municipio del Cantón Loja. Loja, IML.

Álvarez L. (2006). Evaluación Social Seminario taller de Formulación, gestión y evaluación de proyectos, Loja, CADES - UTPL.

Amorebieta G. (2006) Privatizaciones de Servicios de Agua en Sudamérica. El Derecho al Agua en el Sur de las Américas Volume, DOI:

ANDERSEN, A. (1999). Diccionario de economía y negocios. Espasa. España.

Antonio, F. (1994). Análisis económico y gestión de recursos naturales. A. Editorial. España: 373.

Arana E. (2002). Resolución de acuerdo tarifario número 12. Consejo de Dirección del Instituto Nicaragüense de Acueductos y Alcantarillados, INAA. CD- RE-015-02: 7.

Artaraz M. (2002). "Teoría de las tres dimensiones de desarrollo sostenible." ECOSISTEMAS, $\mathrm{n}^{\circ}$ $2002 / 2$.

Barbancho, A. (1973). Complementos de econometría. Ariel. España: 194.

Beato P. y Díaz J. (2003). La participación del sector privado en los servicios de agua y saneamiento en Cartagena de Indias. Washington, D. C., Banco Interamericano de Desarrollo (BID): 28.

Benavides J. y Solano C. (2005). Evaluación del impacto ambiental de los planes de forestación y reforestación ejecutados en la cuenca del Zamora Huayco del cantón Loja, provincia de Loja. Loja, UTPL. Tesis de grado.

Benavides H. (2007). Indicadores de gestión internacional para la eficiencia en la gestión urbana del agua.- El benchmarking en el Ecuador. IX Congreso Nacional de Hidráulica y I de Manejo integral de recursos hídricos. Quito, Asociación de Ingenieros Hidráulicos del Ecuador. IX Congreso

Benavides H. (2008). Valoración ambiental del agua como parámetro de eficiencia en la gestión integral del recurso IUCN: págs. 14.

Benavides H. y Arias J. (2005). Programa de economía ambiental para la explotación sustentable y sostenible de agua de la cuenca hidrográfica del río Zamora Huayco. Gerencia de proyectos para el desarrollo. Guayaquil, Escuela Superior Politécnica del Litoral - ESPOL. Magister

Benavides H.; et. al. (2008). Auditoría de redes de distribución de agua. Metodologías existentes. Dificultades de aplicación y alternativas para soslayarlas en el Ecuador. Valencia: 128. 
Benavides H. y Sánchez J. (2010). Gestión para la eficiencia hidráulica y energética en sistemas de distribución de agua. Sistemas de Saneamento. Eficiência Energética. Joao Pessoa, Editora Universitaria. UFPB - LEHNS-PROSUL.

Benavides, J. y Solano C. (2005.). Evaluación del impacto ambiental de los planes de forestación y reforestación ejecutados en la cuenca del Zamora Huayco del cantón Loja, provincia de Loja. Ingeniería en Gestión Ambiental. Loja, U.T.P.L.: 193.

Berg S. y Lin C. (2005). Consistency in Performance Rankings: The Peru Water Sector., Universidad de Florida.

Bergkamp, G., Orlando, B. and Burton, (2003). Change. Adaptation of Water Management to Climate Change IUCN. Gland, Suiza y Cambridge, Reino Unido, Costa Rica (traducción), UICN-ORMA.

Bourguet V. (2004). Estrategia y organización para la detección de fugas. CEMCAS-Centro mexicano de capacitación en agua y saneamiento. México.

CAAAM (2001). Lineamientos para la Gestión Ambiental y el Desarrollo Sostenible en la Comunidad Andina Comité Andino de Autoridades Ambientales, Comunidad Andina - Secretaría General.

Cabrera E. (2006). El suministro de agua en España. PANEL CIENTÍFICO-TÉCNICO DE SEGUIMIENTO DE LA POLÍTICA DE AGUAS, http://www.unizar.es/fnca/varios/panel/31.pdf, Convenio Universidad de Sevilla-Ministerio de Medio Ambiente.

Cabrera E. (2006). Los cortes de agua y el racionamiento racional en épocas de escasez Noticias y notas de prensa del Ministerio de Medio Ambiente y Medio Rural y Marino de España. Valencia, Ministerio de Medio Ambiente y Medio Rural y Marino de España: págs. 20.

Cabrera E. (2007). Actuaciones orientadas a disminuir las pérdidas de agua. Evaluación y control de pérdidas de agua en redes urbanas. I. T. Agua. Cartagena: 25.

Cabrera E. y Garcia-Serra J. (1997). Problemática de los abastecimientos urbanos. Necesidad de su modernización. Valencia.

Cabrera Jr. E. et al, (2002). "Practical application of metric benchmarking in water supply systems." Water Science \& Technology: Water Supply, 2(4).

Cáceres V. (2008). Pago de pasivo laboral del SANAA impide municipalización del agua en el Distrito Central. Tegucigalpa, Unidad de Investigación de HRN: 2.

Calabuig C. (2008). Agenda 21 local y gobernanza democrática para el desarrollo humano sostenible: bases para una gestión orientada al proceso. Proyectos de Ingeniería. Valencia, Universidad Politécnica de Valencia. Tesis Doctoral: 588.

Cámara J. (2003). "La AGENDA 21 LOCAL, de Río 1992 a Johannesburgo 2002". I Plenario de Municipios, agenda_fempclm_eu: 5.

Canter L. (1998). Manual de evaluación de impacto ambiental, técnica para la elaboración de los estudios de impacto. M. G. Hill. España.

Carrion F. (1996). Apuntes de Hidrología. UTPL. Ing. Civil. Loja.

Castro R. (2004). Métodos de Valoración de Beneficios y Costos. La evaluación ex ante del gasto publico. U. d. L. Andes. Colombia: slides: 50.

Castro R. y Mokate, K. (1996). Evaluación económica y social de proyectos de inversión. Universidad de los Andes. Santafé de Bogota, D.C., Colombia.

CEPAL (2010). Objetivos de Desarrollo del Milenio. Avances en la sostenibilidad ambiental del desarrollo en América Latina y el Caribe. Santiago de Chile, Naciones Unidas: 231.

CEPIS (2009). Recomendaciones para detección y aforo de fugas en tomas domiciliarias. http://www.cepis.org.pe/bvsair/e/repindex/repi48/recomen/recomen.html 
Chain S. (1993). Criterio de evaluación de proyectos. M. G. Hill. Chile: 144.

CISDL (2005). ¿Qué es "Derecho del Desarrollo Sostenible"? Artículo conceptual de CISDL. Montreal, Centro de Derecho Internacional del Desarrollo Sostenible (CISDL).

Colombo A. y Karney B. (2002) "Energy and Costs of Leaky Pipes: Toward Comprehensive Picture". Journal of Water Resources Planning and Management. ASCE Vol. 128, No. 6. November/ December 2002, pp. 441 - 450.

Contreras F. y Thornton J. (2006) "Influencia de la presión en las pérdidas de agua en sistemas de distribución”. Asociación Interamericana de ingeniería sanitaría y ambiental-AIDIS. XXX Congreso interamericano de ingeniería sanitaría y ambiental. Uruguay.

Cruz G. (2005). Economía aplicada a la valoración de impactos ambientales. Colombia, Colección Ciencias Agropecuarias.

Dávila J. (2002). Valoración económica del recurso agua en la comunidad Frijolares, Güinope. Zamorano. Honduras.

Delgado C. (2004) El privilegiado y gran negocio del agua embotellada. El Catoblepas Volume, DOI: 25

Díaz R. y Escárcega S. (2009). Desarrollo sustentable. Oportunidad para la vida. México.

Dourojeanni A.; et al. (2002). Gestión del agua a nivel de cuencas: teoría y práctica. Recursos Natrales e Infraestructura. Santiago de Chile, Naciones Unidas, CEPAL: 83.

Dréo J. (2007). "Desarrollo sostenible." Imágen ext svg, from http://es.wikipedia.org/wiki/Archivo:Desarrollo_sostenible.svg.

Dupont G. (2006). El planeta, hacia un futuro con más habitantes y cada vez menos agua. Los Recursos Mundiales De "Oro Azul". . Tomado de Clarín.com. Montevideo, UITA - Secretaría Regional Latinoamericana - Montevideo - Uruguay.

EATHISA (2009). Correlador acústico controlado por PC, Multicorrelación. www.eathisa.com/dat/archivos/MAQ6000.pdf.

Egremy N. (2009). Trasnacionales, en la privatización del agua. Fortuna, Fortuna. 73.

ExpoZaragoza, S. W. f. t. w.-E. (2008). Agua y desarrollo sostenible. Zaragoza.

Fajardo L. (2008). Desarrollo Humano Sustentable: Concepto y Naturaleza. U. S. Arboleda. Bogotá Colombia, Civilizar.

FAO (2006). Evaluación de los recursos forestales mundiales 2005. Hacia la ordenación forestal sostenible. FAO. Roma, Organización de las Naciones Unidas para la agricultura y la alimentación. Vol.147.

FAO (2005). Protocolo de Kyoto: importante instrumento para el desarrollo sostenible. Roma, FAO Sala de prensa.

FAO (1993). El estado mundial de la agricultura y la alimentación. Los recursos de aguas: economía y política. Departamento Económico y Social, , Documentos de la FAO.

Fontaine E. (1997). Evaluación Social de Proyectos. U. d. Chile. Santiago: 466.

Fundación Ecológica y Desarrollo (2003). Tarifas incentivadoras del uso eficiente del agua. Principios básicos., ECODES: 4.

Galárraga R. (2000). Informe Nacional sobre la gestión del agua en el Ecuador. Quito, Escuela Politécnica Nacional: 120.

Garcia D. (2006). Benchmarking. Wikilearning, comunidades de wikis libres. wikilearning, http: / / www. wikilearning.com/benchmrking-wkccp-11410-5.htm. 
García-Serra J. (2008). Abastecimientos urbanos: problemática actual y propuesta de soluciones. Agua y ciudad en el contexto de la Directiva Marco. Planenado el futuro. I. T. d. Agua. Valencia.

García-Serra J. (2009). Redes de distribución. Trazado y criterios prácticos de diseño. Seminario taller de Hidráulica Avanzada. I. T. d. Agua. Loja.

Gil M.; et al. (2007). "La situación de los Objetivos del Milenio a mitad de camino para 2015." Economistas sin Fronteras: 14.

Global Water Partnership (2003). La gobernabilidad de la gestión del agua en el Ecuador. Gobernabilidad del sector del agua G. -S. -. Japón Global Water Partnership.

Gomes H. (2005). Eficiência hidráulica e energética em saneamento. Río de Janeiro, ELETROBRAS/PROCEL.

Gómez B. (2008). Metodología para la evaluación de medidores domiciliarios - 1980. Informe preliminar para OPS/OMS - CEPIS. http://www.cepis.ops-oms.org/bvsacd/scan3/024553.pdf

Holden, F. (1978). Introducción al análisis econométrico. Ariel. México: 293.

IBNET (2004). Indicator calculator IBNET http://www.ib-net.org/en/ibnettoolkit/documents/IBNET_indicator_calculator_Sept_04_v3.xls.

IBNET (2004). RED INTERNACIONAL DE BENCHMARKING EMPRESAS DE AGUA Y SANEAMIENTO, http: //www.ib-net.org/sp/ibnet-toolkit/documents/IBNETindicatordefinitionsSept04ES.doc.

Idrobo D. y Benavides H.; (2008). Evaluación y diagnóstico de las estaciones de bombeo y depósitos de almacenamiento del sistema de agua potable de la ciudad de Loja. Ingeniería Civil. Loja, Universidad Técnica Particular de Loja. Ingeniero Civil.

INEC (2005). Metodología del índice de precios al consumidor, IPC. Metodología del IPC, Instituto Nacional de Estadística y Censos del Ecuador: 51.

INEC (2001). Censo poblacional. Quito - Ecuador.

Instituto Tecnológico del Agua (ITA) - UPV (2000). SIGMA LITE 2.0 - Indicadores de gestión basado en los de la IWA. http://www.sigmalite.com/esp/contents/downlite.htm. I.-. UPV. Valencia (España).

Inspecciones Técnicas (2009). Detección acústica de fugas de agua. AQUAPHON (Geófono digital). http://www.inspeccionestecnicas.es/geofono.htm

INTERAGUA (2009). Facturación de los servicios de agua potable y alcantarillado para la ciudad de Guayaquil, Interagua.com.ec.

IUCN (2008) Planes de Gestión Integrada de Recursos Hídricos. Volume, DOI:

IV Cumbre de las Américas (2005). "Crear Trabajo para Enfrentar la Pobreza y Fortalecer la Gobernabilidad Democrática". Mar del Plata, Argentina.

IW-LEARN (2009) Planeamiento conjunto Interamericano de recursos hídricos. Red Interamericana de recursos hídricos - Nodo Pacífico Sur y Amazonía Volume, DOI:

Dixon J.; et al. (1994). Análisis económico de impactos ambientales. E. latinoamericana: 250.

Johnston, J. (1975). Métodos de econometría. Vicens-Vives. España: 463.

Jouravlev A. (2003). Acceso a la información: una tarea pendiente para la regulación latinoamericana. Recursos naturales e infraestructura. Serie. . N. U. CEPAL. Santiago de Chile, Naciones Unidas. CEPAL. División de Recursos Naturales e Infraestructura: págs. 72.

Kazmier J. (2000). Estadística aplicada a la adminstración y a la economía. M. G. Hill. México: 416. 
Lambert A. y Fantozzi M. (2010). "Recent developments in pressure management " Water Science and Technology: Water Supply IWA Specialist Conference 'Water Loss 2010", Brasil.

Lambert A. (2002). "International Report: Water Management and Techniques." Water Science and Technology: Water Supply 2(4): 20.

LAMBERT, A.; et al. (1998) “Managing water leakage”. Economic and technical issues. Publicado y distribuido por Financial Times Energy. Gran Bretaña.

Liemberger R. y Partners (2010). WB-EasyCalc. The Free Water Balance Software, http://www.liemberger.cc/.

Macedo B. (2005). El concepto de sostenibilidad. OREALC/2005/PI/H/12. Santiago de Chile, UNESCO - Oficina Regional de Educación para América Latina y el Caribe: 4.

Marah L.; et. al. (2004). Effective cost recovery in a changing institutional and policy environment: municipal demarcation, the "free basic water" policy, and financially sustainable service delivery. WRC Report 1384/1/04. Johannesburg, Water Research Commission.

Marquardt B. (2006). "Historia de la sostenibilidad. Un concepto medioambiental en la historia de Europa central (1000-2006)." Historia crítica(32): 172 - 197.

Medina G. y Benavides H. (2009). Políticas para el control activo de fugas. Loja, UTPL. Ingeniería Civil.

MIDUVI (2003). Guía para la preparación de tarifas servicios de agua potable y saneamiento. Guía tarfaria de agua potable y saneamiento. M. d. D. U. y. V. d. Ecuador., Subsecretaría de Agua Potable y Saneamiento.: 62.

Ministerio de Economía y Hacienda (2005). Fondos Comunitarios 2007 - 2013: Desarrollo Sostenible y Medioambiente, MMA_ES: diapos. 42.

Mokate K y Castro R. (2003). Evaluación económica y social de proyectos de inversión. Colombia, Universidad de Los Andes - Alfaomega Colombiana S.A.

Mokate K. M. (1996). Evaluación financiera de proyectos de inversión. U. d. Colombia. Colombia: 287.

Mokate R.; et al. (1996). Evaluación económica y social de proyectos de inversión. U. d. Colombia. Colombia: 418.

Molinari A. (2009). Objetivos de ADERASA. Plan estratégico. Quinta reunión del grupo de trabajo de benchmarking de ADERASA

Mora C. (2005). Los que nos lega el Benchmarking. Competitividad. Carabobo (Venezuela) GestioPolis. Área de estudios de Postgrado de la Universidad de Carabobo

Moriarty P.; et al. (2006). La gestión “integral” de los recursos hídricos. I.-I. W. a. S. Centre. The Hague, IRC - Netherlands Water Partnership.

Munasinghe M. (1993). Environmental Economics and Natural Resource Management World Bank and CIDIE. Washington DC, USA.

Naciones Unidas (2009). The 2009 Revision Population Database, Population Division of the Department of Economic and Social Affairs of the United Nations Secretariat. http://esa.un.org/unpp.

Naciones Unidas (2008). World Population Prospects: The 2008 Revision, Population Division of the Department of Economic and Social Affairs of the United Nations Secretariat. http://esa.un.org/unpp.

Naciones Unidas (2005). Documento Final de la Cumbre Mundial 2005 (24 de octubre) Asamblea General. A/RES/60/1: (42). 
Naciones Unidas (2005). Objetivos de Desarrollo del Milenio, Informe 2005. NU. New York, http://millenniumindicators.un.org/unsd/mi/pdf/MDG\%20BOOK_SP_new.pdf: 48.

Naturaleza y Cultura International - $\mathrm{NCl}$ (2006). Valoración del Recurso Hídrico en Microcuencas Abastecedoras de Agua para el Cantón Loja y de Energía Hidroeléctrica para el Cantón Zamora. NCl. Loja, Ecuador.

Negrete, J. (2009). Cada persona bebe 39 litros de agua en botella. Expreso. Guayaquil, Expreso.

Obregón S.; et al. (2008). Equidad de género en la gestión y manejo de cuencas una forma de intervención inclusiva y sostenible en la subcuenca Aguas Calientes, Nicaragua. Seminario Internacional “Cogestión de cuencas hidrográficas experiencias y desafíos”. C. A. T. d. I. y. E. (CATIE), Agri2000, Costa Rica: págs. 4.

Pabón L. (2007). Cuestión de prioridades. Entropía. Madrid, Archivo de ideas: 10.

Páez J. (1996). Introducción a los métodos de evaluación de impactos ambientales, recomendaciones para los gobiernos seccionales del Ecuador. Quito, Comisión Asesora Ambiental de la Presidencia de la República del Ecuador - USAID. F. Natura.

Parris T. y Kates R. (2003). "Characterizing and measuring sustainable development. ." Annual Review of Environment and Resources 28.

Peris J.; et al. (2008). La Agenda 21 local como instrumento para la gobernanza democrática local. Grupo de Estudios en Desarrollo, Fundación Carolina: 161.

Pineda E. y Benavides M. H. (2008). Determinación del coeficiente de rugosidad en tuberías, nuevas y usadas, destinadas a las gestión urbana del agua. Ingeniería Civil. Loja, Univerisdad Técnica Particular de Loja. Ing. Civil.

PNUD (1991). Informe sobre desarrollo humano 1991, Programa de las Naciones Unidas para el Desarrollo. http://hdr.undp.org/en/media/hdr_1991_es_resumen.pdf.

PROCEL SANEAR (2005). Programa Nacional de Conservación de Energía Eléctrica del sector de saneamiento. www.eletrobras.com/procel/site/areadeatuacao/saneamento.

RAE (2001). Diccionario de la lengua española - on line. Real Academia Española. RAE. Vigésima segunda edición, http://buscon.rae.es/drael/.

República del Ecuador (2009). Constitución. Carta Magna.

Rogers P.; et al. (1998). Water as a Social and Economic Good: How to Put the Principle into Practice. Global Water Partnership. Technical Advisory Committee (TAC), Global Water Partnership (GWP): 40.

Romero, C. (1997). Economía de los recursos ambientales y naturales. A. Editorial. España: 314.

Rubin, R. I. (1996). Estadística para administradores. P. Hall. México: 1018.

Secretaría General Comunidad Andina (2004). Seguimiento de la Cumbre de Johannesburgo en la Subregión Andina, Comunidad Andina: págs. 11.

Segger C. y Khalfan A. (2004). Sustainable Development Law: Principles, Practices \& Prospects. CISDL, Oxford: Oxford University Press.

Segger C. y Khalfan A. (2004). Sustainable Development Law: Principles, Practices \& Prospects. CISDL, Oxford: Oxford University Press.

Síntesis de la legislación de la UE (2007). Un año después de la Cumbre Mundial sobre el Desarrollo Sostenible, http://europa.eu/legislation_summaries/index_es.htm.

SubSurfaceLeak (2009). How to find Leaks. http://www.subsurfaceleak.com/find_leaks.html 
SSPD (2006). Superintendencia de Servicios Públicos. República de Colombia. Concepto 021_2006. https://basedoc.superservicios.gov.co/basedoc/notindexed/2005/CTO_SSPD_0000021_2006.doc (página inactiva, consultada en 2008). Página actual: http://basedoc.superservicios.gov.co/ark-legal//SSPD/details?docld=7cce758dbbe9-474d-8dfa-424e84ac687d\&channel=\%2fConceptos\%2fConceptos+SSPD\%2f2006\&subEspacio=

UE y PE-CONS (2000). Directiva Marco del Agua. U. E. y. C. P. Europeo. PE-CONS 3639/00: 101.

UMAPAL (2007). Información de archivo. Unidad Municipal de Agua Potable y Alcantarillado de Loja. Loja.

UNICEF (1999). Towards better programming A Water Handbook. Water, Environment and Sanitation Technical Guidelines Series - No. 2. P. Division. New York, United Nations Children's Fund: 116.

United Nations (1987). General Assembly. Report of the World Commission on Environment and Development. t. p. m. A/RES/42/187, United Nations Department of Economic and Social Affairs (DESA): http://www.un.org/documents/ga/res/42/ares42-187.htm.

UPV - Instituto Tecnológico del Agua (ITA) (2006). Curso “Auditoria de redes de distribución de agua”. Programa de Posgrado en Ingeniería Hidráulica y Medio Ambiente. Valencia (España), Apuntes personales del Autor.

Vásquez N. (2005). Gestión integral del riesgo por inundaciones: caso de estudio ciudad de Chone. XXXIII Curso Internacional de Geografía Aplicada: Geografía y riesgos ambientales. CEPEIGE: págs. 19.

Vaud M. (1967). Métodos estadísticos de la econometría. Ariel. España: 706.

Vélez A. (1998). Proyectos: formulación, evaluación y control. A. Editores. Colombia: 593.

Vindas J. (2005). Propuesta de una metodología y herramienta para la evaluación operativocomercial. AyA. San José, Costa Rica, Instituto Costarricense de Acueductos y Alcantarillados - AyA. .

Wikipedia (2009). GDP nominal per capita world map IMF 2008. Wikipedia, Data from International Monetary Fund World Economic Outlook Database April 2009.

Wikipedia (2009). Life Expectancy 2008 Estimates CIA World Factbook. Wikipedia, Data from CIA The World Factbook 2008 - Rank Order - Life Expectancy at birth (as updated until 20 November 2008).

Wikipedia (2009). UN Human Development Report 2009. Wikipedia, Data from The United Nations Human Development Index (HDI) rankings for 2009.

World Bank (2002). Más Allá Crecimiento Económico, Glosario. G. d. B. Mundial, http://www.worldbank.org/depweb/spanish/beyond/global/glossary.html.

Yale and Columbia University (2010). Environmental Performance Index 2010., http://epi.yale.edu/.

Yepes G. (2003). Los subsidios cruzados en los servicios de agua potable y saneamiento. Washington, D. C., Banco Interamericano de Desarrollo (BID): 26.

Yepes G.; et al. (2001). "The High Cost of Intermittent Supplies". Journal of Indian Waterworks Association xxxiii (2). 



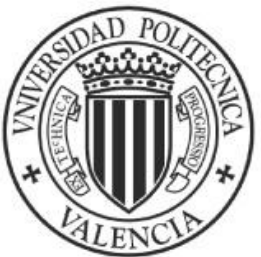

UNIVERSIDAD POLITECNICA DE VALENCIA

Programa de doctorado en Ingeniería Hidráulica y Medio Ambiente

DIAGNÓSTICO DE LA SOSTENIBILIDAD DE UN ABASTECIMIENTO DE AGUA E IDENTIFICACIÓN DE LAS PROPUESTAS QUE LA MEJOREN

Tesis doctoral

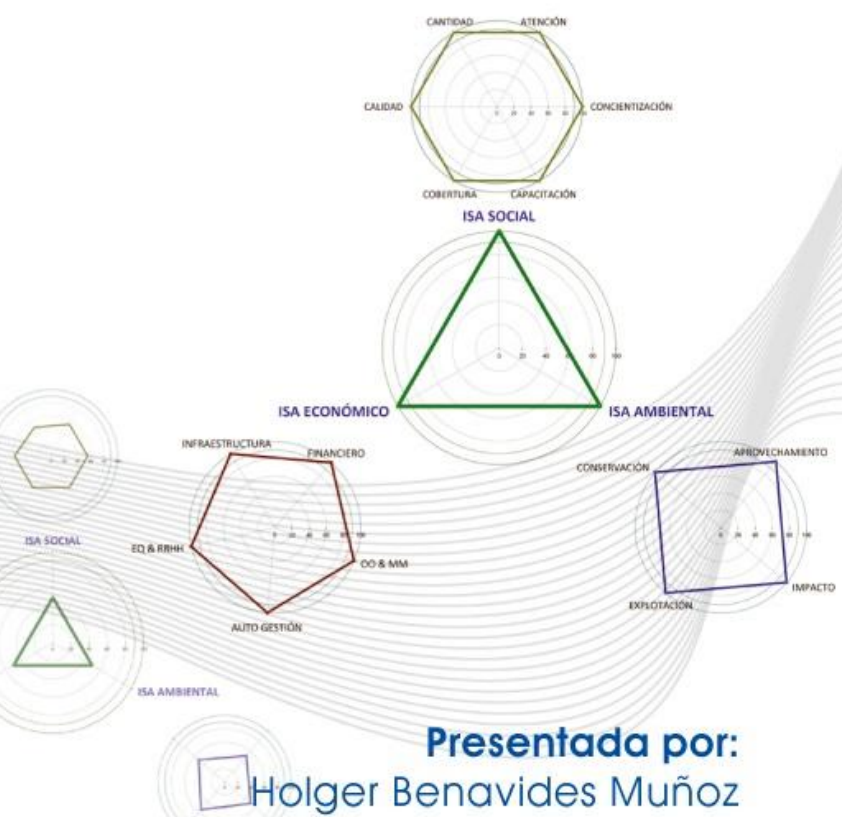

$\Delta$

Dirigida por: Dr. Enrique Cabrera Marcet Valencia, 2010 Dr. Enrique Cabrera Rochera 